\title{
"I'm Proud to Know What I Know": Oral Narratives of Travis and Hays Counties, Texas
}

Maria Franklin

Follow this and additional works at: https://scholarworks.sfasu.edu/ita

Part of the American Material Culture Commons, Archaeological Anthropology Commons, Environmental Studies Commons, Other American Studies Commons, Other Arts and Humanities Commons, Other History of Art, Architecture, and Archaeology Commons, and the United States History Commons

Tell us how this article helped you.

This Article is brought to you for free and open access by the Center for Regional Heritage Research at SFA ScholarWorks. It has been accepted for inclusion in Index of Texas Archaeology: Open Access Gray Literature from the Lone Star State by an authorized editor of SFA ScholarWorks. For more information, please contact cdsscholarworks@sfasu.edu. 


\section{"I'm Proud to Know What I Know": Oral Narratives of Travis and Hays Counties, Texas}

\section{Licensing Statement}

This is a work for hire produced for the Texas Department of Transportation (TxDOT), which owns all rights, title, and interest in and to all data and other information developed for this project under its contract with the report producer. The report may be cited and brief passages from this publication may be reproduced without permission provided that credit is given to TxDOT and the firm that produced it. Permission to reprint an entire chapter, section, figures or tables must be obtained in advance from the Supervisor of the Archeological Studies Branch, Environmental Affairs Division, Texas Department of Transportation, 125 East 11th Street, Austin, Texas, 78701. 


\title{
"I'M PROUD TO KNOW WHAT I KNOW" \\ Oral Narratives Of Travis And Hays Counties, Texas,
}

ca. $1920 s-1960 s$

VOLUME I

\author{
by \\ Maria Franklin
}
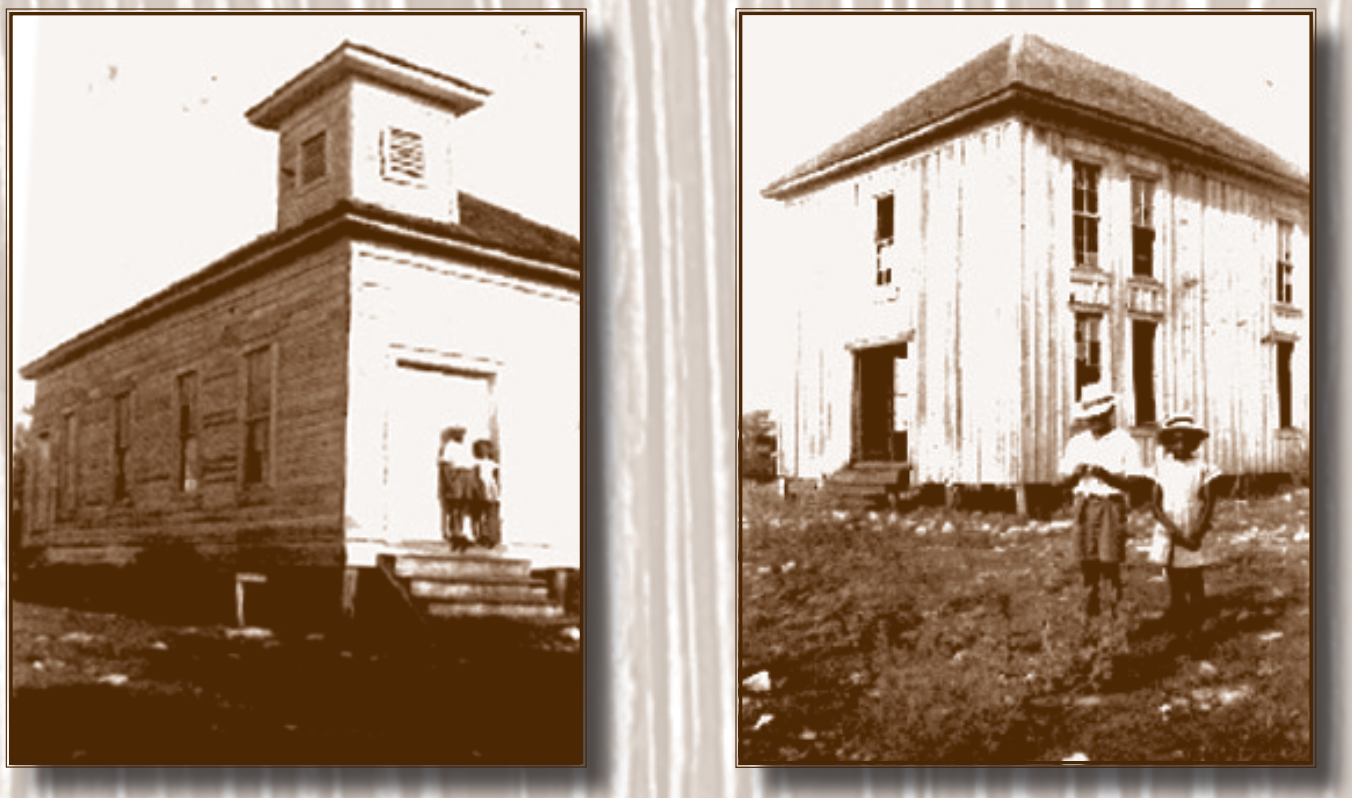

Texas Department of Transportation

Environmental Affairs Division

ARCHEOLOGICAL STUDIES PROGRAM, REPORT No. 136

REPORTS OF INVESTIGATIONS, NUMBER 165

TEXAS ANTIQUITIES PERMIT NO. 4736

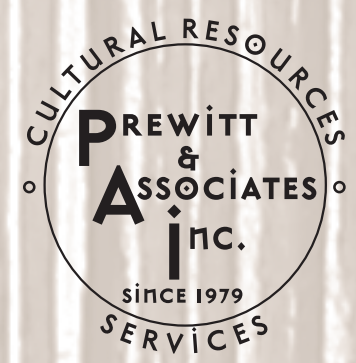




\section{"'m Proud To Know What IKnow": \\ Oral Narratives Of Travis And Hays Counties, Texas, ca. 1920s-1960s \\ Volume}

by

Maria Franklin

Principal Investigator: Douglas K. Boyd

REPORTS OF INVESTIGATIONS, NUMBER 165

Prewitt and Associates, Inc.

Cultural Resources Services

Austin, Texas

PAI Project Nos. 209003, 209015, and 211012

ARCHEOLOGICAL STUDIES PROGRAM, REPORT NO. 136

Texas Department of Transportation

Environmental Affairs Division

Archeological Studies Program

CSJ No. 1200-06-004

March 2012

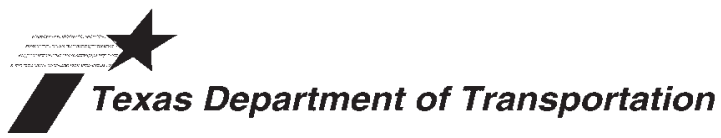

TEXAS ANTIQUITIES PERMIT NO. 4736 


\title{
“I'M PROUD TO KNOW WHAT I KNOW": ORAL NARRATIVES OF TRAVIS AND HAYS COUNTIES, TEXAS, ca. 1920s-1960s
}

COPYRIGHT @ 2012

Texas Department of Transportation (TxDOT)

This is a work for hire produced by the Texas Department of Transportation (TxDOT), which owns all rights, title, and interest in and to all data and other information developed for this project under Contract No. 579XXSA002 (Work Authorization 57903SA002 and 57904SA002), and Contract No. 571XXSA001 (Work Authorization 57101SA001). Brief passages from this publication may be reproduced without permission provided that credit is given to TxDOT and Prewitt and Associates, Inc. Permission to reprint an entire chapter, section, figures or tables must be obtained in advance from the Supervisor of the Archeological Studies Program, Environmental Affairs Division, Texas

Department of Transportation, 125 East 11th Street, Austin, Texas, 78701. A copy of this final report will be submitted to the Texas State Library and Archives Commission, State Publications Depository Program in compliance with 13 TAC §26.24(a).

\author{
jointly published by \\ Texas Department of Transportation \\ Environmental Affairs Division \\ Archeological Studies Program \\ Scott Pletka, Ph.D., Supervisor \\ Archeological Studies Program, Report No. 136 \\ $\mathrm{Al}$ McGraw, Series Editor \\ and \\ Prewitt and Associates, Inc. \\ Cultural Resources Services \\ Austin, Texas \\ PAI Project Nos. 209003, 209015, and 211012 \\ Reports of Investigations, Number 165 \\ Printed by Ginny's Printing in Austin, Texas \\ TxDOT Archeological Studies Report Number: 136
}

ISBN 978-1-935545-06-4 


\title{
In Memory
}

\author{
Of Those Who, in Sharing Their Stories, Helped to Ensure That the Legacy of \\ Their Ancestors Will Be Remembered, As Will Their Own
}

Moses Ollie Joe Harper, Sr.

Born July 26, 1943

Died December 18, 2009

\section{Anthy Lee Revada Walker}

Born September 14, 1915

Died May 10, 2010

and

\section{Essie Mae Owens Sorrells}

Born June 18, 1924

Died January 17, 2012 
Design: Sandra L. Hannum

Front cover: (Left) The original Antioch School (in use ca. 1874-1939), Antioch Colony, Buda Texas (date unknown). (Right) Antioch Church (in use ca. 1881-1942), Buda, Texas.

Back cover: Class photograph taken in 1921 at the original Antioch School (ca. 1874-1939), Buda, Texas.

Photographs courtesy of LeeDell Bunton, Sr. 


\section{TABLE OF CONTENTS}

\section{Volume |}

FOREWORD

The Ransom and Sarah Williams Farmstead Project

xii

What Makes the Williams Farmstead Significant and Why is the Site

Important to People Today? ........................................................................................ xiv

What is the Relationship Between Oral History and Archeology?................................. $\quad \mathrm{xv}$

A Precious Legacy ..................................................................................................

\section{CHAPTER 1: INTRODUCTION TO THE RANSOM AND SARAH WILLIAMS}

FARMSTEAD PROJECT .......................................................................... 1

The Oral History Project Areas ……........................................................................... 2

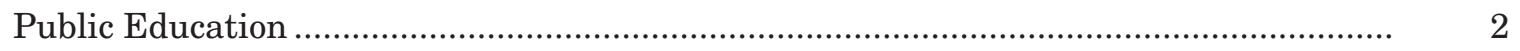

The Roles of Oral History in the Ransom Williams Farmstead Project............................. 4

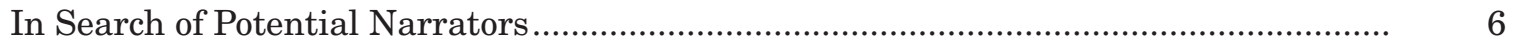

February to June 2009 ................................................................................ 7

September 2010 to July 2011 ...................................................................... 9

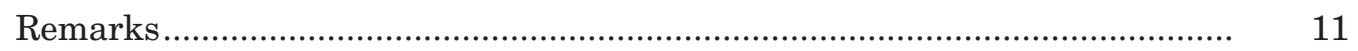

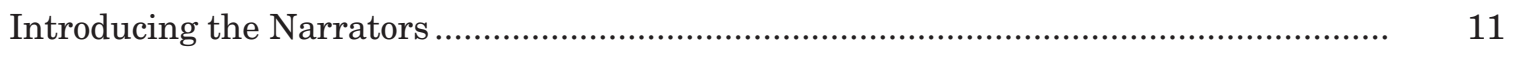

The Oral History of Harriet (Bunton) Smith, 1941 ....................................................... 15

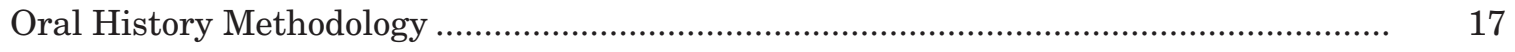

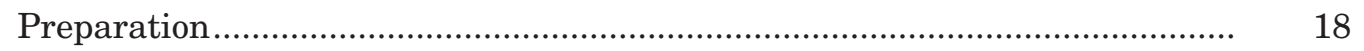

The Interview Questions................................................................................. 20

Pre-session Introductions .......................................................................... 22

The Interview Sessions ............................................................................... 22

Transcribing the Interviews ........................................................................... 23

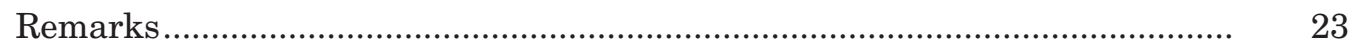

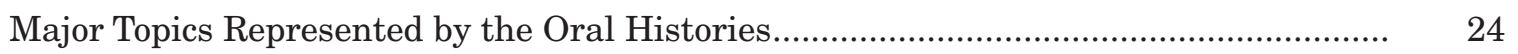

Social Organization and Relationships ............................................................ 25

Household Economy ................................................................................ 25

Material Culture and the Use of Space........................................................... 26

Religion and Education............................................................................. 27

Race Relations ...................................................................................... 28

Socialization and Identity ......................................................................... 29

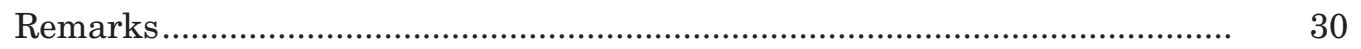




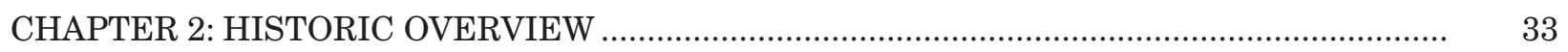

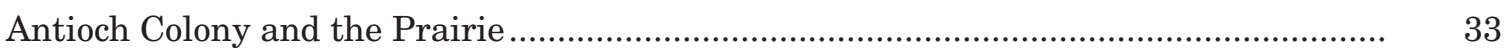

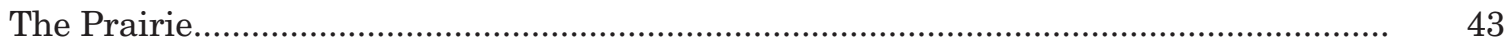

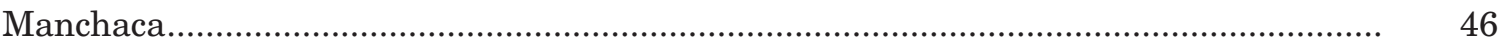

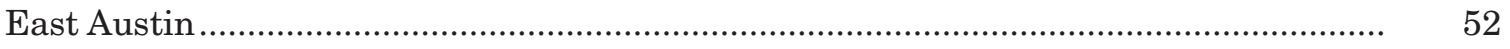

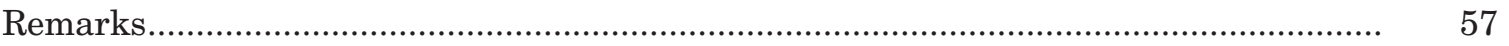

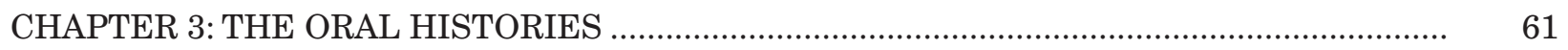

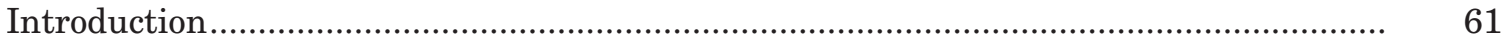

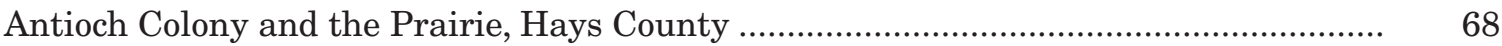

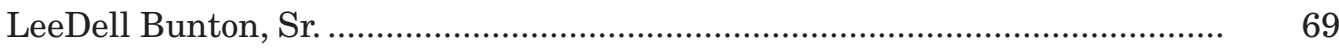

Ruth Roberta (Harper) Fears ................................................................. 119

Moses Ollie Joe Harper, Sr........................................................................ 138

Samuel Leslie "Les" Harper, Sr...................................................................... 162

Winnie Martha (Harper) Moyer ................................................................... 221

Minnie Mary (Harper) Nelson ..................................................................... 293

Marian Missouri (Harper) Washington........................................................ 341

Joan Nell (Revada) Limuel ............................................................................. 398

Anthy Lee (Revada) Walker ........................................................................... 459

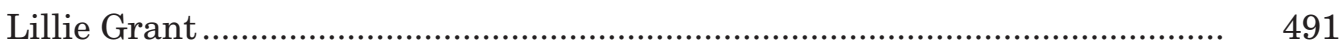

\section{Volume II}

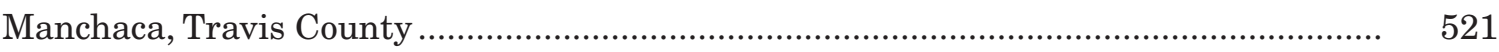

Robbie Freddie Mae (Dotson) Overton ........................................................... 522

Earlee Bunton ............................................................................................ 563

Annie (Dotson) Axel .............................................................................. 589

Estella "Estelle" (Hargis) Black .......................................................................... 605

Marcus Leon Pickard, Jr. .......................................................................... 630

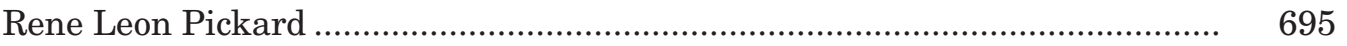

Essie Mae (Owens) Sorrells ....................................................................... 712

Earselean (Sorrells) Hollins........................................................................ 728

Cedel (Sorrells) Evans............................................................................... 766

Kay (Hollins) Randall ................................................................................... 779

Floris Lean Sorrells..................................................................................... 788

Joanne Deane and Lillie (Meredith) Moreland ........................................... 800

East Austin, Travis County ..................................................................................... 842

Jewel (Williams) Andrews and Lourice (Williams) Johnson.......................... 843

Corrine (Williams) Harris ............................................................................ 892

Lee Wildon Dawson .................................................................................... 916 
APPENDIX A: Family Trees

APPENDIX B: Households

APPENDIX C: Introductory Statement for Oral History Interviews

APPENDIX D: Oral History Interview Questions

991

APPENDIX E: Deed of Gift and Release of Documentary Materials Forms

999

APPENDIX F: Harriet (Bunton) Smith Oral History Interview by John Henry Faulk, 1941...... 1005

SURNAME AND PLACE NAME INDEXES

1029 


\section{LIST OF FIGURES}

1. Map of southern Travis and northern Hays Counties showing the location of the Ransom and Sarah Williams farmstead in relation to Austin, Bear Creek, Manchaca, Antioch Colony, Buda, and the Prairie............................................................

2. Emma (Friend) Bunton (b. 1868; d. January 4, 1941), Austin, Texas, date unknown......... 7

3. Eliza Brown Bunton, unidentified woman, Carrie Bunton Dotson, and Ike Brown ........... 8

4. Clara Franklin Williams (b. September 14, 1874; d. December 12, 1977), unknown family friend, and Mabel Williams Medlock, 1974, Austin, Texas ........................ 9

5. Will Williams (b. February 23, 1876; d. June 12, 1954), circa 1940 .................................. 10

6. Nedra Lee (Prewitt and Associates and UT Anthropology graduate student) and Corrine Harris, great-granddaughter of Ransom and Sarah Williams, at the Public Archaeology Expo, Society for Historical Archaeology annual meeting, January 2011

7. Lillie Grant with twin brothers Oscar and Arthur on their family property on the Prairie, Buda, Texas, ca. 1920s

8. Marcus Leon Pickard, Sr., date unknown....................................................................... 15

9. Close-up map of southern Travis and northern Hays Counties in the Buda area............. 34

10. Kate (Friend) Bunton (b. 1872; d. 1954) in front of her house in Antioch Colony (date unknown)

11. Addline (Kavanaugh) Bunkley (b. 1849; d. 1930). Photograph was likely taken at a studio in Hays County, Texas (date unknown)

12. Ella Nancy (Green) Harper (b. August 28, 1866; d. February 6, 1955) in Antioch Colony in 1950

13. Opal (Kavanaugh) Pickard, Texas, date unknown.

14. The original Antioch School (in use ca. 1874-1939), Antioch Colony, Buda, Texas, unknown date

15. Antioch Church (in use ca. 1881-1942), Antioch Colony, Buda, Texas

16. Joan Nell Revada Limuel, Anderson High School (Austin, Texas)

graduation photograph, 1952

17. Class photograph taken in 1921 at the original Antioch School (ca. 1874-1939),

Buda, Texas

18. LeeDell Bunton, Sr.'s class photograph (Percy Jr. Elementary School, Phoenix, Arizona, 1956-1957).

19. Emily Harper and her father, George Champ Harper, ca. 1975-1993 (photograph was probably taken in Buda, Texas, after George Harper and a number of his children returned to Antioch in 1975)

20. From left to right: Interviewees LeeDell Bunton, Sr., Moses Ollie Joe Harper, and Samuel Leslie Harper, 1950, Antioch Colony.... 
21. Lonnie B. Grant (b. January 23, 1885; d. July 4, 1956), ca. 1955, Texas

22. Ola (Bunton) Grant (b. December 2, 1885; d. January 25, 1955), date unknown, Texas

23. Willie B. Grant (left) and Leroy Grant (right), Lillie Grant's brothers, date unknown

24. LeeDell Bunton, Sr., unveils Texas state historical marker for Antioch Colony, dedicated by the Texas Historical Commission on January 22, 2011 ............................... 45

25. Texas state historical marker for Antioch Colony, dedicated on January 22, 2011

26. Map of southern Travis County showing historic locations in the Manchaca and Bear Creek area.

27. S. M. Sorrells with twin sons, Alvin and Virgil, date unknown.

28. Estella Hargis Black and family: Willie Jr., Lonnie, Otis, Bertha, Chatham, and Estella. Front row: Parents Maggie Perry Hargis and Willie Hargis ...

29. Marcus Pickard (left) and brother Alvin Pickard (right), ca. 1940.................................... 50

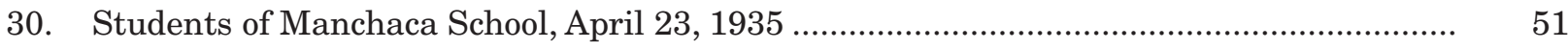

31. The historic community of East Austin, Travis County, Texas ........................................ 54

32. Herman Dotson trimming cousin Arthur Lee Hargis's hair at a barbershop in East Austin, ca. 1960s ....

33. Four grandchildren of Ransom and Sarah Williams

34. Novella (b. April 12, 1909; d. April 5, 1988) and Arnold David Williams (b. October 3, 1902; d. December 15, 1981), a grandson of Ransom and Sarah Williams, ca. 1977, Austin, Texas.

35. George Azberry Champ Harper (b. September 27, 1900; d. August 20, 1994), ca. 1920s (photograph was likely taken in Hays County, Texas).

36. George and Emma Harper, Phoenix, Arizona, ca. 1970s

37. Hattie Sneed Revada (b. 1884; d. 1954) on the family homesite in Antioch Colony, ca. 1952

38. Velma Revada (b. 1908; d. 1954) and Sophie (Peters) Revada (b. 1900; d. 1938), ca. 1936.

39. Carrie (Bunton) Dotson attending the marriage ceremony of her grandson, Eddie Dotson, to Joycelyn Lott, date unknown, Austin, Texas. 


\section{LIST OF TABLES}

1. Interviewees by gender, race, dates of birth and death, and former household's place of residence

2. Interviewees' former households by head(s) of household's surname, place of residence, source of household income, and years of household membership by interviewee 


\section{ACKNOWLEDGMENTS}

We would like to acknowledge a number of people who generously contributed their time and energies to the Ransom and Sarah Williams Farmstead Project. The oral history portion of the project would not have been possible without the narrators, who demonstrated wisdom, sincerity, patience, and a good sense of humor throughout the research process. We are honored to have worked with them all. They are: Jewel Andrews, Annie Axel, Estella Black, Earlee Bunton, LeeDell Bunton, Lee Dawson, Joanne Deane, Cedel Evans, Ruth Fears, Lillie Grant (assisted by Wanda Washington), Moses Harper, Samuel Harper, Corrine Harris, Earselean Hollins, Lourice Johnson, Joan Limuel, Lillie Moreland, Winnie Moyer, Minnie Nelson, Robbie Overton, Marcus Pickard, Rene Pickard, Kay Randall, Essie Mae Sorrells, Floris Sorrells, Anthy Lee Walker, and Marian Washington.

We would also like to express our appreciation to our colleagues, all of whom played a major role in ensuring the success of this project. This ambitious project would not have been possible without the funding from the Texas Department of Transportation and their representatives, Jon Budd and Scott Pletka, who recognized the significance of the Ransom and Sarah Williams Farmstead site and the broader history of African Americans in Hays and Travis Counties. Budd and Pletka lent their support throughout the entirety of the project and had the vision to allow us to help broaden the horizons of CRM archeology through the oral history, community outreach, and public education endeavors. Project historian Terri Myers of Central Preservation, Inc., produced incomparable histories of Manchaca, Bear Creek, and Antioch Colony. We would like to thank Myers for her reassuring and highly knowledgeable presence over the duration of the project. Thank you to Nedra Lee, who assisted with the oral history interviews and was always there to lend a helping hand no matter what the task. Christine Hooten of Afterwords Austin worked to preserve the integrity of the oral histories as she and her staff transcribed them; we are grateful for her commitment to this project. Franklin would like to thank Dominique Batiste, who assisted with the archival research on East Austin for this publication.

Many thanks to the staff at Prewitt and Associates, Inc. Sandy Hannum produced the illustrations in this report, and Elaine Robbins edited the report. Jennifer McWilliams and Aaron Norment were the project archeologists who directed the day-to-day operations during the archeological dig. They also acted as tour guides on many occasions when various people visited the site.

The members of the Manchaca/Onion Creek Historical Association (MOCHA) proved to be supportive advocates of the project, and it was a pleasure to present our research to their organization. Thank you to Marilyn McLeod, Ann and Barry Trask, and Ola Bell for facilitating our research and public education efforts, and to all of MOCHA for making us feel welcome.

Michael Emery of KLRU brought the history of Ransom and Sarah Williams and Antioch Colony to the public's attention with his production of the 2010 Juneteenth Jamboree program, which featured this project. We are grateful for the opportunity we had to work with Emery, and he has our enduring gratitude.

A special thanks goes to LeeDell Bunton, Sr., who paved the way for the oral history project in Antioch Colony, and who drove down from Phoenix, Arizona, on a number of occasions to assist us with our public education efforts. Bunton generously shared his research on, and knowledge of, Antioch

Colony and its descendants, and several of the genealogical charts presented in this publication were completed with his input.

-Maria Franklin and Doug Boyd 


\section{FOREWORD}

\section{Douglas K. Boyd}

This book was created as part of a multi-year historic archeological project sponsored by the Texas Department of Transportation (TxDOT) and under the direction of Dr. Scott Pletka and Jon Budd. ${ }^{1}$ The project was initiated because of federal and state laws that require consideration of cultural resources that may be impacted by development. The project involved archival research, oral history, and archeological investigations at a site called the Ransom and Sarah Williams farmstead in southern Travis County, Texas. An African American family occupied the farmstead beginning in 1871, and perhaps earlier, through about 1905. This book is a collection of oral histories gathered through interviews with people who grew up in the rural vicinity of the Williams farmstead, and also in East Austin; their recollections pertain to Travis and Hays Counties mainly during the first half of the twentieth century. The memories are primarily those of African Americans who are descendants of slaves-people whose lives were impacted by the legacy of slavery and who lived through the Jim Crow and civil rights eras. The story of how and why this book came into existence is important because it demonstrates the viability of community-based research in publicly funded cultural resources management archeological projects.

\section{The Ransom and Sarah Williams Farmstead Project}

Ransom Williams bought a 45-acre farm along Bear Creek in southern Travis County in 1871. Soon after, he married Sarah, and they raised five children on the farm over the next three decades. Ransom died about 1901, and the family moved off the farm by 1905 . They eventually sold the land, and the old farmstead was forgotten. A century after the Williamses left, the farmstead remains were rediscovered by archeologists conducting a survey for TxDOT during the planning stages of a segment of State Highway 45. The rediscovery of the farmstead in 2003 led to archival research by historian Terri Myers ${ }^{2}$ and further archeological investigation of the site by Prewitt and Associates, Inc. ${ }^{3}$ This type of investigation is often done at historic sites found during road building projects. The work revealed that the site was historically significant and contained intact archeological deposits that could yield important information. In 2008, TxDOT and the Texas Historical Commission agreed that the site was eligible for listing in the National Register of Historic Places. This meant that the site was considered significant because it could contribute important information useful for interpreting history by being investigated using historical and archeological methods.

Once the site was deemed significant and found to be associated with an African American freedman farmer, planning for the next phase of work began. I had read a great deal of the literature on African American archeology in the United States, the South, and Texas. I knew that the Williams farmstead could ultimately contribute to the broader realm of inquiry called "African Diaspora studies," which traces the movement of African peoples across the globe throughout human history. As

\footnotetext{
${ }^{1}$ Scott Pletka is the director of TxDOT's Archeological Studies Program in Austin, and Jon Budd is the project manager for the Ransom and Sarah Williams Farmstead Project.

2 Terri Myers owns Preservation Central, Inc., a consulting firm in Austin that specializes in doing archival research, National Register nominations, preservation planning, cultural resource surveys, and preservation education.

${ }^{3}$ Prewitt and Associates, Inc. is a consulting firm in Austin that provides cultural resources services.
} 
a place where the Williams family lived for many decades and transitioned from slavery to freedom, the site was significant as a rare example of a post-emancipation farmstead. Records indicated that the Williams family interacted with relatives and friends in the nearby freedmen community called Antioch Colony, as well as with their many white neighbors whose farms surrounded the Williamses' property. The project had the potential to yield historical and archeological evidence to help answer larger questions about African American farms and communities within an Anglo-dominated society. As the principal investigator for the project, I was faced with planning a comprehensive investigation that would maximize what we could learn from the archeological site but at the same time do justice to the broader scope of African Diaspora studies. It seemed like a daunting task.

The best decision I made was to call Dr. Maria Franklin. ${ }^{4}$ We had never met, and I knew her only by reputation - as a University of Texas professor, a capable archeologist, and a leader in the field of African Diaspora studies in the United States. We met over breakfast on October 29, 2008, and by the time the meeting ended, Dr. Franklin had agreed to collaborate with Prewitt and Associates and TxDOT on the Ransom and Sarah Williams Farmstead Project. Although she embraced my vision for a multidisciplinary anthropological approach to investigating the farmstead, she had an even broader vision of what this project could become. Most important, she described how the historical archeological studies could be made relevant to the modern descendant community-the local African Americans who are the primary stakeholders in the study of their own heritage and history. Although there are no legal mandates for involving the descendant communities in CRM archeological projects relating to African Americans ${ }^{5}$ (see Leone et al. 2005:588), Dr. Franklin and others have argued that archeologists have a moral and ethical obligation to do so (e.g., Armstrong 2008; Bell 2008; Brandon 2008; Franklin 1997; Franklin and McKee 2004; Gibb 1997; Leone et al. 2005; Little 2007; McDavid 2002; McDavid and Babson 1997; McGuire 2008; Mullins 1999, 2008; Orser 1998; Palus et al. 2006; Scham 2001; Singleton 1999). Archeological projects, especially publicly funded CRM projects, need to involve descendant communities and conduct research in ways that benefit the stakeholders, and the Williams farmstead presented an ideal opportunity to do this.

After our first meeting, Franklin became a consultant on the Williams Farmstead Project. Over the next few months, Franklin, historian Terri Myers, and I developed a plan for the next phase. ${ }^{6}$ It would involve a landscape-oriented archeological investigation of the entire farmstead, more intensive and targeted archival research, an oral history component to involve the descendant community, and a search for direct lineal descendants of Ransom and Sarah Williams. Franklin would serve as an archeological consultant as well as take the lead on the oral history work. Terri Myers, a historian with extensive Texas and African American research experience, had conducted the previous phases of archival research on the Williams farmstead. In this next phase, she expanded the scope of her research to include the history of Antioch Colony, the freedmen community located near Buda, and the African American community at Manchaca. Myers also conducted more research on the Williams

\footnotetext{
${ }^{4}$ Dr. Franklin received her Ph.D. in Anthropology from the University of California at Berkeley in 1997. She is currently an associate professor at the University of Texas at Austin, with joint appointments in the Department of Anthropology and the African and African Diaspora Studies Department. She also is affiliated with the John L. Warfield Center for African and African American Studies at UT Austin.

${ }_{5}^{5}$ Federal laws do mandate involvement of Native American descendant communities and tribal consultation in many aspects of cultural resources management, but there are no comparable laws requiring this type of involvement for African American descendant communities or descendant communities associated with other disenfranchised ethnic groups.

${ }_{6}^{6}$ The final phase of archeological investigation in most CRM projects is called data recovery. Once a site has been determined to be significant and it is certain that it will be impacted or destroyed by the development, the data recovery phase is initiated to salvage archeological evidence that would be otherwise lost.
} 
family and was able to trace the family tree into the mid-twentieth century. This eventually led to the discovery of five of Ransom and Sarah's great-grandchildren living in Austin and Houston.

In the summer of 2009, extensive archeological investigations were conducted at the farmstead site. The analyses of the historical records and archeological data are still ongoing, and a detailed report on the history and archeology of the Williams farmstead is being prepared and will be published soon. The old farmstead will disappear once the new highway is built, so it is fortunate that we have had the opportunity to salvage a great deal of archeological information before this happens.

\section{What Makes the Williams Farmstead Significant and Why is the Site Important to People Today?}

"Significance" is a term used in the process of evaluating sites for their eligibility for inclusion in the National Register of Historic Places. One may think of the National Register as a yardstick for measuring the relative importance of archeological sites, and a site's level of significance is tied to what we can learn through archeological investigation. What are the characteristics that led to the determination that the Williams farmstead was significant and worthy of such extensive study?

There are many thousands of historic farmstead sites scattered across Texas, and not all of them are equally important. The significance of the Williams farmstead is linked to two distinguishing characteristics. First, Prewitt and Associates archeologists discovered that the Williams farmstead had a high degree of archeological integrity and that the site was in relatively pristine condition. All of the material remains found there were things left behind by the Williams family. After they left about 1905, no one else lived on the property or altered the landscape features that the Williamses had built, such as a livestock pond and the massive rock walls that form livestock fences and a corral. The wooden superstructure of the old farmhouse (perhaps a log cabin) had disappeared, but archeologists ultimately exposed the foundation rocks, the intact base of the rock chimney, and an underground "potato cellar" near the fireplace. There was evidence of a barn or storage shed near the house and a household trash dump on a slope behind the house. The archeological investigations recovered more than 26,000 artifacts representing the full range of activities that occurred on a typical nineteenthcentury farm.

The second fact, and the one that is most important for understanding the site, is that the farmstead was owned by an African American couple who had been slaves just six years before they bought the land. Historically, it was not unusual for former slaves to have purchased their own farms in Texas. Between 1870 and 1890, for example, the percentage of black farmers who owned their own land soared from 1.8 to 26 percent (Sitton and Conrad 2005:2). But with rare exceptions, these farmsteads remain lost to us today. It is unusual for archeologists to find a post-emancipation African American farmstead in pristine condition, and for the historians to discover archival records needed to thoroughly document the history of the property and the people who lived there. Even though a few African American farmsteads have been explored archeologically, ${ }^{7}$ none of them measure up to the Williams farmstead in terms of archeological integrity and the quantity of interpretable data

\footnotetext{
7 Archeologically reported investigations of African American farms include: 41BZ115, the Ned Peterson Farmstead, 1849-1931 (Carlson 1993a, 1993b, 1995); 41DT192, 41DT208, and 41249, farmsteads of John Derrick, John Hancock, and Wallace Carter in the Friendship Community, 1880-1945 (Green et al. 1996); 41TV875, the Rubin Hancock Farmstead, 1880-1916 (Blake and Myers 1999; Blake et al. 2001); 41NV267, the Mingo and Nancy Burleson Farmstead, 1873-1910 (Jurney and Moir 1987; Moir and Jurney 1987); and 41NV305 and 41NV306, unidentified black tenant farms, late 1870s to early 1900s (Jurney and Moir 1987; Moir and Jurney 1987).
} 
recovered. So when we find a place like the Williams farmstead, it is indeed worthy of special attention. Such sites represent a rare opportunity to investigate, historically and archeologically, the African American Diaspora in the post-emancipation period.

The Williams Farmstead Project is significant because it is a documentary record that chronicles the decades after emancipation, a period that is seriously underrepresented in the historic and archeological records. Historians and archeologists in the United States have long studied the antebellum sites associated with enslaved Africans and African Americans, particularly the plantation sites in the South. But relatively little attention has been paid to the history and material culture of African Americans after 1865. For enslaved blacks in the southern United States, the transition from slavery to freedom did not happen suddenly with emancipation at the end of the Civil War. It happened slowly over the next century and continued right up through the civil rights era of the 1960s and 1970s. During these decades, African Americans were subjected to many forms of discrimination, from the Jim Crow laws and racial segregation to the violent acts of the Ku Klux Klan and other white supremacist groups. Although they faced oppression and setbacks, African Americans were successful in maintaining their own ethnic identities and communities while they interacted with the dominant white society. But our history books are notably silent in this regard. For this reason, post-emancipation African American archeological sites are considered especially important: they contain irreplaceable material evidence of the long transition from enslavement to freedom.

The archival documents and the archeology of their farmstead tell an amazing story of one successful African American farm family, but the archeological part of the story ends rather abruptly when the Williams family left the farmstead in 1905. The story might have ended at this point if it were not for the oral history component of the archeological project. Through interviews with descendants of the people who lived in the vicinity of the farmstead, the project traces the story of African Americans in central Texas from the late nineteenth century through the twentieth century and into the present. The people's memories presented in this book breathe life into the story of African Diaspora in the post-emancipation period.

\section{What is the Relationship Between Oral History and Archeology?}

How do the memories of twentieth-century informants relate to the historical archeology of a nineteenth-century farmstead? In the case of this project, the answer is simple. The narratives in this book and the archeology of the Williams farmstead are intimately related. The oral history, historic documents, and archeological remains represent different types of evidence used for the same purposeto reconstruct an accurate historical narrative of African American life. The historic documents and archeology tell the first half of the story, from the antebellum period through the turn of the century. The oral history narratives in this book tell the second half of that story, but there are also significant overlaps since many interviewees recalled social and cultural practices that were passed down to them by their elders.

In no other archeological project in Texas have the stories of an African American family and the related descendant communities been so fully explored through documents, material culture, and living memories. The farm and household chores that people talked about in their interviews are well represented by the nineteenth-century artifacts found at the Williams farmstead. People interviewed, for example, speak of using horses and mules for transportation and work (e.g., riding to school, pulling wagons and plows, hauling water). This corresponds with the many types of horse-related artifacts 
found at the Williams farmstead that denote the same tasks, such as bridle bits, horse shoes, halter buckles, harness clips, and a horse medicine bottle. Similarly, the narrators talk about the importance of education in their families. It is clear that Ransom and Sarah, although illiterate themselves, valued education and sent their children to school. This was not only recorded in archival documents but is evidenced by the writing utensils found at the Williams farmstead (e.g., blackboard slate fragments, pencil leads and eraser bands, ink bottles). Such links between the oral histories and the Williams farmstead archeological record will be described in the upcoming archeology report.

The rather fortuitous discovery of the great-grandchildren of Ransom and Sarah Williams, three of whom live in Austin and provided interviews that appear in this book, provides an even more tangible link between the past and the present. We did not find out about these relatives until after most of the other interviews were completed, and Franklin had to scramble to get these interviews. Their memories help bring the story of the Williams family full circle, from before emancipation to the present. The oral histories also make it clear that the Williams family was always part of a larger community of friends and relatives. That many of our African American informants are not related to the Williamses by blood does not matter in the broader context. They are all part of the descendant community that is forever bonded by a common heritage shared by many African Americans.

\section{A Precious Legacy}

The set of narratives contained in this book, transcribed from over 46 hours of audiotaped interviews, represents a priceless historical collection. The entire project team felt that completion of this book was a high priority so that we could give something back to the descendant community in a

timely fashion. We freely admit that we can never fully repay the people who graciously agreed to be interviewed and whose stories appear here. We are honored that they shared their memories with us, and allowed them to be shared with a larger audience. We hope that they will consider this book to be partial payment for the gift that they have given all of us. Their stories are a valuable contribution to the state's efforts to preserve Texas history. 


\section{CHAPTER 1: INTRODUCTION TO THE RANSOM AND SARAH WILLIAMS FARMSTEAD PROJECT}

The Ransom and Sarah Williams Farmstead Project is pretty exceptional for a host of reasons. There is the captivating and inspiring history itself of a recently emancipated man who registered to vote and scraped together enough money to purchase his own property. He and his wife Sarah, also formerly enslaved, raised a family, farmed, held on to their land, and managed to escape the poverty that was the intended lot for Southern blacks under Reconstruction and Jim Crow. ${ }^{8}$ Although they were illiterate, all of their children could read and write (Myers and Boyd 2008). Archeological evidence, including writing slate fragments, fine transfer-printed ceramics, toys, articles of personal adornment, and other remains of the Williamses' household goods suggest that the family was attempting to move up in the world and was conscious of the roles that education and consumerism played in their social mobility. Archeologists with the Texas Department of Transportation and Prewitt and Associates, Inc., recognized the significance of the site before its 2009 excavation, and they were later proven correct in their assessment. The site has yielded 26,000 artifacts and several intact landscape features. As a focal point for archival research, it has led to a better understanding of the demographics, settlement patterns, and lifeways of early Bear Creek and Manchaca settlers, both black and white (Myers 2009, 2011).

Yet it was not only the nod from TxDOT to move forward with historical and archeological investigations of the site that merits noting. In their 2008 report to TxDOT, Myers and Boyd recommended expanding the enterprise to include community outreach, especially with local African Americans. Arguing persuasively for the importance of using archeology as a means of public education and raising the awareness of otherwise relatively unknown chapters of central Texas history, the authors also indicated that African Americans had a right not only to learn about this research, but to play a role in producing the historical narrative of black experiences in the region. Thus, the project was expanded to include outreach and public education, with an oral history component added as a way to co-create a history of Hays and Travis Counties.

\footnotetext{
8 "Jim Crow" refers to the era between ca. 1877 and 1965 when state and local laws were passed in the South that sanctioned racial segregation in public facilities (e.g., schools, public transportation, and businesses). Kristina DuRocher (2011) notes, importantly, that racial violence-including lynching-and a culture of white supremacy worked hand in hand with Jim Crow laws to maintain white rule. Historians (e.g., Chafe et al. 2011; DuRocher 2011) identify 1877 as the beginning of Jim Crow, since Reconstruction was at an end, and the gains in black civil rights and political representation made during this short period were soon abolished. Solidifying Jim Crow's grip on the South was the Supreme Court case of Plessy v. Ferguson, which made "separate but equal" facilities constitutional in 1896. The 1954 landmark Supreme Court case of Brown v. Board of Education made public school segregation unconstitutional, and the Civil Rights Act of 1964 and the Voting Rights Act of 1965 finally served to abolish Jim Crow laws.
} 


\section{THE ORAL HISTORY PROJECT AREAS}

The oral histories were co-produced with narrators who grew up in East Austin, Manchaca, the Prairie, and Antioch Colony. While each has its own distinctive history, they were linked by the relationships people formed as they traveled between these areas. The interviewees were instrumental in helping us to understand the nature and contexts of these interrelationships through migration, travel, marriage, church, and school. By way of introduction, the following is a brief overview of each of the communities that interviewees discussed in their oral histories. A more thorough discussion of the historical background of each is provided in Chapter 2 .

The small city of Manchaca (Figure 1) in Travis County is located roughly 13 miles south of downtown Austin. Although founded in 1881, the area had black and white settlers before then, including Ransom and Sarah (see Figure 1). Most families in Manchaca, which was never populous, farmed for a living. They were not alone, as agriculture was a dominant feature of life throughout rural Texas prior to the 1940s. This was especially so for freedmen and their children.

About five miles from Manchaca lies Antioch Colony (see Figure 1). The colony was settled right after emancipation by freedmen who purchased land just west of what would become, over a decade later, the town of Buda. By that time, Antioch, which had its own church and school, was a beacon to other black families. They moved into Antioch and also into an area close by known as the Prairie (see Figure 1). The Prairie is located just east of Buda and Onion Creek, but despite the boundaries, the African Americans who settled there had close ties to Antioch.

While most African Americans, once freed, remained in rural areas and farmed, others struck out toward cities. Austin was already home to African Americans prior to emancipation, and during the late nineteenth century there were all-black colonies in various areas of the city (Mears 2009). By the 1920s, however, the area east of what is now I-35 (see Figure 1) attracted increasing numbers of African Americans. East Austin today is still home to a historically black community that by 1930 boasted churches, businesses, and a number of schools, including two colleges. As the closest major city, Austin attracted people from surrounding areas, who made trips to town for shopping, entertainment, and to visit relatives. African Americans from rural communities also migrated to Austin in search of better opportunities. This included Will Williams, the son of Ransom and Sarah Williams, and Sarah herself.

Given the scope of the project and the interdisciplinary approach that was employed (incorporating archeology, oral history, and history), it has been possible to produce a comprehensive and multifaceted narrative of lifeways not only on the Williams farmstead, but also within the broader area that straddles Travis and Hays Counties. While it has been a challenge to consider the various lines of evidence that result from interdisciplinary research when moving forward with interpretations, it has been most productive. The narratives co-produced by the interviewees for this project played a central role in this endeavor. The lead title of this report, "I'm Proud to Know What I Know," is a quote from Floris Sorrells' interview in which she expounds upon the practices of rural living that her elders taught her, ones that she firmly believes would allow her to live independently and off of the land if she ever needed to do so again. The social transmission of knowledge across the generations is one of the threads that tie the oral histories together.

\section{PUBLIC EDUCATION}

In terms of public education and the goals of raising awareness of, and generating interest in, African American history and archeology, we've attempted to reach a broad and diverse audience. One factor that has helped immensely is that the project hasn't been a hard sell. People are drawn to the 


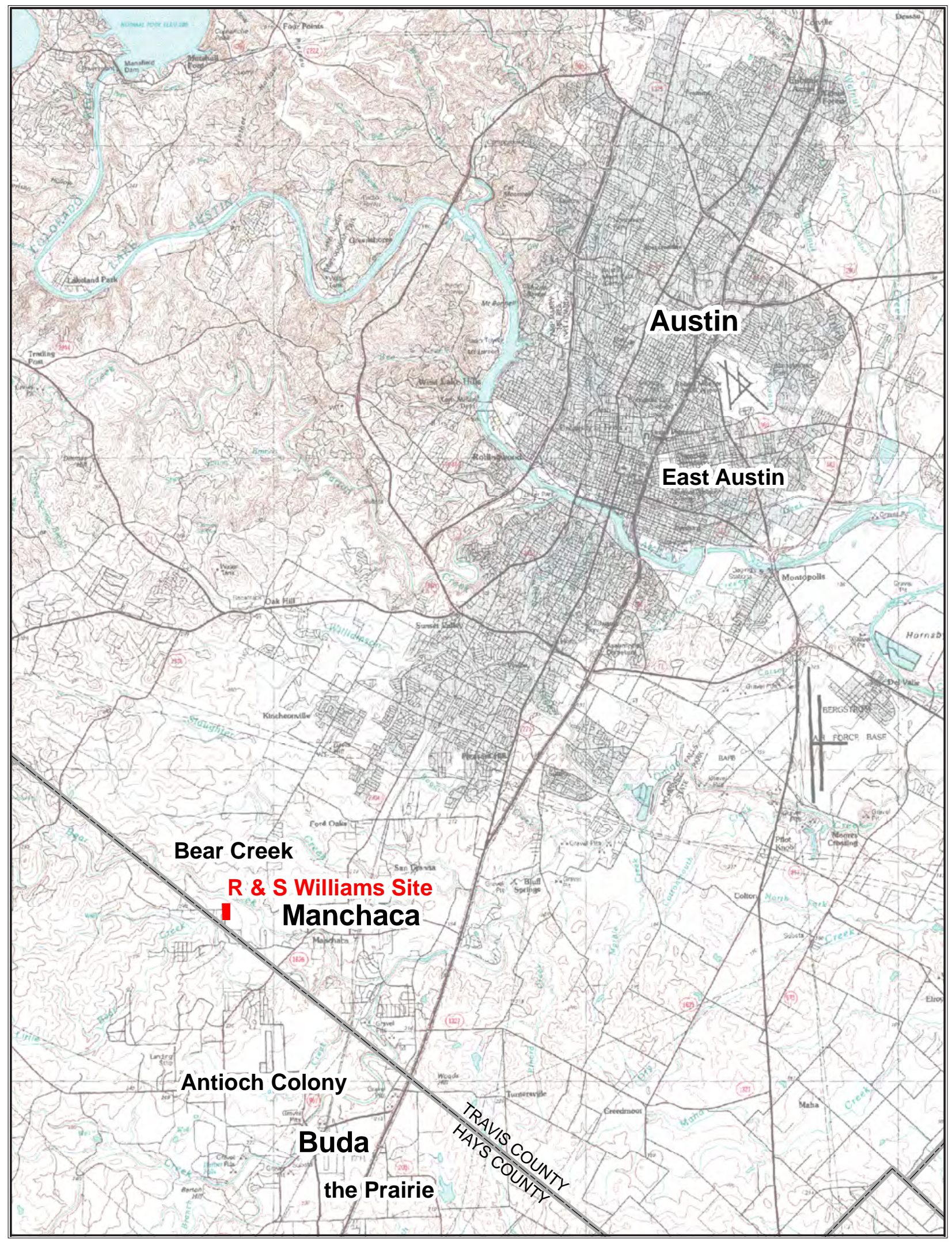

Figure 1. Map of southern Travis and northern Hays Counties showing the location of the Ransom and Sarah Williams farmstead in relation to Austin, Bear Creek, Manchaca, Antioch Colony, Buda, and the Prairie. 
story of Ransom and Sarah, eager to learn what interviewees have shared in narrating their memories, and curious about archeology in general. Michael Emery, a producer for KLRU public television in Austin, highlighted the Ransom and Sarah Williams project in their annual Juneteenth Jamboree broadcast in 2010 in which he interviewed both researchers and descendants who participated in the oral history project. The University of Texas at Austin featured the research as the lead article on its home web page and subsequently published the article in the College of Liberal Arts magazine, Life \& Letters (Wahlberg 2010; see also Boyd et al. 2010). Prewitt and Associates created an exhibit on the archival, archeological, and oral history research for the Public Archaeology Expo at the 2011 annual meeting of the Society for Historical Archaeology in Austin. An estimated 550 people attended the event, including local families with children. There have been other initiatives as well, including academic and professional presentations, community lectures, and organized visitations to the Williams farmstead site.

The Ransom and Sarah Williams Farmstead Project demonstrates the strides that cultural resource management (CRM) firms and state agencies have made in contributing to the increasing efforts, throughout the United States, in public outreach and community-based archeology (Agbe-Davies 2010; Colwell-Chanthaphonh and Ferguson 2007; Herscher and McManamon 2000; Jameson 1997; Leone et al. 2005; Little and Shackel 2007; McDavid 2002, 2004; McDavid and McGhee 2010; Nassaney and Levine 2009). At this juncture, the public education efforts are still in progress. Meanwhile, the interdisciplinary research of the Ransom Williams Farmstead Project has come to a close. This twovolume report is a result of the oral history research over a two-year period. Interviewees were all supportive of the idea of providing public access to their oral histories for research and educational purposes. For some, there was a sense of urgency to record their pasts and that of their ancestors, and to ensure their preservation and accessibility. Nothing underscored these points more poignantly than the passing away of Anthy Lee Revada Walker, Essie Mae Owens Sorrells, and Moses Harper, Sr., less than a year after their interviews. This collection is dedicated to their memory.

\section{THE ROLES OF ORAL HISTORY IN THE RANSOM WILLIAMS FARMSTEAD PROJECT}

While our public education efforts are geared toward a broad audience, we mainly focused our community outreach at the local level and tried to identify African Americans who grew up in areas in close proximity to the Williams farmstead. We attempted to locate individuals who might have an interest in this research and be willing to be interviewed. There was also a second group that we sought to locate: the lineal descendants of Sarah and Ransom. The project team hoped to discover how the Williamses' story evolved and wished to at least share the results of the archeological and archival research with the descendants, irrespective of their willingness to be interviewed.

The oral history project served several purposes. First, it served as a way to engage with locals from the surrounding communities by providing an entry point to introduce the broader research program to them, and to invite them to learn about African American archeology. Second, we never doubted that these stakeholders would have knowledge of interest to us. Thus, the oral histories served as an independent line of evidence in contextualizing and interpreting the findings from the Williams farmstead site. There was also the question of what became of the descendants of freedmen who settled in Travis and Hays Counties. Third, although the oral history effort constitutes an anthropological research project unto itself, our objective is to eventually work with narrators in integrating the oral histories with the results of the archival and archeological research in our public education products. 
Community-based archeology projects have grown in popularity over the years as archeologists have become increasingly aware of the need to engender public support for the preservation of cultural and historical resources, and to recognize that others beyond the profession also have a legitimate vested interest in the past (e.g., McDavid 2002; Mullins 2007; Reeves 2004; Saitta 2007a). Several of these research projects created volunteer programs in which members of the community dug alongside archeologists (e.g., Leone 2005; see chapters in Stottman 2010). Since the Williams farmstead site was located on state property, liability issues precluded the possibility of running a volunteer program. Researchers have also used oral history projects, oral tradition, and ethnographic (or "field") interviews in partnering with communities in defining the research goals and in co-creating the historical narrative of heritage sites (Beck and Somerville 2005; Friesen 2002; see chapters in Hamilton and Shopes 2008; McClanahan 2006; Meskell and Van Damme 2008; Moser et al. 2002; Praetzellis et al. 2007; Purser 1992; Scott 2003; Shackel and Gadsby 2008; Stahl 2004). Thus, the oral history project, while research based, also served as a vehicle for community outreach.

Since the archeological and archival research questions focused on the post-emancipation lifeways of the Williams and other black farming families in Travis and Hays Counties, the oral history research largely, though not exclusively, followed suit. The areas of interest that I developed questions for included household practices, identity formation, and social relationship. In an initial consultation with Doug Boyd, these were some of the topics that we felt would help to better integrate the oral history research into the broader research program (see also Oral History Methodology section below). Thus, our oral history project now had some guidelines to follow in identifying and selecting narrators that we could, simultaneously, conduct outreach with. In contacting potential interviewees, and in conducting the interviews, I found ample time to discuss the archeological and historical research as well. Folks were encouraged to visit the Williams site during the summer of 2009 as excavations took place. Nearly half of those interviewed in that year did so, and some brought family members along as well.

With regard to the role of the oral histories in the Ransom and Sarah Williams Farmstead Project, they made it possible to extend the timeline of our investigations of the Williams family to encompass the stories of later black families who inherited the freedmen's legacy. The narratives, along with the archival research, helped to historically contextualize the site and interpret the data gathered there. Yet our motives for interviewing people were not exclusively defined by the research parameters of the archeology (see In Search of Potential Narrators below). We found interviewees that we hadn't initially planned to interview while doing community outreach. There were also the lineal descendants of the Williamses that the project team and TxDOT hoped to locate and interview. At the time, we had no idea whether or not they remained in Manchaca. In the end, we interviewed people who grew up in households in rural areas near the Williams site during segregation. We also interviewed other descendants raised in Austin. Though most were African American, two of our interviewees were white. What they and their families had in common was a heritage deeply rooted to the region (most of them never left or have returned) and who felt that their family's past was well worth preserving and sharing. All of the interviewees, black and white, are recognized as the descendant community, which Dean Saitta (2007b:275-276) defines as:

...a non-homogenous self-identified group encompassing those who, regardless of background, identify with a particular past or locale through shared traditions, proximity, or collective memories. This is distinct from a narrower concept of "descendants" as individuals with ancestral or familial links to the archeological record.

As stated before, our public education endeavors are still in progress. We consulted with narrators in 2009 on where to focus our efforts during what turned out to be the first of two phases 
of interviews. Joan Limuel, LeeDell Bunton, Minnie Nelson, and others had informed us that they wanted the younger generations to know this history, and specifically for younger members of their family to know who and where they came from. While the Briscoe Center for American History at the University of Texas at Austin will serve as the repository for the oral histories, this may benefit researchers more than interviewees. That a prestigious archive will safeguard their narratives for years to come gave reassurance to some. But having to travel to campus was not what many had in mind when they stated their desires for their narratives to be made available to themselves and their families. People wanted something delivered to their hands that they could literally pass on to the next generation. Thus, TxDOT funded this publication, which will allow for its complementary distribution to the interviewees, local libraries, archives, museums, and schools. We believe that the Ransom and Sarah Williams Farmstead Project has had at least some measure of effect thus far in raising the public awareness of African American history and archeology in the region, but what the benefits will be for interviewees and their descendants over the long-term remains to be seen.

The oral history project, public education, and community outreach overlapped in principle and in practice, as was intended. Interviewees Corrine Harris, LeeDell Bunton, Winnie Moyer, and Joan Limuel have played a part in our public education efforts, and our goal is to expand these efforts and to work more collaboratively with them and other interviewees in the near future. Taking a community-based approach to this research strongly encouraged us to try to meet our responsibilities and obligations to those who played an integral role in the overall project, and who expressed a vested interest in the study of their own pasts.

\section{IN SEARCH OF POTENTIAL NARRATORS}

The oral history interviews took place in two phases because the direct descendants of Ransom and Sarah Williams were discovered two years after the project began. I had already submitted the final report (Franklin n.d.) on what would turn out to be the first phase of the research when the prospect of conducting additional interviews was realized. As a result, the process of identifying interviewees occurred in two episodes.

In the preceding section, I discussed the roles that the oral history research has played in the Ransom and Sarah Williams Farmstead Project. One was to employ the oral histories as a third line of evidence (in addition to the historical and archeological investigations) in interpreting the site, and in constructing a broader historical narrative of black farmers in the area prior to the civil rights movement. Thus, in selecting narrators, we looked for African Americans who grew up in farming households who were over 70 years old and/or who had knowledge of their family's history in the area. We directed our attention toward Manchaca, since the Williams homestead was located near there, and Antioch Colony in Buda, Hays County. Located about five miles from the Williams site, Antioch Colony was the closest black settlement that our project historian, Terri Myers, had identified at that time. Thus, we originally thought that the Williams family sent their children to school at Antioch and attended church there, though Myers later discovered that a black school was founded in Manchaca during the late nineteenth century.

Yet it was also our intention to try to locate and interview the Williamses' lineal descendants. In tracing the Williamses' children in the historical record, Myers discovered in the 1930 U.S. census that a widow named Mary Davis was living with her cousin, Emma Bunton, in Austin (Figure 2; Myers and Boyd 2008). Mary Williams, the daughter of Ransom and Sarah, did marry a man with the surname of Davis. Emma (Friend) Bunton's identity as an Antioch descendant is beyond question, since Emma's mother, Elizabeth (Smith) Friend, one of the founding settlers of Antioch, was living in the house 
with her and Mary. Emma's descendants would be distant relatives to the Williamses, but related nonetheless. We hoped they would be knowledgeable about the Williamses' direct descendants.

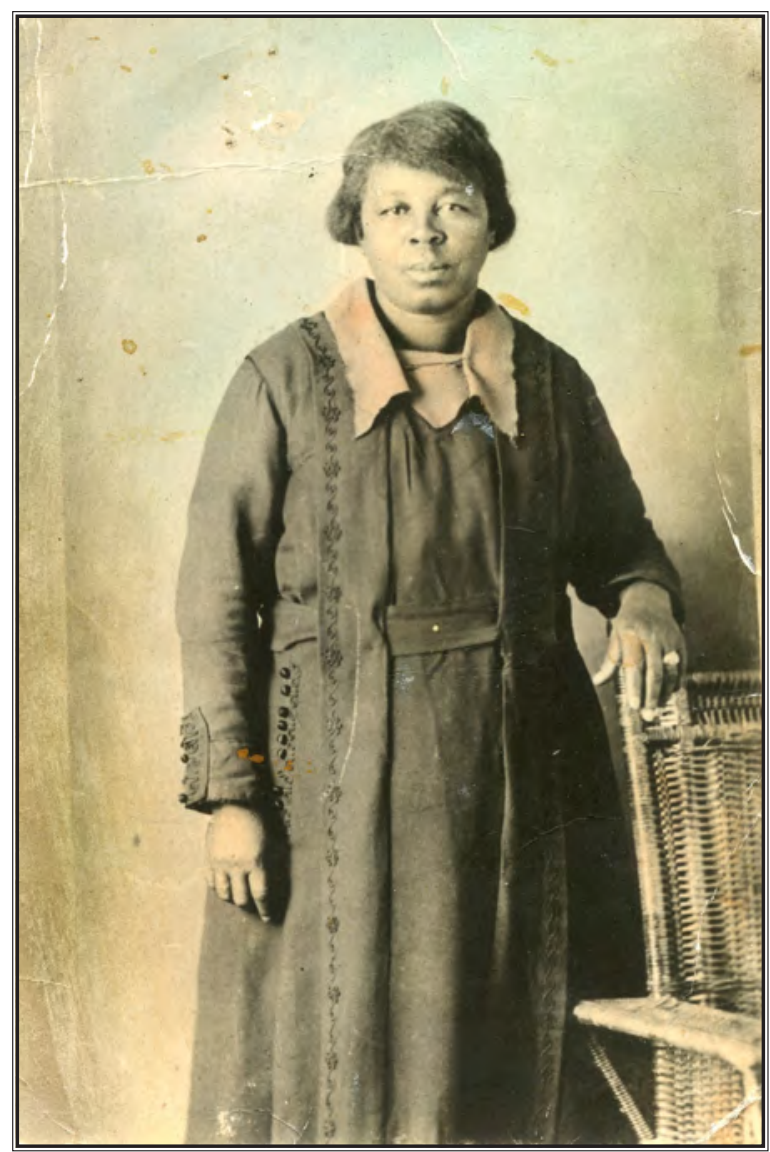

February to June 2009
Figure 2. Emma (Friend) Bunton (b. 1868; d. January 4, 1941), Austin, Texas, date unknown. Bunton is the daughter of Jack and Elizabeth Friend, who helped found Antioch Colony. She is the grandmother of Lillie Grant, great-grandmother of Lee Wildon Dawson, and great-aunt of LeeDell Bunton, Sr. Photograph courtesy of Lillie Grant.

Using the oral history project as a vehicle for outreach, I first sought out African Americans with ties to Antioch Colony, especially Emma Bunton's descendants. News coverage of Antioch Colony descendants in the Austin American-Statesman (Gee 2000) gave clear indication that there were still families living there with strong historic roots to the settlement who might be interested in our research. LeeDell Bunton, Sr., proved easy to locate. I simply called him at his home in Phoenix, and he ended up playing a major role in the project. Bunton is a direct descendant of Dave and Mary Bunton (Emma's in-laws), who helped to establish Antioch, and a great-grandnephew of Emma Bunton. He is also an avid genealogist who has conducted extensive research on Antioch Colony. Over the years he has amassed stacks of family trees, historic photos, and other primary documents. The project team and Bunton have exchanged notes and sources over the two-plus years that we've known him. From there it was mainly by word of mouth that I was introduced to others whom we shared our research findings with, hosted site visitations for, and who were willing to be interviewed. Bunton graciously paved the way for us to meet other Antioch and Prairie descendants, including his aunts and uncles, the Harpers, and the Revadas. Although he didn't know who the Williamses were, he put me in touch with his cousin, Lee Wildon Dawson, Emma Bunton's great-grandson. I interviewed Dawson and his aunt, Lillie Grant, Emma's granddaughter. For some time, Grant, Bunton, and Dawson were the closest relations to Ransom and Sarah that we could find. 
In locating Manchaca descendants, we contacted Rachel Feit, an archeologist with an Austin CRM (cultural resource management) firm, who provided us with the contact information for Rene Pickard, who grew up near Bear Creek. Mr. Pickard and his uncle, Marcus Pickard, Jr., were both interviewed. The Pickards are direct descendants of Chatham and Ann Perry, some of the first African Americans to settle in Manchaca following emancipation (Myers 2011). The Pickards are also descended from the Kavanaughs of Antioch Colony. It was Rene Pickard's mother, Ray Pickard, who provided me with Robbie (Dotson) Overton's phone number. Overton spent part of her childhood in Manchaca before relocating to East Austin with her family. The Dotsons were well known in Manchaca, and Overton is descended from a second group of African American Buntons who had settled in Buda and Manchaca (Figure 3). Overton's mother was born Carrie Bunton. ${ }^{9}$ Overton introduced me to her uncle, Earlee Bunton, and her first cousin, Annie (Dotson) Axel.

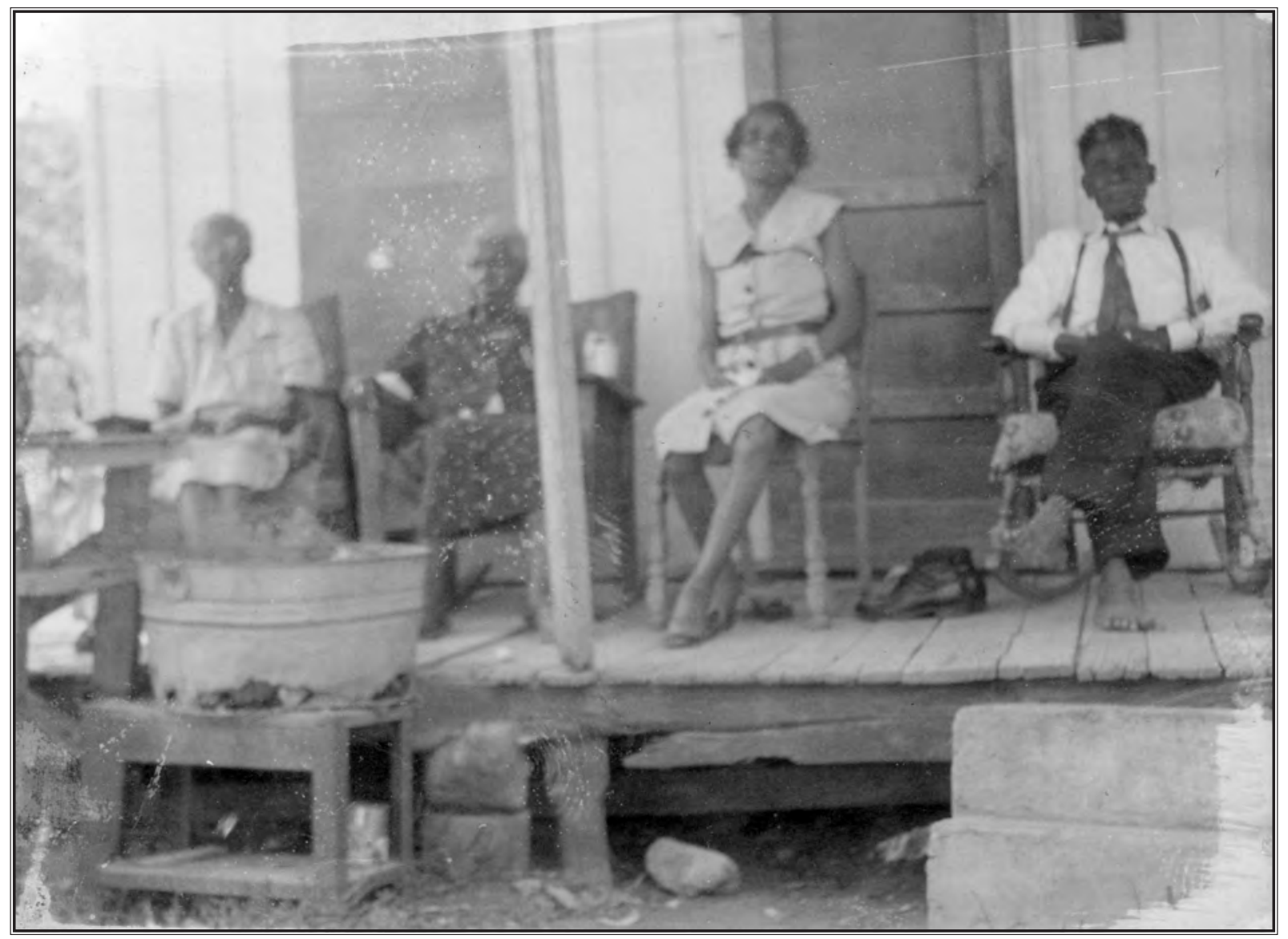

Figure 3. From left to right: Eliza Brown Bunton, unidentified woman, Carrie Bunton Dotson, and Ike Brown. Photograph taken at Eliza Bunton's house at $8^{\text {th }}$ Street and San Saba, Austin, Texas, date unknown. Bunton, Dotson, and Brown are, respectively, the grandmother, mother, and grand-uncle of interviewee Robbie Overton and the mother, sister, and uncle of interviewee Earlee Bunton. Photograph courtesy of Earlee Bunton.

As word spread, and we were able to interview more people (although not everyone reached said yes), Terri Myers tried to locate those who might have knowledge of the Williams family. A strategically

${ }^{9}$ LeeDell Bunton, in tracing his own genealogy, also conducted research on the Manchaca Buntons. He was unable to determine whether he was related to them or not. Robbie Overton and Earlee Bunton were likewise unable to establish this. Undoubtedly, they were all descended from the Buntons once enslaved (though not necessarily all kin related) by the three Bunton brothers who arrived in Mountain City (near Buda) from Tennessee and Kentucky prior to emancipation (Myers 2009, 2011). 
placed flier posted at the Manchaca Post Office led to outreach over the course of this project with the Manchaca/Onion Creek Historical Association (MOCHA), a local grassroots organization whose mission is to "...race against time to preserve local history." ${ }^{10}$ Members of the group shared their family histories and knowledge of the region, visited the site, and hosted lectures given by Boyd, Myers, and myself. Marilyn McLeod's ancestor, Victor Labenski, was a neighbor of the Williams family, though she possessed no knowledge of them. It was McLeod who contacted KLRU producer Michael Emery and told him about our project, which led to its inclusion in the 2010 Juneteenth Jamboree program. We were also able to identify more interviewees via MOCHA. Ann and Barry Trask had contact information for Estella Black, who was born into the Hargis family. It turned out that Black was a first cousin to interviewee Marcus Pickard and likewise descended from Ann and Chatham Perry. I also interviewed MOCHA members Joanne Deane and Lillie Meredith Moreland, both longtime residents of Manchaca/ Bear Creek and descendants of the area's earliest non-native settlers. Deane and Moreland were able to provide an account of life in the area from the perspective of Euro-American descendants.

\section{September 2010 to July 2011}

Despite our outreach and oral history research efforts, for nearly two years we were unable to locate any direct descendants of Ransom and Sarah Williams. Bunton, Grant, and Dawson remained the closest living kin to the Williamses that we had located until September 2010, when Myers managed to find some of their greatgrandchildren. An article published in the Austin American-Statesman (Lowry 1974) included an interview with Clara Franklin Williams, who had just celebrated her $100^{\text {th }}$ birthday in Austin (Figure 4). Clara was the widow of Will Williams, the eldest child of Ransom and Sarah (Figure 5). There was also a list of Clara and Will's seven children, indicating that at least some of them had settled in Austin.

In tracing the names of Clara and Will's children, Myers was able to locate Corrine Harris, a granddaughter of Will and Clara Williams.Harris was unaware of who her paternal great-grandparents

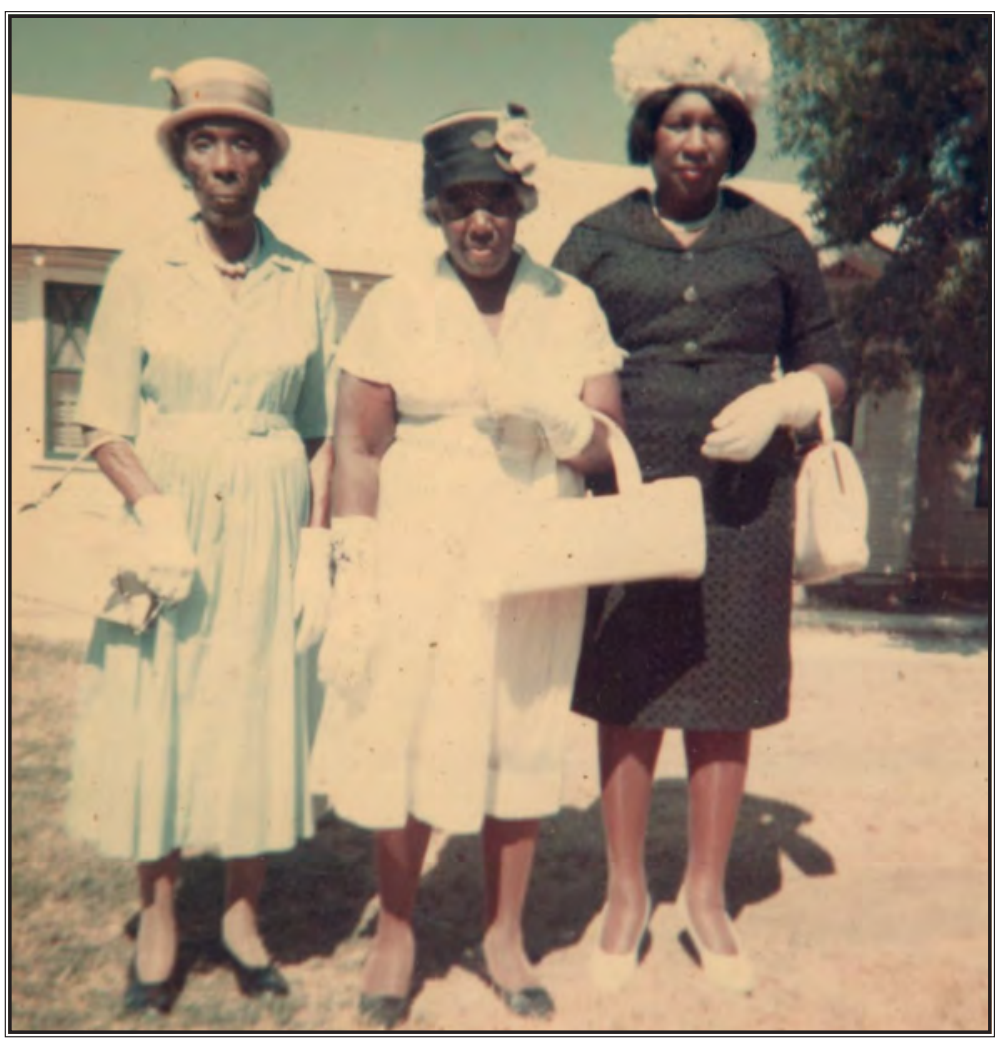

Figure 4. From left to right: Clara Franklin Williams (b. September 14, 1874; d. December 12, 1977), unknown family friend, and Mabel Williams Medlock, 1974, Austin, Texas. Clara is the mother of interviewees Corrine Harris, Jewel Andrews, and Lourice Johnson, and Mabel is their paternal aunt. Photograph courtesy of Corrine Harris.

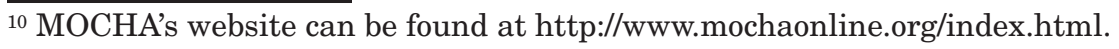


were, and so our project came as a surprise. She accompanied Myers to the annual meeting of the Society for Historical Archaeology, held in Austin in January 2011, to see the exhibit on the Ransom and Sarah Williams Farmstead Project created by Prewitt and Associates (Figure 6). Harris agreed to be interviewed, and she provided me with the contact information for her sisters, Lourice Johnson and Jewel Andrews.

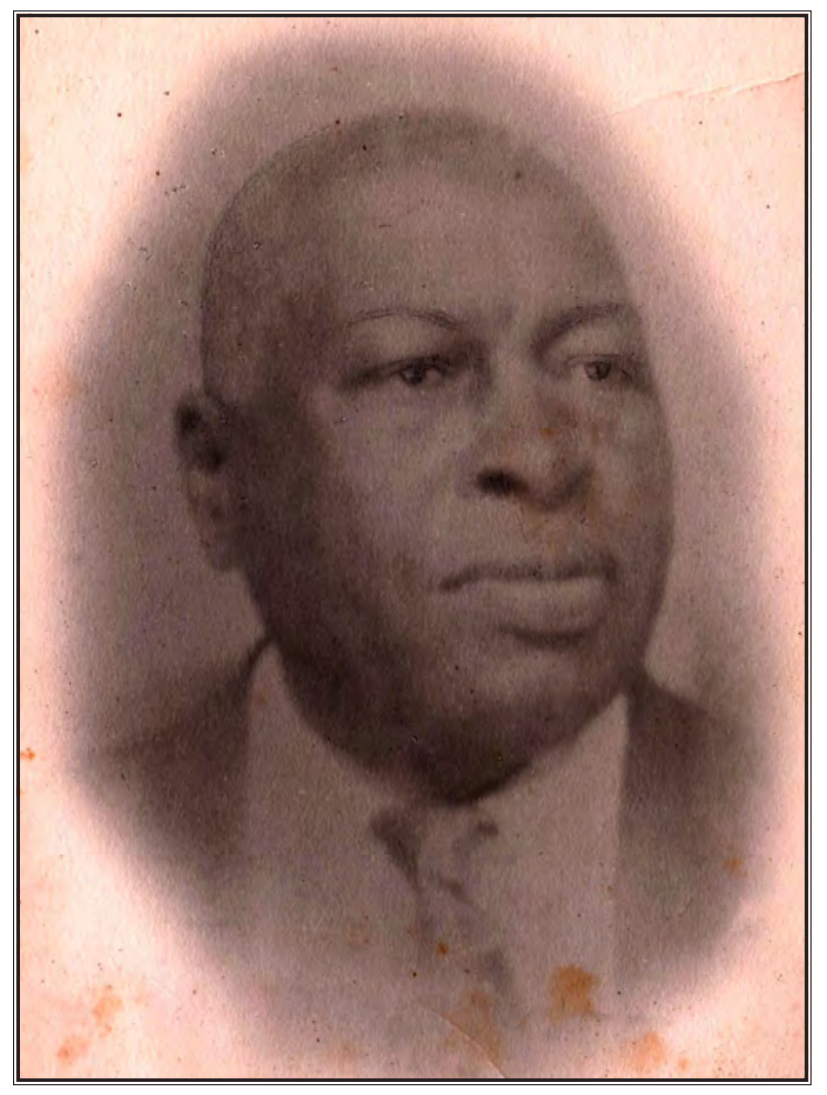

Figure 5. Will Williams (b. February 23, 1876; d. June 12, 1954), circa 1940. Williams is the son of Ransom and Sarah Williams and grandfather of interviewees Jewel Andrews, Corrine Harris, and Lourice Johnson Photograph courtesy of Corrine Harris.

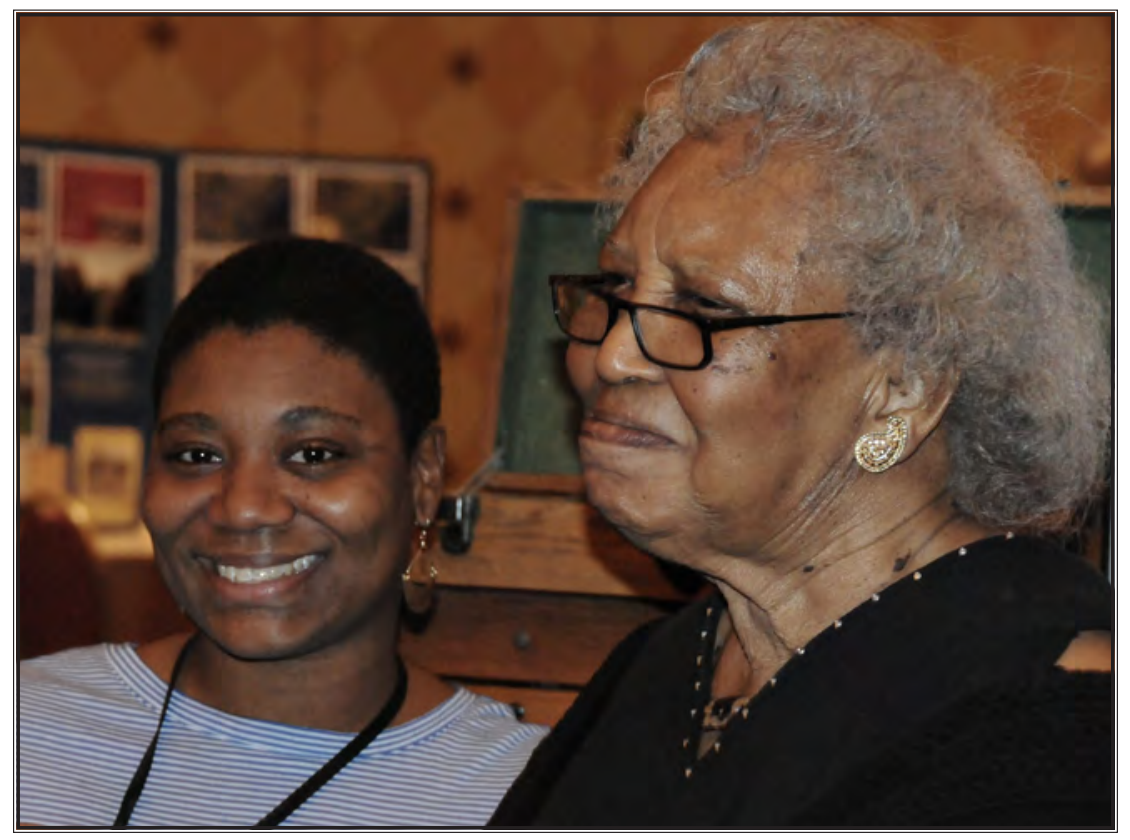

Figure 6. From left to right: Nedra Lee (Prewitt and Associates and UT Anthropology graduate student) and Corrine Harris, greatgranddaughter of Ransom and Sarah Williams, at the Public Archaeology Expo, Society for Historical Archaeology annual meeting, January 2011. Photograph by Bill Pierson, courtesy of the Texas Historical Commission. 
In addition to the Williamses' descendants, I interviewed members of the Sorrells family. The surname was mentioned by a number of people I had spoken to in 2009; the Sorrells were some of the earliest black landowners in Manchaca. Moreover, there were Sorrells who had lived in Antioch Colony and on the Prairie (there are still some Sorrells residing in the Goforth area). At least two Sorrells are buried in the Antioch Cemetery. Given that the Sorrells had connections to both Buda and Manchaca, and may be distantly related to the Williamses (again, through Emma Bunton), I persisted in trying to find at least one descendant. Requests for their contact information, however, led to dead ends ("they're kind of private," "they're not interested in being interviewed," "I used to have their phone number, but it's been years"). Though I obviously preferred to "meet" potential narrators through at least mutual acquaintances (e.g., see Mould 2009:92), I didn't have that luxury this time. In July 2011, I got lucky with an online phone directory on my third try. I spoke with Floris Sorrells, and from there, with her aunt and first cousins. Subsequently, three generations of the family were interviewed.

\section{Remarks}

The selection of narrators began with two general criteria in mind: 1) identifying African Americans, especially those over 70 years, who were raised in farming households in the vicinity of the Williams site, and 2) identifying descendants and other kin relations of the Williamses. We were successful in finding narrators who could speak from experience about rural black lifeways in Manchaca and Buda, although not all of them were born before 1940. However, while undertaking outreach with MOCHA, Boyd and I decided that the project should interview some of its members as well. They were committed to the area's history, and as a group they had done more research on it than anyone else. Interviewees Deane and Moreland have pretty much spent their entire lives in Manchaca, and working with them proved to be productive for both MOCHA and us. We were also able to interview the lineal descendants of the Williamses and other more distant kin. While Harris, Andrews, and Johnson grew up in East Austin and could not comment on rural lifeways, that was never our intention in interviewing them. Instead, we were interested in getting their thoughts about the research on their ancestors, finding out whether they knew why Sarah Williams and her children left Manchaca, and learning more about the Williams family through the generations.

The Williamses' great-granddaughters were raised next door to their grandparents, Clara (Franklin) Williams and Will Williams. Johnson, Harris, and Andrews did not know about their greatgrandparents, but their reflections on being raised by their parents and grandparents revealed some about what Will likely learned from Ransom and Sarah that was passed down to his descendants. The importance of having faith in God and being active in the church, of hard work, getting an education, owning property, and so on are evident in the oral histories of the Williamses' descendants. The story of migration from the countryside to cities, especially Austin, is also represented here as it is in many of the other interviews. Families from Manchaca and Buda, including the Harpers and Overtons, left rural living behind for better opportunities in urban areas, but still the expressed ties to their childhood homes and heritage emerge strongly in their narratives. Thus, as disparate as the interviews may seem at first glance-and there is a range of diverse experiences presented-they all lead back to those ancestors who forged a living off the land in the countryside of central Texas.

\section{INTRODUCING THE NARRATORS}

Altogether, we interviewed 27 individuals from East Austin, Manchaca, the Prairie, and Antioch Colony (Table 1). At the time of their interviews (from 2009 to 2011), they ranged in age from 49 to 93 
years old, and 19 out of 27 were 70 years or older. Thus, taken together, their recollections of childhood and adolescence date roughly to the years between the 1920s and the 1970s but are weighted toward the earlier decades (pre-1950s). In terms of gender, 20 interviewees are women and seven are men. Nearly all of them are African American; two are Euro-American. There was little class differentiation between most of the interviewees' childhood families if education and occupation are used as measures. Over half of them either referred to their families as working class or described family members as having occupations (e.g., as domestics or manual laborers) that denote working-class status. Most of the interviewees were raised in households where agricultural work was the main source of income, at least for a portion of their household's lifespan.

Table 1. Interviewees by gender, race, dates of birth and death, and former household's place(s) of residence.

\begin{tabular}{|c|c|c|c|c|}
\hline Interviewee & Gender & Race & Birth; Death & Place of Residence \\
\hline Jewel (Williams) Andrews & $\mathrm{F}$ & $\mathrm{B}$ & $11 / 24 / 1938$ & Austin \\
\hline Annie (Dotson) Axel & $\mathrm{F}$ & $\mathrm{B}$ & $11 / 2 / 1924$ & Manchaca \\
\hline Estella (Hargis) Black & $\mathrm{F}$ & $\mathrm{B}$ & $1 / 14 / 1917$ & Manchaca \\
\hline Earlee Bunton & $\mathrm{M}$ & $\mathrm{B}$ & $9 / 5 / 1915$ & Manchaca \\
\hline LeeDell Bunton, Sr. & $\mathrm{M}$ & $\mathrm{B}$ & $9 / 19 / 1946$ & Antioch Colony \\
\hline Lee Wildon Dawson & $\mathrm{M}$ & $\mathrm{B}$ & 9/3//1948 & Austin \\
\hline Joanne Deane & $\mathrm{F}$ & $\mathrm{W}$ & $7 / 3 / 1936$ & Manchaca \\
\hline Cedel (Sorrells) Evans & $\mathrm{F}$ & $\mathrm{B}$ & $7 / 3 / 1956$ & Manchaca; Austin \\
\hline Ruth (Harper) Fears & $\bar{F}$ & $\bar{B}$ & $5 / 4 / 1931$ & Antioch Colony \\
\hline Lillie Grant & $\mathrm{F}$ & B & $10 / 18 / 1923$ & Prairie \\
\hline Moses Ollie Joe Harper, Sr. & $\mathrm{M}$ & B & $7 / 26 / 43 ; 12 / 18 / 2009$ & Antioch Colony \\
\hline Samuel Harper & $\mathrm{M}$ & $\mathrm{B}$ & $6 / 10 / 1945$ & Antioch Colony \\
\hline Corrine (Williams) Harris & $\mathrm{F}$ & B & $7 / 19 / 1928$ & Austin \\
\hline Earselean (Sorrells) Hollins & $\mathrm{F}$ & B & $3 / 24 / 1946$ & Manchaca; Austin \\
\hline Lourice (Williams) Johnson & $\bar{F}$ & $\mathrm{~B}$ & $10 / 18 / 1932$ & Austin \\
\hline Joan Nell (Revada) Limuel & $\mathrm{F}$ & $\mathrm{B}$ & $3 / 24 / 1934$ & Antioch Colony \\
\hline Lillie (Meredith) Moreland & $\mathrm{F}$ & $\mathrm{W}$ & $5 / 29 / 1924$ & Manchaca \\
\hline Winnie (Harper) Moyer & $\bar{F}$ & $\mathrm{~B}$ & $7 / 29 / 1937$ & Antioch Colony \\
\hline Minnie (Harper) Nelson & $\mathrm{F}$ & B & $7 / 29 / 1937$ & Antioch Colony \\
\hline Robbie (Dotson) Overton & $\mathrm{F}$ & $\mathrm{B}$ & $5 / 14 / 1935$ & Manchaca; Austin \\
\hline Marcus Leon Pickard, Jr. & $\mathrm{M}$ & $\mathrm{B}$ & $1 / 1 / 1933$ & Manchaca \\
\hline Rene Pickard & $\mathrm{M}$ & $\mathrm{B}$ & $11 / 19 / 1957$ & Manchaca \\
\hline Kay (Hollins) Randall & $\mathrm{F}$ & B & $4 / 10 / 1962$ & Manchaca; Austin \\
\hline Floris Lean Sorrells & $\mathrm{F}$ & $\mathrm{B}$ & $5 / 10 / 1939$ & Manchaca; Prairie \\
\hline Essie Mae (Owens) Sorrells & $\mathrm{F}$ & $\mathrm{B}$ & 6/18/1924; 1/17/2012 & Manchaca; Austin \\
\hline Anthy Lee (Revada) Walker & $\mathrm{F}$ & $\mathrm{B}$ & $9 / 14 / 1915 ; 5 / 10 / 2010$ & Antioch Colony \\
\hline Marian (Harper) Washington & $\mathrm{F}$ & B & $1 / 18 / 1925$ & Antioch Colony \\
\hline
\end{tabular}

The oral histories mainly focus on interviewees' memories of childhood and adolescence. Thus, the social context of their recollections mainly reflected interviewees' former dependent status as members in households headed by-in these cases—single mothers, parents, or grandparents. Thus, although there are 27 interviewees, since a number of them were once members of the same household, the oral histories also represent 16 households. In Table 2, the households are listed by surname along with the interviewees who once belonged to them (see Appendixes A and B). For each interviewee, the "time span" indicates the years in which they were members of that household. This data is important for understanding the life cycle of households, which change in composition and social relations over time. Household heads may divorce, or members of households pass away, are born, or leave (mainly as they reach maturity). The Harper household is a case in point. By the time LeeDell Bunton was born 
into his grandparents' household, a number of his aunts and uncles, who were 10 to 20 years his senior, had already left. Households can also divide. Not long after the birth of Essie Mae and Virgil Sorrells' sixteenth child, Essie Mae moved to Austin, and several of her children eventually joined her. This is why she is listed in Table 2 twice: once with her husband Virgil, and the second time as the head of her own household.

Table 2. Interviewees' former households by head(s) of household's surname, place of residence, source of household income, and years of household membership by interviewee.

\begin{tabular}{|c|c|c|c|c|}
\hline Household & Interviewee & Place of Residence & $\begin{array}{c}\text { Major Source of } \\
\text { Household Income }\end{array}$ & Time Span \\
\hline Harper & $\begin{array}{l}\text { Marian Washington } \\
\text { Ruth Fears } \\
\text { Winnie Moyer } \\
\text { Minnie Nelson } \\
\text { Moses Harper } \\
\text { Samuel Harper } \\
\text { LeeDell Bunton, Sr. }\end{array}$ & Antioch Colony & Farm labor & $\begin{array}{l}1924-1946 \\
1931-1948 \\
1937-1955^{\mathrm{a}} \\
1937-1955^{\mathrm{a}} \\
1943-1955^{\mathrm{a}} \\
1945-1955^{\mathrm{a}} \\
1946-1955^{\mathrm{a}}\end{array}$ \\
\hline Revada & $\begin{array}{l}\text { Anthy Lee Walker } \\
\text { Joan Nell Limuel }\end{array}$ & Antioch Colony & $\begin{array}{l}\text { Tenant farmers } \\
\text { Farm and wage labor }\end{array}$ & $\begin{array}{l}1915-1931 \\
1938-1947 \\
\end{array}$ \\
\hline Grant & Lillie Grant & Prairie & Farmers & $1923-1940$ \\
\hline Bunton & Earlee Bunton & Manchaca & Tenant farmers & $1915-1936$ \\
\hline C. Dotson & Robbie Overton & $\begin{array}{l}\text { Manchaca } \\
\text { Austin }\end{array}$ & Farm labor & $\begin{array}{l}1935-1945 \\
1945-1954 \\
\end{array}$ \\
\hline J. \& I. Dotson & Annie Axel & Manchaca & Railroad section hand & $1924-1946$ \\
\hline A. Pickard & Rene Pickard & Manchaca & Farmers & $1957-1976$ \\
\hline M. Pickard & Marcus L. Pickard, Jr. & Manchaca & Educator; farmers & $1937-1955$ \\
\hline Hargis & Estella Black & Manchaca & Farmers & 1917-1935 \\
\hline Deane & Joanne Deane & Manchaca & Carpenter & $1936-2003$ \\
\hline Meredith & Lillie Moreland & Manchaca & Deputy & 1924-1941 \\
\hline A. \& M. Sorrells & Floris Lean Sorrells & $\begin{array}{l}\text { Manchaca; } \\
\text { Prairie }\end{array}$ & Farm labor & $\begin{array}{l}1939-1948 \\
1948-1962 \\
\end{array}$ \\
\hline V. \& E. Sorrells & $\begin{array}{l}\text { Essie Mae Sorrells } \\
\text { Earselean Hollins } \\
\text { Cedel Evans } \\
\end{array}$ & Manchaca & $\begin{array}{l}\text { Railroad section hand; } \\
\text { Farm labor }\end{array}$ & $\begin{array}{l}1940-1960 \\
1946-1961 \\
1956-1973 \\
\end{array}$ \\
\hline E. Sorrells & $\begin{array}{l}\text { Essie Mae Sorrells } \\
\text { Earselean Hollins } \\
\text { Cedel Evans } \\
\text { Kay Randall } \\
\end{array}$ & Austin & Wage labor & $\begin{array}{l}1960-2001 \\
1961-1969 \\
1960 \mathrm{~s}-{ }^{\prime} 70 \mathrm{~s}^{\mathrm{b}} \\
1962-1969 \\
\end{array}$ \\
\hline Williams & $\begin{array}{l}\text { Corrine Harris } \\
\text { Lourice Johnson } \\
\text { Jewel Andrews } \\
\end{array}$ & Austin & Wage labor & $\begin{array}{l}1928-1953 \\
1932-1950 \\
1938-1958\end{array}$ \\
\hline Dawson & Lee Wildon Dawson & Austin & Wage labor & 1948-1967 \\
\hline
\end{tabular}

aThis interviewee relocated with the Harper household when it moved to Arizona in 1955.

${ }^{b}$ Cedel Evans cited Manchaca as her place of residence while growing up, but she also spent much of her time in Austin with her siblings and mother after 1961.

Interviewees' households also constituted families. That is, the household members were kin related. ${ }^{11}$ Thus, the data for this project has lent some useful insights on the topic of black family and household organization for Travis and Hays Counties (Franklin n.d.). Although 13 of the 14 African American households started off as nuclear families, over their life cycles, six eventually transformed

11 While in the U.S. households are typically composed of family members, this is not always the case (here or elsewhere in the world). The U.S. census simply defines a "household” as “...all the people living together in a housing unit." 
into extended families (the Harpers, Revadas, and V. and E. M. Sorrells), single-parent families (the Buntons and Dawsons), or a combination of both (the Dotsons). Moreover, after moving to Austin, Essie Mae Sorrells became a single householder and within two years was the head of a singleparent extended family. The extended families formed mainly as a result of household heads taking in grandchildren to raise or to help raise. With regard to single-parent families, women were the heads of all four of them for different reasons. With Dawson and Sorrells, each made the decision to establish their own households. Interviewee Earlee Bunton's father passed away when he was eight years old. His niece, Robbie (Dotson) Overton lost her father while she was still an infant.

While the sample size of this study is admittedly small, one interpretation that can be drawn from the evidence given is that it resonates with other studies. Flexibility in family and household organization has a long history among African Americans, extending back into the era of slavery (Dressler et al. 1985; Gutman 1976; Malone 1992; White 1985). Although studies show that most enslaved blacks lived at least a portion of their lifetime as part of a nuclear family, other forms of family and household organization were also common (including extended and single-parent families). Slavery's impact on black families resulted in their being broken apart as people were sold, and in fathers residing on different plantations away from their wives and children. The practice of organizing around extended families, in particular, carried on after emancipation, when labor demands, parental deaths, or other personal circumstances necessitated them. U.S. census records for Antioch Colony (1870, 1880, 1900, 1910, 1920, and 1930; Myers 2009) attest to the commonality of extended families among its black residents. For each decade, there were households enumerated which included grandchildren and in-laws. Even more recently, Winnie Harper Moyer informed me that she had raised seven of her grandnieces and grandnephews; three were still living with her in Antioch during the time of her interview. Her sister, Ruth Harper Fears, adopted her daughter when she was seven months old and also raised two nieces and one nephew.

Most of the African American interviewees were raised in households that farmed for a living at some stage of, if not throughout, their household's history. Yet here there were distinctions since there were landowning farmers, tenant farmers, and farm laborers who did seasonal work on the land of others. Lillie Grant (Figure 7) recalled that her family's 17 acres and livestock provided enough means for the household to live comfortably. In contrast, a number of individuals, men and women, remembered working on farms around Buda and Manchaca, or as far away as west Texas and Mexico. Some families were landowners that also farmed for others. The exception to working-class status was the Pickard family, whose paternal lineage includes highly educated professionals who were notable teachers. Marcus Pickard's father, Marcus Pickard, Sr. (who was also Rene Pickard's grandfather), was the head of the science department at Anderson High School in Austin (Figure 8). Yet, Pickard, Sr., and his sons and grandson afterwards, still owned land and farmed in Manchaca. As Marcus Pickard informed me, his father chose to farm although the income was not needed.

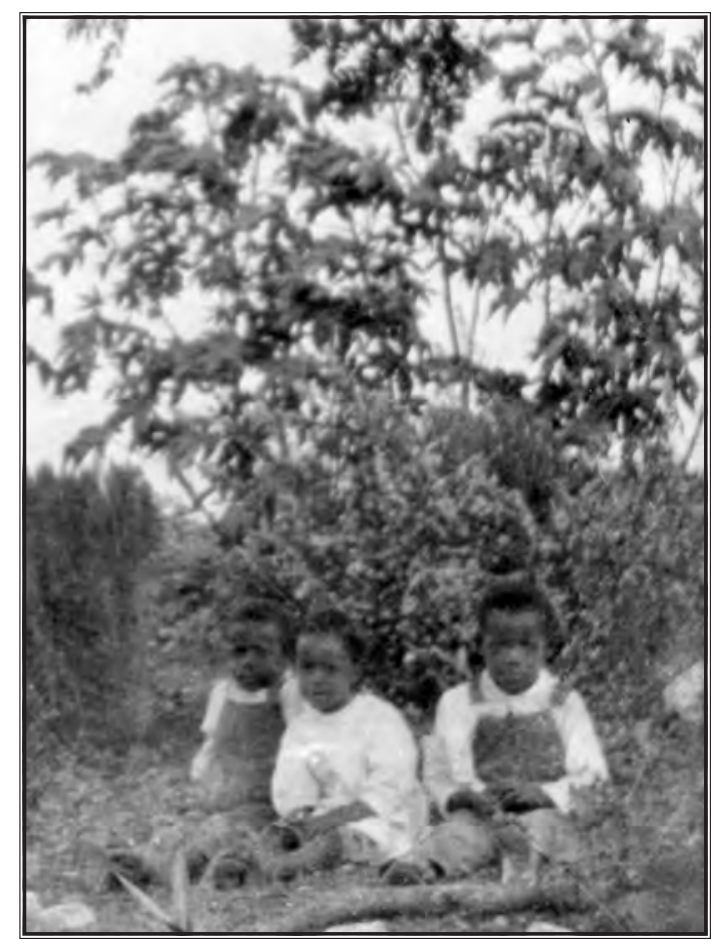

Figure 7. Lillie Grant with twin brothers Oscar and Arthur on their family property on the Prairie, Buda, Texas, ca. 1920s. Photograph courtesy of Lillie Grant. 
To conclude, the interviewees from Manchaca and Buda (Antioch Colony and the Prairie) represent a fairly good cross section of the rural inhabitants who once (or still) called Travis and Hays Counties home. Among them are those raised in landowning and tenant families, some of whom also hired themselves out near and far during harvest times. Agricultural labor and a rural identity were deeply ingrained across racial, gender, and class lines. Even those interviewees who were raised in households not highly dependent on farming nonetheless remembered working in the fields. Families were very closeknit, and more than a few were quite large. Out of the 16 households represented, six were comprised of 10 or more children born to the same parents. Social bonds also extended beyond the household, as interviewees recalled remaining in close contact with relatives nearby and participating in a strong social network with neighbors and the members of their church. For those interviewees raised in Austin, the cityscape and its attendant hustle and bustle were a far cry from the relative solitude of the country, yet the ties that bound them to their rural ancestral roots still echoed in much of what they remembered, and what factors they felt were important in shaping their sense of self and

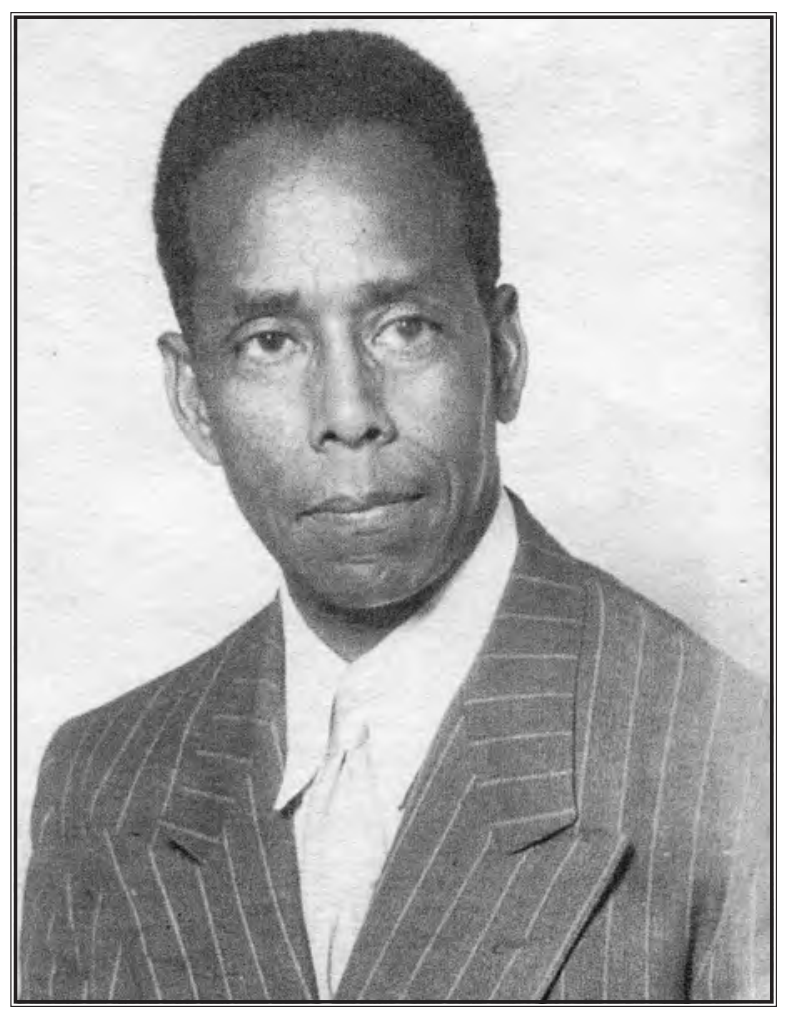

Figure 8. Marcus Leon Pickard, Sr., date unknown. Pickard Sr. is the father of interviewee Marcus Leon Pickard Jr., and was a native of Brenham, Texas. He directed the science curriculum at Anderson High School in Austin, Texas. Photograph courtesy of Marcus Leon Pickard, Jr. identity. Thus, although the temptation may be there to simply differentiate between interviewees and their experiences based on their rural versus urban upbringing, one might also consider the important links: historical, cultural, economic, and social.

In addition to the interviews collected for this project, one other is included here: that of Harriet Bunton Smith. A contemporary of Ransom and Sarah Williams, Smith was also born into slavery, and her family eventually became landowners. All three are directly linked through history and kin ties to a number of interviewees. Similar to the archeological evidence recovered from the Williams farmstead site, Smith's oral history serves to link the historical distances between slavery, emancipation, and Jim Crow as she relates glimpses of her life beginning from childhood. A discussion of Smith, how her interview came about, and what she relates follows below.

\section{THE ORAL HISTORY OF HARRIET (BUNTON) SMITH, 1941}

Harriet Bunton Smith was born into slavery in Mountain City, Hays County, in ca. 1858. She was the first child of Elias and Clarisa Bunton, who had moved with their owner, James Bunton, from Kentucky to Texas in 1853. Following emancipation, Elias and Clarisa purchased land in what was to become Antioch Colony and raised Harriet and her siblings on their farmstead. Thus, Harriet Smith was an Antioch pioneer, and those who possess kinship ties to her today include interviewees Marcus Pickard, Jr., Rene Pickard, LeeDell Bunton, Lee Wildon Dawson, and Lillie Grant. 
Archival records, including those concerning Smith's parents, Antioch Colony, and James Bunton and his brothers, Desha and John Wheeler, provide mainly indirect information on Smith. Still, what these primary sources do relate is likely more than will ever be known about the vast majority of emancipated blacks present in Texas following the war. Yet, a portion of Smith's story can be pieced together using more than the documentary record. In 1941, folklorist John Henry Faulk interviewed Harriet Bunton Smith about her memories of slavery and the aftermath. While over 2,300 former slaves, Smith's contemporaries, were interviewed earlier by the Federal Writers' Project in the 1930s, this number only represents about 2 percent of the freedmen estimated to be living at the time (Musher 2001:1). Had Smith's interview been among them, she'd be one of a relatively few number of ex-slaves who left a testimony of their experiences in bondage on record. Yet Smith's case is even more unique: Faulk recorded their interview, and the oral history of "Aunt Harriet Smith" (Faulk 1941; Appendix F) is one of only 23 known sound recordings of ex-slaves archived at the Library of Congress.

Faulk was a native of Austin and a graduate of the University of Texas. In 1941 he was teaching at UT in the Department of English and conducting fieldwork in Texas. He traveled throughout the state collecting data mainly on African American gospels and church services for the Library of Congress's Archive of American Folk Song (since renamed the Archive of Folk Culture). At the time, Faulk reported to Alan Lomax, who was then Assistant in Charge at the archive. In a letter dated December 7, 1941, Faulk (1941) wrote to Lomax that he'd recorded "five or six average citizens," which probably included Smith. It was clear from the letter that Faulk was hoping that the recordings would be useful to Lomax, who was an established folklorist and the son of pioneering folklorist John A. Lomax. John Lomax not only served as curator of the archive, but also directed the fieldwork related to the Federal Writers' Project's ex-slave narrative collection (Davidson and Lytle 2000:6). Moreover, the Lomaxes were leading experts in ethnomusicology and had already conducted extensive research in Texas among African Americans.

When Faulk interviewed Smith, she was living in Hempstead, about 100 miles due east of Austin (closer to Houston's city limits). Although the interview took place during what appears to have been one session, Faulk said to her at one point, "I remember a long time ago you told me about during the big break up...," indicating that the two had previously spoken (see Appendix F). In any case, Smith sounds at ease speaking with Faulk, even about controversial topics, including miscegenation and the shooting death of her husband by a white man who was never arrested. Given that Faulk's primary objective was to collect black gospel music and sermons, he made a number of attempts to encourage Smith to talk about church, and he even tried to persuade her to sing a spiritual. While Smith does not oblige Faulk with respect to the latter, to his credit Faulk must have realized what a rare opportunity he had in interviewing Smith, and he posed a number of other questions about slavery and her life afterwards that he probably thought would be useful to other researchers.

The interview with Smith is in four parts due to the recording media used at the time. Faulk had to record Smith using both sides of two 33 1/3 rpm sound discs. Other than Faulk's fairly consistent effort to get Smith to discuss church life (which she does) and to recall traditional black spirituals, the interview otherwise seems to have been somewhat informal. There is some chronological order to the questions that Faulk posed, in that he begins by asking Smith about her memories of being enslaved, and then about the "big break up" (i.e., emancipation). Smith then related what she remembered about Antioch Colony's founding, her first marriage to Jim Smith, and the events surrounding his murder. The interview then proceeds with Smith's recollection of her next three husbands before the conversation turns back to Jim Smith.

Although Smith claimed not to know her birth date, the 1870 U.S. census indicates that she was 12 years old at the time, and hence 83 when interviewed by Faulk. She had no harsh words 
regarding her former owner, James (referred to by Smith as Jim) Bunton, or his brothers, but this may be partly due to the fact that she was a young child of seven when freed. Smith was fortunate in that she was surrounded by family during her time in bondage. Along with her parents, Elias and Clarisa Bunton, there were two siblings, George and Ida, her maternal grandmother, Rachel Proctor, her uncle Dave Bunton and his wife Mary, and Smith also mentioned two cousins, Lou and Sallie (Lou was the son of Dave and Mary, although Sallie is not listed among their children in the 1870 U.S. census).

Smith's mother, Clarisa, cooked for the Buntons, while others farmed cotton and corn. Smith boasted to Faulk that she could, "...plow and lay off a corn row as good as any man." Since Terri Myers (2011) noted that the Bunton brothers were mainly known for their cattle, some of the black men were more than likely ranchers. Although Smith didn't mention any abuse or tragedies that occurred among her own family, she did relate the tale of her friend, Mat Porter, an enslaved girl who was roughly five years older than Smith. Porter belonged to Mr. Porter, a preacher who lived across the road from Jim Bunton's place. Charged with crushing cane to make molasses, Porter lost her arm when it got caught between the rollers. Porter, like Smith, was a spectator when black Union soldiers passed through Mountain City on their way to San Antonio following emancipation. When hailed by one of them, Porter hopped onto the back of a horse and followed the soldiers. It was the last time that Smith ever saw her.

Though Smith recalled that "times was hard" following emancipation, her family stayed in Mountain City and sharecropped "on the halves" (meaning that half of their harvested crop went to the landowner) for Ira Breedlove. After two to three years, Elias and Clarisa moved the family to Antioch Colony. Smith remained with her family until she married Jim Smith at age 17 or 18, or perhaps younger; she couldn't recall specifically. Smith was a cattle rancher and worked with various employers on cattle drives. He was shot and killed in 1901 by a white man named Walter Byers for what Smith revealed was a dislike for her husband's political activities and his book learning. Smith had nursed Byers upon his birth, and though decades had passed since the killing, her anger was understandably still palpable. Smith had all of her children by Jim, and although she eventually married three more men, she kept her first husband's name (or went back to it after her final divorce).

Harriet Smith's interview is presented here since it is the only known source that provides a firsthand account of what life was like for enslaved blacks in Mountain City, including, most notably, those who would eventually settle at Antioch Colony. Although she related that the Buntons were "good" slaveowners in that they never allowed whippings, Desha Bunton did split up at least one family when he gave his three sons the three young daughters (ages 5, 7, and 9) of an enslaved woman named Jane (Myers 2011). "Good" though the Buntons may have been, that Smith's family and others enslaved in Mountain City felt no obligation to remain laboring as tenant farmers is underscored by their relatively rapid move to settle Antioch, which Harriet described as "nothing but woods" upon their arrival. ${ }^{12}$ Putting distance between themselves and their lives under slavery, the colony's families managed to improve the land and harvest enough crops and own enough livestock to pay taxes on by 1875 (Myers 2011), indicating their determination to succeed as freed men and women.

\section{ORAL HISTORY METHODOLOGY}

Oral history is unique among other kinds of evidence used to study the past since it is not an object that is collected from an archive or archeological site. That is, unlike a census record, artifact, or old photo, oral history involves actively producing a narrative of the past in the present, one that is co-

12 Sitton and Conrad (2005:22) noted that ex-slaves typically settled in "wilderness areas previous untouched by ante-bellum cotton agriculture," the land that whites found undesirable. 
created by at least two people (Mould 2009): the person conducting the interview and the interviewee (also referred to as the respondent, narrator, or informant). The process, or research method, of this collaboration is referred to as oral history, but so is the product of the interview session.

Oral history became a more formalized research practice in the United States starting in the 1940s (Perks and Thomson 1998:1; Sharpless 2007:9). It gained momentum in the 1960s and 1970s following the civil rights and other social movements as scholars were increasingly drawn to study communities and histories that had traditionally been overlooked (Sharpless 2007:17-19). Oral historians interviewed the working class, women, African Americans, and other historically marginalized ethnic and racial groups in their attempts to write more inclusive histories. This was not only a U.S. phenomenon, but one also taking place in other parts of the world as scholars began to see the potential of oral history as a means of critiquing power and advocating for and empowering subjugated groups (Grele 2007; see chapters in Perks and Thomson 1998). With the growth of the field, oral history has moved beyond the boundaries of academic research and into the public realm, where oral history projects have grown exponentially. Communities, organizations, and individuals seeking to learn more about their local history and heritage have also found oral history research a productive vehicle for exploring the past, and for engaging the public through research and education.

There are plenty of good sources on oral history methods, equipment, and ethics for anyone considering a project (e.g., Charlton et al. 2007; DeBlasio et al. 2009; Ritchie 2003). We also followed the standards and principles established by the Oral History Association, which includes an outline of the oral historian's responsibilities to a project and to interviewees from start to finish. ${ }^{13}$ Other important resources consulted included the Texas Historical Commission's (2004) oral history guide and Baylor University's Institute for Oral History's digital oral history workshop guides (Institute for Oral History 2009). These proved helpful in organizing the project, choosing the best equipment in this digital age, and ensuring that high standards of research protocol were met. In what follows, I summarize the steps taken in preparing for the interviews, the methods Lee and I used during the interviews, and how the transcripts were edited.

\section{Preparation}

Prior to contacting potential interviewees in 2009, I conducted research on secondary sources relating to black history in Texas, the history of freedmen in the United States, black farmers during Reconstruction and Jim Crow, and more specifically, on the histories of Hays and Travis Counties. The secondary sources on freedmen and later black farmers in Texas were relatively few, and some are cited elsewhere in this report (e.g., Mears 2009; Sitton and Utley 1997). Sitton and Conrad's (2005) Freedom Colonies was more in line with our investigations, and the authors' interpretations of black household activities and roles, domestic and public labor regimes, black community formation, and race relations in Texas were useful in preparing questions. Rebecca Sharpless's (1999) Fertile Ground, Narrow Choices: Women on Texas Cotton Farms, 1900-1940 was especially helpful. Based on research of women involved in cotton farming in the Texas Blackland Prairie, Sharpless's analysis of gender, race, and class underscored the need to pay serious attention to the issue of diversity and how identity differentially shapes people's experiences.

As the project historian, Terri Myers conducted the research into primary sources on Manchaca and Antioch Colony. Her contribution included an interim report (Myers and Boyd 2008) that was a wonderful aid in preparation for the interviews. It chronicled the early settlement of Bear Creek and

${ }_{13}$ The Oral History Association's Principles for Best Practices in Oral History can be found at http://www. oralhistory.org/do-oral-history/principles-and-practices. 
summarized the results of the archival research on the Williams family. The report also helped me to better understand the settlement pattern and demographic profile of early Manchaca as I began to conceptualize interview questions. Myers's research into the primary sources related to Antioch also proved invaluable (see "Historic Overview" below). Although Hays County historians have produced two books on Buda with chapters by multiple authors (Giberson and Younts 2003; Stovall 1986), taken together there was relatively little information on Antioch Colony and the African American presence on the Prairie (the exceptions include Giberson and Younts 2003; Schwartz 1986). Interviewee LeeDell Bunton was also a fount of knowledge. As a genealogist, he has researched Antioch's families for two decades and generously shared this information with us. Several of the family trees (see Appendix A), including those of the Pickards, Earlee Bunton, Harpers, and his own, would not have been as complete or accurate without his assistance.

Although oral historians tend to emphasize historical research when giving advice on background preparation for a project (e.g., Larson 2007:117-118; Morrissey 2007:164-169; Paschen 2009:33-36; Ritchie 2003:85; Texas Historical Commission 2004), I also drove out to Manchaca and Antioch Colony before conducting the first interview. This helped me to get a sense of what the areas looked like today compared to the historic landscapes represented on early maps, and to see what remained of historic landmarks that interviewees might speak of.

In Buda, Old Black Colony Road still serves as the colony's major thoroughfare, and today it demarcates most of what is left of the colony from a new subdivision a stone's throw away. LeeDell Bunton met Nedra Lee and me in Antioch, and he walked us through the community's cemetery, showed us the remains of the nineteenth-century church and school, showed us his great-grandmother Kate Bunton's house, and took us to meet his relatives, most of whom we ended up interviewing. Not long after, Lee and I, along with UT colleagues Darrell Creel and Dale Hudler, ended up conducting a geophysical survey of the cemetery in search of unmarked burials.

While Buda has clearly witnessed growth, a good deal of which has begun to encroach upon Antioch Colony, Manchaca's recent development, especially in terms of new housing, was even more sprawling. The Williams farmstead site is located off of FM 1626 (see Figure 1), a couple of miles from central Manchaca. Traveling toward the site, we observed the scenery eventually shift to one that probably would have looked more familiar to the area's earlier inhabitants. There are still pockets of homesteads with much larger lots and more spread out than those closer to town, indicating that some of the older parcels of land may have remained intact over the years. A case in point is the 80 acres still owned by the Sorrells, which remains largely as it was during the nineteenth century, with one house extant (the original four are gone). The land that interviewees Marcus Pickard and Rene Pickard once lived on is now home to a new subdivision, though the family's Chatham Perry cemetery is still used. Maintained by a close relative, the cemetery serves to anchor the past in the present, as do some of the street names that pay homage to their ancestors: Pickard Lane and Marcus Abrams Boulevard. I came to know other important landmarks mentioned in the oral histories a few months into the interviews. Robbie Overton and her son, Greg Davis, took me around to Brown Cemetery, where their family members are buried. We also stopped to visit the spot where the black school and Baptist Church were once located off of FM 1626; Overton lived in a house right next to both.

I made multiple trips over time to Manchaca and Antioch, and later East Austin, and these visitations ended up being just as important as the literature review. When interviewees spoke of changes to their communities, of what landmarks or landscapes still retained meaning for them, or referred to roads, intersections, or "west of the school" as they narrated locations, I understood what they meant. It made me a more astute student of the relationships between geography, space, identity, and heritage. Although the literature review was important in constructing a broad historical context 
for the oral history research, and some sources aided in the preparation of interview questions, there was very little specific information on African American history in the project areas (this includes East Austin, which was researched later). Nevertheless, sources covering such topics as Jim Crow segregation, racism, the agricultural labor economy, and the history of freedmen settlements helped in deciding how the oral history research could contribute to the existing scholarship on black Texans.

\section{The Interview Questions}

One of the standard methods used by oral historians is to devise a list of questions for their interviews. Typically, oral historians select a particular topic or group of related topics upon which they can construct a set of questions to ask everyone they intend to speak with. The topics can be quite specific, emphasizing perspectives from eyewitnesses to a historical event such as the tragedy of 9/11 (DiMarco 2007; Fink and Mathias 2002; Murphy 2010), or an era, such as what it was like to live through the Great Depression (Terkel 2000[1970]) or to serve in the armed forces during World War II (Cunningham 2004; Moye 2010). Some oral histories focus on a group of people from a specific place who collectively relate the long and varied past tied to a location. Allesandro Portelli's (2010) book based on narratives drawn from coal miners in Appalachia over a 25-year period is a good example. Alternatively, oral historians will have a general topic in mind and will cast their net widely in identifying interviewees who can speak to the subject matter from a range of perspectives based on place of residence, age, gender, or other criteria. The WPA ex-slave narratives are a prime example. Though oral historians aimed to gather interview materials on life during slavery in general, the more than 2,000 interviews they conducted covered multiple states and spoke to a wide variety of conditions under bondage (including the work performed and relations with the slaveowner), resulting in a diverse set of firsthand accounts.

In terms of this project, we certainly had a set of research questions in mind. In preparing a survey of questions, we had to consider how the oral histories might contribute to the interpretation of the Williams archeological site, and more broadly, to the writing of a historical narrative on black rural lifeways in central Texas. Yet we were aware that, because this was also a community outreach project, our selection of interviewees should not preclude the possibility of involving individuals who were not raised on farms, or who were born after the $1950 \mathrm{~s}$, or even those who were not African American. In the end, we interviewed people who represented one or more of the latter, and this in no way diminished the relevance of the oral histories to the greater project (it in fact opened up new avenues of inquiry into the area's history).

Ultimately, the narrators for this project included: 1) African Americans who were raised in rural areas, mainly in farming households, 2) Euro-Americans, likewise raised in the country and descended from landowning farmers, and 3) the descendants and distant kin of Ransom and Sarah Williams. While two of the latter (LeeDell Bunton and Lillie Grant) could also be included in the first group of interviewees, Dawson, Andrews, Johnson, and Harris were raised in Austin. One other, Kay Randall, was also from Austin; her interview helped to provide some insight on the intergenerational dynamics of black families (three generations of the Sorrells were interviewed), and she spent much of her childhood on her family's ancestral property in Manchaca. Thus, given their varied backgrounds and histories, one cemented set of questions would not be sufficient in interviewing them. We also had to account for time limitations: in a number of cases, we only had a half hour to interview people. Still, it was possible and necessary to ask at least some of the same questions of most interviewees if any meaningful insights based on comparing responses were to be derived from them. 
The interview questions can be found in Appendix D. I began with a set of themes and then constructed questions for each of them (Mould 2009). One major consideration was how the oral histories could complement the archeological and historical research, but I also took into account their potential for addressing other issues of import. In terms of the archeology, since the Williams farmstead was a domestic site, a number of questions focused on the household economy and household roles (under the theme "The Material and Spatial World," Appendix D). I also thought up questions about how people used space, what kinds of houses they lived in, and the material culture they used, made, or modified-in short, how people interacted with their material and spatial worlds. Interpreting archeological evidence requires knowing something about the social context of different activities and practices. Thus, social relationships, identity, and social roles were topics that were raised during interviews, with attention paid to gender, age, and race in posing the questions (e.g., see "Social Roles and Relationships" and "Creating and Maintaining Community," Appendix D).

Since most of the interviewees expressed an interest in talking about their heritage, and why their ancestors' history was important to them, I also posed questions that covered these topics (see "Remembering the Past," and "Antioch Then and Now: Tradition and Change," Appendix D). These kinds of questions also speak to larger issues surrounding the role of memory and heritage in identity formation. Similarly, in narrating the challenges that they've faced in retaining their ancestral land (e.g., see Earselean Hollins's interview), working to keep their community alive (e.g., see interviews with LeeDell Bunton and Winnie Moyer), or in critiquing the negative consequences of broader social processes in their community (e.g., see comments by Jewel Andrews and Lourice Johnson on the impact of integration in East Austin), narrators have also provided us with important insights on the various problems that "progress" has imposed on black communities.

Another issue that the project team deemed important was trying to discern the extent to which black communities possessed ties to one another. Given that the Williams family lived in a nearly exclusive white enclave during the nineteenth century, we guessed that they must have had social ties with other black families living elsewhere. How and why were those ties created and developed, and did the practice extend more broadly across black communities in Hays and Travis Counties? Most of the interviewees revealed that through marriage, kinship, church, and school, people living in Austin, Manchaca, the Prairie and Antioch Colony formed social bonds that knit their communities to one another prior to integration.

Although Nedra Lee and I used the prepared questions, they did not over-determine the content or direction of the interviews (Morrissey 2007:177; Mould 2009:95-96; Ritchie 2003:102). For instance, with those interviewees raised in Austin rather than in rural communities, I queried them on what values and practices their country-reared parents or grandparents passed down to them in order to understand the continuity and discontinuity of these traditions following migration to the city. One of our younger interviewees, Cedel Evans, was able to talk at length about her experiences going through predominantly white schools right on the heels of integration. Joanne Deane and Lillie Moreland, who are both Euro-American, commented on race relations in Manchaca and the neighborly ties that households shared. Since African Americans also spoke on these subjects, it is interesting to compare these responses across racial lines. I also asked questions that I knew beforehand that interviewees were more interested in being asked about (see "Pre-Session Introductions" below). Further, we tried to remain attentive and responsive to narrators when we hit upon a subject that they wished to discuss at length (or declined to speak much about), or when they took the interview in different directions (Morrissey 1998). That is, while we were gathering information, we were also aware of the importance of the interview process. 


\section{Pre-Session Introductions}

In the process of conducting research on the topics relevant to the project, I began contacting potential interviewees (see "In Search of Potential Narrators" above). I spoke of the project's purpose and how their oral histories would be used (for research, publications, and education). I also informed them that their transcripts, donated photos, and audio recordings would be archived at a repository and made available for public access, and that we would need to have both Deed of Gift and Release of Documentary Materials forms signed by them (see Appendix E).

Following their agreement to be interviewed, I gathered background information (including genealogical data and information on who belonged to their former household; see Appendixes A and B) and tried to determine what topics they had knowledge of. This was typically done in a followup phone call or a meeting in person at the interviewee's home. They often wanted to know what kinds of questions I'd ask them; there were a handful of interviewees who were a bit anxious that I'd ask questions about the archeological project or Ransom and Sarah Williams. (No one I interviewed, including their direct descendants, knew who they were.) Giving interviewees some ideas about the topics we were interested in, and asking them for ideas about subjects they felt were important and should be addressed during the interview, helped to raise their comfort level about the prospect of being recorded. Only Winnie Moyer and her sister Minnie Nelson had previously been formally interviewed. ${ }^{14}$

As previously stated, the oral history project was also a community outreach effort, and our hope was that participants would want to learn more about our research, including the archeological investigation. Thus, in addition to the "nuts and bolts" of gathering background information on interviewees and getting the requisite documents signed, we also used these now open lines of communication as a conduit for sharing the results of our investigations. It is now three years after the interviews began, and we are still in contact with those who wished to remain informed, and those who've expressed interest in participating in any future public education and outreach endeavors.

\section{The Interview Sessions}

As previously discussed, the oral history component of the Ransom and Sarah Williams Farmstead project began in February 2009, but the interviews took place in two major phases with a period of inactivity in between. The first phase of oral history interviews took place from March to October 2009 and included sessions with 19 people. Nedra Lee, a Ph.D. student at the University of Texas and an employee of Prewitt and Associates, conducted interviews with three people: Marian Washington, Samuel Harper, and Ruth Fears, siblings who were raised in Antioch. I conducted the remainder of the interviews during this phase and the next. The second phase took place between late June and early September 2011, over a much shorter period and with fewer (eight) interviewees.

We digitally recorded all of the interviews using a Marantz PMD-660 (recommended by the Institute for Oral History 2009) and conducted the majority of the interview sessions in the homes of interviewees. Three interviews were done by phone because the narrators (Marcus Pickard, LeeDell Bunton, and Rene Pickard) lived too far for a home visit. We had more flexibility timewise during the first phase of the project, and were able to interview eight people over one or more sessions. Yet not

${ }_{14}$ Their interviews are part of the Hays County Historical Commission's series of videotaped interviews entitled "Voices of Hays County History." The video clips can be viewed at http://www.hayshistoricalcommission.com/ voices/index.php. 
all of the interviewees possessed the time or energy for multiple sessions. Thus, the length of each individual session varied from half an hour to approximately two hours (the latter being exceptional; most sessions lasted about an hour). In two cases, at the request of the interviewees, I interviewed two narrators during the same session (Deane and Moreland, and Andrews and Johnson).

While we had a prepared list of questions (see Appendix D), it was not uncommon for interviewees to take the conversation in different directions. Again, we wanted people to talk about what they were interested in, felt confident in their knowledge of, and expressed as important to them. Thus, more often than not we followed their lead (Morrissey 1998:108-109; Sitton 2003:13). In doing so, we learned more about the interviewees and their families than we would have otherwise, and hopefully they in turn created a record of events and the people in their lives that they felt were the most significant. The prepared questions were useful for initiating the interview, jump-starting it when it stalled, and in serving as a general guideline of the thematic areas that we hoped to address. Still, we attempted to keep the interviews open-ended and asked unplanned questions as we took our chances improvising on the spot. There were blunders, of course, and all on record: questions that led nowhere, the occasional failure of the digital recorder, moments when I couldn't remember what I wanted to ask, and so on. But on the whole, we were extremely satisfied with how the interviews turned out.

\section{Transcribing the Interviews}

Christine Hooten of Afterwords Austin and her staff transcribed all of the interviews. Upon receipt of a transcript, I checked it against the recording for accuracy. Only then did I send the transcripts out to each interviewee with a request to read over and make revisions as they saw fit. Most were satisfied with their transcripts and approved them for archiving and publication. Interviewees who asked for revisions typically found typos (especially with surnames), errors in recalling dates or locations, and grammatical errors. Revisions or additions to any transcript that included clarifications or corrections are indicated in brackets. Elaine Robbins of Prewitt and Associates, Inc., did the final copyediting of the transcripts for this publication.

\section{Remarks}

While this section dealt with the basics of how this oral history project was carried out, there is so much more to consider when undertaking this kind of research. The literature on oral history, especially since the 1970s, has expanded greatly as its practitioners have tackled crucial issues concerning the field's goals, methods, ethics, standards and theories (e.g., Abrams 2010; Charlton et al. 2007; Charlton et al. 2008; Gluck and Patai 1991; Perks and Thomson 1998:3-5; Ritchie 2003; Vaz 1997). Some of these debates consider the challenges of interpreting memories (Abrams 2010:78-105; Hoffman and Hoffman 2008), or the influential role that identity (e.g., race, gender, class) plays in shaping memory and the dynamics between interviewers and interviewees (Gluck and Patai 1991; Vaz 1997). Even the time-honored objective of employing oral history as a way to empower marginalized groups or communities has come under question (Abrams 2010:153-174; Sangster 1998:92-94). Although it is beyond the scope of this present text to delve further into these various critiques and developments that continue to influence the field, I refer to some of the tensions and complications that arise through oral history research in the following section. In the below discussion, I offer some preliminary interpretations of the oral history narratives. 


\section{MAJOR TOPICS REPRESENTED BY THE ORAL HISTORIES}

Despite the singularity of each narrative that comes across from individual vantage points and experiences, there were topics that crosscut many of the interviews. These major topics were largely predetermined by the questions asked, and the rural farming roots and/or African American identity shared by most of the interviewees. While the interview themes (see discussion in "Oral History Methodology" and Appendix D) were produced prior to recording sessions and helped to semistructure the interviews, the topics discussed in this section are based on a comparative study of the final product: the oral histories. Thus, some issues (e.g., the household economy, the church, and education) that were originally subsumed under broader themes (see Appendix D) in the end merited their own category. That is, the major themes in this section overlap with the themes produced for the oral history questionnaires but do not necessarily duplicate them. What follows is not an exhaustive list by any means. The major topics are presented here to relate to the reader the subject matter covered in multiple oral narratives if one is interested in comparing responses regarding a certain topic such as child rearing, the household-related roles of women, and hunting and fishing practices. As a group, the oral histories represent various and overlapping dimensions of household and community life, including the everyday work and leisure activities that were routine, especially in the country, and the importance of institutions, such as the church and school, in the lives of interviewees. To summarize, a number of the major themes that emerged from the oral histories are as follows:

Social organization and relationships

Household economy

Material culture and the use of space

Religion and education

Race relations

Socialization and identity

Each of the above topics is discussed in more detail below. Before doing so, it is important to note that there were several significant factors that shaped the life experiences of each interviewee, including gender, race, class, age, religion, and so on (Brown 1997; Etter-Lewis 1991; Turner 1997). This is an important point to keep in mind when reading through their narratives: the themes can help to group certain life events or recollections together, but they are not meant to suggest shared experiences or common memories across the board. For example, with respect to "household economy," while every member of a household was expected to contribute to its support by working in the garden, preparing meals, housecleaning, caring for livestock, and so on, interviewees recalled the different roles that they and others fulfilled depending upon their gender, age, ability at a task, parental expectations, or the expressed desire to tackle it. Patterns do emerge that suggest general similarities in what people experienced, such as in the daily routines of rural home life. There were also shared values and beliefs among interviewees that included a strong work ethic and the importance of God and church. While the overarching narrative that ties this collection of oral histories together will be seen through these commonalities, the differences are also a significant part of the story line. How children were socialized differently at various stages of their life, and depending upon their gender, is revealed by narrators recalling the kinds of toys they were given, and the rules of modesty that were imposed-mainly upon girls. Individuals remembered the work available to their parents or grandparents within a labor economy shaped by gender, race, and class: working-class black women mainly worked in domestic service while their male counterparts largely performed manual labor. 
Within any given theme, therefore, there is a diversity of experiences represented if one pays attention to these variations in race, class, gender, age, etc.

In what follows, each of the major themes chosen to highlight is given a brief overview, including summaries of some of the information that can be gleaned for each topic. Although interpretations of the oral histories for each theme are presented as well, by no means does this suggest that alternative, competing ones are not possible. Moreover, readers might consider what kinds of questions I neglected to ask (see Appendix D), and whether the questions that were posed deserved revision.

\section{Social Organization and Relationships}

Scholars often refer to the ways in which people organize their social units, including families, households, and communities, as forms of "social organization." For example, in the United States, families are often—but not always—organized around marriage patterns and kinship, with two parents and their children (although single-parent families have become increasingly common). The household represents another form of social organization, which in the United States often overlaps closely with that of the family. The U.S. census considers people living under the same roof as a household; therefore, kinship does not necessarily apply to how households are defined. A common definition of a household is a group of people who co-reside, and who variously contribute to the support of the household through domestic chores, childcare, wages or salary, etc.

Interviewees spoke of their families and childhood households (which were often one and the same), many of them at length. In doing so, they revealed important information regarding social organization and relationships when talking about who they resided with; in defining their kin ties; the status and roles given to, or acquired by, each household or family member; and how individuals interacted with one another. Their family and household social relationships were influenced by age, gender, and kinship, as elder relatives, especially parents and grandparents, served as role models and provided for their families, and children were socialized into the expected roles and behaviors for boys and girls.

On a broader level, interviewees spoke of their communities, most often touching upon the support network that was prevalent in rural areas where everyone knew one another and kinship tied a number of households together. Individuals recalled how neighbors were there to watch over each other's children, share resources, and lend a helping hand when needed. The all-black community of Antioch Colony, in particular, was a close-knit one during the time that interviewees resided there. With a small population consisting mainly of extended and nuclear families, most of whom shared marriage or kin ties, the settlement's church and school further served to bind the community together. Still, there were pockets of community life also to be found in the more heavily populated, larger area of Manchaca where most blacks and whites lived in close proximity to one another. Some of its former residents recalled the interdependency between families that marked rural living as well, and the neighborly obligations that were gladly met across racial lines.

Family, household, and community relationships permeated every other topic represented in the narratives in some fashion. Whether one discussed who did different household chores, or the church's role in the community, or remarked upon how blacks and whites interacted, they lived and remembered those experiences through the social relationships that made them possible.

\section{Household Economy}

Household economy refers to the work and activities that household members perform to contribute to the sustenance and well being of their household, regardless of whether or not it was 
paid work. Thus, domestic chores like cooking, shopping for clothes and groceries, sewing, and chopping wood are included here alongside jobs that household members held outside of the home. Memories of subsistence activities, meaning the tasks associated with acquiring or producing food, dominate the oral histories. Most of the interviewees (21 out of 27) were raised in rural areas on acreage that they either owned or rented, where large gardens were common and their households owned chickens, hogs, and at least one milk cow. People spoke of hunting, fishing, gardening, food preparation, raising livestock, milking cows, and churning butter. Since a fair number of these households did not have indoor plumbing, interviewees related how they obtained their fresh water by various means, including via wells, cisterns, rainwater barrels, or by hauling water from nearby creeks. In addition to subsistence-related tasks, there were the domestic chores of sewing, quilting, weekend laundering, general housecleaning, and others.

As previously discussed (see "Introducing the Narrators" above), wage labor and agricultural work were mentioned the most by interviewees as the main source of their household's income. For those who relied mainly on farming cotton for a living, nearly all members of their household over the age of 5-7 years, and regardless of gender, contributed their labor. ${ }^{15}$ This was especially true during harvest time. It was common for household members to also undertake other paid work, and to sell household-produced goods and foodstuffs to earn extra monies. For African American women, taking in laundry, childcare, and housekeeping were typical jobs. For African American men, some of the jobs in the labor market mentioned included working in lumberyards, and yard care and clearing fields.

\section{Material Culture and the Use of Space}

The oral history project's association with archeological research led to inquiries about material culture and the use of space. In terms of the former, most of the interview questions focused less on what was used or owned but on activities and contexts (spatial and social). In discussing tasks within and around the home, for instance, interviewees by extension related information regarding the objects that played a role in helping them to complete their tasks. Interviewees talked about their mothers or grandmothers using wood-burning stoves in cooking, and the iron pots, lye soap, bluing agent, and scrub board or hand-cranked washing machine used for laundering. In visualizing these past practices, interviewees commented on the spatial contexts of different tasks (e.g., canning in the kitchen, gardening behind the house, churning butter on the front porch, making rugs on the floor of the living room), making it possible to map out how space was used. Questions posed regarding who did what served as openings for narrators to discuss household gender roles and labor scheduling. For example, women and girls laundered together on Saturdays, gardening took place most of the year and was neither an age- nor gender-specific task, the male household head butchered pigs during winter, and so on.

Interviewees often produced rich accounts of how people interacted with material culture in their everyday lives for transportation, chores, comfort, and entertainment. They spoke of transforming objects (e.g., recycling flour sacks into pillowcases and bed sheets) and about how objects transformed them as well (e.g., the feminizing influences of a pressing comb used to style girls' hair, and the dresses they wore). Through descriptions of their landscapes and the insides of their houses, one can get a sense of the functionality and meaning of spaces and places. Anyone interested in the relationships between the social, material, and spatial worlds will find the oral histories well worth reading.

${ }_{15}$ Mothers, especially if there were very young children to care for at home, proved to be the main exception when there was one not based on age. 


\section{Religion and Education}

We asked narrators about church and school to find out about the influences of formal education and religion in their upbringing, and the role that the church, in particular, played in their community. Since most of the interviewees were raised during segregation, their recollections also reveal insights into what it was like to attend all-black schools in Manchaca, Buda, and Austin.

Interviewees spoke of being raised in their church (Methodist or Baptist) and cited Christianity as central to their identity, values, and beliefs. Nearly all of them still regularly attend church and raised their children to have faith in God. Some narrators recalled the devoutness of their parents, who read the Bible to them and used it as a guide in child rearing. Since attending church on Sundays, usually all day (for both the morning and evening services), was a communitywide practice, the church was also a vehicle for reinforcing community ties. The African American churches of Manchaca, the Prairie, and Buda also rotated services at one time or another, allowing new acquaintances to be made through fellowship and underscoring the church's role in furthering intercommunity relations.

Responses about education varied, due to a number of overlapping factors including age, race, household economic status, and whether the interviewee lived in Austin or in the country. Regarding age, race, and class, for a number of the black interviewees who attended school during segregation in either Manchaca or Buda, their education ended at the $7^{\text {th }}$ grade. They had to attend Anderson High School in Austin to further their educational goals. Some were fortunate enough to do so either because they moved to Austin to attend Anderson or were able to find a ride to the school. Marcus Pickard, though raised in Manchaca, attended schools in Austin since his father taught at Anderson High. His father also drove other Manchaca kids to Anderson daily. Pickard eventually graduated from Prairie View A\&M University. In contrast, for families who depended highly upon their children to farm, mainly by harvesting crops all over Texas, it was not uncommon for the kids to miss school well into the fall semester. Yet each generation demonstrated progress in terms of educational achievement. For example, as the youngest of 12 , Robbie Overton remembered that her siblings and single mother worked to ensure that she was able to finish high school; Overton subsequently graduated from HustonTillotson College and retired as a teacher for the Austin Independent School District. Cedel Evans, one of the youngest of 17 Sorrells siblings, attended formerly white schools right after integration and went on to graduate from the University of Texas at Austin.

Perhaps because U.S. church congregations are still largely divided along racial lines, interviewees did not remark upon race in relation to church. Yet they did so in terms of what they remembered and felt about race and education. Joan Limuel criticized segregation's myth of "separate but equal" by harshly remarking upon the poor state of school textbooks and the soot that covered everything, including the students, during winter when Antioch School's wood-burning stove was necessary for heat. When the only school for black children in Manchaca closed in 1950, students had to attend Antioch School in the next county over in Buda. Cedel Evans stated, "So as young children we were already being bused fifteen to twenty miles from our school, when there was a school right in Manchaca, Texas." Evans was referring to the all-white school. Yet integration, while opening doors, also presented another set of issues. Jewel Andrews and Lourice Johnson remembered that the highly revered Anderson High School, which was an institutional bedrock in East Austin, was forced to shut its doors due to integration. White families refused to send their children to a black school, so East Austinites had no other option but to be bused out of their community to high schools elsewhere. 


\section{Race Relations}

All but two of the interviewees are African Americans; most of the them, black and white, were raised during segregation, and thus were well-positioned to comment on race even if only to remark upon their attendance at all-white or all-black schools. Yet they often did more than that. Interviewees who spoke at some length on race relations revealed the complexities of black-white interactions in Manchaca, Buda, and Austin. They generally responded to questions regarding racism in four ways: 1) by relating a story that happened to someone else, 2) by relating a personal experience, 3 ) by making generalizations of segregationist practices (e.g., indicating where blacks could and could not shop), or 4) by asserting that they didn't recall feeling victimized, personally, by white racism. Generally speaking — and this includes questions on everything else-how people chose to respond was certainly influenced by their comfort level in addressing racism and with the interviewer (myself, mainly; Abrams 2010:54-77; Hale 1991; Olson and Shopes 1991; Tucker 1988:6), how and why they remembered certain events (Abrams 2010:78-105; Hoffman and Hoffman 2008), and relatedly, what their motivations were for speaking about race relations.

Narrators spoke of specific race-related events, and it is productive to think of how and why they did so. Most bore the mark of deeply ingrained memories, including events that at the time of their occurrence shook the sensibilities of interviewees. For instance, Jewel Andrews remembered taking her three-year-old daughter to the Montgomery Ward's in Austin, and her child being denied the use of its restroom. Although having grown up in the city during Jim Crow, Andrews refused to bend at this moment, and took her child to the restroom despite the silent refusal and growing agitation of the store's sales staff. Andrews spoke of racism elsewhere in the interview, but with nowhere near the same intensity. Why she chose to produce this specific memory, and did so with force, is that it involved her young daughter who was being unjustly treated. Lynn Abrams (2010:92, 119-120) cites research that indicates that women interviewees may be less likely than men to discuss themselves at the center of a story that involves heroism or accomplishment. This rings true here since rather than emphasize the risk that she took to herself, Andrews instead turned the story toward her child in order to make the point that racism is hateful: "I've told my children that story, how they wouldn't even let a child use the restroom."

In other instances, interviewees politely but pointedly provided more than a question asked for to ensure that we understood just how far and deep discrimination ran. When asked about the specific jobs black women and men could aspire to, Winnie Moyer began discussing her mother, who did housework for various white families in Buda. Rather than leave it there, Moyer went on to remark, "But, they would have to go through the back door; they didn't come through the front door. And then she had to carry us with her-she didn't have nobody to watch us." In those two observations, Moyer provides a critical context for comprehending what domestic work often entailed for black women. Domestic work itself was raced, gendered, and classed; in addition to farming, it was essentially the only other job available to working-class black women in rural areas. Moyer understood from the question what I was trying to get at (the limited job opportunities for blacks), but used her narrative as an opportunity to expand her critique of racism, especially against black women. For compounding what was already a highly unequal relationship of power between white families and their domestic workers, black women, who made their lifestyles possible, were further reminded of what was supposed to be their proper place through Jim Crow practices - such as using the back door-that also operated in domestic spaces. Moreover, that Moyer's mother had no recourse but to bring her children to work underscores the tremendously difficult decision that black women, and not men, were forced to make between staying home without the prospect of wages that could be used for household support, or 
working to make white families more comfortable, thereby sacrificing time that could otherwise be devoted to their own households. For Moyer, to let a statement like "my mother cleaned houses" end without specifying all that such work entailed was likely unthinkable.

When the oral histories are considered collectively, what emerges is a range of perspectives that suggest how varied black-white relations were and why it is important to contextualize interviewees' responses. Narrators gave scathing critiques of unequal school facilities and black property being sold unjustly as well as accounts of neighborly relations with whites. Rather than see these as just contradictory or competing insights or memories, one should consider who was narrating, and the "who," "what," and "where" that figured largely in their narration. Generally speaking, African Americans raised in Manchaca appeared to have had more interactions with whites, and more positive comments about those interactions. In contrast to East Austin and Antioch, Manchaca's settlement pattern consisted of some small pockets of black households, but most blacks lived adjacent to whites. Cedel Evans's interpretation of why racial animosity wasn't prevalent in Manchaca is useful here. She spoke of her grandfather, S. M. Sorrells, having built relationships with his mostly white neighbors and suggests that it helped to engender a more racially tolerant environment for his descendants. Her sister Earselean Hollins concurred. Interviewees Marcus Pickard and Estella Black are also descended from landowners who purchased their property as far back as the nineteenth century. Black, who was born nearly 40 years before Evans, similarly responded that her parents never mentioned experiencing racism, nor did she. As I attempted to probe further into the issue for an explanation, Black remarked, "As I stated before, they all respected my father and thought a lot of him."

As with interviewers, interviewees bring a set of expectations and intentions to the table that shapes what he or she chooses to disclose, and this is evident in the oral histories presented here. We have only a partial picture of what each person remembered, or chose to remember, about race relations, yet another key to understanding and interpreting these oral histories are the various frames of reference employed by interviewees. Earselean Hollins's narration is a case in point. The good relations she and her family had with whites were mainly with friends of her father, those who owned adjacent property, and individuals who were helpful to her family over the years. This included the grocer Earl Jones, and a neighbor, W. T. Bennett. Hollins's brother, Earl Benett, was named for them. To better clarify and contextualize these memories, Hollins compared them with others. Her mother, Essie Mae Sorrells, instilled in her children to be sensible about which whites they came into contact with, and strangers were by all means to be avoided, especially if they drove onto the property in what looked like a police car. She also related that it was within the context of coming to Austin that she really came to understand how segregation operated. While Manchaca had segregated schools, blacks patronized the few businesses there using the same means as whites. It was a far smaller town where everyone knew each other.

\section{Socialization and Identity}

All of the preceding topics intersect with that of socialization, or how a person is socialized into their individual and group identities and roles. Through the socialization process we learn to become who we are, how to negotiate our social relationships, and the rules of society. Individuals are socialized along the lines of race, sexuality, gender, ethnicity (including language and religion), and so on. Since the process begins at birth, the various members of the household that one is born into play key roles in socialization.

Interviewees spoke of a range of practices that served to socialize them, relating how they became conscious of the behavior and roles that were expected of them and other children in their 
household, especially as they grew up. Since a number of questions focused on gender identity and roles, interviewees produced a rich corpus of insights on gender identity within black households and communities. Household heads used gendered naming, clothing, and grooming practices to enculturate the very young as boys and girls. Gender-specific toys, especially dolls, served as a means of normalizing girls into their presumed future roles as mothers and wives. Children were also socialized into the labor force by shadowing their parents and grandparents. The gendered division of household labor often served to prepare girls and boys who would need to seek employment, some while still in school. Women interviewees told how girls learned from mothers and grandmothers to cook, launder, and clean house, and how they later used these skills not only to raise their own families but as they entered the workforce.

Within the broader African American social circles of the school and church, children also learned age- and gender-appropriate behavior from others in the community, including their peer groups, teachers, community elders, and so on. For many interviewees, the church and religion, in particular, were central to their socialization over their lifetime. As mentioned before, the church brought families into the communal fold, and across differences of age and class, members of the congregation forged a collective allegiance bound to a shared religion. Interviewees remarked upon the importance of Christianity in shaping their cultural bearings and serving as a moral compass.

The social norms of Jim Crow society were instructive as well for both blacks and whites. Whether or not black interviewees ever experienced overt racism, at some point in their lives they at least became aware of it. For example, regardless of their personal experiences with whites, they made multiple references to, and possessed specific knowledge of, the racial mapping of public spaces (especially in Austin) before integration (and even after). Black identity clearly drew its inspiration from such positive sources as the church and religion, Juneteenth celebrations, black accomplishments (e.g., see Marcus Pickard's oral history), and a shared history as the descendants of freedmen. Yet, as African Americans, they also had to work to challenge the grossly negative stereotypes and unequal (even violent) treatment that characterized most of what blacks lived through in Texas before the 1970s. Those experiences also influenced their sense of blackness.

\section{Remarks}

While the interpretation of any kind of research data requires that the data be categorized as I have attempted to do with the oral histories, the topics above do unavoidably overlap. However, this is a strength of oral history research, that when interpreting an individual's or a group's experiences, there are so many factors, both different and related, that come into play. This provides an opportunity to write a more vivid and meaningful history. Although it also presents a complication, peoples' lives are and were complex; we can't separate home from church, race from gender, or household from society, since that's not how people live their lives.

It is hoped that the thematic areas discussed in this section might serve as points of entry for reading the oral histories, especially for those who prefer a more focused reading. Again, this list is not a complete one, and additional topics that can be explored include: the labor economy under segregation (especially farm work), the meaning and value of property and home ownership for blacks, black heritage (especially Juneteenth and the significance of family history), interhousehold relationships in rural communities, the use of home remedies, consumer behavior, and rural to urban migration.

For those who wish to study this collection of narratives alongside others for comparative purposes, there are a number of sources available that cover topics related to farming and rural communities in Texas from roughly the late nineteenth century to 1950 . One example is the oral 
history research conducted in tandem with the archeology of the Ned Peterson Farmstead (41BZ115) in Wellborn, Brazos County (Carlson 1995). Peterson, who was likely born into slavery (Carlson 1995:63), purchased his 150-acre farmstead in 1893 and lived there with his children until his death in 1913. The interviews with his descendants resonate with those produced for this project. The CRM firm GeoMarine investigated a site east of Old Wallisville Townsite in Chambers County that led to oral history research (Shepard et al. 1995). The project focused on African American history in the area from 1826 to 1994, and the topics included religion, race relations, the local economy, and education. Researchers interviewed 14 individuals, both blacks and whites, and excerpts of their transcripts appear in the report. There are several other references worth mentioning. Thad Sitton, working as a consultant for the Center for Archeological Studies at the Texas State University-San Marcos, conducted interviews with 18 blacks and whites who once resided on or near the land now occupied by Camp Swift in Bastrop County (Sitton 2006). The interviews covered everyday living in their small farming communities, including subsistence practices and social life. Of particular interest are the interviewees' remarks on the area's racial dynamics, which indicate that neighborly relations were the norm (Sitton 2006:1619). Sitton (2006:17) notes that poverty and the challenges of living in the Sandylands had a "socially leveling effect." Prewitt and Associates also organized two projects that are comparable to the one that is the subject of this report: 1) the Fort Hood Oral History Project (Sitton 2003), conducted under contract with the U.S. Army Fort Hood, which led to four years of interviewing former residents of farming communities once spread over Coryell and Bell counties, and 2) the Camp Maxey Oral History Project (Kittrell et al. 2005), completed under contract with the Texas Army National Guard, where interviewees related their memories of living on the Lamar County land that became a U.S. Army installation between 1942 to 1945 (Camp Maxey now serves as a training facility for the Texas Army National Guard). Although nearly all of the interviewees for both projects are Euro-American (one African American was interviewed for the Camp Maxey project), their recollections of cotton farming, household chores, church, school, community relations, and so on coincide with much of the narrative threads presented in this report. 



\section{CHAPTER 2: HISTORIC OVERVIEW}

\section{ANTIOCH COLONY AND THE PRAIRIE}

Driving down Old Black Colony Road in Buda today, it is challenging to visualize what this once rural African American community looked like a century ago. Settled by emancipated men and women sometime between 1865 and 1869, Antioch Colony consisted of roughly 500 acres occupied by at least 16 households by 1880 (1880 U.S. census; Myers 2009). It is uncertain when these pioneers began to refer to their settlement as Antioch, and the name is absent in the archival records as well; outsiders called it "Negro Colony" (Myers 2009). Regardless, the colony had its own churches, cemetery, and school well before the turn of the century (Figure 9).

Today, a new housing development leads right up to the northern boundary of the colony, white families have purchased property once passed down through black families, and the fields once planted with crops are all gone. Onion Creek, which served as a swimming hole for blacks and whites alike during Jim Crow, no longer teems with fish, and on most days, its water level is too low for swimming. Still, there are those who are committed to retaining their connections to the past and their ancestors, and in September 1999, 300 of them gathered to celebrate their ties to Antioch (Gee 2000). A new church is being built on Old Black Colony Road, the Antioch Cemetery has expanded by 1.6 acres and still serves as a burial ground for Antioch and Prairie descendants (see Figure 9, No. 1), and there are families residing on their ancestral property. The legacy that they have inherited still carries a resounding message of hope, determination, and perseverance.

In Freedom Colonies, authors Thad Sitton and James Conrad (2005:2-5) note that historians have traditionally neglected to study freedmen settlements and their success stories and preferred to focus on the continued racial oppression experienced by blacks following emancipation. Sitton and Conrad (2005:2) argue that the "counter movement" of black land ownership demonstrated a "remarkable achievement" deserving of recognition as well. Although their book closes with a quote from Antioch descendant LeeDell Bunton, pulled from his interview with the Austin AmericanStatesman (Gee 2000), the settlement was not among the case studies considered at length by the authors. Terri Myers (2009, 2011), building upon the research of Hays County historians (Giberson and Younts 2003; Stovall 1986), has completed the most comprehensive and detailed history of Antioch Colony's founding to date. Her reports and the primary sources she located for this project are cited in the discussion below.

One of the tremendous challenges facing African Americans during Reconstruction and Jim Crow was that of buying land (Ayers 2007; Tolnay 1999). Land ownership, referred to by historian Sharon Holt (2000) as the "new North Star," increased a family's chance of economic mobility and spared them from sharecropping for whites in what generally became a system of debt peonage. ${ }^{16}$

$\overline{{ }^{16} \text { Although Holt (2000) }}$ was referring to North Carolina, her interpretation of the centrality of land ownership to freedmen is certainly applicable more widely. 


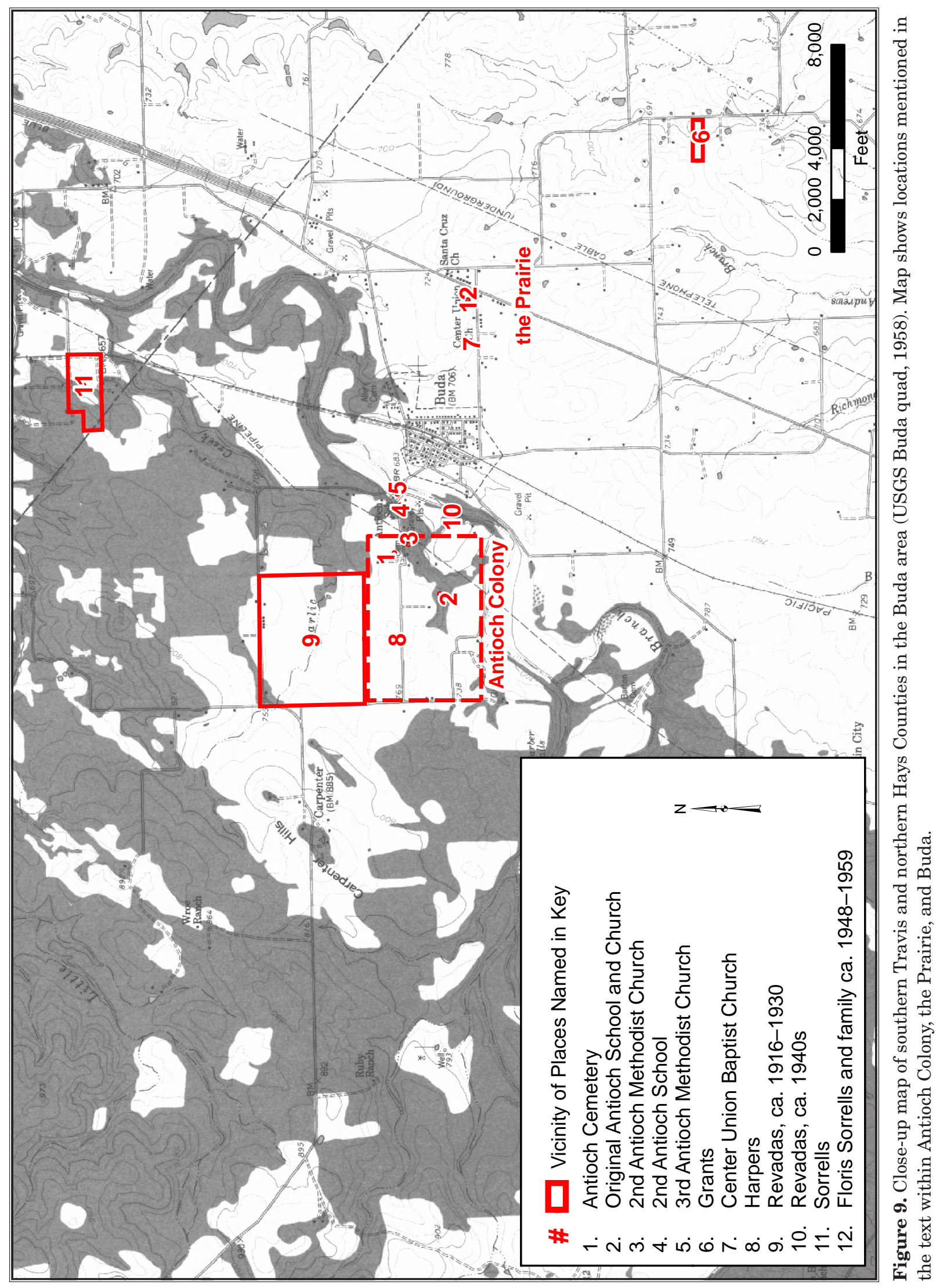


Still, although 20-25 percent of Southern black farmers managed to become landowners between 1900 and 1940 (Ayers 2007:209; Tolnay 1999:13), most of them farmed smaller parcels, had less farming equipment, and their land occupied poorer soils than their white counterparts (Tolnay 1999:12). Seen as a threat to whites regardless of class, landed blacks who attempted to climb the ladder of economic success were often targets for racial violence.

In 1870, 1.8 percent of black Texan farmers worked their own land, yet 26 percent would do so by 1890 (Sitton and Conrad 2005:2). Among those earliest black landowning farmers were the Buntons, Kavanaughs, Friends, and Beards, who helped to found Antioch Colony (Figures 10, 11, and 12). This success would not have been possible without the intervention of Joseph Rowley (Schwartz 1986:351). Though born in Virginia, Rowley, who was white, had spent time in the free states of Illinois and California prior to migrating to Texas with his family sometime between 1858 and 1860 (Myers 2009). While the majority of whites refused to sell land to blacks, Rowley seemed sincerely motivated to help in establishing a freedmen's settlement by selling parcels of land to them at a fair price and adjacent to one another in quick succession. In 1870 and 1871, deed records show that Rowley sold to African Americans parcels of 28 to 65 acres within the Allen and Eggleston Leagues totaling about 323 acres (Myers 2009). Sitton and Conrad (2005:21) note that it was not uncommon for Texas freedmen to come into land ownership through the patronage and assistance of whites. In this case, Rowley was acquainted with a number of the black men he sold land to. Harriet Bunton Smith recalled that Rowley "lived right down the hill from us."

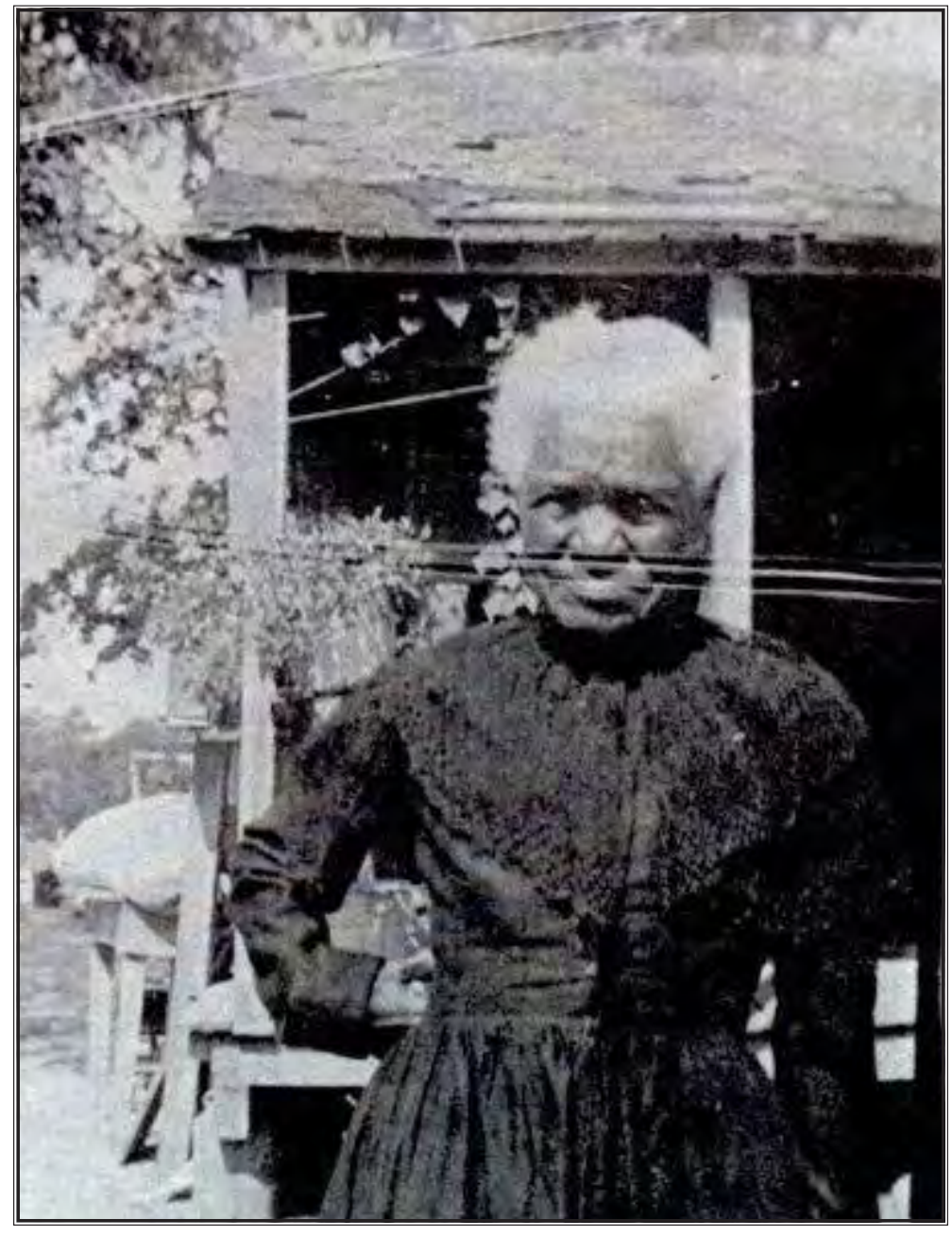

Figure 10. Kate (Friend) Bunton (b. 1872; d. 1954) in front of her house in Antioch Colony (date unknown). She is the daughter of Jack and Elizabeth Friend, who were Antioch Colony pioneers. Bunton is interviewee LeeDell Bunton's paternal great-grandmother and the aunt and great-aunt of interviewees Lillie Grant and Lee Wildon Dawson, respectively. Photograph courtesy of LeeDell Bunton, Sr. 


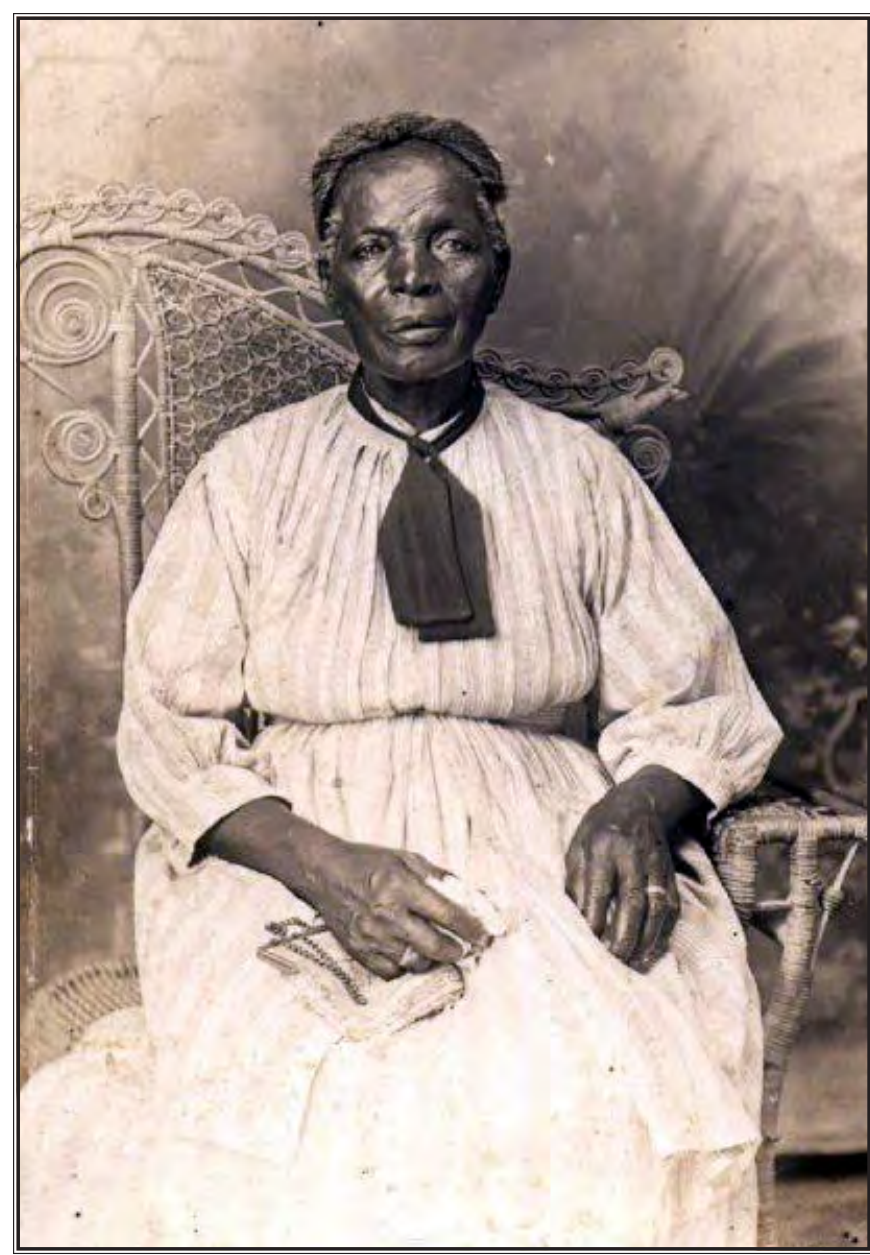

Figure 11. Addline (Kavanaugh) Bunkley (b. 1849; d. 1930). Photograph was likely taken at a studio in Hays County, Texas (date unknown). Bunkley is the daughter of George and Missouri Kavanaugh, who were among the original settlers of Antioch Colony. She is the paternal second and third great-grandmother of interviewees representing the Harper household. Photograph courtesy of LeeDell Bunton, Sr.
The 1870 U.S. census lists eight families residing in Antioch; they were born in Texas and other Southern states, mainly Kentucky, Tennessee, and Arkansas. That residents of Antioch knew one another prior to establishing their community is beyond a doubt. Elias and Clarisa Bunton (Harriet Bunton Smith's parents), his brother Dave, and Dave's wife Mary were once owned by James M. Bunton. James Bunton and his brothers John Wheeler and Desha moved from Tennessee and Kentucky, bringing their enslaved blacks with them to Texas, and they eventually settled in Mountain City (Myers 2009). ${ }^{17}$ Dave and Elias's brother, Rance Bunton, was owned by John Wheeler Bunton, who may have purchased land for Rance east of Antioch following emancipation. Other slaveowners in the Mountain City and Allen Prairie areas, both near Antioch Colony, included Hickerson Burnham, John Hughes, Ira Breedlove, and Thomas and Fielding Rector. The surnames of Burnham, Rector, Breedlove, and Hughes also represent black households enumerated in the 1870 and 1880 U.S. censuses for Antioch and adjacent environs.

Myers (2009) argued convincingly that settlement occurred in the colony a few years prior to Rowley's land transactions. Among the evidence she cited is the 1870 Agricultural Schedule for Hays County, which reveals that landowners had already improved their land and were farming and raising livestock. Moreover, in Harriet Bunton Smith's 1941 interview (see Appendix F), she states that freedmen, including her parents Elias and Clarisa Bunton, bought land from Rowley two to three years after emancipation (Figure 13). ${ }^{18}$ With additional land purchases, by the 1880s Antioch had grown to encompass roughly 500 acres. The 16 households enumerated in the 1880 U.S. census included the Friends, Buntons, Kavanaughs, Beards, Smiths, Champs, and Burnhams. William Smith, Elias Bunton, George Kavanaugh, and Peter Beard seized other opportunities to buy land as well. Each

\footnotetext{
${ }_{17}$ In addition to the Buntons of Antioch Colony, there are African American Buntons who settled in Manchaca. Although LeeDell Bunton was unable to determine if the two lines are kin related, the Manchaca Buntons were undoubtedly also once owned by James, Desha and/or John Wheeler Bunton. Buntons raised in Manchaca who were interviewed for this project include Earlee Bunton and his nieces Robbie Overton and Annie Axel.

${ }_{18}$ Smith may not have known that her family and others moved to Antioch prior to actually purchasing their land there.
} 


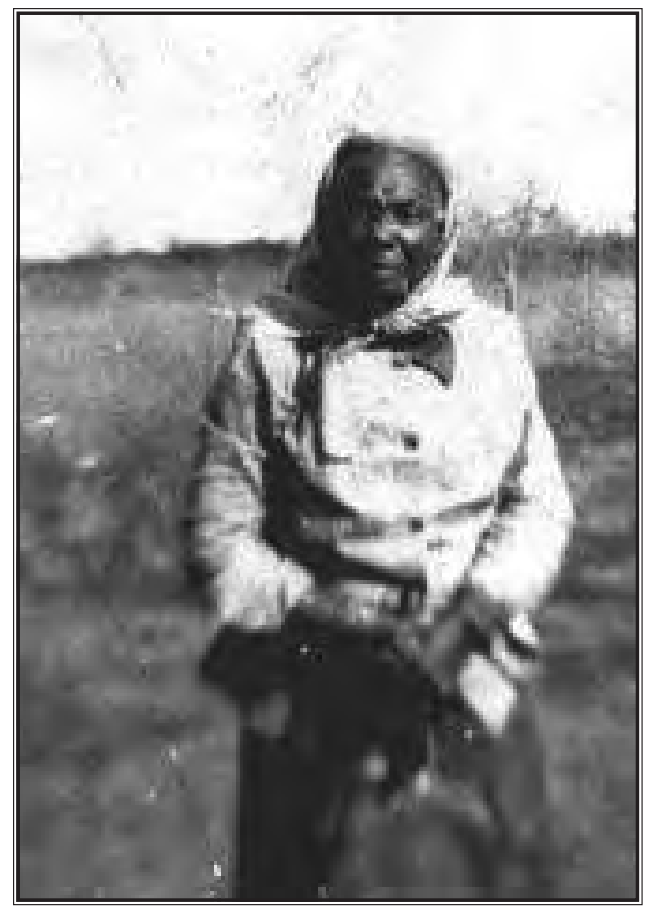

Figure 12. Ella Nancy (Green) Harper (b. August 28, 1866; d. February 6, 1955) in Antioch Colony in 1950. Harper is the granddaughter of George and Missouri Kavanaugh, who were among the original settlers of Antioch Colony. Harper is the paternal grandmother and great-grandmother of interviewees representing the Harper household. Photograph courtesy of LeeDell Bunton, Sr.

purchased 60 acres in the John Brown League north of Antioch. The latter three men continued to amass their landholdings in the area surrounding the colony throughout the 1880s.

Since several of these pioneer households already had ties to one another through kinship and a shared history dating back to slavery (Myers 2011), they likely built upon their existing social relationships in further strengthening their community. Newcomers were warmly welcomed into the tight-knit community as well. Harriet Smith remembered George and Rose Champ, a childless couple who kept her from time to time. She referred to them as "Uncle George" and "Aunt Rose," indicating the fictive kin bonds that played an important role in developing the colony's social network. Marriages between families also served to cultivate relationships. Smith's husband, Jim Smith, may have been

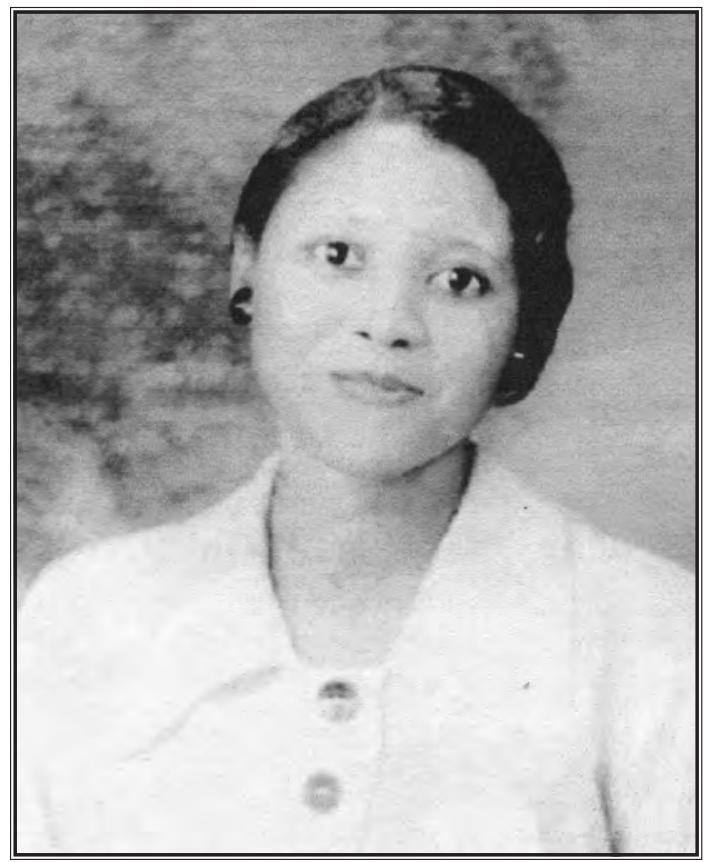

Figure 13. Opal (Kavanaugh) Pickard, Texas, date unknown. Pickard is the mother and grandmother, respectively, of interviewees Marcus Leon Pickard, Jr. and Rene Pickard. She is the great-granddaughter of George and Missouri Kavanaugh and Elias and Clarisa Bunton. Harriet (Bunton) Smith is her grand-aunt. On her mother's side, Pickard is the great-granddaughter of Ann and Chatham Perry, who were among Manchaca's earliest black landowning families. Photograph courtesy of Marcus Leon Pickard, Jr. 
the son of Ellen and William Smith of Blanco, whose household was listed close to that of her family's in the 1880 U.S. census. ${ }^{19}$ The colony's residents soon directed their growing sense of obligation to one another and their aspirations for their children toward ensuring the settlement's success.

On July 15, 1874, Elias Bunton donated one acre of land for the construction of a school, which would serve alternately as a place of worship. The deed stated the following (Schwartz 1986:406):

...one square acre of land for the advantages, privileges, and blessings to ourselves and other portion of the colored population of Precinct 5 for free public school for the use of education of the colored people in the colony... One square acre of land... when not so used for a free public school, provided at all times, on Saturdays and Sundays and also when not used as a school house, be used as a House of Public Worship by the colored people...

The school, a two-story, wood-frame building (see Figure 9, No. 2; Figure 14), also served as a meeting place for members of the Order of the Eastern Star and the Masonic Lodge (Schwartz 1986:352). On December 20, 1881, Elias Bunton donated an additional quarter acre to the trustees of the Antioch Methodist Church. The new church was subsequently built next door to the school (see Figure 9, No. 2; Figure 15). Harriet Smith told her interviewer that her parents traveled by horseback every Sunday to attend the evening service for blacks in Mountain City's white church, and that they also held prayer meetings in one another's homes. That her father gifted land to the colony for the purposes of building their own church must have felt like a crowning achievement after years of having to make do. Another significant communal landmark was, and still is, the Antioch Cemetery (see Figure 9, No. 1). Located on Old Black Colony Road, the cemetery occupies land purchased from Rowley in 1870-1871 (Giberson and Younts 2003:15). The earliest headstone still standing and legible dates to 1880; it marks the interment of Smith's brother, 16-year-old John Bunton, the son of Elias and Clarisa Bunton. John was the first of their children born free.

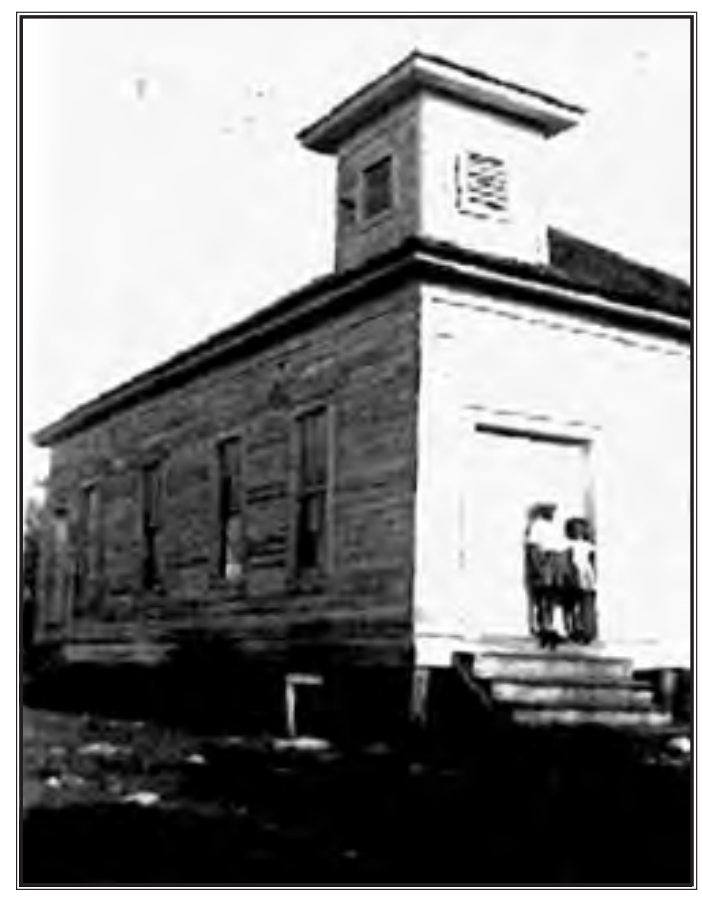

Figure 14. The original Antioch School (in use ca. 1874-1939), Antioch Colony, Buda, Texas, unknown date. Photograph courtesy of LeeDell Bunton, Sr.

\footnotetext{
${ }_{19}$ Neither Jim or Harriet Smith are listed in this census for Antioch (Harriet would have been 22 years old at the time) and were probably married and living elsewhere by then.
} 


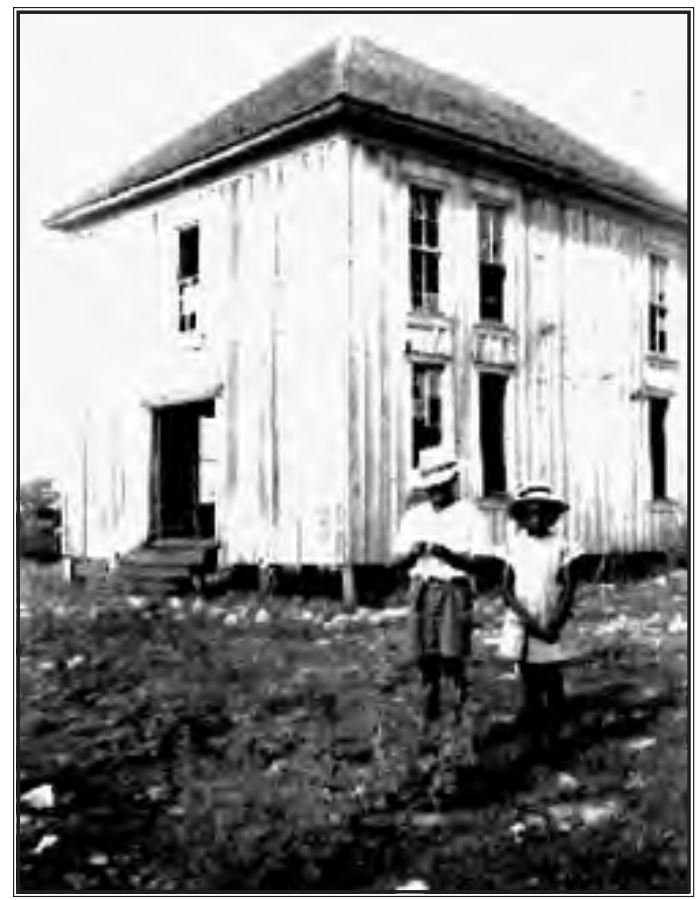

Figure 15. Antioch Church (in use ca. 1881-1942), Antioch Colony, Buda, Texas. Photograph courtesy of LeeDell Bunton, Sr.

The community remained committed to ensuring that people had a place for religious worship. In addition to the Methodist church, Antioch settlers founded the Baptist Church on Cole Springs Road in 1897. ${ }^{20}$ Folks from Antioch and the Prairie both attended the Baptist church (see "The Prairie" below). The original wood-frame Antioch Methodist Church was in use until 1942, whereupon a new church was built on Old Black Colony Road (see Figure 9, No. 3). George Smith, an Antioch descendant, noted that this second church building was moved to Manchaca in 1968 (Giberson and Younts 2003:16), yet LeeDell Bunton remembered that the abandoned church was still standing in 1971 (although he agrees with George Smith that Antioch's congregation subsequently attended services at Bethel AME in Manchaca).

The great-grandparents of interviewee Joan Nell Limuel (Figure 16), Tennessee and Francisco Revada, settled in Antioch sometime prior to 1900. She remembered attending Antioch School in its new one-story building, which was erected in 1939 on Old Black Colony Road (see Figure 9, No. 4). The school was rebuilt with brick and was much larger than the original one. The success of the school cannot be overstated. In 1870, none of the adults in Antioch could read or write, and their children were not in school. By 1880, those between the

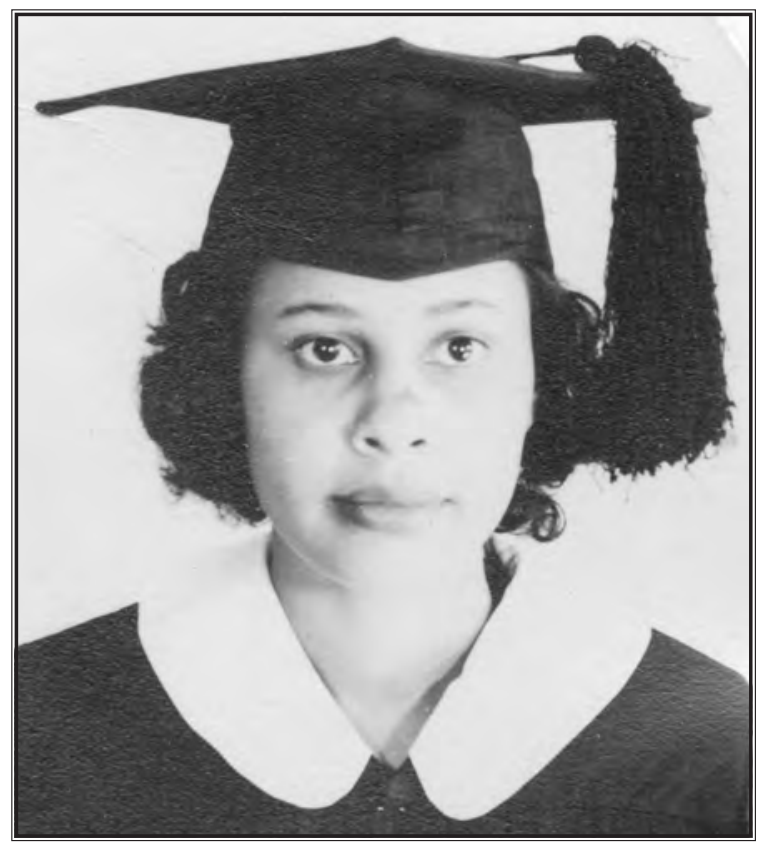

Figure 16. Joan Nell Revada Limuel, Anderson High School (Austin, Texas) graduation photograph, 1952. Photograph courtesy of Joan Limuel.

${ }_{20}$ This date comes from a plaque at what is now Center Union Baptist Church in Buda. However, local historian Barbara Younts wrote that the church was founded in 1894 (Giberson and Younts 2003:12). 
ages of 7 and 18 were attending school and were literate (Myers 2009), and the trend continued for decades (Figure 17). In addition to enrolling children from Antioch and the Prairie, by 1950-1951 black students from Manchaca were bused across county lines to attend the Antioch School when the Manchaca Colored School closed its doors for good. ${ }^{21}$

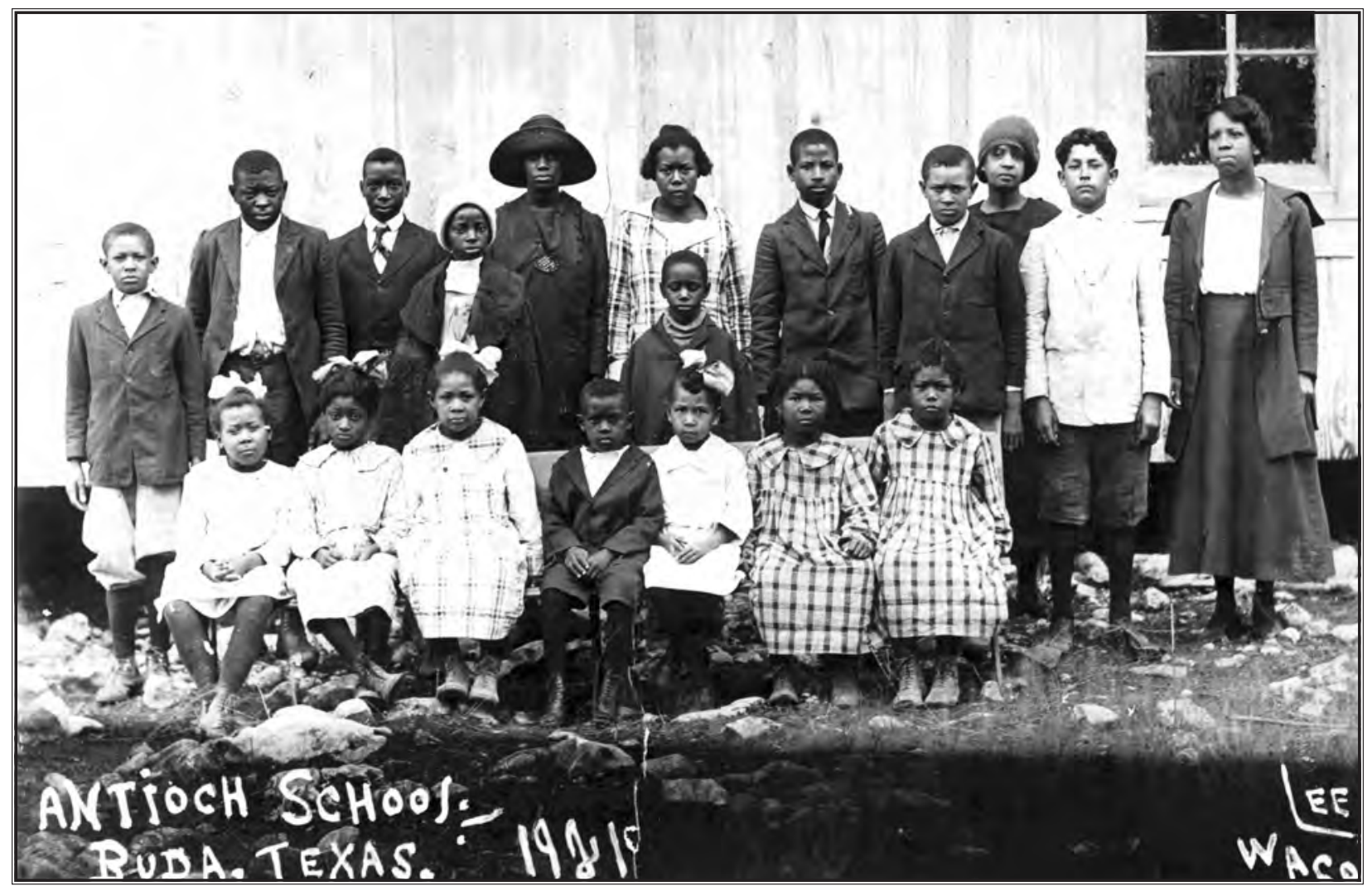

Figure 17. Class photograph taken in 1921 at the original Antioch School (ca. 1874-1939), Buda, Texas.

Photograph courtesy of LeeDell Bunton, Sr.

After a decade in which Antioch Colony's community had a chance to establish itself, the town of Buda was founded in 1881. Its location as a stop along the International \& Great Northern Railroad assured its growth as newcomers, confident in the town's long-term future, purchased property and set up businesses (Giberson and Younts 2003:245-252; Schwartz 1986:376-391). ${ }^{22}$ Even though Antioch residents were largely self-sufficient, they did venture across Onion Creek and into town to buy food staples and supplies. Others went seeking work.

Interviewees mentioned that their households patronized the Buda Grocery Store and Clark and Foster's Grocery Store. But there were alternatives to making purchases in Buda. Folks remembered white traveling salesmen representing the Watkins Company and L. B. Price who would hawk their wares in Antioch. Among the products sold by the L. B. Price company were food flavorings and sofa covers. The Watkins sales rep, universally referred to by interviewees as the "Watkin man," peddled health remedies and household goods. Families also traveled to Austin to shop on weekends, especially for shoes and clothing. Black clientele were allowed into Scarborough's, which interviewees mentioned frequently,

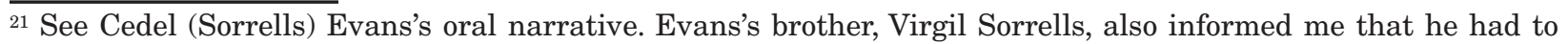
take the bus to Buda to attend school once the Manchaca School shut down (V. Sorrells, personal communication 2011).

${ }^{22}$ In 1956, Missouri-Pacific Railroad (or MoPac) purchased the I. \& G.N. Railroad. 
and Yaring's Department Store. Yet blacks had to put on a sock to try on shoes, and tissue paper inside a hat before placing it on their heads. Shopping from catalogs spared one from the unequal treatment that black customers typically faced. Interviewees remembered their mothers perusing both the Sears and Montgomery Ward's catalogs from time to time.

In terms of medical care, there were midwives in Antioch, including Maggie Revada, Pinky Varner (Schwartz 1986:352), Ladys Revada, and Kate Bunton (see Figure 10). LeeDell Bunton related that women elders, such as his Aunt Kate and his great-grandmother, Ella Harper, were called on to help when people got sick. White physicians also made house calls in Antioch, beginning with William Holtzclaw, who opened his practice in Buda in 1893 (Giberson and Younts 2003:159-161). In 1919, Clay Lauderdale moved his practice from Goforth Road into town, and he and Holtzclaw set up a partnership (Giberson and Younts 2003:201-204). With the passing away of Holtzclaw in 1938, Lauderdale was the sole doctor in Buda. He retired in 1946, and T. C. McCormick, Jr., took over the practice. Four days after McCormick stepped into his new post, he delivered his first baby in Buda: LeeDell Bunton (Figure 18).

Residents of Antioch also worked in Buda, and the numbers that did so increased over the years. In the 1880 U.S. census, one woman was a "servant," and six males (including three household heads) were farm laborers. Twenty years later, in the 1910 U.S. census,

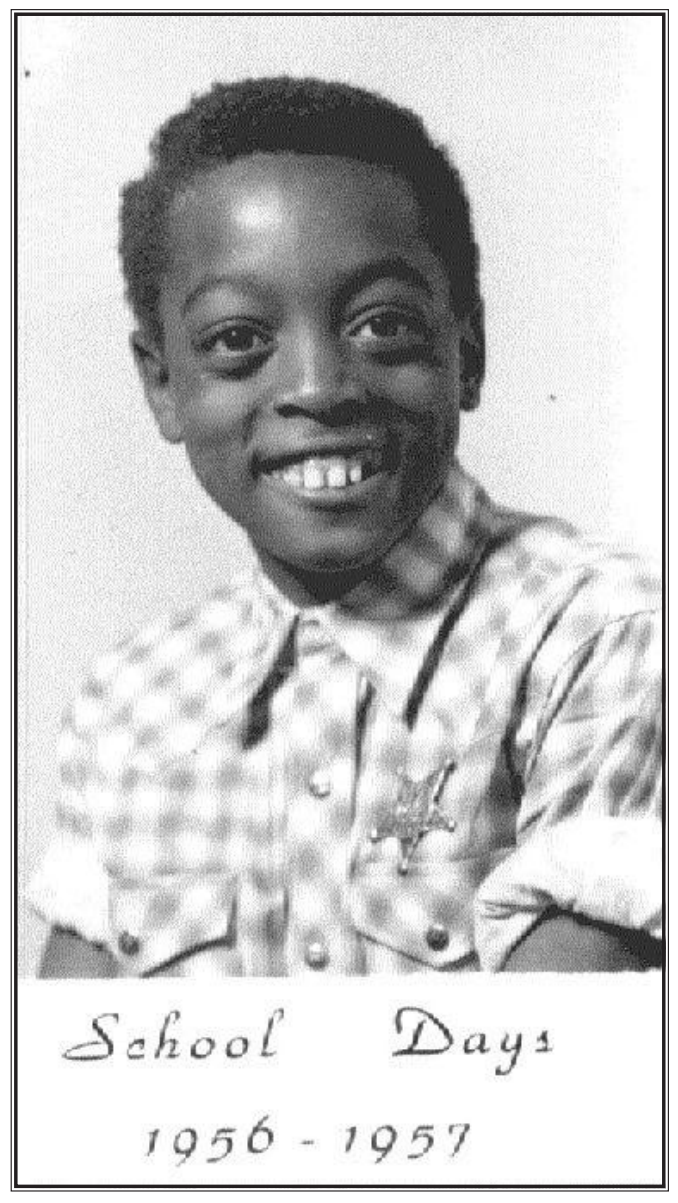

Figure 18. LeeDell Bunton, Sr.'s class photograph (Percy Jr. Elementary School, Phoenix, Arizona, 1956-1957). Photograph courtesy of LeeDell Bunton, Sr. nine women were laundresses, 38 males and females of various ages were farm laborers, and three individuals (a woman and two teens, one male and one female) worked at "odd jobs." The majority of farm laborers belonged to households that rented land. While a more thorough analysis is needed, the data suggests an upward trend of African Americans seeking employment outside of the colony. What is notable and relevant is that 15 of the 26 Antioch households in 1910 rented their land. ${ }^{23}$ They appear to have been relatively recent arrivals. Even if the renters were sharecropping for Antioch landowners, it was common for tenant farmers to also work on picking crews once their own crops were harvested, and the wealthier landowners who needed their labor the most were white. That renters had a higher dependency on wage labor outside of the colony is hardly surprising, and this observation is strengthened by the fact that eight of the women who took in laundry belonged to landless households.

${ }_{23}$ Two households were excluded from this count: Early Lomax's, and Charlie Grant's. Both lived on the Prairie, and it is clear that the 1910 census taker grouped together black households living on both sides of Onion Creek (Myers 2009). Thus, there may be other households as yet unidentified that were actually residing on the Prairie. In addition, although one household head (Charles Bunkley) is categorized as a renter, deed records demonstrate that he owned his land (Myers 2009). 
Despite the fact that Antioch Colony was largely self-reliant, with families raising most of their food, and midwives, skilled workers, and others present to offer a helping hand or to barter with, the colony eventually witnessed a decline. With the out-migration of Antioch's residents, especially its families and young adults, its institutions folded. People began leaving during the 1940s, and the pace increased in the following years as individuals sought better opportunities elsewhere. Today, the return of some of Antioch's descendants, including members of the Harper family (Figures 19 and 20), has led to the construction of a third church (still not completed at this time) at the corner of Cole Springs and Old Black Colony Roads (see Figure 9, No. 5). Interviewee Winnie (Harper) Moyer indicated that while the church will retain the name of Antioch, she wishes it to be nondenominational. Antioch Colony is no longer an exclusively black settlement, and while its descendants still honor its heritage, Moyer and others hope that the new church will serve as a vehicle for creating a new and more inclusive and integrated community.

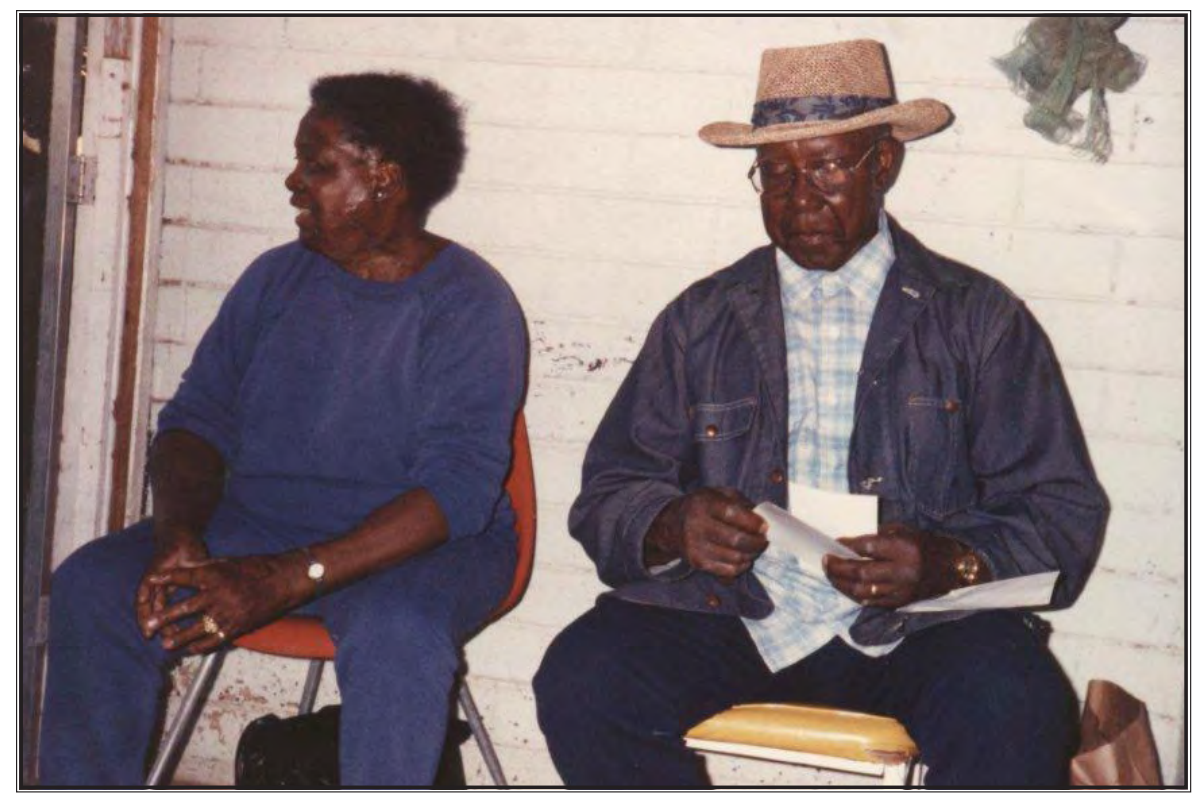

Figure 19. Emily Harper and her father, George Champ Harper, ca. 1975-1993 (photograph was probably taken in Buda, Texas, after George Harper and a number of his children returned to Antioch in 1975). Emily is interviewee LeeDell Bunton, Sr.'s mother. Photograph courtesy of LeeDell Bunton, Sr.

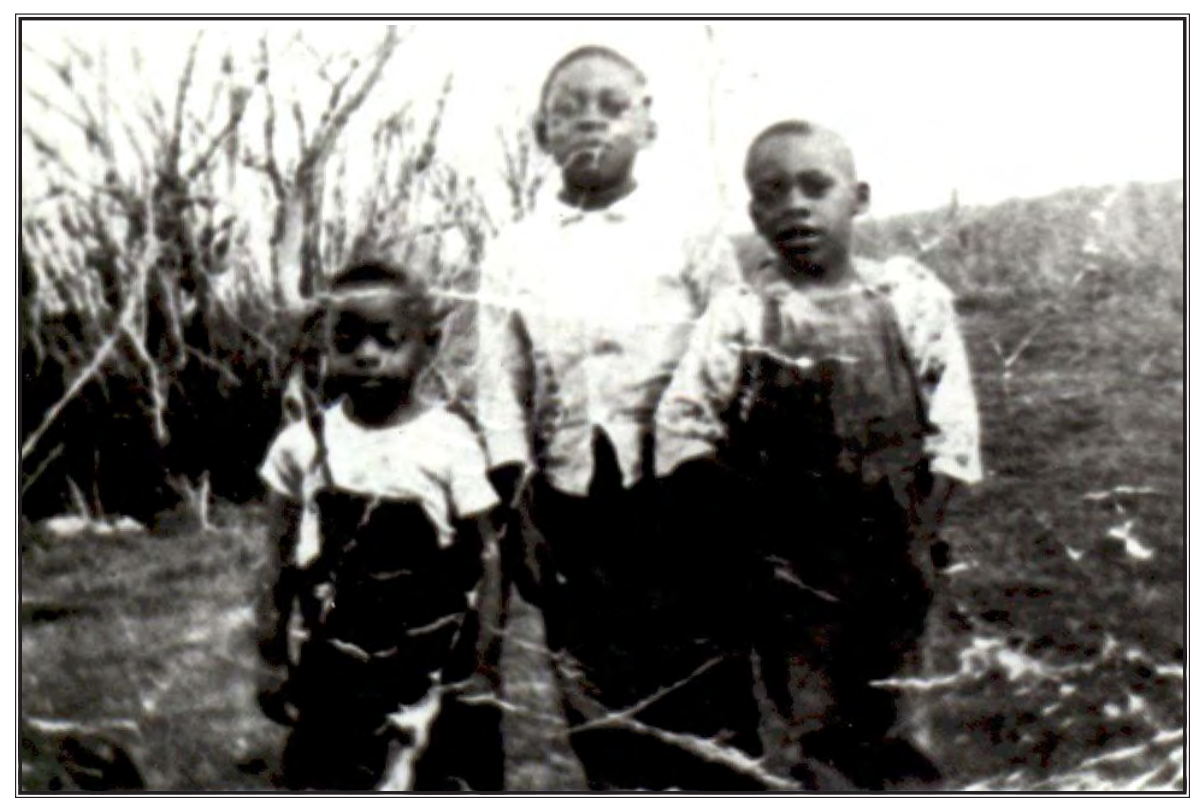

Figure 20. From left to right: Interviewees LeeDell Bunton, Sr., Moses Ollie Joe Harper, and Samuel Leslie Harper, 1950, Antioch Colony. Samuel Harper returned to Antioch in the 1970 s and resides there today. Moses Harper was a resident of Austin, Texas, until his death in 2010. Bunton resides in Phoenix, Arizona, although he still owns land in Antioch. Photograph courtesy of LeeDell Bunton, Sr. 


\section{THE PRAIRIE}

The African American history of the Prairie, which interviewees pronounced as "prayer," is somewhat elusive since secondary sources are scant, and what constitutes the Prairie spatially is difficult to define. Hays County historians do not capitalize it, but refer to locations "on the prairie" that are, or were, east of Onion Creek and Buda, and in the area of Goforth Road (see Figure 9). The decision to turn it into a proper noun rests on the fact that African Americans that we spoke to were quite specific that a black community settled there (see Schwartz 1986:353). Across the creek from Antioch was enough of a geographical designation; what mattered most was the fact that black families on the Prairie collectively defined themselves as a community. Further, they were closely tied to nearby Antioch through kinship, marriages, and a shared history.

By the mid-nineteenth century, whites had settled in areas east of Onion Creek between Hays County's northern boundary and south to San Marcos, encompassing land on the Prairie. Thus, the Prairie never witnessed the founding of a freedmen's colony, and whites, blacks, and Hispanics lived in close proximity to one another over the decades. Twelve black households were enumerated in the 1870 U.S. census as living east of Onion Creek, with "many" located closer to Science Hall (near presentday Kyle) than Buda (Schwartz 1986:354). If this signaled the emergence of a black community on the Prairie, then the simultaneous founding of Antioch, and later the Baptist Church, surely helped to strengthen it. The church was founded in 1897 on what is now Cole Springs Road. Families residing on the Prairie crossed the creek to attend services, sent their children to the Antioch School, and buried their loved ones in the Antioch Cemetery.

Some of the early black Prairie settlers included the families of Charlie and Texana Grant and Letha and Early Lomax. Charlie Grant was the grandfather of Lillie Grant, an interviewee. Born in 1853 in Mississippi (1910 U.S. census), Grant was a tenant farmer until he purchased just over 63 acres from the Birdwells in the Jesse B. Eaves Survey. He paid $\$ 5,742$ due in equal parts from 1918 to 1927 (Hays County Deed Records 60:558-559). In 1920, while he was still paying off the note, Grant sold "15 acres more or less" to his son, Lonnie (Figure 21). ${ }^{24}$ By then Lonnie was already married to Ola Bunton (Figure 22) of Antioch, and the two were raising a family. Before they moved onto the land purchased from Lonnie's father (see Figure 9, No. 6), they sharecropped for Fred Heep and then W. R. Porter (Schwartz 1986:353-354). The Grants' story is exceptional on the one hand, and representative of Prairie families on the other. They shared in common with their Prairie neighbors their freedmen's legacy and farming roots, especially as sharecroppers. Yet, that Charlie Grant was able to buy his way into the landed class at a time when black ownership was declining is remarkable. The parcel that he sold to his son remained in the Grant family until the 1990s.

Although more research is needed on Prairie families, it is suggested here that most were probably tenant farmers and/or farm laborers, much like the more recent (post-1880s) arrivals to Antioch. The presence of an all-black settlement was undoubtedly a major impetus for moving into the surrounding area. Antioch offered their children the opportunity to attend school, and by 1900, there were two black churches there, one Methodist and one Baptist. With families from both communities coming together through church and school, kin relations between the two followed.

By 1930, other families who lived on the Prairie included those with the surnames of Bunton, Royston, and Searcy (LeeDell Bunton, personal communication 2011). In 1948, the community moved to have the Baptist Church sited on the Prairie on Goforth Road, where it still stands as the Center Union Baptist Church (see Figure 9, No. 7). The sons of Lonnie Grant, Willie B. and Leroy (Figure 23), tore the

${ }^{24}$ In the 1930 U.S. census, Lonnie Grant is listed as a renter, which was incorrect. 


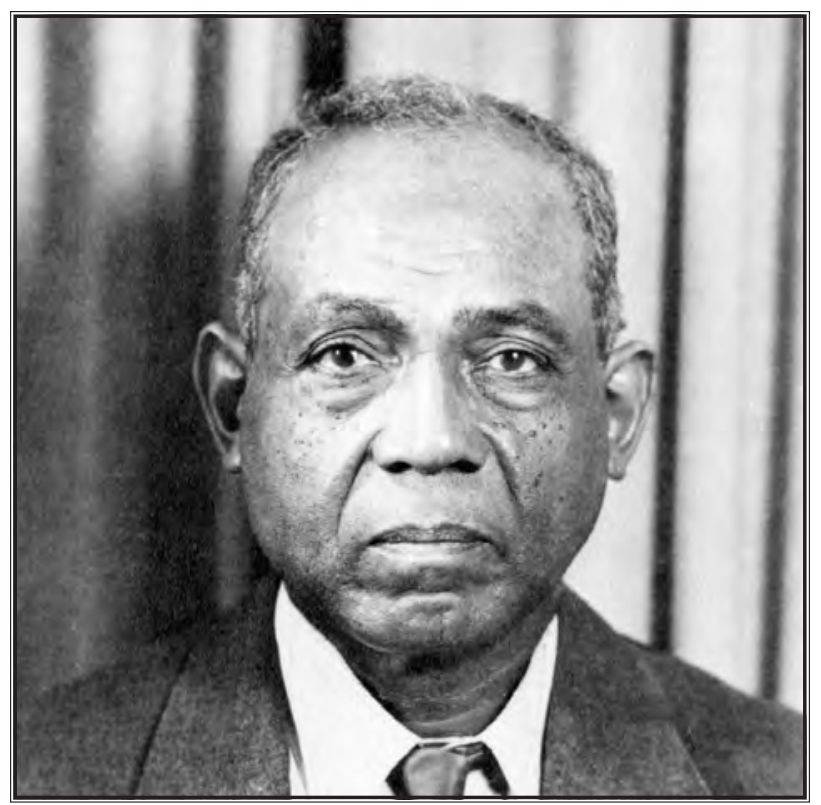

Figure 21. Lonnie B. Grant (b. January 23, 1885; d. July 4, 1956), ca. 1955, Texas. Grant is the father of interviewee Lillie Grant. Photograph courtesy of Lillie Grant.

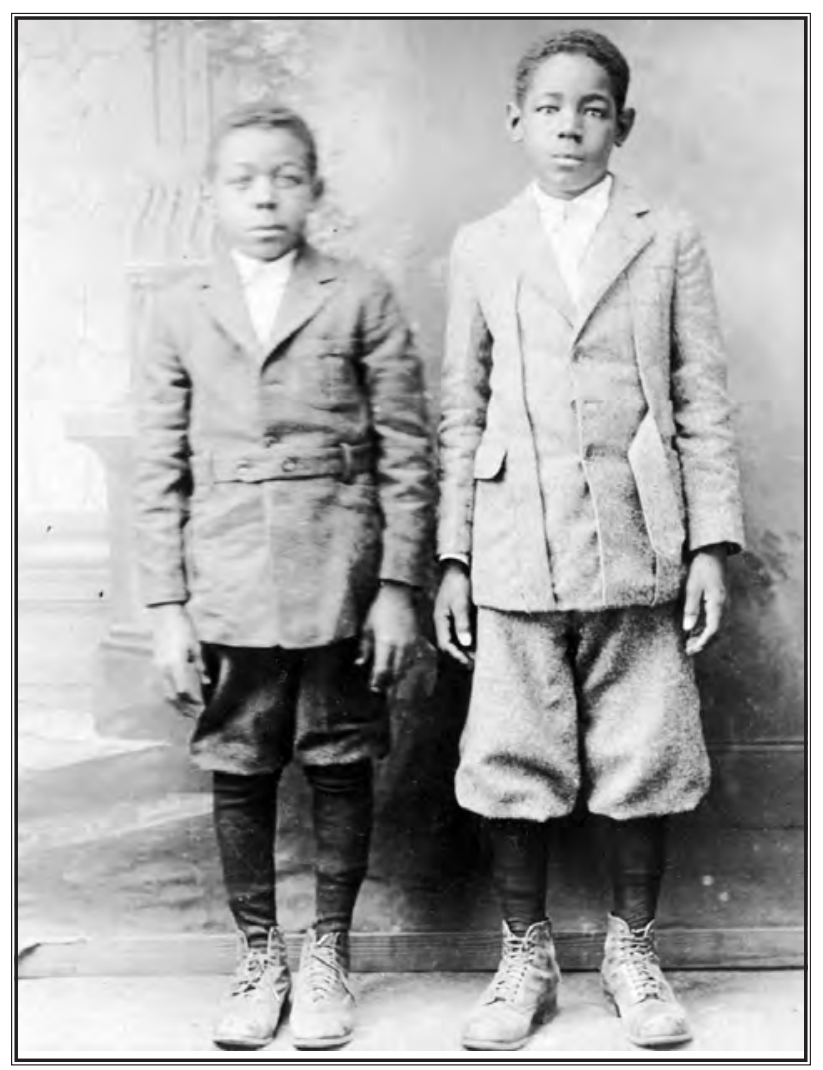

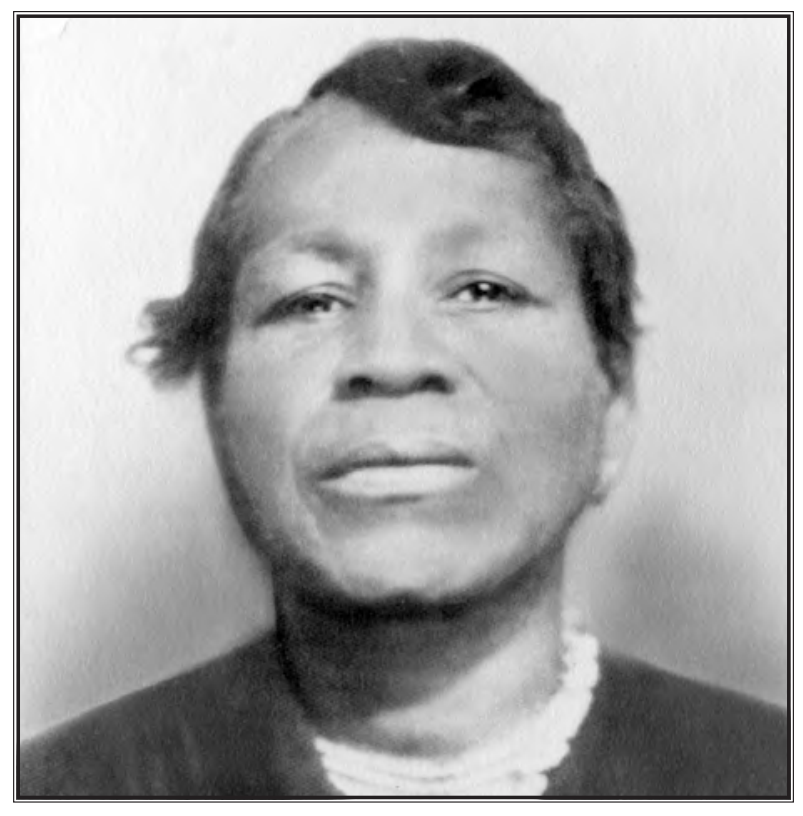

Figure 22. Ola (Bunton) Grant (b. December 2, 1885; d. January 25, 1955), date unknown, Texas. Grant is the mother of interviewee Lillie Grant. Photograph courtesy of Lillie Grant.

Figure 23. Willie B. Grant (left) and Leroy Grant (right), Lillie Grant's brothers, date unknown. Photograph courtesy of Lillie Grant. old church building down and carted the usable wood to its new site, where they reconstructed it. $^{25}$

On January 22, 2011, Antioch Colony was presented with a Texas state historical marker, which stands at the front of the new church (see Figure 9, No. 5; Figures 24 and 25). Antioch and Prairie descendants attended the unveiling ceremony, as did Glenn Erwin, a direct descendant of Joseph Rowley.

${ }^{25}$ Although one author writes that Leroy and Willie B. Grant rebuilt the church in ca. 1926-1927 (Giberson and Younts 2003:14), they would have been 12 and 10 years old, respectively in 1926. A plaque at the church states that the structure was rebuilt in 1948 . 


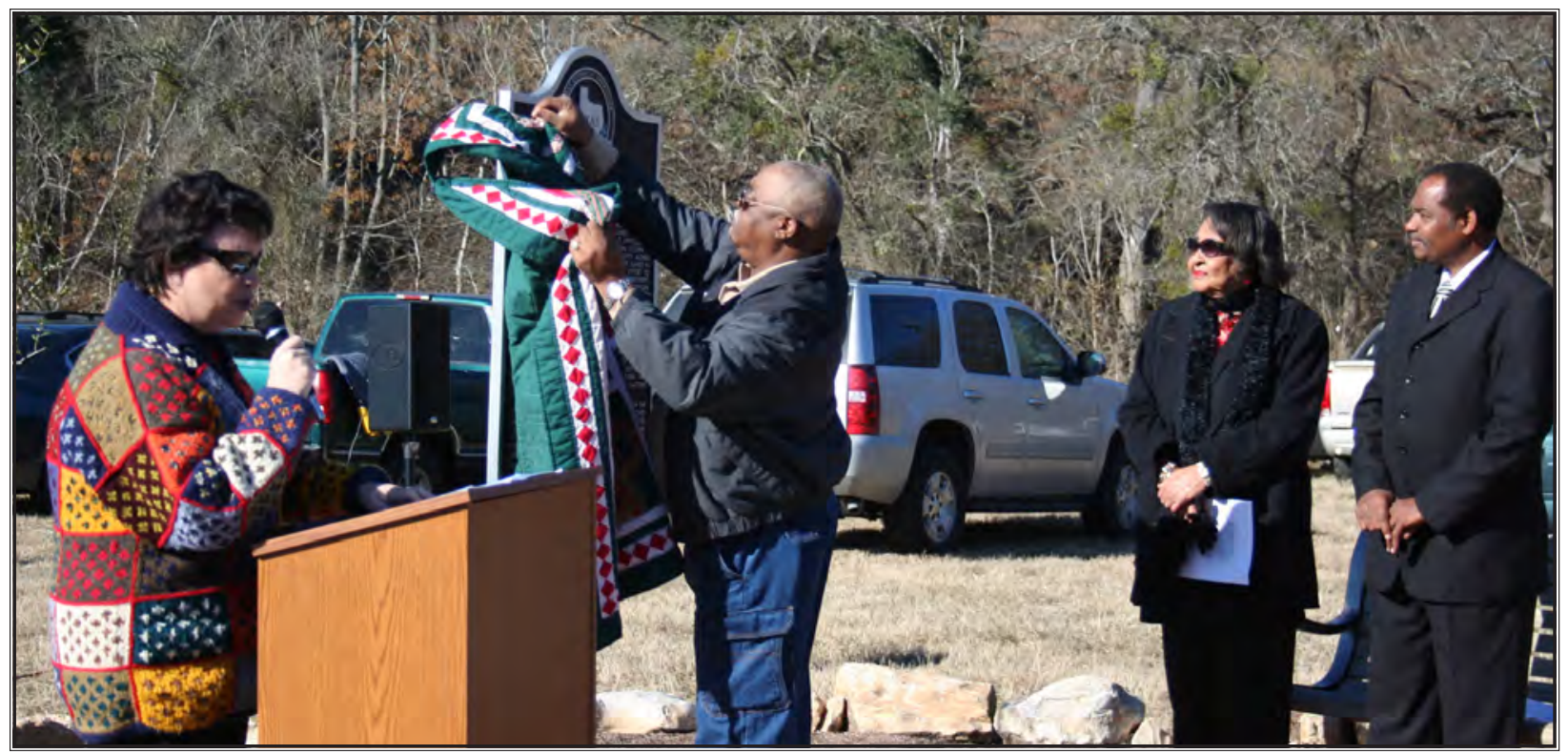

Figure 24. LeeDell Bunton, Sr., unveils a Texas state historical marker for Antioch Colony, dedicated by the Texas Historical Commission on January 22, 2011. Photograph by Doug Boyd.

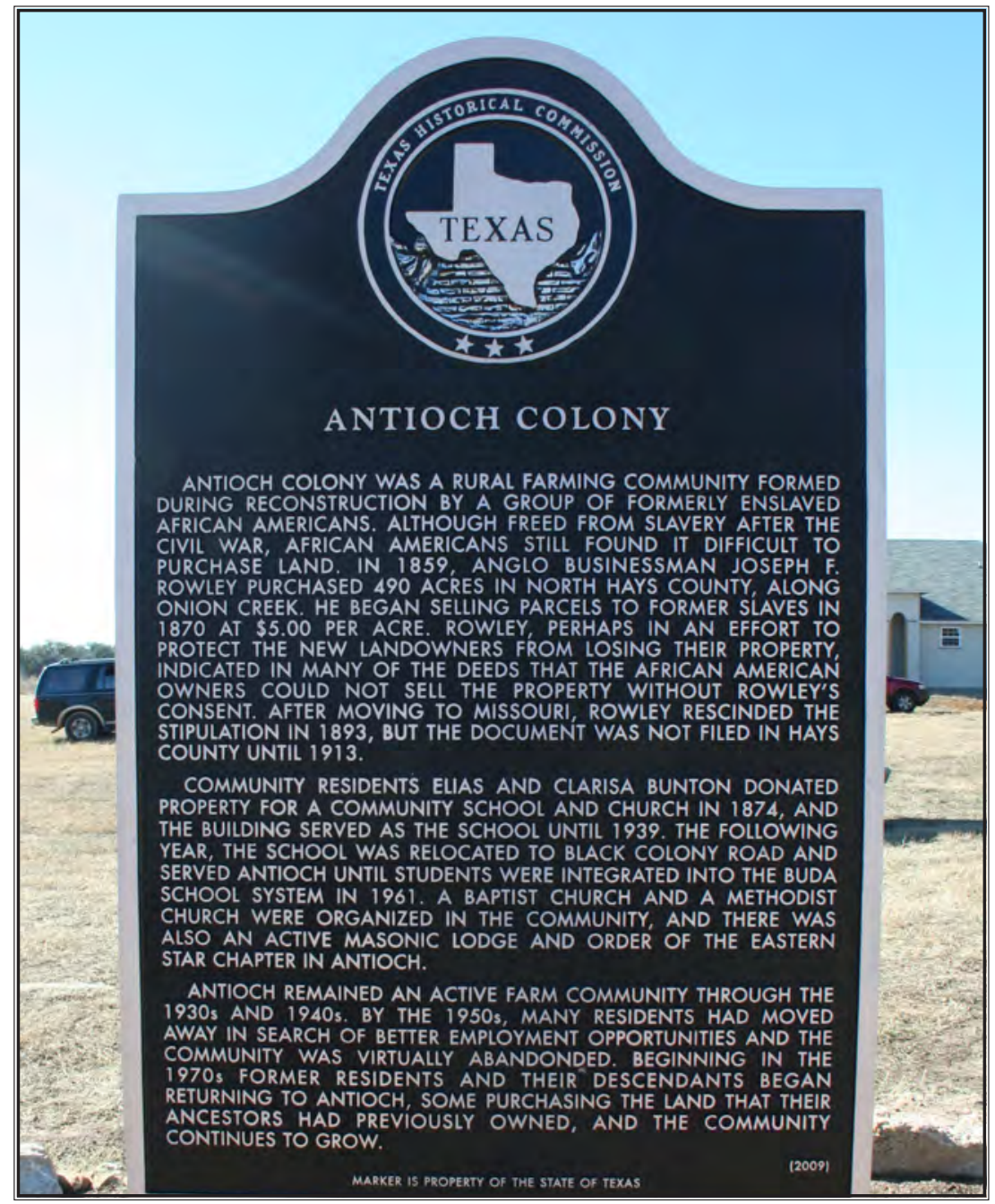

Figure 25. Texas state historical marker for Antioch Colony, dedicated on January 22, 2011. Photograph by Doug Boyd. 


\section{MANCHACA}

During the nineteenth century, two communities sprung up roughly ten miles southwest of Austin. Residents of Manchaca and Bear Creek, though living less than three miles from each other, and despite their almost universal commonality as farmers, nonetheless distinguished themselves by place of residence (Figure 26). Today, few remember the small, historic community of Bear Creek, including descendants and local historians. While recent housing development has impacted the area, there are still acres of undeveloped land, few commercial enterprises, and neighbors are fairly spread out. It still retains the feel of a rural locale. In contrast, the unincorporated town of Manchaca has witnessed far greater growth over the past 30 years, with new homes and businesses having replaced agricultural fields and farmsteads. The City of Austin annexed sections of historic Manchaca and Bear Creek beginning as early as the 1960s, and the remainder exists as its extraterritorial jurisdiction (or "ETJ," meaning that Austin has the sole authority to annex the rest). Approximately 4,000 people live in Manchaca today.

Since Ransom and Sarah Williams's 45-acre farmstead (Figure 26, No. 1) was located within what was once known as Bear Creek, the community's history has been a subject of great import to this project (Myers and Boyd 2008), and Myers (2009,2011) invested much of her time in the archives researching Bear Creek's early settlers.

What was notable to researchers at the outset about the Williams family was that they lived for 30 years in an overwhelmingly white enclave. Bear Creek was subsumed within the John McGehee league (4428.4 acres), an 1835 Mexican land grant bisected by the Travis-Hays County line. Myers and Boyd (2008:10) relate that, according to census data, Bear Creek wasn't settled until the 1870s. In 1871, Ransom Williams was one of the first individuals to purchase a tract of land there. There were 18 households listed in 1880 living along Bear Creek within the McGehee League, with diverse representation, in terms of place of origin for such a relatively small community. There were individuals who migrated from Bavaria, Poland, Ireland, Prussia, and various Upper South states (Myers and Boyd 2008). All of the households farmed, mainly cotton and corn, and possessed livestock. Wells were rare in the area as late as the $1920 \mathrm{~s}$, so residents likely drew their water mainly from Bear Creek and/ or filled barrels from a pump at Blackwell's Store in town. Manchaca was the closest place to purchase goods and services as well as to attend church and school.

Although only two African American households (Williams and Hughes) resided in the Bear Creek area, others did settle land in the surrounding vicinity following emancipation. These black pioneer families, farmers all, variously owned land, sharecropped, and labored on the land of others in what would become Manchaca. Prior to its founding, Walker Wilson and John McGehee were given land grants of one league each in 1835, which together comprised most of the land within Bear Creek and Manchaca. At the time, the area was most notable for Manchaca Springs (located two miles south of present-day Manchaca), a stopping point during the mid-nineteenth century for those traveling by coach on the Austin-San Antonio road. It was the anticipated arrival of the International and Great Northern Railway that quickened the pace of migration to Manchaca, and just as the railroad was completed, the town was founded in 1881 .

As mentioned previously, one of the factors that stood out about the Williamses is that they resided in Bear Creek for at least 30 years in what was overwhelmingly a settlement of Europeans and Anglo-Americans. We wondered what the family experienced as a result, and how common it was for freedmen to reside in otherwise white enclaves. Although a comprehensive study of the settlement pattern of greater Manchaca has yet to be conducted, in talking with interviewees, we learned that the Williamses may not have been that exceptional in this regard. Cedel Evans and Earselean Hollins are 


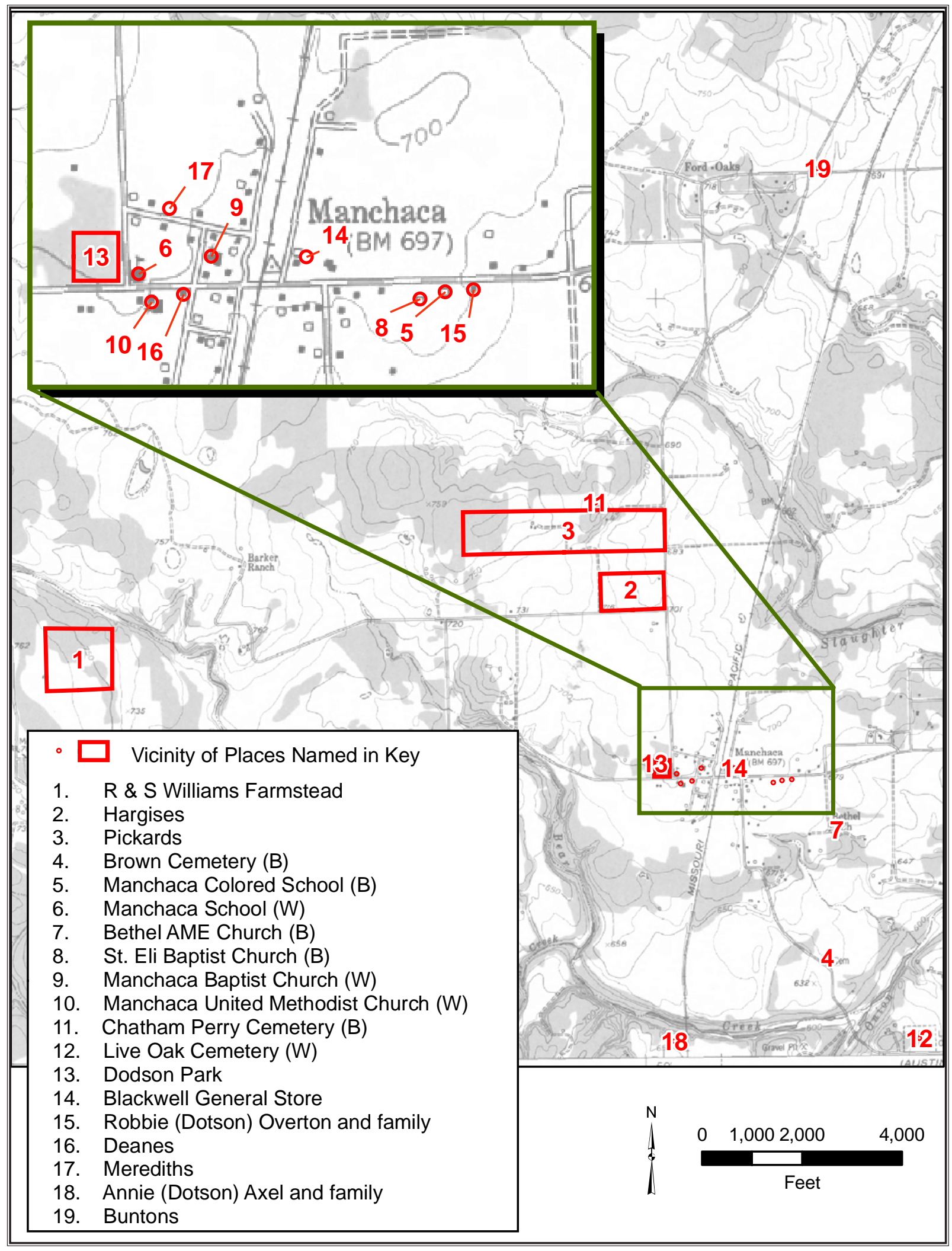

Figure 26. Map of southern Travis County showing historic locations in the Manchaca and Bear Creek area (USGS Oak Hill quad, 1955). 
the granddaughters of S. M. Sorrells (Figure 27), who purchased 80 acres in Manchaca sometime in the $1880 \mathrm{~s}$. By the 1920s, and very likely before that, all but one of his neighbors close by were white. I presented a 1920s survey map of property lots (named by owner) to several interviewees who were able to recall which landowners where white or black. There were far fewer black property owners, and of those, all lived adjacent to whites. Those African Americans who lived in closer proximity to one another included mainly the descendants of Chatham and Anne Perry, who were some of the first freedmen to settle in Manchaca. Perry left his property to his children. As a result, his descendants, including the Hargis (Figure 28) and Pickard (Figure 29) families, lived near one another (see Figure 26, Nos. 2 and 3).

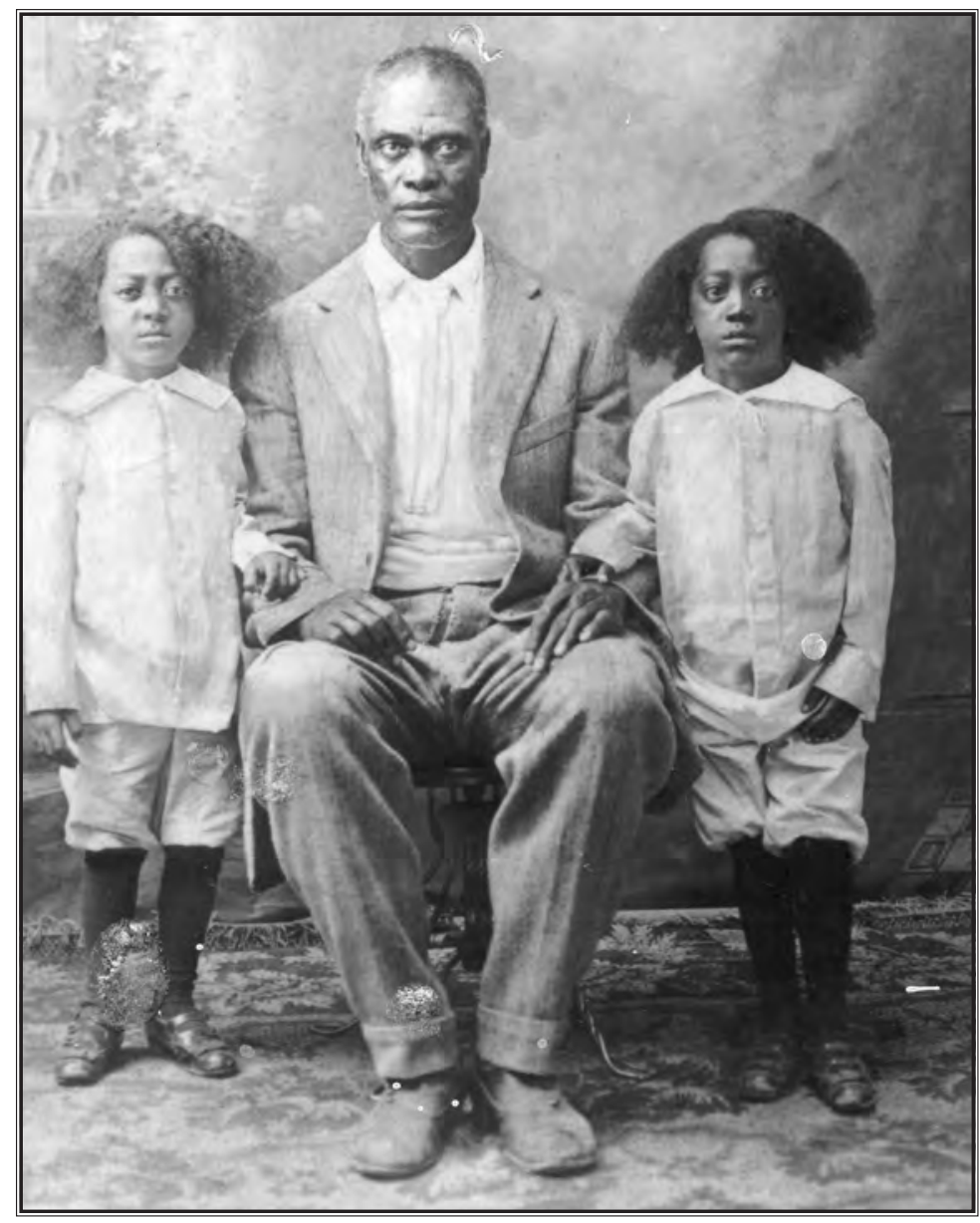

Figure 27. S. M. Sorrells with twin sons, Alvin and Virgil, date unknown. S. M. Sorrells was one of the earliest African Americans to purchase land in Manchaca, property that is still held in trust by his descendants. Sorrells is the grandfather of interviewees Earselean Hollins and Cedel Evans, and the great-grandfather of Kay Randall. Photograph courtesy of the children of Virgil and Essie Mae Sorrells.

Myers's research demonstrates that a number of freedmen successfully purchased property in Manchaca, and by 1880, a sizable enough community existed to establish a school. The first black school in Manchaca, called Union Grove, was founded in 1874. Myers (2011) discovered that the Travis County School District recorded the school as Rose Colony School as early as 1880. The fate of this first school is unknown, but by the time the eldest interviewees were attending school in the 1920 s, they were enrolled at the Manchaca Colored School (see Figure 26, No. 5). This school was not far from Black Colony, a former small enclave of freedmen who lived south of what is now FM 1626 in the area of the Brown Cemetery (see Figure 26, No. 4). By ca. 1950, the school closed down, which left black children in the area with no option but to be bused across the county line to attend the Antioch School. White 


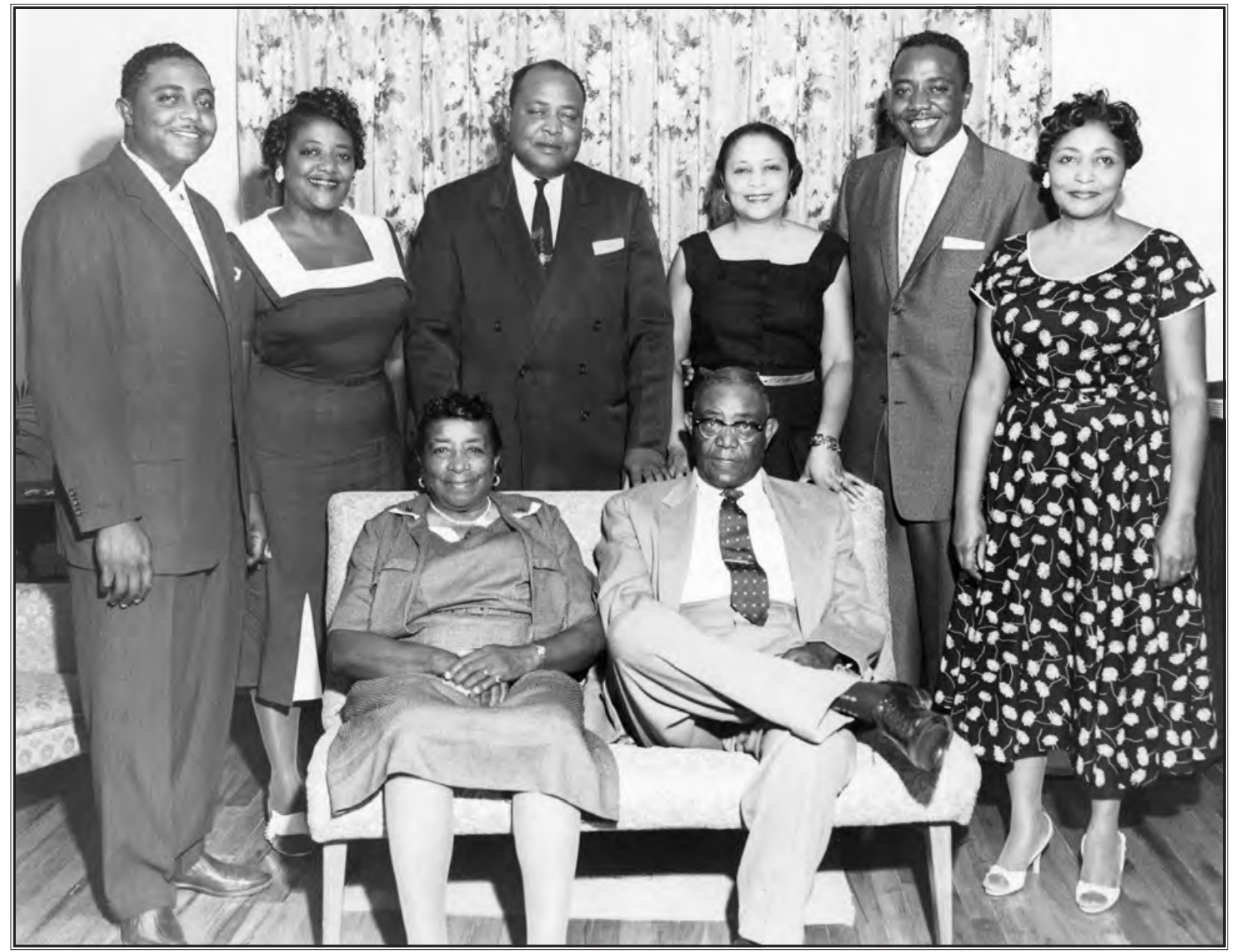

Figure 28. Estella Hargis Black and family. Posed from left to right (back row): Willie Jr., Lonnie, Otis, Bertha, Chatham, and Estella. Front row: Parents Maggie Perry Hargis and Willie Hargis. Maggie Perry is the daughter of Chatham and Ann Perry, who were among the first African Americans to settle in Manchaca during the nineteenth century. Photograph courtesy of Estella Black.

children attended the Manchaca School (Figure 30), founded in 1883 (this replaced an earlier one-room schoolhouse). Unlike the black school, which only went to the $7^{\text {th }}$ grade, Manchaca School enrolled both elementary and high school students. Manchaca School is now the Menchaca Elementary School and is still in its original location (see Figure 26, No. 6).

There were two churches for African Americans: Bethel AME (African Methodist Episcopal), and the Baptist Church (see Figure 26, Nos. 7 and 8). In the 1960s, the Antioch Methodist congregation moved its services to Bethel, but the church no longer exists. The Baptist Church once sat adjacent to the Manchaca Colored School. It, too, is gone. Although historical research on black churches was beyond the scope of this project, interviewees spoke of their experiences of being raised in one or the either. Estella Black recalled the morning and evening Sunday services at the Baptist Church, and the picnics in between that brought the families together. As with African Americans, whites also had two churches. Joanne Deane attended the Manchaca Baptist Church, and Lillie Moreland was a member of Manchaca United Methodist (see Figure 26, Nos. 9 and 10). Although black and white interviewees self-identified as either Baptist or Methodist, in practice it was not unusual for them to attend one another's church services, although the racial lines remained intact. 


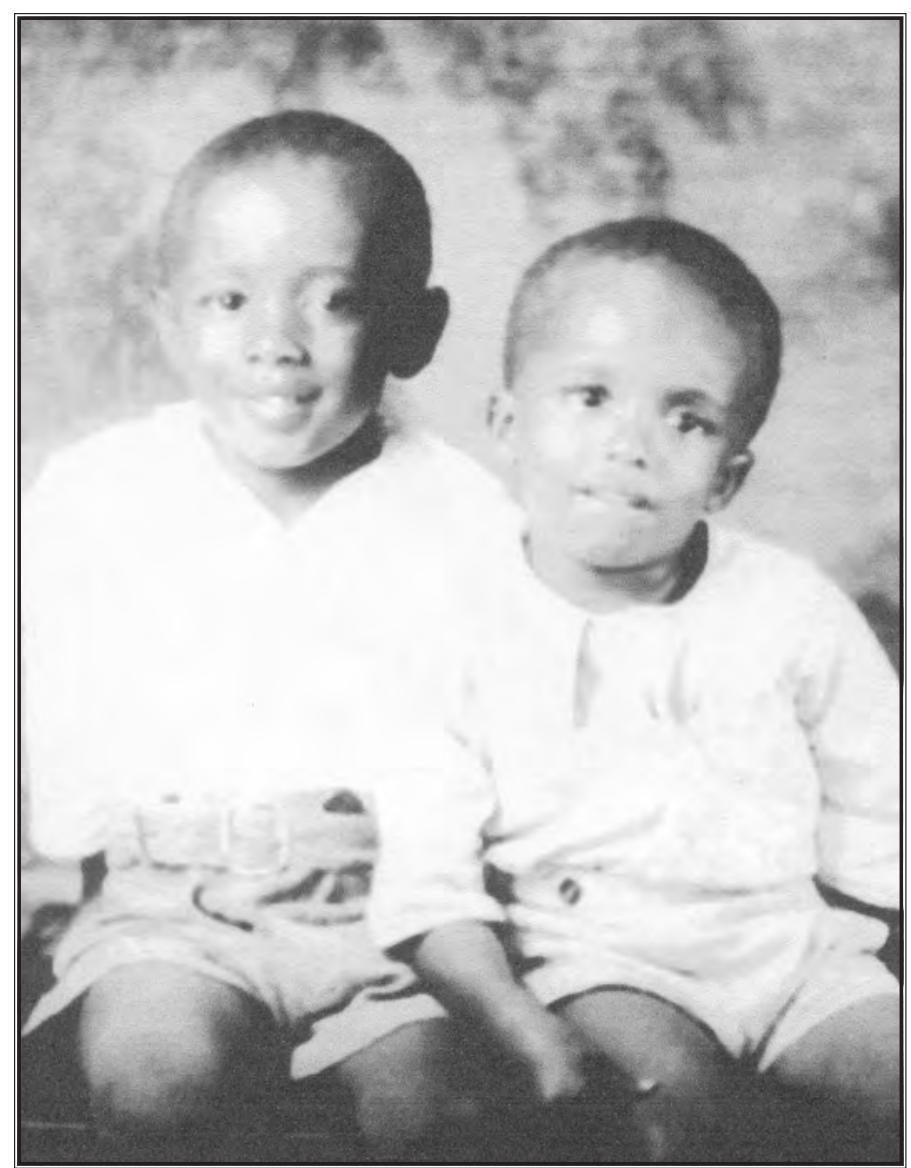

Figure 29. Marcus Pickard (left) and brother Alvin Pickard (right), ca. 1940. Photograph courtesy of Marcus Leon Pickard, Jr.
African Americans in Manchaca buried their deceased in either Chatham Perry or Brown Cemetery (see Figure 26, Nos. 4 and 11). The former was established by Chatham Perry, who arrived in Manchaca not long after emancipation as one of the area's first black settlers (Myers 2011). It is a family cemetery that is still maintained and used, and Chatham and Ann Perry's descendants are buried there. These include the family members of interviewees Estella Hargis, Marcus Pickard, and Rene Pickard, who are all descended from the Perrys. According to Myers (personal communication 2011), Brown Cemetery may be named for Brown Bunton, a freedman who married Susan Rose, who has the earliest dated headstone (still standing, that is) in the cemetery. Susan (Rose) Bunton was buried in 1877. Robbie Overton, Cedel Evans, Earselean Hollins, Kay Randall, Earlee Bunton, and Annie Axel all have kin buried at Brown Cemetery, as does LeeDell Bunton of Antioch, whose greatgreat-grandmother, Elizabeth Smith, was laid to rest there. Interviewee Floris Sorrells maintains the cemetery today. The ancestors of Joanne Deane and Lillie Moreland are buried at Live Oak Cemetery, along with many of the area's early white settlers (see Figure 26, No. 12). The Austin Genealogical Society has recorded the headstones of many of Travis County's historic cemeteries, including the three referred to here. ${ }^{26}$

African Americans celebrated Juneteenth at Dodson Park (see Figure 26, No. 13), a large parcel of land owned by Jack Dodson. Dodson, who was African American, and his wife Mary first rented their land off of Manchaca Road in the 1880s. Both were formerly enslaved by James W. Dodson, who owned a cotton plantation in Fayette County, Texas (Myers 2011). In 1891, Dodson made a down payment on the 115-acre farm and eventually paid the note off. Jack Dodson passed away in 1925, and his widow Mary remained on the farm until 1937 (Myers 2011). She was interviewed by the WPA's Federal Writers' Project that year. The Dodsons are still well known in Manchaca. Both during and after they owned the land, Juneteenth commemorations were held annually at Dodson Park, a section of their acreage close to present-day Menchaca Elementary School. Estella Black related, "They would have big barbecues. And they had a platform there, and they'd have dancing...And just seemed like everybody was lovable, you know." Earselean Hollins remembered that the black churches organized Juneteenth:

${ }_{26}$ The Austin Genealogical Society's cemetery database for Travis County can be found at http://www.austintxgensoc. org/cemeteries/index.php. 


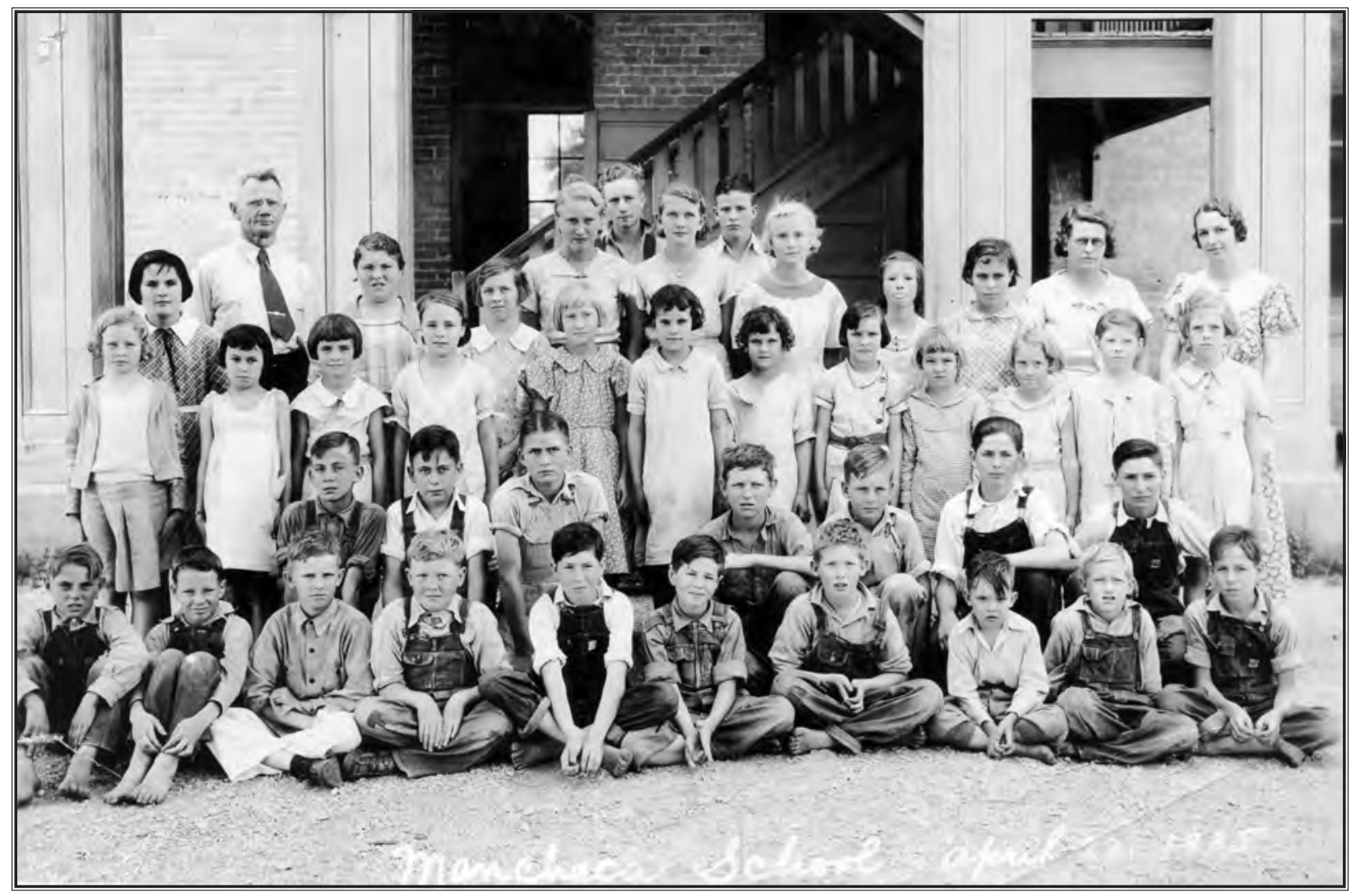

Figure 30. Students of Manchaca School, April 23, 1935. Interviewee Lillie Moreland stands to the far left in the back row. Photograph courtesy of Lillie Moreland.

Like some people would make the homemade ice cream and they would sell that at the Juneteenth. And then the other people would bring the dinners and sell the dinners. Other people would bring the sodas and sell the sodas. And then the men would get together and do all the barbecue. But that was a good fun time for us.

The businesses in Manchaca included three stores that were operating between ca. 1900 and 1950: Down's, Joneses, and Blackwell's (Joanne Deane, personal communication 2012). Blackwell's Store (see Figure 26, No.14) was owned and run by merchant and pharmacist Thomas Franklin "Frank" Blackwell. Blackwell opened his business ca. 1896-1900 (McLeod 2009). According to Lillie Moreland and Joanne Deane, it was not only a general store and pharmacy, but the Manchaca Post Office was housed there, and people hauled water from Blackwell's.

Manchaca remained sparsely populated for some time after its founding. By the late $1960 \mathrm{~s}$, the population stood at just 200 people (Smyrl 2011). Thus, African American interviewees, who mainly talked about living there from about 1920 to 1960, frequented Austin on weekends for their entertainment (mainly on East $6^{\text {th }}$ Street), shopping, and to attend Anderson High School if they were able to pursue their education past the $7^{\text {th }}$ grade. Still, everyone spoke highly of Manchaca, citing their churches and relationships with other families as the basis for community formation. 


\section{EAST AUSTIN}

The city of Austin, especially the historically black section of East Austin, figured largely in the lives of most of our narrators. Some, like Marian Washington and Lillie Grant, left their families and moved to East Austin from Buda to attend high school. Robbie Overton, Lee Wildon Dawson, Kay Randall, Lourice Johnson, and Jewel Andrews were raised in East Austin after their families migrated from rural areas nearby. Others, like Earlee Bunton, Annie Axel, and Estella Black moved to East Austin later in life and still reside there. Nearly all of the African American interviewees from Manchaca and Buda recalled "going to town" on Saturdays as Austin offered department stores, restaurants, and other amenities not available in smaller, rural communities. Whether for work, leisure, education, or to visit family and friends, as people circulated between the countryside and Austin, they forged social, cultural, and economic relations that blurred the boundaries between these rural and urban communities.

There were several sources that I relied on in writing the following overview of East Austin's past. One is the Handbook of Texas Online, an encyclopedia covering the state's history and culture. Sponsored by the Texas State Historical Association, the Handbook features 25,000 articles on Texas authored by scholars, students, and others interested in sharing their research with the public. Another resource that I consulted was The Project in Interpreting the Texas Past (ITP). Directed by Dr. Martha Norkunas, ITP is sponsored by the Intellectual Entrepreneurship Consortium at the University of Texas at Austin. Graduate students enrolled in Norkunas's seminars produced a series of articles on black history in Austin for the George Washington Carver Museum and Cultural Center's online exhibit and for Austin's East End Cultural Heritage District's website. Several of these online articles are cited below. Finally, journalists for the Austin American-Statesman have written articles on East Austin over time. In particular, historian and educator Ada DeBlanc Simond (b. 1903; d. 1989) worked as a columnist for the Statesman from 1983 to 1984 (Barnes 1996). Her column, "Looking Back" (Simond 1984), played an important role in raising awareness of Austin's black history, and I referenced several of her informative articles.

African Americans were present in Austin since the city was incorporated in 1840, when 145 enslaved blacks comprised 17 percent of its population (Humphrey 2011). By 1860, their numbers increased to about 30 percent, with a large number working on farms and ranches, and others as skilled laborers and domestics (Fraser 2011). Following emancipation, African Americans established enclaves in various parts of the city (e.g., Clarksville, Wheatsville), but many also settled in neighborhoods throughout Austin (Humphrey 2011; Mears 2009). Although blacks resided during the nineteenth and early twentieth centuries in the area today considered East Austin, it wasn't until the 1930s that the majority of the city's blacks were concentrated there.

In 1928, the city of Austin began implementing a master plan that led to dividing the city more decidedly along racial lines. In a report entitled A City Plan for Austin, Texas, the engineering firm Koch and Fowler noted that one area of the city, east of what was then East Avenue (now the I-35 corridor, completed in 1962), was exclusively black. They recommended that, "the nearest approach to the

solution of the race segregation problem will be the recommendation of this district as a negro district; and that all the facilities and conveniences be provided the negros in this district, as an incentive to draw the negro population to this area" (Koch and Fowler 1928:57). The plan was successful, and East Austin (Figure 31), which was already witnessing black growth in the 1920s (McDonald 1993:209), thereafter became the focal point for black settlement in the city. J. J. McDonald (1993:213) observed 
that "nearly seventy percent of all African-Americans entering Austin between 1929 and 1931 set up home in East Austin."27

Though East Austin's westernmost boundary has remained fixed, with I-35 demarcating the divide between east and west, its remaining boundaries have expanded over time. A study of the 1927 Austin City Directory revealed that African Americans were concentrated within the area defined by East Avenue (now I-35) to the west, East 11 $1^{\text {th }}$ Street to the south, Pleasant Valley Road to the east (with black households also residing about five blocks east of it from Maple to Ulit Avenues), and Manor Avenue to the north. Figure 31 represents the heart of East Austin in the 1950s, although its residential base extended beyond the figure shown. The following history indicates that as Jim Crow tightened its rein on the city, East Austin blossomed.

With a concentration of thousands of African Americans from various walks of life, the community built upon its wealth of experiences and sense of solidarity in establishing schools, churches, and businesses. By the late 1940s, there were 150 black-owned businesses and over 30 black churches (Humphrey 2011; Figure 32). African Americans who contributed to the community by offering needed services included Wake Fowler, who in the 1920s worked for the Ideal Mutual Aid Association, a blackowned insurance company that insured low-income African Americans at a time when the vast majority of white insurance companies refused to do so (Simond 1984). Fowler was also the superintendent for Ebenezer Baptist Church's Sunday school, underscoring the communal ties that blacks who plied their trades in East Austin also cultivated. Fowler's son, Vernon Fowler, attended the Tuskegee Institute and returned to Austin to become the city's first licensed black electrician. For decades, he operated his own business on East 7th Street and trained black journeymen in his trade. For black American women, the beauty industry has historically been the primary vehicle to entrepreneurship (Gill 2010). The precursor to future black-owned beauty salons in Austin was Mrs. A. W. Rysinger's Central Millinery Emporium, Hair Work and Dry Goods on East $6^{\text {th }}$ Street. During the early 1900s, Rysinger's Emporium stocked cosmetics, hats, dresses, hair braids, and all other goods women needed to be fashionable at the time (Simond 1984). Following in Rysinger's footsteps, Pinkie Lee Henry opened a Madame C. J. Walker Beauty School in 1955 at 421 East $6^{\text {th }}$ Street. She trained many beauticians, and the success of her school allowed her to relocate in 1977 to a building that she purchased at 1702 East $12^{\text {th }}$ Street.

In terms of healthcare, black doctors were present in Austin during the late nineteenth century, including Quinton Belvidere Neale, E. W. Abner, and John F. McKinley (Cannon 2006). Yet, early black Austinites were also fortunate in that a number of midwives served the community faithfully, including Mattie Caperton and Mary Freeman. Simond (1984) noted that not only did midwives deliver babies, they also gave advice on prenatal care, were familiar with herbal remedies and nursing care, and could assist physicians with more difficult deliveries (see also Wilkie 2003). Austin's black midwives were widely respected and played important roles in their churches and organizations. As physician-attended births increased in urban areas in Texas, obstetricians attempted to stamp out midwifery from 19101930, when doctors and the general public increasingly believed that mortality rates among infants and their mothers were higher in cases where midwives were involved (Seaholm 2011). Despite the fact that midwifery has always been legal in Texas (Seaholm 2011), professional nurses and doctors began to replace midwives in meeting the healthcare needs of blacks in Austin. One of the earliest leaders in this area was Abbie Suel-Strong, who received her formal training at Flint-Goodrich Hospital in New Orleans. In East Austin, Suel-Strong trained others in modern nursing practices during night school at classes held at Anderson High School (Simond 1984). In the late 1930s, two black doctors opened

27 East Austin also became home to one of two Mexican enclaves in Austin during the early twentieth century as Mexicans settled south of East 11th Street and north of East 1st Street (now Cesar Chavez Blvd.; McDonald 1993:212-221). 


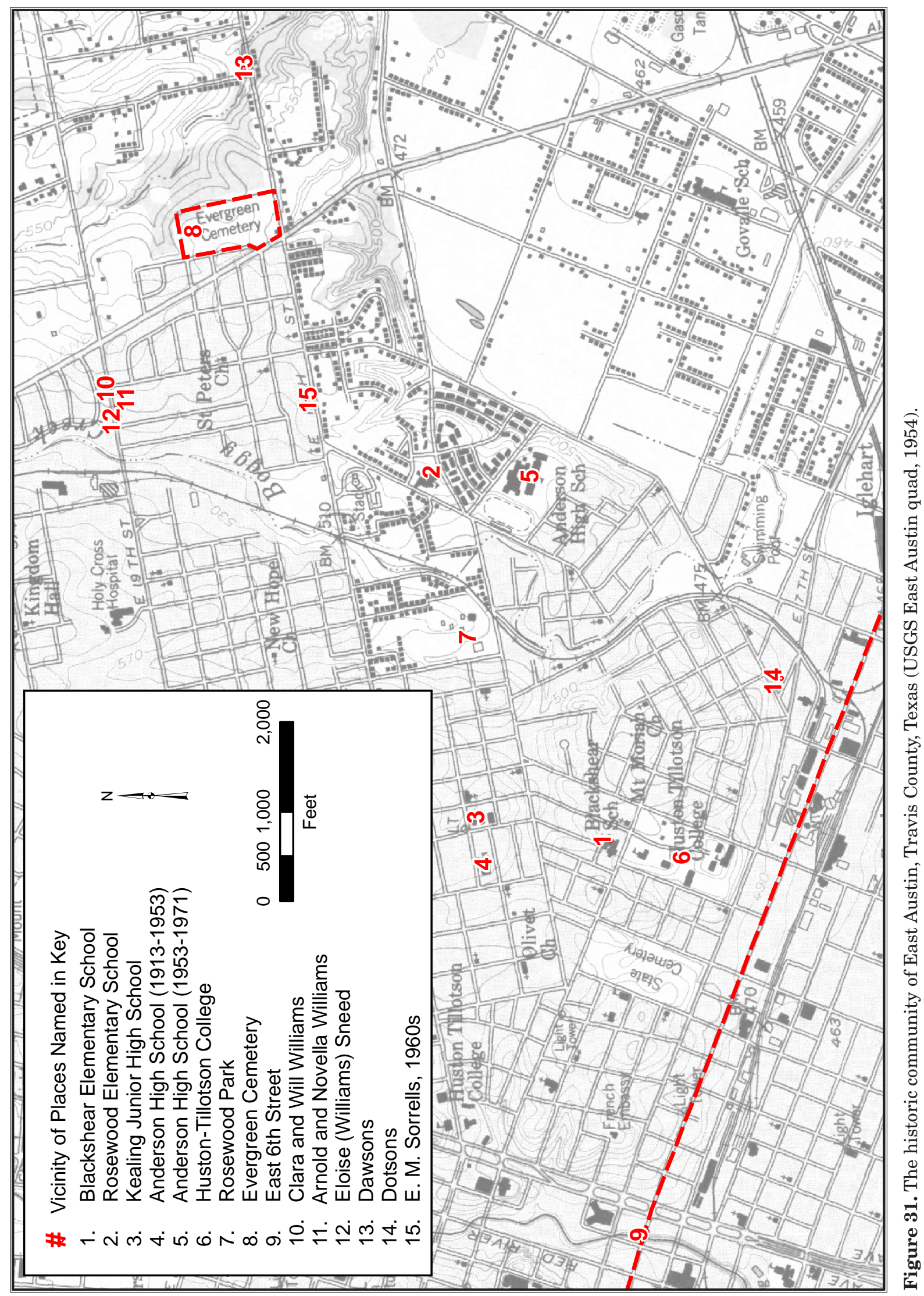




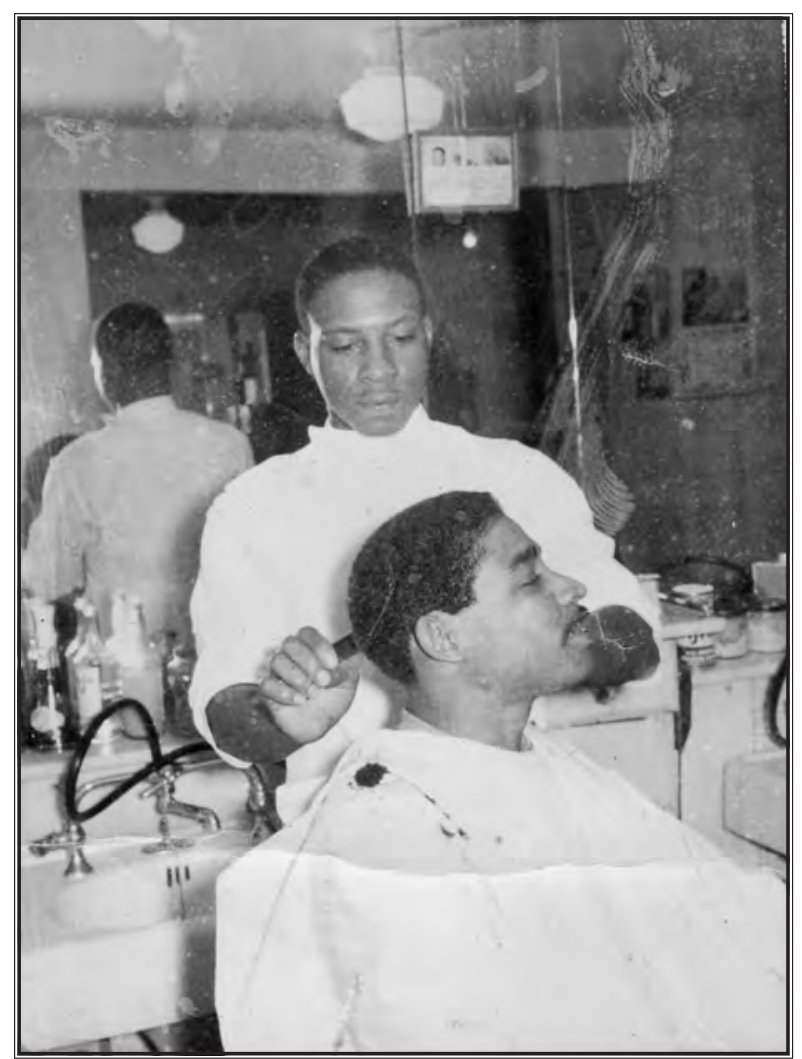

Figure 32. Herman Dotson trimming cousin Arthur Lee Hargis's hair at a barbershop in East Austin, ca. 1960s. Dotson is the brother of interviewee Robbie Overton. Photograph courtesy of Robbie Overton. health clinics in East Austin: Reverend Francis Webber and E. L. Roberts. Interviewee Corrine Harris, the great-granddaughter of Ransom and Sarah Williams, worked for Roberts at his clinic on San Bernard Street, and in her oral history she relates some of her experiences at the clinic and what she remembered about Roberts.

Interviewees mentioned attending a number of schools in East Austin that were established prior to integration. These included Blackshear and Rosewood Elementary Schools (see Figure 31, Nos. 1 and 2). Blackshear began as Gregorytown School in ca. 1894, when a grammar school for black youth opened on Olive Street in Austin. In 1936, the school relocated to its present location on East $11^{\text {th }}$ Street and was renamed for Edward Lavernia Blackshear, who was an administrator in charge of overseeing Austin's black schools (Clark-Madison 2002). Kealing Junior High School was named for Theodore Hightower Kealing, a nineteenthcentury educator and Austin activist. It opened in 1930 on Pennsylvania Avenue (see Figure 31, No. 3) as the city's first junior high school for black students. Integration led to the closure of East Austin's secondary schools in 1971, yet Kealing reopened in a new building (the original building burned down) in 1986 on Pennsylvania Avenue and now houses one of three middle school magnet programs in the Austin Independent School District (AISD).

Anderson High School has a long and storied history, and interviewees recalled fondly and with pride their time as students there. Many of them still attend their annual high school reunions, and it was through Anderson that interviewees knew one another. It was the only high school in the region that admitted black students. Anderson began in 1889 as part of Robertson Hill School (established in 1894), Austin's first "colored" school. In 1909, the high school relocated to Olive and Curve Streets in East Austin and was renamed for E. H. Anderson, Prairie View A\&M's principal during the late nineteenth century (Mixon 2009). In 1913, Anderson relocated once again to Pennsylvania Avenue, and was then adjacent to Kealing Junior High School (see Figure 31, No. 4). In 1938, it was renamed L. C. Anderson High after its former principal, who served the school for decades (L. C. Anderson was the brother of E. H. Anderson; Mixon 2009). In 1953, Anderson then moved to its last location in East Austin at 900 Thompson Street (see Figure 31, No. 5). Like Kealing, integration led to its closure in 1971. Anderson High was a beacon for East Austin, drawing African Americans to the community with the prospect of their children receiving a high school education. Several years later, L. C. Anderson High School opened its doors in northwest Austin, far from its roots in the city's east side. Community members and former students urged the AISD to name the new school in honor of the historic one (Mixon 2009). 
In addition to its primary and secondary schools, Austin was home to two black colleges in the nineteenth century. Tillotson College was chartered in 1877 and named for Reverend George Jeffrey Tillotson, a New Englander and graduate of the Yale Divinity School, and the main driving force behind its founding (American Missionary Association 1911; Anonymous 2011a; Robinson 2011). Assisted by the Freeman's Aid Society of the American Missionary Association of the Congregational Churches, the Tillotson Collegiate and Normal Institute opened in 1881 on what is now Chicon Street in East Austin. At about the same time, Samuel Huston College's (originally called Andrews Normal School) humble but inspirational founding began in the basement of Dallas's historically black church, St. Paul Methodist Episcopal (now St. Paul United Methodist) in 1876. In 1878, the college moved to the basement of Austin's Wesley United Methodist Church and was renamed the West Texas Conference School. An Iowa philanthropist by the name of Samuel Huston donated money in 1880 to purchase land in Austin for a coed black school, and the college was renamed in his honor in 1887. Samuel Huston College's original campus was located on East $12^{\text {th }}$ Street, where a Texas state historical marker now commemorates the college. ${ }^{28}$ Though financial straits led to closures during the $1880 \mathrm{~s}$, the college opened its doors for good in 1900 in the same location. The two colleges merged in 1952 to form HustonTillotson College in its present location on Chicon between $7^{\text {th }}$ and 11 ${ }^{\text {th }}$ Streets in East Austin (see Figure 31, No. 6). In 2005, Huston-Tillotson received university status.

Other notable East Austin landmarks mentioned by narrators include Rosewood Park (see Figure 31, No. 7). Established in ca. 1930, the park became the first city-sponsored recreational facility for blacks, no doubt as a result of the 1928 city plan. When I asked Lee Wildon Dawson where blacks congregated in East Austin for socializing, he replied, "Rosewood, Rosewood Park. That was basically all that we [the children] had." Historically, Rosewood Park was the site chosen for Austin's Juneteenth celebrations, with foot races, beauty pageants, parades, and barbecues marking the event. The tradition continues today.

There are three cemeteries in East Austin, but interviewees mentioned Evergreen most often. Since a number of interviewees and various members of their families were either raised in Austin or eventually migrated there, Evergreen Cemetery (see Figure 31, No. 8) was the final resting place for many of their kin. Previously, blacks were allotted a portion reserved for "coloreds" in Oakwood Cemetery (established in 1839 and a National Register of Historic Places landmark as of 1985). Even though the cemetery expanded (today it covers 40 acres), the section for blacks did not, despite the cemetery's location in growing East Austin (Simond 1984). As a result, African Americans established Bethany Cemetery in East Austin in the late nineteenth century, but over the years the grounds became neglected. When the city opened Evergreen as a perpetual care cemetery in 1928, some black families moved their loved ones from Bethany to Evergreen.

Although East $6^{\text {th }}$ Street (see Figure 31, No. 9) was often the weekend destination of African Americans living in rural communities in the city's vicinity, the center of East Austin's economic and social life, in terms of businesses and entertainment venues, were East $11^{\text {th }}$ and East $12^{\text {th }}$ Streets (see Figure 31). Dr. Charles Urdy, formerly a professor at Huston-Tillotson University and an East Austin community leader, gave an interview for KLRU's Austin Now series in which he stated:

East 11th and East 12th Street were the heart and soul of East Austin. Practically everything we needed or wanted was either on those streets or near to those streets. It was sort of the business hub for East Austin. And it is where most people spent most of their time outside of work. Most people only left East Austin to go to work. ${ }^{29}$

28 The information regarding Samuel Huston College's history is cited from the Texas Historical Commission's state historical marker (Marker No. 15242) installed at the site.

${ }_{29}$ Produced by Michael Emery, the video clip of Charles Urdy's interview can be viewed at http://www.klru.org/ austinnow/archives/gentrification/index.php. 
Interviewees concurred. Jewel Andrews recalled that "East $12^{\text {th }}$ Street was really the area where we spent more time on...because that's where the movie theater was, and they had a drugstore called Yates Drugstore across the street. They sold ice cream and drinks and stuff like that." Andrews and her sister, Lourice Johnson, also remembered the Southern Dinette, Georgia's (a diner owned by Georgia Owens), and the Victory Grill, still in operation on East 11 ${ }^{\text {th }}$ Street, where restaurants and "beer joints" helped to cultivate an active social scene in East Austin. Dawson, though over a decade younger than Andrews and Johnson, affirmed, "When they went out, and I was a kid then, but when they went to party, that's where they went." Dawson and others frequented the Harlem Theater on East $12^{\text {th }}$ Street, which locals referred to as "up on the end." East $11^{\text {th }}$ and $12^{\text {th }}$ Streets were also "ground zero" for what was known as the Chitlin' Circuit, the blues music scene that brought high-profile black musicians to East Austin (Anonymous 2011b).

\section{The Williams Descendants in East Austin}

Will Williams, the son of Ransom and Sarah Williams, and his wife Clara (Franklin) Williams moved their family from Creedmoor to East Austin in the 1930s. They eventually had eight children: Janie, Mabel, Syola, Willie E., Earl Clara, Eloise, Freddie, and Arnold David (Figure 33). The Williamses purchased one acre on East $1^{\text {th }}$ Street (since renamed Martin Luther King, Jr., Blvd; see Figure 31, No. 10). Eventually, the acreage was split evenly between the Williamses and two of their children, Arnold David and Eloise (see Figure 31, Nos. 11 and 12). Thus, there were three closely related households living next door to one another for years. Arnold David married Novella Harris (Figure 34) and raised their five children on East 19th, including interviewees Corrine Harris, Lourice Johnson,

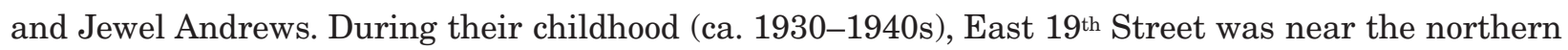
periphery of East Austin and was relatively undeveloped. Their grandparents, Will and Clara, used a pasture across the street to raise cows and hogs. Behind their house they also maintained an extensive garden filled with fruits and vegetables, and an orchard with peach, pecan, fig and pear trees. Though Will Williams never mentioned his upbringing in rural Manchaca to his granddaughters, he and Clara succeeded in reproducing at least a portion of their country roots in the city's eastside.

\section{REMARKS}

After long struggles with racism, and the often painful process of witnessing the transformation of East Austin under integration (which included the eventual dissolution of many businesses and the closure of schools) and now gentrification, East Austin residents are moving forward to revitalize their community. Even though the 2000 U.S. census indicates that residents are now predominantly Hispanic, with African Americans accounting for 31 percent of the community, and more recently arrived whites for about 9 percent, East Austin's black heritage is today more publicly visible and increasingly recognized in a more positive light than in the past. The George Washington Carver Museum and Cultural Center moved into a new 36,000-sq.-ft. facility in 2005 and continues to promote Austin's black history through its permanent and rotating exhibits. Further, central East Austin was one of seven sites to be honored with a State of Texas Cultural District designation. It is now referred to as the East End Cultural Heritage District. Community activists continue to push for economic and social equity, and although the landscape and demographic of East Austin have changed fairly drastically in recent decades, the area's black residents still maintain a strong connection to East Austin's past. 


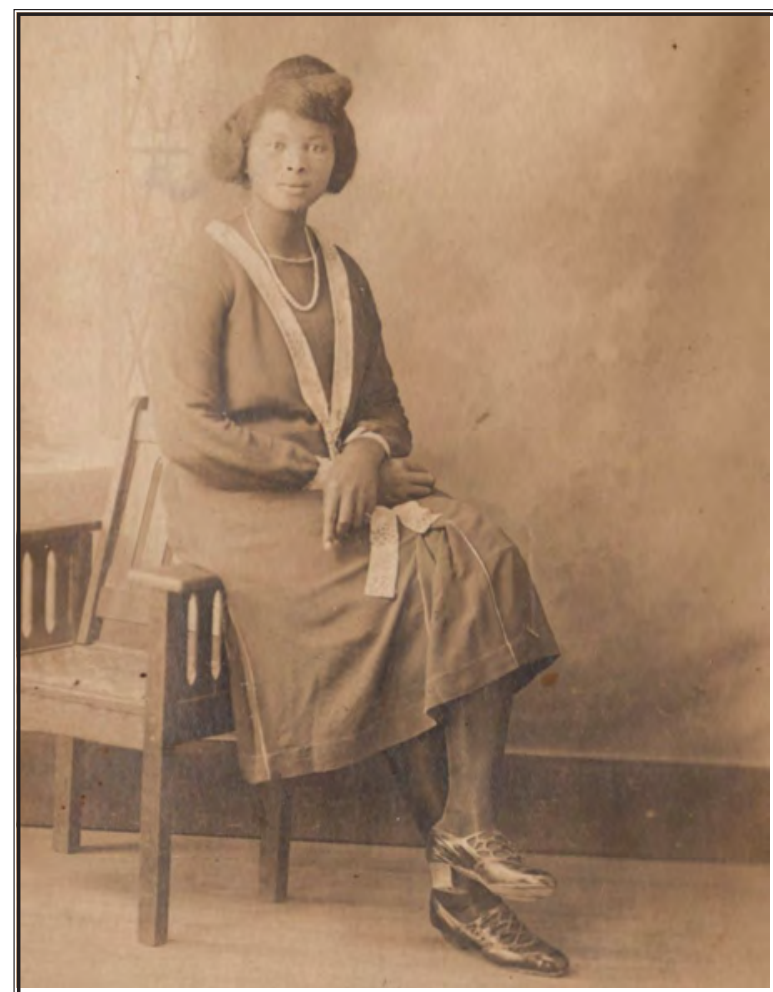

Janie Williams at age 16

(b. $1 / 5 / 1906$; d. 2/9/1977)

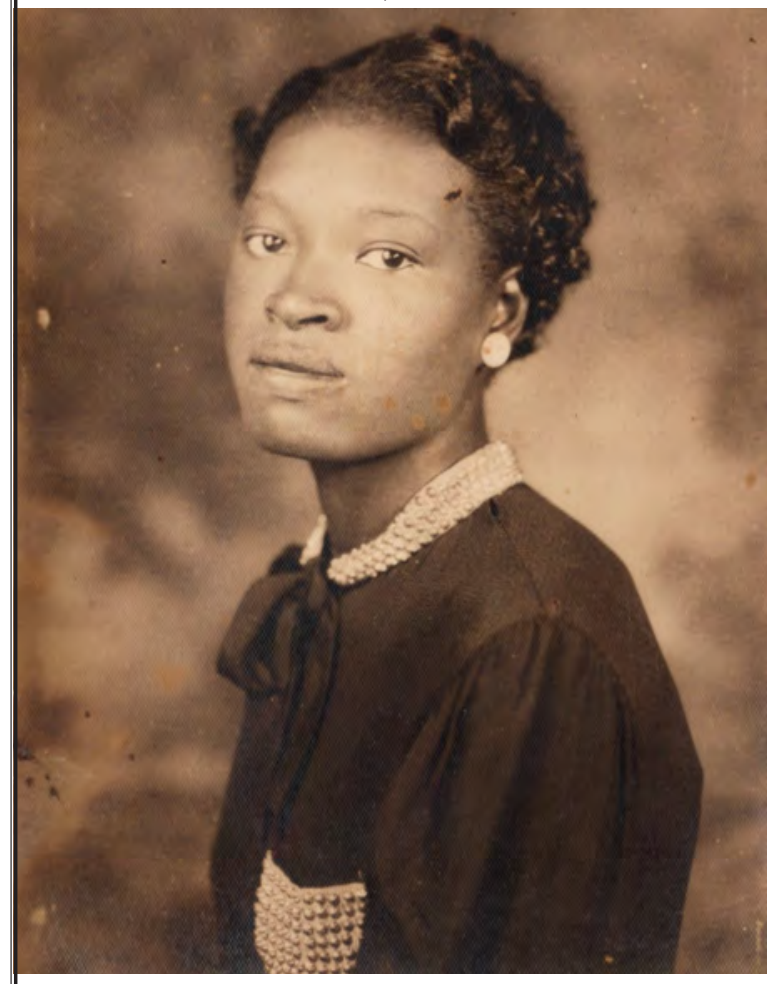

Syola Williams at about age 18 (b. 6/27/1912; d. 11/18/1978)

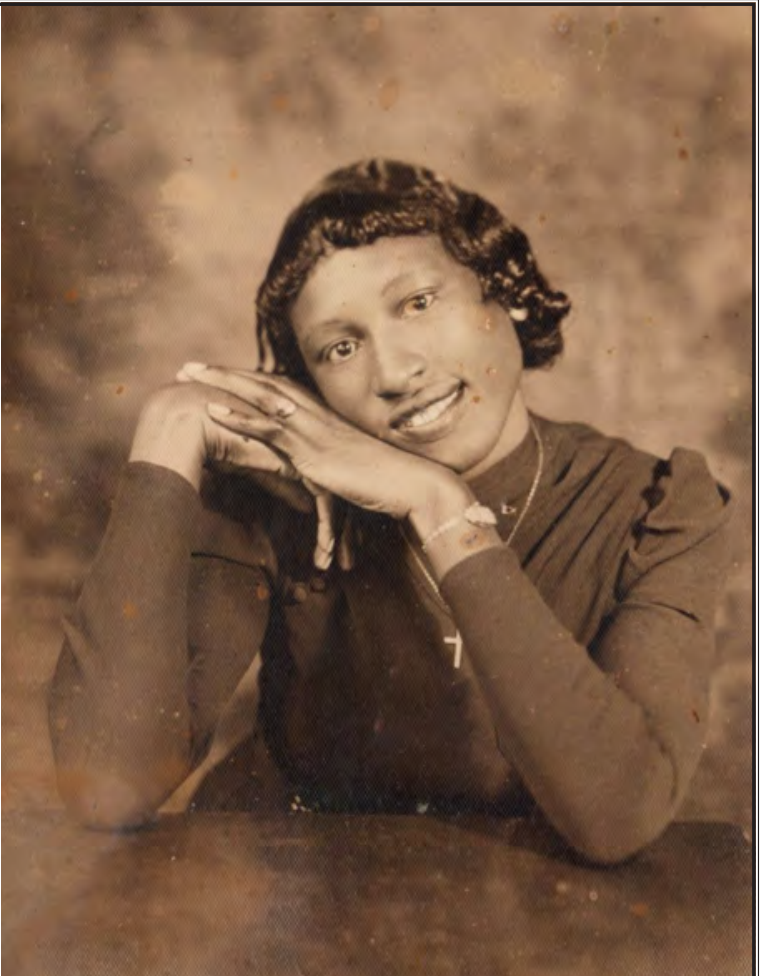

Mabel Williams at age 16 (b. 7/22/1910; d. 4/7/2002)

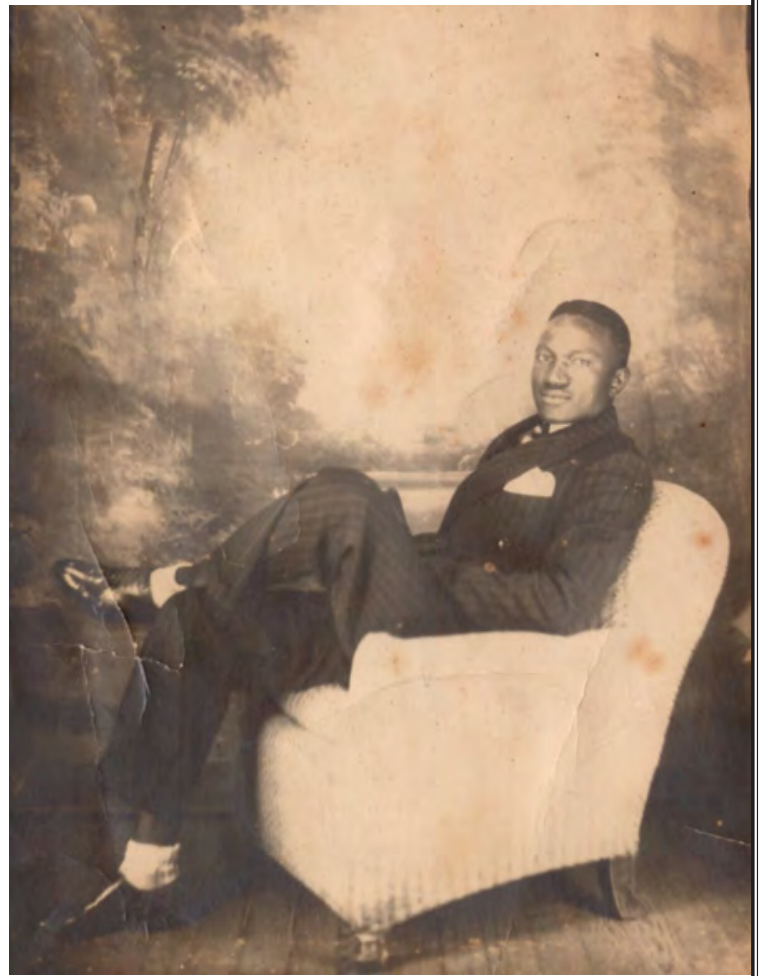

Will E. Williams, Jr., ca. 1950 (b. 10/2/1914; d. 2/25/1990)

Figure 33. Four grandchildren of Ransom and Sarah Williams. All are the children of Will and Clara Williams. Photographs courtesy of Corrine Harris. 


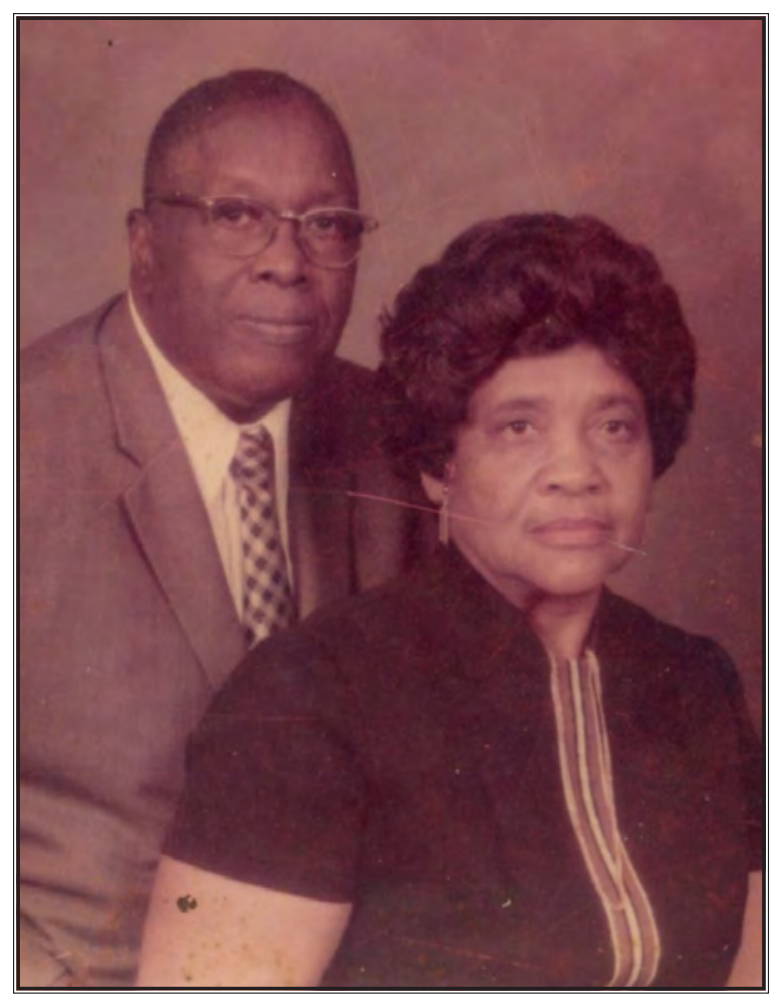

Figure 34. Novella (b. April 12, 1909; d. April 5, 1988) and Arnold David Williams (b. October 3, 1902; d. December 15, 1981), a grandson of Ransom and Sarah Williams, ca. 1977, Austin, Texas. Photograph courtesy of Corrine Harris. 



\section{CHAPTER 3: THE ORAL HISTORIES}

\section{INTRODUCTION}

In general, the oral histories are grouped by the area in which interviewees spent a portion, if not all, of their childhood: Antioch Colony and the Prairie (Buda), Manchaca, and Austin. ${ }^{30}$ Within each group, the transcripts of interviewees who are closely related by kinship are clustered together.

\section{Antioch Colony and the Prairie, Hays County}

To the extent that was possible, Figure 9 includes the locations of interviewees' childhood homes. Some of the spatial data was pulled from a ca. 1920s survey plat (probably created for tax purposes; Travis and Hays Counties Survey Map, n.d.). The survey indicates property boundaries, size of acreage, and the name of the owner, although structures are absent. Thus, while we could identify property lots, the specific locations of houses within them were indeterminable. Still, the survey map proved useful. From it we were able to roughly identify the location of the Harper home. The Harpers (Figures 35 and 36) rented land on Old Black Colony Road (see Figure 9, No. 8) from a relative, John Taylor. They mainly worked as farm laborers, although George Harper and his cousins also operated a cane syrup mill. Harper eventually purchased a lot across the road from the land he rented. Although he and his wife and a number of their dependents moved to Arizona in 1955, they kept their property, and today several of the Harper children and their families reside there. In 1993, LeeDell Bunton, who was also raised in the Harper household, purchased acreage once owned by his great-grandmother, Kate Bunton, and he and his wife Anita visit Antioch annually.

Anthy Lee Walker's family sharecropped, and they moved a number of times. Although Walker was unable to identify on a map where her family lived in Buda, she did recall the names of some of the men her family sharecropped for. Their names were found on the survey plat. Walker's family, the Revadas, first lived on Frank Crews' land (see Figure 9, No. 9), and then on John Howe's land. Since Howe owned several parcels in Buda, the next location of the Revada homestead remains unknown. After Walker left home, her parents, Dan and Hattie Revada (Figure 37), took in and raised their grandchildren. One of them was interviewee Joan Limuel whose mother, Sophie (Peters) Revada, died relatively young; her father, Velma Revada, Sr., joined the navy and left his children to be raised by his parents (Figure 38). According to Limuel, her grandparents eventually quit sharecropping and purchased property in Antioch sometime in the 1940s, and built their house soon after (see Figure 9, No. 10). This was the house that Limuel and her three siblings were brought up in.

Lillie Grant grew up on the Prairie, and like most others raised in either Antioch or the Prairie, she has ties to both communities. Through her mother, Ola Bunton, Grant is a direct descendant of the

30 Some, however, moved from Manchaca and Buda to Austin and spoke also of their experiences in the city. If an interviewee lived in more than one of these locations, it is indicated at the top of their transcript. 


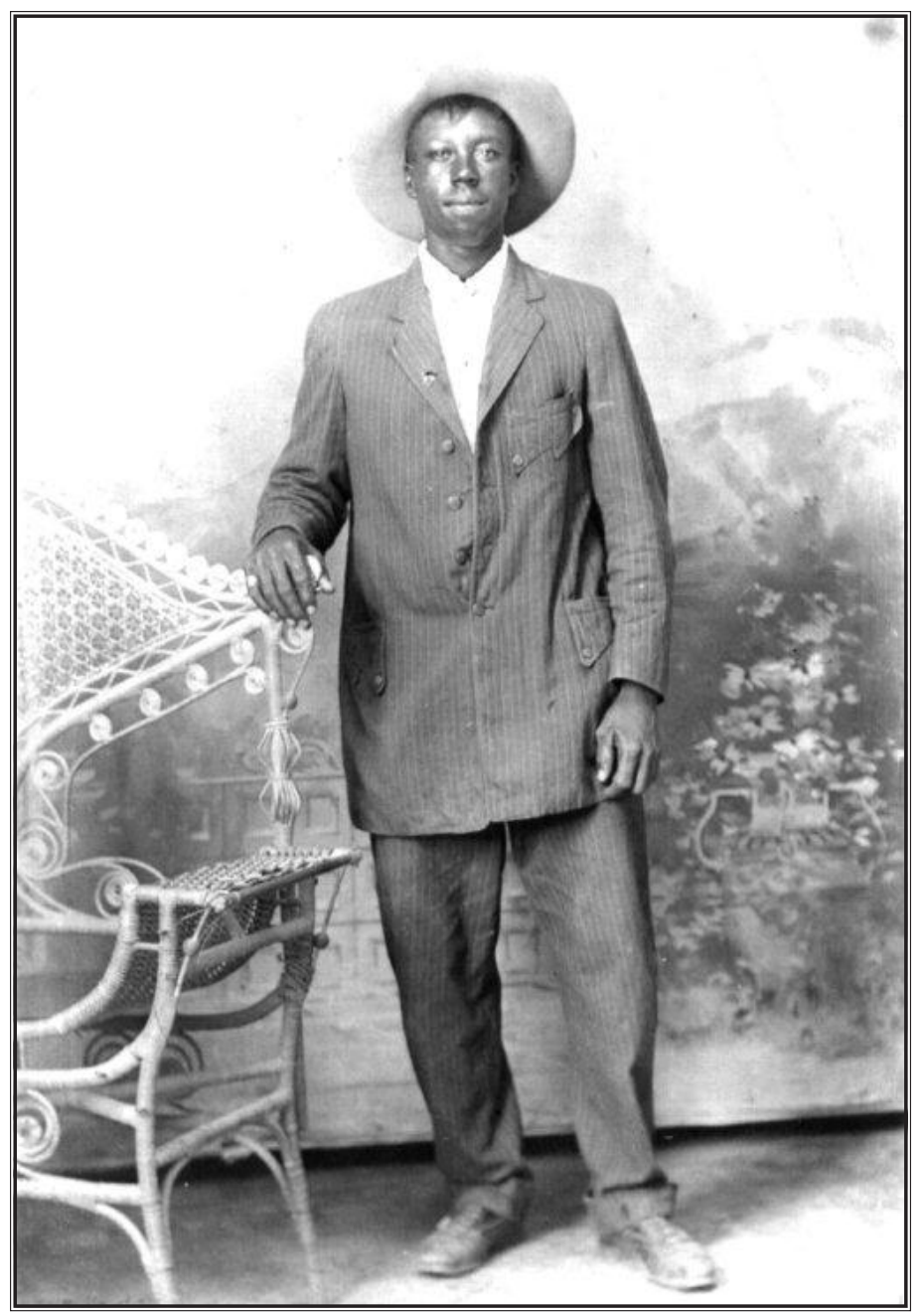

Figure 35. George Azberry Champ Harper (b. September 27, 1900; d. August 20, 1994), ca. 1920s (photograph was likely taken in Hays County, Texas). Harper is the grandfather of LeeDell Bunton, Sr., and father of Winnie Moyer, Minnie Nelson, Marian Washington, Samuel Harper, Ruth Fears, and Moses Harper. $\mathrm{He}$ is also the great-grandson of George and Missouri Kavanaugh, who purchased property from Joseph Rowley in Antioch Colony ca. 1870-1871. Photograph courtesy of LeeDell Bunton, Sr.

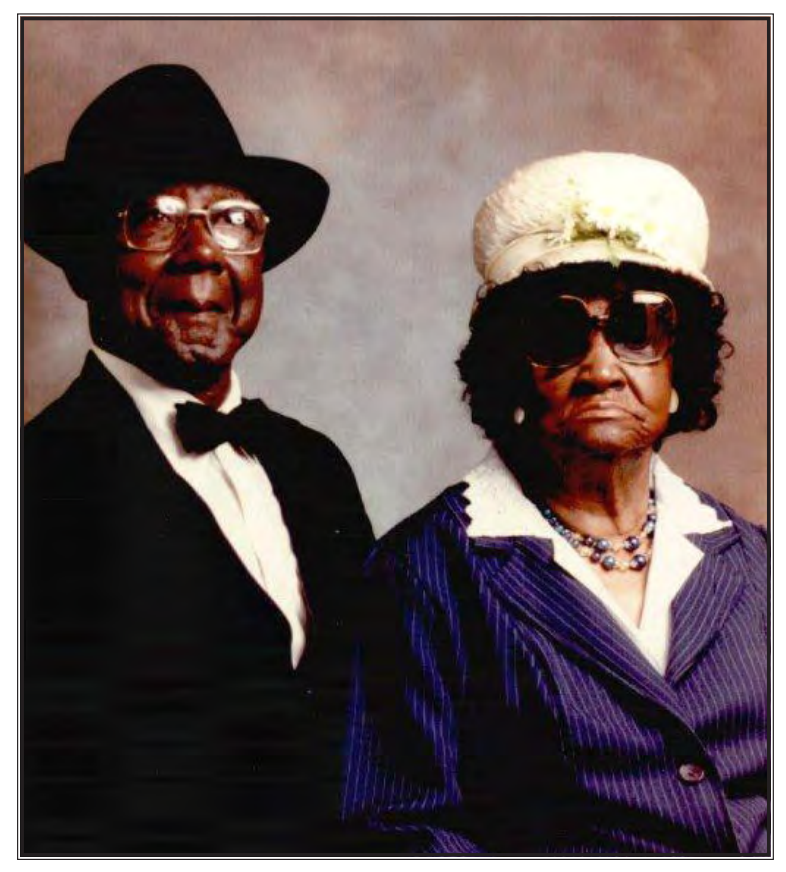

Figure 36. George and Emma Harper, Phoenix, Arizona, ca. 1970s. The Harpers are the grandparents of LeeDell Bunton, Sr., and the parents of Winnie Moyer, Minnie Nelson, Marian Washington, Samuel Harper, Ruth Fears, and Moses Harper. Photograph courtesy of LeeDell Bunton, Sr. 


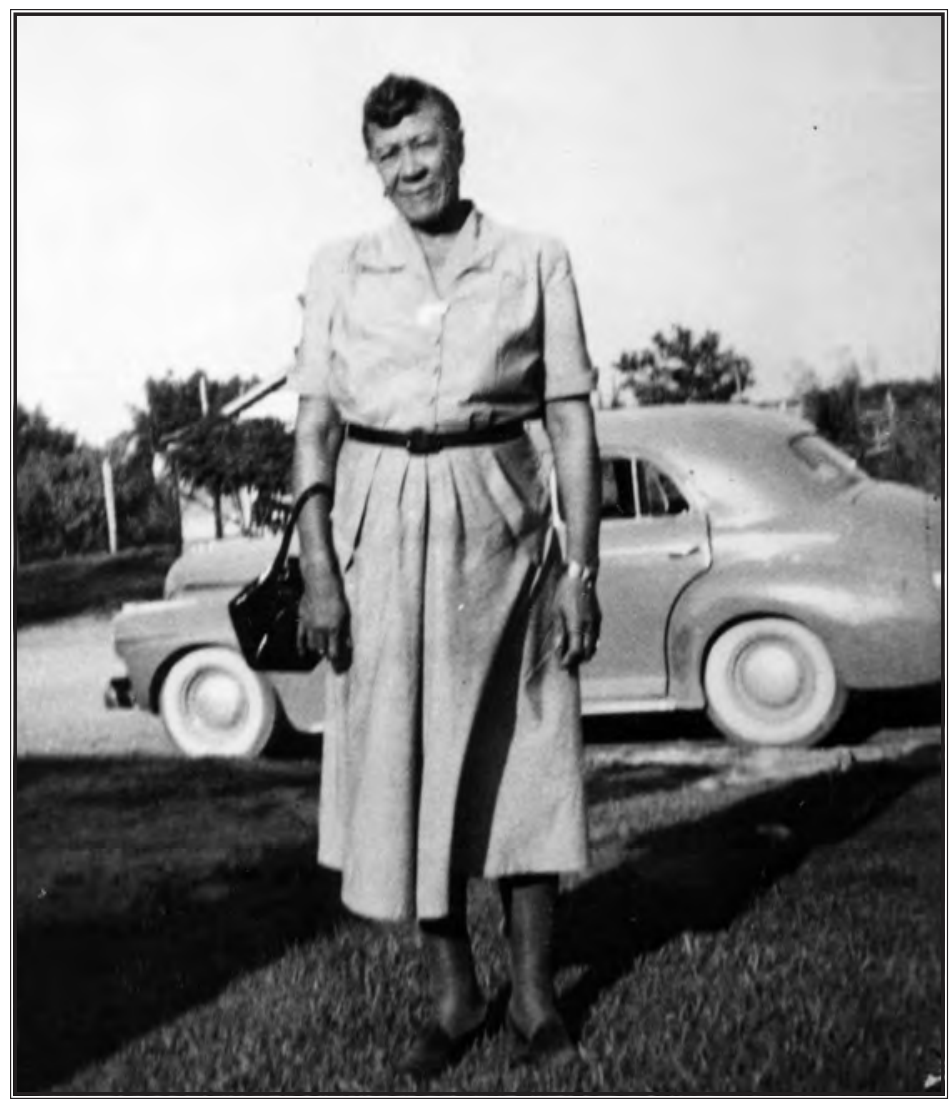

Figure 37. Hattie Sneed Revada (b. 1884; d. 1954) on the family homesite in Antioch Colony, ca. 1952. Photograph courtesy of Joan Nell Limuel.

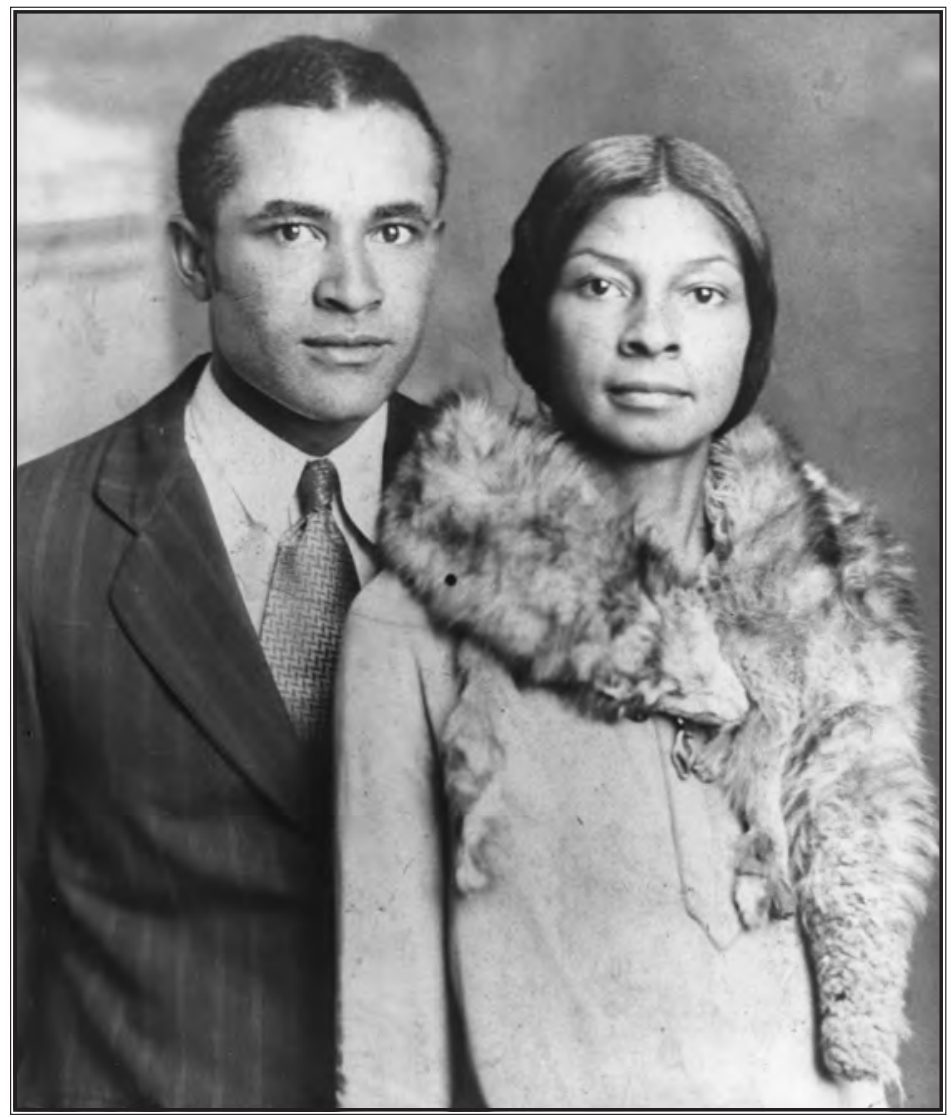

Figure 38. Velma Revada (b. 1908; d. 1954) and Sophie (Peters) Revada (b. 1900; d. 1938), ca. 1936. Photograph courtesy of Joan Nell Limuel. 
Buntons and the Friends, families that were among Antioch's original settlers. Grant attended Antioch School and Center Union Baptist Church. She lived from birth to age 17 on the 17 acres that her family owned and farmed (see Figure 9, No. 6). Grant's father, Lonnie B. Grant, purchased the property from his father, Carl Grant, in 1920. The family held on to the acreage for some time, eventually selling it in the 1990s.

Interviewees whose transcripts appear in the Antioch Colony and the Prairie section are:

LeeDell Bunton, Sr.

Ruth Roberta (Harper) Fears

Moses Ollie Joe Harper, Sr.

Samuel Leslie "Les" Harper, Sr.

Winnie Martha (Harper) Moyer

Minnie Mary (Harper) Nelson

Marian Missouri (Harper) Washington

Joan Nell (Revada) Limuel

Anthy Lee (Revada) Walker

Lillie Grant

\section{Manchaca, Travis County}

Thirteen interviewees, representing ten households, spent at least a portion of their childhoods in Manchaca. ${ }^{31}$ Their narratives largely span the 1920 s to the late 1960 s. Of the 10 Manchaca households, only two did not live on property that their families owned. The property lots varied from 2 to 80 acres, and where possible, the parcels are indicated in Figures 9 and 26. ${ }^{32}$ Several interviewees lived on smaller lots closer to central Manchaca. Robbie (Dotson) Overton's mother (Figure 39) purchased two acres on FM 1626 (adjacent to the Manchaca Colored School and St. Eli Baptist Church; see Figure 26, No. 15) following the death of her husband, and her heirs eventually sold the land in the 1990s. Joanne Deane and Lillie (Meredith) Moreland lived on Deane Road and Meredith Road, respectively, the streets clearly named for their families (see Figure 26, Nos. 16 and 17). Further out, on land that had historically been farmed over the years, were the Hargis, Pickard, and Sorrells households (see Figure 26). Estelle (Hargis) Black's family lived just north of Frate Barker Lane on 20 acres of land inherited from Black's maternal grandfather, Chatham Perry (see Figure 26, No. 2). Just north of the Hargis family resided both Rene and Marcus Pickard's families. Marcus Pickard, Jr., is a first cousin to Black, and Chatham Perry originally owned much of the 80 acres that his family farmed (see Figure 26, No. 3). This land was eventually passed down to Pickard and his brother, Alvin, where the latter raised his family, including son Rene Pickard. The Pickards sold their land to developers in the 1980s.

A number of the direct descendants of S. M. Sorrells, who purchased 80 acres in southern Manchaca in the late nineteenth century (see Figure 9, No. 11), grew up on their ancestral property. At one time there were four houses on the property, allowing their large extended family to live close to one another. I interviewed the children of Virgil (Earselean Hollins and Cedel Evans) and Alvin (Floris Sorrells), both sons of S. M. Sorrells, as well as Virgil's wife, Essie Mae Sorrells, and granddaughter

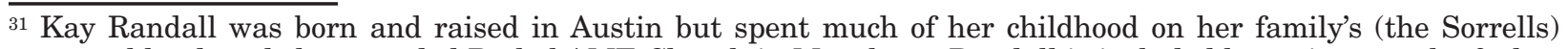
ancestral land, and she attended Bethel AME Church in Manchaca. Randall is included here since much of what she relates in her interview refers to those memories.

32 As with Figure 9, a 1920s survey plat of Hays and Travis Counties was consulted to try to determine the property boundaries for several of the homesteads indicated in Figure 26. This includes Hargis, both Pickards, Sorrells, and one of the properties sharecropped by the Buntons. 


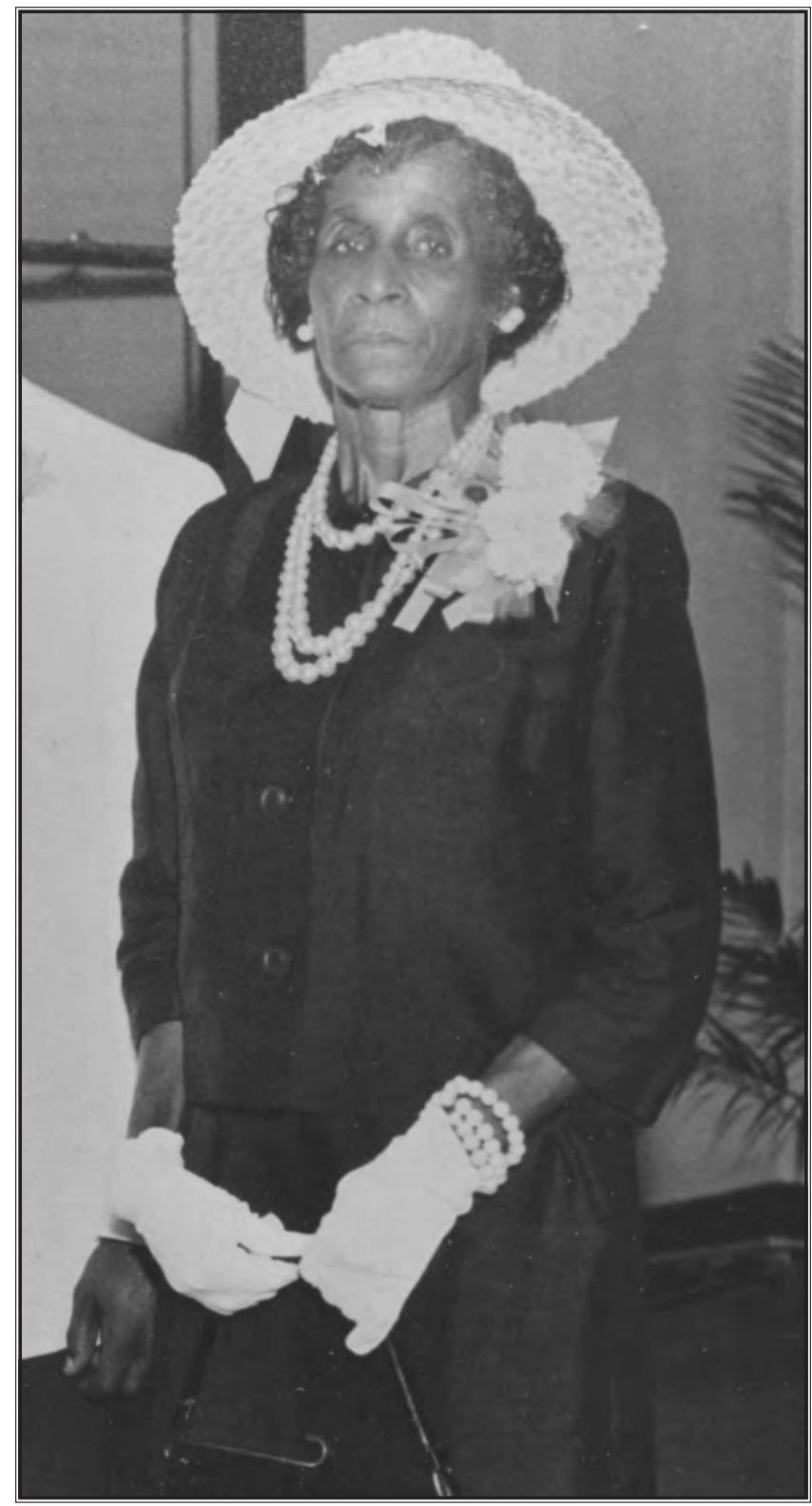

Figure 39. Carrie (Bunton) Dotson attending the marriage ceremony of her grandson, Eddie Dotson, to Joycelyn Lott, date unknown, Austin, Texas. Mrs. Dotson is the mother of interviewee Robbie Overton. Photograph courtesy of Robbie Overton.

(Kay Randall, daughter to Earselean Hollins). The Sorrells land remains in the family. Hollins, Evans, and Sorrells all grew up on the Sorrells' land in Manchaca. Floris Sorrells' family, however, moved to the Prairie (see Figure 9, No. 12) in 1948, when she was about 9 years old. Sorrells mentioned that her family made the move so that she and her siblings could live closer to school. Her family continued to make its living as farm laborers, while her mother also worked as a cook for a school for boys to supplement the household's income.

A cousin to Robbie (Dotson) Overton, Annie (Dotson) Axel's father worked for the MissouriPacific Railroad until he retired, thus the Axel children were raised in a section house. Owned by the railroad company, the section houses were once located close to the railroad tracks where they crossed Onion Creek in southern Manchaca (see Figure 26, No. 18). The family of Earlee Bunton (the uncle of Axel and Overton) sharecropped, and he recalled living on two properties during his childhood and youth. Although he could not identify either on a map, he remembered that the Buntons first 
sharecropped for a man named Joe Davis who owned land where a Walgreen's Drug Store is situated today off of Slaughter Lane (see Figure 26, No. 19). The family then sharecropped for the Heeps. Since the Heeps owned a number of properties spread out in both Travis and Hays Counties, the second Bunton homestead location remains unknown. Bunton was only able to recall that the property was somewhere in between Buda and Manchaca, and close to Onion Creek.

Interviewees whose transcripts appear in the Manchaca section are:

Robbie Freddie Mae (Dotson) Overton

Earlee Bunton

Annie (Dotson) Axel

Estella "Estelle" (Hargis) Black

Marcus Leon Pickard, Jr.

Rene Leon Pickard

Essie Mae (Owens) Sorrells

Earselean (Sorrells) Hollins

Cedel (Sorrells) Evans

Kay (Hollins) Randall

Floris Lean Sorrells

Joanne Deane and Lillie (Meredith) Moreland

\section{East Austin, Travis County}

The Williams and Dawson families are represented here by four narrators who spent most, if not all, of their childhoods in East Austin. Jewel Andrews, Lourice Johnson, and Corrine Harris are the great-granddaughters of Ransom and Sarah Williams. In the 1930s, their son Will moved with his wife and family to Austin from nearby Creedmoor. As Harris, Johnson, and Andrews remembered it, East $19^{\text {th }}$ Street (see Figure 31, No. 10) was located in the northern outskirts of East Austin, and much of it was undeveloped.

Lee Wildon Dawson is the direct descendant of the Buntons and the Friends of Antioch Colony and the Grants of the Prairie through his mother Lorene (Grant) Dawson. ${ }^{33}$ Although born and raised in Austin, Dawson remains active in the Antioch Cemetery Association, and like other Antioch descendants, expresses concern that the colony's history is being lost due to the deaths of its elders. The narrative he creates of growing up in East Austin speaks to the challenges that his single mother faced in raising five children, and the values that she passed down to him and his siblings-values she herself learned from her parents. Dawson lived on Donna and then Ulit as a child but spent most of his youth on East $12^{\text {th }}$ Street (see Figure 31, No. 13).

Although there are only three oral histories in this section, a number of the others are also relevant here since some interviewees moved to East Austin while still young. Robbie (Dotson) Overton's mother relocated the family from Manchaca to Austin to a house that she purchased on Morelos Street (which is still standing; see Figure 31, No. 14). Overton's narrative refers to this transition and her life in Austin. Essie Mae Sorrells eventually left Manchaca for Austin in 1960. Though her husband, Virgil, remained in Manchaca, some of their children eventually migrated to Austin to live with her once she established her own household on East 12 ${ }^{\text {th }}$ Street (see Figure 31, No. 15).

Finally, nearly every interviewee, regardless of where they were raised, mentioned East Austin. Most spoke of visiting relatives, attending school or church, shopping, spending weekends on East $6^{\text {th }}$

33 Dawson's maternal aunt, Lillie Grant, was also interviewed for this project. Her oral history is included in the Antioch Colony and the Prairie section. 
Street, working, or selling produce in town. People living in rural areas were not nearly as isolated as one might assume, and once cars became more commonplace so, too, did the social, economic, and other networks that people created between the countryside and the city.

Interviewees whose transcripts appear in the Austin section are:

Jewel (Williams) Andrews and Lourice (Williams) Johnson

Corrine (Williams) Harris

Lee Wildon Dawson

\section{Concluding Remarks}

With the oral history project, what began as a focused investigation of one African American family following emancipation developed into a far more comprehensive and meaningful history of a region from Reconstruction to the end of Jim Crow. This oral history collection now joins others produced in Texas with African Americans in more recent years (e.g., Carlson 1995; Shepard et al. 1995; Sitton 2006) that relate the memories of a generation that holds answers to questions regarding what became of those descended from nineteenth-century Texas settlers.

Over the past couple of years, the oral history project proved successful in opening up lines of communication between the research team and the individuals we were fortunate to work with. Although we've gotten to know some interviewees more than others, we hope that all of them felt as we do that the oral histories were produced on good terms. Some of the narrators visited the Williams farmstead site both during and after the excavation, and we've gratefully shared research results as they came to light with everyone we interviewed. We will continue to work with a number of the interviewees on this project as we move forward with public education and on other projects that have emerged from it, including collaborative archeological research at Antioch Colony. Sharing information and knowledge has played an important role in our community outreach efforts. While we humbly acknowledge that we learned more from the descendants we interviewed than they did from us, we hope, as expressed earlier, that this publication will serve as a partial means of demonstrating our indebtedness to them. 


\section{Antioch Colony and the Prairie, Hays County}




\section{LeeDell Bunton, Sr.}

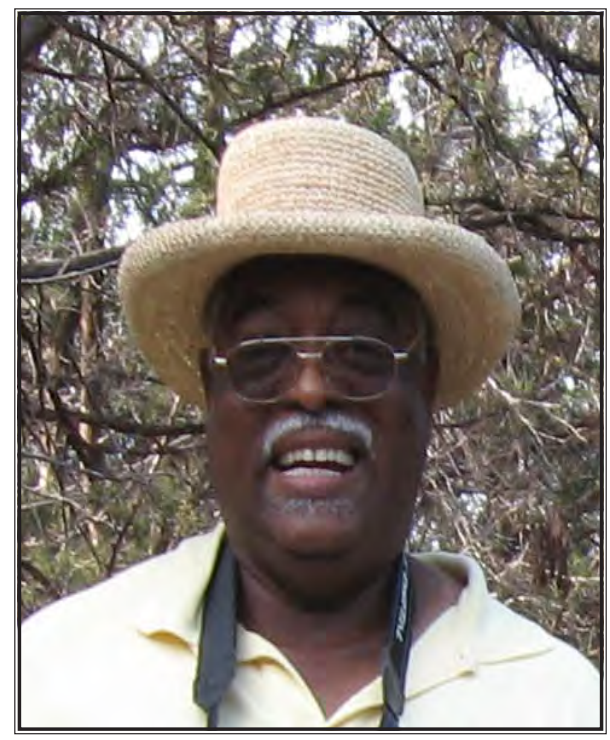
Birth Date
9/19/1946
Residence
Antioch Colony, Buda
Time Span
1946-1955

Note: ${ }^{* * *}$ within brackets indicates revisions to transcript made by interviewee.

Interviewed by: Maria Franklin

Phone Interview: May 26, 2009 (1 of 2)

MF: This is Maria Franklin and today is May 26, 2009. I'm interviewing for the first time Mr. LeeDell Bunton, Sr. This interview is taking place over the telephone. It is part of the Oral History Program for the Ransom Williams Farmstead Project.

Mr. Bunton, one of the first things that I've been asking people is to draw kind of like a map of Mr. Taylor's property, telling me about the house that they were raised in and when it was built and so forth. Do you remember that house?

LB: $\quad[* * *$ Yes, $]$ I remember the house.

MF: And how many rooms did it have?

LB: [***It had three bedrooms, a kitchen, and a living room. It had a porch across the front of the house, and one on the side of the house off the kitchen.]

MF: And did the house have electricity or plumbing? 
LB: [***It had no electricity; we used coal oil lanterns, lamps, and wood-burning stoves. Neither did it have indoor plumbing; we had what was known as "an outhouse."]

MF: Okay, and do remember what the house was built of?

LB: It was constructed out of wood.

MF: And was that raised on piers or did it just sit on the ground?

LB: It was raised on piers.

MF: Piers, on cedar piers or something like that?

LB: Yes, cedar piers.

MF: Right. And do remember about how big that house was?

LB: In square footage?

MF: Yeah.

LB: $\quad$ [***I didn't know the exact square footage; however, as a child it seemed like a very large house to me.]

MF: Did it feel like you had a lot of room in the house?

LB: $\quad[* * *$ Yes, I felt like we had lots of space.]

MF: And how many people were living in the house while you were there?

LB: $\quad[* * *$ There were nine of us. $]$

MF: Do you remember which ones?

LB: $\quad[* * *$ Yes, there was: my grandfather, and my grandmother. My uncles were Joshua, Elijah, Moses, and Samuel; my aunts were Mary and Martha; and myself.]

MF: Okay. And can you tell me a little bit about how you ended up living with your grandparents instead of with your parents.

LB: [*** My mom and dad were quite young when I was conceived. At the time, my mom was still living at home with my grandparents in Buda. After having me she decided to move to Austin. She being young, my grandparents did not feel comfortable with her taking me and moving to Austin. Therefore they strongly suggested that she not take me, she agreed, and left me in Buda with my grandparents. My grandparents took very good care of me, showed me much love, and reared me to be the man that I am today. For that I am very grateful.]

MF: So your mom was Emily Harper, right?

LB: [***Yes, my mom was Emily Harper; she was the daughter of George and Emma Harper.]

MF: Okay, okay. Now your father, though, his last name should have been Mullins, I think you told me that, right? Because his father was a Tom Mullins. 
LB: $\quad[* * *$ Yes. $]$

MF: Now why did he keep the name Bunton?

LB: $\quad[* * *$ Because his mother was Ada Bunton. Ada Bunton and Tom Mullins were not married. Augusta, their son, took his mother's last name.]

MF: Okay, all right. So you stayed with your grandparents and your aunts and uncles for the most part?

LB: Yes.

MF: Now in terms of the house that you were living in, do you remember any other buildings or other structures on the property, like a storage shed, smokehouse?

LB: [***Yes, we had a shed and a smokehouse. In addition to those two building we also had barn, we had a cistern where we kept water. We had chicken pens, a windmill, and my grandfather had tractors and trucks and farming equipment.]

MF: Okay so in the front of the house, then, the front door of the house faced Black Colony Road, right?

LB: No, that would be the kitchen side of the house that faced Black Colony Road. The front of the house actually faced the [***west].

MF: So the kitchen side of the house would be the south side of the house then?

LB: Yes, and it would have been facing Black Colony Road. [***There is one thing that remains in my memory, and that is, there were six of the largest oak trees I had ever seen that stood in middle of Black Colony Road. It would have been nice if they had left those trees standing, they were beautiful. At that time the road wasn't called Black Colony Road-it was just a road that ran through the colony.]

MF: And it was dirt?

LB: $\quad[* * *$ Yes, it was a dirt road, and the part that ran in front of our house is where the six large oak trees were. After I became an adult, I went back to Buda to visit, and the trees were still there, that was in 1968. I went back in the early seventies and the trees were gone and the rode was paved.]

MF: Okay, and how did most people get around back then, do you remember, when you were living in Antioch?

LB: $\quad$ They drove; they had cars and trucks. [***There was one gentleman whose name was Fred Carpenter; he was the grandson of Joseph F. Rowley. Joseph Rowley sold property to freed men in the Antioch Colony. Fred Carpenter rode a horse to Buda almost every day.] I never knew him to drive a truck or car. He rode a palomino horse, and almost every day we would see him pass down Black Colony Road by our house, on his way to Buda. He was the only one that I knew that used a horse as his method of transportation.

MF: Okay. Now do you remember how space was used on the property? That is, where your grandmother might have done the washing and things like that? 
LB: $\quad[* * *$ Yes, she had an iron kettle that she used to boil water and wash our clothes. That was close to the cistern. She'd wash clothes and bed sheets and she would use soap that she made, that was lye soap. She used a long stick to punch the cloths as they boiled. She'd take the cloths out of that boiling pot and put them in a tub of water and she'd scrub them on a rub board. She would then put them in a tub of clear water and rinse them out. She would then wring them out and hang them on the cloths line to dry. Those white sheets would be so white; they were as white as the clouds in the sky. That's another memory that stayed in my memory bank. She had to wash on a rub board, and she used the big number three tubs, and she used that iron kettle out there with boiling water in it.]

MF: Yeah, I think one of your aunts might have mentioned that she eventually got one of those hand-it was a washing machine that you could wring the clothes through.

LB: Yeah, she may have, but I know that we didn't have electricity. [***So it must have been a hand crank that had to be turned by hand.]

MF: Right, and what about the garden there? What kinds of things do you remember growing in the garden?

LB: $\quad[* * *$ We did have a garden on the north side of the house. We grew all kinds of vegetables: carrots, tomatoes, string beans, greens, squash, okra, cucumbers, just to name a few. Those are the ones that I can remember; I would bet my grandfather grew more because he loved gardening.]

MF: And was that mostly to feed the family or did you feed the family and sell things from the garden as well?

LB: [***I can't recall my grandparents selling anything from our garden. What was grown was to feed the family.]

MF: Okay, because some of your aunts and uncles mentioned that your grandfather would go into Austin, east Austin, and sell produce. Was that grown on another piece of property?

LB: I know that he used to sell wood, and he sold milk and butter, but he could have sold some produce, I just don't remember-He sold eggs, too. I don't remember the produce, I don't remember him selling it, but I was pretty young at the time. It seemed like our garden was huge.

MF: Did you grow corn out there?

LB: [***Yes, I do remember my grandfather growing sweet corn.]

MF: And where do you remember throwing out your trash? What did you do, because obviously there wasn't any trash pickup at that time?

LB: [***You're correct, there was no trash pickup, and we burned our trash.]

MF: Oh, is that right. Was there a certain part of the yard that you used to burn it?

LB: [***Yes, we had a large barrel out by the stock pens, and we burned our trash there.]

MF: Okay, okay. And where did you get your fresh water?

LB: [***We had a windmill; we got our fresh water from the windmill.] 
MF: Oh, you mentioned a cistern.

LB: $\quad[* * *$ Yes, we did have a cistern; however, all the cistern did was hold water, rainwater, not water from the windmill.]

MF: Right, because I thought your uncle Moses had mentioned a well that him and one of your other uncles almost put you in the well because they needed to go off and do something else and they were left watching you.

LB: That's the cistern that they're talking about.

MF: Oh, that was the cistern? Okay. [Laughs] Good thing that didn't happen.

LB: [Laughs] Yeah, I'm happy about that.

MF: Do you remember going much into Buda or to Austin to shop for store-bought goods?

LB: [***Yes, we usually would go into Austin on Saturday and purchase store-bought goods. We would also visit my grandmother's brother.]

MF: Which brother was this?

LB: I'm sorry?

MF: Which brother was this that you would visit?

LB: [***His name was Jerry Tennon. He lived across the street from Huston Tillotson.]

MF: Oh, okay.

LB: $\quad[* * *$ There were times when we would stop on Sixth Street, we would purchase hamburgers and visit with other people that were in town shopping or taking care of business.]

MF: Right, so was Sixth Street where a lot of African-Americans from different neighborhoods and communities came to congregate then?

LB: [***Yes, African Americans from rural areas around Austin did congregate on Sixth Street, mostly on Saturday. There were a couple of movie theaters on Sixth Street, the Ritz and the Carves. We would sometimes go to the movies. There were also cafes on Sixth Street and we would congregate in the cafes.] My grandmother, if she needed to do some shopping, she could, and most of the time after, we sat out there and she visited with other people who would come to town, and we waited until my grandfather got done unloading his wood and whatever else he was selling, and he picked us up.

MF: Now do you remember those being black-owned business down there on Sixth Street?

LB: $\quad[* * *$ No, I don't know if they were black-owned; however, there were many blacks that were working in the cafes. I believe that there could have been some of them that were black owned. We had relatives that worked in some of the cafes.]

MF: So they could have been white-owned where they just had black employees to serve a black clientele.

LB: [***Yes, that's correct; they could have been white-owned.] 
MF: Right. And do you remember your grandparents ever shopping out of catalogs?

LB: $\quad$ Shopping out of what now?

MF: Catalogs, like you know a Sears catalog, or-

LB: [***I believe they could have; however, I'm not a hundred percent sure.]

MF: Okay. And how about medicines. Did your grandmother or grandfather ever use homemade remedies?

LB: [***Yes, they did. They used many homemade remedies. Sage tea grew wild in Buda, I remember them collecting the tea and brewing it. We would drink it for just about anything that ailed us.] If you said something was wrong, you were going to get some sage tea. [Laughs] [***I also remember them using trephine and sugar for fever, they also used what they called rock alum for coughs.]

MF: Was that good or bad?

LB: [***Being a young child I really believed in what my grandparents did. I don't remember ever getting sick, or should I say getting worst, after taking any of the home remedies. I believe it was good. In addition to home remedies, I also remember the Watkins man, they bought; liniment and different medical remedies from the Watkins Man.]

MF: The Watkin Man.

LB: [***The Watkins Man was a man who came around the community and sold medicines as well as home cleaning supplies; he always had a remedy that was good for something. We also had people like Aunt Kate and Grandma Ella who had lived a long time, and I would imagine didn't have medical doctors to go to. They had to do the best they could in making their own remedies, and I believe they were good at making home remedies for anything that ailed you. There was a Dr. Lauderdale that traveled throughout the community visiting and caring for the sick. Later there came a young doctor whose name was Dr. McCormick that moved to Buda and took over Dr. Lauderdale's practice. I was the first baby that Dr. McCormick delivered after starting his practice in Buda.]

MF: $\quad$ Either black or white?

LB: [***Yes, I was the first baby Dr. McCormick delivered. After he started his practice, we would go to his clinic to get treatment. Prior to that, there wasn't a clinic that we could go to in order to get medical care. It was either home remedies or Dr. Lauderdale caring for us at home.]

MF: And this was the doctor before McCormick?

LB: Yes.

MF: I see. But did he deliver babies? Because I understand there was a midwife that did that, right?

LB: [***He may have delivered some, I can't say for sure that he did or didn't; however, I do know that we had midwives throughout the community that did deliver babies.]

MF: Do you remember what the names of the midwives were? 
LB: $\quad[* * *$ One of them was a Revada, I think her name was Ladis Revada, and Kate Bunton, those two I'm sure of. There were others; however, I can't name them.]

MF: You mentioned two names that you said of elder folks who knew a lot about healing, and one of them was Aunt Cake, did you say?

LB: Yes, well, I said Aunt Kate.

MF: Oh, Aunt Kate, I'm sorry.

LB: [***Aunt Kate, as she was called, was my great-grandmother, and there was also my other great-grandmother, my grandfather's mother; her name was Ella Nancy Harper. If someone was ill, they would get word to one or both of these ladies, and they would go and care for them. They would give you instructions on just what you needed to do.] It would either kill you or heal you! [Laughter] That's what they used to say!

MF: Right! Now what do you remember about your chores around the house when you were young?

LB: [***Being so young, I didn't have too many chores to do. I had so many aunts and uncles, they took care of everything without needing my help. I didn't have a cow to milk every day as did some of them.]

MF: Were your uncles and aunts assigned a cow?

LB: $\quad[* * *$ I don't know if they were really assigned a cow to milk every day. Nonetheless, cows had to be milked every day, and they were the ones that had to do it. I did gather eggs. I can remember gathering eggs and me being too short to see in the nest. I put my hand in to get the eggs, and I grabbed hold of a chicken snake. To this day I'm afraid of snakes.]

MF: You get bit pretty badly?

LB: $\quad$ No, it didn't bite me.

MF: Just scared you?

LB: $\quad[* * *$ It scared me because it was a snake, and I was a child. Back then, snakes were plentiful, and we were warned daily about avoiding snakes. We were told you don't play with them or fool around with them. And being a little kid, I believed my grandparents. Unknowingly I grabbed that snake, and I almost couldn't turn it loose. Fortunately, my uncle was with me, and he came to my rescue. I'm a hunter; however, I don't like snakes.]

MF: It's interesting, because the people that I know that don't like snakes the most are people who were raised in the country. And like my dad, my dad is terrified of snakes, and it's like, "But you grew in the country, I mean there must have been lots of snakes around."

LB: $\quad$ There were, but you took your precautions and you did what you had to do and tried to avoid them. [***Whenever I hunt, I make sure there are not snakes in the areas where I shoot birds.]

MF: Right. Now, you learned to hunt when you were a kid?

LB: Actually, I was a teenager when I learned to hunt. 
MF: Do you remember people hunting in your household when you were living in Buda?

LB: Yes, we had dogs that they used to hunt with. [***Portion of transcript deleted.] Sometimes our dogs would take off, and they would be out and they'd come across the pasture and through the bushes, and they would run up a rabbit and they would catch that rabbit. And we had a long pipe that was on our property, and it was like a water pipe but it must have been about eight inches in diameter. And that pipe was laying out there where my grandfather kept the tractors and different equipment, and that rabbit would run into that pipe for protection, and the dogs would run up there and stop at both ends. They knew the rabbit was probably in there. So, then we'd make the dogs get away, and some of the older kids would come out, and they would lift the pipe or stop it up on one end and make the rabbit come out.

MF: Okay. So who did the hunting? Was it the men in your household?

LB: $\quad[* * *$ Yes it was the men in the house; however, it wasn't my grandfather. There were also older men in the community that would hunt with my uncles.]

MF: So you kept rifles in the house?

LB: [***Yes, we had a rifle and a shotgun.]

MF: Did you ever trap or fish for food?

LB: [***No, I didn't.]

MF: Do you remember people in your household doing that?

LB: $\quad[* * *$ No, I have no memory of any trapping or fishing. Really the only time I can remember going around any creek was when someone was being baptized.]

MF: Was that typical, or were you treated, were you sheltered a bit?

LB: $\quad[* * *$ I may have been somewhat sheltered. My grandparents would say they were trying to keep me safe from danger. I had a cousin that drowned in Onion Creek, and that may have had something to do with them trying to protect me. I didn't know how to swim, and had no reason to be around large bodies of water, especially alone, so I was warned to stay away. My cousin was on his way home from school, and there was a place along Onion Creek where there was a spillway. He was walking across the spillway and fell in the water, it was deep and there was a current. Evidently he must have gotten trapped and he drowned. That brought much heartache to our family. Some of my aunts and uncles could swim. I couldn't, so the message I heard often was to stay away from water. After moving to Phoenix, I learned how to swim and loved it.]

MF: Okay, so you were a bit older?

LB: Yes, a little older.

MF: And how old was your mother when she had you?

LB: [***She was seventeen.]

MF: I'm going to ask you some questions now about-Well actually, before I do that, one other thing. When you moved to Phoenix, did you stop raising livestock and growing your own food, 
keeping a garden and things like that, or did you continue that when you were there? Or when you moved to Arizona, I should say?

LB: When we moved to Arizona everything changed. My grandfather was a farmer in Texas, but when he moved to Phoenix he started a landscaping business. [***He also started a cleaning service, and worked for Googie's Coffee Shop. He would work nights cleaning the coffee shop, and during the daylight hours he would do landscaping. Now, let me back up; before he started the landscaping and cleaning service, he did do some farming work for cotton farmers. He would contract with the farmers to chop their cotton, and he did very well at it. He was able to get a couple of trucks, and he would load it with people, and take them out to the fields, and they would chop cotton for various farmers around Phoenix. When that type of work started to play out, he brought lawn mowers and he started cutting grass and doing landscaping for private homes or anyone that needed him. He finally stopped the cleaning business and kept the landscaping; he did that until he returned to Texas.] He was about seventy-five years old then.

MF: Okay, all right. So the next thing I'm going to start asking you about is how Antioch has changed and what it was like in the community. When you came back-Well, you didn't move back, actually, but when was the first time after you left that you came back? So after you moved to Arizona in 1955, did you come back and regularly visit?

LB: $\quad[* * *$ I went back once as a child with my grandparents, probably in the early sixties. We visited the Antioch Community and everything was pretty much the same as it was when we left in 1955. After I married in 1964, I took my family to Antioch in 1968, and everything was still pretty much the same; the large oak trees were still in the middle of the dirt road. The next time I went was in 1971; I attended a funeral service for an aunt who lived in Antioch, and things had begun to change. Black Colony Road was no longer dirt; it was paved, and the large oak trees were gone. The school was gone, and they were no longer having church services in the church; however, the church was still standing. All this took place in the early seventies. More white families had moved into the Antioch community north and south of Black Colony Road. Basically the Antioch community geographically is still pretty much intact. In the early 2000s developers started to put in new housing developments; the Elm Glove School was also built doing that time. That school should been named Antioch, as it is built in Antioch. About 2005 a park was built on the north side of Black Colony Road.]

The old church that we used to attend, it was still sitting there, but there weren't enough people in the community to attend its services. And I remember as a kid, when we were there, they would have service every other week, I believe it was, in the church. And then, sometimes if we weren't having service in that church, then we would go out to where we call the Prairie at the Center Union and have church, or we would go down to Kyle and have church, and some Sundays we would go to Manchaca and have church. So it was like on a rotation, depending on where they were going to have a pastor. They didn't always have a pastor at any one of those churches regularly every Sunday.

MF: So the places that you worshiped in Kyle and Manchaca, these were the black communities and the black churches that you would sometimes rotate?

LB: That's correct.

MF: And those folks would also come out to Antioch sometimes.

LB: [***That's right, the churches all rotated, because no church had a full-time pastor. It didn't matter what denomination the church was; we would all gather at the church where the minister would be on Sunday morning. Sometimes he would be in Antioch, sometimes it 
would be Kyle, or Manchaca, it didn't matter. We would all meet at that church and have worship service. That's the way it was when I was a child. I remember going back to Antioch to visit and seeing the church, and it looked as though it had been abandoned. People had moved away from Antioch, and there weren't enough people to attend services and keep the church open. The few people that still resided in Antioch were attending church service elsewhere.]

MF: And that church was called the Antioch, was it the Baptist church?

LB: No, it was the Antioch Methodist Church.

MF: Methodist Church, okay. And do you remember the names of the churches in Manchaca and Kyle that you went to?

LB: [***The church in Manchaca was Bethel AME Church; the church east of Buda was called Center Union Baptist Church. Center Union was actually in Buda; however, we called that area "The Prairie." And the church in Kyle I believe was called Sledge Chapel Baptist Church.]

MF: Now, when you say The Prayer, I just want to make sure I got that spelled right, P-r-a-y-e-r?

LB: [***Actually, I'm saying it like I heard it from a child to now. It's really The Prairie.]

MF: Okay, the Prairie, got you.

LB: [***Yes, it's located on Goforth Road.]

MF: $\quad$ Goforth Road?

LB: $\quad$ Yes, just before you get to Interstate 35 is where Center Union Baptist Church is located. As a child I would hear so many older people talking about people who lived out there, they would say, "Yeah, they live out on the "Prair." It was supposed to be prairie, they just cut it short.

MF: That wasn't considered part of the colony, though, right?

LB: Correct, it wasn't a part of the colony.

MF: Now owning land was clearly important to your ancestors. Did anybody ever talk about holding onto the land and why your ancestors bought the land and why it's important to have it and so forth?

LB: $\quad[* * *$ Owning land was certainly important to my ancestors. For years I have had conversations with older people about the land. Owning land determined a person's wealth. If you were a property owner you not only had wealth, you had stability. You remained in that area, that's where your roots were. The property was passed down through the family from generation to generation and remained in the family. It was understood that unless you had an awful lot of land, you just didn't get rid of it. There may have been those that owned large amounts, therefore they may have sold some, not all but some in order to generate cash over the years.] But you take a lot of the people who I'm closely related to, like coming down through Dave Bunton, Dave and Mary Bunton, from what I understand, they bought a total of ninety-six acres and they sold off part of it, and then they wound up living on the other forty-five. You know, they sold off forty-five, and they wound up living on the other forty-five. [***My grandfather owned eleven acres, and he had eleven children. I was his first 
grandchild, and he and my grandmother reared me. Before his death, he divided his property in parcels among his children. Because I was his first grandchild and had lived with him all of my young life until I was married, he gave me a piece. I own that piece of land today and will always keep it unless I have to let it go. After Anita and I are gone, it'll go to our children.]

MF: Oh, I didn't know that.

LB: $\quad[* * * Y e s$, he gave me a share, and I wasn't aware of it until his will was read. I do appreciate the piece that he gave me; however, I wanted a little bit more. I was here visiting in 1995 and I had a conversation with an older gentleman concerning purchasing property in Antioch Community. At the time I was talking with him, he was a cousin and I didn't know it until he made me aware that we were cousins. I told him what I wanted to do, and he informed that the very property we were standing on was part mine. He said this very property here is you alls and you're losing it to taxes. I started doing research, and I found that my greatgrandmother Kate Bunton had been left a portion of property from the Dave and Mary Bunton estate, and no one had been paying taxes for some time. I talked to the attorney that was handling the sale, and he kept me up on everything that was taking place. In 1996 we drove back to Texas, and on the courthouse steps in San Marcos, Texas, I bid on the piece of land and I now own it.]

MF: And that was in what year?

LB: $\quad$ That was in '96.

MF: Ninety-six, and that was seven acres?

LB: When I had it [***surveyed], it turned out to be 7.1 acres.

MF: That was part of the original, did you say ninety-six-acre plot that Mary and Dave Bunton had, right?

LB: [***Yes it was a part of the first forty-five acres that Dave and Mary purchased. They lived on that forty-five acres, and later purchased another forty-five acres and worked it. In 1939 their eldest son, Tony, sold off forty-five acres. He then deeded out the remaining forty-five acres to his brothers and sisters, or the spouses of his brothers and sisters that remained. That's how Aunt Kate wound up with the portion that I purchased, it surveyed 7.1 acres.]

MF: And who will inherit your property?

LB: $\quad$ My sons and my daughter. [***Actually, I plan to have a trust so that everything will be put into the trust and then divided 50 percent to my children and 50 percent to my grandchildren; this will happen only after me and Anita are gone.] I don't think that they'll ever live on it, but they'll inherit whatever comes from it.

MF: So do you want them to hold onto the property and pass it on down?

LB: $\quad[* * *$ In a fantasy world, that would be the ideal choice; however, seeing the way Buda is growing, I believe that one day Antioch will have the same growth as Buda. It would be foolish to think that it will never happen. I believe that eventually we will have to yield over to the developers.] When I bought the property, the reason that I bought it, I bought it with the understanding and with the intention that one day I would go back and I'd build a house on it and just live the rest of my life there, you know. And you know what, when I came to Texas and I bought that property and I was able to walk out across there, at the time, I had 
a couple of cousins that were alive. George Smith, his property is adjacent to mine on the east side, and Louis Anderson, his property is located on the north side of mine. I always visited with them, and for a long time, I didn't even realize we were related. But you know, we always got along well, and they would walk along there and they would tell me stuff. And at the time, I should have been writing it down but I wasn't, and I didn't know that I was going to wind up with that property. But I found out who those people were, and they just told me more and more, and they showed me how way back when the church and the school were further down in the woods, the original church and school, how people used to cross that property, and they would stop at the springs and they'd water their animals or to get water for their cars and stuff. And it just meant a lot. Every time I go down there and I walk around and I look at the trees, I see where my great-grandmother used to live, it makes me feel like I'm a part of something, you know. I mean this land, there's nothing on it but these big trees and the weeds and stuff, but if those trees could talk, boy, they would have a lot to tell. So sometimes when [chuckles], sometimes when I'm walking around out there, I just let my imagination go to work, you know, and I really I feel like if my ancestors can see me as I walk-you know, what would they think here after all of these years, that property is still in the Bunton family and it belongs to a great-great-grandson. You know, what would they feel? To me, I would think they would be rejoicing, because I know that's what I would do. And that was my intent, to just buy the property and hang onto it.

I retired a little bit sooner than I thought, but I thought, you know what, I would go down there and build a home and just live the rest of my life. And I haven't ruled it all the way out, but I haven't been in a hurry to go down there and build a house since I've retired. The economy's changed and all of that, so I'm just going to ride with it a little while and see what's going on, and we don't know what the future holds. But I try to encourage everybody that I know that owns property in the Antioch community to hang onto it, and try to make them feel what I feel.

It's hard for me to imagine- think about this for a minute-it's hard for me to imagine what it took for a free black man to come up with the money that they came up with to pay for that property. You know, five, six years after slavery, both of those people couldn't read and write.

And whatever skills that they learned while they were in slavery, they had to use those skills to make money. Some of them may have been blacksmiths, some could have been in masonrytype work, carpentry, farmers-whatever they did, it took a lot. And I believe that they must have worked like they were in some type of a commune. A man had several kids, and they could have been adult children with families, and they must have pooled their money, otherwise, how could they have accumulated enough money to buy, say, forty-five acres at $\$ 10$ a pop? That, to me, is something. You know, and then turn around a year later and buy another forty-five acres. You know what, they made a lot of sacrifices to get that. Because I don't believe there was a bank around or people that would just loan you money to buy that. And I don't know, there's not an awful lot documented on transactions and stuff like that. You can see at least some of the historical records where they paid their taxes and that kind of stuff. But on free black men, there's not a lot of documentation on things that happened to us. So you don't know how they got the money, but that just interests me. And I tell you what, I try to go to Texas as often as I can because I get-there's something that I get from being a part of that. And right now, I can't imagine not being a part of it. As long as God gives me favor and I'm able to hold onto it, there's no reason why I shouldn't be able to hold onto it for a long time.

MF: So do you tell your kids what you've been telling me? Do they know this?

LB: [***Yes, they're all aware of what's happening right now with the property, and what may happen in the future. Really we have only one child that might live on the property; the other two have displayed no interest at all in living in Buda.] And I know that you can't 
stop progress, but for as long as I can, I'm going to be a holdout. Because when I really look at what's going on down there, and I look at that property, my grandparents, my greatgrandparents, whatever they did to get that property, they gave a portion of it to their family. [***After I purchased the part that I have, I started researching my family's history. I've met several people that are tied to different branches of my family, and none of that probably would have happened had I not bought that land.] After buying that property, a couple of gentlemen came over and they gave me a copy of the original deed and they said, "You've got a nice piece of property there, but you're landlocked." [***I spoke with a few of my cousins and they told me that wasn't a problem. They reminded me that we were all as they called it, "kinfolk" out here. [Laughs] "Arrangements were made long time ago to get to that piece of land. Just be sure when you have it surveyed to have that easement drawn in."]

MF: Well, yeah, those were neighbors, people helping each other out, so you could make those kinds of assumptions back then.

LB: $\quad[* * *$ Dave and Mary Bunton's name was on the deed, and I wondered who they were. I started doing family history, and I know so much more about my family now.]

MF: Now when was this that you started doing family history?

LB: $\quad$ In 1996.

MF: In '96. So you didn't know anything about, I assume, how to do genealogical research at that point, right?

LB: [***No, I wasn't familiar with researching family history. However, I became familiar with Family Tree Maker and began a journey that took me many places. On this journey I became acquainted with a cousin name Evelyn Houston; I had never heard of her until I started my research. After learning about her from my aunt Winnie Martha Moyer, I decided to give her a call, and she opened avenues for me that I had no idea existed. She was also doing genealogy and was as excited as I was; we spent many hours on the phone and on the computer sharing information.]

MF: This is Evelyn Houston?

LB: [***Yes, Evelyn introduced me to another cousin I didn't know. After meeting her, I met so many more. It didn't all happen overnight, but it opened so many doors that I never thought would open. The information I've share with you is just the tip of the iceberg. I have so much information, and I'm glad that I have it, but it probably wouldn't have been possible had I not purchased that property in Antioch.]

MF: How have you been doing most of your research? Does it involve talking to people and finding out when they were born and who their ancestors were? Doing research in the archives or doing research on the Internet? Or all three of those things?

LB: [***It has included all three. I began my research by talking to various people, I found our conversations to be very interesting, and I recorded several of them. After talking and listening to the recordings, I did a lot of pondering about what was said, and what wasn't said. I found that speaking with two people about the same subject, the facts were not the same, so who do you believe? I decided I needed to save my sources in order to prove what the facts were, and rely on recorded documents more than word of mouth; it's much easier to document your sources. I spent long hours at the Mormon Temple research department in Mesa, Arizona. I've subscribed to Ancestor.com and can access their database. When I first begin my research, I was told Elias Bunton and Dave Bunton was probably brothers. That 
could be true; I can see where they might possibly be brothers.] But when I got to where I was able to research and use the census, I started going to the Mormon temple and I found in the census reports, the oldest one that I found showed Elias Bunton was born in 1840, and Dave Bunton was born in 1826. Now, I'm kind of thinking that Dave and Elias, they just may be brothers-

MF: Yeah, but fourteen years apart, that's pretty long.

LB: Yes, I agree that is a lot of years apart.

MF: Not unless one was the youngest and one was the oldest of like a ten-kid family.

LB: $\quad[* * *$ That could very well be true; however, I haven't found anything that could prove they are brothers, or anything that says they aren't. I believe that I'd need to see a slave registry and get information from the registry to help determine whether or not they were brothers.]

MF: Yeah, they didn't necessarily say who was related, brothers and whatnot like that.

LB: I haven't seen any of that. I haven't gone back further than that because it's very timeconsuming and I just haven't had a strong enough urge to just dig back that way. I've just been filling in from 1865 forward.

MF: $\quad$ Right, and let me ask, you mentioned Evelyn Houston was a cousin on the Taylor side. So was John Taylor the man whose property you lived on? Was he a relative, then, or is that a different Taylor?

LB: No, that's the same Taylor.

MF: Okay, so how is Mr. Taylor related to you?

LB: $\quad[* * * M r$. Taylor married my grandfather George Harper's great-aunt Sarah Kavanaugh. Sarah Kavanaugh was the sister to Adeline Kavanaugh, who was George Harper's grandmother.]

MF: $\quad$ So do you think Mr. Taylor was, because everybody refers to him as Mr. Taylor, so I didn't think you guys were related.

LB: [***Yes, we were related; however, we were related by marriage only.]

MF: Right so he wasn't blood-related, but through marriage. Do you think that the reason why he allowed you to stay on his property-I mean did you pay rent to him?

LB: $\quad[* * *$ My grandfather leased the property from either Mr. Taylor or one of his children. I would imagine he allowed us to rent the property because we were related; however, we didn't live there for free, and we paid to live there.]

MF: Okay, but they still referred to it as Mr. Taylor's property?

LB: $\quad$ Yes, they called it the Taylor property. But listening to my grandfather talk about John Taylor, John Taylor was a good man, and he was a very knowledgeable person about a lot of things. As a young man, my grandfather was taught how to make sorghum syrup from John Taylor. [***The most valuable lesson he taught my grandfather, though, was how to be an independent businessman. John Taylor was born in 1861; at my grandfather's birth, he was thirty-nine years old.] 
MF: He was already kind of old, older anyway, yeah.

LB: [***He died in 1937 at the age of seventy-six. Mr. Taylor was gone long before I was born.]

MF: Now do you know why it is your grandfather rented-leased Taylor's property instead of living on the property that he had inherited?

LB: $\quad[* * *$ At the time he didn't own the property that we were living on. Later he leased the Taylor property and eventually purchased it. The Taylor property was the only property he owned in Texas, that's the property that his children live on today and the property that he gave me a share of.]

MF: Okay, so that was Taylor property that Harper Village Road is on right now?

LB: [***Yes, correct.] [Recording ends]

Phone Interview: June 2, 2009 (2 of 3)

MF: Okay, I'm starting up again. Sorry about that. I was just asking you where Brown Cemetery was located and you said it was if you take Old San Antonio Road-

LB: $\quad$ Yeah, if you take Old San Antonio Road north to I think it's Twin Creeks to go into Manchaca, and you turn on Twin Creeks Road and you head west going into Manchaca, just before you get into Manchaca, you'll see it on the right-hand side. It's a small cemetery. And one of the first headstones that you can see, because it's standing up pretty big, will be Elizabeth, it says Elizabeth Smith Wren, I think. I'd have to look at the headstone to see what it says, but that's - she is the mother of the lady that we called Aunt Kate, which is my great-grandmother, so she would be my great-great-grandmother.

MF: Okay. And who else of your family is buried there?

LB: Well, you know I really don't know, except that I believe her husband is buried there, but I couldn't find a grave marker for him.

MF: And are there any other cemeteries around in this area that you have family buried?

LB: Yes, there's another cemetery but I don't know the name of it, but it's on the main road that runs into, runs through Manchaca that connects with Interstate 35, just as you cross the railroad tracks in Manchaca headed [***east]. Go down about a quarter of a mile or so past down near where the barbecue place, the Railroad barbecue place.

MF: Yes, I know where you're talking about.

LB: There's a cemetery just sitting to the north over there and you'll find a lot of Kincheons buried over there, and those are relatives, too. They were related to me through my grandmother, Emma Harper.

MF: Emma Harper, okay. And so those are folks who are from Manchaca more than likely?

LB: Yes.

MF: So that's not too far from Manchaca Elementary School? 
LB: It's not too far at all.

MF: Yeah, I know exactly where you're talking about. I didn't know there was a cemetery back there.

LB: Yeah there's a cemetery. Now they buried both blacks and whites in that cemetery, but in Brown Cemetery, you'll find that it's all black, and same as Antioch. And there's another cemetery in Kyle where we have relatives.

MF: And who were those people?

LB: You know, I don't remember all of those relatives; I'd have to look back through my records to be able to name them. I can't remember them all.

MF: Now how did you find out that your relatives were buried at these different places? Did you do research on it or did people just tell you, family members tell you?

LB: Well, family members would tell you, and then I had to stop going on what people said because people mean well sometimes, but as we get older we get kind of confused or we make mistakes, and then you've got information that's not accurate. What I started to depend on is I started asking relatives to share their obituaries with me, and at least whatever they had on their obituary, then I would be able to use that as my source of information. So going through all of those obituaries, they usually tell where they were interned because a lot of us, I mean these are relatives, are buried in Evergreen over in Austin.

MF: Oh, okay. And what was the name of the cemetery in Kyle that they're buried at?

LB: I want to say Skyview or something like that.

MF: Okay. It's just good for us to know where people are buried because if someone later on is interested in researching the folks from Antioch, they'll know where ancestors are buried and they can find out information from that.

LB: Yeah, and that's fine, but that's what I know. So working in the genealogy side of it, I try to find out as much information as I could about cause of death, where they were interned and that kind of stuff. Then after a while, you start to see all of the diabetes that's in your family, and different things that caused our demise, and you start to see little patterns. But these programs are pretty good because sometimes you can go back and do reports that will show those things, you know where they're buried, cause of death, and different things like that.

MF: Now let me ask you. I have talked to you before about Ransom Williams, because that's the gentleman who owned the farm where we're going to be doing the archeology. Had you ever heard that name before?

LB: Well, I had heard of Ranson Bunton, but not Ransom Williams, and so Ransom Williams was new to me until you brought it up.

MF: Right. And so in terms of anybody by the name of Williams, besides Lawrence Williams and his kinfolk who are out of, who lived in Antioch, right?

LB: Mm-hmm [yes].

MF: Had you ever heard of any of the Williams living in the Bear Creek area? 
LB: In the where?

MF: In the area of Bear Creek, Manchaca?

LB: No, I hadn't heard of them.

MF: Okay. Now the one connection that we had between that family, the Williams family, and Antioch was, I'd mentioned, was your great, was it your great-aunt or your great-great-aunt Emma Bunton?

LB: Emma, yes.

MF: Did you know anything about your great-aunt living in Austin?

LB: $\quad$ All I knew is she married Tony Bunton and she had a lot of kids, and I have all of them on my tree, but I didn't really know them. Some of them, some of the people that I've met recently since '99, but I didn't know them prior to that.

MF: In terms of the relationships between Manchaca, Kincheonville, Austin, Kyle, what have you, it's clear from where your family members are buried in what you talked about in terms of the communities switching services to different churches. What about marriage patterns? Did you have a number of relatives who married spouses from other areas?

LB: Yes, you know, they married people from all of those communities that I just mentioned. There was a lot of our relatives married people from Kyle, Manchaca, Austin, and some of them I don't know where they were from. That's one of the questions that I guess I failed to ask, where they were from, because I didn't think about it.

MF: And how do you suppose people met? I guess through church is one thing.

LB: Yeah. See back then, church, that was the social gathering place for most of us. It wasn't a concert or some of those other things that we have today. Everybody looked forward to going to church on Sundays, and I mean everybody, even if they were out drinking the night before [chuckles], they went to church on Sunday. That's just the way it was, because that was the social event of the week. You was going to see everybody there, you know. And some of the people who came didn't always come into the service, but they were there for the after service, you know what I mean, and they were. There would be carloads of folks, you know, and that's just the way it was. It was the event of the week.

MF: What else kinds of things did the church do for the community? I mean, what would you say was the main role that the church played in the community besides it being a place for social gathering and religious worship?

LB: Well, I think the church gave the community stability in terms of the moral support, family building. It gave us the support that we needed to find families. For example, most of the families that I knew when I was a little boy, people like the Smiths, my grandparents, those people who were married and had families and stuff, they stayed together until one died. And, like my grandmother and grandfather, George and Emma Harper, were married for seventy-two years before she passed away. And the Smiths, Albert and Alma Smith, they were married for I don't know how many years before Ms. Alma passed away. The Revadas, one of the couples, they had twenty-one kids, and they were married forever, you know, it seems, until somebody passed away. And I think when you raise your family, you give them good moral support, a stable Christian background, and everybody, like I said, they got together on Sundays for the church service so they would give them tools that they needed 
to support all of that, you know. That's just the way it was. You knew that's what you were supposed to do.

MF: Is that how, the church—would you say that applies to you as well?

LB: $\quad$ Oh, yeah, definitely to me. That's, you know, when I came up, it was unheard of for a young person to address an older individual without saying "sir" or "ma'am." You know, you just had to show some respect to your elders, and it went without question, you had to respect them. And it was-it was something that's desperately needed today, and I think that everybody I knew was like that.

MF: And you think the church was the one behind helping instill these kinds of values in people?

LB: I believe that the church had a lot to do with it, yes. Because the church is in you, you know? Yeah, we came to church, to the church house, on Sunday, but when you went away, you had all those things in you. We was coming up in a time when, if I wasn't doing what I was supposed to do, or if I was down the road someplace, I was one of the young ones, so I didn't have no problems, but if some of my uncles was down the road and one of the neighbors seen them acting in a manner that was not respectable or something, someway that they should not, they'd get a whipping, and then they'd be taken home and my grandfather would whip them again.

MF: Oh, so your neighbors would whip?

LB: Oh, yeah. If they didn't they'd take you home because they knew what you was going to get when you got home, and you did what they said, and you were told that you were going to respect them. That's just the way it was growing up, and there was none of that stuff, the, "You put your hands on my child so I'm going to have you arrested." None of that kind of stuff.

MF: So you think the community acted basically as a large family.

LB: $\quad$ They did, they did. And you know, I can remember when during the winter months with my grandfather, if he killed a hog, if he butchered a hog, lots of people got some of the meat. It wasn't just for us. And people came from town and the neighbors got a piece. The same when they did things. Everybody shared with it. So it was a community that worked well together. I think that's how it was meant to be. And you talk about being neighborly-there's a lot of communities today you don't know your neighbor.

MF: That's right.

LB: You might say hi and bye, but you don't really know them. If my grandfather was having problems with some of his stock, a cow or say it was a delivery or something, or a cow was sick, you'd see different men in the community come down and give him a hand, you know, to try and diagnose the problem and see what it was. Maybe one person knew more about the veterinary-type work, and know medication, know what to do to help that animal along, and they'd come down and give a hand. And you never heard about, "I'll send you a bill." None of that kind of stuff. People worked together as a community. So I think that's what was really important. And you find a lot of men and women that came up in communities like that, there's something deep in them that they haven't let go. They still hold some of those values today.

MF: So the community was like that even when you were a kid in the 1950s? 
LB: $\quad$ Yes, it was.

MF: And you think that this was how it had always been in Antioch, from the time it was founded?

LB: I think that's how it must have been, because they often say that Antioch was settled by maybe fifteen families. Well, that's just fifteen men and women who had a lot of kids, and that could have been over a hundred people out there. But all of them knew that just because you're the sons and daughters of one of the Revadas, that didn't mean that you could go down to the Harper's house, on their place, and act crazy, because you'd probably get a whooping, and then your parents are going to be told and you'll get another whipping. So when you went down there, you was going to be on your best behavior, you know. And I've talked to, well they were relatives on the Bunton side, who had memories about my grandfather and things that they did. They came down there and the respect that they had, you know, because they were treated like they were supposed to be treated, and so they showed the respect that they was supposed to have while they were there. And I'm sure that my aunts and uncles had to do the same thing when they were at someone else's property, and they couldn't go down there and just be whatever they wanted to be, or disrespectful. It was just automatic. I know my grandmother on my dad's side, Ada Bunton, when I became an adult and I had gotten married, and Anita and I went to Texas, I stopped in Austin to visit her because she had never seen my little kids or my wife, and my grandmother was a very outspoken person, and Anita was wearing a dress that was just above her knees, and she was sitting on the porch. And we walked up so that I could introduce her to Anita, and she said, "What you wearing that short dress for?" [Laughter] It shocked Anita; she never forgot that! She said, "She didn't even know me!"

MF: [Laughs] It didn't matter!

LB: A little sundress you know, and she's trying to be cute. [Laughter] My grandma said, "What you wearing that short dress for? I don't need to see your legs."

MF: And so this was something she would have said if it was a neighbor's kid, she would have said the same thing.

LB: She would have said the same thing.

MF: What other kinds of things do you remember hearing about what life was like for your grandparents and their parents on back? Did you ever hear stories about that?

LB: Yeah, life was good. I tell you why I say life was good. Although we was in rural America, out in Buda, out in Hays County, at the time that I was coming along there, being brought up on the little farm that my grandfather, the Harpers had, every other-almost every day, we would see-well, not every day of course, but several times a week, we would see Mr. Herman Heep's who used to own all of the Heep property along I-35 there, and I don't know where all he had property.

MF: Yes, you know Robbie Dotson Overton's father worked for him as a foreman.

LB: Lots of us did. My grandfather used to work for him at one time.

MF: Oh, is that right?

LB: Yeah, lots of people did. But my point is this, you know, he would pass by our place sometimes and he would stop and he'd get water to drink. And sometimes, this is one thing that I 
remember about him, he always had a new truck, and he would, he'd stop and he'd speak to my grandmother and he'd talk to my grandfather if he was home. And then sometimes my grandfather would be out in the field and he would be plowing or whatever, and he'd stop. And the one time, because I'd always be with my grandfather, and he told me, he says, "Well," he says, "I'm killing, I'm gonna butcher a steer," and he says, "I got a lot of meat in the freezer up there. I want you to come and get this meat, we can't eat it all." So it was, you know, people like that.

MF: Herman Heep would say that to your grandfather?

LB: Yeah, he would say, "Come and get this meat because I'm cleaning out my freezer. I'm killing a steer today." And so my grandfather would go get the meat.

MF: So this was probably one of the wealthiest white landowners in the area?

LB: Yes indeed-ee. I tell you another thing that happened in the twenties, not long after my grandmother and grandfather were married. My grandmother and grandfather got married in 1919, and they didn't have no children right away. I think their first child was born in like 1923 I believe, and my grandmother and grandfather, these are the Harpers, were in Buda, and my grandfather said that there was a man that he worked with at the lumber yard there disrespected my grandmother. I don't know what he did, but whatever it was, it was enough to make him mad, so they got into a fight. It was a white man. And my grandfather had a little pen knife. The blade was maybe an inch long, but during the course of this fight, my grandfather tried to cut his throat, and he cut him on the neck pretty good but it didn't cut him deep enough to kill him. And so, of course, I think the sheriff was Mr. Evans at the time, they locked him up. But he wasn't in jail long, because Heeps heard about it. Heeps called and told them to turn him loose: "Now you know George is not that kind of person." And the guy that he was fighting evidently was a brawler. And he never heard no more about it, and he said, "Turn him loose and let him go home. He's got work to do, a family to feed." You never find anything like that that was written up in the papers or anything like that, historical papers, but my grandfather told me that story all his life.

MF: Right, you know one of the things, when reading about these freedmen colonies is that blacks would mention that if you had someone who was a white man, an important white man who knew you and could vouch for you, then usually you could get out of circumstances that other blacks would not be able to.

LB: Well, that happened to my grandfather, and he never forgot that story because-

MF: Oh, yeah, he could have been-

LB: Oh, he could have been lynched.

MF: Yeah, exactly.

LB: He could have been lynched for that. But you know what, all of the people in that community that knew him, my grandfather George Harper, and that may be the same with a lot of other blacks in that area. I didn't know them like I know my grandfather. They had, they seemed to have respect for him, you know. And because in those days, see I was taught that your word should be your bond, and if you told somebody something, that's what you stuck with, you know, and you didn't go around lying, and you said what you meant, you meant what you said, and people respected him for that. And because of that, up until he died, there was children of people who knew him and had heard of him, when they heard that he was living there, they used to stop by and visit with him all the time. So, I think that's the way it was 
in that community from the beginning. You had a lot of men who were men, you know. They were honorable men who did right by their wives and children and the community, and by their neighbors, and that's what made them the kind of men that they were, and that's the reason that the community was a success.

MF: Right. Now did any of your elders ever tell you about problems that they might have had with racism? Or those kinds of things? Obviously because Antioch was an all-black community, so they chose to live on their own, right? I mean it would have been, I'd imagine the life was better for, you know what I mean, if you were living in a close-knit black community as opposed to having general racism every single day.

LB: Yeah, I've heard stories of racism, which, they were really bad. For instance, my grandmother-my grandfather's mother, her name was Ella Nancy Harper, her husband, our great-grandfather, died in 1908. And when my grandfather, when his father died in 1908, he dropped out of school and went to work in different places, helping neighbors and different things, as a little boy, mostly doing chores for older people and stuff like that, to help support his mama and he had two younger brothers. And he said that during that time, not long after his dad had died, he had a couple of older brothers who went over to Buda, and they would charge stuff on the family account. I don't know what they were buying, but they bought stuff, and he said one evening, a group of white men rode up on horses and they took the cow or two, whatever they had, gathered up the chickens, and they rode off and took that for payment of what they owed. And so it left his mother, our great-grandmother, without milk, you know, or a cow. They took the chickens so she didn't have any eggs.

MF: $\quad$ And she had kids?

LB: Yeah, she had three little kids at home. Plus the two older boys that were actually older and could have been gone, so they finally left for the service and other stuff, you know, got out of there, and it left her with three little boys at home. Now they survived, but it was hard, and it was through no fault of their own.

MF: Of course not.

LB: And without trying to reason with them or anything, they just came and gathered up their stock, took it. And prior to that, my grandmother, her dad, his name was Oscar Green, something happened in the community. I never heard what happened, except that white men rode up on horses, called him outside, so he went outside, opened the door, went outside, and they shot him down like a dog.

MF: This was in Antioch?

LB: $\quad$ Yes. And I looked through the historical papers to see if I could see anything that was written up about that, you know, and never found anything.

MF: No, it's not the kind of thing that makes it into historical records.

LB: I'm sorry?

MF: That's not usually the kind of thing that would make it into the historical records.

LB: Yeah, well you know, if there was any arrest or if someone was killed, you know they would have something in it, you know, but it wasn't. And then in 1914, there was a black guy that killed my grandfather's oldest brother, Ollie Harper, and I didn't find anything about that 
either. But when we had the '99 reunion, I met a man whose dad told him that his uncle told him who killed Ollie Harper.

MF: Was it a black man or a white man?

LB: Yeah, it was a black man.

MF: Another-someone from the same community, from Antioch?

LB: Yep. They were all neighbors.

MF: Oh, wow, so there was definitely conflict in that close-knit community?

LB: Yeah, there was conflict. You've always got a bad apple, you know? And those things happened in the community that wasn't good.

MF: Now growing up, did you ever hear about who might have been sort of like the leaders of the community, like if there was a problem, like if you had two families fighting or something like that? How did those kinds of issues get resolved; was there someone you go to and say, "Hey I got some problems. Can you go talk to that family over there?"

LB: You know what, I never heard of anything like that happening, but I would imagine there were people like John Taylor who was one of the older people in the community; he was stable, he probably was one of the more prominent people; Elias Bunton, another one. And they would probably seek help from people like that.

MF: Now John Taylor, when was he living? What period? What time, when was he living?

LB: Okay, John Taylor, I can tell you in just a second here. He lived the longest.

MF: Was he alive when you were a young boy?

LB: No.

MF: Okay, that's what I was trying to find out.

LB: He passed on when I-when I was born, he was gone.

MF: But you had heard about him?

LB: Yeah, yeah.

MF: Was he a relation to you?

LB: He was married to my grandfather's great-aunt, Sarah.

MF: Okay, so by marriage you were related. And so what did people see-Why do you think that people saw him as some kind of a leader? I mean, what makes you think that was the-?

LB: Well, I think he was one of the more prominent people in the community. He was born in 1861 and he died in 1937, and his wife died before him. She died in 1931, but he owned a lot of stuff. He owned a lot of property all around, not just in Hays County. And all of his kids were-like, Roberta was a teacher, Nina was a teacher, I think her name was Ava and Myrtle, 
all of them were teachers. They were educated people, you know, so they could read and write. That meant a lot.

MF: $\quad$ And he lived in Antioch?

LB: Yes.

MF: So you think the reason why a lot of people respected him or looked up to him is because he was prosperous and so forth?

LB: Yes. And he was somebody that they could trust. He had a syrup mill-you know where the Antioch church is being built now? Well just up the hill, back in the woods, they've torn it down now because that's part of the area that they went through and cleaned out all the trees and stuff, he lived in an area back up there.

MF: It was a syrup mill still standing there?

LB: $\quad$ At one time it was. You could see the mill part of it was still there.

MF: Oh, that's too bad that they tore that down.

LB: All that's gone, as clean as a whistle. And he lived near Jim Bunton and Tony Bunton, all of them, you know, they lived back up in that area. There used to be a little house on Black Colony Road on the south side, we'd call it Cousin Ted Kavanaugh. But they lived back in the woods down from him. And all of us were, all of them I was related to. And all of those homes are gone. I think he would have been someone that they looked up to because he was older. Elias Bunton would have been one, and his son, Pete Bunton, he was like the foreman for the Kirkendall [?] Ranch for years and years. And that ranch still exists near where the city of Hays, the town of Hays used to be. So all of those people. And George Kavanaugh, Jr., would have been one that they would have probably looked up to because he and his wife owned quite a bit of property, up until he passed away in the early 1900s.

MF: Let me ask you and kind of switch topics here a bit because one of the things I was interested in, you had mentioned that at some point in the near future you hoped to write a book about your family's history. [Yes.] Because obviously given the genealogical research that you've done, that your history is important to you. Can you tell me a little bit about what you hope to write about and why?

LB: Well you know, I've been just collecting a lot of information, and because I really don't know where I ought to begin the book-I don't know anything about writing - I'm hoping to find somebody that can help me with it. Because I need-what I need to do is be able to take all the information that I have and put it together in some context where I can start back, say from the beginning, and work forward. I not only have, you know, the history that I've collected, but I've got a lot of pictures, and I even made a CD with-it gives people a good visual history of people-I've put their names in there, I've got still pictures, put a little music with it, you know, and just made a slide show. And so I think that that's something a lot of people would like to see and would like to have.

MF: Yes. When you say a lot of people, do you mean your own family members?

LB: Well, yeah, not only my family members, but other people who are looking to do some of the same things. And you know, I bought the books, I read some of them where people have talked about various communities like this last book that you shared with me, and 
people that talked about things that happened. But I want to tailor it mostly to the Antioch community and the descendants of it.

MF: $\quad$ Of course, right.

LB: And I'm really-I've been waiting and just continuing to collect this information, hoping that I would find someone who has the skills to help me put it together and make it happen.

MF: It seems like you've already got those skills. I mean, it seems all-the knowledge is all there. You just need to kind of like organize it and put it into some kind of a narrative.

LB: That's what I'm talking about. I've learned a lot since I've started doing this from 1996, so I think I've collected the kind of information that would, that could be used in a descriptive. It would help you to know who these families are, because when you look at my history collection here-I started out just trying to find out who the Buntons were. But we're connected to so many different people and families, prominent families, that came from the Antioch community, I can break off maybe seven, eight, or ten different families and have a whole family history on them, but collectively, it's one heck of a pack of information. So I think that it's very worthwhile, and it's going to be bigger than a lot of the stuff that I've seen. I just need to make sure that it's organized and put into a book form that would be easy to read, and accompanied by these pictures. So actually, I'm looking for help with this.

MF: [Laughter] So what do you hope people will get out of this, out of your book?

LB: You know, what I really want to happen is I want people to know who they are and where they came from, at least be able to go back and look at their lineage. There's a lot of people doing this, I've been running into a lot of people who collected information. One of my cousins on the Bunton side collected a lot of information, but she put it in boxes and stuff. Now she's gotten old, and if you ask her something, she don't remember, and the boxes, she's got so much stuff crammed in her boxes, she don't know where to start and how to dig it out to get you what you need, and it would be so time consuming, she never does it. So she's got all this information and it's not going to really do her any good.

MF: Which cousin is this? Is this the one that's in California?

LB: No, this is the cousin that lives in Austin. Her name is Katherine Davis (she married a Davis). And then for some reason, some people, you meet them, and Katherine is kind of one of those people, she's very nice, but she's one of those people who holds her cards pretty close to her chest.

MF: She doesn't want to share the information even though you can help her?

LB: No, she don't want to share it. At least that's the feeling that I get. Whereas me, on the other hand, I freely gave her a lot of information. I mean, a lot of information that I had based on our family because I had it on the computer, and all I had to do was print it off, and I maybe mailed her like 200 pages of stuff. And she read through it and she was amazed that I had a lot of the information that she say she had, and then some she didn't have. But missing pieces that I have-I'm up to a point where I got some pieces that I wish I could connect, but I haven't been able to find anything that would actually connect us, and so I'm kind of just in limbo. And then when you came along, I thought you know what, it would be a wonderful thing if I could find a way to take this information that I have and archive it through the genealogy section of the University of Texas so that I could still update it and people would be able to access it and see all this information. Because I may never be able to get it in a book. And for me to have it and not be able to share it, it's useless to me. 
MF: That's not the point of collecting all this.

LB: Yeah. You know, I think it has more meaning-the more people that you can help, it seems it would be better than to just sit on it, even if I don't ever get a book out of it.

MF: Yes, right, I know what you mean.

LB: But, you know, over the years I spent a lot of money with programs, taking trips to find stuff, spending time in the county records looking through stuff, and I did it because I wanted to, but still, I think that we should be able to share a certain amount of information without looking to make a profit on it. And at the time when I started, my older grandson was just a little fella, I wanted him to know who we are, and so I have to be able to do some things to assure him when he's getting older he'll know where he came from and he'll know all these things that I never knew. So, that was another reason that I continued to work on it.

MF: Okay, well Mr. Bunton, I'm going to go ahead and end the interview here.

Phone Interview: June 9, 2009 (3 of 3)

MF: This is Maria Franklin. Today is June 9, 2009. I'm interviewing for the third time LeeDell Bunton, Sr. This interview is taking place over the phone. It is part of the Oral History Program for the Ransom Williams Farmstead Project, \# 209003.

Mr. Bunton, the last time we spoke, I was asking you questions about Antioch, of course, and one of the things I had a question about is what kind of work most people did for a living?

LB: To my knowledge, most of them were farmers. Now there were some of them who had a specialized trade, like there were some of them who did masonry work, there were blacksmiths among them, then there were others who did carpentry work. And so they worked outside of their own personal little farms and they went probably into town or a nearby neighboring community, and they got jobs, they contracted jobs-I'm assuming they contracted or worked day labor on their trades, like blacksmithing, carpentry work, masonry work, stuff like that.

MF: Did these folks work for both black and white clients?

LB: Yes, yes. When they worked outside of the Antioch community, I'm sure it was for the neighboring white people in the area.

MF: And did you know any of these people personally?

LB: I didn't know them personally, but I'm related to some of them like the Revedas, who, there is a fence, a masonry fence with Andress Revada's name on it over in the town of Buda just as you cross Antioch, the Onion Creek, and go up the hill. Anyway, there's a home over there that has a rock fence that one of the Revadas built, and it had his name on it, and I was told the story, so that's why I'm relating that to you.

MF: Now how are you related to the Revadas?

LB: Well, actually it's through marriage. And I would have to look on my tree to show you the exact connection. 
MF: Okay, I'll ask you about that next time we talk then. Now, would you describe most of the families you knew as working or middle class?

LB: I would say 99 percent of them were working.

MF: Working class. And so there was no one there that you would consider that was well-to-do, had a lot of money?

LB: Well, you know, in those days, well-to-do, yes, the Taylors, I believe they were, you would consider them upper middle class.

MF: And how was that? What did he do to make a living?

LB: $\quad$ They owned a lot of property, and because of his lineage, most of his family were educated people. His daughters, all of them were teachers, they taught in the Antioch community. And they always were, they were professional people who were in a position to earn more than your average, everyday farmer people that was running their own little farms out there.

MF: Now, right, would you say the relationships between a family like the Taylors and other working-class families were still good, or do you think there was class tensions because they were, well, better to do.

LB: No, I think that it was very good, because at the same time they were blood-related to a lot of the people that was in the community. Although the Taylor daughters were educated and they were professional ranked like teachers and stuff like that, when you look at the people that they married, they married into the Buntons and a lot of, some of them I think married Grants. I'd have to go look at my chart to see all of who they married. But they married people that was right from that community, you know, and they didn't always have the same level of education as the Taylor girls. But they all got along because then they all became family, not necessarily by blood but through marriage. And so to me, the Antioch community, in my estimation of what happened, turned out to be one big, happy family.

MF: And then speaking of that, I know we've talked a lot about the kin relations you had in Antioch and folks that you were related to by marriage. Now I know you know a lot more about that history now than you did when you were a youngster growing up in Antioch, so as a young boy, who do you remember as your family members who lived there in Antioch that you spent time with?

LB: Well, of course, the Harpers, because I grew up on that side of the family, but the Smiths-Mr. Albert, Mrs. Alma Smith-they were one of my close neighbors. The family of Pete Bunton, they lived just across the way from us, and then my great-grandmother, Aunt Kate, she lived down, you know where the Antioch cemetery is, and my grandmother, Ada Bunton, lived right in that vicinity. Then my grandfather's brother, Melvin Harper, he was probably our closest neighbor at that time, and my other great-grandmother, her name was Ella Nancy Harper, she lived very close to us as well.

MF: And so you spent a lot of time with all of these folks?

LB: Well, yeah. All of those people I seen on a weekly basis because they were right there, you know.

MF: With so many kids in your household-I know your grandmother was primarily responsible for raising you, that's what your aunts and uncles have said-but who helped her out? She must have had some help. 
LB: $\quad$ At the time I was born, she had-most of her kids were home at the time I was born, and then some of them were so much older than I, like my Aunt Marian and Eunice, my Uncle George, Jr., all of them had moved away. My Aunt Ruth, they had migrated to the city, you know. They were grown and they got out of the house. And then my mother, she left after I was born, and that just left the remaining siblings, their siblings, you know, starting with my Uncle Joshua, and the twins, Minnie and Winnie, my Uncle Elijah, Moses and Samuel.

MF: And so they took care of you?

LB: Yeah, Moses and Samuel, they're only like three or four years older than me, and the others was a little bit older, but they helped to take care of me, watch out for me.

MF: Right, did you know that they were your uncles?

LB: I knew that they were my uncles, but I grew up in their mom and dad's house, with my grandparents, I considered my grandparents my parents. I always called them Mom and Dad, and to this day they're Mom and Daddy, so I knew that they were my uncles because my grandmother and grandfather, they always taught me that. Augusta is your daddy and Emily is your mom, and they didn't want me to forget that because I guess it seemed that I really just thought that they were my parents. But to this day, after my mom got remarried and had a new family, my brothers and sisters and all of my little cousins, they think that I'm their uncle. Well, they don't really think that, but-

MF: That's what they treat you like.

LB: $\quad$ Yeah. They still treat me as if I'm their uncle.

MF: Now you mentioned your grandfather's brother, your Uncle Melvin, and said that you were closest to him, or that the family was closest to him out of the relations that were living out there.

LB: Yeah, he lived the closest to us.

MF: Okay, so and he had a family as well?

LB: Yeah, he had a family. He had a wife, Elsie Harper, and he had two children that he was raising out of wedlock, but he raised them. He and Elsie raised them. Nell and Harry Harper. And they lived the closest to us and we seen them practically every day, and they happened to be the first family that I ever knew that had a television set in the community, and Aunt Elsie used to let us come down and we would watch, I believe it was Howdy Doody, way back, and I think they only had one channel [laughter].

MF: Right, right. Now is the Nell that you're talking about, is that Mrs. Anderson?

LB: Yes.

MF: Okay, so her uncle, excuse me, so Melvin was her biological father.

LB: Melvin was her biological daddy.

MF: But Elsie was not her biological mother?

LB: No. 
MF: And you mentioned the television. I find that interesting. Did you, before that television appeared in the community, did you have a radio in the house?

LB: $\quad$ Yes, we had a radio and that's what we listened to.

MF: Do you remember what you listened to?

LB: Well, I can remember-there was a guy, I think it was Tennessee Ernie Ford, he used to sing gospel songs. And there was another guy, I think his name was Red Button, they used to play that radio when they would be on. And everybody — that was like having a TV, you just sat there and listened [chuckles]. And then sometimes I believe a fight was on and we could hear it, and a lot of people would gather around and listen to see what Joe Lewis was doing.

MF: Right, so was this a weekly event or every night you sit around the radio?

LB: No, it wasn't every night, but it was like a weekly thing, because that radio was like a battery-operated radio, and so it didn't play every night.

MF: And so when you said everybody would gather, do you mean just your family, or did people walk over to your house to listen to the radio?

LB: No, that was just our family.

MF: Was it common for people to have radios in their home in Antioch?

LB: I believe so. I believe a lot of other families had radios as well.

MF: Okay, and one of the other questions I was interested in is what do you think were the joys of being part of Antioch's community growing up?

LB: Most of the time, it was the events that took place at the church or at the school. They had, from what I remember, they would always have, like, softball games, and it seemed like everybody in the community turned out when the Antioch School had a game. And I can remember all of the people there. So those were the events that we as a community got to share together, and the church events, of course, that was almost a weekly thing because whenever they went to church, they would just about seemingly it was every week that they had church somewhere and they would take picnic lunches. And after church, everybody sat around and they got to visit with each other and catch up, and the kids played. In the Antioch community, they had all of those, it seemed like, giant oak trees that we as kids just got to play and have a good time. That's the kind of the thing that I remember.

MF: So what would you describe as the greatest strengths of the community?

LB: Well you know, again, I've got to go back to the church, because even though everybody that attended service, from what I know today, I don't believe that they were just really Godly people. I mean, you know, just because a lot of those people drinked and they might have been out almost all night, but they came to church to be a part of that social event. But they showed the respect that you would expect church people to have. And I was in a unique situation because I'm related to so many people in that community that everybody knew me, they knew my lineage, and so I was tied to somebody, so everybody always-I think, it seemed like they just went out of their way to be nice to me. And the older people, they knew who I was, and so I always seemed like I got_and I was a little fellow so I don't know, sometimes people are just nice to kids. 
MF: $\quad$ Right, did neighbors tend to help one another out?

LB: $\quad$ From what I can remember, they did, and that's amazing to me how people like my other grandfather, Tom Mullins and Mr. Albert Smith, and those were the people that I remember. There was a man by the name of Walter, he was Walter Sneed, he used to work for my grandfather [George Harper], and they were always coming around helping and doing stuff. And my grandfather did the same thing with them when they needed help.

MF: What kinds of things would they do?

LB: Well, usually it had something to do with the, like if you had a cow that was getting ready to deliver, someone would come down and give a hand or if they, if he was going to kill a hog or something like that, they came down and helped. If he was trying to get the hay in the barn before a storm, they went out and gathered the hay and he was trying to get it in the barn, and he didn't have enough help, people helped. You know, they would stop and they'd get Harry and some of the other people to come up and give them a hand. It, to me, at the time it almost seems automatic that they did that now. If there was money or anything exchanged, I didn't know about it. From a kid's viewpoint, it looked like-people would say Mr. Harper needs some help, so they stopped by, and I don't know if there were other arrangements.

MF: And your grandfather would do the same thing?

LB: Yes, he would do the same thing.

MF: Now what about the women?

LB: The women, the women seemed to work together. It was almost like in concert. I know, I can't, I don't really believe that they got together and called each other to say, well, you bring this and you do that and we going to plan it, but every time something happened, people would show up with pots of food and different things, and it was like having a potluck as we do today, and they would just work together and fed all the people. Everybody had plenty to eat and the men sat around and told stories and did whatever they did, and the kids were playing and everybody seemed happy. It didn't seem like there was anybody out there mad at anybody, and I never remember a fight where men got together or boys got together and argued and fought each other. I can never remember that.

MF: Let me ask, were your relatives members of any social organizations, because I know, for instance, the school was used as a Mason, as a Mason hall, right?

LB: Yeah, they were members of that Masonic lodge, and I came across a list somewhere in some of my research that gave the names of a lot of the founding members of that community that served in that lodge.

MF: And some of them were relatives of yours?

LB: Yes.

MF: Okay, and was there an Eastern Star lodge?

LB: I'm sure that they had the Eastern Star as well because I've heard them talk of it, but I've never seen anything that I can document that said that these are the people who were a part of it, the Eastern Stars. 
MF: Right, do you know much about what the Masonic lodge, what purpose it served within the Antioch community?

LB: I tell you what I think, I think that in the Antioch community, they looked at that as a way to bind each other. They'd taken an oath to do something that meant that they were-it's sort of like the covenant of old, you know, that they were doing something that was going to bind them together into a type of brotherhood, but as I grew older and understood it a little bit better, I kind of seen it as something different and never become a part of it.

MF: You did not want to become a part?

LB: No.

MF: Okay, now where did you go to school? You started off at the Antioch School?

LB: $\quad$ Yes, I started off at the Antioch School, I think I went-I started the third grade or I completed the second grade, I don't remember, and I remember being in the third grade out in Arizona.

MF: And do you remember what your teacher's name was?

LB: $\quad$ Yes, her name was, we always called her Ms. Woody. I don't remember her first name, but I know that I have it in my files because I have a copy of her obituary.

MF: And what can you remember about the school?

LB: I remember that the school was a huge brick building because I didn't go to the original Antioch School that was built back down in the woods, but the one that I went to was at the bottom of the hill that you start up Black Colony Road off of Onion Creek, and it was a large brick building. It almost looked like, well, it was a huge building to me, but it only had two real large classrooms, and on one side of the school which was the north side, closest to Black Colony Road, it had grades one through four, I guess, and on the other side it had fifth grade through eighth grade, I guess, and it might have had one row of first graders, second graders, third graders, or something like that.

MF: Do you know when that school was built?

LB: No, I don't know when it was built.

MF: And so when you moved out to Arizona, you continued your education out there?

LB: Yes.

MF: Do you remember the name of the school that you transferred to?

LB: Yes, Percy Julian.

MF: Okay and that was in Phoenix?

LB: Yes, that was in Phoenix. It was Percy L. Julian, named after the doctor.

MF: Okay, and then after elementary school, where did you attend-?

LB: South Mountain High School. 
MF: South Mountain High School, okay, and did your education continue after that?

LB: $\quad$ Yes, I went to a lot of, well I went to Maricopa Tech, to Gateway Community College, South Mountain Community College, Mesa Community College, and Maricopa Tech, I mentioned that. But I don't have a degree, a college degree. I just, all I did was I took classes to help myself after I got promoted within my company to manufacturing engineer, I took all the classes that I needed to help myself in that position. But I got lots of certificates, but I never completed the courses to get a manufacturing engineering degree.

MF: And so after high school, did you go straight into trade school or technical school or to college?

LB: No, after high school, what I did is I got married before I was out of high school.

MF: And how old were you at the time?

LB: I was seventeen. What I did was my wife and I, before she was my wife, we ran away and went to California.

MF: Oh, my—at seventeen?

LB: Yep, she was sixteen and I was seventeen. We were supposed to be going to school one morning and we went to the bus station and went to Los Angeles, and I got a job, I started working, so I had to come back and get my GED. We stayed over there eleven months, but we got married and then we stayed there for eleven months. I worked at the Caravan Inn, it was a hotel restaurant, and I worked at a grocery store in Carver City, California, and then I started to work as an orderly at John C. Lincoln's-not John C. Lincoln's, but it was Pacoima Lutheran Hospital. I was an orderly in the operating room. And I stayed over there for eleven months and then I came back to Phoenix and I started going to the trade school and learned to read blueprints and stuff like that because every time I looked in the paper, I found that there were machinist jobs, and I wanted to be a machinist. My goal was to become an airline pilot. While I was in California, I tried to enlist into the military, but I wasn't old enough and I didn't have a guardian or anyone to sign me in, so I couldn't go into the service at that time, and the Vietnam War was just getting started and they didn't take me. So I started working in the hospital, and I came back to Phoenix and I started working for John C. Lincoln hospital. And I knew that I couldn't make enough money to really support my wife and baby. We had a baby. And so when I was looking in the paper, I was looking for jobs, and I'd always seen machinist jobs, and I knew that if I could become a machinist, I wouldn't have to have a seasonal-type job like construction or something like that. I could work yearround. So I pointed myself in that direction, and went to this trade school, it was Maricopa Tech, and I learned to read blueprints and run machines like lathes and grinders and stuff. And I graduated at the top of my class. And five of the major companies here in Phoenix had sponsored that class because they didn't have very many minorities working as machinists. So I took the course through the NAACP, and they helped to sponsor it, and because I graduated at the top of my class, I went to-I was-at that time, I had changed jobs and I went to Sperry, Sperry Rand of Phoenix. And Sperry had a small machine shop, but I wanted to work for Air Research, because it was closer to home. And so the head of HR presented me with a gift, a set of zero to 1-inch mics, and he was part of the Garrett Corporation, so I thought if this guy is presenting me with an honor for being at the top, graduating at the top of my class, maybe he'll give me job. So I took a day off, and I went over and I interviewed, and they gave me a job. So I worked for Honeywell. I retired with thirty-four and a half years.

MF: At Honeywell? 
LB: Yes. Garrett became Honeywell.

MF: And how old were you when you graduated from that class and got that job there?

LB: I was eighteen. I might have been nineteen because I had worked at-I was nineteen, almost twenty, because after I graduated and turned twenty, I started to work at, I started to work for Garrett. Actually they called it Air Research. Air Research and Garrett was a part of the same corporation, so it changed names several times over the years, then from Garrett to Honeywell. And so I retired. Well it went from Allied and then Honeywell, back to Honeywell, and I retired after thirty-four and a half years.

MF: And so you were what, like fifty-four, fifty-five when you retired?

LB: $\quad$ Fifty-three. I retired from Honeywell at fifty-three.

MF: That's amazing, and so you obviously had a good experience there, then, to stick it out.

LB: Oh, yeah, a wonderful career. I don't regret it. It afforded me a really good living and the opportunity to save well, and my wife and I talk about it all the time because it allowed us a better than average income-Anita got a job with Motorola, and with me working at Honeywell, we were able to live in nice communities, enjoyed some of the better things, and we made better than average incomes.

MF: And did you work as a machinist through that entire time?

LB: No, I worked as a machinist for thirteen years, and then I got promoted into manufacturing engineering because they needed someone with my background with the machines to help others to calculate time standards. They needed someone who knew the equipment well enough to help buy the kind of tooling that they needed to make the shops run better, and that became my job. And so that's what got me into manufacturing engineering.

MF: Wow, so you pretty much learned your trade on the job?

LB: Yes, it was on-the-job training, but along the way, I knew that in the beginning, when I first went to work for, it was Air Research, but it became Honeywell, I was one of the youngest people there, and by the time I got into manufacturing engineering, I was still one of the youngest people in that department, and when I started to see new people come into the department because the company was expanding, and all of those young people that were coming in were college graduates. They knew how to use personal computers-they had started coming out. And my manager had bought three or four personal computers, and he gave me one, told me to learn it, if we could use it in our jobs. And when I got my first computer, I didn't really use it the way he had intended for me to use it. And so I had had it for eight, nine months, and he came to me one day and said, "Bunton, you're not really using this the way we had intended, and we've got three or four guys here that could really use it. They know how to use it." And so I looked around and I had already noticed that these guys were straight out of college, graduates, and they know how to use them, and boy I'm not the young guy in here anymore and I need to really get on the ball. I had something that they didn't have, because they didn't have the on-the-job training like I did, but I didn't know how to use that personal computer. So what I did is I went out and bought one, brought it home, and I started networking with a couple other friends who had gotten them, and we worked together, and that's how I got to know them. And from there, I started building all kinds of data sheets to control my inventory and the inventory of all of the things that I was buying for the company, I would log that stuff, and I learned how to use it from that. So what happened is as the company continued to grow and the next time, the next year when we got 
a new budget and we had enough money to buy some more personal computers, I presented my management team with a proposal and explained to them why I thought I needed a [PC], and showed them the benefits that the company could benefit from my having it, because I had done these things at home on my own time, and so I printed it out and brought it to them and wrote up a proposal, and they bought me a new [PC]. And so I went from there.

MF: When you retired at age fifty-three, you were still relatively young. Did you just-?

LB: What happened is I had enough time, but I wasn't old enough to even get my pension, so I didn't know what I was going to do. A person with, a man of color, and you looked at Phoenix and some of the large companies that helped sponsor the class that I took to help me get into that field had shut down, they had closed. Goodyear Aerospace had closed down, and GE had turned into something else, and they wasn't doing the jobs that they were doing like it was back when I started. And so the bill was getting smaller, and I thought now who's going to hire me and my background is mostly grinding? Most of the small companies couldn't afford to hire a manufacturing engineer to just deal with grinding. He had to have some of the turning stuff and all that, and although I knew that, I wasn't as knowledgeable in it as I was in grinding. So what happened is I came home that day after they laid me off, October the $26^{\text {th }}, 1999$. The next day I got a phone call, and it was from a company that I had been buying stuff, equipment and different things from, and the lady called me up, the owner, Mary, she said, "Hey LeeDell, I heard you're not over there, and I'd like to offer you the chance to work with me. I'm building a new company." And she needed someone with my background to help her build this company.

So, I took a month off and I went out and I took the training that Honeywell had provided, showing me how to network, redo my resume and see if I wanted to send some resumes out to get a job. But I never had to send out a resume. Mary had asked me to go to work with her, and so I worked with her for three months, and my sales was really good because Honeywell had eliminated my job, they eliminated all of the manufacturing engineering people who took care of the tooling part of that company's functions. So when I started working with Mary, I knew so many people there because I had been there so long and I had worked in all of the areas, every time I would go in, I would come back with a notebook full of requests for tooling orders. So my sales were incredible. I worked with her for like ninety days, and then I realized that we should be selling super abrasive grinding wheels, like I still sell today. And so I call up another friend who I had done business with over the years, told him what I was doing, and he said, "Yeah, I know you're not at Honeywell anymore," and he said, "I'll do that for you because I've known you for all these years."

Anyway, we had a little spill there, and two weeks later, he came out and I set up a meeting with him, with John Pope, myself, and the lady that I was working with, Mary Dillon, and halfway through that meeting, John said, "You know, I've got to be honest with you. I really came down here to offer you a job. You ought to be working with me." And that changed everything, because I knew that what I was doing with Mary I could continue to do, but what I was going to need is I really needed to have insurance, and I needed to make a good wage all of that time because I was still making house payments. And so what happened is I told him at the end of the meeting, I said, "John, if you're serious about that, send me a package. Let me see what you're offering me." Well, I think he must have already had that package together, because a couple of days later, a FedEx truck rolled up to my door and they brought me this big package, and the first page was a memo making me an offer, and actually, it was more than what I was able to make at Honeywell, and I had been there thirty-four and a half years. So I called my wife and said, "Hey, I'm signing this and faxing it to John. I'm accepting it and I'm not even going to negotiate more." And the rest of it was, well, it had a few pages in there telling me that I could select the type of car that I wanted. The company would pay 
all the expense. I could pick the car, and they wanted me to cover the West for them, so I took that job.

MF: $\quad$ So you traveled quite a bit, though?

LB: $\quad$ Yes. And my territory was from Brownsville, Texas, all the way up to Wichita, Kansas, and then back west to Seattle, Washington.

MF: Okay, so that's why you said you would come to Antioch very often, because you had to come down here for your sales job?

LB: Yes, yes. I would make my rounds about every three months down that way, and so I was in Antioch quite a bit.

MF: Okay, I see, but you're retired from that now even?

LB: Yeah, I worked for Universal Super Abrasive for a little over two years, and then they got bought out by a larger company, and one Thursday the boss told me he was coming in, and he laid me off, and that was on a Thursday. And the following Tuesday I got a call from the gentleman I worked with up until retiring, and Tim King called me up and said, "Hey, I heard you're not with them. Don't go to work for nobody else! I want you to work for me and take all that business back. Cover the same territory." He offered me more money, and I went to work for him, and they provided the same thing: company car, good salary, and covered the same territory. So I worked for Wendt up until-I was on payroll for Wendt up until April '07, and then they got bought out by another company. And they said, the new company said, that out west we didn't have enough large aircraft companies that could support a sales guy with my salary and expense, so they was going to have to lay me off. Well, Tim talked them into allowing me to continue to work as an agent, which means that they gave me a listing of companies and said, "You get paid by what you sell," and they offered me a good percentage. I took it, and I still do that.

MF: I'm going to switch the conversation a little bit towards family and what you remember about growing up as a young kid, in terms of what your elders expected of you. Now, when we tend to think about family, a lot of times we think about mom, dad, kids-you know typical nuclear family. You had grown up in the household of your grandparents with your aunts and uncles. Was this typical of Antioch that you had families that were not necessarily these nuclear-type families, but that had an aunt living with them or a grandparent or so forth?

LB: Yes, yes. Because I can remember as a little boy, before I left the Antioch community, there were people like Albert and Alma Smith who were raising some of their grandchildren. The three that I remember was George Smith, Jr., and his sister Henrietta, and they had a young brother at the time, Albert Smith. They were being raised by their grandparents because their dad had went to the service, and at that time, when we were leaving, he was just returning home from the service, so they were being raised by their grandparents. There were others that I don't remember as well, but most of the rest of them were being raised at home with their parents.

MF: Now I remember your Uncle Moses mentioning that your family took in a young boy that Moses and a friend or maybe one of his brothers found out in the woods. Do you recall that story at all?

LB: No, it must have been before my time, I don't remember that. 
MF: Okay, all right. Now when you were growing up, who taught you about the proper roles that men and women played within the family and community?

LB: Well, you know what, my grandfather, because from the time that I was born, from what I can remember, I was always hanging out with him. When I got big enough to walk and run and be able to [***go where he wanted without him having to carry me, I was always in the truck with him or] on the tractor with him when he was out in the field plowing. I was always with him, and even during the summer months when there was no school, and he used to go up on the different ranches and cut their dead branches and trees and stuff, and they would put it on his truck and he would sell it. And so my grandfather was my role model. He and my grandmother were married for seventy-two years. My grandmother was the type of person who, if you got out of line, she would whip you, you got a whipping. She'd say, "Cut me one of those switches out there," and I don't remember the type of tree it was, but it had long branches, skinny branches, and you pulled the leaves and stuff off that branch and that thing was almost like a whip. You got cut with that, well, I mean not really cut, but she would whip you with that. And then sometimes she'd say, "I'm not going to run after you." She was a little bit more lenient than my grandfather, but she'd say, "When your daddy come home, I'm going to tell him. He's going to get ya," and you know you was going to get it.

MF: Worse from him.

LB: Yeah, you was going to get it, and if she got you, you was going to get another one. So what you tried to do is you tried to do what was right [laughs], because they didn't cut you no slack.

MF: So what kinds of things did they teach you about being a young man that was proper for you?

LB: Okay, the one thing that I know all of my aunts and uncles was like that when they were growing up, and myself, you had to respect your elders. It was always "yes, sir, no, ma'am." You had to show the most courteous mannerism that had ever been taught. Even when somebody was older than you, and maybe you thought that things wasn't just right, you better come back and tell them, but you still had to show respect, and that to me, it stayed with me, and I seen other people that were in the age group with my older aunts and uncles that did the same thing when they came to our house. It was always Ms. Emma and Mr. Harper or Mr. George, you know, and they showed the utmost respect. And then when you were raised up in a household where my grandparents didn't smoke, drink, or swear. Very seldom my grandmother sometimes would use a little profanity when she was mad at my grandfather, but he never cursed. I never heard him use profanity. And you had to go to church every time the doors was open, and if they went, you was going. So there were times when we sat at home and he would read the Bible to us and we had like little Bible studies that most of us probably didn't pay an awful lot attention to, but the thing that I remember from that is because he had you in that setting, some of it slipped in. Because when I got to be an adult out in Arizona and I was on my own-I wasn't quite twenty-one yet, but I was on my own, I stopped going to church for a lot of years, and the only time I went was weddings and funerals. But one day, you know, I felt like something was missing, and it turned me back to what I knew from a child, and that was to the church, and I got acquainted for the first time with God. Jesus came into my life, and I've been doing that ever since. I was thirtythree years old when that happened, when I got to know Jesus as my Lord and Savior, on a personal level.

MF: And what church, is this the church that you're still with?

LB: $\quad$ No, no. When, like I say, when the Lord came into my life and I started reading the Bible and praying for an understanding, my family was always Methodist people, but I came to 
believe that it didn't matter so much the type of church that you go to as long as you go to one that believes that Jesus is the son of God, that He died and He rose again, and He's going to return. And you're following that type of doctrine, you can't hardly go wrong. So the first church that I, as an adult, after I had that experience, I joined a Baptist church, and I stayed with that church up until 1997. And then I felt like I had gone as far in that church as I could go, and I'm talking about in my growth in the Lord, and so what happened is my wife was listening to the radio on the way to work, and Bishop Keith Butler was coming to town and he was starting a new church, and his church is a nondenominational church. It's a Word church. Instead of getting a lot of theology, they actually preach from the Bible, mostly its teachings. And I went over and after I heard the first message and seen how they were doing it, I knew that I had to take a notepad with me. I had to take a little notebook because they gave so many scriptures, which was unheard of at all of the other churches I had attended or visited, and it was just what I needed, because the Bible that I took with me was so marked up. But they were going over the same scriptures and I was getting so much more out of it that I knew that that's where I was going to have to go.

MF: And this is the church that you're still with?

LB: Yes.

MF: And you raised your children, I assume, in the other church, in the Baptist church?

LB: They were baptized in the Baptist church, and they all migrated over to where we are because they were old enough at the time. My oldest son was married and he and his wife were in the Baptist church, but they came over, and then when my young son got out of the military, he was divorced by then, but he came over as well.

MF: Let me ask you, you had mentioned when I started down this line of questioning, that your grandparents rarely cursed. Your grandfather certainly didn't, but your grandmother did sometimes when she got upset with your grandfather.

LB: Yeah, she would use a little profanity.

MF: $\quad$ Right. So the question I was wondering about was, what kinds of things, you know, would you say that if there was conflict between men and women, like between your grandmother and grandfather, what usually caused it? What was usually the root cause of it?

LB: You know what, I think my grandfather was a little overbearing sometimes. Now that I'm as old as I am and I look back at some of the situations, I really don't think he had cause to stir up stuff, but I think as I look back, I think my grandfather was a little overbearing. He was the type of person that, when he came home, he wanted his food ready, you know, he wanted everything to be ready, and it was like she didn't have anything to do because she was at home, and he'd get angry really quick, and he would say some things that not true, like not true, like, "You been around here all day and you ain't done nothing." Well, that's not true, because even though we were in Arizona, and my grandmother wasn't washing on a rub board and that kind of stuff, she still had to wash, and she did a lot of stuff, because by then she had a lot of grandchildren that she often babysitted and they kept her tied down, and she couldn't always have things exactly the way he wanted it. He would come in and he would start in on her, and she would get upset because she had those kids all day. You know, maybe she'd have dinner almost ready, but it wasn't always just right; I mean ready when he walked in?

MF: Now you might not be able to answer this question since you were so young, but did you know, I mean perhaps with your aunts and uncles, was this kind of a common tension that 
was between husband and wife in Antioch? You know, you had the housewife who was staying at home and working all day, but the husband sometimes coming home and saying, "Well, where's my dinner?" or, "Why didn't you get this done?" In the meantime, she's been working all day pretty much.

LB: Well, you know what, I don't know about the other families, if that was a common tension in their homes or not, but I just know about my house, and most of that happened after we was in Arizona. Because when we were still living in Texas, I had aunts at home that was big enough to help her and they did-I was the only grandchild for a long time, and so I didn't experience that in Texas; that happened after I got to Arizona. And then when we first got to Arizona and my grandfather was out and he started the two businesses that he went to, my grandmother went out and did a little housecleaning as well, and she did that for a few years, and so she didn't always get home in time to just go through the house, clean everything up, and cook before he got home. One of the things is, I think my grandfather was always overworked. I think that he was a very kind man. He had really good intentions. But he came along at a time when black women, they didn't vote. And whatever the man said, that was law. His family did what he said. So, that was still in him. And so a lot of times when he came home and he was in between jobs and he knew that he was going to have to try to sit down, and he'd go in maybe to get a bath, he'd come back and he was ready to eat, because he knew he was going to have to get a little sleep before he'd go on to his next job. He did that for years, so I think that he might have been a little stressed. This wasn't something that happened every day, that there was a lot of tensions. There was a lot of good times. For instance, my grandmother was the bank. He earned really good money and she took care of it. Well, I mean, she didn't pay the bills, but she put the money away, and they didn't put it in the bank. I don't know if she hid it in a mattress or where she hid it, but I know she did. But you know, Anita and I talk about that sometimes and kind of laugh and wonder, because most of the stuff that he bought he just paid for and he had saved up enough money to pay for it. And we talk about it, because I say to myself, if I had been taken care of the money like now, I would have put the money in the bank.

MF: You would have been saving it and getting interest on that money.

LB: Yeah, and I think they came from a time when they really didn't trust them, and I never knew him to have a checking account. Never knew him to.

MF: Even into the seventies?

LB: $\quad$ Even into the seventies. I never-now when he got so old that he was sick, and he had moved back to Texas, my aunt (we call her Martha, but her name is Winnie, Winnie Moyer), she handled his money, so she put money in the bank. But I never knew him to have a checking account prior to that. And I just think that as much money as he made, he earned over the years, and the things he was able to buy and accumulate when he was handling it, if his money had been better managed, he would have had a lot more. But a lot of what happened to his money went to his kids. After they got grown-and they were really grown and they had children and grandchildren-he gave them too much, I believe.

MF: Okay, okay. Now I remember asking you about when you were growing up that you really didn't have chores because you were the baby of the family and you had it pretty easy, so how did you spend your time when you were a young boy then?

LB: Most of my time was spent just playing and hanging out with my grandfather. You know, another thing that I remember is my uncle, Ollie Joe, which his name is Moses, he and I had lots of conflicts, and my Aunt Minnie, she was quite a bit older, but we had conflicts because I think sometimes they were jealous. They thought that their dad showed me too much favor. 
And because my Aunt Minnie, you would think that her being quite a bit older than I, she would have known that I was their grandson and I was the number-one grandson, and they were just being nice to me, but it seems, from when I look back, it seems she was a little bit jealous because she would say things like, "Well, he ain't your daddy, he's our daddy." [Laughter] I never forgot that.

MF: Oh, no [laughs]. Kids can say mean things to other kids.

LB: Aw, kids are cruel. They can hit you hard.

MF: Right, right, that's true. No filter there.

LB: And one time when I was in Phoenix and I must have been about thirteen, fourteen years old, we had a cousin who would live with us sometimes. We called him A.B.; his name is Abraham. He's buried out there in the Antioch cemetery. He pulled me over to the side and he said, "Boy," he said, "you know those are not your parents." He said, "We've got to do for ourselves." And he always called my grandfather Uncle George and Aunt Emma, my grandmother and grandfather, he called them Uncle George and Aunt Emma, and he would say, "They're not your parents," and he said, "we got to do for ourselves," and he said, "you might as well get used to it. Those are not your parents." And he acted like I was confused or something! [Laughter]

MF: Right, as if you didn't know.

LB: Yeah, but you know what, I never forgot that, and so all of the things that my grandfather taught me about working and good work ethics and stuff, I took it to heart, so that when I got married, I wanted to be a good provider for my family, my wife and my children. I wanted to make sure that my rent was paid and I wanted to buy a home and make sure everything was taken care of, and that's what I set out to do. My life changed when Anita and I got married, and so I set out to do those things, but do them the way that I thought they should have been done. I incorporated all the things I had learned from him, from my grandfather, and people that I met that helped show me the way. And that's why I'm where I am.

MF: $\quad$ Let me ask, who named you? Because LeeDell is an unusual name.

LB: You know, I'm told that my Aunt Marian named me after her husband. His name was L. D., but L. D. stood for LeeDell, and L. D. was the son of Pete and Mary Bunton.

MF: Now, so she was already married when you were born?

LB: $\quad$ Yes, she was married to L. D. Bunton.

MF: Okay, and do you know how it was that she came to be the one that named you?

LB: Well, no I don't, except that she was my mother's oldest sister. And she must have been around at that time and she named me. And what happened is my mother got pregnant, and so I'm told that my grandfather went down to my grandmother, to my daddy's momma's house and told them what had happened, and told them that Augusta was my father and he didn't want me to be born a bastard. So they got the preacher and, or wherever they went to get married, and they got married just so that I could have his name. They never spent a night together after the marriage. He went back home, and she stayed at home. And that's what I've been told. And they all-my dad's side of the family, as far as I know, always treated me nice. I never had a problem with them. 
MF: Now, Augusta, his father was Tom Mullins, right?

LB: Yes.

MF: And so he was born out of wedlock because he didn't take his father's name? Is that correct?

LB: $\quad$ Yes. His mother never married Tom Mullins. I believe it's because, well, Tom Mullins was already married. He was married to a lady, her name was Effie Wynn, and her dad was Ben Wynn, and Tom was married to her. And things happened. I don't know how that came about, but he went down to Ada's house and Ada got pregnant with Augusta and then later had Daisy, so he fathered two children by Ada.

But they all lived in a close-knit community. And I remember when I was old enough and I was down visiting Ada with my grandmother Harper, Emma Harper, and Tom Mullins came along, and he stopped and visited and we all visited. And so, I can remember when Tom's wife Effie was sick, Ada went down there and helped nurse her, give her baths, and changed her. I don't know what was wrong with her, but she had sores on her legs like she was a diabetic or something and didn't have circulation, and she changed the bandages and cleaned her sores and all that kind of stuff while she was sickly.

MF: And so this was her father's wife, but not her-so basically, she was the illegitimate child going to take care of-

LB: Ada was the lady who got pregnant by Tom.

MF: Oh! Okay, I was thinking it was her daughter. Oh my goodness, okay so Ada herself did this.

LB: Yeah, Ada herself did that. And then, I was told a story about-Ada worked for, she cleaned house over in Buda, and she would walk from where she lived near the cemetery down Black Colony Road across the bridge up into Buda and cleaned house, and then she would be coming back sometime in the evening when she was done. Well, one time she was on her way to work and Onion Creek was flooded, and at the time, the bridge wasn't like the new bridge they have across there today. The bridge was overflooded, and it must have been a foot of water over the top of the bridge, and she had to go to work, and she waded that water to go to work.

MF: Oh, my goodness, that's dangerous.

LB: $\quad$ Maybe it wasn't quite a foot of water, but cars would still drive across the bridge, and I was told a story about Ada on her way to work, and Tom and his wife and someone else was crossing the bridge, and his wife Effie forced him to stop and give her a ride. So it wasn't like they were enemies just because Tom got kids by her out of wedlock. And evidently Ada and Effie had some kind of relationship that was civil.

MF: Yeah, obviously. And so was this, was having kids very young and out of wedlock common?

LB: No, and that was a no-no, so I'm surprised that all these things happened and everybody was able to-no one got sent away or, you know.

MF: Yeah, so if it did happen, no one, like you say, no one would be sent off to a relative in Austin or someplace else.

LB: $\quad$ Most of the time they were very quiet about it. The way that I found out that Tom Mullins was my grandfather was from my grandfather George Harper. He told me, he said, "That's 
your grandfather." You know. Now, he said that to me, he didn't say that in the presence of Tom, and the time that I remember Tom being in my presence, he would speak to me and ask how I was doing and different things, but he never acknowledged that he was my grandfather or tried to pick me up or show me any kind of affection or anything like that. I didn't know him that way.

MF: Okay, and did your mother stay married to Augusta for long?

LB: No, four years later, she was remarried and had a whole new family.

MF: And so were you the only child of their union?

LB: Yes, I was their only child, and I was Augusta's only child that I know of.

MF: Oh, wow. And did he ever father you? I mean, did you have any kind of relationship with your biological father then?

LB: Yeah, when I was a little kid and I would see him, you know he'd come around, and I'd see him, and he always gave me money. I don't think he ever supported me. I never heard of him contributing to my well-being or my upkeep or anything. But whenever I seen him, whether it was over on Sixth Street on Saturdays when we were there or just being in the community, he always gave me money. If he gave me a dollar, that was a lot of money. And I remember him giving me a fist full of change, and it might be 75 cents, and some of my older uncles would beat me out of my money. [Laughter]

MF: Oh, no! Now you mentioned that you and your wife, Anita, ran off when you were seventeen and sixteen years old. [Yes] And so obviously, you said that was a no-no, from the way you were raised, that's not what you did, so what were the repercussions of that? What happened, what did your grandparents at that point say?

LB: Well, you know what, they didn't know I was gone until after I was gone. I was in Los Angeles. I went to my uncle's house, Elijah, I went to his house, and then I was able to call back home and tell them what happened.

MF: And what did they say?

LB: And I explained to them that I'd gotten Anita pregnant and I went to Los Angeles to find work and I was going to marry her. Which I came back to Phoenix a month or two later, Anita and I came back to Phoenix and we got married, and my grandmother and grandfather attended the service. And so at that time, I was accepting the responsibilities of being a man-a husband and man and all that kind of stuff. So, I went back to Los Angeles because I had a job. I went back the next day, and my grandmother-I'll never forget-she told me, she said, "Boy, there's something that you got to always do. You gotta keep a roof over your head. You pay the rent and you know ya'll have a place to stay. Save your money. Put away enough money so that if something happen and times get really bad, ya'll can come home. You don't want to be in a place like that and you're stranded, you don't have nothing, and no way to get home." So, her encouragement was to save my money and pay my rent so that we wouldn't be homeless.

MF: And what did Anita's parents say?

LB: Well, she called her mother-well, she went to her sister's house. At that time, she lived just north of Los Angeles in Pacoima, and she went to her sister's house and of course they called their mom and let her know that she had made it, so the same day we left she was able to 
call home. And so her mom was upset, but she understood, and she wanted to know what my intentions were, and so she told them. And I got a job right away, and I was constantly in touch with Anita, although I lived in Watts and she lived in Pacoima, and we talked about getting married and we planned a time to come back to Phoenix and get married. But I worked enough to save up enough money to buy her some wedding rings—cheap wedding rings [chuckles] —and we came back to Phoenix and got married, and I went on back to Los Angeles because I had a job.

MF: $\quad$ So you stayed with your Uncle Elijah, and she stayed with her sister then? While you were out there?

LB: Yeah. But when-After we got married and she came back to Los Angeles, she stayed with me at my uncle's house, and we stayed there for a few months and then we moved to Pacoima. I changed jobs and got a job out in Pacoima at the hospital, and we lived with her sister. So we lived with her sister and her family, and we stayed a total of about eleven months out in California, and then we moved back to Phoenix. And what happened is when we moved back to Phoenix, I had to find a job, so I found a job right away. And then our daughter was born while we were in California. So we stayed with her mother for a while, and then her mother had a house built next door and she gave that house to us. And so we lived in that house from 1966 up to '73, and then I bought our first new house, and well, our first home, I bought it. Our first home was the one that my mother-in-law built.

MF: And you were still quite young, too? You weren't even thirty at that age?

LB: No, I wasn't. Actually I was twenty-six when I actually bought the first new house, our first home, and we went from there. But we made a lot of mistakes, and we learned from them, and we just went on as best we knew, but we were learning as we go. Because her mother passed away in '68, so she wasn't with us long, and that sort of left her without—she really depended on-she was a momma's baby, and then when momma died, boy that just left her with nobody, it seemed. She had a couple of sisters that was a lot older than her, but you know, they had their families and we just-it sort of bonded us a little bit closer, and we just had to learn as we go. But we were really blessed, because we had a lot of people in our corner that was older than us, and all we had to do was listen, because they was telling us stuff that we should do and things that they didn't always do, but they had made mistakes and so they could tell us the way to go. And so we made some mistakes of our own, but we learned from those things. That's how we got to where we are.

MF: Now, you've had a life of working very hard, and in different jobs and whatnot. But one of the things, in talking to other members of the Harper family, was just how hard it was to put food on the table for that many kids, and that they remember a constant kind of cycle of working, especially going out to pick cotton and traveling around.

LB: See, because they were older, they had some experiences that I didn't have. For instance, back when they were doing a lot of farm labor and stuff like that, they were older and they were able to do that, whereas I wasn't always a part of that. Now when we moved to Phoenix, when we first came to Arizona, we stopped at a little town called Florence, Arizona, and there my grandfather did-he contracted a lot of farm labor, and he went out and he took people out to these farmer's fields and they chopped cotton. They chopped it. And I wasn't always a part of that. One thing is, I wasn't really old enough, but I was old enough to carry water from one end of the field to the other, and he would have me doing that. So, I mean, when he talked about working, it was a serious thing-you really had to work. And I mean everybody did it, and that's how it was. And they were long hours that we worked, but you know what, it taught us a lot of things. My grandfather used to have a saying, well, my grandmother said this, well, both of them said it, but it was like, "If you don't work, you steal." And that was 
something that they were not going to have. You ain't coming up in here stealing, and you going to learn to work for what you get, and that's what we had to do. I was always troubled by some of my uncles who, after they got older, they would go to him, and to me, they were taking advantage of him because they took advantage of his kindness, and he would wind up-he would give them, he just kept giving them money and money and money. I thought that was bad. But it was him that did it, and I couldn't change that.

MF: Yeah, you're going to want to help your kids out. When they're in a tough spot, it's hard to-I mean, I can imagine if it were my kids, I might complain about it, but I hate to see them do without, even when they're adults.

LB: Well, you know what, they're doing without, it wasn't because they didn't have jobs or made money; it was because a lot of times they were on the streets. Some of the boys gambled and they good-timed it, and that's like throwing it away. And I didn't think that that was fair that their father was getting old, older. But when he was seventy years old, he was probably stronger than a lot of them, and, but they were taking money that he had worked and saved, and the way that they came about it, I knew they were lying for it, and so that was always a straw that got stuck in my throat, and it was hard to deal with. Because to me, that was Momma and Daddy. They would need that money later on when they got older, and the boys didn't seem to-it seemed as if they really didn't care, they didn't even think about that. They were just thinking about what they were getting for now.

MF: And so would you say it was mainly the sisters that ended up taking care of your grandparents, then?

LB: Yeah, it was mostly the sisters. I credit my Aunt Winnie (I call her Martha), but she's the one that took them in and did a lot of the work. But my Aunt Marian, the oldest one, sold her home, moved from Phoenix to Buda so that she could be there for them every day, and because what happened is my Aunt Martha worked every day, so she really couldn't—she could prepare food and stuff and have it there, but my grandmother had gotten so old and she couldn't see as well, so she couldn't really cook the way that she had been used to all those years. And so my Aunt Marian was the one that was there preparing food and doing whatever it is that they needed, but when my grandmother and grandfather moved from Phoenix to Buda, my grandfather was-both of them were very healthy. They worked in a garden that was enough to feed the community, and they come out there every day, and they did it because they enjoyed it, but at the same time, it kept them physically fit. I don't think they would have lived as long as they did had they not done that.

MF: Where'd they keep that garden? I've been out there, of course.

LB: You know between where my Aunt Martha's house is and Black Colony Road? That was the garden. I mean it was a big old garden, and that's where they kept their garden. And they did that up until just before my grandmother passed away. They got out there every day and they would weed the garden, they were planting stuff when it was planting season, and they did all of that stuff by themselves. And I tell you what, it was a lot more work than I would care to do.

MF: Yeah, I think so. Most people-

LB: It really was. To me, that's amazing when you look at their age at the time. My grandmother died when she was eighty-nine years old, and she would be out there, and you think, well how much work are they doing? Well, when you seen the size of that garden, you know that that was a lot of work. 
MF: Serious garden, huh?

LB: $\quad$ But they always said that she had a green thumb, she could grow anything. But as I look back and I remember a lot of the things that went on-After my grandparents moved to Texas and we would have conversations, I taped a lot of those conversations between myself and my grandfather, and I come to realize that actually those were things that they enjoyed doing. They did them together, and it was stuff that they really enjoyed, getting out there and doing that, and that's why they did it.

MF: It's also kind of different, you know, gardening because you want to as opposed to you have to because otherwise your family won’t eat.

LB: Yeah, no, yeah, that was it. They did it because they wanted to, but at the same time, I can appreciate the fact that they just did it because they wanted to. They had the time; they really didn't have anything else to do.

MF: That's nice that they were able to end their years enjoying things like that.

LB: Yeah, yeah. But after my grandmother passed away in '89, a couple of years went by, and then I started to notice my grandfather, he started sitting on the porch and the garden went away. I noticed his ankle swelling and his fingers, he couldn't get his ring off, and they started the medication for high blood pressure, and different things started to creep in, and then in '94 he passed away.

MF: So you think a lot of that had to do with the fact that with your grandmother's passing, he didn't take care of himself like he used to?

LB: Yeah. I think that after she passed away, I think that he sort of gave up. Like "what's the use."

MF: You said they were married seventy-two years, right? [Yes] That's amazing.

LB: And that's just me thinking. I don't really know, but that's the way it appeared.

MF: I just was reminded of that story that you told me about how your grandmother lost her eye; because they were living in Kincheonville, right?

LB: Yeah, I think it was Kincheonville, south Austin there, I went through the historical papers and it said south Austin. But there was a storm in 1922, April the fourth, and that storm came up, and my grandfather was working on the railroad at the time, and he seen it but there was no way for him to be able to get home and get them out of the house or anything.

MF: It was just him and his wife at the time, right?

LB: Yeah, they didn't have any children at that time. I think their oldest son was born in '23, somewhere in there.

MF: And so they were in south Austin so he could work his job on the railroad?

LB: Yeah. And it's not far from Manchaca-you know south Austin, wherever the border is, Kincheonville is right in there somewhere. Because he took me over there when I was, I don't know, about thirteen, fourteen, somewhere in there, and he showed me the spot, but I can't find it today. And he showed me where-He said, "Now if you look right back over there," and he was showing me, and he said, "you could see the tornado coming." And he said, there's 
no way that we could get from where he was to warn them of the coming tornado. And his brother lived right next door, his brother Limuel lived right next door, and he said when the tornado hit his brother's house, they just figured, when they went over there, they would be searching for bodies. You know, they didn't figure nobody would survive it. And so that was just a lot of worry on them right then. So they stopped working and they went, when the tornado passed, and they went to recover bodies. But what happened is the tornado, when it hit the house, it picked it up, I guess my grandma fell out, and she made it to the barn. But it stripped off all of her clothes, and she made it to the barn. A 2x4 hit her in the hip, the splinter of a $2 \times 4$ hit her in the hip, and that's what crippled her in later years. And she made it to the barn, and there was a little boy, a little white boy who the tornado had dropped, and she took him in the barn with her for protection, because he was scared, didn't know where his family was. When they found her, she and the boy were in the barn. And his brother's family, the wife didn't get hurt. She fell out of it right away. And they had three kids. The oldest daughter got killed in the storm, and the others, they found them. They found the baby early the next morning, and the dog was right there next to her, and the dog was dead but the baby was still alive. And the little boy, they found him later on that night, and he was found [alive]. But the oldest girl was-they found her dead.

MF: And these were all Harpers, right?

LB: Yeah, they were all Harpers.

MF: Limuel Harper, do you know-?

LB: Limuel Harper, that was the father, and Limuel Jr., he lives out in Oakland, California now. He is close to ninety years old.

MF: He's the baby?

LB: No, he was next to the baby.

MF: And do you remember what Limuel Harper's wife's name was?

LB: Yeah, her name was Luellen.

MF: Was she from Manchaca or was she also from Kincheonville?

LB: Actually, she was from Antioch, I believe, because she was a sister to Pete Bunton's wife Mary. She was a Sampson.

MF: Okay. So was it common for people to move out of Buda into Kincheonville and Manchaca?

LB: Yeah, see all of those people really that were brought up in Buda, Manchaca, a lot of them were related through marriage. And I don't know how they got to know each other or whatever, but I guess it's from all those church visits and stuff like that. They got to know each other and they wound up tying the knot. But I'm sure that's what happened. Now, my grandfather had several brothers that was older than him and they married, one of them married a Bunton, and then Limuel married a Sampson, and her sister married a Bunton and all that.

MF: Were these Buntons of your Bunton family or Buntons from Manchaca?

LB: Now, the Buntons that she married was from Elias Bunton's set, which could be one of my blood relatives. I haven't really found a connection. In that report that you sent me, I 
seen where that genealogist lady, Terri Myers, that Elias and Dave could be, they could be brothers, but because there was like a ten-year age difference in there in her report? And so they could be brothers, but I haven't found anything to say that they were or were not. They may have just come off the same farm. So I don't know. But I can remember L. D., the person that I was telling you that I was named after, from some of the things that he used to say, it really sounds like we might be blood relatives. We could have been blood related, but I don't know that to be a fact. After I started doing family history and was really, really into it, I wanted to be sure that all of the things that I put in the report, I had some documentation for it. Because so many times you talk to people, and even in the census where you see these reports and it's conflicting information, and you're not sure when they gave that information if it was really accurate. So I was kind of concerned about that, and I wanted to be sure that whatever I put in there was accurate. So I stopped going by what people said, and was trying to make sure that I had something, some kind of document or something to prove what I was saying. And that's the same thing about my dad and Tom Mullins. People for years had always told me that Tom Mullins was my grandfather, but after I started doing family history and got to where I kind of felt like I knew what I was doing, I sent for the SS5 forms for my dad, his mom, and his oldest sister, because they had passed away, and I seen where on the SS5 form, my dad said that Tom Mullins was his dad. So that sort of settled that for me.

MF: $\quad$ Right, I see. Well, I've got a last set of questions I wanted to ask you about, and that has to do with the importance of history to you. What I was interested in is, what is it that you want people to know the most about the history of Antioch?

LB: Well, you know what, the reason that I started doing the history is because I'm a grandfather, and my grandson was about two years old. And I brought him to Buda for that reunion in '99, and I wanted him to know who his lineage-I mean, he knew me and I can, you know, tell him all the stuff that I knew about who raised me up and he knew that side of the family, but neither of us really knew much about the Bunton side of the family. And so I started out trying to find out about Bunton, and every time I would look, I found that we were connected in so many different groups that I just started recording all of that stuff, and then I started to see where it fit together. And so my whole goal was that not only my grandson, but I have a granddaughter now that's twenty-two years old, I wanted all of them to know. I didn't want them to be in a situation like I was in, not knowing their lineage. I wanted them to know. I want them to know who Aunt Kate was and who Dave and Mary Bunton was. And so now all they have to do is look at my tree. I can send them a descendant chart and it tells them all of that, and so that's why I started doing that. It's important to me, because I met a lot of other people after I started doing this research, and they, too, wanted to know, and I had already collected the information, so I didn't mind sharing it with them. So I started giving it out just freely, and I was hoping that in return there would be those who would share more information with me, and I would be able to continue to pass it on, you know, but that doesn't always happen.

MF: Right, right. I'm going to go ahead and switch the tape real quick because I have a couple more questions to ask you. [Stops tape.]

[Part 3b]

MF: So it's clear that you started doing this family history so that you could pass this on to your kids and your grandkids. Now, these oral histories that I'm collecting, they're going to be publicly accessible, and so in terms of what the general public learns about Antioch history, what do you hope that is? I mean, what would be the most important things that you hope people learn about the history of Antioch Colony? 
LB: You know, really, I want people to know that just because you had people who were freed men and women who hadn't been long given their freedom, and some of them might have been illiterate, they couldn't read and write, they were still people. They lived and they raised their family, and they wanted all the things that we want today. They were looking for security, they wanted to build good homes and raise their family in the sight of God and do all of the right things. I want people to know that they did the best that they could to make all of those things happen. Even during all the hard times that they had to endure, they did it. I don't think that they made much of a fuss about it. If they did, there's no real evidence, because they continued to do what I think they felt was right in terms of trying to make a good, honest living for their families. They realized the importance of owning property, so they worked hard, they bought their property, and they hung onto it. And some of them, they hung onto it for a long time. That's how I wound up with the little piece of property that I've got is because somebody within our family continued to pay the taxes up until they got sick and couldn't, and then God blessed me to hear about it-

MF: Was that Katie Bunton, I'm sorry, no it wouldn't have been Katie Bunton, it would have been-Who was paying the taxes after she died?

LB: Well, see Katie had, she had several kids and some of her grandkids were continuing to pay the property. I believe it was a cousin, Vivienne Bunton. She was the daughter of Fred Bunton, which was a brother to my grandmother, Ada Bunton. His daughter who was a teacher, a long-time teacher there in the Austin area before she retired to that and moved up to the Fort Worth area, she continued to pay the taxes on that property. After I investigated, I found that Katie had actually left her property to her daughter Ada, and after Ada died that's when the cousins started to pay the taxes to keep it from being lost. But the legacy of her grandmother that she passed on must have caused her to do that. Her father-

MF: So you never got to talk to her about it?

LB: No, I never got to talk to her about it. She had been in the nursing home for a long time, and I had no contact with her, didn't even really know her. I really never got to know her, although I met her I think when my father died, she was at that funeral, but I really didn't know who she was. But for whatever reason, she continued to pay the taxes up until she couldn't pay it, when she went into that nursing home. And it just happened that I was, like I say, I feel like I was blessed to find out that property was on the market and going to be sold, and after I found it out, I came down and bidded on it and got the property to keep it in the family. I would have just paid the taxes-not trying to get it for myself, you know, just to keep in the family, because when you walk out across that property like you and Nedra did, when we were out there looking at it, that, to me, boy, that's a heck of a thing every time I walk out across that property. I get chills because I know where it came from and who it belonged to. I often say to myself as we ride along and talk, and you drive from Texas to Arizona, you got a lot of time to talk, you know. I often tell Anita, you know what, if trees could talk, what kind of stories could they tell about my great-grandmother and my great-grandfather? My great-great-grandparents who were out there and owned that property? Boy, I would have a good time, and if God would bless me to be able to have a sit-down meeting with them one day, what kind of stories could they tell me and how happy would they be to know that I was successful in hanging onto it for all of these [***years]? You know, it was picked up and not allowed to be lost. I want all those people who don't know, and I'm sure there's a lot of people that I'm related to that don't know, what happened and what is happening, because one of the reasons that I organized that community reunion was to bring some awareness to what's going on. And as a result, there's a young lady who lives in DeSoto, Texas, up near Dallas, who found out that one of her uncles or somebody had passed away, and they were able to get through an auction his property. Now, it's not much, but they didn't even know where the property was, but because I had done so much investigating, some of the people remembered 
me from I'd been coming out to that appraisal district, and they told her she ought to get in touch with me, and she did. And I wasn't really able to help her, because I didn't know as much as I felt like I needed to know. I couldn't give her a lot of information, but there are some things that are happening, that has happened, in the Antioch community that I don't think is lawful, and if we could prove it, it might be bad for the county. Because I tell you what I think. I think that a lot of the property was lost because there were a lot of people who didn't know where the property was located, and although they had paid the taxes on it, it was someone else who claimed it, and they probably still have that property today. And the reason that I say that is because when I went down to bid on Aunt Kate's property, I also bidded on another piece of property that belonged to a relative that I know now, it belonged to another relative, and you know what? They allowed me to bid on it, but another gentleman from Houston got it. And after that property was sold, I went to that relative and told him that his property, I believe it was his property, that had been sold, and when they checked into it, they had all of the receipts and everything, and that property had to be given back.

MF: Oh, wow.

LB: Yeah. So, and it's adjacent to where Nell Anderson's property is now? They sold that property.

MF: But it's back in the hands of the descendant?

LB: Yeah.

MF: Who is that person?

LB: Japheth Walker. Japheth Walker and his sister, and his brother's property, it used to belong to their dad, Japheth Senior, who's been passed on for a long time. They'd been paying that property, the taxes on that property for years. But the county records must have been screwed up or something because they had that property up for auction, and they had to go down there and present their receipts and all that kind of stuff and show that they owned that property, and from what I understand, it was given back.

MF: And so, but no one's living on the property now?

LB: No, no one lives on it. And I tell you where it's at. You remember when we went down and met Frank Wilson? Okay, as you turn down that road, that little lane to go down to where that old house was, that property, it's the middle piece of property from that road, between Nell Anderson and that little road, and that's where that property is. And when they started auctioning it, they opened up the bid at like $\$ 6,000$-some dollars, and I bidded on it. And the other gentleman from Houston, I guess he said to himself, "Well you got that one piece of property, and I'm going to keep on bidding on this one." And what happened was he ran it up pretty high, and I was satisfied with what I had, so I stopped bidding on it, and he got it.

MF: But you were trying to keep as much land that belonged in Antioch within-

LB: Yeah, I was trying to keep it for that community because he was an outsider, you know. I thought that it would be better if I had gotten that property. I bidded on it, and I wouldn't have had any problem turning it back over to Japheth Walker and his family, you know, but all I would have wanted was my money back. Guy had to give me my money back because I thought once they got rid of it like that, it was gone, but that didn't turn out to be the case. Because once Japheth and his family found out about it, they were able to go down there, and the property was given back to them. But I think that that's a shame. So I say to myself, and Frank Wilson pointed out that there was some property over there where I told you my Uncle Melvin lived? Now, somebody bought a few acres in that area and they just fenced off 
all of that property, and all of the property wasn't supposed to be a part of that. And so there is some property in there that they've included, the county has included or whomever bought the property, that it doesn't belong to them. And you've got descendants out there who don't know, like the girl from DeSoto, she doesn't know where her relative's property is because they never came down here, didn't even know the guy, I guess. And when they found out that he was gone and he owned that property, they came down here to claim it and make sure the taxes was paid, and the county couldn't really direct them to where the property was, so.

MF: Now, are there any more lots out there that people have not come down to claim that are in risk of being lost?

LB: I don't know, I don't know.

MF: Well, let me ask you two more questions. The first one is, why is it that you agreed to do this interview for the Ransom Williams Farmstead Project?

LB: Well, when I got to know you and I realized all of the exposure that the Antioch community could get from this, I thought it was a wonderful idea. Because there are not a lot of places-now you can go and buy one of those books that Mary Gibberson and some of the other historians put together and read a little bit about life in the Antioch community, but it doesn't really tell all of what I thought should have been told. But when I met you and I realized the potential that could come from this, I thought you know what, it would be-it's a wonderful idea for the community to be able to get as much exposure as possible, and this, to me, was one way of assuring, well being assured, that it could happen. And so, I went online and I read a lot of stuff that you have written.

MF: [Laughter] Uh-oh!

LB: I think you've got it going on.

MF: You didn't tell me that part!

LB: And then I thought, you know what, it might even be a good idea if I could work out some kind of deal where they would take my information and put it on their website so that everybody could access it that wanted to and still allow me to maybe maintain it and add to it and that kind of stuff. And that way it would be an opportunity for any and everybody to see what this history is all about. Because you know what, you can't go online and find a lot of stuff that was written about the Antioch community and the people in it, like John Taylor and his syrup mill or the horses that he raised or the horses that were raised by the Early Lomax and his family, or the people that helped to build that community. I got a letter from one of the Grants who was talking about his great-grandfather and how he built, way back he built bridges on some of the ranches that are still in existence. Back during the time when they didn't have calculators or computers, and he had to determine the water pressure and the different forces that, when those creeks would rise, and how much pressure those bridges were going to have to withstand, but he was able to cut timber, anchor them, and build bridges that are still being used today out there on some of those ranches. And he did it through his head, just of calculations, you know.

MF: And this was a former resident of Antioch that did this?

LB: Yeah, Charlie Grant, and he must have been brilliant. I mean, he must have been really-I'm not just saying that, but he must have been brilliant to be able to build a bridge that would span the creek that might be dry most of the time, but in the rainy season when water was running down through there, especially before they built all of the dams to hold it. And then 
even today the new bridge get overflooded down there. So, a lot of those bridges had a heck of a lot of water coming through it, and for them to still be there today, and that's probably 100 years later, that's saying something, you know that? So that's the kind of information that I want people to be able to know about. Yeah, these were black people who were once slaves, got their freedom, they came out to the Antioch community, they built homes, raised their family. And when you look at all of the descendants from this community, we've got doctors, lawyers, all kinds of professional people, tons and tons of teachers, preachers-just a lot of professional people. All of us are not stupid and ignorant and unlearned. There was a lot of good stuff that came from these communities. When I look at the news today, and I heard on CNN the other day, I can't think of his name, Rick Sanchez, and he was giving the lowdown on people who had been successful who lived in the barrios and the projects and they still went on to do great things, and he went on to explain that everybody that came out of communities like that, it didn't mean all of them were stupid, in so many words that's what he was saying. They had a lot of potential. Well, we had the same thing way back. Way, way back. When our people got their freedom, we turned that knowledge into something that would help to take our families from then up to where we are now.

But you can't go into a lot of your history books or any of the stuff that was written and find the information like that. Now, there's a family in Kyle who did some extensive research on their family, and you see where a lot of them did some great things, and I think a couple of them put out some books about it, but it's about their family. I'm talking about this entire community - a lot of good things happened within that community. Everyone policed themselves, they worked together. Yeah, we had some bad things happen. But when you look at the incidents, the number of things that happened back during the day that I heard about was nothing to what you hear today throughout the city. You got people like Dr. Gerald Burnham, who is a descendant of Barry Burnham. We haven't talked much about Barry Burnham. But they named that hill after Barry Burnham. He was one of the people who brought water to all of the, most of the people in that community. He sold it for twenty-five cents a barrel. So they did a lot of things that, to me, was absolutely amazing. They didn't have a mayor and they didn't have a city council or none of that kind of stuff. It was just a little community, a handful of people working together trying to survive. And it's absolutely amazing that a fistful of people can get together, one of them had the foresight to donate enough property to build a church and a school, and they knew that they needed a place to rest after they'd gone on, so he donated a little piece of property for their cemetery so they could be interred. I think that's absolutely wonderful. And for our descendants who have moved on to greater things and didn't know anything about it, they just know of it because some of their ancestors was born or raised up out there, and they should be able to know more about it. And the tragedy is you have some who are not really interested [chuckles]. And then some of them just don't- they don't show an interest until they know about it. But if you don't have nothing available for them to see or know about, it just goes right on by them.

So that was my concern. I just wish that there was a way, and I don't know how to do it, but there should be some type of historical marker to show that that community was there. And one of my deepest disappointments was when they built a brand new school in the Antioch community and named it Elm Grove. I don't understand that.

MF: Right, I remember you mentioning that before, right. Well, we covered a lot of territory, but I did want to have one last question because I wanted to make sure that if there was something that I didn't ask you about that you think I should know, what would that be? Is there anything that I didn't ask you about?

LB: Well, not that I'm aware of. You asked me a lot of questions! [Laughter] You know, I was trying to be ready and open so that I could answer them as best I could. There is a lot of information that people that—names I didn't mention that I've covered that was a part of 
this community, and I by no means wanted to leave anybody out because my grandfather and his folks might not have been the first ones there. There were other people who started the community and worked in it whose names I'm not as familiar with that I may not have mentioned. Like I said, I by no means meant to leave them out or not give them credit. Like Mr. Burnham, Barry Burnham and his wife Emmaline, those people-I was reading one of the things there that I had saved and it talked about all these people how a lot of them, they not only spoke English, but they spoke Spanish and some dialects of Indian and all of that kind of stuff. So they had a lot going on for them that we will never know about unless it's published.

MF: Right, right. Yeah. Well, there are so many people that have been, over the years, of course, that have been associated with Antioch, and you know more about that than anybody that I've talked to, and so one of the things that's really difficult to do in a three-hour, even in three or four, even in a twelve-hour session, is to cover all of these individual folks. So that's going to be your task is to put that history together and get it out there. [Yes.] Definitely. Okay, I'm going to cut the tape off here. 


\title{
Ruth Roberta (Harper) Fears
}

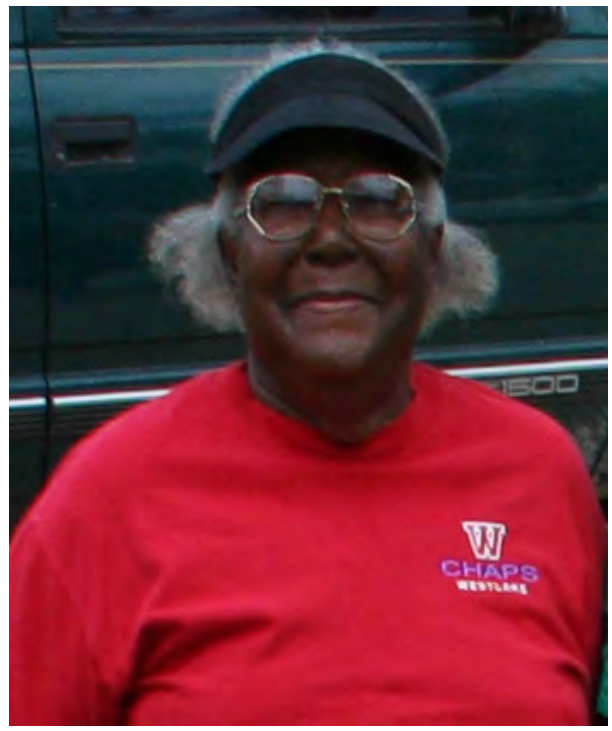

\author{
Birth Date $\quad$ 5/4/1931 \\ Residence Antioch Colony, Buda \\ Time Span 1931-1948 \\ Interviewed by: Nedra Lee \\ March 19, 2009
}

NL: $\quad$ Today is March 19, 2009. I am interviewing for the first time Mrs. Ruth Fears. This interview is taking place in the home of Mrs. Ruth Fears in Buda, Texas. This interview is part of the Oral History Program for the Ransom Williams Farmstead Project.

So why don't we actually start talking, and we can actually just begin by telling me how old you are and how long you've been living in the colony.

RF: I'm seventy-seven years old. I was born in 1931. And as far as living in the colony, I was raised here in this colony. But I left and came back, but I been back here ever since 1980 .

NL: Now, do you remember the house that you were raised in? [Yes] Can you tell me when it was built?

RF: I don't know when it was built. [Laughter] It was up the street from me. We lived in a house up there, the street up there. The house that we lived in belonged to our cousin, the Taylors. And then after we lived-I don't know how long we lived there. We used to go out and picked cotton every year. We'd go down south and pick cotton, and we'd come back and register in school. Then we'd go to school about a week, and then my father would take us out in West Texas to pull the boles then. We'd go out there and pull boles. And then we'd come back about December, and then we stayed here you know the rest of the time, that was in school the rest of the time.

NL: How many rooms did the house have, did the Taylor house have? 
RF: I think it had four bedrooms, I believe, and then a living room and dining room and kitchen, outdoors.

NL: Do you think you could actually draw the plan of the house?

RF: I doubt it. [Laughter] I was kind of small.

NL: Tell me, do you remember whose room was where, and what some of the rooms were used for?

RF: Well, I can kind of remember. It had two porches, one come up this way and one come up this way. And when you come up this step you came in through the dining room. I believe the living room was over on this side. And then from the living room was a bedroom where we girls slept. And Mom and Dad's room, they room was kind of like past the dining room, I believe, but I'm not quite sure which way they bedroom was made now. But the brothers, all the boys, they slept when you come in the front door this way, over on that side would be the room they slept in. And the kitchen was on that side from the dining room. But I can't exactly remember which way my mother and father's room were. I know we had a room over. Maybe they had theirs over on that side too, I'm not sure. [Chuckles] And then we had a fireplace in the living room. We had a big porch on the front, on this side. We had one on this side, too, as you come in. I don't remember where it's going. And that's just about all I remember. [Laughter] We had a smokehouse, outhouse, out in the back of the house. There was a well out the front, and the well is still up there.

NL: It's still up there? [Yes.] Now do you remember what the house was built of?

RF: Now, that I wouldn't know. Mostly plank I guess, something like plank wood.

NL: Now you mentioned that the toilet was outside.

RF: Yeah, we didn't have the inside toilet, no.

NL: And you said there was a smokehouse as well?

RF: Yeah. We'd hang meat up in there when they killed the hogs. They'd get bad if they didn't.

NL: Were there any other areas around the house that were used for household work or chores?

RF: No. All the chores we done was we'd clean, mop, and get all that ourselves. We had washing machines but they was just outside, you know, the roller type. [Chuckles] But chemicals, we kept in the high cabinets, they did, so the kids wouldn't get it, but that's about all I remember about the house.

NL: Did you all have a garden?

RF: Yeah, my father had a garden. Like the house was here, the garden was kind of like in back of the house toward the road up there.

NL: What'd you plant in it?

RF: Oh, we had sweet potatoes, ice potatoes, carrots, just beans, okra, onions, just about anything you know eatable that you put in a garden. We had that. My father mostly did that, kept the garden clean. And we planted corn, and watermelon, cane, sugar cane. And out from the house, we had a barn because we had cattle and you know hogs out there. And he had a-I guess you would call it a molasses—machine that would make molasses. We made molasses. 
And that's about all I can remember. We had a field out there from the garden. We had a windmill that pumped fresh water. It was out from the house, not very far.

NL: Now where'd the water come from?

RF: After the rain, I guess. I don't know how it would come. But you know, the windmill would turn-you know, you may see some of them now turning but I don't know if they got the water in them, but they would pump cold water. We had a big tank that water would go into the tank, and we'd go out hollering and get that cold water, and it was so cold. So, we used to do that. And I guess when the tank got full it had some way, it didn't just keeping going, filling up because it would run over. That's about it.

NL: Did you all have electricity in the house?

RF: No. We didn't even know what electricity was. [Laughs] That sounds funny, but that's true. We had a lamp. I don't really know what kind of lamp he called it. I think he called it a levening [?] lamp. You see these lamps now that they take fishing with them? They got that real bright, have that little mound that goes on it.

NL: Okay, it has the little hook that you kind of turn to brighten it up. Is it similar to a kerosene lamp?

RF: Something like that, but it had two little things sticking out like this, and you'd put little mounds on that, and when you set them on fire they brighten up, like a light. That's what we used. We had one of those, and it looked like you had electricity to somebody that was passing by, but it wasn't. We didn't use regular lamps for lights.

NL: But you didn't plug the lamps in, so how would the lamps-

RF: $\quad$ No they was-Martha had one sitting around here somewhere. There's one over in that corner. See that with that globe on it? [Yes] That's the kind of lights we had, kerosene lamps.

NL: Did you ever sweep your yard?

RF: Oh, yeah. We got out and swept the yard, swept the yard clean. We used the-they had yellow flowers on them. I can't think what they is, but they weeds. We'd go out and pull them and make a broom out of them, put them together, and sweep the yard with it.

NL: Who did your hair when you were young?

RF: $\quad$ My mom and my oldest sisters.

NL: How often did you all get your hair done?

RF: Well, just about every day. They'd wash it and plat it in little plats. We'd have little plats, something like what you got on your head [Chuckles]. And some of us would have long ones and others they would have three plats. She would have one here, two back here. Of course, mine was always in little bitty plats.

NL: Did you all ever use any homemade beauty products?

RF: No. We mostly bought Vaseline, and we used Vaseline like that, sometimes we used—Oh, lord. It's what you cooked with. 
NL: Lard? [Yes] Like what you'd actually fry food with?

RF: Right, uh-huh. We'd use that a lot of times. We'd grease our hair with it, and then use that sometimes grease your legs because they would get ashy in the winter.

NL: Hm. Lard. Could you press hair with the lard?

RF: $\quad$ Yeah. We used to do that, too. We'd put a little on there and then she'd press it out a little bit so it wouldn't be so nappy.

NL: Where would you actually get some of the beauty products from, besides the lard? Would you buy from a store?

RF: Yeah. It'd come from the store.

NL: Was the store nearby?

RF: Up in Buda, in the town of Buda. We had two stores up there. They had two stores at that time and a post office. It didn't have very much. Buda was very small for a long time.

NL: How would you get there?

RF: We'd walk.

NL: It wasn't far from the colony?

RF: Nm-mmm [no]. We lived right up there where that house is, nobody in it on that side, torn down. I know you can see what look like a barn or something sitting on this side. That's where we lived, and so we'd walk. Way down that road and across the creek. Or ride a horse up there sometimes.

NL: Who owned that store?

RF: Um, I don't know what was his name. Hmm, let's see if I can remember. Armbruster's, I think. Well, no, I think they owned it after the-I know the Armbrusters, I don't know if they owned it or not, but they ran the store. And they had another store that Mr. Clark would run. Clark is all I know of his name.

NL: Did they live here in the colony?

RF: No. They lived in Buda, on that side in Buda. They were white.

NL: Were they white? Were they nice to the colony residents?

RF: $\quad$ Oh, yeah. We'd go up and get stuff on credit. My father would pay on the end of the week. And we'd go to school, he allowed us to go up and get a piece of candy or something. We couldn't go up and get a whole lot of stuff. [Laughs]

NL: What other places did you shop for food or household stuff?

RF: Those stores. Unless when he went to town sometimes, he would, Austin. He would get stuff like that.

NL: Where would you get clothes from? 
RF: $\quad$ They ordered our clothes as far as I can remember when we was coming up from JC Penney's and Sear and Roebucks.

NL: Really? Now did JC Penney's have a catalog?

RF: Yeah. They had a catalog, so would Sears and Roebucks. And they used to order stuff from that.

NL: What kinds of medicines did your family keep on hand?

RF: Um, now when we were young we'd have bull metal. It grew in the field. It was green, and it had a green, round thing on it. They would take it off and cook that. It was for colds and stuff like that. But I don't remember too much medicine that they bought. They would buy turpentine, you know, and what else. Black Draw.

NL: Black jaw?

RF: $\quad$ No, Black Draw. I know I'm not saying that right, but it was a laxative. They had it in a syrup and then they had it in a powder. They would give the syrup to the little biddy, small ones and the powder to the bigger ones. That was a laxative. Ew, it was bitter.

NL: I was going to ask you was it bitter or sweet. It sounds bitter.

RF: The liquid wasn't so bad, but the powder was. We'd take it and they'd give you a spoon full of it and you'd drink water behind it. And Three Six. I don't remember what that was for, but they had three sixes, "666." You took that, I think, for cold or something like that. I forgot what it was really for. Well, they'd give us so much stuff that was homemade.

I know what we swept with: broom weed. It was broom weed that grew out in the field, and they was a yellowy bush. We'd get them and tie them around at the bottom and sweep the yard up. That's what we swept the yard with.

NL: I'd never heard of sweeping the yard until-

RF: Yeah, well we didn't have a lot of grass in the yard. It was just kind of dirt, so we'd always swept it.

NL: Tell me, what can you remember about your family tree?

RF: You mean like, I know that one thing our father didn't allow us to eat until we was all at the table. And we'd all have to be at the table, all the food on it. Everybody would sit down together and he would bless the food. It wasn't like prayer prayer. What else would he do? He'd have each-Each one of us had to pray at night. He gave each one a night to pray. That's how he learned us how to pray. Let me see what else. We went to school. We would walk to school most time but if it's rainy or cold, he'd put us in the wagon and take us down to the school. I'm sure them others done told you that.

NL: No, actually, I didn't hear that before. In fact, can you actually tell me a little bit more about your father, where he came from?

RF: Now I don't know exactly where my father comes from, or too much about him or too much about a lot of his people. And my mother's, either. Some of them I did, but some of them was dead when we was old enough to know anything about them. But his mother lived down past here, right next to there. She lived over there, and I think that's where they was raised 
up there, over there. He went to church and Sunday school, like everybody else. He was a deacon in the church, the Sunday school superintendent. That's about all I think I remember. Church, he built that, and that church he had us living there now.

NL: Did you say living?

RF: Yeah. [Laughter] I used to say when I got grown I wasn't going to nobody's church.

NL: Did you stick to that?

RF: No. [Laughter] Well, for a while I did, you know, when you get to be a teenager where you can get on your own. I kind of didn't stick to it. But there come a day I realized where I belong, so I turned around.

NL: So you said your father-tell me your father's name?

RF: $\quad$ George Aaron Harper.

NL: George Aaron Harper. Now his mom and dad actually lived here in the colony?

RF: $\quad$ Yeah, they did, as far as I know from him, you know, people say. But I never did know his daddy. I knew his mother, and I didn't never know his grandmother.

NL: Do you remember their names?

RF: His mother was named Ella Nancy Harper. And I'm not sure what his grandmother's name was. They called her Adeline. Now, I don't know if that was her name or just the name they called her. But I didn't know her, either. She died before we was born.

NL: Did he ever tell you how they got here to the colony?

RF: No, not me. Might of told some of the older ones but I never did know how they got here, so I don't know if they was born out here or what. Only thing they told us about the colony was back when the slavery time was, a man come through and sold all the black people and all the-what you keep calling them? I guess low-class people, people that didn't have any money, sold them land. Then mostly in here was just plain black, this whole colony. On that bridge, you come across that bridge, and come up in here, once you keep all the way around that road, go all the way around and come right back around and come right down that same road, well, we was mostly all black in here. That's why they call it the black colony.

NL: Did they ever tell you where the name Antioch came from?

RF: Antioch came, I think, from the first church. I can't even think of the man's name now. Anyway, this was a guy, they wouldn't let him go to the white churches, so he stretched out and got a church-I can't think of what his name is. Anyway, that's where Antioch started from, from this guy that made this church. They wouldn't let him in the church. They put him out of his church when he went in it. Now that's what I heard. Now I don't really know that to be true.

NL: That's interesting. Do you know where the first church was located?

RF: No. I think it's up the country somewhere. I don't think it's nowhere around here. But we had a church, we built a church down here, and it was a church and a school. We had a two-story school and a church, and that's when they named it Antioch. That's why Antioch comes from 
here in the colony, because of that. But I think Antioch started from the first church, in the Bible, somewhere. I think I seen it, read it, heard them talk about it.

NL: What do you remember about your mom? Tell me about her.

RF: [Chuckles] She was a nice lady. She kept all the kids, kept everybody's child [chuckles]. And she worked uptown for the white ladies ironing, cleaning they house. I know she done that. And she was just a sweet person. She'd talk to you, tell you what you should do and what you shouldn't do. And she'd mean that, and if you didn't, you'd get tore up. And that they believed in.

NL: $\quad$ They believed it?

RF: $\quad$ She used to get the huckleberry tree, they call it, switches on the ends of it. She used to get those switches to get me and my sister down on our far end. I think we was about the baddest two around, getting into stuff.

NL: You and which sister were the baddest?

RF: $\quad$ Emily, the one that lives down on the end, just ahead of me. She would come in the room, you know, she'd get us when we'd go to bed. We used to go get the switches, and we'd see them when she had them, we'd get them and tear them up, so we probably wasn't going to get no whooping, but she would put them where we could get them on purpose. She'd have another set. Soon as we'd get in the beds, said our prayers and get in that bed, she'd come in there and just tear us up. [Laughter] She didn't whoop us every day, but she'd always tell you, "I'm going to get you because you didn't do what I told you." But she might not get you right then. It might be a week before she got to you, but when she get you for something you done, she'd tear you all the way back. She going to say, "You did this Monday. I told you I was going to get you, didn't I."

NL: Do you remember anything that you got a whipping for?

RF: Let's see [laughs]. I don't know. I did so much when I was little. [Laughter] By not minding, for one thing. She'd tell us not to go somewhere and we'd go any how, then we'd get back. [Chuckles] I don't remember the last thing I got a whooping for. I know I got a whooping one time. She was getting me for something, and she had my head down between her legs, and she was tearing my back end up, and I bit her. What'd I do that for? I thought she was going to kill me. [Laughs] But she didn't whoop us too much. But she didn't do the whooping until you did something you really didn't have no business, kind of serious stuff you really shouldn't do, and she'd tell Daddy about it. He would line us all up out there and get that switch and that lamp. When he got off from work, it'd be dead dark, and he'd start whooping, all the way down the line. The person would get his licks and pass the light back to the next one, and get all twelve of us. So we'd never tell on one another, so he'd get everybody. You know he'd done got you. But he didn't whoop us too often, either. They mostly talked to us and tried to teach us what was right and wrong without a whole lot of whooping. But you would get it. [Laughter]

And, I don't know. I know we raised some turkeys. And we had chickens and hogs, cows, pigs. We had all that kind of stuff. And we had to milk the cows, feed the hogs and the chickens and stuff.

NL: Did you have any other chores that you were supposed to do? 
RF: Well, we'd bring in the wood for the night because they had a fireplace, and they may had one of them potbelly heaters that you keep. We'd have to bring the wood in. And then we, like I said, had to milk the cows, feed the cows, because he worked in the field. And he would sell milk, butter, eggs, all that, go to town and do that. So we did most of the chores out here. He did, too, sometimes. He would milk the cows, too, because I remember when I was small he used to milk the cows and I would waddle out to the barns and milk the cows in the morning, and I had a tin cup, we had tin cups, like we ate out of little tin plates, and I'd go out there and he'd milk me some milk into the cup and I'd drink that. But I don't remember too much more. I mean, about that.

NL: What kind of games did you play as a child?

RF: Oh, we played ball, and did marbles, shoot marbles. And kind of played around with the doodle bugs in the ground-

NL: What kind of bugs?

RF: $\quad$ Doodle bugs, they called them. They'd scoot backwards. They'd be down in the ground and they made a little circle like that, and the dirt would be real soft, and we'd get a stick and stir in there, tell them to, "C'mon." They'd scoot out backwards. We'd catch them, play with them, and stuff like that.

NL: Do you remember any toys that you or any of the other children owned?

RF: We had some little red wagons we used to have. And then we had dolls, us girls. The boys they would get little cars and stuff like that that boys played with. I don't know what all.

NL: Did you all ever share toys? Like would the girls ever play with the cars?

RF: Oh, we never bothered the boys' cars too much. We didn't. I don't think any of them ever played with our dolls, either, that I remember. We was taught boys don't play with girls' toys and girls don't play with boys. And, my father used to-Of course, he'd go shopping, I think in town when he'd be over there selling that wood, he would buy apples, bananas and things by the bushel, and once in awhile he'd bring us a big thing of donuts [chuckles]. And we'd buy light breakfast [?] sometimes for Sunday. Then my mother cooked all the bread that we ever ate, except on Sundays. They'd bring up four or five loaves of bread to eat among us. That was like a treat.

NL: Now, growing up as a teenager, how did your role within the family and the community change?

RF: Well, I got to go more places than I did when I was smaller. The bigger kids, they was up big enough to be courting and sometimes they'd let us go and sometimes they wouldn't take us to town to the show.

NL: Now you would court at the movies, or-?

RF: No. At that time Mama wasn't quite old enough for that, but they would take us to the movie, or sometimes they'd tell me, "Y'all take the kids to the show." They'd take us to the movie and then they'd disappear, and then they did tell it.

NL: So how old would you have to be to start courting?

RF: I think we had to be eighteen or older. 
NL: Really?

RF: $\quad$ For real. And he'd let your boyfriend come out and they would sit on the porch, we would usually sit on this porch. But he'd come out. He had him a chair he had there. He'd be sitting there with the paper. Or, he'd be sitting there reading his Bible. We know what time-when it be getting close to time they need to be getting out of there, he'd cough, you know. We'd know to tell them that you'd better get going. We'd sit out there and hold hands. That's about all you could do. [Laughter]

NL: Did he have any other rules when it came to courting or anything?

RF: He didn't allow us to wear shorts. If we wore them, they had to be down by your knees and they had to be fitting right around your knees kind of tight, where nobody could see up them. He was a strict father.

NL: He was?

RF: Yeah, but a good father.

NL: Was he strict on the boys, too?

RF: Yeah. No, the boys got to go a little more than the girls did. They got to go places when they got bigger. They could even come in a little later than us girls. I don't know why the boys get all the breaks. They can get in just as much trouble as the girls could.

NL: Now what did the boys do for fun as teenagers?

RF: $\quad$ They played ball. We used to play ball every Sunday and they'd sit out and watch us, even some of the people from the community would come and watch us play ball, and things like that. We'd make up our own little play things sometimes, play hide and go seek. Somebody would count and you'd run and hide, and they'd have to find you before you beat them back to the base. It was a wonderful life.

NL: It sounds like it. Did you go to the colony school?

RF: Uh-huh, right down under there under the hill where they're building that church, there's a brick school there, and that's where we went to school at. Of course, we went to school, too, up there at this, well, I'll tell you where we had that church and big old school until that storm one tore it down.

NL: Now the one back there was the first church?

RF: $\quad$ The first church and school.

NL: And it was two separate buildings?

RF: Yeah, like they're together, like the church was in where that room is and school was here. And it's two stories.

NL: So the school was two stories, the first one. Was the church two stories as well?

RF: Nm-mmm [no], just a plain church. I think Minnie has a picture of that over there, but I don't. She have pictures of the school, some of the kids sitting on the porch and stuff like that. 
NL: And you said the school burned down? The first school.

RF: No, I don't think it burnt down. I think they kind of like had a storm, or didn't—no I don't want to say that on TV. Because probably all the windows come up broken, and we just had to quit having school up there. Then they built the rock school down there under the hill there.

NL: The rock school. Why did they call it the rock school?

RF: Well they didn't call it a rock school. It was built out of rock. They built it, and then had that rock going around. Like this man putting this stuff around house right up here from us. It was like that.

NL: Where'd they get the rocks from?

RF: $\quad$ Mm-mm-mm [I don't know]. I guess from different places. They've got gravel pits around here and stuff, so that's the way they build it.

NL: $\quad$ Was it pretty?

RF: $\quad$ Oh, yeah, it was a beautiful school. And we had a kitchen in it, and that's where they start learning us how to cook, so many cook like maybe they'd be our time, we'd cook breakfast for kids in school like that. The world has changed. But our school didn't go no farther than the seventh grade, but then you had to either go to Austin School or what. But finally they start letting them go up there in Buda because nobody didn't go to that school in Buda but white folks. So then they started letting them when they graduated, a few of them went up there from here. Daddy sent my oldest two sisters to town to stay with my uncle. They went over there and went to school. When we passed out of this school down here, we didn't get to school nowhere else.

NL: $\quad$ So you only did the colony school?

RF: $\quad$ Mm-hmm [yes]. The two twins did. When they got out, he let them go over there and stay because the bigger girls then was leaving home, you know, and everything, so they went over there and stayed with him and went to school. They didn't finish over there. They went to school, but at that time Mom and them had moved. My daddy and them had went to Arizona. He was a contractor on cotton fields. They had moved up there, and so the kids up there and Martha [***and Minnie, the] twins, they stayed here and went to school with the bigger sisters. And then they decided they wanted to go to Phoenix where Daddy and Mama was, so they went up there, and that's where they finished school at, up there.

NL: Now what about you? Where did you go?

RF: Didn't go nowhere. This school only went to the eighth grade. When you got in the eighth grade, you go to another school. I only went to the seventh. Well, I passed into the seventh but I didn't get to-

NL: Did you go to work immediately?

RF: No-in the fields. I didn't know what it was to go to work. Sometimes we'd go help our mother because she washed for the white folks, and we'd go help her wash and clean up.

NL: Do you remember any of your teachers from the colony school? 
RF: Yeah. One of them was named-I don't know what her first name was now, but her last name was Callahan. She'd come from down in San Marcos, and then, because she's dead now. And then we had one, Ms. Robin, Robbie Bolls. I think she was the first one that we had. She was from Seguin. And then we had, I think her name was Orie Lee. She come out of Austin. Geneva, Geneva was her name. She was a-What was she? Bunton. She was a Bunton that taught us down there, too. And then we had a man teacher, but I can't think of-I was too little to remember what his name was. I can't remember. Bet you never thought they'd have a to man teach us at that school.

NL: What did he teach?

RF: He teached, I think we was like in third and fourth grade. And he did something like that. He would teach us, too. They had two classrooms. The oldest ones would be in one room and the small ones would be in another one.

NL: So it was two classrooms in the school? [Yes] How many students were in the school?

RF: $\quad$ Shoot, I can't remember how many. It was quite a few of us, but I'm not sure how many it was. I think most of the bigger people, all of us that lived in the colony went mostly to the school up there. And kind of graduated from there.

NL: Mrs. Washington was telling me about, she said it was something called the "Prair[ie] and Goforth." Have you ever heard of that?

RF: A prayer?

NL: The Prair[ie] and Goforth. I think she said there were communities.

RF: Goforth Community?

NL: She said that students sometimes would come-

RF: Oh, yeah. The Prair[ie]. They called it on the Prair[ie].

NL: Now what's on the Prair[ie]?

RF: It's a kind a like a prairie, not a whole bunch of trees, just like it, so they'd called it the prairie. And they had a school and church out there, too. They just got a church there now though, school is gone from on there. And they would participate with us because there, I don't know if they just didn't have that many preachers or what, but I know they had a preacher, he would come preach for us like on second Sunday. First Sunday I think we went to the Prair[ie]. That's what she was talking about. It was church. Then like the second Sunday they would come. The preacher wanted a whole bunch of people in church, so the church was kind of different Sunday at each.

NL: Now what about Goforth? What is Goforth?

RF: Goforth is the same thing out there. I think they named it, but I just got kind of fuzzy, like they did this over here.

[Note: "Goforth" is the road that leads out to the Prairie; the road still exists.]

NL: Who was your favorite teacher at school? 
RF: Mrs. Callahan.

NL: Why?

RF: I don't know. [Chuckles] She just was, just seemed like we got away with a lot, up with her.

NL: What did she teach?

RF: Well she just teach straight class, English, math, the regular classes. Reading.

NL: Now, who named you?

RF: My mother named me Roberta. My father named me Ruth. He named all of us out of the Bible.

NL: Now, did he call you Ruth and she called you Roberta?

RF: No. They named us-well, the way you did it is Ruth Roberta. I just put a "R" a lot of times, but I don't use it too often.

NL: And, do you know who delivered you?

RF: No. I was too little to know that. I think they stayed in Austin, that I was born in Austin. Me and my sister down there, me and Ms. Hill. We was born in Austin, they said. And I think then they moved out here in the country.

NL: Do you have any children?

RF: $\quad$ No. I didn't birth any child, but I got a daughter.

NL: So who taught you how to care for her?

RF: Well, I just learnt the way my mom did us, you know and all. I adopted her when she was nine months old out in Arizona, and then I raised her there. She's thirty-two, I think, thirtytwo or thirty-three. I'm always getting her too old or too young, she always tells me. But she had a birthday on the sixteenth.

NL: Of this month?

RF: Uh-huh [yes].

NL: Did anyone help you when you were raising her?

RF: $\quad$ No. I kind of raised her by myself. I didn't even have a husband at that time. Well, I had had one, but we had done and got a divorce. And I raised her by myself.

NL: Now, how did you meet your spouse?

RF: Hm. I'm not sure. I don't think I want to talk about that. Everybody might think I'm a bad girl. [Laughter]

NL: Well, can you tell us how long you all were married? 
RF: I think, I'm not sure, we got married in 1965 or ' 64 , somewhere along there. And when did we get a divorce? It was in the seventies when we got a divorce, so I'm not sure how many years that is, but.

NL: It's about a little bit more than ten. And you were only married once?

RF: Legally. [Laughter]

NL: $\quad$ So tell me, did you court them? Was there a courtship beforehand?

RF: Yeah, I guess there was. We went out.

NL: You're pretty much an adult by that point.

RF: Yeah. [Laughter]

NL: I'm curious to know, when did you first leave the colony, outside of when you were just with your parents?

RF: I was probably about sixteen or seventeen, I think. Me and my sister down there ran off. [Phone rings; paused.]

NL: $\quad$ So you were telling me when you first left Antioch, when you were sixteen or seventeen.

RF: Yeah, I was about seventeen, I think. I think she was eighteen or nineteen, somewhere along in there. She's older than me, I'm not sure. But we just decided to run away from home.

NL: Did you tell anybody?

RF: $\quad$ Nobody knew we was gone but my mother. Didn't tell nobody but her. We told my mother about it. She just, you know-She didn't try to stop us or anything. Of course, she gave us a little change. We had some friend-girls that lived over there, and we took off over there to they house. And just kind of got tired of chopping cotton, corn, and all that stuff. You know, you do stuff like that you get tired, so you think you grown, so you take off.

NL: Now, how long were you gone for?

RF: I never did come back home.

NL: Really?

RF: $\quad$ But the one down here did. I went to-We went to Austin and stayed with these girls and got a job working in different places, working for some people and stuff, and they had a rental house-well, I guess you'd call it a rent house. You know, well, I don't know if you know, I don't how old you are. They used to have houses like this, big house, but they'd have a long hall going down like that, and there'd be rooms on that side and on this side, and they had a place for the bathroom and kitchen, kind of like at the end, and everybody used the kitchen, and used the bathroom, which you had to keep it clean. If you used it, you kept it clean, cooked, you do that-keep it clean. And we rented us a room there, she and I did. And didn't cost us but $\$ 3$ a month. [Chuckles] It was real cheap.

NL: Now, was this you and Emily? 
RF: $\quad$ Mm-hmm [yes], me and Emily. And we stayed for a long time. I mean, I stayed there and didn't come back. I stayed. But being young and all, she was running around, and she got pregnant, so she come back home. But I didn't. I was determined not to come back. I was kind of a stubborn girl and evil-minded and didn't want to do it.

NL: Now do you remember your first job when you were-?

RF: $\quad$ Yeah. My first job when we got over there was, my older sister, Marian. She was living over there, and she had a boyfriend that he had been working for some white folks out in Enfield, you called it, and he did the yards and stuff. And he asked me one day, "You know how clean a house?" and I told him, "Yeah. I was brought up cleaning the house." So he took me out there and I worked there and you didn't make very much, like $\$ 15$ or something like it. It wasn't very much then. They didn't pay you $\$ 75$ an hour. You may not work but an hour or two hours, you know, then, and so we didn't have to pay them but $\$ 300$ for the room. And, so you kind of made that. At night I worked in a bar, you know, serving. I was old enough to do that, waitress. I worked there as a waitress.

NL: Do you remember the name of the bar?

RF: $\quad$ Ari Littlefield used to run that bar. I don't know if you know his last name, though. His last name is Littlefield, I mean, Ari Littlefield. That's right, that's what his name was. So, we just ran about like that and made it.

NL: Do you remember, were there any other jobs? Did you have a particular job that you just really liked, that you remember the most?

RF: After I got through awhile, I went around and just worked for different people, like day jobs, just doing such day jobs with people. And then I got a job working in a laundry, we worked in a laundry, me and my sister, Marian, the oldest one. We used to work in a laundry folding sheets and getting them out like that, worked there for a long time. And, then I had moved with my cousin, the cousin I had over there in Austin, which we both had, and worked for a policemen that had five girls. I worked for them for a long time. I think after I worked for them, no, I turned around and worked for some more people. I can't think what their last name was. He had two boys and a girl. So I worked for them. And later, just odd and end jobs and around about, never had nothing real steady. I worked doing all the time, no more than housing, you know. Then I started working-Later I worked at the Travis State School. But before Travis State School, where did I work at? Oh, I went to Arizona. That's what it was. After I had worked there, I turned around and went to Arizona. But I never did just come back here. I'd go to Arizona to visit, and I liked it, and then I moved out there for a while. But then before that time, I didn't have to work.

NL: Now what did you like about Arizona?

RF: Well, my family was all out there then, except me and Mrs. Washington. We had us a house here in Austin. And, after my so-called husband got killed [Chuckles], well, he was, commonlaw, but anyways, after he got killed, I went to Arizona and she stayed here. And, I kind of liked it out there. It wasn't cold, always warm. You'd wear shorts all the time. No rain and all that there stuff. So I kind of liked it. And then my mom and dad and my other sisters was out there, so then I decided I'd go out there and stay. So but when he got done, he got killed, I went back out there to stay. But I couldn't get her to go right then. But she came later. So we all was out there at one time or another. So then Martha, owned her own-another one that once she set her mind to do something, she'd do it. [Laughter] She'd killed me if she hear that. But she came down here with a friend up there that she had up there, a friend-girl, and they come down here and got a job and worked and went on. And then she got sick. 
They always said twins can feel when another is sick, so she came back up there when she found out she was sick. And Minnie wanted to come down here with her, so she come down here. And then kept talking to Mama and Daddy about coming down here. And so this place, he had bought it for us, you know, way back. So they come down here and started just lived down here in Buda. They bought a trailer house, both of them, and got on this little piece of land here. And that's how it got to be two in the front, so they come in and did all of that. And then after they was here, then they wanted Mama and Daddy to come. So they kept on, kept on, and them twins was his babies. He didn't mistreat nobody from him, but them was just his babies. So he decided he was coming back down here with his babies. Everybody else was grown and had homes out there. So he came back down, and after he came back down, then what happened after that? I think I was the next one that came here. I came later. I came down here and stayed awhile and got caught down here in snow, and stayed here for awhile, me and my daughter stayed down for a good while down here. Then we went back to Arizona and carried them back up to Arizona with us because it was kind of cold, so Mom and Daddy went back to visit up there with us until it warmed up down this way. And then everybody just start to following after Daddy got down here. He just told him, he said, "If you want to come live," he didn't pick no spot for nobody; everybody picked their own spot. So then Stubby-we called him Stubby, Elijah, who stayed on the other side of us, Ms. Washingtonhe had came down here to visit, and he decided he wanted to pick him a spot. He wanted the spot down there where I was, but Daddy always said each one picked their own spot, so I had to ask for that spot when he first told us we'd picked our spot. I said, "Daddy, I want that on that end." You know. So he called me one day, and he told me, he said, "Ruthie, if you want that spot you want, you got to come on down here, because I said first come, first serve. You know, where you want to go? Stubby is wanting to get over there." I told him, "Daddy, no you don't." That's when I come down there and stayed awhile, me and my daughter. And we cleaned the spot off down there and everything, and he helped me to get a little trailer to put on there. And then I went back to Arizona and stayed awhile and got all my business straight there. Then I moved down here. Then they just start coming one by one.

NL: And you all stayed?

RF: All of them got here except one, and that's my brother that just passed away. He didn't leave-well, my oldest brother never did get back down here, either.

NL: Who was your oldest brother?

RF: George. Junior. He never did get back down here, either. And he had a place out there, but he never did come back. He always said he was coming back, but he never made it, and same way with Joshua. He had a family out there.

NL: In Arizona?

RF: Uh-huh [yes]. He come down here, was intending to move back here because that's his place down there on that side over there where all that stuff is over there. And he never did make it down here. So he never got back down here, but they both got a place over there. George's place is right next to me down there where that brown house there. And then Joshua was next to George where that little trailer in front of my house up there, where that boy got them dogs down there. That's his son. And that was his plot there. And then on up past him to the next spot that ain't got nothing, there is my brother Ollie Joe. He lives in Austin, on Monroe. He moved to Arizona, too, and he stayed there for a long time. He had a family out there, and finally decided to come home, and two of his kids-Well, he got two families. He got one in California. But the one that's in Phoenix followed him down here, and he bought a trailer and put it on there. He got married to Francis Smith, and so he lived in Austin, and his kids stayed in the house. And then they finally decided they didn't want the country no 
more, so they left and went back to Phoenix. And he stayed over there with her. He just had a house that he rented out for awhile. Then he decided he was going to go, I think after he found out he was sick, he wanted to go where his kids was. He left and went there and got rid of this trailer, and it still got that empty spot in between. But he lives over in Austin.

NL: $\quad$ So if I drew a map, so this would be Black Colony Road right here, and then from Black Colony Road you turn into Harper's Village. [Draws map]

RF: Yeah. Harper Village come right down between that two lines.

NL: Like right there. And then so on this side, let's see, actually I would have to turn it around. So on this side would be-

RF: Minnie. We always call her Mary.

NL: $\quad$ So she's Minnie Mary?

RF: Yeah.

NL: $\quad$ Okay. And then here's-

RF: Winnie Moyer. I mean Winnie Martha.

NL: And then the next person-

RF: To Minnie is Samuel Leslie, the one that stay right next to her on that side.

NL: $\quad$ And they call him Les?

RF: We call him Leslie. We call him Les-Boy. But his name is Samuel. Yeah, he got Leslie in it, Samuel Leslie Willie Harper. He don't use no Samuel.

NL: $\quad$ Does he not like it?

RF: No. [Laughter] Leslie came after Ms. Washington's boyfriend, she was going with, she wanted him named after him, so she give him that name. Her father named him Samuel because he knew a whole lot about the Bible [?]. And then Mrs. Rimes was married to a guy called Willie, so she give him her name. So that's why he got so many names. And next to Winnie is Mrs. Rimes.

NL: Now that's Mrs. Eunice?

RF: $\quad$ Yeah, Eunice Rimes.

NL: And then coming back up here-

RF: Let's see. Leslie, Ollie Joe-Moses, rather. He's the one that lives in Austin.

NL: Now you said his trailer is still there?

RF: Oh, no, he got rid of his trailer. It's an empty lot between there.

NL: And he's in Austin? 
RF: Uh-huh [yes].

NL: $\quad$ Now does he come and visit a lot?

RF: Yeah, he come out here a lot. He come out here and get water because say he doesn't like that water in Austin.

NL: $\quad$ Yeah, to get fresh water. And then next to-

RF: Next to Minnie is Mrs. Washington, Marian.

NL: $\quad$ Next to Minnie or Mrs-

RF: No, next to Mr.-Eunice, next to Eunice is Marian. Next to Marian, Leslie, Ollie. Then next to Ollie is Joshua.

NL: And he's the one that came and went back?

RF: No, he didn't come. He's the one that never got here, that passed away that we went to December to his funeral.

NL: But that was his plot there that he stopped there?

RF: Yeah, that's his plot. Yeah, he had that special for his daughter. He didn't come back, but he wanted to make sure she had somewhere to live.

NL: Now does she come back very often?

RF: $\quad$ She stayed here for a long time until she got picked up. She was on that drugs. She should be getting out pretty soon.

NL: Do you think she'll come back here?

RF: I'm sure she will if she knows that home belong to her. Just ain't in her name. They asked him why he didn't it put it in her name because he told her, "You know how she is. She soon sell it." He wanted to make sure she had a place to live.

NL: $\quad$ To keep it in the family?

RF: Right.

NL: $\quad$ And then next to-

RF: $\quad$ Let me see, Martha, Winnie-I get confused trying to call everyone by their real name. [Laughter] Eunice, Marian, and then Elijah.

NL: $\quad$ And he's next to?

RF: Next to Marian.

NL: I put Washington, but he's a Harper. It was Joshua who passed and George who passed.

RF: Uh-huh [yes]. 
NL: $\quad$ And then on the other side-

RF: $\quad$ Let me go down and see. Mary, Les, Ollie, and Joshua. On the other side of Elijah is Mrs. Hill.

NL: Now who's that?

RF: Emily.

NL: So she's way down.

RF: Yeah, she's down there by me. I never would have thought she'd had got out of there. But I think because all of us was already down there before she got there.

NL: Now are you right next to her?

RF: Nm-mmm [no]. I'm on this other side. Let's see who you got on there. Mary, Les, Ollie, Joshua, George come after Joshua. That's the other one that passed away.

NL: And his is just a plot, too.

RF: Mm-hmm [yes]. He don't have no trailer on it, neither. Then on the other side of Ms. Hill is her son, my nephew.

NL: Now he has his own separate plot, your nephew? [Yes] How did he do that?

RF: My father raised him. That's Mrs. Hill's son. And by him being his grandson, he raised him because he called them Mama and Daddy. That's why he don't call us auntie, he just calls us by our names. His name is LeeDell.

NL: Now wait a minute-this is LeeDell's plot? [Yes] I didn't know that LeeDell actually—the one who's in Arizona? [Yes] Okay, I didn't know LeeDell had his own spot back here. So he has two spots, then?

RF: Yeah. He bought that down there. That was his daddy and him's land down there where he bought down there.

NL: So he's right next to his mom?

RF: Yeah. His grandfather gave him that.

NL: Is this where he stays when he comes down?

RF: No, he hasn't been because there's nothing on it. It's across from me, too.

NL: And so your father left a piece to him?

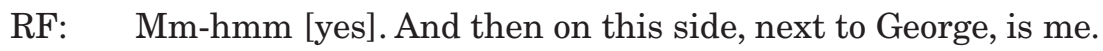

NL: $\quad$ So you and Emily and LeeDell are all the way at the end.

RF: Yeah. And George would've been there, right about there, if he had lived.

NL: Now where did your parents have their place? Where were their-? 
RF: Nm-mmm [no]. They stayed with Winnie. That's how come this thing is so big.

NL: Wait a minute, Winnie or Minnie?

RF: Winnie.

NL: $\quad$ On this side then?

RF: $\quad$ Yes. She came down here. And see, this part right here sitting here is a trailer. All of that and all of that back there and back there she built onto it. That's why she got such a big house.

NL: And this is Old Black Colony Road. Did your father ask that the road be named after the family?

RF: Uh, yes. After so many of us got down here, they thought-they wanted to name it the Harper Ponderosa, but [chuckles] then they changed it and decided they'd name it Harper Village.

NL: Now how far was the Taylor-you said the Taylor farm?

RF: The Taylors lived right up there on that side up there, up the road. If you went that way, they on the left side.

NL: Okay, so actually further up, maybe back here?

RF: Yeah. Going towards Buda, that's where they lived at.

NL: So do you remember what year your father purchased this land for you all?

RF: Oh, I don't know exactly what year it was. Mrs. Washington can tell you that because she made the last one up there, she kept her taxes up on it. I'm not sure when it was. I think was along about maybe about in my twenties.

NL: But land was very important to your father?

RF: Yeah. He bought it. Well, it belonged to a cousin of him. I don't know if it was him or-It belonged to a cousin. Anyway, he had that whole ten acres. He had ten here and ten up there where them houses built right there. And he sold him this ten. He tried to get him to sell him that ten, but the kids-you know, when you've got kids and things-so he never did sell that to him. He sold this ten part here. And that's how come that-otherwise we would have had the whole thing.

NL: Can you tell me what parts of the community bring back memories for you?

RF: Yeah, when I see up there where when we pass, I think about that house, how much fun we had there. You know. And picked cotton down here in this field.

NL: Before it became the Ponderosa? [Laughter]

RF: $\quad$ Yeah. Then, as you was saying about me, when I told you I adopted my daughter at seven months old, then I moved back down here, and when I did, I raised two nieces and a nephew. I raised them. The oldest girl was, I think she was six because she went to school, first went to school when she got here. And the little boy was three when I got him. And the baby was seven months old. And so I raised them in there. 


\section{Moses Ollie Joe Harper, Sr.}

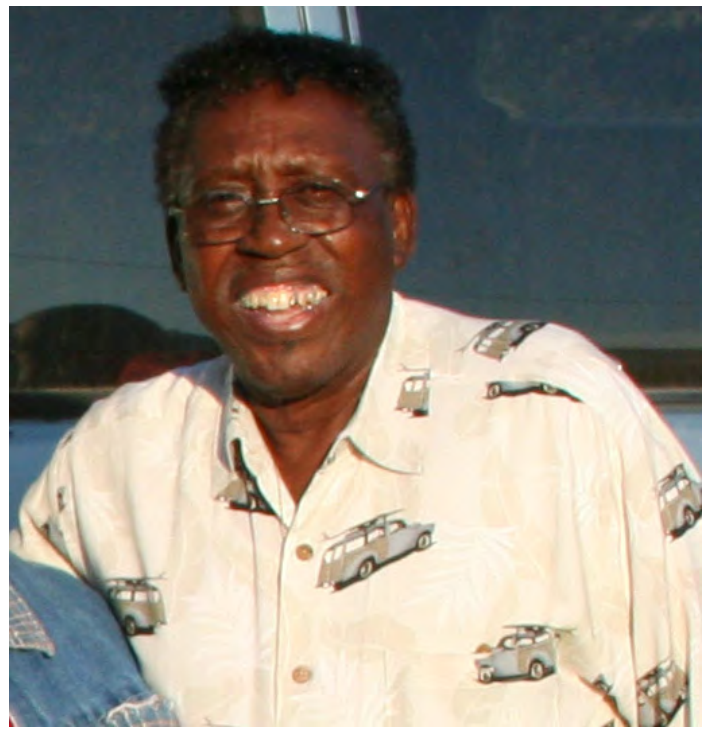

$\begin{array}{ll}\text { Birth Date } & 7 / 26 / 1943 \\ \text { Residence } & \text { Antioch Colony, Buda } \\ \text { Time Span } & \text { 1943-1955 }\end{array}$

Interviewed by: Maria Franklin

March 30, 2009

MF: This is Maria Franklin. Today is March 30, 2009. I'm interviewing for the first time Mr. Moses Ollie Joe Harper, Sr. This interview is taking place in the home of Mr. Harper in Austin, Texas. This interview is part of the Oral History Program for the Ransom Williams Farmstead Project.

Okay, Mr. Harper, so I had you start off with trying to draw a map of what you remember of growing up in Buda and Mr. Taylor's home, a number of your sisters of course recall that you lived on Mr. Taylor's property in the house that he had built. They weren't sure of the date, but they recall that it was a wooden house with a number of rooms and a number of outbuildings outside, and so forth. So what you've got here, is this the house here, then?

MH: No, that's where all the cows and all the calves was staying out in there. We had like a big flat, like a big flat out there. This is where all the calves, we kept the calves at night.

MF: Now is this fenced off here?

MH: Yeah, this is where all the calves is, and this here is the hay barn back there, where the hay barn at. And this here is a-this the house, that's the smokehouse. Yeah. And this is where she had a washing, wash stuff over here. This is a well out here. And this is over here, is where he had his syrup mill at, where he made syrup. 
MF: And so what would have been out there at the syrup mill?

MH: They had a lot of troughs across it, like that.

MF: Troughs? [Yeah.] And what were those used for?

MH: Each one of them had a type of syrup. Yeah, see he made different types of syrup. Yeah, see we raised sugarcane, yeah, we raised sugarcane, and we cut it every year, and he had a mill that he put that cane in and the juices squeeze out, and they turn it into syrup.

MF: Do you remember, so he would have to boil it?

MH: Yeah, he boiled. He had a fire all the way down that thing. And each one of them troughs is a different type of syrup. He got white syrup, dark syrup, brown syrup-all kind of colors syrup.

MF: So each trough had syrup-

MH: Yeah, had a different color syrup.

MF: So these were metal troughs then? [Yeah, yeah.] And then you had a fire underneath? [Yeah.] Okay, and what did you use to start the fire? I mean, was it just wood-burning?

MH: I don't know, he did it. He just, he lit everything around there. He knew how to do it. He set it afire, and when it get hot, and it start a bubbling and boiling, and that's when you making syrup.

MF: And who did he learn how to do this from?

MH: Lord, I don't know. I don't know where my father learned a lot of that. He learned a lot. And see he had his, he had his own meat grinders, where he'd take meat and grind it up into sausage and stuff like that. He had all that. He had a big smokehouse where he hung his meat up out there. It would cure for so long, and had a nice smoke, smoke smell to it. But he had a barn that he hung all his meat in, and then he had a machine that made-We milked a lot of cows, and he had his own milk and he made his own butter and everything. And he had a separator, that we call a separator that divided the sweet milk from the cream. He had a machine to do all that. I mean, I don't know how he come up with it, but he had it. And he would make, he was selling butter and eggs and he was selling everything he made in the country. That's how we made our living, he raised a lot of stuff on that farm, and he would take it to town and sell it, and that's how he would make money. And he sold wood, he was a woodmen out in the world.

MF: $\quad$ He sold wood?

MH: Yeah, yeah. He had a big saw that he cut wood. And we go up to Driftwood, west of Black Colony, and we would cut wood up in the mountains up there. And he would bring it back down to the farm, and he would stack it up, he would do that for a week or two, and then in a week he'll cut it all up, and then he'll sell it.

MF: So this was for firewood, then?

MH: Yeah. He would sell wood to the city. And yeah, he had it all in the machine, and he bailed his own hay. We picked our own corn-we would pick corn every year. We would do our cane every year, we would-Everything that we raised on the farm, we did it every year. 
MF: Now did you grow that corn and cane?

MH: We growed corn and all that, we had all that.

MF: Was that on your own property, or was that on Mr. Taylor's property?

MH: That was Mr. Taylor's property. Well, we had some on our property, too. We had some, he had some down across the street. He had a watermelon field. He had a corn field, cotton field, yeah, he had a cotton field, he had-He had some of everything, and he would, we would gather that up, and he would sell it. And that's how we survived in the country.

MF: So here, then, was where the syrup mill was?

MH: Yeah, out here, and this is the tree that the road go down by.

MF: So this is, is this old Black Colony Road then?

MH: Yeah, that's the-yeah, yeah, yeah. This is the house right here.

MF: Okay, now I'm going to ask you to draw the house a little bit bigger, so we can get an idea of the house.

MH: It was a nice-sized house. It was a nice old house.

MF: Hold on, I'm going to give you another sheet of paper here for that. Okay, so, if you drew the house as a big square, could you tell me-

MH: Okay, the house is here, and then this is the front. That's the front of the house, out here. We had a porch on there, out here. A porch ran across here. And we had a room-well the kitchen was back in here, in the back of the house. We had a room here, we had a room here, and a room here.

MF: One-story house, right?

MH: Yeah. Had a room over here. We had rooms all over the place.

MF: Those were bedrooms then?

MH: Yeah, they were the bedrooms.

MF: How many bedrooms do you remember in the house?

MH: It was about six, six or seven.

MF: Six or seven bedrooms. And this is the kitchen over here?

MH: Yeah, the kitchen was back there.

MF: So this is if I'm looking down at the house like that, right? [Yeah.] And then you had, where did you sleep? Which one was your room?

MH: Well over here, on the side right there.

MF: And who did you share that room with? 
MH: $\quad$ Me and my two, my brother and my nephew. All three us slept in the same bed, on this side right there. Then my sister and them slept down here. And then, my mother and father slept over here. That was the dining room, yeah, one of the dining room right there.

MF: Which brother did you share a room with?

MH: Les and LeeDell Bunton.

MF: $\quad$ Yes, yes, yes, right, right, of course.

MH: We three would sleep up in that room. And he was born next door to it. He was born next door to the room that me and him and Les was in.

MF: Oh, okay. I thought he was born at the, a doctor delivered him, though?

MH: Nah, he was born right there in that house, because me and Les was there. We seen our sister when she was pregnant, but we didn't really understood what was wrong with her. And one day-

MF: This was Emily, right?

MH: Yeah, Emily, yeah. And one day a doctor came, and it was a few ladies there, and they was in there where my sister was, and we had them skeleton keyholes, and they plugged it up. Me and Les was trying to see what was going on in there, and then we know something was going on in there but we didn't know what. And we couldn't see. So there's something going on in there, he was the baby. He didn't know too much of nothing. I told him something is going on in there. And so we sat around and sat around there trying to see, see if we could find a peephole, and we couldn't find that. Next thing we know, we heard a baby cry. I said Les, that's a baby in there. That's when we know she had my nephew.

MF: And you were really young weren't you?

MH: But we always thought he was our brother, yeah. Me and Les thought LeeDell was our brother.

MF: Les said that. Well, they're very close in age, aren't they?

MH: Yeah, oh, yeah. We was always, my mother had him ever since he was born. So I didn't understand that part, but-

MF: But your sister raised him?

MH: No, my mother. Yeah, yeah from the day he was born.

MF: Where was your sister? Did she stay at home?

MH: She was around, she was with her husband, she was around, but she didn't have nothing to do with the baby. My mother raised that baby. Yeah, and we didn't find that out until we was almost grown. We thought he was our brother, yeah, we didn't know he was our nephew. So we learned that later on in life. But after my grandmother, I was real close to my grandmother. She stayed down the road there.

MF: And that was, was this Katie? 
MH: Yeah, my father's mother, Ella Harper. And we looked after her, my mother did, my daddy, he went west. And we had to take care of the farm while he was out west, and so she, my mother took care of her, until she died. And my father, he came back home I think two weeks before she died. And he stayed there until she died. Then that's when we, we stayed there, I think, almost a year after she passed, and then he said we going west. He had a big truck, a big truck he had. So he told us we was going west, and loaded that truck up, and we had a lot of animals. We had cows and hogs and everything. But I notice things was dry around there for a long time, it was a drought had came, and I didn't understood it, but I know it wasn't right. It wasn't nothing growing, we didn't make no crops, no cotton growed or no corn, no nothing growed. Everything was dead. So he saying it was time to move on. So he packed up his family and opened the gates to them animals and let them walk free. Just turn them a loose and let them wander around the Black Colony, until somebody probably finally got them. But he walked away and left everything. He had a lot of equipment, he had tractor, hay bailer. $\mathrm{He}$ had, man, he had everything, but he couldn't pay for it, so he just walked away and left it.

So we went west, and that's where we stayed until we was all grown. We went there to do farm work. We went and pick cotton. We did all farm work. So he got, well, he started being a contractor, working for other farmers, and they pay him so much for doing farm work for them so he got pretty good to where he could hire a lot of people to do the work, and he started making money that way. He did real good, so the whole family be working. We all worked, we'd go to school sometimes. Probably half of a school, we would go a half of a school year. Rest of the year, we had to go work.

MF: And this is when you went to pick cotton, right?

MH: Yeah, we was picking cotton and all that, doing all farm work. So we moved from one little town in Arizona to another town, wherever there was work at, that's where we would go.

MF: So even in Arizona you didn't settle down too much, or did you?

MH: Well, we did after we got into Phoenix. We was on the, little town in Arizona, but we hadn't got to Phoenix yet, the big city. We hadn't got there yet; we was still out around the little country towns, you know where farm work was. And he finally, when work got slow out there in the country, then he finally went to the city. Somehow he met some people, and I guess he asked them where could he rent a house at, and they told him, so he came back where we was in the country, and said, "Well, we fixing to pack up and go to Phoenix. I got us a house in Phoenix." That's where we got our start at, and he rented a house and we stayed there in Phoenix, and went to school there in Phoenix.

MF: How long did you spend in the country in Arizona before you moved to Phoenix?

MH: About a year or two. And then he, once we moved to Phoenix, then we all were getting older, and we didn't want to do that work no more, so everybody started getting jobs here now, and so everybody was able to get a job. So then that's when our farm work quit.

MF: So what year was that about?

MH: It was around '60.

MF: Okay, so you farmed for about five years? [Yeah.] And so you were maybe a teen, seventeen, eighteen years old?

MH: Yeah, I was still a teen, yeah, I was still a teen. I was like twelve. 
MF: When you left here? When you left Buda, right?

MH: Nah, I was about seven when I left Buda.

MF: Oh, were you seven years old? Okay.

MH: Yeah, and then I-I was about twelve when we finally moved to Phoenix, but then my daddy, he was still doing farm work, but he was able to hire other people to do it and he would hire sometimes forty, fifty people to do farm work and paid them every day. He did real well.

MF: Okay, but this was on other people's land, right, it wasn't his land, right?

MH: Yeah, it wasn't his land. But doing all of that, he was able to make enough money, he was able to make enough money, he made money. Oh, my daddy was a money man. He made enough money. As hard as we worked, he told us, "I know I worked you all harder than anybody ever have in they life, but it's going to pay off. You watch, it's going to pay off." So we didn't think nothing of it, we just said, "Okay, Daddy." We did whatever our daddy said, and soEverybody here had got they own jobs, and my daddy was still doing farm work, but he was contracting it, and next thing you know, my daddy bought a whole block. Every child he had had a home. Yeah, he bought that whole block-that whole block.

MF: In Phoenix?

MH: Yeah, all his kids. Everybody had their own home, every one of us had our own home. That's what paid off all of the hard work we did all our lives. And yeah, from there-

MF: Now could I ask, you mentioned that you left, because it seemed like there was a drought, and it didn't seem like your father at that was doing very well-

MH: Nah, he couldn't make no money on his farm, so-

MF: And he didn't have any money when he left here, right?

MH: Nah, nah, he didn't have nothing. We didn't have nothing.

MF: So you basically started from scratch when you moved to Arizona, and he was able to-

MH: Yeah, everywhere we went, everywhere we went, we started from scratch. We'd get out there and work and make money, but we didn't have money.

MF: Who moved with you? It was you, LeeDell, Les?

MH: Yeah, all my family I think moved, yeah. We all moved together, then my sisters and them, they came back here and went to high school to get their education. They came back to Austin and stayed until they got their education and then-

MF: Who did they stay with?

MH: My sisters, I had some sisters that was staying. The older sisters was here.

MF: So the younger sisters came back?

MH: Yeah, they came back, the twins. 
MF: Oh, so Marian was here?

MH: Yeah, Marian was here. They didn't come west until way late, way late in life before they decided to come, but they finally came. They all came, and we was all in Phoenix then. But yeah, that's how we was raised, and then everybody started going they separate ways. I went off to myself. I left home at sixteen. I left home at sixteen. I didn't know where I was going, but it was just something was driving me to do things that my family would not never think I would do, and so I left all of my brothers, they was having kids. I didn't want no kids, and I didn't have no kids. I wasn't married, and they had their little girlfriends, and they was having kids. But I left, I left and I had a girlfriend, I'd been chasing her for a long time. I finally, her mother gave me consent to get married, and my father-in-law, he didn't want me not working, and he was a roofer.

MF: And how old were you at this time when you asked this girlfriend-

MH: I was about seventeen. [Laughter] I was about seventeen, she was about thirteen, I was robbing the cradle. He taught me how to be a roofer. He said, I'm going to take you to work with me, you going to work, because my wife didn't want me to work, we was young and she didn't want me to work. But he took me on his job and had took me out of town, and I ain't never been out of town on nobody's job and didn't know how to do the job he wanted me to do, but he going to teach me. They took me out on a reservation, and they had a big school out there.

MF: A reservation? The Indian reservation? Do you remember which one?

MH: Indian reservation, yeah. At the four corners of Arizona. Four corners of Arizona.

MF: Do you remember which Indian tribe?

MH: Navajo. Yeah, we went and roofed a school out there, they had built a new school in the reservation. So I learned how to become a roofer, and that was my trade, yeah, that was my trade. I quit about twenty times before I decided to keep doing it, it was the way I got started, it was just too hard for me. I didn't like working that hard.

MF: And you had already been working hard, so this must have been really, really hard work?

MH: Yeah, all my life, yeah. So I was tired of working hard, so I didn't want to do that kind of work for a long time.

MF: Do you think it might have been also because of your age at the time that you just wanted something different?

MH: Nah, it was just what they had me doing. I just didn't want to do it. It was too hard-I was throwing rocks with a shovel up on a roof. Oh no, that wasn't, that wasn't me, but I kept working at it and I kept working at it. Then they, the better I got, the more money they started giving me, and then I was working for this one white man, and he told me, he said, "I know you look like you ain't the type that want to do too much hard work." I said I'm not. He said, "Let me tell you something." He said, "You get sharp enough to know how to start this roof and finish it, when you get that sharp, you don't have to work hard no more, you use your mind, use your head, use your knowledge how to do this roof. And you won't have to work hard no more, you have everybody else doing your hard work, because you just use your mind." He told me that. And I listen to people real easy. I listen to peoples. I used to love to sit and talk to elder people, old people, people seventy-five, eighty years old. I would sit down 
there and talk to them and would learn wise things from them, you know. So that helped me out in life a lot.

So I decided to take him up on what he said, and I start getting better in roofing, and I got the place where I had my own crew to go out and do jobs, and do roofing jobs and complete them. And that's when I didn't have to work hard no more, and I started using my head, and they shouldn't have let me get that in there, because I went hog wild then.

MF: How old were you, when you started hiring other people?

MH: I was eighteen.

MF: Oh, my goodness, so you were still, were you still married then?

MH: Yeah, yeah, I was married for a couple of years, and then we was separate. But I took off on my own. I got where I would have my own crew, go out on different jobs and complete them, and I got where I was good at it and I was, I had certain time to do a job, I would get through before time. I would get a bonus from my boss. He would give me bonuses, and I started making money, money, money, money. And I started traveling, and I got up in there, got up in the roofing to where I became a master roofer. I became that. And then I roofed all out west. I roofed all of Las Vegas, San Francisco, north of San Francisco, and worked my way on. I did a lot of my work in Phoenix. Phoenix was growing then, I mean they was growing. They was building all, they was building houses every day. They would build a house every day. They was building houses so fast, and everybody was making money, I mean everybody was making money. Carpenters, plumbers, everybody, electricians-we all was just making money, money, money, money.

MF: Now did any of your brothers come with you?

MH: No, they never did do nothing like that. I had a brother worked at Avis, and I had one that worked like at a restaurant or something like that. My dad, he worked at a restaurant as a night porter, you know, cleaning up. He did that, plus he still was contracting the farm jobs, and yeah, he did this for years. He had a good retirement come in when he retired from doing a being a janitor in restaurants. But I wasn't around the family that much, I was always gone somewhere. I was in Colorado or Las Vegas or-

MF: Traveling for work?

MH: Yeah, I traveled, I followed money all over the west. All over the west.

MF: Were you just, were you working for a firm, did you say?

MH: I worked for a company.

MF: What was the name of the company, do you remember?

MH: I worked for Progressive Roofing, and he was a millionaire. His father was a millionaire, and so he gave his son that job of running that company called Progressive Roofing, and me and him got to be real tight friends, and he trusted me a lot, and he gave me a lot of work. And yeah, he would fly me different places to do a job, you know, and I fly up there and work and fly home every two weeks or something like that. I had some good jobs. And I went some places that a lot of black men ain't never set foot on. I been to places that I was the only black man in there. You know, and I had to learn to deal with different races of people and how they would feel about me doing a job on they building, because some of them from back here, 
they didn't believe in-, they didn't even know a black man knew how to roof. And so they wouldn't, it was a lot of times they didn't want me on their job. So I had to deal with stuff like that.

MF: Did you have to deal with stuff like that, do you remember as a, growing up in Buda?

MH: No, no. I never heard the word "nigger" until I was in Arizona going to school with some white kids, because down here we didn't go to school with white kids, when I was going to school here. It was all black school.

\section{MF: You went to the Antioch School?}

MH: Yeah, it was all black, so we never went to school with white kids until we went west. And we went west, yeah, well, we had to school with white, Indians, Mexicans, everybody. So yeah, that was a big time for us.

MF: Do you think growing up in the colony, since it was all-black, kind of helped, like it pretty much sheltered from racism, then, right?

MH: Yeah, yeah, well, our father you know, he, we had what you call hillbillies would come by the house that stayed up in they mountain. They white people but they like, they ain't like ordinary white people. They all got a different tone of life and they talk different, they some funny people. But they would come by my dad's farm and sometimes he would help them out, he would give them milk and butter or some vegetables or something to try to help feed them up in the mountains. But other than that-

MF: $\quad$ So these were poor white people that came down, what mountains did they-Where were they from?

MH: They call them hillbillies. They was up in the mountains. [In Texas?] Yeah, they was up there by Driftwood and places up in the hills up there.

MF: I see, so those were the only whites that really came into your community?

MH: Yeah, yeah. We had a couple of old white people that lived around the community, but they wasn't in the black community, but they was around the black community. My mother worked for one, and they would come by there, they would come by there, but then they would speak or give us a quarter or something like that. But as far as us being around white people that much, we never was. I would be with my father sometimes, and some of them white men out there at that time, I guess they called them rednecks at that time. But my daddy never was afraid of nobody. He never did fear 'em. He did his job, he went and got his wood. And every now and then he would have a word or two with a white man, but he set him straight.

MF: What was it usually over?

MH: Like one time my daddy killed a deer, was on a fence, his deer got hung on a fence so my daddy went over there and cut its throat, and he was going to bring him home so he can have food for his family. So the white man seen him and going to tell him that that was his deer, and my father told him that it wasn't his deer, it was his. But the white man going to try to scare my father, well, it didn't work, and my father brought that deer home. But he never feared no white man, he never feared nobody.

MF: Is that what he taught you? 
MH: Yeah. Ain't nobody in my family fear nobody, he just told us we going to die, die like a man. That's what he said. And the way we was raised, my father had guns in every window. $\mathrm{He}$ had a gun over every window, over every door he had a gun.

MF: What was that for?

MH: Protection in case somebody going to come by and harass his family or something like that, you know, some wild white man up in them hills decide he want to, you know, meddle with people every now and then. He didn't play that.

MF: Now did everyone know how to use a gun in your family?

MH: Oh yeah, from day one we learned how to use a gun.

MF: Boys and girls?

MH: Yeah, my mother knew how to use a gun. Everybody in my family knew how to use a gun. My daddy kept a .45 on him, he never did let away from his sight. Everywhere he went, he have overalls on, but he got a .45 in there, and he never left home without it. And he had a gun in his truck, yeah, he kept a gun in that truck. He kept a rifle in his truck and he kept that .45 on him everywhere he went.

MF: And this was just in case there was trouble?

MH: Anybody start trouble with him, he was going to handle it.

MF: Did he have reason to be concerned, do you think?

MH: Yeah, because you sometimes you run across a group of white men that just want to harass a black man for some reason, but he just never did take that. And they learned he didn't and they respected him for it, yeah, they respected him. They didn't cross him.

MF: $\quad$ So how old were you when first learned how to use, I assume maybe it was a rifle?

MH: Oh, man, a gun, I was about seven. I was driving at seven. I was driving trucks at seven, we all learned at seven and eight years old, we had to because my father needed us, man. We had to learn how to, we was driving tractors.

MF: How could you even see over the dashboard?

MH: Put a pillow, they put two pillows under me and I can see, boy, I be gone. Yeah, that's how they did it. I was driving at seven, sure was. All of my sisters and brothers was driving. My sisters drive a tractor, they jump on that tractors, and be driving it. We drove everything that had wheels on it, everything had wheels on it. We came up in a strange way of life.

MF: Was this typical for people who grew up in Antioch, or was it just your family?

MH: Well, our family the first one that started a bunch of kids driving, that's for sure. We was the first on that started that. They couldn't believe what they was seeing half the time, they see a little bitty head going down the road in a truck and they just be having a fit trying to see who it is. Be a little bitty person driving that big old truck. They'd be really looking, too, man. They can't believe they eyes half the time. But yeah, that's how we came up.

MF: In terms of the families, most of them were farming families, right? 
MH: Yeah, they was all mostly farming families. A lot of them had big families. A lot of them had ten, twelve kids. It was a big family in Black Colony.

MF: In terms of, you mentioned that you raised a lot of crops and so forth, so did you hunt and trap and do that kind of thing, too?

MH: Oh, yeah, my dad he killed, we ate more rabbit than anybody on earth. My daddy was so good at what he did.

MF: Did he trap them or did he hunt them?

MH: I'm going to tell you some strange things to keep us fed, I mean to keep us fed, my daddy would-We would go, we'd be out in the field and we worked until dark. Sunup until sundown. And when we get off of work and start home, down them roads over there where the fields and things at, my daddy be driving and he'll be hitting rabbits all the way down until where we going, by the time we get to our camp, my daddy got about seven or eight rabbits.

MF: Hitting rabbits?

MH: Yeah, he'd do it with his truck wheel, yeah. Yeah! That's how he did it! [Laughter] He knew just how to do it. Boy, he would turn that wheel just a little bit and there goes a rabbit! And he'd stop and get him and put him in there, and we'd take them home. He'd clean them, hang them on the fence, and we'd have fried rabbit that night. Man, we ate every day, every day we ate rabbit-more than any other meat in the world, because my dad sure would know how to kill a rabbit. He killed them rabbits. They said that's why y'all be running so fast, you all eat all them rabbits. [Laughter] Boy, we had rabbits and gravy, fried rabbit, rabbit stew, boy we some rabbit-eating people. Boy, but it kept us going.

MF: And what other kinds of animals do you remember hunting, trapping, or running down?

MH: Armadillo. We ate armadillos and we ate some possum.

MF: How did you get the armadillos?

MH: Aw, man, my daddy he'd run over them like he do them rabbits. They'd be trying to cross the street, and there he go he got him an armadillo right there.

MF: How does armadillo taste?

MH: It taste good once you, when they cook them right. My mother knew how to cook them, too, she knew how to cook all wildlife, because that's all we ever had. And deer meat.

MF: And possum?

MH: Yeah, possum.

MF: He would run them over with the truck?

MH: Yeah! He'd take that front wheel of that truck, and somehow he'd do it and he got it. It don't mess up either, it don't, you know, squish them or nothing, he just he hit that head somehow. I don't know how my father was doing that, I never figured that out, but I know he'd stop that truck and next thing you know, here he comes with a rabbit. I said, "Man, I don't know how Daddy done this." [Chuckles] But we ate. He kept us fed like that. My mother, boy, she 
would take a possum, she'd get through with it, and you won't know what you eat. She had a big old black pot that she would have a fire running most of the time I seen.

MF: Did she cook outside with that pot?

MH: She'd put that possum in that pot and boil all the hair and skin off of it. And then she'd clean him and he's just white as snow. She'd clean him and she'd put all that seasoning on him, you'll eat it.

MF: Now when your mom did this boiling, she would do it outside, right?

MH: It was a black pot. Yeah, outside.

MF: So where would she do that?

MH: Well let's see, the wash machine was right in here. Yeah, over here. Well, she had a pot right out here, a big black pot right there. It stayed there, and whenever she, she would boil everything in that thing. She would, I seen her, she boiled clothes in it. She boiled clothes in that thing. She was a, she would have three tubs, three big old tubs, she had, she would take. She had a wash machine she would use, before then she was using a rub board. Boy, she was using the rub board cleaning all them clothes, and my daddy finally found her some kind of wash machine.

MF: No electricity though, right?

MH: No.

MF: So when you say wash machine, you mean-?

MH: Motor. It's a motor wash machine. Put a little gas in it and that little motor run, and the little twister goes. She washed in that, and then she would have a tub, and when they come out the washing machine she'd put that in that tub-I never did understand how she was doing all that. And then she'll rinse all the clothes in that tub, then she put it in the next tub and she'd do that same thing, rinse all the clothes in that tub. And then the last tub she got a blue tub, a blue one, bluing. She'd put them white clothes in there, and boy, you can see white clothes from miles, miles and miles. She had them on that hanger, the clothes hanger. Be the prettiest white clothes you ever want to see. But that's how she did her laundry. As things started winding down and everybody started going they separate way, I-my father had-he started doing landscaping, my father did. He was doing landscaping.

MF: This was in Arizona?

MH: Yeah. He started landscaping in Arizona, but I was into roofing. I was all over the place. But I come home to see about my parents. Whenever they get on my mind or anything, I come home and see them, and then I take off again. And they didn't ever know where I was half the time. And I had went to San Francisco and I worked in San Francisco, and then I did a job in Las Vegas. Did a job there. Came back to Phoenix and did some more work. And then my sister, twin sister, decided to come back here where we had our property out there in Black Colony, and they came back here to retire and live here and bring my parents back here. And that's where they came back to Black Colony, and they started living out there.

MF: Now when did you return to Austin?

MH: I returned to Austin in '87. 
MF: Now why did you come back?

MH: I came back, the reason I came back was I had-My kids and they mom had separated, and I became a bachelor. I had gotten on the wrong track for a while, so my father had a friend that he had watching me that I didn't know was watching me. But he was letting my father know how I was doing, because I was the only stayed behind in Arizona, and they had came here, but my father was worried about me, so he had a friend of his to keep an eye on me and watch and see what I do, or if I'm staying out of trouble or something. And I had a house. I had a house. My father had, I had my own home, yeah, I sure did. I had a nice big fivebedroom house. I had got behind with my taxes, so my father helped me catch it up, and I said, well, I know what I'll do. They was all saying I was going to lose it. He done got on the wrong tracks, he going to lose that house. But I wasn't as far gone as they thought I was, so I went and was going to sell it. My neighbor across the street, she found that out that I was going to sell it. And everybody was trying to cheat me out of it, you know, they was trying to cheat me out of every, talking about they'd pay the taxes and give me a few thousand dollars. I said you must have thought I done lost my mind, but it didn't go that away. A neighbor of mine that I'd been knowing for a long time, she said, "Moses, if you sell your house to me, I'll pay you this amount of money, and I want to get it for my boys." She had two twin boys, and she said, I want to get it for my boys. So I thought it about, and I said, "Well, yeah, I don't mind selling it to you. I'll let you have it. So I called my dad and told him, I said, because my dad had sold his house before he came back to Texas. He didn't get but like $\$ 12,000$ out of his house, and his house was bigger than mine. Well, he couldn't figure out how did I was able to get what I said I was going to get for my house. He said, boy, if you can get that, you go ahead and sell it. I said, well, that's what I'm going to do. I got $\$ 16,000$ out of mine, yeah, sure did. I sold it to her, but before I had that house, I had bought a house when I was sixteen. I had bought a two-bedroom house when I was sixteen, wasn't old enough to buy a house. My daddy had to sign for it. But I bought it, I bought it and paid for it. I had a house when I got married. Yeah. But after I sold my house in Phoenix-

MF: So that was '87 did you say, when you came back here? After you sold the house and you came back here?

MH: Yeah, it was in '87. And I came back here and I worked, started working in roofing here in Austin. I had changed the way I was doing things and I messed around here, I mean I messed around there and got hold to some alcohol and kind of got off track. And you know what happened? I didn't have a car. I was riding in a taxicab and I had a young lady, and I decided somehow to stop at the liquor store to get something else to drink and whatever, but it didn't work. You know what happened to me? I don't know how I did it, but in the back of that liquor store, it was a great big mud hole, almost big as this room. Big mud hole that I ran in it several times with my car. That mud hole was there. I don't know how, I had on a $\$ 300$ suit and a $\$ 200$ pair of shoes and a $\$ 100$ hat, and you know what happened? Somehow I end up in that mud hole, I end up in that mud hole, and I was in that mud hole all the way up to my chin. Mud was all around me up to my chin, and I was in there half the night in that mud hole.

MF: Nobody noticed that you were missing?

MH: No, they didn't know I was, nobody knew I was in that mud hole. Didn't nobody know I was in the mud hole. And what woke me up early that morning was the sun. The sun was beautiful and bright. When I'm laying up there and my eyes close, but the sun seems like-this is strange what I'm fixing to tell you-but sun seemed like it stood still for a few minutes, still enough to penetrate in to my eye deep enough that it woke me up. And the first thing that I looked at when I opened my eyes, when I looked at that sun, I looked at the sun, and the sun I knew should have been a little higher than it was, in my recollection. It should 
have been higher than it was, but it was right there. And I couldn't understand that. So I'm laying in this mud hole, I said Lord, have mercy, what have I done? I said what have I done? I'm soaking wet in mud and I said I know somebody done took all my money. I had about $\$ 400$ in my wallet. I said somebody took all my money they got my clothes, shoes. And being awoke, I'm still laying in this mud hole, trying to figure out what I'm going to do. How I'm going to do this. I got to get up and walk five blocks like this here. And I sat there for a little while and something came to me just like a spirit of an angel came to me and said, "Now you know what?" I said "What's that?" She said, you get on up, I'm going to walk with you, and I know you going to be embarrassed and I know you going to be ashamed. But let me tell you something. You get on up and you walk home and you get out of them dirty clothes you in and put them up in a bag, and cleaners will clean them clothes. But I'm going to clean you. Just like that, I was talking to him. I said yeah, yeah.

So I eased on up out the mud hole, and I looked on the bank of that hole right there. There were my shoes, they were setting together. There were my wallet laying right there, didn't have a drop of mud on it. There was my hat laying right there, didn't have a drop of mud on it. I said no way in hell that's supposed to happen. What is it doing setting-Just like somebody took it and set it there real neat. Wasn't a drop of mud on it, wasn't even in my pocket. And I said, I can't believe this. I reached down there and got all my belongings, and I took that stroll. And it said, "You are not alone. I'm walking with you. Go ahead on. It's going to be all right." And I walked, and I went in that apartment, I went in that apartment and I commenced to getting out of my clothes. Like the angels, they was talking to me telling me to do, I got out of them clothes and I put them in a bag. Went in there and took me a shower, cleaned myself up like the angel said. Cleaned myself up. And you know? It said now come in the bathroom and close the door. It talked to me. I went in that bathroom and I closed that door and I got on my knees and I said I done went as far as I can go. I don't know which way to go from here. I said you going to have to show me the way, I said you going to have to show me the way up out of here, because I done lost my way to know which way to go. He came to me and he gave me, he gave me the knowledge that I hadn't had in a long time. He told me, he said you got sisters back there in the south, and they are singing in a church and choirs and stuff, and they need a leader. Now this is my orders I'm getting to show me the way up out of there. Now you go home, and you go to choir rehearsal with your sisters, and I want you to lead them in they choir. I said, "Lord have mercy, I don't know how to go about doing all that." And he said, "That's your orders. You on a mission, I'm fixing to send you on a mission." And I talked to him, and when he told me what he wanted me to do, he said you go there and you do that and help your family. I said, "Now how is I going to do that? I don't have no money, I don't have no car." Next thing you know, I had a car, he showed me a car that I can get, when I was employed. And I went and asked that girl about that car and she told me it was for sale for $\$ 200$. I bought that car. And the next thing I know, I heard somebody knocking at my door, and there was my brother Les! I said, wait a minute, wait a minute, what's going on? What's going on? I said, "What are you doing here?" He said, "I come to take you home." He said, "I come to take you home." I said, "Come to take me home?" He said, "Yep, the angels came, they told me to come get you, and don't stop 'til I have you in Buda, Texas." I said, "Yeah, all right, all right." So I packed up, and we loaded up.

MF: And who did you move with?

MH: And I went and got my son. I had my son, Moses Junior. And I told his momma that I was taking him with me.

MF: How old was he at the time?

MH: He was four. He was a baby. So I got him, and we came here to Austin, Texas. 
MF: $\quad$ So this was in 1987 when Les came and got you in Arizona, and you came here. [Yes] And then, but you did go to Buda, or did you come-

MH: No, I went to Buda, we went straight to Buda. My father had a trailer there that my nephew and them was staying in, but they had messed it all up. We had to clean it up and straighten it up, and a place for me and my son to live. So we cleaned it up and stayed there. Then he told me, he said, "You know what?" He said, "Everything that your family didn't think you can do, I'm fixing to give you the knowledge and know-how to do it and do it, and they not going to believe who you are." And I just said, "Yeah, all right." But I did what I was told. I was setting there one day and my sister and them said, Moses we fixing to choir rehearsal. I said, you is? And then you know what, that angel said you on a mission. You on a missiondon't forget your mission you're on. My sister said they fixing to go to choir rehearsal, my mind said you better get up and get on that train. I said, well, I'm going to go down there and see what you all are doing.

So I went down there to see what was they doing. Show you how God work in mysterious ways. I went to see and listen to them, and see how they sing, because I never sung with choirs hardly. I was a gospel singer, and I didn't know how to sing with choirs, choirs had different versions of Gospel singing. So I listened to them sing a few songs, so the choir director she was a minister. They told her and said, well, that's my brother Moses, he just came here from Arizona, and he know how to sing. And she said, "Let's see if we can hear your voice a little bit." So I said, "Well I don't know. I don't know nothing that you all want to hear. I don't understand none of this." And she said, "Well, just sing (a scale)," all that kind of crap. I did a little of that, and all at once she come up with a song that she said, "You know what, I want you to learn this song, Moses, and it's called 'Lord I Tried." And what made her come up with a song like that, only the angel knew, because I sure didn't. But she come up with it, and she played it and she played it, and she taught it to me and taught it to me until I got it down. And I begin to sing that song. I was singing with my sisters, I was leading the choir, I did what I was sent to do. I did what I was sent to do. I was on a mission then.

So then I got smart and I went, I told my wife, I said, you know what, I said my family never thought I was going to do nothing to my property out there in Black Colony. I got smart and I got my son one day and I took off and went to where they had the trailers. And they had took my property and put a lot of trash on it, because they said well they ain't going to never put nothing on this property, he ain't going to do nothing with his property. He ain't going to do this and do that. I didn't say nothing, I didn't tell them nothing, I didn't tell them what I was thinking. I didn't say nothing. So I went on, I said all this off of my property. Had a little hog pen on my property, I said I want this off my property now!

MF: We have to stop this right now and hold that thought. I just want to make sure I get this all on tape, so let me just quickly turn this tape over.

MH: So now I'm getting down to, why I'm going to tell you why I came to rebuild my community. And I told them to get that off of my property right now! And they thought I done lost my everlasting mind. And I said, "You know, my father told y'all he was going to turn it over to me to run this whole Harper ranch." My sister and them pitched a fit, man, and had my father not to do that, and they got their hand on it. But then I kept on working and doing my thing. And I went to where they make trailers at out there in Hays County, and I went up to that trailer place. I looked at them trailers, and I told that salesman, I said, "You know what, I want a three-bedroom doublewide, I said with a Jacuzzi in it, and a master bedroom." I told him how I wanted that trailer, them people up there went and built me that trailer. And now I'm talking to people with no money. I don't have a dime in my pocket! I don't have twenty dollars in my pocket. I'm using some knowledge that I picked up on. I told that man what all I wanted, I said I want my septic tank put in, I want electrical hooked up, I want my 
plumbing hooked up, I want a light pole put up there. I told him all I wanted, they written it down. And them people built that trailer for me. I didn't have a dime. My family didn't know what I was doing. They didn't have no idea what I was doing. And I said, you all get all that stuff off my property, so they got it off, they got it off, they didn't know what else I was fixing to do to it. I had that dude to come out there, he went out there, I told him where I wanted that doublewide, and I never told my family nothing, didn't tell them nothing. They was all out on the porch like they usually do out there talking and listening, and I'm just standing up there looking at them and waiting. I know what they fixing to do, but my family didn't.

I went and told my brother-in-law, I said, "We going to have to come in this end of the property, on that property, because they fixing to take me a double wide back there." He said, "Are you joking, man? Ain't nobody fixing to put a-How you going to get a double wide back there?" I said I'm going to get one. So they was all out on their porches and stuff and I said, "You know what, I'm going to change the way this place looks. I'm going to change our community, and they ain't going to believe me." Sure enough, about ten o'clock here come them big old trucks with this big old house, and everybody out there looking saying where in the world is that going? Wonder who in the world done get them a house? They didn't know it was me, they didn't know it was me. Looking good, he's stopping up there! You know how country people is, he's stopping up there! Somebody out here done did something, girl, this a big old house! They didn't have no idea that it was Moses Harper house. They looked up man, and them dude's on the bulldozer had came down and cleaned off the area where I told them I want my house to set. But they still didn't understand what was going on. And when came they came down through here with that big old house and set it up there, my whole entire family came up to see and all of them stood out there with their arms folded looking. What has this boy done done? I changed the community right then and there.

MF: How so?

MH: I changed it. I had a big beautiful house sitting right where they said it would never be a house on that property. I set a big doublewide up there.

MF: Now which one is it? I'm trying to think. I know where Les's house is.

MH: Yeah, well, mine was next to it. Next to Les's, south of Les's.

MF: Is it an empty lot there now?

MH: Yeah, it's empty now. They took, they came and got my trailer, but it was setting right there. I got pictures of it. I had it pretty out there. I had trees, nice beautiful yard, and I had a porch built on it, and it was real nice. And I never spent a night in it.

MF: Oh, no, not a single night?

MH: Never spent a night in it, big old Jacuzzi was in there. I asked one girl that was renting it could I come take a shower? She said no.

MF: Oh, you mean somebody was renting it?

MH: Yeah, I was renting it out, I rented it out. I rented it out to a couple of good renters and then I got on to some bad renters. My kids was able to stay there, my son and my daughter stayed there for a long time. I let them stay there. I mostly bought it for them. Well they wanted to go back to Arizona, and my son got where he wasn't helping me make payments, so I told them to come get it, I wasn't going to stay out there. 
MF: You didn't want to stay out there in Buda?

MH: No. Well I didn't want to rent it no more, because people didn't want to pay. They didn't want to pay the rent, every month they want to have excuse. And I couldn't have excuse because I had payments to make, you know. I just got them and told them come get it.

MF: Why won't you move out there yourself again? Why wouldn’t you try to?

MH: Well I thought about it. I thought about it, putting another one out there, I would go talk to them about a house, I don't know, and put another one there, I could do that. I could that. I had that skill. I could do that, yeah, I thought about doing that a couple of months ago. I said well, nah, because you know, I changed my mind, because you know why? They start charging too much. They charge too much for everything. They want to charge me for my taxes on my property, they want to charge me taxes on my house, they want to charge me taxes on environment. I said, oh no, that's too much.

MF: That piece of land there is still yours, then?

MH: Yeah, yeah, I paid on my taxes on last month and I go this month and pay on them again. I been keeping my taxes up pretty good.

MF: How often do you go there?

MH: I pay maybe $\$ 60$ a month.

MF: No, I mean how often do you go to visit? I'm sorry.

MH: I just went the other day. I go out there and get all my water. I don't drink Austin water. No, I don't drink Austin water. No I go to Black Colony and get my water. I have a bunch of water jugs.

MF: You just get it out of one of your sister's faucets?

MH: Yeah, me and my wife go out there and we fill up all our little water jugs and bring them back. Either one of the houses you get, either one of the houses is the same water. We have a well that supply the whole ranch. It supplies the whole ranch that one well.

MF: Do you go to church there, too?

MH: Oh, yeah. Well, I go to church out there with them sometimes, they have the little church service in Buda. I visit them a few times out there, but I don't go out there that much, no more than visit my sisters and get me some water, and then I get upset sometimes the way they be doing things.

MF: What do you mean?

MH: You know they don't keep it clean like they should, and I get upset because they don't do what they should be doing. And I can't do it by myself.

MF: What do you think they should do out there?

MH: Like clean up and pick up and don't bring no bunch of junk that they not going to use. I don't believe in junk being around a property and you can't use it. I don't believe in that. And they do and I don't so, that we don't get along with too much. But other than that, I have a pretty 
good life. I had a pretty good life until I started getting sick here and there. And I been here with my wife Frances, I been with her for twenty-three years.

MF: And how long have you been in this house?

MH: About twenty, I guess. Or twenty-two years, somewhere in there. Yeah, I been here quite a while.

MF: I love this neighborhood.

MH: I was here when her father, we kept her father until he passed. Yeah, I helped to look after her father, she and I been here all that time except for a year. I took off for a year and went back to Arizona.

MF: So what do you think is the future of Black Colony, as you call it?

MH: Black Colony is being sort of chewed up behind the new system they got going or some kind of way that, they done stepped out of their bounds, really. They, since all the elder people done passed away that lived in the Black Colony, and they kids didn't understand how to handle business and stuff, so other people is coming in and buying parts of Black Colony that shouldn't have never been sold, but somehow they worked their way into getting their hands on Black Colony. What they've been trying to do for years and years, but it didn't work. But then after these older people started dying, and their kids didn't have the mind and understood the valuable of Black Colony and started selling they property to move to the city, so they got, I guess, a different lifestyle, but they made a big mistake by selling they property. Now they back out there looking for it and it ain't there, they don't have nowhere to go now because they sold it.

But it's something about that Black Colony that a lot of white people don't really get the drift of. That Black Colony that was there for the black people, descendants of slaves, for them to own that and farm that, that was they land. That was they land. That was they land. And every time that a white man would move in that area, they wouldn't live long. They wouldn't live long. My sister was telling a white guy about the Black Colony, and he was talking about he bought this and he bought that. And I told my, sister talk to him. A few days later he had a heart attack and died. And there's something about that Black Colony that they not supposed to be there, but they there anyway. Well, they don't seem to be having good luck out there, for some reason, I don't know why. I don't know. But it's something about that Black Colony, it's got a lot of power left around there. A lot of old people, I've seen a lot of them, a lot of them old peoples when I was a kid.

MF: Who do you remember seeing?

MH: Well it was a lady named Kate Bunton I think, and Mary Anderson, and Ada, Liza, and then the Mullins down there on the hill by the school. It was quite a few black people lived there. A lot of-

MF: Now who was considered like the respected members of the community? When you were a kid?

MH: Everybody. Everybody out there was respected. But I used to see them do things when I was little. I would see them, see my mother and the neighbors get together and they'd go, I'd see them go over to somebody's house and I always wondered what they was doing. Wondered why all the women would get to together and go over to this house. So one day I finally found out. I was with my momma, she had me with her, she had to go to one of the neighbors and 
help them bathe. Somebody had passed on, which I didn't know. I didn't know what they was doing, but that's what they did every time somebody passed-they'd go clean them up.

MF: This is the women?

MH: Yeah, the women go clean them up. And doggone [laughs] thing to me! I didn't understand it. I seen them handling this man, and I didn't know what was wrong with them. I seen them handling him and holding him up, I said, well, what is they doing to him? I didn't know, but I said well. So finally one day I asked my momma, what do you all do? And she said, "Well, we got to clean him up for the undertaker." I said, "That's what y'all be doing? That's what you women be doing?" I said, "Well I'll be doggoned." So I was learning about that, about being with my mother, seeing some of the things they did.

MF: What other kinds of things did you see them do?

MH: Oh, man, I seen some of the weirdest things in that country. Wouldn't nobody believe half the things that went on in that country. But I enjoyed myself. I usually played by myself mostly. I'd usually be out there playing with an animal or walking around chasing chickens. I always found something to do on the farm. But sometimes I just wander off by myself doing things, and sometimes I walk up on stuff that maybe I shouldn't see. I'm always, I'm always curious. I always been curious, and I would run up on stuff I know sometimes I shouldn't see, but I seen a lot of stuff that a lot of people don't even know I see. I just don't say nothing about it. I just keep it to myself. [Section of narrative deleted by request.]

MF: Well, let me ask you about this then. Because your family goes back to, I know that it was settled like in the 1870s. So clearly your father passed on the importance of owning land to you, right. [Yeah] So how do you feel about, what's important to you about owning that, the property in Black Colony now? Why do you think it's important to do that?

MH: I feel proud, because I seen the fruit of what we did all our lives and how we worked all our lives. And what we accomplished out of all that, that our work didn't go in vain. We worked, but it paid off for the work we did. My father was a strong believer, and he was very, and him and my mother both was very religious people. But he always had a mind of doing things, and he instilled that in all of us. We was, like I tell them, we was bred to work, boy, because we did it. We worked, boy, we worked in places that a lot of people wouldn't have worked, man. We stuck together through all that. We stuck together through all that.

MF: And still together as a family?

MH: Yeah, and it paid off. Sure did. It paid off big time.

MF: Now will you hold onto your land and then pass it on to your eldest son or eldest child?

MH: I got two daughters and a son; it goes to them.

MF: Do you think they'll live there?

MH: I got grandkids that-

MF: One grandkid? 
MH: No, I got a bunch of them. A bunch of them. It was supposed to have been one or two I thought all I was going to get out of him, but I ended up, they started having two at a time! That's my son had twins, my daughter had twins. She had two sets of twins.

MF: $\quad$ Your daughter did?

MH: Yeah, and I said y'all too young to have this many kids, so they slowed down on that. But my son, he got five, I think. So I got grandkids, but it's getting past my kids, then it'll go to one of my grandbabies.

MF: Do you hope it stays in the family then?

MH: Yeah, it'll stay in the family. But it'll go to the grandbabies.

MF: You mentioned that you brought Moses Junior out there to live with you for a little bit. So do you think that he appreciates it?

MH: He might would, he might would. Yeah, he got the right to, yeah.

MF: Do you ever sit down and tell your kids about the history of your ancestors out there?

MH: Oh, yeah, yeah, yeah. I talk to them all the time. And yeah, I tell them. They know me pretty well, my kids know me pretty well.

MF: Are they interested in that history?

MH: Yeah, they, oh, yeah. They take it with a grain of salt, because they know their daddy's right. They pay me attention - they listen. They listen. They know I wouldn't tell them nothing wrong. I came through the hardest part of life that I don't think the average man could handle, and if Daddy can do that, then-

MF: What kinds of things did you pass on to your kids that were passed on to you by your parents? What kinds of ideas or beliefs or values?

MH: Have faith and hold your head up. And have a lot of will. Stay on the right track, and pray man, because that's what it's going to take survive in this world, because it can get out of hand. I remember one time, I had told my kids about a gas shortage. They was too little when we had the first gas shortage that I had to go put gas in two cars early in the morning before they ran out and I told them how it was. And it came down to one day it happened in Arizona, they ran out of gas, and my kids freaked out, they didn't know what to do. They called me, called me, Daddy, we can't get no gas. What we going to do? I said, "Oh, lord." I said, "Well, I tell you one thing, you get a chance, go find you a gas station you shoot up there and you get as much gas as you can get, and just go to work and back home, because it's going to be hard to get gas, and I can't bring you no gas from where I'm at." So they listened to me, and I told them, I said, "You just have to catch a gas station home and shoot and get some gas, because that's the only way you going to get it. Ain't nobody going to give you a chance to get in there. You going to have to work your way in the gas station." They couldn't believe that, but it happened to them, and man, that was a new leaf in their life.

I had told them to be ready for stuff like that. I had already told them, I said, "There are going to be days, it's going to be days sometimes that it's going to be hard to feed your family, it's going to be hard to get hold to a dollar, it's going to be hard to do a lot of things. But you got to understand one thing. You got to understand, you got to have patience and you got to have knowledge. You got to have wisdom, you got to know something, you know learn 
something. Understand something about elder people you hear talking, understand what people been through in life. And if you see the direction that they've been, and if they didn't succeed in it, it didn't work out for them, well, then, don't you go and try to do what they did, because it won't work for you. What won't work for somebody else won't work for you. You got to make your own plans in life. You got to figure your own way out in life. You can't depend on nobody to show you every step of the way. You got to learn something on your way." And I said, "You get jobs, try to get the best jobs you can get and learn, learn real fast, real fast learner about anything. Just slowly, you see somebody do something, you watch them for a few minutes and see how they do it, understand what they doing, and then you try to do what you think that they did, you try to do it and see how you come out." You know what I mean. But if you try to do things yourself sometimes, figure things out your own self, instead of waiting on everybody to tell you which way to go. Man, that's going to be rough. You got to figure things out your own self. And understand what's good for you, because it can get hard out there sometimes. And when they got to them points, they seen that Daddy was right.

MF: $\quad$ Now you knew from experience, too.

MH: Oh lord, yes. They get with them kids, they can't buy them kids what they want to eat, it's a different picture there. And when they learned that, when they seen that, they changed. They changed a lot of things they was doing that wasn't right. They sure did. They started looking at what Daddy said, and it's working out for them pretty good.

I've had my two daughters that graduated. I flew to both of their graduations. I was flying back and forth like I own an oil well. I was flying, boy. I was flying a minute. And people would get upset because I was flying so much, and they didn't understand what I was doing. But my daughter, when she started having them kids, I was here for her, boy she was sure glad Daddy was here for her. Sometimes her car stop on her out there, and them twins being there. She'd mess around and lock them up in the car and leave the key in the car, and, oh, man. She called me, I got to go where she at and help her get the kids, get her car open so she can get to the babies. And when you have a parent that can do that, it helps her out so much that they appreciate their parents.

MF: Did your parents do those kinds of things for you?

MH: Well, no. I didn't have a lot of kids for my parents to do too much. Man, I helped my parents more than anything. But if I had to leave a kid over there for about a hour or thirty minutes or so, I would leave them with my mother, yes. I would leave them.

MF: Now I spent a little bit of time out at the colony. It seems like everybody kind of depends on one or another for that, kind of like child care and things like that.

MH: Yeah. Yeah, we helped each other out a little bit. But it came a time-Like in my family at the time, I was the only one could make the money I made. I made more money than anybody in my family. I had the top-priority job that I made more money than anybody in my family. I was the only one with that money thing. And my father, since I been born, I never known my father to be broke, to be broke, period. I didn't understand it. One day in Phoenix, while they was still living in Phoenix, I had seven kids, and my kid's momma didn't work, she stayed at home.

MF: You had how many kids?

MH: Seven.

MF: They were your-you had- 
MH: No, they wasn't all mine, but I was taking care of seven kids. Because I had three of my own, and she had four. So I was, like I said, I was in the money. But one day I had got off of work and I was sitting around my house doing something. I'm always working around my house. And they came over, and they said Daddy. I said, "What's the matter?" They said, "Daddy's broke." I said, "Daddy's broke?" "Yeah, Daddy's broke." I said, "Well, why God Almighty, how in the world," I said, "how in the world Daddy get broke?" They said, "I don't know, but Daddy's broke." I said, "You got to be kidding me! I ain't never known Daddy to be broke." They said, "Well, he's broke." So they said, "Well let's come up with some money to give Daddy so he won't be broke." So I think they all chipped in and gave $\$ 50$ a piece. They gave that to him, and I gave him $\$ 100$, and I said well, that will help him out for a while. But I gave him $\$ 100$ every week until he got back on his feet. I gave him $\$ 100$ every Friday that I got paid, I gave my daddy $\$ 100$. I made sure he wasn't broke.

MF: And it sounds like everybody helped take care of him.

MH: I did that, yeah, I did that. I gave him $\$ 100$ a week for about two or three months before I realized he was back on his feet and then I didn't have to give it to him no more. But yeah, if one of them get in a clench hard enough, they all come together. They'll come together and do what they have to do. But if they don't have to do it, they won't do it. If they don't have to spend they little money, they won't spend it.

MF: $\quad$ Tight with money?

MH: Yeah, they won't spend it at all. But if it get down to it, and they really, somebody in the family need it real bad, they'll find a way to come up with something. They'll come up and help each other out. Because I always helped them out when I was working. I was able to do it, because I guess wasn't nobody else in my family ever made that kind of money.

And my father, I helped him get more money than what he was getting for his job. I told them people that I wasn't going to let him work out there no more if they didn't give no more money than what they was giving him. And they didn't like it, but they liked his work. But they didn't want to pay him much. I made them pay him; I said he ain't got to work at all if you don't pay him right. So they started pay him right, and he was tickled of it. He couldn't believe that they was paying him like that. I said, "Daddy, you can't continue to do things like you used to do doing. Things change in life. You got to change with time." But he was a goodhearted man. He would help people, boy he would help people. He see somebody needed a loaf of bread or whatever, you know, he would buy you the bread or give you the money to buy it. He was that type of man. Sometimes he was, he was too freehearted. We had to get on him about it sometimes as he got older. We would have to get on him and watch him because he let his money slip away from him. People know how kind he is and they asked him for money all the time, loan me this, loan me that, and then they don't pay it back. But he was a giving young man.

MF: Let me ask you this. In terms of what your father and mother taught you about being a young man. Did they, did your parents treat the boys and the girls differently growing up?

MH: Not really, not really.

MF: You don't think so?

MH: No, because them girls was just like boys. No, I didn't. Well she took care of the girls, oh yeah, she would take care of them girls. She take care of them girls. She made they clothes all the time, she take care of them girls. She didn't want nobody messing with them. She didn't want nobody messing with them girls or tearing their clothes. 
MF: What did your father or your mother tell you about how to treat women?

MH: Oh, my mother, man, she told me about how to be nice and kind to women. And I did that. She told me, don't be mean to them, be nice to them, and treat them with respect. She taught me a lot about how to be nice to women. Which I did, I did do just what she said, too. And it worked, it worked.

MF: And how old were you before you were allowed to date?

MH: Before I was allowed to date?

MF: Or did you just date without asking?

MH: I was dating whenever I said I'd like it! [Chuckles]

MF: Okay, so how old were you when you started dating?

MH: I never did ask nobody could I date. I never did. I never did. But I did some real crazy things when was all young. We did stupid things. My daddy had me watching my sister mostly, trying to keep boys away from her, you know. Because he didn't want no boys messing with them girls, because that was his help, and he didn't want nothing, nobody messing them girls. And if they go somewhere he would have me to follow. He would have me to tag along so I can tell what they doing. I did for a while, but they got smart on me.

One day, them twins, you know twins, they come up with some weird stuff, boy. And I was following, but I couldn't follow them both at the same time because they split up on me. If they split up, I'm lost. I don't know which one to follow, and I just be trying to follow. I'll follow one of them if I lose the other one, I'll follow one of them. Because I know they going to meet up later. But then they got where they changed language on me. They started talking another type of language, and I didn't understand what they was saying. So I couldn't keep up with them no more. They started talking pig Latin or something. I don't know what it was. I didn't understand it. E-tay a-tay o-tay. Oh, no. And then they split up, boy, and they'd lose me then.

MF: So your parents obviously thought in terms of the boys and girls that they worried about the girls obviously.

MH: Yeah, yeah, they was growing up, and he didn't want no boys messing with them, because he needed them girls to work. They worked. Them twins, they was something else. They worked like men, boy. And during the-like when he bailed hay or something, them twins worked together. One on one side, she's threading the wire, and the one on the other side is tying it. Yeah they worked together. Them twins.

MF: Now were there duties around the house that were just for the boys and just for the girls or-or everybody had to do everything?

MH: No, we did everything. We did some of everything together. Everybody had a certain amount of cows to milk. And everybody had they chores, oh lordy, yes. But the girls, they would, well, Martha, she would learn how to cook. Martha would learn how to cook from my mother. Mary, she was mostly was into books. She wasn't a cook—she didn't never do much cooking. But Martha did, she cooked. And then my mother taught all of us how to cook, the boys, too. Said one day you going to need to know how to cook. She said, "You can't go buy food everyday at the cafes and stuff. You going to have to learn how to cook." So she taught me how to cook. 
Well, she taught all my brothers how to cook, yeah, they learned how to cook. Them boys can cook, oh lord, yes.

But Martha, when she was home, she did a lot of cooking. But mostly my mother cooked all the time. But everybody worked. My mother worked, and she would make sure we had lunch before we go to work and everything. She did it all. Sometimes she'll go home, fix dinner, and we'd be out there working, and when she'd get it done, she'd call us and we'd go eat. And then we get through, go back to work. But she took care of all that, yeah, my mother did. And my father, he can cook, too. He learned how to cook quite a bit.

But him and my mother, when I came along, my mother she had one eye when I came along. I remember, well, I was just, I would always look at her, but I never did understand why she didn't have two eyes. But as I grew and got older, I learned.

MF: Oh, it's from the storm right?

MH: Yeah. She was in the storm, my dad told me about it. And he was working on the railroad track when it happened. He was looking at it happening, but it wasn't nothing that he can do. And he told me the problems she had and things she went through, and then she still had twelve kids. And she was a woman and a half. She did all that, boy. She could see good, she did everything she wanted to do. One day, in Arizona once we was in Arizona, one day my sister, one of them twins, decided to get her and put it in there. Lord, that blew my whistle clean out the top!

MF: You weren't having it?

MH: No, I said, "I ain't having that, no." No. You got-no, no, you can't do that. No, you can't do that. [Chuckles] I was born she had one eye, and that's the way I want to see her. Let it go back like it was. I couldn't deal with that, I couldn't deal with seeing her with two eyes. That was strange. But I just, if it wasn't the way it was when I was born, I wouldn't understand it, you know. So don't change it now. No, no, been too long. Don't change it now. But they wanted to see, well she wanted to see, too, what she would look like with both eyes, because she knew before it happened, but she never did really know after it happened how it would be with two eyes. And they finally let her see, and she wasn't really too thrilled about it herself. She didn't seem to really.

MF: So she got a second, she got another eye put in?

MH: Yeah she had it for a few months, and then we didn't want it there.

MF: Was it just a glass eye?

MH: Mm-hmm [yes], yeah, it was a glass eye. She looked nice with it, but I just, it just didn't seem like my mother. We led that one slide away. But other than that, we had a pretty good life out in the country. Everybody that was raised there, we finally moved away, and then they back there. Right back where they started, years ago. 


\section{Samuel Leslie "Les" Harper, Sr.}

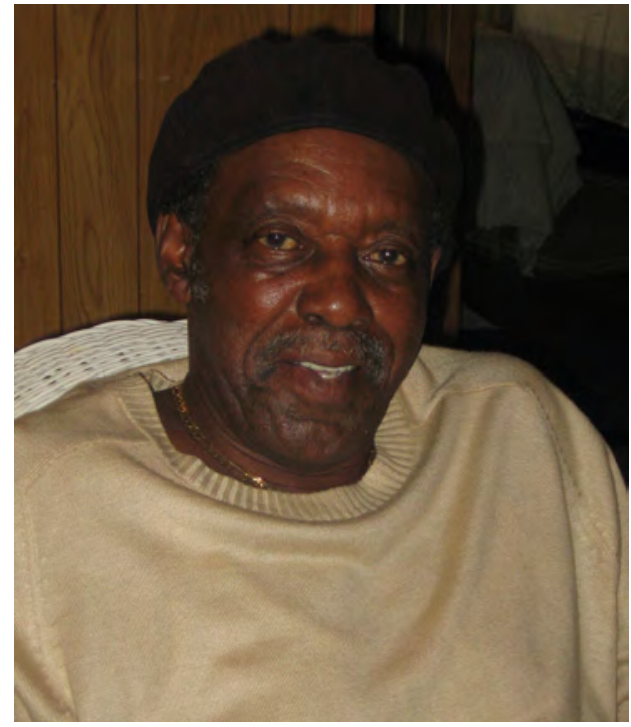

$\begin{array}{ll}\text { Birth Date } & \text { 6/10/1945 } \\ \text { Residence } & \text { Antioch Colony, Buda } \\ \text { Time Span } & \text { 1945-1955 }\end{array}$

Interviewed by: Nedra Lee

March 23, 2009 (1 of 2)

NL: Good morning. This is Nedra Lee. Today is March 23, 2009. I am interviewing for the first time Mr. Samuel Harper. This interview is taking place in the home of Mr. Harper in Buda, Texas. This interview is part of the Oral History Program for the Ransom Williams Farmstead Project.

Good morning, Mr. Harper. How are you doing?

SH: I'm doing fine.

NL: I wanted us to start off by talking about where you grew up here in the colony, and I was wondering if you could actually start off by telling me about the house that you were raised in?

SH: Well, it was an old house, and we cooked, we used wood. Back in that time, we didn't have electricity, so we had kerosene lamps and wooden stoves, and just old stuff, you know? My grandmother's stuff, my father's parents' stuff, you know? Stuff like that.

NL: Do you remember when the house was built?

SH: No, no, no. It was built when I was born, so I don't know.

NL: How many rooms did it have? 
SH: Well, maybe two, two or three, three maybe. It was-it wasn't like the modern houses. It was just some rooms sectioned off. And it was okay. No electricity, but we used, like I say, kerosene lamps for lighting, and wood to cook. And we raised most of the stuff on the farm. It was a farm, and-that's about it, you know?

NL: Do you remember what the house was built of?

SH: Wood. Wood, and we had a fireplace with a brick chimney, but the rest was wood.

NL: Did you have outdoor plumbing or indoor plumbing?

SH: Outside. Outhouse.

NL: Did you share a room?

SH: Yeah, my brothers.

NL: If I asked you to draw like a floor plan of it, would you be able to draw a floor plan?

SH: How the house was?

NL: Uh-huh [yes].

SH: No, I couldn't draw it.

NL: You couldn't draw a floor-now you said you were on a farm. Did you have any other outbuildings outside of the house?

SH: Had a shed like for a washroom and washed out there. You know, we had one of them old ringer washers and stuff.

NL: Okay. What about a smokehouse?

SH: Yeah, we had a smokehouse, yeah.

NL: $\quad$ How else did you keep your food if there was no electricity?

SH: Had a icebox. We get a big, maybe twenty-five-pound block of ice and put it in there. That keeps the stuff in the icebox cold, keep it from spoiling. And then, you know, and the smokehouse. Mostly we had a lot of smoking.

NL: $\quad$ And it would keep it cold for a whole week or two weeks?

SH: Yeah, keep it cold, you know, and ice would get low and we'd go get some more ice.

NL: Okay, okay. Can you tell me about other areas of space? Were there any particular areas that you used for doing particular chores?

SH: No. Most of our chores were outside.

NL: Outside? What kind of chores did you do?

SH: Slopped hogs, feed the cows, milk the cows, get water out the well, stuff like that. 
NL: Was that only things that the boys did, or did girls help with that?

SH: They helped. They helped, yeah. Mm-hmm [yes].

NL: Did you have any chores that you specifically had to do?

SH: No, we just all did whatever needed to be done. There wasn't nothing that I just had to do or he had to do. If it's feed the hogs, we'd go, both of the boys go out and get the slop and feed the hogs or whatever.

NL: Okay. Now are you the youngest?

SH: Youngest, youngest.

NL: $\quad$ Are you the baby out of -

SH: Yes, out of my family.

NL: Okay. How many siblings do you have?

SH: Boys?

NL: How many total siblings were there?

SH: There was twelve. Let's see, seven and then [counts to himself]. Thirteen.

NL: Okay. So when you actually talk about family, who are you specifically referring to?

SH: $\quad$ My family? My sisters. Parents, sisters, and brothers.

NL: All right. What do you remember about your parents?

SH: Everything. How they brought us up and you know, all the teaching that come from my parents, you know, what I know.

NL: Tell me about some of the things your mom taught you.

SH: How to wash, sew, clean, and respect, and you know. My father taught me how to work and respect. It was all about respect and working. It's mostly-

NL: It's okay! [Laughter] It's just a conversation. Don't worry. So do you remember any kind of games you played as a child?

SH: Oh, wow. We didn't-You know, like I said, it was back in the forties and fifties. We didn't have no bunch of-Well, we played games. Like, you know, between us and all. We worked, mostly. There wasn't too much playing, you know. But we rolled tires, put some acid in the tire and roll them down the road. You know, it looked like a car coming, but it would be me and my brothers rolling them tires. Be all dusty. We drove tractors, and like I said, work, work, work, you know. There wasn't too much play. [Laughs]

NL: Okay. So besides the tires, did you ever have any toys that you remember?

SH: I remember getting a little fire truck. Maybe it was like in '50 or something with a little siren and a little lights. That's about the only really toy that I can think of. The rest of the stuff 
we just made things, you know, like took a bucket, a gallon bucket, a serve bucket, you know, after all the stuff was gone. We'd fill it up full of dirt, punch some holes in it, and put a clothes hanger, and we'd pull it, and make it pop a wheelie and all kinds of stuff, you know? Other than rolling tires, chasing cows, riding cows, and just country stuff, you know? That's-most of the playing we'd go to the neighbors and we just played. Run around, maybe hide and go seek, roll tires, or just climb trees. Just kid stuff.

NL: Mm-hmm [yes]. Now who were the children that lived next to you that you played with?

SH: Well, whenever I say next to us, we had to come over here from Buda. You know, there's some more black peoples over there that, who came up. We came up to Buntons and Sorrells, we came over there maybe some nights and all weekend, and while the parents talked to the parents, the kids played. We just played whatever come in our mind. That's it about that.

NL: Now what about when you became a teenager, what kind of things did you start doing for fun?

SH: I was in Arizona when I became a teenager.

NL: How did you end up in Arizona?

SH: We left in-My father and mother died in '55, 1955, and he left and went to have his own farming cotton. Well, they was out there working anyway picking cotton, and then my sister wrote him a letter to tell him that his mother died, and they came back. He buried her and sold everything — cows, tractors, and everything — and then he went back out there where the cotton was where make more money, and been out there ever since.

NL: Now I'm a little confused. Were these your grandparents who had passed or your parents?

SH: $\quad$ My grandmother passed.

NL: Okay. What was your grandmother's name?

SH: Ella.

NL: And what was your grandfather's name?

SH: I had never seen my grandfather.

NL: Okay. Now when she passed, that's when your-

SH: That's when my father came back to take care of the burial and stuff, and then he went back and sold everything and packed up what we had-stoves and sacks and cotton sacks and everything - and then left, went to Arizona. The first place in Arizona we stopped was Florence, Arizona, and we just chopped cotton, picked cotton and chopped cotton. That stopped, but I think it was-like cotton pickers came in like in '62 and then I started doing other work like harvest work, field work, potatoes, onions, you know stuff like that. All vegetables, fruits and stuff like that. Pick oranges, potatoes, lettuce, watermelons, carrots, cabbage, you know, all that kind of stuff.

NL: When you moved to Arizona, was that your first time leaving the colony?

SH: Yeah. The first time we'd ever been out of Buda. [Laughs] 
NL: How old were you then?

SH: I was ten.

NL: You were ten?

SH: Yeah, yeah.

NL: Were you scared about moving?

SH: No. It didn't—no. As long as my mother and father were there, we weren't scared of nothing, because he provided for us, so-And we didn't have no worries at a young age because everything was provided, you know. He seen that we ate, seen that he had the livestocks and things and chickens to feed his family, you know. Yeah.

NL: $\quad$ Are your fondest memories of growing up here in the colony or actually out in Arizona?

SH: I had some, like I left here when I was ten, so I had a few little memories. Yeah.

NL: $\quad$ Mm-hmm [yes]. Let's go back to kind of growing up as a child here in the colony. We talked about your house and what it looked like. You told me that you kept animals. Can you tell me what type of animals, and you mentioned like cows and hogs-

SH: Cows and hogs, mm-hmm [yes].

NL: -and things like that. Do you remember where those animals were kept?

SH: In the pasture.

NL: In the pasture? Okay. Was that close by the house or far from the house?

SH: Some was close to the house and right around the house, outside the, you know, house and the fence.

NL: Do you remember when you were growing up, did you ever help in fetching water?

SH: $\quad$ Sure, yeah. We had to pump our water. By the windmill, we'd pump. We had this faucet, and you'd set the bucket up on it and pump it until the water get up and then fill the bucket up and then take it in the house. Yeah, be a lot of drinking water and cooking water. It was the only water we had! [Laughter] If it wasn't for the windmill, we wouldn't have had no water. And we hauled water. Or if we broke something and went to Buda, and they had a big thing. They had a-Where they can fill it up, fill the barrels up. We'd take the barrels up there and they'd fill them up and maybe three or four barrels and bring them back and dump them into another barrel and then that's how we got our water. Dip it out of there, fill up the pail and then take it in the house, and water the hogs and cows and things. That's the only source of water.

NL: $\quad$ Now I hear you all went to Buda a lot. Is that when you all went shopping for food and other kind of household products and clothing?

SH: Well, a lot of clothes. Yeah, clothes, some she made and some we bought. And food, everything was there. Chicken, you know we had everything. Wanted some chicken, we'd go wring his neck. You know, want a hog, you'd kill him and clean him and put the meat in the smokehouse. Or you might kill a deer out in the fields or a rabbit or something like that. But 
a whole bunch of food we really didn't have to buy. It was all provided for us there on the farm.

NL: Now what did you all mostly buy in town?

SH: Well, as far as I can think of, that'd be some flour and maybe sugar or something. As far as I know. But, most of the stuff as far as needing any type of vegetables, we had it all on the farm.

NL: Mm-hmm [yes]. What stores do you remember going to or your parents going to?

SH: $\quad$ Up there in Buda? Mary Montague, Mary Stacy.

NL: Was that a black-owned store or a white-owned store?

SH: $\quad$ Grocery store. Huh?

NL: Was it black-owned or white-owned?

SH: Oh, white-owned.

NL: Do you remember the owners at all?

SH: $\quad$ Mary Stacy? [Yes] Yeah.

NL: Was she a nice woman?

SH: Yeah, she was nice. She-you know, my father perhaps he went there and got some stuff and didn't have to pay at the moment, but he'd pay it when he sells milk and eggs and stuff like that.

NL: Did you go shopping with your parents often?

SH: $\quad$ Shopping for what?

NL: $\quad$ At the stores, or did kids stay home?

SH: No, we stayed in the car, yeah, and my mother and father went in and got the groceries, what groceries they got, yeah.

NL: Did they ever shop from catalogs?

SH: No, I think we just went to the store. They go to the store and buy clothes. But that was about all the shopping, best I remember.

NL: Do you remember ever trying clothes on in a store?

SH: No, he knew what size to get.

NL: How did you know?

SH: He know what size you need.

NL: $\quad$ He knows what size. 
SH: Parents know what size to get. Yeah. He know what we wore. We didn't wear that much different stuff anyway-blue jeans, overalls. We were really down and country. But wasn't way back in the bushes, but we was country. It was a dirt road, where we stayed at, and we just lived and played out there. My father was gone picking cotton, and him and my brothers and people, and we stayed home with our mother and done the chores, feed the cows and all of that stuff. That's it. We was like the man of the house while he was gone. She knowed what we had to do, so she-We knowed what to do. Feed the cows, slop the hogs, go milk the cows in the morning if we needed some milk. Needed some eggs, go out there and run the chicken off the nest and get the eggs. You know, stuff like that.

NL: So when your father was away, did you have other responsibilities? You by yourself?

SH: No. She would just say, "Slop the hog," we'd go slop them. Go milk a cow, or she might send one out there to go get some milk or something, and we'd probably both go out there. We liked to milk them cows, you know. So whatever she told us to go do. We really knowed what to do.

NL: Right. Now tell me. Did you all have a lot of store-brought medicines on hand in the house?

SH: Watkins Man.

NL: What's that?

SH: [Laughter] Old Watkins Man, you know, they go around and sell medicine, like old remedies and a lot of stuff that my mother and father, you know did. If we was sick, you know they get some turpentine and some lard and rub it on us for colds and things. Not that we never did-Not too often we see a doctor. They did all of that. They'd give us some if we was sick or such. [Laughs] Johnny-[laughs] Yeah, so-yeah. They was our doctor, unless there was something that they couldn't handle, and I don't know what that could have been. But I think I seen a doctor come to-They were making house calls. I was thinking about one time that I remember.

NL: Growing up?

SH: Yeah, from one to ten, yeah.

NL: Oh, wow.

SH: Yeah. From then on, we was in Arizona where, a little cold or something, they know how to do that. They got their own, all of my sisters and brothers. People learn that, just like a midwife, you know. They know how to deliver. And the men-he knowed, my father knowed how to doctor. He learned from working or his mother or neighbors or something. But they did all of that. There were no doctor too quick.

NL: You said you saw a doctor maybe one time from one to ten?

SH: $\quad$ One to ten. I can only remember a doctor came out there one time, and I don't know what it was we was sick of. I don't know if it was the mumps or some little thing that you know he came out to check us out, but that was all. One doctor, one time.

NL: $\quad$ One time.

SH: Yeah. I don't think we needed him then, but he came out. They called him and he come out with his little black bag, and you don't see that no more. [Laughter] It was all good. 
NL: How would you call him out?

SH: The doctor? [Yes] We'd have to go up there and get him. You know, go up, you know, go by and tell him he can come out. You know we didn't have no phone or nothing like that. He go through town. He's go by and tell the doctors when he come by it might be a day or a couple of days or something before he come out, but he'll come out. He may come out that evening or that night or something. Yeah, and check us out, little things, check us out, and tell my father and them what to do or what it is like that.

NL: Now did your father ever share any of those sort of home treatments with you? Did he ever share them with you?

SH: He'll tell us what it is when he put us on it. Like liniment, maybe some turpentine and certain things, you know. Like I say, he had some turpentine in a little pan and heat it up with some grease and then he'll rub our chest. Or Vicks and stuff, he'll rub that, and he'll rub all the stuff on our throat. And take one of them old iron irons and if we had a real bad cold or maybe something about pneumonia, he'll wrap it, heat it up, and put it to the bottom of our feet and keep our cover up. And that draws the stuff out or done something-we were well in the next day or two. Yeah, and you know with rubbing, and staying up under cover, we'd cough that stuff up, and like I said, a day or two we were right. We were back out in the field. Yeah, so-

NL: Oh, wow. Do you ever use any of those treatments today?

SH: I've used some. I've used some Watkins liniment, not none of that heating iron, because I don't really know how to do it. But you know like the Watkins man liniment stuff, you know, for stiffness and some of that salve they had look like some axle grease. If you get a cut or something, put it on and [Snaps fingers] it would draw it right up and draw it and heal it. You know, I'd use it right now if I had some! But the Watkins man don't come out like they used to. They drive around the country and have stuff in the car, medicine and stuff that all the people buy to use on their kids, or they-But for us, just medicine and maybe some other little stuff they'll have that keeps them going to the store. They just ride around the colony and sell that stuff and black people bought it. You know, white people, too.

NL: What other stuff did the Watkins liniment man-Watkins liniment?

SH: They call him the Watkins Man, but that's what he sold. Liniment, you know, all kind of stuff for the older people, stiffness and, you know, if they sick, they have some stuff that you take and you'll be all right. You don't have to go to the doctor unless you got all cut up or something, shot, but other than that, as far as a cold, pneumonia, they take that away.

NL: $\quad$ So the Watkins Man and the midwife and your parents were really your main source of doctors.

SH: Yeah. Yeah, yeah. I know a midwife delivered. I don't know if they delivered me or not, but uh. LeeDell, he's the first black baby that doctor delivered up in Buda, and the rest of them, you know, we was home deliveries. They had a midwife. It was a lady named Aunt Kate, we called Aunt Kate. One of them women get pregnant, she'll go do it. You know a lot of them know how to do it theyself.

NL: Her name was Aunt Kate?

SH: That's what we called her, Aunt Kate. She was related to LeeDell. 
NL: $\quad$ She was the midwife?

SH: Yeah, she was the midwife. There's a couple of them around that knew how to do it. [Laughter] Yeah.

NL: Do you know how she learned midwifery skills?

SH: That's before my time, I guess, because back in them days, they didn't go to doctor and stuff. They knowed. I don't know how she knowed, but she knowed. I'm sure she learned it while she was young or something or maybe her mother taught her or somebody. But she knowed how to do it, and that's where everybody went.

NL: Did Aunt Kate deliver any of your siblings, any of your sisters and brothers?

SH: She might have, she might have. We never talked about it, but I'm sure she delivered a lot of them out here, yeah.

NL: Do you remember what Aunt Kate looked like?

SH: Yeah. She was a heavyset lady. You know they wore them aprons and things then. I don't know if you know, an apron over her dress. She just dressed, stay out in the country. You know they didn't have nothing. They didn't try to style or nothing. They dressed for work and whatever 'til they go to church.

NL: Now did she have her own set of medicines when she'd go from house to house that you knew of?

SH: No, no. Not—no, no. She just go if they needed something or you know like they deliver a baby, maybe sick or something, you know. Stuff like that.

NL: Mm-hmm [yes]. Did you ever go to Aunt Kate's house?

SH: Yeah, lots of times, lots of times. My mother used to go by and see her, and we went wherever she went. We didn't - they didn't believe in babysitters. Wasn't no babysitters in that time. We'd go where our parents go, and she maybe leave us if my father takes some wood to sell in town, some milk or some eggs, my mother go with him, she would take us over to her niece's house and leave us for maybe about a hour or two or till they sell the wood and the milk and the eggs and whatever they sell. Then she'd come pick us up and we'd come back to the country. Yeah.

NL: Okay. Now you mentioned that your parents would sell milk and eggs. They also picked cotton. Do you remember any other jobs that your father did?

SH: He—all I know my father did was pick cotton and sell, you know, stuff work work out—We'd go back up in back woods and cut down wood. You know, that clearing off the land. Cut wood up and he'd go sell it, he'd go to town and sell it. Milk we got from the cows, we had some old milk jugs look like bowling balls and go to town, sell milk, sell wood, sell egg, sell whatever he could, you know? Yeah, to support his family.

NL: What about your mom?

SH: She was there with him. You know, she was always-She was mostly a house lady, but she'd work right along with him. She picked cotton, too. She done everything that he did. Yeah. 
NL: Who did most of the disciplining in the house?

SH: Both of them. Yeah, both of them. Both of them. There wasn't no "He say, she say." Whatever one of them say goes. Yeah.

NL: Who was more strict, your mom or your dad?

SH: Dad did all the providing. She mainly cook and wash and sew and took care of the kids, but she, when it come down when we had to go to work some place, she went. She chopped. She done everything. So yeah.

NL: Of your parents, who taught you the proper roles of what it is to be a man?

SH: They both.

NL: Do you remember any of the things they told you specifically?

SH: Well, we were brought up on work and respect. You know, we respect the elders. We all were taught to respect the elders, and then she taught us how to do things that she say, you know, anybody, everybody, anybody go through the things for us that she'd do, like take care, wash your clothes, and this and that. She just taught some things that take you through life, as far as, you know, providing for yourself and keeping clean. Just stuff like that.

NL: Was there ever a saying that she would always tell you that always sticks in your head?

SH: $\quad$ Stop playing so much, you know, and learn how to do things. You know, they prepared us for these days.

NL: Tell me about school.

SH: Oh, well, they had a little school right down here, just a building, and they separated it and maybe like from this side went to the first to the maybe the fourth or something. Then on the other side, it went like from the fourth to the, I guess to the eighth. But we had a building with one room. All of them on this side, them on this side, and they'd cook. They had-We had stuff like peanut butter. Oh, most, a lot of them brought they lunch. They'd bring some syrup, biscuits. Whatever you had at home, they'd bring it to school for lunch. They had a cafeteria where they'd cook some stuff, and you'd get it and you walk out there in the fields and eat it. We'd all walk out there in the bushes and have lunch and then come back to class.

NL: Did you like school?

SH: You know, take it or leave it. I had to go, but it was a black school. The white school was over here, and the Spanish school was over there. After we left in '55, the segregation came out where they put the blacks with them, you know, with the whites, but we was gone before then. When we were here it was blacks over here across this creek, wasn't nothing across this creek but black, you know. You couldn't go to school over there. You know blacks couldn't do a bunch back then. Yeah.

NL: Could blacks go to school with the Hispanics?

SH: Nah. They had they own school and the whites had their own school. The blacks had their own school. We wasn't all together until after '55. Far as I know, after '55. When we came back, guys, you know, that went to school would tell us that they went to school with the whites and how they was fighting and they was calling them the N-word and a bunch of 
things, you know. So they wasn't used to that. We never did experience it because we had left and went to Arizona, and there you know, they wasn't doing that then.

NL: $\quad$ Oh, really?

SH: Yeah. When we went to Arizona we went to school with everybody, whites, blacks, and Hispanics. But down in Texas, it was pretty rough.

NL: Now was that your biggest shock when you came back to Texas from Arizona was the racial tension?

SH: Yeah. You know, we came back and we seen the people that we grow up with, and they was telling us about how they were done to when they went to school when they bussed over to the white school, how them kid would treat them, and they was fighting all the time and stuff and names and stuff. It was kind of rough, you know, for them. Like I said, we never experienced it because we was gone before then. But if we had stayed a little longer, well, we'd have went through it, too. But my father's, grandmother died, he left. He booked up and left Texas. He didn't have no reason to be here no more, I guess. He sold the stuff that we had, like tractors and rakes and things we used. We had old things, where we'd do the milk. Pour the milk and it would separate it, separate the cream from the milk. Then, you know, the cream would make the butter and we had a churn, we'd churn it to make the butter and then had a wooden thing block it. Then he'd go to town and sell that and sell the milk and whatever. So the same thing we was eating, you know. Whatever we ate, we took some. And stuff he killed he'd put in the smokehouse and we ate that. A lot of people that need some things come from town, come by here and get eggs and get them some and go back, take home to feed. They had a lot of kids, too, and feed their family. We just helped out. Everybody out here back in that day, they helped each other. They'd look out for one another. If you didn't have some, they'd give it to you or help see that you, see that you could make it. That's how that went.

NL: I actually want to go back to the separate schools for blacks, whites, and Hispanics. Do you actually think that-because Antioch was an all-black colony, right?

SH: Yup.

NL: So do you think that growing up in an all-black community helped shelter you from the racism that other blacks had faced in places like Austin or Buda?

SH: Excuse me. Could you repeat that?

NL: Do you think that growing up in an all-black community helped shelter you or protect you from the racism that other blacks experienced maybe like in Austin or Buda?

SH: Did it protect me?

NL: Yeah. Like did it pretty much shield you from experiencing that?

SH: Yeah, yeah, yeah, yeah, yeah. Yeah, yeah.

NL: Did your parents or any of the other elders ever talk to you about racism?

SH: No. Racism didn't appeal to us, you know. My father know where to go and what to do, and he never drank or smoked anything. He mainly just worked, and he never did mingle with them no more than doing some work for them, for the whites. But he never did fool around. Only 
time he go to Austin is to sell stuff and go to see his sister and nieces and things like that on Sundays or Saturdays or something. But he never did fool around with peoples, and we never did fool around. First time I ever heard the N-word, I was in Arizona. I think I was about thirteen years old, first I ever heard it. You know, I never heared it down here, never heared that talk, and people didn't talk like that. But the older one knowed what not to do and what to do and they taught us. You know places maybe not to go or you don't go to this building on this property or such and such. But we just mainly just-We had enough out here where we didn't have to go outside of Buda, outside of Antioch. We didn't have to go to town to play. You know my mother go to work for some white lady, and she'd take us with her and we'd play with their little boys while she cleaned the house and stuff, and after she'd get through, we'd walk on back to the house.

NL: Huh. So tell me about the first time you heard the N-word.

SH: It was in Arizona, and like I say, I was about thirteen.

NL: What happened?

SH: It was this boy, he was a black boy over there. He was a neighbor. And my brother Moses, he was calling him to make friends, I guess. "Hey man, you know, hey, come here. Come here," and that boy said-We didn't know nobody. We was green as a can of peas when we got there. We're in town and he was calling this boy, and this boy was saying, "N, what you want?" you know? We didn't know what he was talking about. Like I said, never heard it. We thought he was calling somebody name when he said, "N, what you want?" We just looked. We just kept calling him. He kept saying that, but you know. Finally one day or two, he came over there and asked us, you know, name, "Where y'all come from, blah, blah, blah," and we didn't really know what to-We just played with each other out here. We didn't know how to fight. We didn't know nothing. I went out there and seen some people fight and I didn't know what was wrong, you know. Then I got into it, because you know, guys, you see it, you know. They taught me this and that. But we come from the country, and like I said boy, we were green. Talk about green, we were green, you know? We just played with us, you know, just the brothers. And like I said, when we went to somebody's house, we'd play with their kids because we all went to school together. But I never messed around with no white kid, Hispanic kids, nobody. Like isolated. But there was so many little kids out here-well, there wasn't that many. My father had-you know, we was the youngest, and Mr. Albert, Mr. Smith, he had a couple of grandkids. We'd go down there and play with them. But we didn't play with no whole bunch of people. We worked. Like I said, we worked, and I didn't have no really good childhood. When we went to Arizona, you know, we'd get out of school maybe like two o'clock during then, and the rest of the kids go to the park or go play and play basketball or whatever. My father sent my brother there as soon as we get out of school and go pick us up, go home and change clothes, and we'd go into the field and work for the rest of the day pick cotton for the rest of the day or chop cotton for the rest of the day. On Saturdays, kids go swimming, go play. We'd go into the field, you know. We didn't play around. Them kids wondered why we always going places and they wanted to try to do it, too. So they'd go home and they'd chop up all them people's cotton so my father could handle that, you know. So you know, we was just country people. We didn't know nothing about the city. Nothing about city until we went to see our auntie or something, but we didn't know nothing. [Laughter] We didn't know nothing. Like I say, we didn't even know how to fight. You know, or what we call fighting. I didn't know what fighting was. Never seen nobody fight.

NL: Did you ever ask that guy what was that word he used?

SH: Nah. He kept calling us that, but we didn't pay it no attention. We just thought he was calling somebody names, you know? We didn't know what no-Like I say, we never heard 
that word, and I was thirteen. That's pretty funny, you know, thirteen and never heard that, you know? Then Peter all tell him, "Man, you know, somebody call you that, you know, jump on them or beat them up or something," you know. But that's-You know, didn't pay me no attention. I ain't know what you calling us, you know. And it was kind of weird, but I learnt a lot as I grew up and went to school out there. I learnt a lot. We had to learn, you know? But I never heard that. We didn't know what he was talking about-we laughed. He goes, "N, what you want?" We laughed, you know? We didn't know what he was talking about, you know? I look back on it and think about it sometime, but you know, that's messed up, you know. They didn't use that word out here in the country, the black boys, you know. We-They didn't call each other that. I'd never heard it.

NL: Did you tell your parents what that boy said?

SH: No, I don't think we told them. But, you know, when we started going to school and started hanging around with, we heard him call me some of that and asked him what they were talking about. That's when they told us you know, somebody, some white person, somebody call you that, you know, beat them up. I'll go beat them up, don't argue with them. And I grew up. I knew how to do it. I got pretty good.

NL: Okay, so you did learn how to fight.

SH: Oh yeah, yeah. We learned pretty quickly. I didn't have, like back in my young days, even in grammar school I think I had about two fights, and in high school I had one. I didn't have no more. Ain't nobody fooled with me.

NL: Now your fights in grammar school, that was here in the colony?

SH: No, Arizona. Yeah, I think when we left here. You know you had to be about six before you'd be in the first grade back then, you know. So, you know, went to school here like maybe three or four years, and then we left and went out there. Then a lot of times we didn't go to school because school was about out, and then you know, we'd pick cotton and they'll say, well, school's almost out, you got to start when school started back, and, they kept putting you behind, you know. Like my birthday was in June. Okay, I couldn't go to school. I mean I turned another age before time to go to school again. So you know, that kind of held us back, you know. Not held us back. We couldn't keep up with it because the work, you know. It wasn't that we were dumb or nothing. It just when we went out there, there was a certain time of year where school about out and then they wouldn't want you to sign in, try to get in when you ain't got but two or three months to go to school or something like that.

NL: Who would help you with your schoolwork?

SH: Parents.

NL: Do you remember any of your teachers?

SH: One woman down there, she was a teacher all the time. There wasn't but two teachers, one on this side and one on that side, you know.

NL: But do you remember their names?

SH: Miss Woody.

NL: And she was the teacher here in the colony? 
SH: Yeah, she was teaching. Mrs. Joy Smith, Mr. Yancy, you know. Them's the only two teachers there was here.

NL: What did they teach?

SH: They taught-I don't know. Whatever they taught, you know, spelling and arithmetic and stuff like that. Yeah, they called it math, arithmetic, spelling, not too much. But when we went to Arizona, they taught you everything. It was kind of way back.

NL: So there were no white families that actually lived in the colony per se?

SH: No. All this here was blacks. The whites stayed a little further up that way or they stayed on the other side over here. It was scattered out, you know, a house here, a house way over there. It wasn't like it is now, you know, and our house, wasn't no other house around it. We went down a little-My father and brother stayed down that little old lane. We went down to him and his wife and stayed, and it was a little house over there where some more of his relatives stayed. But it wasn't a whole bunch of-My grandmother stayed down at the end of the field over where we at now, way down there where my sister, Ruth's house at, a little past her. She stayed down there in that little house, and that was it. Miss Smith stayed way over there. The lady stayed down there, older lady, and Aunt Kate and them stayed behind where that cemetery at on this side over back there, back there.

NL: Do you remember, did your parents ever tell you how the colony came about?

SH: Well, my father told me that you know-Well, he was you know, put it to me what he told me, too, that it was a missionary, somebody came through here one time and bought all of this property here and sold it to the blacks. I thought somebody-I seen it in the paper somewhere they sold it to the blacks for $\$ 2.50$ a acre, but then somebody sold it to the whites for $\$ 5$ a acre because they had the money for what they bought. That woman up there told me that they sold it to the blacks-He bought it all and sold it to the blacks for $\$ 5$ a acre and then told and had it put on the record and everything that they could never sell it. It was ours, but we couldn't sell it. You know, we always had a place to stay. The blacks always had a place to stay. That's why the black colony because there wasn't nothing around in here but blacks, and then the white folks went up there and changed what they could, and that's how they end up getting it now. They changed it to where-After that man died or something, then they went and changed it and took that off where they couldn't sell it and put it where it can be sold and such. Then after old ones died out, their kids and grandkids just sold it to people for money. You know how people do, once you die. You know, they just go through everything, take a bunch of it. It was like that, you know, but it wasn't nothing from over yonder to-wasn't nothing in this whole thing but black people.

NL: Did your father tell you how he and his family came to be here in the colony?

SH: No, they stayed somewhere back up here. But all I remember is that house up there, and upbringing in that house. You know, I heard him say things about who owned this. A lot of them people that owned it was our cousins and things, and he sold it to my father. You know, he didn't sell it to my father, you know-Well, after they got it, they switched things around after the man died and all that kind of stuff. But he stayed over there. Then Dayton's sister told me where we used to stay, you know. But I think that was before I was born, though, and stuff, but you know-But since I was born, what all I know is as I come up. But this lady up here could tell you everything you need to know.

NL: Okay. One of the things I would like to know-I mean clearly owning land was very important to your ancestors. Do you know why it was so important to them, owning land? 
SH: Well, they didn't have nothing, nowhere really to go. You know, back then it was really discriminating and prejudice and stuff. So like I said, this missionary came through here and bought all this for the blacks. They couldn't-they didn't have nothing. He bought it all for them and fixed it where the white people couldn't take it from us, couldn't buy it, you know. But after he died or whatever, they changed that. They put it on record down there and they changed that. Just stay where you could, I guess. Ain't got no fancy places, just a house, you know, and maybe some rooms in it and you know, big families, a lot of kids. You know, you couldn't have no room by yourself or nothing like that, so we just lived. Like I say, we stayed there cooking. We'd go out and chop wood and put it in that stove, and my mother cooked food on it, cooked whatever. Beans, whatever could cook, she cooked on that wooden stove, and that's for cooking and heating and everything else. We didn't have nothing running from room to room, you know, and it kept the house warm by keeping the doors closed and windows shut. It'd warm it up, and then all the quilts they made back in them day when they make them quilts, you throw a couple quilts on and you'd be all right. And stuff like that.

NL: How did your ancestors pass the importance of holding land on to you?

SH: $\quad$ My father, he had bought that, you know, way back, and he just kept it. He had a chance to sell it, but he just wanted to have a place for his kids, him and his kids to always have a place to stay. Back in the day, older people, that's what they bought a lot of things so their kids and things would always have a place to stay because they know how it was then and figured they might, you know, if they couldn't-if they didn't have anything, where would they go? So my father kept that all that time, and he had it before I was born.

NL: Really?

SH: Yeah, so he just kept it, you know, and when he died, he made the will to everybody. But they just bought it for their siblings-That's to have a place to stay.

NL: Did he tell you how he got his land?

SH: That man bought it.

NL: So your father got his land through the missionary?

SH: Well, I don't know if he got it through the missionary, but I know the missionary bought all this. But see, there was somebody before him had the money to buy a bunch of it. So they sold my father some. I don't know if my father actually bought it himself. I think it was a little piece he bought, but where we was staying, it was my cousin, his nephew. They was kind ofthey had jobs. You know, back then they had jobs, maybe like he might have been a teacher or something where they had the money. My father, he didn't-The only money he had, was you know, on the farm, you know, and he used to work for 50 cents a day.

NL: How much?

SH: $\quad$ Fifty cents. 50 cents a day. You know, a day—all day for 50 cents. Then, he couldn't really buy no whole bunch, so he just bought what he could, enough that, you know, take care of his family. My cousins let him have some, this and that, let him stay on they's land for I don't know what, you know, if there was any money involved, but just gave him a place to stay because he had quite a few children. Like I say, they looked out for you then. But this we're on now, he bought it. And I don't know if it was $\$ 5$ a acre, $\$ 2.50$ a acre. That's, $\$ 2.50$ a acre, you know, that was a lot of money then when you're making 50 cents a day or something like that, that's a lot of money. They bought just what they got. But you know, it was kind of tough. But we didn't have nothing to worry about because my father provided everything. He 
knowed what to do. And my mother, clothes and things she made and other stuff that if she couldn't make it, we bought it. But he did all the work. He done all kind of work to take care, you know, buy gas and just what you really have to have. Yeah.

NL: Wow. We talked a lot about you leaving Antioch to go to Arizona and you talked about coming back. When you got grown, do you remember any of the places that you left after Arizona?

SH: $\quad$ Places I left-

NL: That you moved to. Or did you always come back and stay in Antioch when you got grown?

SH: Oh no, no, no. My sister, I had a sister was—my oldest sister stayed-Marian, the one you interviewed-she was staying over in Austin, and we'd come down to, you know, maybe about a year or so to come down to see her, and like I say, my father's sister, and he had a brother. Nieces and nephews and everything, we'd come down. After we'd stay with her when we'd come down and spend maybe a week or something and go back up there. But as far as moving down here, he moved down here in '80. I think it was '80, my sister and them, they had moved down here and working, and they want him to come down here, you know, and just enjoy, kick back, and retire from work, you know, whatever. We all would come back just to see her and his sister. And after they died, we didn't—now my sister go out to his-my father's sister and things died, we didn't come back that often, that's how come my sister moved out there. So we really didn't have no really serious reason to come back, no more than just to get away. But he didn't really come back. When he left, he left, you know. [Laughter] He left, and he just come back to visit and go right back out there and do what he was doing.

NL: $\quad$ So when you decide to come back?

SH: I came back when they came to visit, but as far as on my own came back, I came back in '76, you know, brought my family down here and worked. Then it didn't seem too good. I wasn't into some of the stuff there, so I went back to Arizona because my parents were still there. Anyway, I went back out there and stayed. And then '80, after I got a divorce in '80, I was just-my partner moved down here. I came up where you know, I'm a daddy mama baby. So they moving down here, so I'm moving down here, you know. Then I stayed for a while. Like I said, it was all good and handled everything. Then I went back out there, and then I came back. Then I came back for good in '93.

NL: And you've been here ever since?

SH: Yeah, I believe so.

NL: Was it important for you to raise your children back here in the colony?

SH: They didn't know nothing about it. I ain't have them born here. They was all born in Arizona, you know, from '64 to '75. So they was all born out there. Now when I left, I wasn't but ten myself. So I didn't have no kids then. I wasn't but a kid myself. Then I brought them down here, you know, but I wish they'd never came down here, you know, in a way. But my wife or my sister and them brought them down here to get me down here, because I wasn't coming back down here. Because when I left, the way things was, I wasn't going to come back to that. You've got more freedom out there. So I don't want to come back.

NL: Now when you say freedom, you mean the racism wasn't so bad out there.

SH: Yeah, yeah, yeah, like it was when we left. Now after we left, things changed the way everything came together, but we didn't know that, because we was gone. Then when we 
did come back, well, then we learned that it was just about like I said, some of the blacks, it was kind of dangerous. But the whites, they never did fool with them anyway no more than working for them.

NL: What were some of the relationships like between local whites and the Antioch community when you were young?

SH: What it was like, how they feel toward each other?

NL: Yeah. Were they negative relationships? Did people keep a nice distance from each other except when it came down to working?

SH: Yeah. Yup, yup, yup. That's the only time they'd halfway mingle is work. They wasn't visiting none of them and they didn't visit none of them. So you know, the blacks visit the blacks out here, and the whites visit the whites. The Hispanic visits the Hispanic. As far as I know, we never did, and nobody did really. They worked for them and some they might have went to school with they might see, but they still don't go to their house and stuff. They don't really do that now. [Laughter]

NL: $\quad$ That was going to be my next question. Has any of this changed?

SH: Yeah. It changed, but you know, you really have to know. You know, you can tell when something ain't right. If it don't fit, don't force it, you know, and stuff like that jive. That's just-Like my sister and them, they talking about the, you know, be all up in their face and stuff. It's all good, but when it come down to it, I seen this for a fact. You know when it come down to it, they, police and everything, they come by and talk about how nice it is and blah, blah that. But when it come down to something flips, breaking the law, you ain't talking about la-di-dah. They'll skin and grin in your face, but what they mean-You know, you ain't all of that, you know. But they don't seem to want to pay it no attention, you know, when I tell them, I say, "You know, y'all ought not to be having these people come up and doing all this, and you know, they ain't going to do what they say. They go do they'll tell you anything," but some okay. You know, there's good and bad in every race. But some of them's all right and mean what they said, and some of them don't care, you know. But most of these people here whites here now come from other states or grandkids and stuff and they got grown and they've been to school, mixed school. So they don't look at it the way they parents did and they grandparents. They grandparents, you know, they had that hang up by, you know, you not equal in a sense, you know, and they treat you that way. There's some will treat you that way now. Yeah, in 2009 there's some. There was a place back out here in Kerrville, I think it was in '62. They found a slave camp out there, you know, and that was in '62 or earlier, and they think stuff like that don't exist. There's some around here now, and nobody don't know where they're at. You know, it's white folk got thousands of acres. Got signs "No Trespassing." You don't know what they got on there. And there's a lot of things-I don't fool around. I don't be walking all around and doing things that I used to do because people don't see it that way. You know, something bad could happen to you, mm-hmm [yes]. Find out nothing. There's a black guy got run over up there- there wasn't nothing about it, you know? Anybody — had no money, they just, he got run over. Some white guy think he was up there fooling with the white girls, and some of those guys caught him walking home. He always walked, but he riding a bicycle that day and run him over, and they found him next morning over in the grass over there.

NL: Was this recently?

SH: Back in '80-something. 
NL: Oh, wow.

SH: It's a lot of things happen way before then, you know, that people ain't never forgot. You know, it's some whites done killed blacks and some blacks done killed whites. You know, it's some blacks who just hard-core. They didn't care what you was, you know. But people like my parents and some of them, they kind of stay away from of them. They didn't want to get in no trouble, lose what they had, so they overlooked some thing. And some of them, didn't bother them. They came from somewhere else. So some blacks will kill some whites and whites will kill some blacks out here back in the forties or thirties or something. This lady was telling me about this black man killed this white man, and he was driving some mule and a buggy going, coming home. This old guy was coming home and this white guy was out in these bushes and he came out. They shot him and killed him for killing that white man, and stuff like that. Back in them days, white man killed a black man, there wasn't a whole bunch to be said, you know? [Laughs] But there's something happening now. There's somebody-You know, I'll be telling these kids, they'll be walking down these roads all through the night and stuff, because, you know, some of them white boys get to drinking and riding around through there trying to have fun. They'll run over you or grab you and take you somewhere and hang you or something. I don't put nothing past them, you know? My kids go to school when they think it's all good, but they don't know. They ain't been where I've been in. I keep telling them don't do that. That black man up here in Jasper, Texas, he went to the store, walking back home and white boys riding and drinking and throwed a rope around him and drug him behind their truck, you know, drug him, all his skin and leg stuff falling off. And they acquitted them. So you know, that's some stuff that can happen around here that you don't know. But I just don't-I don't fool with nobody. I know how it is, you know, and I don't put myself out there. I don't go where I know how, if I'm not comfortable. But a lot of them out here do. My sister and them, they just think they just still do, but I don't do that. I tell them not to do it, but they go on. They think everybody's the same. It's not.

NL: So they sort of think that times have changed.

SH: Yeah, it's changed some, but you know, it's still there's some haters, still some haters out here. You know, prejudice, very prejudiced people. But like I said, I just don't fool with them. They speak to me, I'll speak to them. You know, I don't put myself on them, you know, and I don't go to their house and they don't come to mine.

NL: Now Mr. Harper, do you remember when you all would go to Austin to shop, do you ever remember having to go through a particular door, like blacks not being allowed to go in the front or being able to sit down?

SH: I've been to a place in Arizona like that where the blacks had to go in the back door to this little club, little juke joint, and the white people go in the front door.

NL: Really?

SH: Yeah, in Florence, Arizona, back in '55, '56, '57, like I tell you. Those that went. I didn't go in there because I was too young, but after I got grown, I went to that same place. Black go through the back back there and party, and white folks come through that front door and go in there and sat up there and drink, shoot pool, and stuff like that. But the blacks didn't go up there. There was a door. Once you got up to the club [?], but they didn't come up in there. [Laughs]

NL: Well, how would you hear the music? 
SH: They got a jukebox back there for us. They've got the jukebox, beer, whatever you need back there, the same as they got up in the front, but you just didn't go up there. We didn't go up there. You go back out where we at and partied like you want to. But around there, you couldn't go through that door. You couldn't go up there where they was.

NL: Hmm. Was the place where blacks partied, was it a nice place?

SH: I guess so. Building where you know, a bar, but the blacks had to go back in the back to the bar. You know, go inside. There's some places right now in Texas that they tell you, "Don't let the sun catch you-Don't let the sun go down on you down there."

NL: Are they close to here?

SH: A little past Houston going back toward us. I don't know about Van Inkle [?]. I never fool around over there. We had a little black joint out where we went over there in Manchaca. Black people go in there. Them white bars and saloons and things, they didn't go in there. Maybe some of the older blacks that work with them might have went in, but the young men didn't go in there because they wasn't going to put up with some of the stuff they might would say, you know? They get you niggers to drinking and start talking about my best friend was a colored boy and all that kind of stuff. I don't want to hear that. They quick about saying that, so I'm not going to start no trouble. I just don't like to be around them, because I know what they do when they get to drinking, some of them. All of them ain't the same. You know, everybody ain't like that, but there's some. There's still some, and to avoid you know, getting in trouble, I don't fool around.

NL: Now when you were in Arizona, did you have many white friends?

SH: Well, I'm going to tell you, I never really had a friend, what you called a friend, because friends ain't like friends was when my parents came up. Friend nowadays, you know, you take your buddy to their house, he look around, see what you got. Looking at your old lady, you know, see what she got on and blah, blah, blah and talking about it, so I never cared about a friend. Or always with you when you got some money or something but when you ain't got nothing, he go the other way when they got stuff. So I don't-I'm not into friends. There are some kids I went to school with and people that I know are okay, but just a friend, straight up and down friend what I can go to something, I ain't got none. I'll be alone now. I mean I wouldn't mind having a nice friend, but I don't have-I wouldn't consider myself-I tell my kids, you know, "This is my friend." "That ain't your friend. That's just a little boy or a little girl you go to school with," you know, which is nice and all, but it's not a friend, because once she'd leave and go out, you liable be all kind of N-s or blah-blahs. So don't you knowmight go off and leave you in your time of need, and so I don't see that. I don't think a friend would do that.

NL: Right. So you saw real friendships when you were growing up in the colony.

SH: Well, yeah, real friends. Yeah, I would say that. You know, the black kid around here, we consider you know, friends in a sense-for a playing friend. Now I wouldn't-You know, I couldn't say he would do this for me or do that or blah, blah, but we really didn't never hardly play too much with these other kids. Like I said, we worked and they worked, too, but you know, there wasn't too much playing unless my parents went to their parents' house, you know, sat around talking, reminiscing. Stuff like that.

[Recorder paused.] 
NL: Okay, so we're starting back up. Let's see. Let's actually talk a little bit about about traditions or practices. Can you tell me what kinds of practices or beliefs that folks grew up with in Antioch that you remember?

SH: Beliefs? They just believe in God then. You know, it was time to do that and one another to extent, you know, and they just believe in working. They just worked.

NL: $\quad$ So you would say work and religion were pretty much like two big important things.

SH: That was the main thing. You know, the main thing was work and religion, respect, and stuff like that. You know, everybody was to theyself.

NL: Was church a big part of-

SH: We had a country church down there.

NL: Where was that exactly? Where was the church?

SH: We had a church about where Miss Smith, back off in them bushes back there. It was out in them woods back there, you know, and they ran a light to it, or they had a lamp they would go in there and light it up or something, but they ain't have no lights in there neither.

NL: So there was no electricity in the church?

SH: I don't think it was none in there. They might have run a line from one of them, somewhere just to have a light for that church for people to see, but I mean I've seen times when the church turn out, they park a car out there to shine their light in there for people to see how to leave, you know, go back to their cars. You know, been went in there and preacher man, and it got dark, you couldn't see nothing around there. They're shining light inside so you can see how to open the door with a flashlight or something. You go in there and light up somekerosene lamp throw a lot of light. You light up a few of them, there's enough light for you to be in there. They didn't have no microphones, nothing like that. When the preacher preached, he just talked loud enough where you could hear him. You know, and he was a black man. He was - they didn't have all that stuff. Like I say, there wasn't no electricity running around in there then.

NL: Was there a piano or organ?

SH: They might have had a piano. There wasn't no organ because they didn't have no juice, but a piano-Oh, we used to-You know, my cousin-My daddy's brother stayed, I told you he stayed down there, down the lane down there. We used to go down to his house-You know, my mama and daddy went there and talked to his brother. He talked, she talked to his wife, and we used to go down there to listen to the cowboys on the radio. Listen to the cowboy Amos and Andy. You ever heard of Amos and Andy? [Yes.] Well, we used to go down and listen to them. We'd sit down in front of that radio just like we sit down in front of the TV, but it was a radio. Listen to cowboys and listen to stuff like that. You know, wasn't no juice. He didn't have no TV. He just had a radio. We'd go down and listen to that, listen to cowboys on the radio, Hopalong Cassidy. Boy, them cowboys, Leslie, a [?], that's the old cowboy. And that's so-you know, we-it was just dark out here. I remember my mother used to go this lady's house and be sitting there, sitting down there running their mouths, and then it'd get dark and we'd got to go home then. I mean it'd be dark. And, you'd be [?]. And she'd tell me and my brother and LeeDell to catch her by her dress tail. We caught her by that dress tail. Man, she come out that people's house and hit them bushes. He had a little trail. Man, we used to get home, there was rattlesnakes singing all around it, but you know, you could hear 
them but you couldn't see them because of the dark. She'd walk through there, man, just tell us little bits to, you know, walk on through there, in that dark couldn't see nothing and make it to the house. Never got snake-bit. That's what I say about religion. Never got snake-bit or nothing ever happened. I mean it was dark. We holding on that dress tail. You could get our fingerprints off that dress tail we held it so tight. You know, just hold on to it; don't turn it loose, and she just started walking. She didn't have but one eye. You know, start walking going to the house. You know, for something like that nothing not to happen, you got to have some faith and stuff. They prayed. Like I said, they prayed, and that's why a lot of them got by. That's how we got by. My father was very religious, and mother was, too. You know, there wasn't nowhere to go. We just-very few people she fool with, talked to, and very few people he talked to. He talked to them, but I mean he never did socialize. He was always working. Time he get through working, time come home and feed the stock and eat, go to bed, and get up early the next morning and do it again.

NL: Was your father involved in any activities in the church?

SH: No, he just went to church. You know, he went to-he prayed or something, but he wasn't no-you know, he wasn't no drinker or nothing like that. He just went to church and stuff. Not as I knowed of.

NL: What about your mom?

SH: She went to church, and when she went to Arizona, she got in with these ladies some kind of things, mission or something, and she got into that. You know, they'd be encouraging her to do some of that. My father, he just went to church and cried and stuff. He was just very religious. You know, read the Bible all the time. But that's what got us where we are. I ain't got to be as old as I am because I wanted to. I pray, too, you know. But I go to church, but I don't want to be all-I'm not going to be no-I don't want to be no deacon. I don't want to be that. I just like to go to church and listen to the Gospels and leave. And, that's that. I don't want to be no-I do not want to be a-I don't want to be depended on in a sense, like, "Well, you got to come here for usher meeting or you've got to come here for deacon meeting or something." I don't want to do that because I might can't go. I might be doing something and won't be able to go and if you go do something like that, you ought to be really committed to it to do it. I know that, you know, right now I'm not that serious about some things. I don't mind going, but I'm not going to be no part of them. If there's somewhere I'm going to be, well you know, I don't want to [?] have to talk to you after church about nothing, you know? I ain't got nothing against it, but I just feel I ain't ready for that.

NL: So are you a member of the Antioch church?

SH: Sure. I got baptized in that creek down there, right down over there.

NL: That creek over there?

SH: That creek you come down that road, right down there by that swimming hole. I got baptized in there.

NL: Is that where everybody got baptized?

SH: No. A lot of them got baptized-a lot of them just joined church. I wanted to get baptized, and we went down there and look like the creek we had, we scared to get in that water. [Laughter] They got in there and dipped me down in there because, you know, I got baptized. I think it was in the nineties or something, eighties I got baptized. Right over there. 
NL: $\quad$ So you weren't a kid at that point. You were pretty much an adult.

SH: I was forty-something years old, almost fifty. Yeah, forty-something years old I imagine. Thirty-eight, forty, yeah. Yeah. I had joined the church, but I just wanted to get baptized in the creek. These churches that had these pools in there. I didn't want to get in one of the pools. I wanted to get in the creek, you know, like it was, and I got in the creek.

NL: Now is that how they did it back when you were growing up?

SH: Yeah, back in the day, I seen a lot of people get baptized. They'd dip them down in that same little creek down there. There are certain parts of it. Mainly right down there and dip them down in there. [Laughter] Walk in their with their clothes on. You know, get some old shoes or get barefooted. I walked down in there looking around. I think the preacher was scared there might be some snakes and stuff, and they went on off in there and I went on off in there and dipped down in that water. [Laughs]

NL: $\quad$ So they didn't baptize everybody. When you joined the church when you were young, baptism wasn't automatically a part of it. You had to say you wanted to be baptized.

SH: I'd never seen no young people get baptized. It was mostly them old, older ones. You know, they might not been that old, but they was grown, I would say, for what I seen, and they'd dip them in there. Some didn't want to be dipped, but you know, I guess getting dipped is a personal decision. It's up to you. But I just wanted it for myself. I've joined the church, but I wanted to get baptized, and I did. That's it.

NL: Did the church play an important role in the community over the years?

SH: Yeah, yeah, sure. Everybody out here. When it church time, they went to church. They put their little dudes on and suits on, little suits, and they went to church. I'm sure some of them back in the day, they went in buggies, but they always went to church.

NL: Do you remember the minister growing up?

SH: No, not really. I've heard of him. I've seen him, but I really couldn't talk on that. When I was right up there, you know, you know, then your preacher come to your house and your mama done cooked all that chicken and stuff for him and they sat there and get full and take off. But nowadays, they don't have a preacher coming to your house. Some-Martha and them do it. Preacher come over, you know, they done cooked everything for the preacher, and he sit there and get his belly full. [Laughs] Always eating some chicken. Always wanting some chicken. [Laughter] Boy, oh boy. Can't wait till the preacher get through eating before we can eat. We're sitting around hungry, that preacher sitting there, mouth greasy, eating chicken. We sitting around there waiting till he get through eating before we can eat, yeah.

NL: Would the preacher bring people also to come with him when he ate?

SH: No. He come over there after church. You know, after church he'll come over for dinner, and if he got a wife, she'll come with him and have dinner and that's it. You know, they didn't invite nobody but the preacher.

NL: Would he stay over in the community, too?

SH: No, he didn't stay out here, I don't think. I think he might have stayed up in Austin or out in Manchaca somewhere. I don't know. He didn't really stay out here. Any of them, he didn't stay around here. 
NL: Now tell me, is the Antioch Church, is it a Baptist church or a Methodist church?

SH: $\quad$ Methodist.

NL: $\quad$ Your older sister, Mrs. Washington, mentioned to me that there actually was a Baptist church in the community.

SH: $\quad$ There might have been, but we're Methodists.

NL: Okay. So were the majority of the people who lived in the colony Methodists also?

SH: Yeah. Them people over yonder, they had a Baptist church, and I don't know, I think it's still a Baptist church. The church we had out here, I think it was Methodist.

NL: Now tell me, when you were a kid, were you a member of any church organizations?

SH: No, we just went to church, just went to church.

NL: Really? Now what about your sisters?

SH: They just went to church. They just went to church. Then they didn't have no choir and things. You know, we went to church and when they sang, everybody sang, you know.

[Laughs] Everybody sat in their seats. Maybe preacher start a song, and if they know it, everybody sat there and sang. Ain't no choir like you got now. Choirs and them-Well, maybe they had it in Austin, but I mean out here, they didn't have no choir. Not that I know of. They just sang, you know?

NL: Do you remember any of the songs that they would sing?

SH: Oh no, no, no. I didn't sing. I just-we had to go to church. My parents, we went to church and we'd sit down there and listen till it's over and then go out there and rip and run till we go to the house, and rip and run and chase chickens, jump on them hogs and calves, ride them. So it was like just kid's play to a certain extent, but there was a time limit on that. You know, and they didn't want you riding them calves and break they back and riding them hogs, you know, something hurt them because that's your food. But we just played for the little time we could. And when it got dark, you know, you can't see nothing, so you don't want to be out there playing and run up on one of them snakes or things.

NL: How long was the church service usually when you were growing up?

SH: I don't know. I think they stayed a little longer than they stay now, you know, back then. I think they stayed in there a pretty good while. Sunday school and church and he would say a few things, and them women shout and blah, blah, and then they'd come out. I don't know. You know, they went to church, but they didn't-I don't think they spent no-I think they spent a little time, but they wasn't there for no 2 or 3:00 o'clock or nothing like that. You know, they go to church in the morning, and by 12:00 a little bit, I guess, is turn that off. He wasn't paying no attention to the time because I couldn't go nowhere no ways, so I was just sitting there, I don't know how long it went anyway. [Laughter] But I know we went. That's all I know.

NL: Now tell me, who would you include as members of the Antioch Colony community? Who would you include? Would you say it's mostly people who are kin related, or most people who had either their parents or their grandfathers or great-great grandparents moved here back in the day and- 
SH: What to go to church?

NL: No, in the community in general. How would you identify members of the Antioch Colony community?

SH: They all stayed right here.

NL: $\quad$ So do you have to have been here for a certain number of years?

SH: Oh no, no. Well, the ones here been here, you know, for a long time. Yeah, but everybody out here just, they been here. You know, they wasn't really no outside limit or visit or something, but those stayed here and they done everything here, went to church here, communicate, all this. Everybody that did it, just lived here. Mm-hmm [yes].

NL: $\quad$ Are relatives who move out of Antioch still considered members of this community?

SH: In a sense, in a sense, in a sense, in a sense. I would say yeah. You know, they recognize they came up here, but once they get out outside, I guess they get attached to everything else and places. They want to change, they, you know, change their label, in the sense they want to be, "I stay in Austin," or "I stay in such-and-such a place." You know how people do like they go to California. Been here all their life, went to California; they don't even want to talk about Texas. They you know, hey, they left it, they left it. After my dad left, he left it. The majority of peoples on the West Coast really come from the South in some way. Went out there and seen a little freedom, a little thing they can get away with, and they stayed. If they really checked on the background out there in California period, half of them come right from Texas and Louisiana and Arkansas and places. But they want to, you know, they don't want to claim it because they done good.

NL: Now what do people consider to be the physical boundaries of the Antioch community?

SH: $\quad$ Let me think about this. They just try to-They work, try to keep it, you know, keep their land and keep things. You know, just keep a little community.

NL: Well, actually what I'm curious about is where does the colony begin and where does it end? For example, we know that Black Colony Road goes right through the colony. But is Cole Springs where it begins?

SH: Yeah, yeah, yeah, yeah. Cole Springs all the way to 1626, you know, down there at the end, down there at that stop sign. From Cole Springs to that and from Black Colony-Well, Cole Springs go all the way around, but there's some Burnhams have some property back over there. They still got it, but it's still considered a black colony because the road go around there and it's still black colony over to Burnham's.

NL: How many miles is that exactly? I mean, how many miles are within the colony? How big is it?

SH: Miles?

NL: Yeah. Is it like five miles, six miles wide?

SH: $\quad$ Over there to over here. I-Yeah, maybe something like that, four or five miles from over here to Black Colony. I would say maybe about three or four miles maybe. It might be longer this way. But this way, it's from Cole Springs to other side of Black Colony, I mean Harper Village Road to that thing down there. However miles you think that is. 
NL: $\quad$ So would you say it's actually gotten smaller over the years?

SH: No, it ain't got no smaller, you know. It just people done moved in. You know, they done sectioned it off, you know, really. But back in the time, you know, back then, we didn't have all these fences and things. They used to bring greyhounds out of here and let them run rabbits. Now they done tore up a lot of trees, cut down a lot of trees and put places for things. But it was just open. It was all black people. It was just open. Back then, you could do something and that lady down there could see you doing something, throwing rocks or something and give you a whipping, and then you go home and you get another, you know? Well, see people really -it was like a village. Everybody looked out for everybody, you know? So that's how I can put it. They all looked out; they all helped. There wasn't no, really no fussing and about this and that, or if somebody kill a hog, they know you got a lot of kids there, offer to use something and they just shared. Like you see on some of these old black pictures here where they look up. But it's about the same.

NL: What I wonder is how would, you know, when you actually left the colony? If I was walking like a long time ago, how far was the Hispanic community from the colony versus the white community?

SH: From the colony? [Yes] Across that creek.

NL: $\quad$ So the creek was really the dividing —-so if I had to draw a map-let me get a piece of paper out. See, I didn't even know that there was actually a white and a Hispanic community right in the area.

SH: Yeah, they were over there. You know, I didn't really know it at the time because we was over here, but you know, my sister and them, people told me that there was a white school and a Spanish school right over there.

NL: Did they have names for them?

SH: For the schools?

NL: Yeah, the way that Antioch is called Antioch, did those communities have names as well?

SH: Well, that little school down there, called that Buda Elementary, but that big school up there, I don't know. Just a school, a white school. They might have had a name, but I wouldn't know it. But I don't think they had no name for that black school that was right down there, but just a big old-big blocks. Big, real, real blocks, you know, school. It wasn't none of these little bitty bricks. It was made, you know. I think that lady's uncle and Daddy and them built that school. But it was made out of stone and big rocks. It was made out of rocks.

NL: $\quad$ Sounds like it was a pretty nice structure.

SH: Yeah, yeah. It stayed there. They just tore it down a little bit before I came back down here. They had tore the school down. They should have left that school there because you know everybody out here went to that school. Aunt Kate, the people that was eighty or ninety years old went to that school. I mean, you know, they had went there. They had to be that old, but they had went to that school. That was the only black school around here.

NL: It had been standing that long?

SH: Yeah, yeah. It was. And wasn't no slack in it, you know? It was solid as a rock, but they tore it down, though. It really was a historic marker. They should have left it there, but they-I'd 
be up there, I would've took all my kids down through there you know, when we came down here, if it was still there, just told them, "You know, this is where I went to school and this the room we was in, we had this and a little kitchen back there." But they tore it down.

NL: Why did they tear it down?

SH: $\quad$ Somebody wanted it tore down. I think the people want it tore down. You know, they-white folks tore it down, though. It was old as that school up there.

NL: $\quad$ So not too many people know the history of Antioch, then.

SH: No, because the ones that really knowed it and stuff is really gone on, and, you know, some know a lot about it, but they done moved to Austin. Maybe them Grants might know a lot about it, but this woman up here, she seem to keep up with it. Yeah, she know a lot about it. But all I really know is we went to school there and just the blacks. Every black here from Manchaca all the way by [?] went to that school. I don't know, not no other blacks nowhere else but the one was in, right here in Black Colony and Manchaca. That's the only blacks were around here. The rest of them was in Austin, Creedmoor or somewhere scattered out, but this was just a big community. But there wasn't no whole bunch of them, but there was some here. You had a good ways to walk to go to somebody's house.

NL: I believe it.

SH: You know, and they had to go through all these bushes, but it was some here, but it wasn't no whole bunch. It wasn't no whole bunch like the East Side or somewhere. It was just a house here and a house there, they had built way back and they just stayed there, stayed there till they died. That house down over there [inaudible], those people been there all my life. Long as I remember them people were staying up there. And after they died, they kids stay there and they stayed there, too, until it got burnt that time. Them white kids set it on fire and her husband died. He had been working with the railroad like for eight years or something and had a bunch property and stuff down in San Antonio, and his wife went and had her house built over there in town, that big old house. But she stayed right up there, too. Everybody out here stayed out here.

NL: Wait a minute. You said some white kids set a house on fire?

SH: You know, you go up that hill, you see that house on the left there that been burnt? It's got two big trucks parked up there now. Well, that was Tom Mullins, LeeDell's Grandpa [Chuckles], stayed up there, and he had some people, his kids and things, stay up there. And then one of his sons married this girl, Debbie [?], and after he died, she stayed up there, she got that money, she went to town, you know. But they stayed up there. They was up there when I was born. So everybody stayed, stayed in the same place. They didn't just move around from here to move over there. They stayed there. They fixed their place up or kept it clean enough or whatever, but they stayed there.

NL: Why did the white kids burn the house down?

SH: Oh, that girl had moved out and they go over there fool and they just set a fire, you know, and it burned down. They caught the kids, some of them white kids went back up there, but they didn't do nothing to them. If that had been one of these black kids setting one of those white kids', white peoples' house on fire, he'd a went to jail or juvenile or something. They didn't do nothing to him.

NL: Was anybody hurt? 
SH: No, wasn't nobody in it. They were gone, but they just set it on fire. Had nothing else to do. They used to go around, tear these mailboxes, get some bats and things, just beat these mailboxes all up, and knock them off the posts and stuff. That's why they come out with these mailboxes like they got now, you know? It's the government stuff that if something happened to it on the street and whatever, they'll fix it, but if you got it inside your property, somebody back into it or tear it up, you got to get it fixed. You know, like when Martha and them got theirs were they put it [?], I told them. I said, "You shouldn't put it right there. You should put it outside." Then you can't see out [?] on your property unless they move that thing. You know, like where they got it sitting there, they want to put it there. "Well, that's on the property. We ain't got to walk all this way." That's all good, but set it outside that gate, and then if somebody, if them kids tear it up, they'll probably find out and do something about it because that's federal stuff. But on your property, if they tear it up, you just have to handle it yourself because they don't really look at thing to certain extent they're going to make it convenient for this and that. But as far as the law goes in such-and-such thing, you need to go back. But you know, they up in age and they don't look at things the way I would look at it. Yeah. They might would take a chance where I wouldn't. [Laughs] So but, you know how seniors are. Yeah. They all picked cotton, chopped cotton, too. [Laughs]

NL: $\quad$ Yeah, they told me. In fact, they told me. Your sister, Mrs. Washington, she told me-

SH: $\quad$ She picked a bunch of it.

NL: She said it. She said that she pretty much remembers when she was a child going-

SH: She used to go out on cotton picks. Yeah, they done it, so. I done it, too. You know, when we got big enough to start walking, we used to go out in front of my parents and pick that cotton, make a little pile. You know the pile, you know, go and make piles out in front of my daddy and then he come along, put them in the sack with the rest of the cotton. Then after we got up a little bigger making them piles pretty good, they had them flour sacks, you know, flour come in on up in there about that size. My mother sew a little strap on them. We'd put that cotton in that sack, flour sack, and my father would dump it when we fill it up. And after we get good with that, he'd go get one of them Kroger sacks that potatoes and onions come in, you know, and put a strap on that and we used that. After we got good with that, then he'd go get a real cotton sack. [Laughs] So it be like, traveling steps, and got up to a ten-foot sack.

But you know, we've been working all our lives down there. We, like I said, there wasn't no bunch of playing and stuff. We played, you know, after we come, you know, we run around there and played. But like I said, our playing was chasing chicken, riding them calves, jumping on them calves or hogs or something. That's what we were playing. Like I said, rolling tire, put the ashes in them tires that come back from the store, go to our place, and we'd be riding that tire down there. But look like little white kids, all that ash blowing in our faces and stuff. And like that. Take a bath in the tub. Don't have no man tub. They had different size, ten or five size. The bigger the higher it go, the bigger the tub is, big enough for ourself in it. My mom would pass gas in that. [Laughs] Real country, I'm talking about real country and stuff like that. We just didn't play. Like we ain't never seen a swing. We just didn't go play like a lot of kids. Like I said, we got out of school, we had to go to the cotton field from about 2:30 till it got dark. Then come back home and you know, and get ready for school the next morning or Daddy give us a whipping [?]. We didn't go play like a lot of kids, you know? Wasn't out there shooting no basketball until we got older. Like I say, the first time I heard that word was about thirteen years old. That's pretty old for a youth. Just a kid now just can walk and will call you one, you know, now, nowadays. Back then, we wasn't in that kind of environment. My father believed in working and going to church, coming in and buying us stuff, livestock and stuff to feed his family. That's his purpose, you know, everything, and keeping that land. Working, just work, really work. He just worked. Work, 
work, work. There wasn't no play. But he didn't work on no Sunday. Worked five, six days a week, but he didn't work on no Sunday.

NL: So what would he do on Sundays?

SH: Go to church and sit around and read the Bible, and my mother would be cooking cookies or cakes and all kind of stuff, and just being home. He didn't work on no Sunday.

NL: $\quad$ The people you just say, “Oh, Sunday was a day of rest," but did it feel like a day of rest to you?

SH: Yeah. Was it-?

NL: Well, a lot of people always say you work five or six days of the week, but Sunday is the day of rest. So I was going to ask you, did it feel like a day of rest to you when you were growing up?

SH: Sunday? [Yes.] I'd knowed that wasn't no work going be done, you know, but by being kids, you know, every day, we never did-we know what Sunday was. We know this and that, but you know, what playing we did do, we did it all the time.

NL: Right. So you didn't have a lot of chores to do on Sunday. You were able to relax a little bit.

SH: Cows got to be fed and milked and stuff. My father might get up before day by daybreak and been out and done that, and we'd still be asleep or something. But if he did it on Sunday, for we had some-he had some people, just hired hand like some-and I guess they did it on Sundays. I don't know if he did on-he might feed on Sunday, but he ain't going to work. I mean, like going grabbing a tractor or chopping or nothing like that. Yeah, he fed them. He had to do some things. But we had some guys that did a lot of work. Had one guy just stayed there, did a lot of work. When my father was gone, well, you know, he had a guy to you know, just do a little something, but we did it, too.

NL: $\quad$ Right. Tell me, I have actually read somewhere that around the 1950 s, people started leaving Antioch. Is that true?

SH: In the fifties? [Yes.] I don't know. We didn't leave till '55. So I was standing outside—I don't know. Ain't too many people started leaving. You know, maybe those city slickers, you know, they raised up. They didn't actually leave; they was already staying in town. They just come out here, like Aunt Kate or them people that her grandkids or something, you know, that they stayed on the town. Some of them left and went to town. But as long I was here, there ain't nobody left went nowhere. They stayed here. What happened after we left I don't know. When we was here, everybody that was here when I was born and everybody else, they stayed here. They didn't go nowhere.

NL: This will kind of take us down a different road. Do you remember attending any funerals when you were young?

SH: Attending a funeral? Yeah, I remember. Didn't have a whole bunch of them.

NL: Did you attend any out at the cemetery here in the colony?

SH: Yeah. Everybody around here buried up there. Yeah, I remember my grandmother's funeral. I remember going to town to my mother's sister and mama's funeral. But I don't know. Wasn't too many people croaking around here. [Laughs] You know, they was eating good and good 
food and you know, gardening and things. They wasn't eating a lot of stuff like you hear now in these stores, this peanut butter. You didn't hear of that kind of stuff.

NL: $\quad$ Everything was fresh.

SH: They grow their own stuff, and I guess that's what kept them, you know, probably kept them going so long. They wasn't—nobody hardly ever got sick. I'd never been sick. No, wasn't no bunch of funerals. It's some here and there, but not nothing like that you attend-You can liable go to a funeral every week around here, and I mean, back then, people wasn't dying that quick. They was pretty healthy.

NL: Was there a wake before the funeral?

SH: No. They brought the casket to your house.

NL: Hmm. Not to the church?

SH: No, didn't have a church. When my mother died, we went over there. They had that casket in that front room. First time I ever seen it, you know. I didn't—I was like, "What's going on?" I didn't know what it was, you know. I think that probably been about the first one I went to, and had it laying in that room. What's wrong with that lady doing laying up there asleep, you know? But it was a casket, and they had it covered up. That's the first time I ever seen a man cry, and that man was just hollering. I said, "What's that man hollering around there for?" That was my cousin. You know, he lives with [?]; it was my mother's sister. He was hollering and stuff. That's the first time I ever seen something like that. We went to a funeral; we didn't know. We just see somebody laying up there. But they bring it to your house, bring the casket to your house. Then after that, they'd take it to the cemetery, you know. Take it to the cemetery, take it to the church. Well, the wake they'd leave it there all night. They stay and leave it there all night.

NL: $\quad$ Oh, really?

SH: Yeah, leave it up there all night. You can handle it.

NL: Will people sit with the body?

SH: Yeah, people sit around. They sit around and talk just like if they went to a wake, but only difference, the casket was at the house. They'll bring it to your house and they put it in there and come back and get it when it's time to go bury them, I guess. They don't leave them there too long because it thaw out, but they left it in there overnight. You keep it in there overnight or something. Yeah, I seen that.

NL: Would they sing songs?

SH: No, you just come sit around. You know, the family just come sit around and talk. You come visit at the house just like you visit in a funeral home. Come by and see it. Yeah, come around and look at it. Getting old and just a funeral, you know? Didn't bother me none, other than being in the house and that. I wouldn't want to be in the house, and the casket in the living room. I wouldn't-You know, now I wouldn't. I probably wouldn't have then, you know, if had a choice, you know. But you know, that don't happen no more. They don't take no body to nobody's house, but I experienced that.

NL: Do you know why they would actually take it to the house instead of to the church? 
SH: Well, people wanted it at the house, I'd imagine, because it was in church and they just had it in the house. I don't say everybody did it, but I went to-My auntie's was at her house over on Twelfth Street and Chicon. It was up in her house, that casket and her body. Everything was there, just like in the church. First time I ever seen something. I mean we wasn't in the funeral and stuff because of the funeral. We went and we just kids. We, you know, we probably didn't even pay no attention, at least to the older people. They'd let the kids go outside. Kids wasn't as nosy then like they are now. Sit around. When grown-ups sit around and talk, you'd be outdoors playing somewhere. You don't sit around be listening to them, what they're talking about. So we never did-It didn't never did mean nothing to us because if they did have something, like they'd have some people come by, we got some playing or chasing chickens. We didn't sit around and listen like they little kids sit around and listen to you run your mouth and then go out and say a thing. Just kind of isolated from some stuff like that. I guess they didn't want you to-We ain't got no business knowing nothing about this, you know, or something like that maybe. I don't know, but they didn't sit around grown folks. We all went out there and play.

NL: Now, your auntie, was that the first funeral that you remember going to, your auntie's funeral off of Twelfth Street?

SH: Yeah, that's the first time I ever seen-I think that's the first funeral I ever remember and the first time I ever seen a casket in the house. I think that was the first one, the first time I ever seen a man cry. Freaked me out, you know, as I got older. You know, some things you ain't never seen. I try to-

NL: $\quad$ So you remember being scared that day?

SH: At that house? [Yes] Yeah, I was scared. After they told me what it was, what the purpose was, that kind of shook me up. I was ready to get out there when I knowed. You know, I don't want to sit up there with somebody deceased. Yeah, I was a little shaky. But I couldn't do nothing about it. [Laughs] So there ain't nothing I could do, just go up there and stay out as long as I can, yeah.

NL: Now do you remember people planting flowers at the funerals or leaving flowers?

SH: Planting them? [Yes.] No.

NL: Will people leave anything at the gravesite? Will people like maybe something that belonged to the person?

SH: No, they didn't put nothing there. They didn't leave nothing in there. Put you on down in that ground and they gone back to that house and do what they were doing. You know, if they had any personal feeling, we had it in your house, or whatever, here. I don't know. You know, but just like I say, it didn't mean a whole bunch. It meant something, but I didn't look at it like I look at it now. As I done got older, now I can see things. I can feel for some things. But then we were just kids. We stayed in the kids place. Some things kids don't do then. Conversations people have, you don't listen to all that stuff. I may, I guess if I'd have been nosy, I might have heard that N-word before I did, so yeah.

NL: So how do you see funerals now or dying now?

SH: I accept it. I know what it's all about. I know you got that coming, and ain't nothing you can do about it, so I don't see it nowhere. I get emotional at any funeral because I know what it's all about. It's the last stop. But I don't have nothing against them. I'm not scared of them, the 
cemeteries. Back in the day, you know, a person be scared to go around a cemetery, but that stuff don't bother me no more. No. I can accept all things now.

NL: What funeral homes did people use back then?

SH: I don't know no funeral home. They take them to your house, and then they take it to the cemetery. If a little country church-I don't even remember ever seeing a funeral at that church. They didn't go that way. Over in Austin, but out here there wasn't none of that stuff. Not as I knowed of, you know. I don't know about that. But like I say, we didn't participate and get into a whole bunch of. We just done what we was told. If we didn't, we get a good whipping. You don't get them that often because when they gave you one, it would last a while.

NL: Do you remember who gave you your first spanking?

SH: My daddy gave me one. My daddy [?] out whippings. My mama whipped us a few times, too. She wasn't as good as he was. She kind of be a little lenient. Old Pop, boy, he'd make you think about it before you do it again.

NL: Do you remember why you got that spanking?

SH: I don't-Maybe knock one of them chickens out or done something we didn't have no business doing or something like that, you know, get a whipping. But didn't get them that often. I didn't get them that often because I was the baby. But we got them. I got them, you know, cotton field. I didn't get them because I knowed what to do. I knowed how to keep from getting them. Do what you supposed to do, you wouldn't get them. My brother got them a bunch of times. He just, look like he just liked them.

NL: Which brother was this?

SH: Ollie Joe. Moses. He'd get a whipping for just being—Things he 'posed do, don't do. Daddy'd get one of them switches, one of them branches off and put it on him, he'd be all right. [Laughter] I'd be all right, too. We got-We didn't really get a bunch of whippings because we knowed what to do. He'd tell you, "Go do this." You'd go do it. We ain't say you know, "I don't feel like it, or do it tomorrow" or something like that. We didn't talk back. Back then we didn't talk back. You done what you told to do, and that's how I come up, you know, like that. Nowadays, you tell a kid do something, he'd go in there and watch TV or go out the back door or something or some kind of old stuff. But then, kids was really pretty disciplined then. They really knowed. That's why I say like a lot of them today is, you know, from their upbringing got them where they at, you know, other than you know, praying, blessings and things. But you just didn't do everything. We worked. I would say my whole upbringing is about work because we worked. Like I said, we didn't have too much playing. It was work. You know, we had our moments at school, but once you left school, boys, the buck stopped there. The playing stops there, you know. [Laughs] Yeah. It was-I don't know how you would have handled that back then, but you know, but this just country living. Now those kids in town, they-You know, that's just a whole nother, just like another country, you know. But out in this country out here, we worked and fed and fed the animals and slopped hogs and milked cows and shucked corn and baled hay-everything that belonged to a farm, you know, that's what we done. You know, had to go out and do stuff. We just took care of this, you know, took care of our stuff.

NL: What were some of the particular burdens of being a man in this community?

SH: Burdens? 
NL: $\quad$ Mm-hmm [yes]. Like were there any hardships? What were the greatest trials of being a man in this community that you saw when you were growing up?

SH: Being a man?

NL: $\quad$ Like were there any hardships? Like I know when I asked your sister this question, Mrs. Washington, one of the things that she thought was one of the biggest burdens for women was actually having to raise children and lots of children.

SH: Burdens, you say.

NL: Yeah, burdens.

SH: The biggest burden out here? Just raising children. The woman raised the kids and done the house stuff, cooked, and the men worked. They went out and worked, you know. They worked. They just worked. You know, and they socialized. Those that drank and stuff, they mightBut my daddy, he didn't do all that stuff, so he didn't really fool around with people that do that.

NL: So how would you say most of the people in the colony made a living?

SH: Made a living. Back then? [Yes.] Work.

NL: Were they primarily farmers, though?

SH: Well, we was, and there's a few more, but most of them went out-you know, they worked, like going baling hay. They didn't really have no punch a clock as I knows of. You know, they were, had a little place where they caught a knuckle, that's where you used to go out and pick up these dead cows and things and then take them to this place and skin them, and then they take it and get soap and stuff out of them. But that's the only work they done. We had a tower plant or pick cotton and chop cotton or shuck corn or something like that. They didn't really - wasn't no - or they'd go up on one of these ranches and work for some of the white folk, you know. But they didn't really have no job where they had no hard hat or had to go punch in and punch out. They went to work a certain time. Back then, they were really working sun to sun. You know, you worked-You didn’t work like seven or eight hours; you worked all day, you know, or something like that. That's all I know about, they just worked. Work for theyself. We work for ourself. If it wasn't for us, we working for somebody else. Work with somebody that own the stuff and get the corn, take it to the mill, and that's where they make the meal and grind it up and make the cornmeal stuff. And, all the rest of the stuff they grew. They grew all their vegetables. Like I say, killed things, go hunting. Rabbits and deer the most. They got something to eat-armadillos, coon, possum. We never ate that. My dad never gave us none of that. You know, these peoples love them coon and things. All I remember eating wild was a rabbit and a deer that you know, got caught in the fence or get hit. You skin him and take him or something like that, but you didn't eat everything.

NL: $\quad$ So you didn't do too much hunting when you were growing up.

SH: Didn't do much what?

NL: $\quad$ Hunting when you were growing up.

SH: No. No, no. You know, not really. We had some little snakes out there or we may catch us a little bird when we were playing around. But no. When I went to Arizona, first time I actually went hunting. Then after I got a little older, I said, man, I don't want to do that, you know, 
killing them rabbits. Be sitting up there and then shoot them. And times wasn't that hard. I had a job and wife out there. I didn't have to kill them. I don't like to kill nothing, so why should I kill that little rabbit out there? He ain't doing nothing. Trying to make it, and I done kill him. And I might not eat him, you know, and that's wrong. So I stopped hunting. I don't kill nothing. I don't even kill no-nothing. Maybe step on a roach if I see one, but I used to just run around and step on little grasshoppers [stomps foot], just kill stuff, you know, and that's wrong. As I got older, you know, start, you know, had a family and stuff, I just don't kill nothing. People wonder why there be snakes over there. "Why don't you kill that snake?" I ain't killing that snake. That snake ain't bothering me. Let him go ahead on. Or one night I was asleep and there was a scorpion crawling up on the bed. I kept seeing something and I got a towel and got him and went out the house. Then I took him way back out there by some trees and put him out, you know, throwed him down. Just don't like to kill nothing no more. Back then I was young and didn't know no better. I knowed better, but I mean, I didn't feel the way I feel. I don't look at life like I look at life now, you know? So I just don't do that. Like I didn't look at funerals, I mean life like I-I may have went to a funeral and then, eh. But now you know, okay I don't care if I don't even know the people you know, I get emotional, you know, tears and stuff. But I just don't-A lot of things I used to do I just don't do no more. I'm more serious about things that I did, and I really regret it. I can't bring it back, but I can not do it no more, so that's how I look at a lot of things.

NL: Well, I think this will be my last question before we finish and then we'll schedule another time for some follow-up stuff. But one of the things that I did want to ask you-Before I leave here, I'd like to maybe draw a map of the community just so I can understand where it begins and where it ends.

SH: Cole Springs and 1626 and Black Colony. Well, Cole Springs go all the way around. Cole Springs start, it go around to 1626. But on the other-for this thing here. But like the Burnhams, they own the other side of Cole Springs, but the blacks own a lot of that stuff there, too, right by that creek bed, all around through there. But the main thing is from Cole Springs to Black Colony and from, well, Cole Springs here and all the way up to that highway.

NL: $\quad$ So let me get a map out.

SH: It's just like a, you know, circle.

NL: $\quad$ Like a circle. It sounds like a circle.

SH: It's not necessarily a circle, but you know, it's just-It's a circle in a sense, but not just round.

NL: So on the map, like here-I know this is where the cemetery is.

SH: What, Antioch?

NL: Mm-hmm [yes]. That's the Antioch cemetery.

SH: What's all this?

NL: This right here is a gravel pit. There are like two or three gravel pits around here.

SH: Well, if this is the cemetery, all of Black Colony should be all over here, then, huh?

NL: Yeah, let me see if I can get a better map so you can see it, because I actually have a few maps. 
SH: It should be, you know, if that's the cemetery. Antioch really is south of the cemetery.

NL: Oh, really? Sort of around this area? Let's see. Let me try and found a good map. Here's one right here that may be-so this is the cemetery right here. But this one doesn't have the streets on it.

SH: Well, I don't know what the name of that. That's been a few years ago when they named it Old Black Colony. They named it Old Black Colony because that's what it was, a black colony, you know? Some peoples want to protest not to put it up there, but the people up in Buda-of course, I say that'd been like that all their life. That's what it supposed to be, so they wouldn't change it, and some moved out because they didn't change it.

NL: Oh, really?

SH: Yeah. Okay, this is Antioch. Well, see, then they didn't have all them names. They didn't have hardly no names, you know. Everybody know where it was.

NL: Okay, so this is a more recent one. I don't know if any of these-I'm trying to find one map that actually has 1626 .

SH: Well, see, 1626 ain't been like that no long time, you know? If these maps is an old one, they might not would have it. But you just had a road. A lot of things wasn't opened up then like they-this gravel pit. Yeah, see, they got a gravel pit over there on 1626. Then there was a gravel pit back down there where the school was. Used to be a dump.

NL: This is from 1958. Here's the school, and there's the cemetery.

SH: [Chuckles] Where's the school?

NL: Right there.

SH: Right here? [Yes.] And this is the cemetery down here? [Yes.] Well, the gravel pit is part of, was Antioch, too. So, like I said, it's like not a complete circle, but it's a big-like if you go down Cole Springs, you can go all the way around. Have you ever been around that way? [No] Go all the way around, come back down 1626, come back then, and come right back to here. So all on the inside-would you like to go that way? [Sure] You want to ride down to it and I could point out what's what.

NL: Yeah, that'd be great. I'd love to do that.

SH: You want to go do it?

NL: Yeah, let's go do that.

SH: Then we can come right back and finish it.

Interviewed by: Nedra Lee

May 28, 2009 (2 of 2)

NL: $\quad$ This is Nedra Lee. Today is May 28, 2009. I am interviewing for the second time Mr. Samuel Les Harper. This interview is taking place in Buda, Texas, at the home of Mr. Harper. The interview is part of the Oral History Program for the Ransom Williams Farmstead Project. 
Mr. Harper, why don't we go back. We're just going to try to pick up on some of the questions that we didn't answer during our first interview. So let's start off by talking about history. What is it about knowing your history that you feel is most important to you?

SH: $\quad$ My upbringing.

NL: Your upbringing. What about your upbringing?

SH: What we did, a lot of work, worked the fields. Worked the fields. Picked and chopped cotton, corn and all those things that it take to survive in the country. You grow most of your own stuff to eat and cows, hogs, everything. Yeah.

NL: Okay. Has a sense of Antioch's history always been important in this community?

SH: Yes.

NL: Who did you learn that history from?

SH: Parents, and neighbors and sisters and them. Sisters and brothers and relatives.

NL: What did they tell you about it?

SH: How it was. The work and stuff to survive. Like we worked and they shared things, you know, food. And we just, it was just everybody just kind of stuck together to a sense, in a sense.

NL: And your parents talked about that?

SH: Yes. Well, yeah, yeah. He was kind of - he had a big family. He really devoted all his time to his family, running it, help the kids, send them to school, and just work, work, work. Brother Tommy worked, and he had the farm. We looked after the farm while he was out of town working, out of state working. We went to school down here in Buda, a black school, and that's it. My grandmother died in '55, and he left and went to Arizona and he resided out there till ' 80 , then he moved back to Texas.

NL: When you were in school, did the teachers talk about the history of Antioch?

SH: Yeah, but then, that small, we really wasn't interested in it. Just really know nothing about this. But they talked about it.

NL: Now how do you try to pass on the history of the community to the younger generation?

SH: Of mine? [Yes.] Well, they were born in Arizona, but they kind of, they came up out here out in the country. Well, in the city, then they moved to the country. They kind of came up and made people talk to them and they learned some things, see things that they didn't see out there and how our lifestyle was here. They ought to enjoy it, some of them, they know quite a bit. But, explaining it and really knowing, it's a difference in a sense. We know things, but we never talked it. The kids never talked about it to somebody, but they know it was a change from Arizona to coming here in Texas. The living and the eating and the laws-everything was different. They was pretty young when they came here, maybe like six, seven, and eight or something like that, three. [Laughter] Yeah, so they're okay. Maybe they wasn't cut out for the country, but I came up in the country. They're little city slickers, them. They wasn't used to this kind of environment. Once they got here, they loved it, seeing all the animals and a lot of things they hadn't ever seen. It was okay. It was fun. It was a good experience for them. Yeah. 
NL: $\quad$ Are there specific areas of Antioch that bring back memories for you?

SH: $\quad$ Right over there, over there where we at.

NL: In Harper's Village?

SH: Yeah, Harper's Village. From there to, all the way to down to Cole Springs. Yeah. What were you asking?

NL: I was asking about what areas of the community bring back memories for you.

SH: Oh, just this whole-Where we went around that road and came back around, all of that. Everybody there was-They didn't have too-the older people didn't have too many young kids. We'd the only young, really young ones when we was down there. Last of them was, maybe in their twenties or older, and we just played and gave respect and done-Just survived, just had a good time as kids, as kids, as country kids.

NL: $\quad$ So would you say that all of your memories of Antioch are good memories?

SH: Yeah, yeah, I think so. I benefit from some of it now. I respect the way we came up and worked, and that played a big part of my life now.

NL: Can you tell me about one of your fondest memories here in the community?

SH: Just doing what country kids do-playing in the dirt, chasing hogs and cows and riding hogs and cows and all the other animals out here and armadillos and things. We just played. We just played. The parents guided everything. We just played and did some things for the chores, but we really didn't have nothing to worry about. It was old in those days. We really know what to do or what not to do or where to go and where not to go. As kids, we know where not to go, but we just played, play till time to go and eat a go to bed, that's all. That's the main lot we did. I won't speak for nobody else, but that's about all we did.

NL: $\quad$ Mm-hmm [yes]. Those are really good memories. Do you have any items that your parents passed down to you?

SH: Well, not to me. Maybe my older sisters and brothers or something like that, but at my age, no. No more passing down. No. You know, hard to be at the end. Work and don't do all this stuff, and just be a young man.

NL: So in a sense, you got rather than like concrete things, you got like wisdom passed down to you.

SH: Yeah. Yeah, yeah, yeah.

NL: Hmm. But when you actually go to your sister's house, and if you see-I know someone told me once about a cupboard or a cabinet that your parents had. Do you ever think of anything when you see that cabinet? I think it was your sister Marian who told me about this.

SH: Oh, china closet?

NL: Yes, that's it.

SH: Yeah, well, that was my grandmother's. Yeah, I looked at it and I just-it don't really bother me. I mean, I know where it came from. I know what it is, and I leave it at that. I don't 
just praise it or nothing. You know, I know. I don't really—it don't really do nothing to me. [Chuckles]

NL: Right, I see. Okay.

SH: My sister and them value it, though. I mean I wouldn't do anything to destroy it, but I just don't-

NL: Just a very different relationship.

SH: Yeah. I don't say, “Oh, this is my grandmother's." I just don't praise it. As long as I know. That's good enough for me.

NL: Right, right. So what are the most important roles that members of this community have for one another? I want to talk about how community was maintained here in Antioch, and last time we talked, we talked about the church and how important the church was, and we talked about the school. But I guess one of the things I'd like to know is when you were growing up, who were some of the leading members of the community when you were young?

SH: The elders, LeeDell's grandmother and my parents and all the elders around here. They was all-you know they was all leaders in a sense. We all looked-we'd get whipping by them and go home and get another whipping. That's how it was. If we did something, all the kids, all the elders looked out for everybody kids. Somebody else tell you what you can't do, go home and something - all them was parents in a sense.

NL: So once a person automatically became an elder or old, they automatically became an elder and a leader of the community.

SH: Yeah. Yeah, I would say. Mr. Smith is my father's brother, and like I said, LeeDell's grandmother, and Grandpa, and some more people that, we looked up to them in a sense. That was about all the people that was up here. There wasn't a whole bunch of people out here. It was scattered out like up there where we at on Harper Village road, okay, right down by Nell's behind there where LeeDell's grandmother stayed, and some more stayed to the left going down the hill, then at the bottom of the hill. Mr. Smith stayed up by the side of cemetery, and another cousin stayed over by across from Black Colony, down in there. There's just a few, few blacks. They just been here so long, but it was just a few of them. It wasn't no big old whole bunch of them. It was just house to house there, scattered out.

NL: Mm-hmm [yes]. Now were they also leaders in the church?

SH: They went to church. They just went to church. We had the preaching and the-I was small. Just the preaching. But I don't think they had no stuff like no big choir or all these meetings and these things that they do now. They didn't do that then. They just went to church, go home, and did what they had to do.

NL: Now you talked about Mr. Albert. Was his name Albert Smith?

SH: Mr. Albert Smith.

NL: $\quad$ And you said he'd been here for quite a while.

SH: Yeah. He'd been here, yeah. Yeah, he was here way before I got here. Everybody was here. Yeah, he owned some stuff around there. Yeah, he-you know, everybody knows everybody. 
NL: Mm-hmm [yes]. What else do you remember about Mr. Smith?

SH: That he used to ride a horse. He used to ride a horse.

NL: He rode a horse around the community?

SH: No, he didn't ride it around there. But he may go-like one of them get out or something, he can ride. You know, he can ride a horse. I mean he ride a horse to death! Yeah, he did, and you know, a lot of people, they didn't-They might walk some place just to get if their cows got out there, walk to get them. Or if a horse get out, he'll walk and get them and ride him back, ride him back hard. It was just the country. You just in the country. And we used to see what they've done. They just worked and made it. Wasn't nothing special. They went to work and came home. And we worked, doing all the corn, cane, all that kind of stuff, and picking and chopping cotton. Lived off the land. That's about as far as I can go. You know, there's a lot of things happen with the black and white, but I didn't ever hear about it till I got grown. But they had they differences. They had their boundaries, but everybody respected everybody.

NL: Right. How have the roles of I guess the elders or who were the community leaders changed over time?

SH: Well, how did things change when they came here? Most of them around here, they never did move. They just passed away. They really didn't move, go to town. Those was here when I was born stayed here. Like I said, we left in '55, so I was there and I really don't know what happened. But next thing I know, they was saying that Mrs. So-and-so died and this so-andso passed or something like that. And people bought their land. It went to their kids, but they didn't pay their taxes, and whites just came in and bought out, bought out everything, except Nell and where we at. That's all.

NL: Oh, and I forgot to ask you about LeeDell's grandmother. What was her name?

SH: Ada Bunton.

NL: $\quad$ Ada-no, no.

SH: $\quad$ We called her Miss Ada. You know, Grandma. Miss Ada was his grandma and my mother was his grandma, too. Yeah, he had a couple grandmas. [Laughter] Because Miss Ada was his daddy grandma, and then my mother was his mama grandma. Yeah, my sister, yeah.

NL: Do you remember Miss Ada at all?

SH: Yeah, I remember Miss Ada and her mother. Yeah, and all the guys, LeeDell's daddy and Grandpa. I remember all of them.

NL: Did you get spanked by them at all?

SH: They know how to do spanking, but maybe Miss Ada or somebody like that, everybody couldn't put their hands on her. No, we didn't do nothing really for them to do it anyway. But yeah, like Miss Ada and Aunt Kate, and I said Mr. Albert if we got out of line, he probably would. I don't know if he ever did it or not, and that's about the only whipping we got. [Laughter]

NL: Now where did Miss Ada live?

SH: Right there behind Nell. Behind there and then off in there. 
NL: $\quad$ Okay, and where did Aunt Kate live?

SH: Right there with her. I think Aunt Kate was Miss Ada’s mama, I think, something.

NL: Okay. So was Mr. Smith the only person right near the cemetery?

SH: Yeah. No, he wasn't. He was out there. There was another lady they called Miss Liz. She was a black lady. She stayed there, I remember her. And our cousins stayed across the street, and then LeeDell grandpa, Mr. Tom Mullins and mother stayed on that hill up there. And go down the hill, there was Revadas, these people, aunties and uncles and things. Yeah.

NL: Wow. Okay. If there were ever any conflicts in the community, how were they resolved back when you were growing up?

SH: Conflicts where they might have been fighting or something? [Yes.] Wasn't none of that.

NL: Wasn't none! That's good!

SH: No, wasn't none to talk about. Somebody might have done something about the kids that-Well, really it wasn't that. Everybody played, and like I said, everybody looked out for everybody. The older looked over all the young ones. So you might not like them, but you didn't get in no fights with them. I don't think I ever had no fight.

NL: Right. Did the elderly people talk to you all a lot about what would be considered "back in the day" for them? Maybe like slavery times or-

SH: $\quad$ All the older people? [Yes.] Oh, back in the day for them probably was. Yeah. I ain't never experienced nothing like that. My daddy wasn't no slave, so I don't know about his daddy and his daddy's daddy, but I never experienced no slave stuff. I heard them say that they had guys working on these ranches and farms and things that were slaves, but I never knew nothing about that. I don't even really think about that. Ain't nothing I can do about it. What's done is done.

NL: Right. Were your relatives members of any social organizations? Okay. Was anybody maybe a member of the Eastern Star or maybe the Masons?

SH: I think my daddy's brother might have been a Mason, but I don't know about the women in Eastern Star. My father wasn't-There were some black guys and some Masons around here. Like these people up here, their folks are Masons. But my family, we-no. We wasn't nothing like that in our families I knows of. Not out here in Buda. Maybe in town somewhere. My mother's folks was in town, so she had some brothers, sisters, and I don't know what they do. Back then-you're talking about back then, right? [Yes.] Right, nothing back then, no.

NL: Hmm. Where did you go to school?

SH: Right down there bottom of that hill. I don't even know-I think it was Antioch School. I don't even know the name of it. We just went to school. Yeah, like I said, it didn't have but two rooms, so we just went to school. I couldn't tell you what we studied or nothing. [Laughter] That was back in '54 and '53, so-just went to school. Nothing special about it; just went to school. Yeah.

NL: Do you remember any of your teachers? 
SH: Miss Woody. That was my teacher, Miss Woody then. Then it got to be they got another one, Miss Hardeman, and we had one man named Mr. Yancy. Them were the three.

NL: That's three? That's good.

$\mathrm{SH}: \quad$ Plus some of the people in the community cooked. The women, they cooked, go back there and cook in the kitchen. But that's all there was. That's the school, man. That was the school. You had to see it to believe it compared to schools now. [Chuckles] You know, it's just a school. They cooked stuff like they cook at home.

NL: $\quad$ Like turkey and mashed potatoes?

SH: I don't know about all of that, but they went to school and some of them took, like them boys up on the hill, they took, they might take a five-gallon bucket with syrup in it but they have something off in there and they may have some biscuits and whatever their mama have cooked. Some syrup or something like that. We ate peanut butter. There was a lot of peanut butter, I know a lot of peanut butter and jelly. [Laughter] And, they fix it-They fix you something at home, it was something that y'all had last night [laughter], and they bring that to school. It wasn't no lunchmeat ham sandwiches. There wasn't none of that. So we just ate, ate. You know, potatoes. We had some potatoes, beans, rice, and corn.

NL: That sounds good!

SH: Macaroni and stuff. We ate a good meal all right, but yeah, it was all right. In fact it'd be good now, I imagine. I remember a lot of, that there'd be a lot of peanut butter. We had a whole bunch of peanut butter, that big thick peanut butter. You almost had to cut it. [Laughter] And yeah, everybody bringing different stuff. Somebody might bring some fish to school, biscuits and syrup, bacon or something. Just have some lunch. Yeah. Just about it.

NL: Did you all have programs in school, like assemblies?

SH: No, it wasn't like that. I don't think you can imagine the kind of school it was, like compared to some school now and everything they have. It just was school, and after that, they get out of school, they go home. Wasn't no meetings or wasn't no-I don't think they had no PTA stuff then. They didn't do much. Just went for them little hours and then you go home. We didn't have to stay after school or nothing like that.

NL: What time did school start?

SH: Probably about eight o'clock or something, I guess, and maybe over like four or five back then.

NL: That's a long time.

SH: Yeah, yeah. We didn't go there for no two or three hours, I don't think.

NL: Were you all in class that long?

SH: Yeah, we were in class, unless they had a baseball game that Friday. Then they'd let you go to the game, but you're still in school; you can't go home. They let you go watch the game or something like that. No, just strictly school. Couldn't imagine nothing like what they do now after school and in school back then. That was a little black school and everybody knowed everybody. It wasn't all of that. Everybody knowed everybody anyway. It wasn't—not when I was going in '55. I mean '50, '52, '54, '55, '53 when I went there through the years and then we out. 
NL: Wow. Were you a little surprised when you came back and the school-

SH: Was tore down? [Yes.] Yeah. I really was-I hated to see that, and a lot of more things that was here that they had destroyed while we was out in Arizona. And the peoples that I would love to have seen when I came back, especially after learning some things I learned in Arizona, come back to see the country people that passed on. So really it was just a few, you know. It was almost like a ghost town. The land was still here, but you know, you go to see the land and roads and things, but it's changed a lot now.

NL: Why did they tear the school down?

SH: I never knew that. They never talked about it. For some reason, the city tore it down. I don't see why they had to. I would love to see it now and let my kids see it. But I don't think they ever seen it. I think it was tore down when I came back.

NL: What other stuff changed in the colony when you came back?

SH: The roads. They were dirt roads when I stayed out here, dirt roads. Three big old trees in the middle, you had to go around this way and go around this way, but it come back into the same road. Yeah, a lot of stuff they had tore down, except where LeeDell's grandpa stayed up there. That's still there, but what is burned down now. But it just changed. It just changed a lot. You can see the change. You can see the change when we left. Like I say, we left in '55. We come back here '80-somewhat. It's a lot of difference.

NL: Right. Was it kind of hard to adjust to those changes?

SH: $\quad$ No, because I know where everything was. I know who stayed here, I know who stayed there, and we can still go out across the pasture and stuff. But it was a big change. Not too much, but it was changed. Our house we stayed in was still up there, and my sister and them put some trailers over there. So, that used to be a field that we'd plant cotton in, corn and stuff down in there and then to see those houses there, it just looked different because that was just-wasn't nothing out here. The houses that people stayed in, there wasn't no extra houses. You know, wasn't no two or three houses over here where nobody stayed in it or moved out of it. Just the house you stayed in. And then they started to buying up land and change it around, putting the houses, putting this, putting that. I just know how it was. I just know how it was because I come up out here.

NL: Right. Was there a really big push to get people to keep their land and not sell?

SH: Yeah, well, the others just took it for granted that it will pass on. Like my father passed his on to us, and we value it and a lot of them did. But like Mr. [?] he has some kids and stuff, but they go to town or go to California somewhere. They been in country. They, half of them was here because they parents; they couldn't go nowhere. But after they got old enough to go somewhere, they went and never looked back. So they didn't come back, but the parents kept it, then later part of the family kicked in, then after a while, he deceased. Taxes will eat it up. That's why they got all this land here, taxes ate it up. They play what you call the outside or something and got it. They really, I don't think they really ever just money, "I'll buy your land, buy this." I think most of them left behind taxes. Those that did come and sell for little or nothing and booked up, but other than that for quite a few involved in it, taxes will eat that up, because anybody going to pay their part and anybody could do it, so they just sat there and sat there until the tax collector and they go down there and pay the taxes and then they stake it out. 
NL: Did lots of people want to leave the community after integration and the civil rights movement to go other places?

SH: No. No, no, not the elders. Peoples, the elders that was here when I was born died here. They didn't leave. They stayed. They about all died out here in this country, and they're buried up there at this cemetery. Yeah. Didn't none of them leave. The kids, those that had to, they didn't have no young kids until they was grown, they went to town, went out of state and stuff. But the originals, they stayed right here till their time was up.

NL: Now when did your sisters come back?

SH: I think they came back '76. One of them moved, then the other one, they came. They stayed in town for maybe about a year or so till they-Then they sent for my father to come back down here, and that was '79. Then they lost some trailer they had him put out here, out over there. But they stayed over in town till they could get all this squared away.

NL: Now when they were away, would they still come back and check on the land periodically?

SH: Yeah. Well, I had an older sister who stayed over in Austin who came back here like every two or three years or maybe every year or something. You see, then my father still had a sister and some nieces and nephews, we'd come down here and see them in year or so, then we'd just go back. You know, just come down here for a little while, mainly to see my sister. My father had my sister taking care of taxes and stuff, because she stayed here, and he sent her the money. She would go and pay it, and that's how we still got it now. Then when he moved back down here, wasn't really nothing to do, just move back down here and keep it up. Then they had a-At his age, I think because he was sixty-five, they didn't have to pay this or have to do something.

NL: Okay. So what made you come back to Antioch?

SH: My parents. My parents. They moved back, so I moved. I came back, too. Then I had some kids down here and they wanted me to-They was getting out of line, change of lifestyle. Then they wanted me to come down and help straighten them out. Then my father got sick. I had left and went back to San Francisco. Then my father got sick and they was all working, so they tell me to come back to help look after him. So I came back and looked after him until he deceased, and then I just stayed on here. Yeah.

NL: So you don't think you'll ever leave again, do you?

SH: If I did, it'd be just for a moment or something. I wouldn't just pack up and go back now. I think I'll end up being just like everybody else out here, be buried up there.

NL: It's a great place.

SH: Yeah. I think I enjoy that better. Now I don't know what the kids going to do, but I don't know. They'll probably be just like the rest of them. After all me and all my sisters and us pass on, they might stay, pay the taxes. They might just sell what they can, go get them an apartment or a duplex or a new car or something. I don't know and have no idea. That's what the oldest thought they kids was going to do, but they didn't. Move back and have a home and stuff. Shoot, they went out there to California and seen them bright lights. They ain't thought about it. They off in Houston or somewhere and they ain't thought about out in this country. You know. Now it's just really a lot of things going on now. But then, it was dark out here. Wasn't nothing to do. Wasn't no girls to be chasing or nothing. Number one, you had to go to town over to Austin. Everybody out here kidding everybody [inaudible] no way. So they 
just couldn't deal with this. When they got to get to them lights, that did it. Flip on the light and walk down the street at night just fine. They love that. You walk around this street, it's dark. It's dark! Yeah, they don't want that stuff there. So that's how it go. Wasn't nothing to do then. They got that guiding must [?]. [Laughter] They'd go to town. Yeah.

NL: $\quad$ So clearly, owning land was important to your ancestors, and that importance has passed down to your generation. But there are some questions on whether or not that importance will be passed down to the generation-I guess the generation that you're referring to would be my generation, to the people I guess the kids who are like my age.

SH: Mm-hmm [yes]. What's your age?

NL: I'm twenty-eight.

SH: Twenty-eight? [Mm-hmm (yes).] I ain't got none twenty-eight.

NL: They're older than twenty-eight?

SH: Yeah.

NL: So, but we'd still be considered the same generation.

SH: Yeah, yeah, yeah, yeah.

NL: So do you think that they know the value of land?

SH: Yeah, they know. They know.

NL: But they just can't-

SH: Whether they would do it or not, I couldn't put my life on it. They know that belong to they grandpa and that it passed on to me, their daddy, and then I don't know. They might, if they can afford to pay the taxes, they always got a place to stay. That's what my-That's what the old ones would tell them, it passed down. You know, you work. "We bought this land for you. We done this and done that, and so when we gone, all you got to do is just keep your taxes up and you always have a place to stay," is what my father told me. If you value it, fine. You always got a place. If you don't see nothing out here for you or the laws get so bad or something, I don't know. As long as you paying these taxes, you got it. Ain't nobody take that from you.

NL: Do you want your children to maintain the property that you have, your family's property?

SH: Mm-hmm [yes].

NL: Why?

SH: Why? [Yes] What-?

NL: If you were to pass, would you pass your land on to your children?

SH: Yeah.

NL: And you would want them to keep it and not sell it. 
SH: Yeah. Yeah, yeah, till the last one. From the oldest down to the last one. That's the only one could be able to sell it if it's the last one or something. It go to them in steps, yeah. Go to the kids, so whatever they want to do with it. I would request not to doing so, but they could change the law, and man, if you want to sell it, they'll buy. But I would recommend-I would like for them not to sell it. Like he told me, "You always have a place to stay." You go to town, it could be-You don't own that to a certain extent, if it's an apartment or something, and like you want to buy a home, it'd cost so much that-but here, you can build one, build your home. If you just really want to be settled and comfortable and got a family and don't like where you at, you know, afford the house, get you a job and save some money and get your house built like everybody else, and stay there. If they wanted to, but I couldn't say. I see so many that assumed they go on or the house go. They just sell it. They like that fast money. So really can't never say what your kids going to do. They might be something real nice and good in your presence, but once you're gone for good, they-I've seen some go another way. I've seen families have a dispute over stuff, greed over money. You know, "She left this for me." "They left this for me." "This is mine." "You wasn't here." "You was in California." See them go through all them changes. That's everywhere though, really. They come down, want to sell up stuff. "Oh, you're getting stuff," going on back. They didn't value it as they parents did, you know, mean nothing. Like it might not mean as much to them as it did to me. I don't know. Everybody change.

NL: $\quad$ Right. Hmm. What kinds of traditions do you see disappearing here in the community? For instance, when you talked about the youngsters, it's clear that so many young people don't have the same kind of - because they didn't grow up the way you did, their whole idea-like you said, they're city slickers. So they don't really have the same kind of love or fondness for the country or maybe for that lifestyle as maybe you all had, and while it's probably broad to say that that's a tradition, but there are certain things that come along with that that were important to you guys and maintaining that and that kind of helped you all value that. So I'm just wondering what other sort of traditions or values do you see disappearing in the community?

SH: $\quad$ They just not interested in being out here in the country. They don't value it. They don'tthey come out here. They like to come out here because their parents out here and stuff. But see, all that don't belong to me. I just have a certain part. You know, I just have a certain part of that. There are sisters that don't have kids, which is one, two, three-three of them. Well, if things was right and people really looked at things as they go-Like my father say, well since I'm the youngest, as they go, it should all go to me or something. You know, I should-Since I'm the youngest, they figure you're the youngest; you're going to be the last one, but that don't work that way. But in case, they going to say, "Well, I'll give this to you or will this so you have to go about and get it." That, and hers and hers and hers, and if I am the only one out here, it should be mine. But they've got husbands. Two or three of them got husbands, so they husbands got the say so there. But other than that, if I inherit all, most of it, like seven, eight acres, and I could afford to keep them up, that don't mean the kids going keep them up. They just have more to sell or something. But then again, I don't know. They getting older, too. They might want to say, "We got a nice house, this my father's land," and blah, blah, blah. "So I'm going to respect it. I'm going to take care of it." Well good, then. They'll hold on to it as long as they can. But the way they buying around here and live around here, now if you don't keep your property up to a certain standard, they can condemn it or say something's wrong with it and take it from you. But if they do right, keep it nice and clean and keep it tidied up, keep it, water stuff going on, well, they can't, they wouldn't even try to do nothing out here. If you looking like you don't cut the grass and keep it with the new home and stuff on the road, they have it all junked up and junked up where they don't like that. It don't look nice in the first place. It'll lower the value of the property and then just like having a junkyard on a main street or something in a sense. But, there's some things need to be done that nobody wants to do, so I just, I really couldn't say what going to happen to me. 
NL: Do you see the church that's being built down the road, do you think that that's sort of going to be a way to rejuvenate the community a little bit?

SH: Yeah. That kind of bring it back up. But I'd never thought I'd see one down there, not in my time. I thought it'd never be down there because it's a lot of stuff that you know, common sense. And I see how some people lives in a church and with that kind of stuff goes on in church. It's hard to get something done. Everybody want to be the man or want to be the woman. It's not a good understanding, not only in that church, a bunch more out here. So I don't know. Once the church get built where it's open, for us, the church though, that should brighten it up around here, once they got new roads and how this should make things bigger, I'm sure they might have some more people coming to the church and enlarge the community. See white people maybe coming in. If everything like a church should be, but-It looks good, but I just can't really say what going to happen. Besides, peoples causing this [?] church is steady getting older, so hey. How much [?] And then I don't think none of them young ones, none of these young ones out here going to go into the preaching business to happen overnight, and I don't think-I think that going to go end up somebody or something unless they go and get a good preacher in there and something. But still, they getting older, and I think if it wasn't for them, they wouldn't be happening, no way. So I don't know what to say about how long it going to last. But it's good, though. It's really make things look good as far as the blacks go, because like I say, I never thought I'd see nothing down in here, not like that. That's a pretty nice looking church. Then somebody going go out and get jealous of it and burn it down. All kind of things happen. It's kids. So, it's hard to say. There's some stuff goes on a lot of people don't realize, don't pay attention. Still that hating in there. There's still some hating in there. Some of these new people move in may come from a state where they all been together, but it's some down here in Texas still by that old tradition and you know, racism stuff. So I really can't say what going to happen.

NL: What happened to the old church?

SH: $\quad$ Back off in them bushes, I think it burned down or they tore it down or something. Might have tore it down, because at that time, people still staying here so nobody'd come in and set it on fire. So they probably just, boards rotting and stuff, just tear it down.

NL: Where did folks go after that?

SH: Where they go?

NL: Yeah, to go to church.

SH: I think they went nowhere. I know they didn't go up there to church, so I don't know. That church is right there on the Prair. If they had a ride, they went out there, out there on Goforth. They went out there. That's the only two black churches in town.

NL: Oh, wow. What are the names of those churches?

SH: That church over there is Center Union. That's about 100 and some years old, and thenbecause that church burned down. Out here, we just been going to church over there and over in town or somewhere going to some church that you just really want to go to. They have one in Manchaca. Yeah, we had a church in Manchaca. That's where they went, to Manchaca.

NL: Hmm. Wow. Hmm. Do you think you've been successful in passing down at least some idea of the importance of not just holding on to the land but really working to keep the community together? 
SH: Well, it's too late now. But as far as the community like it originally was, Black Colony is still Black Colony. But I mean the land and stuff, it's already-most of it's already bought up. Like I said, only landowners that's blacks is over there on Black Colony, right there by Nell by the cemetery and these people up here.

NL: So that in those areas and pretty much where you all live, that is the remaining part of the Black Colony as in Antioch Colony as we know it.

SH: Yeah, yeah. All right around in there. Yeah, yeah, right around in there. Yeah, and we the only ones still there. Now, you come on up there before you get to the cemetery is black, but they selling it. They've got people selling in there. You know, on the end down there, that white lady bought that. So really, it's vanishing. Slowly but surely, but it's vanishing.

NL: Do you think any of the new people who are buying land in the community have any idea of its rich history, of its rich black history?

SH: No, they just-it's just about the money, like they turned that into that gravel pit up there. They just getting this gravel out of the sale to make money. They really don't care nothing, about how old it was or who lived here or what it means. It's all about the dollar bill now, the way I look at it. But all the way back there it's just over who got it. Like Nell, she done hold on to hers the rest of her life, and where we at, well, that's going to stay until it come to the last or whatever and up here. So maybe a few more years or maybe ten years, fifteen years from now it liable all be a gravel pit. It's liable to all be houses over there. So there won't be a black memory to them as it is now. It's slowly inching on up, and like I said, it used to be a whole lot, and they ain't but three now. So you might tell, the three that's got it, they seen it. They're up in age and bad health and such. So who knows how long you going to be around? It's sad, but it's-I see it's going. If everybody-if blacks would really value their inheritance and stuff, there wouldn't be nothing from way over there, way over there all the way down, there wouldn't be nothing but black. You wouldn't see a white face out there. If they valued it and appreciated it and really looked at it, how hard it took to get it and how proud you should be of owning something, it wouldn't be like it is now. I'm sure that will continue to pass on to some. So who knows? Ten years might not see a sign that say "Black Colony." If there ain't nobody here to really uphold it. Like my sister and them, they didn't really want that sign, "Old Black Colony." They didn't want to have it-

NL: Your sister?

SH: Yeah. They want to have a colony, but they ain't want to have the Black Colony on it. One lady that stayed down the street, she wanted to have it changed, she moved. She didn't want that label, Black Colony Road.

NL: Well, what did they want to call it, just Colony Road?

SH: $\quad$ Something like that. They didn't want that in it, and I think it was the preacher preaching down there. He went up to there to see the stuff. Him and Martha and him, they put up a little, had something to say about it, so that's why it stayed there with them. Then the man that owed that, he knows it's Black Colony. He wouldn't change it. He flip it to Old Black Colony, but they the one who changed - a lot of them over there didn't want it. But he knowed what it meant. Evidently he'd been around the whole time. Well, he know what it meant, I guess, from these people, black people home and stuff, and he valued it and he stuck up for it. So that's how that-why it's like it is now.

NL: Right. Hmm. Wow. Well, we've actually gone through—that's all of my questions. That's really all of them. So unless there's anything else you want to tell me before we close down, but 
I've asked you-we've covered a lot. So if there's anything you think I need to know about the colony or about your family's history, you can tell me. This is the time for you to share something that maybe we've talked about, maybe think about something else and you'd like to talk about it. We have a little time left.

SH: What you like to talk about for this other little time?

NL: About Antioch? [Yes.] Hmm. I guess one of my biggest questions would be how did people go about buying their land back in the day?

SH: How they get it?

NL: Mm-hmm [yes], like how did they do it? I always think about-

$\mathrm{SH}: \quad$ How did they come about getting this?

NL: Yeah, having to really come up against a lot of odds-a lot of racism, a lot of poverty. The fact that it was really hard picking cotton and not getting much from it, how did they get that money to do it?

SH: Well, my sister told me that it was a missionary. People used to know missionary work. They came through here and it was all blacks around here, and they bought the land. The missionary people bought the land, and then I see it in some book and they sold the land to the black peoples. I think it was $\$ 2.50$, but Mary said it was like $\$ 5$ an acre, but I see in the book said $\$ 2.50$ acre, and then sold it to the white people for more because they know the blacks didn't have that kind of money and stuff. Then those that had it bought up what they could buy. You know, $\$ 5$ an acre, you got for-you know, bought up a bunch of stuff. That's what I was told. And that's how they come about this land down in there. Then the land we got, it was the same thing, bought it. My father's nephew bought it and sold it to him or some kind of way. But that's how they got the land around here. Those that really had the money, like maybe some of the blacks was teachers or something that had enough money to buy more. That's why they maybe bought-They might have twenty or forty, fifty acres because they had the money, but like my father, he'd work, he used to work for 50 cents a day. You know, that take a while to come up with $\$ 5$. You have to have $\$ 5$ to buy just one acre. So, I guess he come up with enough to get ten and a half acres. Or however he come by getting it, but that's how the black got their land. The missionary bought it and sold it to them, I guess before the white folks got it. They couldn't afford it, or they wouldn't sell it to them. But that's what my older sister was telling me. Then I had read a paper or a book or something in black history and it's telling me where it was $\$ 2.50$ an acre. They sell it to a black for $\$ 2.50$. But she said they bought it for $\$ 5$ an acre, and I'm sure she know because she been back in them days. So it's one of the two. That's how they come across some of this land that they could buy. It was a little colony, so I guess he just bought this section around here. But the peoples over there in Manchaca, Ms. [?] they bought land. They got a whole bunch of land. So I don't know how they come up with all the money unless they worked and stuff, but I don't know the price of it, either. But over here, Black Colony, that's how they come about that. And he, my father had some nephews and things that well educated and had good jobs and stuff, so they could afford to buy quite a bit and they bought quite a bit. But it's still all right here in Black Colony. Then I guess he gave to his, some family and it was all. It was a whole black thing. It was nice, but it ain't like that now. You can just walk anywhere or cut across any field. You never heard no-You didn't see no sign, "Private Property" or this and that. It was just open, just open. But that went to some of the seniors, and like I said, they don't value it like our ancestors did. They really strived to have some land and they strived to keep it, and then just to-all that work, then they just come up and let somebody do, some of your family just give it away in a sense, or sell it for a new car or something. That's hurting, but that's just the way 
it is. Money really is the root of all evil. You got that money, you just about get anything you want. You get out of anything you want, so-

NL: But it's very sobering when you think about somebody having to work for 50 cents a day and to raise their children.

SH: Yeah, and trying to buy some land.

NL: $\quad$ And to buy some land?

SH: That's 50 cents a day there by itself. That's why he had chickens and hogs and cows and things, to feed his family, us. We'd go out there and wring a chicken neck, have some meat that day, and we had a big, big garden. We just, we live off of that. Kill a dead antelope and we got that. We had a big smokehouse, so we were well fed. Cows, we got milk. Go out there and milk them. So we done good!

NL: Right! Oh, I agree!

SH: We did better than a whole bunch of people. But now just own a cow, just milk from a dairy, I guess. You go out there and take you a glass or cup, milk you a glassful of milk, go on back and drink it. That didn't cost you nothing. We got a garden with all kind of stuff in it-lettuce, okra, something. That didn't cost you nothing, so you done good for the amount of money he made then. Had a little job where he go on these people property and cut wood, take it to town, sell it, make money like that. But there wasn't no whole bunch of money floating around. And what money you had you put it to good use. You didn't just-He didn't drink or smoke or gamble or nothing, so all the money made went to all his family and his pocket and his livestock. It seemed hard then, but now, you look at it, well, you really didn't know how blessed you was. How things was then, you didn't have to worry about a lot of things that goes on as far as the law or a lot of things. But you was kind of like free then, in a sense. You didn't get into that much, because there wasn't that much to get into out in the country. When you went to town, you had a variety of the good and bad, but down here people respect. I always say respect. You ain't got no respect, you ain't got nothing. That's what I say, but who am I though. But, respect. Respect got me where I'm at now, respecting elders and respecting everybody, really, not just elders. And knowing right from wrong, and you know, you what she-you know if they don't want you over there, don't go over there. Common sense. But a lot of people push their luck. I would say let them.

I learned a lot from my parents. The stuff they taught me help me today. We used to play. My momma used to tell us stop playing. "Okay, now stop playing so much, boy. You all need to sit down here and watch me sew these clothes and cook and stuff." Because she said, "You get you a woman, ain't going to be, ain't going to be another woman like me. A woman ain't going to do these things that I do for you and stuff. You need to learn these things so when I'm gone, you can if you still single or something, you can tell your parents you can't afford nothing, you can sew them. You know how to cook, you know how to clean, you know how to make beds, and you know things. Stop all that ripping and running and giggling [chuckles] and learn something." So I learned it. It may have been more than I thought it was. I was looking, so I could do it all right now, just everything she told me. Wash, iron, anything to be done as far in the house I can do it-making beds, everything. And I wouldn't have known better if I'd been running around there, and I wouldn't have been paying no attention. And yeah, my momma going to cook, but when she's gone and you don't know, you're stuck. So I took advantage of that. And, my father used to tell us about working, going to work. We'd work from sun to sun. I was a little bitty fellow. I worked for $\$ 7.50$ a day from sun to sun chopping and cutting.

NL: $\quad$ You did? 
SH: Yeah. I did. It wasn't nobody else did, I did. As soon as that sun come up in the morning, and that sun go down for $\$ 7.50$ a day-not no hour, a day. Then I got a job after that cotton played out in about ' 62 , I got a job washing dishes where my brothers and my daddy was working at, and I was getting $\$ 1$ an hour for working. And I worked eight hours, that's $\$ 8$ all day [laughs]. Well, I done this. This is not what they done, this is what I done in my time. So, people tell me about working sometimes, "Man, you don't know what you're talking about." Some jobs I get, they say, "Man, I've never seen anybody work like you." My daddy taught me how to work. You be out there working in that sun, you'd like to drink a glass of water, maybe coke glasses all day. And as bad as I come up, I find myself doing the same thing, yeah, working. Just work, work, work. When I work. When I don't work, I don't work, and when I work, I work. But a lot of that come from him, seeing him work and how he worked and teaching me this in a very business manner. And seeing how my mother stuck there with him. And, uh, like I said, I benefit from that right today. As far as working going, doing the thing you should do, and you value what you have. And, uh, yeah.

I worked for $\$ 7.50$, so. People getting $\$ 15, \$ 20, \$ 30$ an hour now. I was all day sun to sun, and I was a young one. I wasn't no grown man. I was younger than that, thirteen, fourteen, fifteen. Then I went and did some harvest work when I got a wife and some children. And I had to- the young folk couldn't get no job. I had to go to the field, pick potatoes, pick onions, pick watermelon, lettuce-all that harvest work. It'd be like 25 cents a sack, half a sack of potatoes or sack of potatoes, get all that sack in, and you're going to give me 25 cents for that sack. But, you have to get maybe fifteen, twenty sacks, and that's what? That ain't a whole bunch. And when you got two or three little children, and have to pay rent. It was a great job, paid for your stuff. Ollie said to me, "Ah, he don't know about no-he ain't never picked no cotton." I just laugh. I don't say nothing, because he don't know this business. When he ain't done nothing I ain't done. It don't look like I've been, it don't look like I've ever picked no cotton, but I have. I enjoyed it. Know that good. I'd do it right now if I had to. I liked it. Well, you survive it. I had to feed my family. I took care of everything. And my wife worked, she-I had to put her in the field near me. I had my wife out there, she was pregnant, sat down on the-put a pillow down there in the sand, we [inaudible]. And them boys, they'll go down there and pick them up, put them in the thing. They were like, I'd say like six and seven, some of them about six or seven. One of them might've been five. We had to work out in the fields to support, take care of them. I'd been working a pretty good spell, and I'm 'bout tired.

NL: Wow! I can understand that.

SH: Yeah. Shoot. But, I don't know. I just sit back and think sometimes, just sit out there and look around, "Remember when all this used to be this." And, how things is, how peoples is, and how it would've been if they were still living, and-I got some down moments sometimes when I think about all the people that I come up with and not all the people-the older people, how they used to do it and how all of this would just-Having something just for all blacks is, that's another thing. You know, it's something to think about.

NL: It's powerful.

SH: Yeah. Then to see it just vanish, and people just step on it, just push it to the side, that's bad. But I can't do nothing about it. And, like where we at, my father had-He just had big old thing, okay. Then after he died my sister had his survey sectioned off, and he said before he died just leave it like that and just pay the taxes. The taxes wasn't that much, because he was over sixty-five, there a certain thing, and the rest of them is, too. Just pay the taxes and just put you down where you want to go. Don't section it, so if something did happen, you wouldn't have to this is hers, she got this, she got that. It, it'll be just one person. It'll go to the last of his kids. Not our kids, the last of his kids. But the way they got it now, well, like Minnie across the street, well, if something happened to her and her husband, obviously it's going to 
go to their kids. They ain't going to stay out there. They don't stay out there now. They sure ain't going to stay out there if she ain't there. So somebody got to sell it or something, but they should have left it like it was. They want to change it, they selfish and stuff, so it's all messed up. Like Winnie's will go to the state or unless she put somebody in there, the other one'll go to the state or she have somebody sell it, and then go to her husband, and see what. He ain't going to stay out here if she ain't out here, so he's going to sell it and go on, and then there'll be a big gap in there. It's all screwed up. It will, it'll be all screwed up, especially if it goes to the husbands and the kids. So, unless those who don't have none put me on there, which I doubt it. All I have is just that. And I got so many kids it's going to be a heck of a time to split that all up, so I don't know. They'll sell it, and get them some money, and split the money up for all of it. Unless they really be a family and just build a nice big place where piece of land so they could stay there. They'd have a place to stay somewhere or something like that. You can't put no bunch of trailers on it because you can't have no more than one on that amount of land, and I've got too many children for that.

NL: How many do you have? [Laughter]

SH: I got eight and one deceased.

NL: You have eight children?

SH: Yeah. And my son died back, I think it was like 2003, I think, and now I just got seven.

NL: How many girls?

SH: Well, I ain't going to say it like that. I got two.

NL: Two girls and five boys.

SH: Yeah. Yeah. It, it was two girls and six boys, now then there five boys, yeah, and two girls. One for show. One is Daddy's baby, Momma's baby, Daddy's maybe or something. And I got, I got seven more. Now how can you split up a little piece of that, you know, as far as having a place with that many kids? You can't. They would have to-Provided they keep the taxes up and everything else, I know the rest of them going to sell that. If they keep the taxes up, they can sell it and split it for whatever they could get for it, you know, twenty, thirty, forty thouwhatever they can get, and split the money, get a lawyer to split the money. That's the only way all of them come out with something out of it just because, I mean I don't know, I mean I don't know if none of them want to stay out there anywhere, except the one that's out there. And then if it comes down to it, he, he might want to go, he always talking about the country. But, it's hard to say this stuff. Do what you can while you can, and you can't take it with you. So let's hope for the best and then-What would you say if you had about $3 / 4$ of acre, and you had about five kids and they all grown, how would you, how could you split that up? And maybe some, maybe four who love town or out of state, you've got one to stay out there with you, but he's there because you're there. And you don't know if he's going to stay there once you gone. He, if he-He's there, but he may show you some signs that if he got that chance, if it wasn't for you, he'll go to town with the rest of them. How would you get rid of your land? You've got them five, and they can't put no five houses on a little bitty spot. So what would you do? Other than selling it or they sell it, because you're going to be gone anyway. That's when the stuff going to start. They sell it, and split it, that's the only thing I can see.

NL: That's a tough one. I don't know.

SH: What would you do? I mean you've got your fact that you have three-quarters acre. Now and like I say, you can't put no whole-you've got five. You can't put no five houses out there. 
None of them are going to want to come back no way. Okay. Then the one that's stayed there with you, he's there. He's a momma's baby or something, he's there, but if you wasn't there no longer, well, he probably wouldn't be there, either. He would be showing signs where he's going to go where his other sister or brother or somewhere close or go to town or something. So what would you do with the land, and you had it all this time? What would you do with the land that really, you've done all you could, and you just don't want it to just go to waste? What would you do if you had enough strength in things or you had a son that you, you know, a son or daughter that would take care of business like sell it and split it between everybody, or if this was, that you really, your time was really up, would you try to sell it and split the money or leave it up to one of your sons or daughters? That's a heck of a decision, you know.

NL: It's a hard decision. I don't know. I mean that's a tough one. It's a real tough one. I can tell you-

SH: If you figure that out, I can figure mine out.

NL: Well, I can tell you from that I couldn't figure it out. But it's funny because my mom is one of eight children, and there's seven of them left, and they have a little parcel of land that their parents left them that my uncle lives on, and has been watching over it. Now that his health is declining, that's what they have to think about. They have, actually it's now six of them left, and they can't figure it out.

SH: Do any of them want to move out there?

NL: Well, they got into a pretty nasty little row about it one time. And one aunt said she didn't want anything to do with it. She doesn't have any kids at all.

SH: Yeah, I hear that a lot, too.

NL: $\quad$ So she signed over her land over to one of the other ones. Then the other one, one of the older, like my mom's older sister, she has four kids, so she won't sell none of hers or sign it over, because she feels like she doesn't know what her-she wants her children to decide.

SH: He child to take her of hers.

NL: Exactly. And so they still don't know, to be honest with you.

SH: That's the same thing.

NL: They have no idea.

SH: The same thing, what you're telling me, the same thing happened out here and is happening now, you know about it. You don't have that much to give nobody an equal share. He had enough to give out, not a full acre, but he had enough for all of us to get a piece big enough to build a house on, whatever. But, well, like me, I've got, I've got more kids than all of them. What about mine? And then Mary, she's got a bunch of them, so how you're going to do that?

NL: I think my uncle, at one point, I think his idea was that they all together lump it all together as one, and do something, make improvements to the property, that way rather than it being, eight and then divided even amongst all the other children that there's one big thing and that people work with it. I think for the sake of it being easy in maintaining land, it's easier. It's easier to like-I mean even if you decide to sell, in the end it's even easier to sort of deal with like whatever kind of money is being divied out. But that's a challenge, because I think you then have to sort of make a decision of who is actually the most fit person to sort of like 
deal with the money issues. It's a real sensitive issue, but I think-But you're right, you see it happening in a lot of these kind of-

SH: And then a lot of them thinking that someone is, she's getting more than I'm getting, and all. Then you've got a big squabble. But, that's happened. I've seen it happen. But, I'm just saying how could you get rid of something so small for something so big that being a kid? What would you do?

NL: Right. I can tell you I have-I couldn't, I can't answer it. I couldn't answer it. And I don't, and looking at my mom's people, I don't think they can answer it, either.

SH: Yeah, because it's more than just one. Yeah, so I thought about that a lot of times. Man, hey. And then it wouldn't be fair to give one some, but don't give the other one some. That would cause them to have conflict between one another. So, it's just, it's a hard pill to swallow. I don't know how to swallow it.

NL: It is hard. But I think it's important to have those kind of conversate-like to have those conversations and to be really open, because I always think that one of the reasons why it has become such a touchy issue in my family is that they never could come to, I mean even in the beginning, they could never come to any kind of agreement, even amongst us siblings. And I think the challenging thing is now there's siblings that all live in very different places, and then like their children live in very different places. So it's like well, what do you do with it? But I think most of us, like my generation, we have no idea. We would've never even known that there was even property had, we didn't have uncles that started passing.

SH: Yeah. And then, you might have maybe one or two of the children might say, I would like to go down there and, you know, maybe not gotten married, got a family, well, I'd like to go down there and stay on my mother's property, and try to do what I can, prove that it was-It might be one, it might be two, but okay, then the rest of them they're going to feel like they ain't getting no money out of it or some kind of stuff. But hey, like one of them said, you said that [inaudible] go on and take it. She already said it. But a lot of them feel that way about other things: "Well, you all can have it. You all can fight over it. I got a home. I've got some kids. I've got this and that. I don't want nothing to do with it." Okay. Maybe one or two of them will say that. But some of them, there'll be one of them more on whatever he can get, he or she can get. He going to take it to the limit. And then you got a lot of things to deal with, a lot of disagreements, and a lot of them feeling this way about the other one, and feeling that you doing this, and all, just a bunch of stuff. So-

NL: Right. I do think in that instance though it's best to be united together. I mean in this day and age you can't do very much when it's so divided that you can barely, you know, but if you can kind of find some way to come together, even if it's just two or three people who can kind of start coming together and thinking, you sort of end up making-I guess doing better for yourself, or at least being able to better equip yourself to make a decision. But it's a tough one.

SH: Yeah. So, I think about that situation. And I say, "Well, hey, man, what the heck can I do?" I know some ain't going feel right, some going feel cheated, some going feel this way and that there, and so. And if you did go sell it, you've got to do it while you was around in your right mind to do it and split the money, because somebody going mess up then. It's-I don't know, it's mind boggling to me. What the heck can I do? Well, it might be one or two that want to stay, but some are going to want some money. If he ain't out there, he don't stay out there, he wants some money to catch up on his bills and this and that or do something with it. And, uh, I don't know. 
That's why a lot of property they have, when it's a lot of heirs should they evenly divide it, people don't want to evenly divide it because too many, too many peoples in it, and they've got to, everybody got to have a say so whether you want it or not. Because you got to go through quite a bit, so they don't want to divide it because they buy it from them, somebody else, he got the right, he hear about it, and he come up then you know now the law, they take them to court and have to go through a whole bunch of stuff for one person, you know. If you're a heir, and you've got your say so that you've got this, well, one person can mess up the whole thing. So they don't want to get tied in with-Now if you're just a man and his wife, and both of them deceased, they got a hundred something acres, well that's fine. Ain't nobody going to steal it, no kids. But when you got kids all around, properties are kind of hard to get rid of. They really got to be in a good place, too. Like I tell them, the way they're building, they'd be dared to suck that up.

NL: That's why it's important for people to think together, like you said, to be of one, at least on the same page about something.

SH: Yeah. Yeah.

NL: Because in the end, everybody gets, if you're not together will get, they won't get anything. They'll be completely messed over.

SH: Yeah, yeah. Well, I don't know, but I just, to me personally, because I ain't speaking about it, I'm going to just enjoy what I can while I can as long as I can, because when I'm gone it's over with, and I can't take it with me, don't want to take it no way. But, what they're going to do, I won't know, but just try to make things right, get a good understanding with you and these kids and everything while you can. You know, don't favor one. I mean all of them. But I don't know. I know that day's coming, but I don't know when, and I really don't know what to do [chuckles], to be honest about it. And all I was just saying was what would you do if you was in that position?

NL: I couldn't even tell you. I couldn't even tell you. And that's, like I said, that's a tough one. I don't know. I mean I think about that in relation to my mom and their situation, because-

SH: Yeah, it's the same thing. [Phone rings]

NL: I even think about if there was an acre left, what would I do with an acre?

SH: Yeah, but see, you ain't got no kids though. But, you're going to have, got some kids, and then you got this acre. Well, you're going to have to do something.

NL: Yeah. I don't know. I don't know.

SH: How would I by myself? I'm by myself.

NL: I don't know. It's funny. I'll have to ask my mom and see what resolution they came to.

SH: Okay. Then you tell me.

NL: I would. I'll tell you. But I can tell you, though, it hasn't been an easy one. At all. It hasn't been an easy one. And I don't suspect that it will get any easier.

SH: No? 
NL: No. Because I mean there was eight of them. Of that eight, two have passed. Of that two that have passed-

SH: They have some kids.

NL: They have kids. My Uncle George had two boys, one of them who just moved back to the area, and he has now three children. And then my other uncle that passed recently has a daughter that, his biological daughter, and then I guess you could say his son, which is more like his adopted son. But right there that's four kids, that's four grandkids.

SH: Yeah, and they going to want something.

NL: $\quad$ Mm-hmm [yes]. So. And I don't think they were ever-Then I have my uncle who was living on the property, he has a daughter. But she may not be interested in that property. There's other property that has less conflict attached to it.

SH: Yeah, they might want to, if they sell that to get some money and go buy them some of their own, for they kids. So, it's tough.

NL: It's a tough one, but I think one of the good things, though, too, is that it helps having-I mean having family that's still close by to discuss that, and having not just like your siblings close by, but your grandchildren close by to discuss it and talk about it. Because like my mom, they're not far, far away for the most part, for the most part most of them are within about three, four hours of each other. But the grandkids are scattered. So there hasn't been any kind of conversation with the grandkids about the importance of okay, well when we pass, when we leave, like whereas you all have this memory of this being owned by black people and being in our hands for almost a couple of hundred, more than a couple hundred years now. Whereas for us, that land has been there. It hasn't been there that long, and we don't really know. For us, like you said, it's different. It's like for me, I live in Texas. What am I going to do with an acre of land? So that importance is not-We don't have the same sentimental value to it, which I think makes this a little bit different. Because for us, like our ties to it are very different, but I mean it's very hard to let go of something that has that kind of historical and family value to it.

SH: Yeah. And then what you know about historical stuff, well, you value it a lot more than someone else probably would that don't. They don't see it the way that you see it. So, they might not feel that way, but you live on it, and maybe it's something in the way or something, but. That's the same thing about all this stuff out here, about they have some kids, they kids have kids, and all that's tied up and they don't know what to do with it. They haven't heard from this one in so many years, they haven't heard from this one, but as soon as something happens, here they come and looking for their share. And there's so many tied in there, and the taxes got so high, nobody pays, so they step in, they get it. That's how, that's just how Black Colony disappeared. This big old hole in there that's big enough [inaudible], that belonged to somebody. But they done died, they kids ain't saying nothing about it or they family members don't know nothing about it, so they just, he just spread it. They made about a million off of that, I know. So that's what going to happen to a whole bunch a more stuff. It's not going to be on that flood bottom, hard rock, really can't build nothing by digging down because all this rock, like on that creek so. I guess that's all they could do about it. Well, they could've put some houses over there if they did clean, they clean everything else, clean it out, but the water goes back up in there, so that really, that wouldn't have worked. But all that other stuff over there, like behind the cemetery that way, they going to be the only ones left on that road pretty soon, Black Colony Road. Then anything else they see in there that they can get, they going to put houses out there, so anybody left-You know, that man that just bought that right next to us, he just bought that, so I know he might just bought it to 
fix it up real good and wait until the value go up on it and sell it and go buy him somewhere, somewhere. I don't know. Nell, she ain't even have nobody, she ain't no spring chicken. So if something happen to her, she ain't got get nobody to go get that, push all them trees down. You might come through there and see houses all the way down to the creek. That's how it go. I don't see nothing I can do. It's sad to say, but you can't do it, you just can't do it. I don't have that much, being my acre a piece. Now if I had, like I said, eight acres, and I've got five kids, I could give them a good acre a piece, and maybe a little bit more than an acre to even it out, or at least just an acre a piece, and take and maybe sell the other two, so everybody'll have some. But when you ain't got but one, one to two acres and you've got seven, eight kids, it just don't fit. Because something just ain't right for everybody to be happy.

NL: Unless you started buying up land in other parts of the colony.

SH: Yeah, somewhere out there. No.

NL: Which isn't a bad idea.

SH: Which ain't nothing down here in the colony really being bought. It's all bought up. You might buy somewhere [inaudible], maybe out in Del Valle or some other place where they probably wouldn't want to be, but to me most people that want to keep some land where they was they uncle's or they grandpa's or something like that, keep that land going. But, just to go buy some land somewhere, well, it's okay, too, but it don't have that-

NL: That same value to it.

SH: Yeah, that it was my grandpa's. So, I don't know. Now if I had the money, and could talk to my sister, if I had the money or could get the money, now I'd buy all of it, all of it, and have it put back in one thing. And then I've got these kids that if they outlive me, then they got ten acres they could get them a nice little piece of piece. But it wouldn't be right because my sister has some kids. They might want it. They want what they momma had. I just-but, that's-I think that's some work that I just can't get out of it. You have to hit the lotto somewhere and buy a bunch of land for your kids that just no houses on there. That inheritance. To leave it for somebody just, you know, and some families, you know, it's everybody. Some people don't, they just don't value their land. You see it's a lot of, man, they come up with all kinds of stuff once you're gone. And they just cause so much stuff, and these lawyers, they're taking half of the stuff, too. So if you ain't know what you're doing, you mess around and done gave it away and don't know it.

NL: I don't know.

SH: You know where I'm coming from. You're in the same situation. Well, at least you know about the same, you know about the same situation then. I don't know.

NL: I don't know. I'll have to ask what they did. I know they haven't resolved it. I know they were just talking about it in December.

SH: It might be one or two out of your uncles, then they needs to-I don't know, might not see eye to eye to somebody else.

NL: They don't see eye to eye. They don't. I mean they don't. I mean I think they don't see eye to eye on it, partially because they don't know what their children will do to it. Now I think that in the back of their minds they have an idea that there may be a few of us who may do the right thing by it. But for the most part they don't know, and I think the biggest fear may be, well, whoever has the larger stake in it, because I don't know if the land is divided equally or 
they do, and how it would impact the others. And, how many people want to come back and stay here. So, I don't know. It's a tough, it's a tough fight. It's one that a lot of them don't, they don't always have to talk about. But I do think you've got to talk about it.

SH: Yeah. Yeah, you should. But then some ain't going to want to hear this because this and that. You know, I don't know. When we come down to the property and there's a lot involved, it's just tough.

NL: It's tough, but I think when people talk about it early, even in the midst of it being tough, that's how kids begin to have a value for it. It's kind of hard when someone finds out about it after they've kind of gone out and sort of established their own sort of like values or some of the things they find important. I mean, I think it's almost—-talking about that early makes them have a respect for the past and for the hard work that went into it. Or at least it gives them that hesitation to let go of it. So if they don't know about it, it's not that hard for them to get rid of it.

SH: And then with some, like a family member is out of state or something and hear about what they're talking about doing was that, and they haven't been there in so long, they just figure oh, you're getting a while bunch of money, but you're not. They think you're getting a whole bunch, and then they come wanting their share of stuff, and it ain't like that. You know, they just-And there's some that want to stay there, so why do you want to go sell it if you got a couple who wants to stay here on the property. They going to go make improvements and make it look nice, and just stay here because that was they grandparents' or something. And then you've got some say, "Aw, this," and they're just going to cause a bunch of stuff, one way or the other. So I just soon find somebody, some of us, you know. We're hard to please, you know. I'm telling you, girl, we have so much trouble out of us it's a shame. I've seen like some of them Hispanic and the White, they have stuff, they can die and sell it and split it up with no problem. When we get something man, it's just like we just ain't giving it up. We always got something to say.

NL: But sometimes with them they have so much.

SH: Yeah, they have enough to do that.

NL: They have enough to do that. Whereas I think with us, it has been such a challenge for black people to come across land, and to get real estate, and to hold on to real estate. There was all these laws that made it hard for us to even buy property, to buy good property.

SH: In the first place, yeah.

NL: Yes. So I think it makes it hard. And I think that's sometimes is the irony of it, there's always just enough. Sometimes when it comes down to those more privileged families to have it and to give it to others.

SH: Yeah. I don't know. But once upon a time this was really, really nice. You really felt it when you walked across here. You didn't have to see no signs or nobody talking about get off my property or no shooting, no nothing. You know what I mean? I mean walked, walked, we never had no trouble here. To look back now and know how things is now, but that was really something to think about, something that really was a good time at that time. And, you'd go over to this person's house and eat. They offered you something, to eat or something on your way home. And, everybody know everybody. They know your parents, your grandparents, everybody. So, it wasn't no house theft stuff. Everybody respected everybody, because everybody had to work. There wasn't no freeloading. You had to work, the men and the women and the kids, too. So you really valued and respected what you had, because it 
wasn't no gift. You had to really work to keep it up. And nothing never experienced something like this, like some kids, grandkids, or sister's and them kids, they just say, "Aw, this my momma property," and this that. But they really don't value it like they did. You know it's your momma, you know it's your uncle, your grandpa, but you really don't value it. You talk good about it, but you really don't value it. You ain't trying to improve it. You ain't trying to make a stand or nothing. So like I could see now, somehow Minnie and her husband, I don't think neither one of them kids actually live out here. They'll stay out here as long as some of them angels out here hunting for something, but I think if it weren't for that. Like I said, they can't see nothing, and with these houses coming, they ain't going to be able see nothing. They want to be able to see them girls chasing down the street, and see them boys running up and down there and cars or something. There ain't nothing out here. You come out here to enjoy, enjoy. You come out here to kick back. You come out here because you don't want to deal with all this noise and all this shooting and stuff. You come out here to be, this is your home right here. But you can't—-they don't see that that way at twenty, thirty years old. Some of them don't. And I can't see where it's going. There's too many tied in-kids and grandkids, there's too many involved in something. Like Ms. Washington, it's just her and her husband. Okay. So whichever one goes first, the other one will go do the thing, okay. My other sister, (Eunice) Rimes, she's so selfish and stuff, and she ain't got no kids, but she's the godmother of some kids. So who knows, she may put them on there or something, so-Or if she did and nobody knew nothing about it, well, I guess somebody can get it or they can sell it. She got LeeDell over all of that stuff, so I'm sure he-the way LeeDell is, he's going to sell it and get the money, probably spread it between everybody. But how can you split a little amount? I don't know how many there is, six, six, six girls and two boys. How are you going to-You can split it, but I don't know how to, you know, what-I don't know how it's going to go. I don't know if he going to sell the land and the house or if he just going to sell the house and the car and just see how the land is going to go. Pay the taxes on the land. I don't know. It's up to him because of the other six. Now I'm sure he wouldn't want to sell the whole thing, and then everybody else around him, because if he sells to somebody, they're going to put what they want there, do what they want to do with it. So then they won't like that because they're coming in and out. If you even got a big truck or something, whatever you got, you got the right to come in here and pull in the yard or whatever. So I don't know. I don't know. I mean if you sell the house, they damn near get anyway anyway. I don't know. I know it's tough to be tied up with whole bunches of them involved, and you've got to split stuff up with a bunch of kids or grandkids or something. Yeah, but I often wonder how I'm going to deal with that. I might outlive all of them, huh.

NL: You may. I think it's good to start talking about it.

SH: Yeah. Whose, see who really, see who really feels interested in it, and who would really uphold it. Or who will say let's sell it and get the money. Who will say no, let's straighten it up, man, and maybe could get another twenty back or something. But you've got to talk to them first.

NL: It's a tough conversation. It wouldn't be easy, but I do think that you have to-I mean, I think it's good that my family has started talking about it. And each time that we try to talk about it, it has been hard, like really hard.

SH: But the only thing is, is it getting closer and closer to really understanding what could be done, though, by talking. Know what I'm saying?

NL: I mean-it's hard because I only know this, like I don't know it because my mom has told me. I know it because my cousin, who's older than me, my cousin is forty, so she's around a little bit more. She's beginning to pick up, I think to handle a little bit more of the family responsibilities as her parents have gotten older, and as they began to care for some of their 
older siblings who have gotten sick. So what I know, I know from what she told me, like through gossip, like, "Oh, such and such happened." So I know, I've never heard my mom talk about it. They never really sat down and discussed it. But in my opinion I think that they would be able to come to an agreement a little bit easier if they sat down, started having some kind of conversation with the grandchildren just to kind of sort of see what's happening or where are they, where are their heads. I mean I know it's hard to part with property, but I think that it's a lot. If they could sort of see well, how many of you all are really trying to come back here or how many of you all want to come back here. How many you all want land? You know, like what's the deal. I think it'd be easier for the parents to come in, rather than for them, for everybody to sit down there and say well, I want such and such to have it because I know that they're going to want it. That's not necessarily the case. Everybody may not want to come back to Virginia. But I think that if they had a-like it's important to have that conversation, because I think right now everybody's just so excited about it, but no one really - they can't come to any kind of agreement yet because they have no idea where the other person stands with it, or where their own children stand with it.

SH: Yeah, I know what you're saying. But, like you said, so exactly. The hard way is getting me to talk about it.

NL: You do. And I think, it's hard, but it's something that has to be done. And it's something I think that should be done while people are still, before people get sick or before people start passing off. Because I look at my own family and recognize that part of the discomfort now, it was always uncomfortable to talk about. They never could get along. They just kept passing it. You know, we'll discuss it later, or we don't want to deal with this.

SH: $\quad$ Time raised a new dawn.

NL: Yeah. And now they have no other choice. Time is really upon them. So, but-

SH: Yeah. My family about the same way. They need to sit down and talk about—Some things they talk about they shouldn't be, but they need to talk about this stuff we've got out there, and work something about or something, before it's too late. Nobody, they don't, they just think, I guess they think they know, but they got no sympathy on their hands [inaudible]. But you can't tell about tomorrow. You don't know what tomorrow could bring. Accident, death, fell out, stroke, anything, so do what you can while you can. Are you in your right mind? Some, but they don't, they don't talk about that. They just think, "Oh, this is so and so. I'm going to be around so and so." So and so might not be here. I mean I should sit down, like you saying, get my boys over there and my girls over there and just really ask them how they feel about this out here. Who would want to live out here? Or do you all want to sell it or what.

NL: Right. Or least recognize the importance of having it. Because I felt like, I mean you may not want to live here-

SH: You own some property, man, you've always got a place to stay. [Yeah.] You've always got something. [And, you never know where life will take you.] You got a house that grandkids can come live with you or some of your kids come live with you. But it's yours. It means a lot. And you've got that kind of, you know, you've got some that want to fight and steal and do all this, but everybody ain't going to get along. Somebody ain't going to, you know, it ain't going to work. I don't want him around here because he's stealing. I don't want her because she ride around - just a bunch of stuff. So what the heck can you do? You know. And ain't no two people the same. There's always, there's always somebody a little off a little bit. Something, something, something ain't right. I've got a bunch of kids, and the thing, but I don't know. [Chuckles] 
NL: Yeah. Well, just I say keep thinking on it. Keep thinking on it, and something may, you know. I mean time's been good. I mean, like you say, tomorrow's not promised to anybody, but just keep thinking on it, and always think that the time will be right at some point to kind of -

SH: Some, yeah, something going go like that, yeah. It's all good. I don't know, as time goes, I'm looking at them, and they don't know I'm looking at them. I'm looking at them and see their little lifestyles, and see what they're doing and how they do it, and how they getting along with one another. I see all that. But you know. And then you can might say, "But I know so and so is going to do all right. He's going to be able to do this and do that." [Inaudible] I got an eye on a son that I thought would uphold it as his daddy's stuff and history stuff, but there ain't nobody I know that's going to want to do it. And I know my daughter ain't going to be out in that country, and I know another son ain't going to hang out in that country. He'll come out there to see you all, but I can't see him trying to get no house or something.

NL: But even if they don't live out here, I mean I think that there's still an importance to holding onto it and keeping it in the family.

SH: Yeah. If you do stay there, just keep the taxes. It's still yours. They can't do nothing with it. It's still yours. Pretty good, take your grandkids and say this is your daddy's property, this is Grandpa's property, this is mine. Just to have it. You decide you going to while you can. I've known people that they folks died and they stayed in town. Say, "Man, my grandma or somebody left me about two or three acres, and I'm going out, I'm going to move out there." They move out there, and make the best of it. A lot of them, they'll say, "Aw, to heck with that. I'm not staying out there in that country stuff. But, to each his own. Some will value it, and some just don't care. Well, really just hard to say how to deal with it, just come what may the only thing I see.

NL: $\quad$ Let me cut this off. 


\section{Winnie Martha (Harper) Moyer}

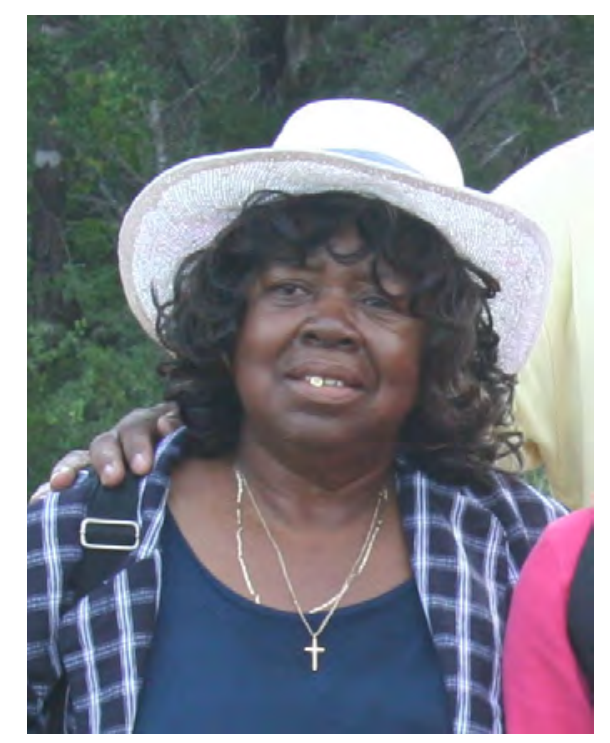

$\begin{array}{ll}\text { Birth Date } & 7 / 29 / 1937 \\ \text { Residence } & \text { Antioch Colony, Buda } \\ \text { Time Span } & 1937-1956\end{array}$

Interviewed by: Maria Franklin

March 10, 2009 (1 of 2)

MF: March 10, 2009, at 11 AM. I am interviewing for the first time Mrs. Winnie Moyer. This interview is taking place in the home of Mrs. Moyer in Buda, Texas. This interview is part of the Oral History Program for the Ransom Williams Farmstead Project.

Thank you so much, Mrs. Moyer, for agreeing to meet with us and to grant us this series of interviews. So I have a set of questions that we were thinking about would be interesting, but please feel free to remark on things that we don't ask you about, because I'm sure that there are a lot of things that I've probably left off of this list of questions. I thought I would start with some of the more simpler question in terms of what you remember about growing up, things about the kind of house you grew up in, what kinds of things did you use in your hair and beauty care products, and things like that that black women often spend a lot of time thinking about and worrying about from the time we're young. So I thought first that we could start with the house that you grew up in. Your parents were, what were their names again?

WM: George Harper and Emma Harper.

MF: Okay. And the land that we're on right now was the original property that your parents owned?

WM: Owned, yeah, but we lived on the Taylor Farm. 
MF: On the Taylor Farm.

WM: Up the street, up there where you see a well, up there. Okay, that's where we was born.

MF: Okay, where Frank Wilson keeps his animals.

WM: Oh no, right here, right up the street.

MF: Oh, this, this here. Oh even closer.

WM: You see where that house has been remodeled?

MF: Yes.

WM: Okay, it's right across the street from there, directly across the street.

MF: Oh, okay. And who was Taylor?

WM: Um, was one of our relatives.

MF: Okay, and so you lived in the house on that property, your own family had a house on that property?

WM: No, their house, but we lived in it.

MF: Oh, I see.

WM: The granddaddy of the Taylors, he gave to Daddy to live as long as he wanted to live there and raise his cows, and you know, he was farming. And he farmed it because all the family moved to Austin, and they was in Austin, and they wasn't living out here but one, and he lived down there in the bushes way down there, one of the brothers.

MF: Okay, and the house that Mr. Taylor had then, was that house already built on the property or-?

WM: Right.

MF: Okay. Do you remember much about that house?

WM: Oh, yeah.

MF: Do you know when it was built?

WM: Oh no, not that part [laughs].

MF: Okay [laughs]. But you were born in that house then?

WM: Yes.

MF: Okay, and what did it look like?

WM: It was a frame house. We had a fireplace in the living room, and it had three bedrooms and a dining room and kitchen. 
MF: Okay, and so who had to share those bedrooms then?

WM: The girls shared a bedroom.

MF: Oh, and we're talking six girls then?

WM: No, they had left home, the two oldest girls, three oldest girls, yeah, left home, and it was just three of us girls left. And then the boys, they shared the other bedroom.

MF: And which boys were those?

WM: My second brother, Joshua, Elijah, and Ollie Joe.

MF: Okay, and then your parents had the third bedroom?

WM: Yes, they had the front bedroom on the front side of the house.

MF: Okay. So I have a piece of paper here. I'm wondering if you could just sketch what you remember about how the rooms were partitioned. That would be fantastic. Okay, if you could just draw a plan of the house that would be helpful.

WM: It's like this and like this. We had a front porch on the front, and on the back we had a gary.

MF: A gary?

WM: A gary, what you call a gary [gallery], and it went all the way from the end of the house, all the way back to the bedroom.

MF: Ah. So it's like another porch except for it's longer. I see.

WM: And this was a bedroom here, and my dad's mother's bedroom was up here. And then the living room was here. It came out of their room into the living room, and this was where the fireplace was right here. And then you come out of the fireplace and into the living room-I mean the dining room, and this was the dining room. And this here, the boys' room was on this end down here. The kitchen was right here, and then that was a wall, and the boys' room was down here on this end.

MF: Okay, I see, so three bedrooms. Well, actually it had four bedrooms then. Your grandmother had her own?

WM: No. Mom and Daddy's was here, and this is the living room, and this is the dining room, and I really got it too big because this is the dining room too little. I mean the whole thing was dining room. This was a door to go on the porch, and this door went into the boys' bedroom. And this was the kitchen, and this, I guess this whole thing was the whole kitchen, yeah. That whole thing on the end was the kitchen. And the back door goes right back on here, go outside and to the outdoors.

MF: And so the gallery was at the front? I see.

WM: Gary was in the front of the house.

MF: What was in the back of the house, did you say? 
WM: What they call a smoke house. That's where we kept all the meat. And then the outdoors toilet was over here.

MF: Okay, okay. Did you have a well there?

WM: A well was here in the front, right here, right in the front of the house.

MF: And did you have a garden where you grew vegetables and fruits?

WM: Yes, we had a garden. The garden was in the back of the house, so it was right from the kitchen door, you could go out there to the garden. Out there on the side over here was a big old orchard, where we raised all fruit trees.

MF: And where did you throw your trash? Because I know they didn't have trash pickup back then.

WM: We didn't have much really, but they would burn it.

MF: $\quad$ They burned it, in a barrel.

WM: Yeah.

MF: And that would be done in the back?

WM: Yes, out here in the back by the hog pen. The hog pen's like over here. The lock and the barrel would be like sitting somewhere right in here.

MF: What did you do with things like bottles, though? Did you recycle much stuff?

WM: We didn't recycle anything.

MF: Okay, so glass bottles even got thrown out?

WM: Yeah. Thrown out there in the yard, in the field.

MF: $\quad$ Out in the field?

WM: Mm-hmm [yes], just threw them out of the back door, you know, out there. And we really didn't have that many bottles, glass bottles. We didn't buy stuff in glass bottles.

MF: Yeah, okay. And then the well was over here and that's where you got your fresh water?

WM: Mm-hmm [yes].

MF: And did you have chickens, chicken coop or anything like that?

MF: Yeah, we had a chicken house. It was on this side of the house, kind of in the back was the chicken house. Well, really kind of on the side in the back.

MF: Okay. And did your mother grow or your father grow any kind of like decorative plants like flowers and things like that?

WM: Mama grew every kind of flower you want to name. She had a green thumb, and you name it and she grew it. She'd go to the drugstore and buy her seeds. [Telephone interruption] 
MF: Okay, so we were talking about the house. Did it have electricity in the house?

WM: No electricity.

MF: When did you start—do you remember what year you started living in the house?

WM: No, not really, because I was born there, so they were there before I was born.

MF: Right, okay. And did you move out and your family stay there, or did the whole family eventually move out?

WM: No, we all moved out and went to Phoenix, Arizona. Well, we went to Florence, Arizona, first. And my daddy contracted cotton and vegetables and fruits and stuff like that, and we went out there to pick peaches, apples, bananas, grapes, stuff like that until the cotton got ready.

MF: Okay, and when did you move out of the-

WM: Nineteen fifty-five.

MF: $\quad$ Nineteen fifty-five. Okay. Now can you tell me about how space was used over here on this property in terms of now you have got all these different structures out here? Now if you had to do laundry, if you had to cut up a hog or something like that.

WM: Well, we did the hog out there at the hog lot, cow lot.

MF: This was called a what lot?

WM: Cow lot [laughs], where we kept the cows and the hogs and the horses and all that stuff.

MF: Cow lot. And so this is where you would do the butchering?

WM: Yes, and they did that out there. On this side of the lot rather, not inside the lot. But it was on a divided lot outside, you know.

MF: Okay, right. And then household chores, like laundry?

WM: Mama did it, and she had a wash pot right in between like in here, out there, and then we'd go out there and wash in two number-two tubs.

MF: Number-two tubs. Is that what you call them?

WM: Yeah.

MF: Okay, and the chickens-plucking feathers, things like that?

WM: Yeah, all over the place.

MF: All over, wherever you caught them, huh?! Did you sweep your yard?

WM: We had some weeds that grew out in the pasture called broom weeds, and we would go out there and pull them up and tie them together with shoe strings and put them together to sweep the porches and the house, wherever we needed to sweep.

MF: $\quad$ So but for the most part around the house it was probably mostly just dirt? 
WM: Yeah.

MF: There was not any other kind of vegetation there?

WM: No.

MF: So you didn't have to worry about keeping that dirt swept or anything?

WM: Oh, no.

MF: $\quad$ So let me ask you then about hair care products and taking care of your hair when you were younger. Do you remember much about that?

WM: Yes, we used Excellento for our hair, and Vaseline, and we didn't have any grease, she used lard.

MF: Oh, lard! Cooking lard. Right, right, right. Okay, so your mother did everyone's hair?

WM: Oh yes. Daddy did the cutting of the boys' hair.

MF: And as you got older, did you take care of your hair differently, as a teenager?

WM: Oh, we did our own after we got big enough, grown enough, we took care of our own hair.

MF: Nobody used the straightening comb?

WM: Oh, yeah, she'd use that on Sunday. We got our hair pressed once a week, pressed and curled.

MF: Ewww, painful.

WM: Oh, yes.

MF: I remember that. So the first product that you named, that was a store-bought product that you used in your hair? Not the lard but the, you said the-

WM: Excellento. That's to grow it.

MF: And that's to grow it? So that's something that your mom would have bought at the store?

WM: Right.

MF: Okay. So did she shop in Buda then?

WM: Yes, she shopped in Buda and in Austin.

MF: Do you remember the names of the stores that she shopped at?

WM: Buda is Buda Grocery Store, and Mr. Clark's Grocery Store, only two stores we had in Buda. But she'd mostly go to Kress's in Austin to buy products and laundry powder and stuff, whatever she wanted to get, you know, that smell good.

MF: Right, right. So it was mainly beauty products that she would buy store-bought, but were there other kinds of things that you didn't raise or grow here that your mom would have shopped for at the stores? Can you remember? 
WM: Nothing but sugar and flour. Vegetables we didn't buy, fruit we didn't buy, ice cream. Then once a week if we were good, we got soda water, on the weekend [chuckles]. But other than that, they didn't buy any canned food because they canned it, all they food. And jellies, we didn't buy that. We made syrups, so we didn't buy syrups. And we had butter, milk, you know and buttermilk.

MF: Because of the cows?

WM: Right.

MF: That's what you used it for, dairy. Okay, wow. That's pretty amazing. Did you ever shop from catalogs? Did your mom like have a Sear's catalog, or Montgomery Ward's?

WM: She had a Sear's catalog. She used to order dresses out of for herself, but she made all ours.

MF: Is that right? [Laughs] Right.

WM: She made the boys clothes, too.

MF: Okay. Did she buy anything else out of the catalogs, do you know?

WM: No, I think all she really ordered was just dresses.

MF: And so those were probably, were those special dresses for Sunday, her Sunday best dresses, right?

WM: Yeah.

MF: Do you remember thumbing through those catalogs when you were a kid?

WM: Yes, and better not tear no leaf, either. [Laughter]

MF: What about store-bought medicines?

WM: We only got whatever the doctor gave Daddy to give us, but most home remedies was what we used. If you had a bad enough cold or had pneumonia, then he took medicine from the doctor.

MF: Do you remember what the doctor you used?

WM: Dr. Lauderdale.

MF: $\quad$ Okay, so he was here in Buda.

WM: Yeah.

MF: Right, okay. And home remedies, can you tell me who made those?

WM: Daddy.

MF: Is that right? Did he talk about who he learned how to make home remedies from?

WM: His parents, his mom. 
MF: His mom. And so what kind of home remedies did he make?

WM: Like for whooping cough, he had what they called horehound tea, and he'd go out there and pick what looked like a bug off a tree with little stickers on it and bring it back and boil it, and then he'd use the juice off the tea, the horehound to make the tea, and that's what you drank.

MF: Pretty tasty?

WM: No. [Laughs] Nasty.

MF: Do you remember any other kind of home remedies that he made?

WM: Yeah, he made, well, just about every kind of thing. If you got burned, he used sulfur and soot out of the stovepipes, mix it together with Vaseline and put it on your sores, if you had any kind of sores. And then we'd drink what they called broom wheat tea. And sage tea, he'd go buy that, and that was good for coughing and colds and stuff like that. And it still grows out there in the pasture, that tea do. I don't know about the horehound. I don't know if it still comes up out there or not. I don't get out there in the weeds no more. [Laughter]

MF: I can understand that.

WM: I don't know what's in there. But oh god, we made a whole lot of home remedies. Turpentine, if you had-I think that was for pneumonia, too. Two drops of turpentine in sugar, that's one teaspoon of sugar and two drops of turpentine. If you had a bad cold, like a chest cold, it'd bring all that green phlegm up out of your throat. You'd cough it up.

MF: So was that pretty common among the families here, that everybody kind of treated their kids with home remedies?

WM: Mm-hmm [yes], yeah, that all they believed in. Fever, if you had a fever, I know they did something with turpentine, put it I think in a towel and put it over your forehead, if you had a high fever.

MF: To kind of draw out the fever?

WM: Mm-hmm [yes].

MF: I see, I see. So it sounds like your mom and your dad took care of a lot of the household needs.

WM: Oh, yes.

MF: So your mom did a lot of sewing. Did she quilt also?

WM: Oh, yes. She'd quilt, and made all of the clothes.

MF: So nothing went to waste, then, it sounds like-

WM: Aprons. Oh, no, she did housework for the white people, and they would give her clothes, and she would rip them up and make stuff out of them, you know, dresses, scarves, and you named it, she made it. Pillowcases she'd embroider. She'd go to the Kress's, she'd buy that embroidery thread, and we bought flour in a white sack, and she would take that white sack and wash it and clean it up and then she'd embroider it and make pillowcases. 
MF: Wow. Did she have a sewing machine or did she do everything by hand?

WM: Yeah, she had an old-fashion' sewing machine up there, and I've got it back there, and she would pedal it. When she finally got one, but she didn't have one for a long time and she'd sew on hand. She made everything on hand. And then one of the ladies she worked for finally gave her that Singer sewing machine to pedal, then she would, you know, make clothes. I guess she was telling her that she did it on her hands and stuff, so they finally gave her a sewing machine, and she sew up everything with that sewing machine. She would go to Kress's and buy up all colors of thread, and then she would take the-like Daddy wore overalls all the time, and when they would wear out on the knees, where he got on the knees all the time, she would take an old, old pair that was faded and she would cut patches out of them, and wherever there was a whole in your pants she'd sew it over. And she darned socks. You know, she didn't throw away any socks because they had a hole in it. She'd sew them up. And he'd have a shoe, or like a shoe stand made out of metal. I've got one in my room. And if you had a shoe that had a hole in it, he'd get a piece of leather and he'd put it over top of it and glue it and tack it, cover the hole in the bottom of the shoe. Didn't buy any shoes.

MF: How often did you get shoes as a kid? Do you remember?

WM: Oh, lord. Well, we got shoes for Easter and Christmas. Those were the only two days we got shoes.

MF: $\quad$ Easter and Christmas.

WM: And then the beginning of school we'd get high-top shoes that we would wear all year for school.

MF: Right, okay. Well, the next set of questions that I want to ask you about are about Antioch and what you remember about the traditions here in Antioch and where you think Antioch's future is going. So the first question I would have is, you know, we often to refer to African American or black culture when describing the kinds of practices or traditions that have been passed down the generations. Are there any things that you can think of here in Antioch that people practice that you would consider an example of African American culture or tradition?

WM: Church. They went to church all day, in the morning and come home and eat lunch and then we'd go back to church at three o'clock in the evening, and then we'd come home, feed the animals. [Interruption, someone stops by.]

MF: I was asking you about African American culture and tradition, and you were talking about how church you felt was an aspect of it. Can you think of others?

WM: The things they did in the church. They had box suppers to raise money. Had a shoebox and they'd fill it full of food, different types, you know, cake and chicken, and whatever they had in their boxes, meatloaf, and vegetables to go with it. And that was a way they raised money for the church, you know, to take care of the church and pastor. And when the preacher would come out, they had church twice a month, the second and the fourth Sundays of the month, and he would spend the night with one of the deacons for that weekend. He would come out Saturday day and spend Saturday night, and then he'd go home Sunday afternoon after church was out.

MF: Now did everybody in Antioch belong to the church growing up?

WM: Yes, most. Yeah. 
MF: To the same church?

WM: Yes.

MF: The one that was here? That was an AME church, right?

WM: Right, yeah. Yeah, everybody on this side belonged to it. And then we had Mr. Williams, who lived on what we called The Prair [Prairie] across I-35, well east of I-35. Well, he belonged over here.

MF: What was his name?

WM: Emmett William. And his wife belonged to the Baptist Church out there, and he belonged to the Methodist Church.

MF: So would you consider him part of the community, or just a member of the church?

WM: Well, yeah. Member of the church. Because well his family lived over here.

MF: Okay, so he's one of the Williams that we see their name associated with Antioch.

WM: Right.

MF: I see. Do you know why he lived across the road?

WM: That's where they lived. They had a home over there on that side of the creek.

MF: Well, now did Antioch extend over that far?

WM: No.

MF: Antioch is just on this side of Buda, right, 35?

WM: Right, right. Yeah, Antioch Colony.

MF: I see. What kind of traditions does your family keep alive besides maintaining your membership and participation in the church? Are there other kinds of traditions? You mentioned a Sunday dinner, for example?

WM: Yeah, right, Sunday dinner. And then my dad would have, starting on Monday he'd pray. We had prayer service every night, and he would start out praying on Sunday night, and mother on Monday night, the oldest brother would read Tuesday night, and sister would be Wednesday night, and the next sister would be Thursday night, and the next one would be Friday, Saturday, all the way back up to Saturday, Sunday.

MF: So is this something you still do now?

WM: No. [Laughs] Family dinner, yeah, but the family houses don't pray. I did with the kids. I raised six kids, and when I had those children, we'd do that.

MF: Now do you remember if your father did this when he was younger? Was this something that he started in this family or was it something that he learned from his own parents? 
WM: You know, I really don't know if he got that from Grandma or not, but I know he did it in his family, we had to do it.

MF: Are there traditions that you try to pass on to the younger kids here at Antioch, or elsewhere that are related to Antioch?

WM: Yeah, read the Bible, learned the Ten Commandments and Lord's Prayer, and how to pray even if nobody's not around. If you have problems, you don't have to call on Mom and Daddy, you can call on God. I teach them, the kids that I raised to do that, to learn to depend on Jesus and not your family, you know. It's all right to ask Mom and Daddy for stuff, but God will come on giving it to you then they will. He isn't going to let you down. I tried to instill that into the schoolkids especially, you know, the ones that, some of them slow about reading and writing, and I tried to tell them, don't get frustrated because you can't understand what's on that paper. You know, just whisper a prayer and tell Jesus, "I don't understand this. I can't do this." Instead of getting mad, "I ain't going to do this. I don't want to do that."

MF: Do you think that you've been successful?

WM: Pretty good [chuckles], because at least the oldest boy that I raised, he's seventeen and he's hanging out in Austin, and I tell him all the time, you know, I'm trying to keep him in school, and I want him to go to a trade school to get some kind of trade in life. And he says, "I tell you what, I ain't forgot to pray," he says, "I pray all the time." He has a what you call, it's an allergy, but it's between asthma and bronchitis, and I'm always scared that he's going to be around too much smoke, that's what sets it off, and I tell him all the time, "Robert Jr., don't be around smoke, and please don't smoke," so he told me, "I ain't." He said, "I pray every night before I go to bed." I said "Oh, good for you." You know. So his grandmother, he stays over at his grandmother's, and she told me to come one day. She said, "Girl," she said, "I wanted to tell you, Robert Jr. scared me to death last night." I said, "Oh, goodness. What happened?" And she said, "I got up in the middle of the night to go to the bathroom." She's a diabetic. And she said, "And I went in there," and she said, "he was down on his knees," and she said, "Oh, gosh darn it, something happened to him." And said she said, "Robert Jr., get up from there! What's the matter?" So he said, "I'm praying, Grandma," so she said, "Oh, I'm sorry." [Laughs] But it scared her because she thought he had fallen out of the bed and was trying to get up and was on his knees. So I said, "Well, I guess he didn't lie to me, then." [Laughs]

MF: He's seventeen?

WM: Mm-hmm [yes], seventeen.

MF: And you said you raised him pretty much?

WM: When I got him, he was five and his sister was three, Ashley. And then his mother was pregnant with Xavier, and he's fifteen, and I got him from the hospital. Well, his daddy went and got him because they wouldn't let me get him. See, she's an addict, and she had run off and left him in the hospital. So, his sister-in-law worked with Ms. Limuel that lives here in the neighborhood. Well, it isn't really sister-in-law but anyway, the auntie, Sandra's sister, older sister, worked in a rest home, and she knew about it and she knew, too, that Joan was from Buda, and she knew we lived here in Buda, but she didn't know where in Buda because they had never been out here. So she asked Joan did she know them Harpers that lived in Buda, so she told her, "Yeah I know them Harpers." Well, one of them got a baby by my sister, and she left the baby in the hospital. So she said, "Oh, well, I don't know which one it is, but I can ask them." And she said, "Well, tell them they got today to get this baby out of the hospital or they're going to put it up for adoption," because she slipped out and left the baby, because you know, they had past this law when you're an addict and have a baby, they'll 
lock you up and put the baby up for adoption. But she had left to keep them from locking her up. She got up and left at two or three o'clock in the morning when nobody was paying her no attention. So she told them to find the daddy and tell him to go to the hospital and get the baby. So me and my older sister, Marian, we were at a washateria in Buda, and we were washing our bedspreads. We had a washing machine, but like my bed's king-size and my washer wouldn't take it, it's too big, so I went to the washhouse to wash my blankets and my bedspreads, and she said, "Well, can I go? I want to wash my bedspread." I told her, "Sure." So I went down and picked her up, and we was up there washing our clothes, and we'd just got through, I'd gotten my bedspread out and was folding it. And she got out and come in, and she said, "Martha," she said "I seen your car and I knew you were here." So I said, "Yeah." So she said, "One of your nephews got a baby by a girl in Austin, and had a baby," and I said no at first, then I got to thinking and I said, "Oh, yes it is." I said, "Robert got a baby by Sandra." I said, "She just had it, a little boy." So she said, "Well that's probably the one, then." She said, "I work with," she told me the girl's name. Then I said, "Oh that's Sandra's sister." So she said, "Yes, and the baby's going up for adoption tomorrow. You all have to get it out of the hospital today." I said, "Get it out?" I said, "What's wrong with it?" So first thing I thought was he probably had AIDS or something, a kind of disease. And she said, "No. The girl just got up and left the baby in the hospital." He had just called her the day before that and asked her how was the baby. You know, he hadn't gotten a chance to see it because he was working at the Fire Department in Manchaca, and he said he was so busy he hadn't had a chance to get over there and see it. So she said, "No I'm fine." He said, "Well, when are you going to bring him out of here?" She said, "Oh, I'll bring him out there." He said he left it alone. But when I called the hospital, I called Brackenridge where it was at, and I asked them about it, and she said they called it the Chase baby. I was asking for the Harper baby, but her last name was Chase and they went by her last name, so they said they didn't have a Harper baby. I said yes they do. I said because this girl just came by here and told me they you all have a baby that's going up for adoption tomorrow if nobody don't pick it up. So she said, "Oh! That's the Chase baby." And I said, "Chase baby?" Then I thought, "Oh, her name is Sandra Chase." I said, "Yeah. That's the same baby." I said, "The boy she had the baby boy is a Harper." So she said, "Oh, well she didn't got that on here, on the paper." She said, "But yeah. It's going up for adoption tomorrow, so if he want it, he's got to get here before five o'clock." I said, "Well he's at work now, so can I come pick it up?" She said, "Oh, no, ma'am. It has to be the parent, you know, the mama or the daddy." I said, "Well, lord knows I don't know where to find her at." It was after two then, so I said well I just have to go home and see if I can get them to let Robert off of work and let him go up there and get it. So she said, "Yeah, and tell him to bring a blanket," and something else she was telling me. I said, "Lord, lady, he ain't got nothing." She said, "Well, then come on." She said "Go on and get her before five." She said, "The social worker's gone out in the field, so come get him. We'll release him to him if he's got his credentials." So I said, "Okay."

So I left and went home, and then I got on the phone and called the boss man, and told him that he had an emergency and he needed to go to Brackenridge to pick up his son. So he told him okay, and he let him off. When I told him what happened, he went to cussing. I said, "Don't you do that, you're on your job. Better not use any bad words." He said, "I'm going to kill her." I said, "Don't you say that, either. You ain't going to kill her. You leave her alone." So he took off and went over there, and they told him they'd give him a thing to bring the baby home. The baby wasn't any bigger than this, little bitty something. And he brought that baby home. I said, "Well you all can keep him," because he got married to a Spanish girl. So I said, "Well, you all can keep it." I said, "I'll help you see after it." He said, "No. You're going to take it." I said, "Take him! What am I going to do with him?" [Laughter] He was so little I had to carry him on a pillow. That's how little it was. And I said, "Now Lord Jesus, I can't pack nothing this little. They fall out of my arms. What am I going to do?" And I thought about the pillow. So I went and got a pillow and put him on it. When I hold him, I'd lay him on the pillow so I could hold him up without dropping him. And that's how long I had Xavier. 
MF: Now Xavier is how old now? Fifteen?

WM: Fifteen. He just turned fifteen.

MF: Now how old was your nephew when he fathered Xavier then? Was he pretty young?

WM: I think he was about in his twenties probably. He had just made 20, if he was 20. I don't remember how old he was.

MF: But you were Xavier's guardian, and you basically raised him.

WM: Yes, mm-hmm [yes].

MF: And where is he now?

WM: School.

MF: Okay, so he still lives here with you?

WM: Yeah, uh-huh. Yeah, he's at school.

MF: All right. How is he related to Ashley?

WM: That's her brother.

MF: Okay, so they all three? Okay, I see.

WM: Those three kids, and then my niece. At one time her mom was into drugs, and so her grandmother called me to come pick her up, one of Robert's brother's daughter, so I went and got her. And then this guy I was dating, his daughter was on drugs. They lived in Elgin and he asked me would I go see after those kids. I told him I couldn't stay down there. I have a house and I have kids. So he said, "No, I don't mean stay with them." He said, "Take them with you." I said, "Take them with me!" [Laughter]

MF: You already had your hands full, right?

WM: Yeah! I said, "I already have three." I said then this girl's told me her grandma wants me to come by and pick up her granddaughter, said she couldn't see after it because she had to work and there wasn't anybody to leave her with. And she was about six during that time, and I said, "Now, that'll be four kids." So he said, "Well, there's three of them." I said, "Three!!" So I said, "Well I guess I'll go down there and see." So he came and picked me up and I went down there, and she didn't have nothing but a mattress on the floor and didn't have sheets, you know, and the house wasn't clean.

MF: It's three kids?

WM: Three kids. And you know how they show those little African pictures over there where these little kids are sick and bony-that's how her little boy looked. He was about I guess three months or four months old. She was starving him to death. And the little girl, she looked okay, and the boy, the older boy. So I looked at them kids, the only one I really fell for was that little bitty one, and I said I'd take him. I said and I can't take these kids, and they don't have any papers on them or nothing, I can't take them to the doctor, and she said, "Oh I'll sign a paper for you." She said, "But I'm going to do better. You know, I am. I'm really going to do better." She said, "I'm getting a job and I'm going to do better," and she said, "I'll help you." 
I said, "They aren't going to give me any food stamps or anything for these kids," so she said, "Well if I sign them over to you, you can go and put in for it." So I told her, "Okay." And then they didn't have no clothes; everything they had was piled in a corner, dirty, so I just picked out the best things, but it was all dirty, and took those so I could have something to change them in, to fix them. She said, "He doesn't have any diapers," and his diaper was dragging on the ground, like Ashley's was when I picked her up, when her grandmother had me come get them two. Her mother was sick and she had a bad heart, so she said, "Martha, please come get Sandra's kids, because I can't take care of them." She had one of her daughter's kids over there. She had about three or four kids herself, you know, grandkids. "So if you all can take care of these two, I really would appreciate it." So I went and got them, and the diaper she had was dragging on the ground, and a shirt on, that's all she had on. The little boy, Robert Jr., all he had on was a pair of pants and no shirt and no shoes and no socks or nothing. So I took them. And then they were the first two until she had Xavier, and then I got him, which made three. Then I went and got Miesha and brought her home. Well, she did have some clothes. Her mama had bought her some clothes, so I didn't have to worry about her for a while. But when I went and picked up the kids in Elgin, they didn't have anything but dirty clothes. I just got them something to change for a couple days until I made a payday, and took them. So now they were the ones I think that were in that paper when I had that interview with six kids.

MF: Oh, okay, yeah, the names that I named off. Let me see. I think I named Evelyn.

WM: No.

MF: No, the ones I named were-

WM: They might not have put them in there.

MF: Oh, you know what, they were really young and that's why I didn't write their names down, because I knew I couldn't interview them because they're too young.

WM: Yeah, right, those. Because I had seven kids at that one time.

MF: And they pretty much stayed here—-their parents didn't come back and get them?

WM: Oh, no. I had to give them back to them. They didn't come after them. I sent them back home after they got big enough, especially the three in Elgin, because she did get off of drugs, and she had married a Spanish guy that was a minister so they told me she was living pretty good in Bastrop. So Annie and I were very good friends, so she called me, "Winnie, take those kids back to her." She said, "She's living good. She's got a job. Her husband's got a job." She said, "Make her take her kids." And then whenever I'd call and tell her to come pick them up, she'd tell me, "I'll be there." Then she'd never. "We didn't get out of church in time." And they were in school, so I didn't want them to miss school, so I told her to come get them on Friday evening when she could have them ready for Monday to go change schools for them. She was going to do it, but she never did. So I just packed them up like Annie told me and put them in the car, clothes and all, and I found out where she stayed, because I didn't know where she stayed at. And I called up Daddy, which was the one I was dating which we had quit, and I told him I needed to know where that girl lived at so I could take them kids. He said, "She hasn't come and gotten the kids?" I said, "No." He said, "Well I'll be out there." So he came out here and I followed him to Bastrop where she stayed at, and she had a nice three-bedroom house - didn't think about the kids. [Chuckles] So I carried them all, and dumped them all with all of their clothes and everything they had, including their birth certificates.

MF: How long did you keep them for? 
WM: Oh, Marvin was, shoot, god, how long did I-?

MF: Was Marvin the oldest or the youngest?

WM: Uh-huh, he was the oldest, and I think he was fifteen when he left here, when I carried them home rather. He was fifteen and the girl was ten.

MF: And how old was he when he came here?

WM: He was about five.

MF: You kept them for ten years?

WM: All six of them, and I've still got these three. But Miesha, her mother got off of drugs, and she finally came back and got her daughter. Then I carried the other three home, so that just left me three, and their daddy hasn't got them yet. He keeps saying every year he's going to get him a house and he's going to get them, and drugs just don't let him.

MF: What made you feel that you were the one that needed to take responsibility for them?

WM: Because I didn't have any kids, no husband, and I had this big house and the rest of them all had families. And my oldest sisters were not in shape to take nobody's children. They liked children, but they were set in their ways. They're all right as long as they're playing, and they get hollering and throwing up and they get on their nerves, so I wouldn't push them off on them. So I told the Lord if he helped me feed them, that's all I wanted to do, to make sure they had food, and I did. I ain't never been hungry. None of them never went hungry. They might not have wanted what I cooked, but they didn't have to go hungry. A lot of them don't like vegetables, kids, so I was forcing vegetables down them and different kinds of vegetables some of them didn't like, like peas. You know, some of them, "I don't want no peas." Other greens, stuff like that, they always had something they didn't want. One didn't like corn, or the other one didn't like peas, or green beans, or something, you know, they didn't like but I made them eat them anyways. I told them it ain't going to kill you. "If you die before in the morning, I'll tell them what happened to you." [Laughs] They'd go ahead and eat them. So I was, "Don't you all forget now," like the little girl Terry, she'd always have a fit about them green beans. She'd pick one green bean at a time, eat it. So I told them, I said, "Marvin, you be sure and tell your mama what happens if she dies. She said these greens going to kill her, so if she dies you be sure and tell her and be my witness that she ate the green beans, I made her eat them." When I'd go to wake her up to go to school, I said, "Terry, is you dead?" She'd roll her eyes. [Laughs] I said, "Oh! The green beans didn't kill you, huh?" Oh god, but there was just different stuff like that I would do and tease them, because they just felt like if they ate it, everything they ate was going to come back up, or they were going to die or something, just to keep the eating vegetables. It didn't bother them, it didn't hurt them. I knew it wasn't going to hurt them in the first place, but they did because they didn't want it. But they ate a full, decent meal every day.

MF: Yeah. Did you have help with the kids at all?

WM: I finally got food stamps and got them on Medicaid, but they didn't give me any money, cash money or nothing. And they didn't give me a whole lot of food stamps but I think the highest food stamps I got since I put in for that was $\$ 125$, and that's when I had all six of them. And then one lady finally came through and she saw on my next interview that I had that, and then I think she ended up giving me $\$ 200$. It's been so long now, I forgot, but I think it was $\$ 200$ and something. I didn't ever get $\$ 300$ and $\$ 400$ and $\$ 500$ like a lot of these kids are getting nowadays. But they said I didn't qualify because I owned my own home and my own 
property, so that was against me and I didn't have to pay nothing but utilities and a car note, you know, because I didn't qualify for that reason. But I made it. I was working at APD and I made good money, so I didn't have nothing to worry about.

MF: What did you do for APD?

WM: Was in the billing service.

MF: Okay. How many years did you work for them?

WM: Seventeen, short of three months I would have made eighteen, eighteen years.

MF: When did you retire from them?

WM: In 2000, what was it, was it 2000 and-shoot, I done forgot that, too! I think it was 2001. I forgot, but yeah, I think it was 2001. I forgot, but I think it was somewhere along that now.

MF: Now, everybody you had mentioned to me before that your father had left three-quarters of an acre to all of his survivors.

WM: No, ten and a half acres.

MF: Well he owned ten and a half and he split that up among all of the siblings, right.

WM: Right.

MF: And out of your siblings, there are seven that came back to Antioch? Is that correct?

WM: Yeah, let me see. Mary and Eunice moved to-and Ollie Joe, that's this—yeah, oh Stubby. It's nine houses.

MF: $\quad$ So nobody had actually stayed here? Everybody left in $1955 ?$

WM: Yeah.

MF: And then most of you came back?

WM: I came back first, and then my twin sister came back, and then I went to Arizona and moved my parents back when my mother started getting ill.

MF: Now when did you first move back?

WM: I moved back in '75.

MF: Okay. And this was not out here, this Harper Village Road, none of it.

WM: It was just a field.

MF: Yeah, because I don't see that on the map out here.

WM: Right. No, it was only a field, just a field, and I had all the work did when I moved out here, and then my twin sister moved across the street, so there wasn't nobody here but us two. And then I got a guy to do the, you know, to make a road between houses, and then I got another man to put the gravel on the road in front of the house. They found out I was George 
Harper's daughter, and my daddy carried a beautiful name here in Antioch Colony working for people, and he being a Christian man, you know, they respected him. When you mentioned you were George Harper's daughter, they said, "Oh, well, I was going to charge you this and that, but since you're George Harper's daughter, I'll knock it off.” You know. [Chuckles] So the electrician or whoever you get to do work for you like our man that has the gravel, did our road for us, he didn't charge us what he'd charged everybody else, and he would do any kind of work for us that we asked him about, and they would give us a discount.

MF: Now, it seems clear to me in talking to people that the land was very important to your ancestors. [Oh, yes.] Now, did your father ever talk about what owning his own land meant to him? Or do you know why he saw it as so important?

WM: He bought it so that he would have a place for his children to go if anything ever happened to him and my mom. They bought it back in the forties. He paid $\$ 50$ for it, fifty for about ten and a half acres. And that was his desire, to have a place that he could build on, but he farmed it as long as we were staying in the Taylor's house. He planted cane.

MF: So this was all cane, did you say?

WM: Uh-huh. He planted cane and corn and watermelons, and all kinds of stuff that grow up with the corn, that it wouldn't hurt, you know, vines, vine food. What he really planted, cantaloupes and watermelons, and anything that grew on vines that had grown on lots, you know, filled the place all over the place. In the garden he would plant the tomatoes and stuff like that that grew on vines that go up, but the kind of vines that run on the ground he'd plant in the fields.

MF: $\quad$ So did your mother and father do most of this planting?

WM: Uh-huh. He would dig the holes, and she would come along behind him and drop the seeds in the ground.

MF: Okay. So some of this went to your family to feed your family, I take it?

WM: Oh, yeah.

MF: And then the rest of it, would he sell it?

WM: Sell it, yeah.

MF: And where would he sell his produce?

WM: In Austin. For some of the families that live around here in Antioch that didn't have a garden, like Aunt Kate, Miss Ada Bunton, and Miss May Peet, different ones that didn't have any children to raise it, and he would sell them eggs. Well, some of them had chickens, but he'd sell them the vegetables. And when he'd kill a hog, he'd take them meat from the hog.

MF: So did people barter things, or if you needed something you would buy it from a neighbor?

WM: No, we didn't buy nothing from no neighbor. Everybody had their own turkeys and chickens, cows, horses, and ducks, and geese, guineas, dogs and cats.

MF: This is what your family owned?

WM: Yeah. 
MF: But you had mentioned Miss Katie Bunton didn't have a garden, and so your father would sell some stuff to her.

WM: Yeah, right, give it to her.

MF: Or give it to her?

WM: Hm-mmm [yes].

MF: So people didn't usually trade things?

WM: Oh no, not like that, unless it was cows. Daddy would trade a Burma bull, he had two of them or three, and then he'd trade to Mr. Smith or somebody that wanted to sell it to some of the white people. Something like that, because they didn't keep too many bulls.

MF: Now how did he get his produce to Austin? Did he have a-

WM: A truck.

MF: Okay. He had a truck.

WM: He'd haul rick wood. We went to the pastures of the white people and cut down trees, and we ricked wood up and put it in the truck after we sawed it up and brought it back here. We had a saw out there in the lot, and we'd saw the wood so far, you know, all sizes, the little ones on up to the big stumps for people in Austin that had stoves, that had to burn wood. And he'd sell the wood, and eggs, and butter, milk. He would take it to town, and vegetables, and sell it on Saturday.

MF: Do you know where he would go in Austin?

WM: Yeah, he went to Montopolis. He had a lot of people out in the Montopolis area that bought from him.

MF: Were these blacks or whites?

WM: Blacks. And then he had a lot of over in Austin. He would go around Rosewood, and Chicon, and different areas up in there he would sell.

MF: And it was mostly to other black people?

WM: Yeah. Only very few white people bought stuff from us. They'd come through, they wanted butter for certain things, and they'd buy a pound of butter or something like that, but it was very few.

MF: Why do you think that is?

WM: Because they didn't do it themselves. They didn't sell it in the stores, so they had to get it from somebody that had a farm.

MF: Right, but you said that he had mostly African American customers?

WM: Well, most of the white people had ranches around here and they had they own. 
MF: So the black people that he was mostly selling to were living in city areas where they couldn't raise their own cows and do things like that.

WM: Right, mm-hmm.

MF: So what does this land mean to you now? I mean, now that you're older and thinking back. I mean, did you ever think about that this was your family property growing up? Did you think about it a lot even as a youngster?

WM: Yeah, yeah. And I don't want him to sell it, because once we had moved to Arizona he had changed his mind about coming back here, after he got out there and found out it was so much different. When we was living here, a lot of the white people were prejudiced, and wanted to give him a hard time about different stuff. He found out that they wasn't that way in the West when we moved out to Florence, Arizona, and he said, "Oh, no. I'll never move back to Texas." I said, "Oh, yes we is." I didn't like that desert out there. [Laughs] But I told him, "Oh, no. We're going back to Texas." He said, "No. If you go back to Texas, you're going to have to be grown because I'm not moving back to Texas. And I said "Oh, no." We had left a house with all our stuff in it. You know, we didn't take nothing but a cover and half of the bed mattresses to put in the back of the truck for us to lay on. I was thinking, "Lord, when I finish high school, I'm getting me a job. I'm going back to Texas."

MF: Why did you want to come back here so much?

WM: I just didn't like it out there. I didn't like Arizona. It was hot. When they said you could cook an egg on the sidewalk, they weren't lying. You could cook a steak on the sidewalk, well done, and I not just half done. That's how hot it was, and I just didn't like that heat. It was just too hot, and we never had no heat like that here, when we was living here. Just like when the wintertime come December through March, you'd get white-snow trees. It'd be full of ice all of February, and it would start melting in March. March has always been a windy month, and when the wind start blowing, and then the ice start melting on the trees. So I was used to that. You didn't see no ice out there. You didn't see no snow until every once in awhile. So I wanted to come back where it was snowing, and I haven't seen it snow but twice since I've been back here since 1975. But I was used to that, and that's what I thought it was going to continue to be. I didn't know it was going to change. I didn't like that desert part out there.

MF: Were there things about Antioch or Buda that you did like that made you want to come back here?

WM: Yeah, my schoolmates, and being in the country. I didn't like the city, too many folks all around it, and we didn't have all of these folks around us when we lived here. The houses were way apart. So I wanted that part back. I didn't figure when I moved back here, I didn't think my other sisters and brothers were going to come back here, you know, so there wasn't going to be nobody back here on the property but me and my twin sister.

MF: That's what you thought, right!

WM: So I thought, I said, "We don't want to go down in that field." She said, "That's what the [inaudible]." I said, "Aw no. Put it right up here by this road." So that's why we got the first two houses on the road, because I told them we'd be close to the road, and there wasn't any pole lights out here when I moved out here in '76. I came in '75 but I moved out here in '76. I bought me a mobile home, and we didn't have any lights. When you left Buda, it was black dark all the way to where you were going. You couldn't see a hand before you. If you put your hand like that, you couldn't even see it. That's how dark it was. "Oh, lord," she said, "We have to stay out here in all this dark." I said, "Well, we'll get some porch lights and put them up." 
When I had PEC to come put our electric in, they told us that we could get pole lights, and I said "Pole lights?" And he said, "Yeah. We could put a pole light up on the outside and you could see your house before you get to it," because you couldn't even see the house coming down the road from the graveyard until you got here, unless you left a light on. He said, "Yeah, we could put a pole light." I said, "Lord, put up some then." And that's how we got pole lights, and then it wasn't but $\$ 3$. Now they dug one up to $\$ 11-\$ 13$ now for a pole light.

MF: $\quad$ Thirteen dollars?

WM: Uh-huh, thirteen for a pole light, and then they didn't charge us but three, so you add it to your light bill. Electric wasn't as high then because I think I paid like twenty something dollars a month for electricity. Now it's $\$ 200$ something, $\$ 300$ and $\$ 400$, all the way up.

MF: Especially during the summertime?

WM: Yes.

MF: Right, right.

WM: But I like it. My dad wanted to sell the property and I wouldn't let him. I kept telling him, "No, Daddy, because I'm moving back to Texas." "You aren't going to stay back there. You aren't going to be able to get along with them white folks. They going to fool around and kill you out there by yourself." I said, "No. They aren't going to fool with me, and I'm fixing to move back to Texas." I said, "I don't like Arizona," and I didn't. I decided one day after I got married, my husband didn't turn out to be what I thought he was going to be, so I said I want to get away from him, and that's the only place I knew I wanted to go. Because I had lived in California and went to San Francisco and stayed with her, and I didn't like that. Then I went to Los Angeles and stayed with one of Daddy's nephews, and I didn't like that. So I said the best place is for me to go back to Texas to get out of Arizona, so I told him he couldn't sell it. "Aw, yeah," he says, "I'll divide the money up with you all," and I think the man was going to give him $\$ 3,000$ for the land, and I told Daddy, "That ain't any money." I said, "You get through dividing up twelve ways, we aren’t going to have but $\$ 25$ apiece," so I said, "That ain't nothing. I'm making more than that, so I don't want the money." I said, "You just give it to your other kids. I don't want it." So he said, "Well, if I sell it, I've got to give all of you the same amount, and then I can't just save you a part." I said, "Well you save me half of it and you sell the other half," I said, "because I'm going back to Texas and I'm moving on to the property." So he thought about it and then, "Well, Lord," he said, "I want to sell it. She doesn't want me to sell it." He said, "Now you tell me what to do." So he was talking to one of our cousins that lived in Manchaca, Hanson Dodson, so I told him, I said, "Daddy, the Lord ain't pleased." So I stayed all night with the, who was down here on vacation, so I stayed all night with my brother-in-law, Mrs. Nelson's husband's sister, because we were best friends in school. She said, "Martha, come stay with me," because I was going to stay with another one of my relatives, and she said, "No." I said, "Well, I can go get a motel. I don't have to stay with anybody, and let Mom and Daddy stay with Mama's sister." And they stayed down on Rosewood with her. So I said, "I'm going to go get a room. Now I don't have to wake anybody up. Nobody has to wake me up when they're getting ready to go to work and stuff." She said, "No, you come stay with me. Come stay with me." So I said okay. So I went over there and stayed with her, and I gave them the phone number in case something happened to Mom and Daddy they'd be able to call me. I can't think if Mary was down here with us or not. I don't think so. Who came with us but me and Daddy and Mama and somebody?

Anyway, they called me early that morning, six o'clock, and I said "What on earth?" And she said, "Martha." She said, "Yeah, Martha's here. Just a minute." So I said, "Who in the world is calling that early?" because she told me she didn't have to go work until late and I 
could sleep late because I did all of the driving. And I got up and went to the phone and my auntie said, "You need to come. Something is wrong with your daddy." I said, "Oh lord. What is he doing?" She said, "I don't know. He keeps shaking his head, and he keeps saying that his head is hurting," so I said, "Give him a aspirin!" You know, I said, "But I'll be over," but I sure didn't want to get up. I got up. And I had taken psychology when I was going to Phoenix Union, and my subject to finish school, and they had taught us when you get real disturbed your head hurts, and you've got problems, to pull off your shoes and walk on the gravel floor, and whatever is on your mind, you're going to forget it because you're going to be thinking about your feet if you're not used to walking barefoot. So I thought about it, and then I got on over, and I said, "Daddy, what's the matter?" I checked his head and his head wasn't hot, he didn't have a fever. So I said, "Lord, I don't need to be putting you in a hospital." I said, "What's wrong?" He said, "I don't know. My head just keeps hurting." I said, "Well, you've got too much on your mind." So I said, "Just forget it." He said, "I just can't forget it." I said, "Well, then take some aspirin." "You know I don't believe in taking pills." I said, "Well, you need to take an aspirin." So I told my Auntie to give him a couple of aspirin, they called them Anacin at the time, so he went on and took them. I said, "Well, have you ate?" and he said "Yeah," so I went on and gave them to him, and then I told him, "Come on," so he came out and sat on the porch. I said, "No," I said, "Pull your shoes off." He said, "What are you doing?" So I untied his shoes, pulled them off, and made him leave them on the porch. He said, "Martha, now what are you doing?" I said, "Well, I'm going to do what they taught me in school." I said, "You come on down here and we're going to walk out here on this side." "Not barefoot. I can't walk barefoot." I said, "Oh, yes, you is!" So I dragged him out that gate and closed the gate and made him walk up and down the sidewalk, and he just kept fussing, "My feet hurt! It's got rocks down here!" I said, "I know!"

MF: That's terrible, isn't it?!

WM: So I walked him up and down there about three or four times. So I said, "Well, how does your head feel now?" He said, "You know, it's going away." [Laughs] I said, "Uh-huh." I said, "You're worrying about that darn property." I said, "You leave that property alone. God will tell you what to do about that property. You can't solve nothing." I said, "I don't want you to sell it, and I'll buy it. I'll pay you for whatever this man's going to pay you." He said, "Well, you don't have that kind of money." I said, "Oh, but I can get it." So I said, "When I get back home," I said, "I'll go to the bank and get a loan and give it to you." He said, "But it would be yours." I said, "I know it would be mine." He said, "But the other kids won't have anything to do with it." I said, "You're right." I said, "So you want the money, I'll give you the money, so you don't have to worry about it no more." If Hanson don't come over here, and I hope and pray he doesn't because I prayed before I went to bed last night he doesn't show up, and he didn't show up. So I said, "We're going to keep this property." So he said, "Well, if you want to give the money, I guess I have to buy that part with them." I said, "Yep." I said, "Now they won't have anything else to do with the property." But then we got back to Arizona, he changed his mind. He didn't want the money. "I guess I'll just keep it since you're going to be so stubborn, and want us to keep the property. I guess I just won't sell it." I said, "You just don't want me to have it." "No! Now, that ain't it! I thought about it, and I thought, well, that little money isn't any money, so it isn't going to be enough for them, so I'll just go ahead and keep the property. Maybe some of them will go down there and stay." I said, "Well, I'm going to stay." I said, "When I get the chance, get the money," I said, "I'm going to move to Texas." He said, "All right, if you're determined to do it, I just guess you go ahead."

So that's what I did. I moved down there, and after I got down here, then my twin sister wanted to come. "I just can't stay up here no more." I said, "Yeah, you can stay up there. You've got all of those kids. You stay right on in your house." She had a fit. "Come find me a house." She said, "I don't want to stay up here no more." So I went out and I told her, "Well, you come on down here, and we'll find a house after you get here." I was staying over on St. 
Bernard. So she moved down here and I went to the project and told them she had those kids, and she needed a place to stay. They talked to me and told me, yeah, they could give her a project. So they gave her a project on Rosewood, and that's where she stayed until we went out looking for some mobile homes and finally found one for her to get before I got mine because she had kids, so I wanted to make sure she had a decent place to stay with them children. And then I went out and found me one and had it moved in here. And then we gotwell, I had got Mr. Biber to dig the well before we moved out here, because they said we had to have water-you got to have your own water and electricity. And Mr. Moore up the street up there, he had moved out here, had bought some property, some of the relatives that didn't pay they taxes, and so most of the white people got they property. They paid their taxes. And they moved to Austin, the older one had passed away and the younger ones didn't pay they taxes, so they bought it through the county. Most all the property around here.

MF: Yeah, because it was like 490 acres that was originally settled by ex-slaves, and so there's not much left that's still in the hands of the descendants.

WM: Right, right. About one, two, three, four, five with us, about five families are the only ones that still own property. Six with L. D. Bunton's daughter, she still have they part up there, so it's about six - well, I forgot about the Grants. They still have theirs, so that's seven. Seven families-Kavanaughs, the Grants, the Andersons, L. D.'s daughter, and what Frank got, that's five, and us is six. And you know more Buntons[?], I can't think what their last name is, and it's Scales, Scales family has theirs, so that makes seven, but she sold most of hers to the developers. That's what they're clearing off on the right side over there when you come up that hill after you leave the graveyard. They're doing that construction over there on the right, and that was the Scales' property, thirty-five acres, and she lives there and she's the only one left out of the family. And she's old, I think she's in her seventies or eighties and she lives in El Paso. So she was going to move down here before her husband died, but after he died, she decided to stay on up there in El Paso, and her great-nieces and nephews she says are not interested in living in Buda, so she up and sold it to the developers.

MF: Were you aware of the history of Antioch Colony when you were growing up?

WM: Mm-hmm [yes].

MF: Did the elders talk about how the colony was founded and who founded it, and so forth?

WM: Mm-hmm [yes], yeah.

MF: So you knew the history?

WM: Right, that about this guy had gave it to the black slaves to get them out of the houses with the white people living in they quarters, and so they could raise they children on they own property.

MF: $\quad$ So what does the property mean to you now, knowing all this history and everything else?

WM: It means very much to me. They couldn't give me a million dollars for it.

MF: Right, because you could have gotten a loan to buy land anyplace that you wanted to if you wanted to come back to Texas, but you specifically wanted to back to this.

WM: Yeah, Buda. I definitely wanted to come back to Buda, and I wouldn't live in Austin or none of these other places around here because I was raised here, ever since I was a kid until-I think we was seventeen, eighteen when we moved from here in '55, me and my sister. So this 
all I ever known, you know, besides being driven all over West Texas and East Texas and picking cotton. When my dad went to Mexico, we went all over, farming, doing crops, all the way to East Texas, all the way down to Corpus Christi and all the way back East and then Mexico then Arizona. We didn't go to Arizona because some guy was telling me, we used to go to West Texas, in Lubbock, out there in that area, and that guy told me he wasn't making no money. He said them children you got, you go to Arizona and you'll double what you're doing now, you know, in money. So he said, "Really?" and he told him, "Yeah." So he said, "Well next year we won't have to worry about it," because the man that hired us, he had a house there for us to come to every year in Floredada[?] and he told him that he passed away, and he said it just isn't the same no more, since the guy that hired us-well, his son treated us fine, but we just not seeing him there. My dad didn't want to go back there no more, so he told Robert that he wasn't going to come back that next year. He was going to try going to Arizona. He said, "Well, George, you're always welcome to come back," and he did. He kept checking on the city and how to get out to Arizona, because we had never been that way, and different ones would tell him, "Oh, George, all you had to do is go out 290, go straight on out through Wiccam Bear. You stay on that road until you get way on out there, and you'll see a sign on the highway that will tell you West, and as long as you see West, you keep going West, and you'll run into it." So that's what we did. He got that truck loader. He'd get hands from out of Austin, a lot of the single men, families, women that wanted to go pick cotton, and he'd load the truck up full of hired hands and taken them out there. And he'd put us up there to the front when we was little kids, and the very littlest ones be inside the cab.

MF: How old was the littlest one of you when you started picking cotton?

WM: Out there in West Texas there was a baby boy, Bess, and I think he was about—oh, he was baby.

MF: How old were you when you could actually be out picking cotton? What's the youngest kid that they would have out there?

WM: Oh, shoot, you started picking cotton when you was two years old. You'd get you a flour sack and she'd put a strain on that flour sack, which was a twenty-five-pound sack, and that's what you would put around your neck and go out there and pull them both out there.

MF: How old, though?

WM: Two, two or three years old, and you would be picking cotton, unless you was babysitting under the wagon. If you wanted to pick cotton, she'd make you a sack, and that's what you'd pick. You'd get right in the front of her and you'd pick that cotton out of them bolls.

MF: How old were you when you started?

WM: Shoot, I think I was about three years old, because we had to babysit, me and my twin sister my other two brothers that's younger than us, and the one that's next to us, he had to pick cotton. So we was three, he was two, he put a sack around his neck and he let us babysit the other two, which is Ollie Joe and Lester. We'd have a baby a piece up under the wagon. She'd put a blanket on the ground and give us a bottle and we'd have to stay there and watch them. Because Elijah, he wasn't old enough to watch the kids. He was a boy so they didn't trust him. They trusted me and my sister. So we'd play when we got them to sleep, we'd play all around the wagon, have a good time while they were down there in the field picking cotton.

MF: Right. And how many hours would they be out there?

WM: Sunup to sundown. 
MF: Right. And how long was the season?

WM: We went out there in September. When school started we was supposed to be going to school because we'd go in September and stay until December. We'd come home Christmas and we'd leave two or three days before Christmas and get home for Christmas, so we'd be out there until then. And my dad named all us biblical names. He had thirteen children and all thirteen of us was named out of the Bible, all the girls and the boys.

MF: $\quad$ That must have been a tough decision for your parents to have to decide whether to keep you in school or take you out to pick cotton.

WM: Yeah. They'd take us out and try to get us to make up from September to January because school didn't start back until January, and he'd help us with our math and reading and stuff like that at home to try to keep us, you know, to catch up rather, with the other kids that was here from September to January.

MF: So, did he get his education here at the Antioch School, then?

WM: He got far as sixth grade.

MF: At Antioch School?

WM: Mm-hmm [yes].

MF: Okay. So he was literate, and your mom was as well?

WM: No, she got hers in Austin. She lived in Austin, and I think she made it to the seventh eighth grade, no seventh grade, sixth or seventh grade, too, because he didn't get no farther than sixth grade.

MF: Do you know if your grandparents were also literate?

WM: Oh, no, they was good, Grandma because she read the Bible all the time, and so she could read. I don't know how far she got in school, but she was a good reader.

MF: Your grandmother on your mother or your father's side?

WM: Daddy's side. I don't know too much about my grandmother on my mom's side, except we visited her on Sunday evenings after church. We'd go to town and visit with her and my aunties over there.

MF: And so when you say town, you mean Austin?

WM: Right, yeah.

MF: I guess Buda probably wasn't much of a town back then? [Laughter]

WM: No. One service station, one post office, and two grocery stores.

MF: That's it, huh?

WM: That's it.

MF: You miss it if you blink, go on by. 
WM: Yes. And the gin for the cotton, it had that, and for the railroad they had a booth for the railroad, and that's all we had in Buda.

MF: I see. And so you said that most of the whites that lived around here owned their own ranches, basically-

WM: Uh-huh, oh, yeah.

MF: What were the relationships like between whites and blacks when you were young? Do you remember?

WM: Very bad. They didn't care for blacks at all, most of them. The only ones that really cared is like the farmers, and they knew they had to get the blacks to do the work because they didn't do it themselves. So though they might have been a little prejudice, they did treat them right, by letting them work they farms, and milk they cows, and slop they hogs, and you know.

MF: $\quad$ So did folks in Antioch provide that kind of labor then for the white farmers around here?

WM: Yeah, right.

MF: Were they paid what you thought or what people felt was a fair wage?

WM: Fifty cents.

MF: Fifty cents a-.

WM: A day. Before we was born. I think after we was born they got up to a $\$ 1$.

MF: Okay. And you were born in 1940-

WM: 1937.

[Interview ends.]

Interviewed by: Maria Franklin

March 18, 2009 (2 or 2)

MF: $\quad$ So I thought we would take off with thinking about what the history of this place means to you. [Recorder paused.] So what is it about the history here of Antioch, and African American history in general, that's important to you? Why do you think knowing that history is important to know?

WM: Because I can tell my great-nieces and nephews, since I don't have any children for grandchildren and children, all about how I was raised and how the black people got along here in this Antioch with white people's and other people's, and the neighbors. And I really think it's beautiful because in our neighborhood everybody cared about you and your family, and my family cared about other people's family. If they was hurting or somebody was sick in they family, they went down and seen about them. You know, my mom used to walk across them dirt clogging fields many a day to go see about the neighbor that was sick, and she would carry her cleaning stuff with her, you know, change their sheets, deodorizers for the house. The room wherever the lady was sick at, she'd go there and wash down everything 
with Lysol and clean it up, you know. And then we would have to go out and pull them broom weeds and tie them together and sweep, me and my twin sister did that.

MF: So this is the kind of way that people in Antioch cared for one an other?

WM: Right.

MF: So it didn't matter if you were kin-related or not?

WM: No, it didn't matter who you was, what race, creed, or color you were. They went if they knew about it and if you tell them we need some help—-my grandma's sick, my mama's sick. And then she would take off after she got us off to school and the house cleaned and Daddy off to work, she would go. But if it was time when we wasn't in school, then we would go with her.

MF: And so you're hoping to pass this kind of knowledge onto your nieces and nephews?

WM: Yes, mm-hmm [yes].

MF: And what do you think they might take from that? What do you think they might learn about knowing that?

WM: That they knew that they great-grandparents was Christian, and the only way that you going to be able to do that yourself, that you have to take a pattern after them, and learn from what they did years ago. If they do it or not, at least they can say, "I know how my grandparents was raised, my great-aunties and uncles and stuff like that." And hoping that they would do this. Not to everybody - you can't do it to nowadays. Things are so different than they was back then until you can't just go to anybody's house and clean now, you know, help them unless you know them or they're a church member, they going to the same church you going to. And I hope that they learn to be more kind and courtesy from it because that's what it really boils down to, that you have to be kind, lovable and courtesy and understandable of other people's problems.

MF: Do you often talk to the younger generation about this history?

WM: Yes, I often tell them about how we was raised, and they think it's funny because my parents are such strict Christians until- they would tell the girls, unless we was with my oldest brothers, when the sun go down, you come in. You don't stay outside, so whenever it got dark, we couldn't play no more. And if my older brother or sister was going to somebody's house, you know, dusk-dark or something, and they carry us with them, then we could go; but other than that, you didn't go out that door.

MF: Right, right. Is there anything about the history of Antioch or your family that you hope to learn about one day, that you don't know now, obviously, and that you hope to learn one day, questions about that history?

WM: I don't know of anything, but yeah, I'm willing to learn anything that I can about anything, anybody, you know. And especially about a neighborhood, but everything I know about it since I was old enough to remember was always good thing. They told us about some bad things happening before we came along about the family.

MF: What kinds of bad things happened?

WM: You know, like one family the daddy killed the mama over jealousy, you know, stuff like that, but you don't mention the names. But bad things like that happened. Somebody killed my 
daddy's brother. He was out there, he had horses, raised horses, and he went out and he heard his horses racing, and he knew somebody was out there, so he put his gun in his bosom and walked with his hands on it, with it inside his clothes, and he got almost to the horses, and somebody shot him, killed him. I think they never found out who did it, though.

MF: What was your uncle's name, the one who got shot?

WM: Ollie.

MF: Oh, is that who Moses is named after, because he's Moses Ollie Joe Harper.

WM: Right, mm-hmm [yes].

MF: Oh, I see. So in terms of the land, when you came back or when you're here now, are there areas that you look at that bring back memories for you?

WM: Oh, yes.

MF: Which parts?

WM: Behind my sister's house.

MF: Which sister's?

WM: The twin sister's.

MF: What happened out there?

WM: That's where my grandmother lived. She lived over in them bushes, behind Minnie, and that's where we'd go when we'd get in from school and do our chores. We'd have to run down to Grandma's before it get dark and come back.

MF: Okay. Was she living there on her own?

WM: Yes. She had a house down there.

MF: Oh, when did she pass on?

WM: She was eighty years old. I think it was '55.

MF: Oh, okay. So right about the time you left here?

WM: Yes. That's why my daddy really wanted to leave.

MF: Is that right? When she died, he had no reason to want to stay anymore?

WM: No, he didn't want to live here anymore.

MF: Did she just die of old age?

WM: Old age, yeah. Yeah, she sure did.

MF: Who took care of her? 
WM: My mom when she got where she couldn't take care of herself. My dad moved her in the house with us and my mom took care of her.

MF: So you remember her pretty well as a child?

WM: Oh, yes.

MF: What did you do over there at your grandmother's house?

WM: $\quad$ Played. We did a lot a lot of playing. My grandmother cooked great big biscuits, so when we'd get ready to go, she'd give us one. When we'd come, and when we'd get ready to go, I'd say, "Grandma, I want another." She'd say, "No, you better go home." I said, "No, I'm not going nowhere until I get a biscuit and jelly." And then she had a big old rock outside her backdoor, and I'd go out there and sit up on that rock, and I wouldn't move, and she said, "Girl, it's getting dark. You better go home." I said, "I'm not going nowhere until I get some biscuits and jelly."

MF: Did she give in?

WM: She'd give in and give it to me to get me out there before it get dark. Back in there the snakes was bad, and dusk dark they start crawling, so she said you all got to get home before it get dark. I said, "I'm not going nowhere until I get some biscuits and jelly." So my older relatives teased me about that. They see me. "I'm not going home until I get some biscuits and jelly." And I'd lag, because I sure did, and I sat right down on that rock, and Mary [sister Minnie Nelson] kept hollering, “Come on! Come on! Let's go! Come on!" She was scary so she wasn't about to go by herself.

MF: Now, did your grandmother tell you much about her life growing up?

WM: Yeah, she used to tell us how much fun they had, her and the kids, and how they made they toys out of sticks and different stuff like that, things they wanted to play with.

MF: They made their own toys?

WM: Uh-huh [yes], and how they learned to count with grains of corn at home, and like kids do homework now, they would do that, put so many pieces of corn in one row and another one, and they'd learn to count them, and learn to subtract it. You know if you had two, and you subtract it from four, you going to get two.

MF: Could your grandmother read?

WM: Mm-hmm [yes].

MF: But she was too old to have gone-There wasn't a school here when she was a child, though? She grew up here in Antioch?

WM: Yeah. I'm trying to think if she went to school here. I think they was in Kincheonville.

MF: Oh, is that right?

WM: Yeah, they lived in Kincheonville. I think that's where they was.

MF: So they probably had a colored school out there? 
WM: Yeah, a school. I don't know-yeah, I imagine it was a colored school because they didn't start desegregating until when I came along, so I'm pretty sure it was.

MF: So, your grandmother pretty much helped to raise all of you kids?

WM: Oh, yes.

MF: You said you went out there pretty much every day?

WM: Yeah.

MF: And were there other family members around here that you spent time with that helped to raise you?

WM: Yes. My daddy's brother, Uncle Melvin, and his wife, we used to go down there with them. They had two kids. Both of them was older than us, me and my twin sister, but we'd always go down to her house and play. And get food [chuckles], because she always had some cake or cinnamon rolls or something, you know, different than what we had, and I'd always go down there to play with Nell, so I'd get something. When we get ready to go, she'd give it to us.

MF: Oh, is this Nell the one who lives-

WM: Uh-huh [yes], right across from the graveyard.

MF: Right. Oh, so her parents.

WM: Yes. And then our neighbors, we always went to they houses. LeeDell's grandma, Kate, we used to call her Aunt Kate, and we'd go to her house [chuckles] biscuit and jelly. [Chuckles] I would. Sometimes my sister wouldn't eat it, but I always wanted that biscuit and jelly. [Laughs]

MF: That's funny. So the adults pretty much took care of everybody's kids? I mean, if you showed up at somebody's door, they would feed you, and watch out for you?

WM: Yeah, right. And if you did something wrong, they'd whip your behind.

MF: Would they really?

WM: Whip your behind and then call and tell your parents, because we didn't have telephones. When Daddy would come by they house, they'd stop him and tell him, "I had to whip such and such a person. They did this. They did that." He'd say, "All right, thank you." That was the whole neighborhood.

MF: So you couldn't get away with anything being over at somebody's house?

WM: No, you didn't get away with nothing. Playing, coming from school, because we walked from school, and I saw peaches on the other folks trees that I wanted, and just had to have me one [Laughs], so I got a whipping for climbing trees with a dress on and stealing a peach [Laughter].

MF: Who did that whipping?

WM: The lady that owned the tree. 
MF: Oh, and she told your parents?

WM: Uh-huh [yes].

MF: And then what happened after you got home?

WM: I got another whipping, sure did.

MF: Not a good idea to do things like that, then.

WM: No, not a good idea at all.

MF: So, we're talking about parents and your brothers and sisters. So when you say family, you know there are different ways to think about who your family is, you know, because a lot of time when I say family, I'm thinking about my own kids and my husband, and then of course the family I grew up in, my parents and what not. So when you say family, are you thinking of it very broadly in terms of anybody that you're kin-related to?

WM: Right, Uh-huh [yes].

MF: How do people use the term "family" around here? When people said "family," who did they usually mean?

WM: Your close, close-knit families like your grandparents, Daddy and Mama, stuff like that. So that's family, those the ones that got together on weekends, came over-aunties from Austin and my mother's sisters, my daddy's brother-would come out on Sundays.

MF: Oh, so your family got together pretty regularly on the weekends?

WM: Yeah, yep. We was always—if they wasn't out here, we was over there.

MF: Okay. And this was family on both sides, on your mother's side and your father's side?

WM: Yeah.

MF: Now when you were growing up, what were you taught about—because you had mentioned like you weren't supposed to climb trees when you were in a dress, so there must have been other things you were taught about what the proper role for a young girl or a young woman is. So what kinds of things did they teach you?

WM: Sit with your legs closed [laughs], so that was with a dress on, you know.

MF: That's probably still a good idea, actually.

WM: And to always read your Bible, trust in the Lord. Those things were drilled into us. And always carry yourself in a good way, manner, not be naughty, don't use bad words in the presence of adult peoples. Don't use them period, but especially not around adults. You don't disrespect the elderly. I don't care if they ain't but a year older than you, they still your elder, so you respect them, whoever it was-brothers and sisters, cousins, uncles, aunties, friendsit didn't matter, you still had to respect those people.

MF: And what about in terms of how you're supposed to behave around boys?

WM: You didn't get there [laughs]. 
MF: Right, well, because you did say that you had to be in first of all before it turned dark, you were supposed to be inside.

WM: Right.

MF: And then you mentioned that you weren't supposed to be someplace unless you had a chaperone?

WM: Right.

MF: One of your brothers chaperoning you?

WM: Uh-huh [yes], brother or sister, one. Yeah, it's true.

MF: So what did they expect when you were a teenager and you wanted to go out on a date, or a young man asked-

WM: Oh, no, it didn't happen. No, that didn't happen. I was eighteen years old, almost nineteen, before I was allowed to court.

MF: Is that right?

WM: If I courted, I sneaked and did it. He didn’t never know about it.

MF: Did you sneak? Did you actually sneak, though?

WM: I actually sneaked. [Laughter]

MF: Okay! So, here with another boy that grew up here in Antioch then?

WM: Oh, yeah, oh, yeah. Oh, you didn't get to town unless you was with your parents, and the only guys that I dated from Austin, they parents lived out here, or they grandparents, and they'd come out here on weekends and then we'd go up there on weekends. And every Saturday the mothers of the country would meet up on Sixth Street and they'd give us a nickel to go to the movies. So we got a chance to meet up in the show [laughs]. My daddy was out peddling, selling his goods that he brought from the country, and my mother and other children's mothers would all meet on the corner of Sixth Street up there. I can't think of the name of the other street, the cross street, but it was on Sixth Street.

MF: Right. Okay, so you were able to meet with boys before you turned eighteen, nineteen, but around eighteen, nineteen. You're still living at home, and at that point it was okay to start dating, so how did they expect this to go, you're parents? Was someone supposed to come and introduce themselves properly, that kind of thing?

WM: They had to come introduce, and then tell him what time he was going to have us back home.

MF: And what time was proper for that?

WM: Proper was nine o'clock.

MF: Nine o'clock?

WM: Ain't no ten, eleven like these kids get now, twelve or one o'clock in the morning. Nine o'clock you better be going through that door or you don't get to go no more. So we had to make sure 
we was back wherever we went, and then we wasn't supposed to been going nowhere but to the show because we weren't allowed to go to beer joints or nothing like that. Or partiesDaddy never did like parties.

MF: Okay. So you weren't supposed to be drinking, either?

WM: Oh, no. No, you better not do that, drink or smoke.

MF: The sons or daughters?

WM: None of them wasn't allowed to do it. They did it after they left home, and they got involved with alcohol and cigarettes, but they didn't do it there. None of them-they wasn't even grown enough when they got in they twenties and thirties and come home drinking or smoking-nothing like that. You didn't bring that around my parents.

MF: So did you notice, was there different ways in which your parents treated the boys and the girls? I mean, you did mention, for example, I guess the boys were allowed to stay out when it was late?

WM: Yes, right.

MF: Were there other kinds of things that they did differently, how they treated their sons and daughters?

WM: The boys got to go to town, whether we did. We had to stay home with Mama. And the little kids and the older girls got the chance to go. But the boys, they went all the time. And then he would let our neighbor's sons that could drive, they'd come by and pick up my older brothers, and take them to town. But we wasn't allowed to go with nobody but Daddy and Mama.

MF: Were you jealous?

WM: Yes. [Laughter]

MF: I would have been!

WM: We wanted to go, and we'd cry, and it didn't do no good. Mama said, "You better get back in here," and that's what we had to do, get back in the house. We'd go to the fence hollering, "Daddy, can we go? Daddy, can we go?" "No! Get in that house!" We'd stay out there on the fence and holler for ten or fifteen minutes after he done gone clean out of sight. And she'd tell, "Y'all better get in here." She didn't have to say it but one time. Second time she was on her way, so you didn't give her time to say it the second time.

MF: I'm sure. So the girls were mostly responsible for taking care of the younger kids?

WM: Yes.

MF: Did your brothers ever have to do that?

WM: No. They didn't do nothing like that. We had to wash, clean the kitchen, wash the dishes, and help on the weekends when she's baking for Sunday's dinner, then we had to help her-go get the eggs. "I ran out of eggs! Run out there and get the eggs in the nest." So we had to go out there and do that. If she needed some milk, we'd go out there and milk the cow, bring her some more milk. But I used to take my cup, we had tin cups, and I'd catch Daddy busy and 
Mama busy, and I'd run out there, and Mae West was one of our black cows, she was more gentle than the others.

MF: $\quad$ Mae West?

WM: And I'd run to Mae West, and I'd sit down there and milk, and I'd milk my cup full of milk and take off before they see me come out the lot. [Laughter]

MF: Do you miss milking cows?

WM: Oh, yes, I miss it all, really because we used to separate the milk from the cows and make butter. Daddy bought a separator, and we used to do that. Really, I miss all that, and it was very educational for us growing up, and we never seen anything like that. I has a girlfriend that lives in Houston, her mother was my godmother, and she told her daughter about that. She said, "I would a never learned nothing about cows, or where the milk comes from, or none of that stuff if I hadn't a visit the Harpers." She said she'd come up there and they parent would let them spend the weekend with us sometimes. And she was telling her about that, how she learned all of that, because they lived in the city, and her daddy worked in town. He didn't do no farming, so she said, "I didn't know anything about pulling peaches off of trees. Mama would bring them home from the store." But she said we would have to go out there and take a bucket and go pick peaches off the trees, or plums, whatever mama wanted off the tree. She said, "I never would have learned that if I hadn't been playing with them." And she would sit home one day and her girlfriend was over there and her daughter was talking to her, and she said, "We going to end up way out in the country to visit some of my mama's friends, and since she was telling me all about that stuff, how they used to pick fruit off the trees, and different stuff." She says, "She thinks I believe that." She says, "She knows she didn't do nothing like that." She said she told her, "Yes I did!" She said she heard her talking, she says, "That's good learning. Y'all didn't get the opportunity to learn that, and how to pick cotton and stuff like that." She said, "We learned all of that from the Harpers." She said, "All my sisters. We'd go spend-" because she had sisters the age of my older sisters, and they'd come spend the weekend with them, and she told them how they have to milk the cows, be out there at the lot where they was milking, feed the hogs, slop the hogs-that's what we called it, slop the hogs-feed the chickens, ducks. We had chickens, ducks, guineas, geese, all types of animals around here, dogs and cats. And she said they didn't get to learn nothing like that, how they was raised. In the city it was completely different life than how we was raised out here in the country.

MF: Now when you were living in the country as a young girl, though, did you appreciate living in the country, or did you think life was better in the city?

WM: In the city? No, because I didn't like all that traffic over there and I didn't like all them people. I wasn't used to being around a whole bunch of people until on Sundays, you know. But we'd go to the movies on Saturdays and they would be crowded, and coming down the highway coming home would be crowded, going to town, and I didn't like all them cars on the road. Wasn't used to seeing nothing like that. Out here you'd see a car every once in awhile because there wasn't that many black peoples had cars. We had horse and buggy, and we was raised up that way, so you didn't see no crowd of people. Today I really don't care for a lot of crowd of people. I was so used to being out here. I like the quietness, hearing the owls holler at night, and the frogs croaking, and the crickets hollering-when you sit out on the porch, you can hear all of that. In the city you can't, so I appreciate very much the way I was raised. I really do.

MF: Do you think it was harder-well, not harder, but like you said, you had friends in Houston, girlfriends in Houston, so they were raised in the city, and you were raised in the country. 
Did you notice that they had different kinds of values, and that as women they were able to behave differently?

WM: Yeah. They wore their hair fixed all the time, and they would wear lipstick, you know, and fancy clothes and stuff like that, and new shoes when we didn't get but one pair of new shoes a year. [Chuckles] It wasn't funny, but I mean you got them on Easter, and that's about the only time you got a pair a new dress shoes, until that next Easter, so you only wore them on Sundays anyways so you never did wear them out, and the only ones you really wore out is the ones you wore every day. We all wore high-top shoes to support our ankles, and they didn't want us wearing no sandals until like Easter Sunday, something like that when we'd get them. We didn't no dress shoes no two or three times a week, or every time Daddy got paid, we didn't get that.

MF: So they wore makeup?

WM: I didn't.

MF: Nicer clothes?

WM: I didn't never like it anyways, so I never wore makeup.

MF: Yeah. What other kinds of things do you think that women here, being raised in the country, were the kinds of values that you had?

WM: Values is knowing how to take care of yourself. My mother was a very clean person. She didn't allow you to have no odor. She made sure that you bathed. She used to tell us girls you had four heads to keep washed and clean, and I said, "I don't got but one that I have to worry about."

MF: Your own, right?

WM: Yeah. She said, "Well, on your body you got four heads that need to be washed," and I just couldn't figure that one out for a long time.

MF: What did she mean?

WM: She meant the top of your head, between your legs, and under both arms [laughter] that grew hair.

MF: [Laughter] I've never heard that expression before! That's funny.

WM: She said that they all got hair and hair holds odor, so you have to keep them clean. So that was a long time before I really—and she wouldn't tell us, she'd laughed at us when she said, "You better make sure I don't smell nothing from them." I thought, "Where is they at?" you know. Then I finally learned. But they had a lot of sayings that they told us that worked, you know, that you had to do.

MF: As a child you said that you remembered going over to your grandmother's house and playing a lot. What kinds of things did you play as a kid? What kinds of things did kids play?

WM: We had what we called stilts, and we'd take a can a corn that she'd throw in the trash, and a screwdriver and punch two holes in it on each can, and then we'd take that bailing wire. My daddy'd bail hay, so he'd have that bailing wire, and we would take it and wrapped it until we 
get it the size of our hands, and then we'd put our foot between the wires and walk on top of the cans.

MF: Oh, right, right, yeah, yeah!

WM: We did that, shot marbles, you know.

MF: The boys and girls shoot marbles, too?

WM: Oh, yeah. I used to tear them boys up. [Laughter] As good as I was to beat them.

MF: And what other kinds of things do you remember, games?

WM: Hide and go seek, we'd play hide and go seek. And roll caissons.

MF: What's that?

WM: The old tires that come off of cars, they'd lay the tires out there to the side, so we'd race down the road to see who can go the fastest and who could beat the other one. So we'd like go-

MF: You'd roll the tires down?

WM: Yeah.

MF: You'd race the tires. Oh, okay.

WM: Roll them and keep running until you beat them to where we'd mark it by, like say a algarita bush, say, "I'll beat you to that algarita bush," and then we'd come back up here to the elm grove, the trees, the big elm trees would be in the road, we'd start there and then run down there to that tree and beat them coming back, see who could go the fastest.

MF: Now did boys and girls play together a lot or did you mostly kind of separate out to play?

WM: No, we mostly played a lot together, the boys and the girls. We'd do things together just like, you know like that, do that and then we'd jump rope, take Daddy's rope and jump rope. We had a lot of things we did that would keep us amused, because you wasn't allowed to go around the grown peoples when they was talking. [Chuckles] You had to play with the kids and stay away from them.

MF: But people probably just let their kids just go out, and as long there are older kids around, it was no problem, right?

WM: Right, and as long as they could see you. They didn't want you behind the barn or nowhere where they couldn't see you. You had to be out there in the yard where they could see you.

MF: Is that for safety reasons or they just didn't want you getting into trouble?

WM: Safety reasons. And they didn't want you getting into trouble. [Laughter]

MF: Didn't want you to start burning something down?

WM: Yep. 
MF: So then as you grew up, as a teenager you said that one of things you would do is go into town and go to the movie theater. What kinds of things did you do around here when you got too old to jump rope?

WM: Nothing really but read stories. Mother would get storybooks from people she worked for, the white folks would give her books to give us, and we'd sit, the oldest one that could read would read us the stories out of the books, about the mother hen and the little red hen, and all that different kind of stuff, three pigs, you know, and the ducks; forgot now what the ducks did, but they had a story on the ducks that did something. That was our amusement when we wasn't playing and riding horses.

MF: You rode horses, too?

WM: Uh-huh [yes]. Rode the pigs.

MF: Rode the pigs?! I don't think I've heard of that one yet!

WM: Yeah, we'd ride the pigs and chase the ducks, get a whooping for running them out of the pasture. But we did all kinds of stuff, things, kept ourselves amused.

MF: So, what was your fondest memory as a child? If you could think back to a really happy memory when you were a kid, what would it be?

WM: Traveling.

MF: Traveling?

WM: Uh-huh [yes]. My dad would go different places in the city, I mean in Texas and take us on trips and stuff like that.

MF: Would you travel by car, then?

WM: Truck.

MF: $\quad$ By truck. Was this his truck? He had a truck? And so what would you do, pile everybody in the back?

WM: Yeah, everybody but the very littlest child and mama.

MF: And they would sit up front?

WM: And he would put a mattress down on the back or either a quilt for us to sit on and one to cover up with, and we'd sit in the back of the truck.

MF: What was so great for you about traveling?

WM: Seeing different stuff we'd never seen before. You know, new houses where the white peoples lived, and service stations, grocery stores in the other cities, you know like go to San Marcos and Kyle and San Antonio, once a year I think we'd went down there. And going to Austin, seeing things on your way to Austin that you don't see out here in the country: new cars when they was coming out, said we going to get us a car like that when we get grown. [Chuckles] Different things like that, wishful thinking, but we enjoyed it. And stopping at the store. When we come back he'd give us money to buy what we wanted, and my favorite was vanilla wafers and ice cream, and get some soda water. We'd buy that and we'd travel and go 
out of the city. We never went out of Texas except for Mexico. Well, on the road when we were going to farm other peoples' crops, then he'd let us buy like crackers and bologna and cheese, and stuff like that, snacks for us to eat, food. And he'd stop in New Braunfels, my favorite place when we was going to West Texas to get barbecue, and we'd have barbecue and sausage and red soda water.

MF: $\quad$ So the barbecue, it was a black-owned business?

WM: No, it was white.

MF: But they catered to black clients as well?

WM: Uh-huh [yes], yeah. He had to go around to the back though to give his order; he didn't go in the front door. But he would fix it all up and give it to us, and he would give us a little extra because Daddy had so many kids. It was a beautiful place. And the barbecue was really good. I talked to a guy not too long ago. He told me he was from Brownwood, and I asked him if that barbecue place was still there. He said yeah but he didn't think the original people was the ones that still owned it. He didn't really know because he said he didn't go down there that much.

MF: It was in New Braunfels or was it in Brown-

WM: Brownwood.

MF: Brownwood. Okay. Who named you?

WM: Both of my parents.

MF: Now I thought that you had mentioned that each one of you were named after someone in the Bible, right?

WM: Right.

MF: So I was trying to figure out who Winnie is in the Bible.

WM: It wasn't. Winnie and Minnie was two girls, and my mama read a story about it that she really liked, and she said if she ever had twins she was going to name them Winnie and Minnie, and my daddy wanted all of us to be named out of the Bible.

MF: That's where Mary and Martha came in, then?

WM: Yes, so he said they'll be named Mary and Martha, and Dr. Lauderdale was our doctor, he said, "I'll tell you what. She has the privilege over you, George, to name her twins. But if both you all want them named, then you can name one Winnie Martha and the other Minnie Mary," and so that's what they did.

MF: Ah, okay. I'm glad I asked because I was wondering about that. Now Dr. Lauderdale delivered you, right?

WM: Yeah. He helped out, but Mrs. Mary Revada actually delivered us.

MF: Her name's come up a couple of times, so she was the midwife here?

WM: Yeah. She was one of them. 
MF: One of them? Do you remember who the other ones were?

WM: Ms. Ada Bunton and Aunt Kate. I don't know whether Mrs. Anderson was or not. But I know those three. Let me think of another lady. There was one or two that did my older brother and sisters, but I can't remember what her name is.

MF: Now I wanted to ask you about your spouse, because we've been talking about having a boyfriend when you were a teenager and whatnot. So, when did you meet your husband, or your former husband, I should say?

WM: Back in '59, I think. Fifty-nine or '60.

MF: In '59. So it was few years after you left here, and you were in Arizona at the time?

WM: Right, yeah.

MF: Okay, and so he was obviously from Arizona himself then.

WM: Philadelphia.

MF: Philadelphia.

WM: Uh-huh [yes]. He was in the service, and I met him going out. He was in the Marines.

MF: Okay. Did your parents like him?

WM: Yeah. They grew to like him. [Laughter] They actually didn't want us to court no how, I don't care if we was forty years old.

MF: Until you were forty? Oh, boy.

WM: Uh-huh [yes]. Mostly my dad.

MF: What did he tell you to look for in a husband, or did anybody say anything to you about that?

WM: Man, yes, preached to us every day. Look for somebody that wanted something in life and somebody that wanted to be somebody and a man that has a future, a man that was a Christian. You didn't need no, what did he call them-men's that back then that—oh, he had a name he called them, mens that didn't want nothing but your body. They didn't care for having nothing or buying you nothing or giving you nothing. All they was looking at was your body, so he didn't want us running across none like that. But-

MF: But it was your father who normally told you this.

WM: Oh, yes.

MF: Your mother never gave you advice on that?

WM: She gave us advice so you can tell when you meet a person, the first conversation they have, you supposed to be able to know what type of person they is, listen to they conversation, what they after. You know, if they want long-term relationship, they would talk about what you could do in the future, what they looking for in the future, and what they'd like to be, what they don't like about women-you know, fast women with short dresses on, use bad language - they didn't care for them type of people. Well, when you find a man talk like, that, 
you know he wanted to be straight. He didn't want just a one-night stand. He wasn't that kind of person. And they wouldn't want to make love to you the first time they see you. They'd tell you, "Check you later. We got plenty a time," stuff like that. They turned out to be nice people, nice menfolk.

MF: So how long did you date before you actually got married, then?

WM: Oh, lord, years.

MF: Did you really?

WM: Uh-huh [yes]. I think I was about the last person-I know I was the last person in the family that got married.

MF: $\quad$ Out of eleven kids? Wow.

WM: Uh-huh [yes]. I was kind of a tomboy, so I really didn't care for getting married. I was on the trick of one night stand: if I see you, it's okay; I don't see you, it's okay. [Chuckles] I never fell in love where I just got to see him all the time, or want to see him every time he was off from work. Never was that kind of person.

MF: Never was, huh. So you married this man who was in the army, in the military.

WM: Right, the Marines.

MF: And how long were you married for?

WM: Eleven years.

MF: That's a good long time.

WM: I told him when I got to that number you couldn't change it around and make it be another number. It was time for me to go. And I left.

MF: So, well, then that would have been, if you got married in '59, did you say?

WM: $\quad$ Somewhere along in there, '59, '60. I think it was '60.

MF: $\quad$ So you were divorced by the time you moved back here?

WM: Oh, yeah.

MF: You came here by yourself, then?

WM: Yeah.

MF: Well, let's talk about the church, because I know that's really an important part of your life. What's been the role of the church in this community over the years?

WM: Being on time. Doing what you think God want you to do in church, whether it's speak or sing or whatever. Put your heart and mind into it, not do it for shape, form, or fashion. Like you playing, or singing and you singing to be cute, stuff like that. Or praying long prayers, he said, "God ain't hard of hearing, so you don't need to stay on your knees twenty and thirty minutes talking to the Lord." And when somebody else is speaking up there in front of you, 
you be quiet. You don't talk. And give respect to the preacher and make sure you stay there until the benediction is said, don't leave.

MF: This is your parents telling you these things? How old were you when you started learning these things?

WM: Joined the church at six years old.

MF: Join the church at six?

WM: Uh-huh [yes], so we knew from then that you don't play in church.

MF: Right. And how were you baptized? How did they baptize you?

WM: A sprinkle.

MF: They sprinkled water on your head?

WM: Uh-huh [yes], yes. We was Methodist, AME.

MF: Right, right. And so what did the church do for the community back when you were a kid that you remember the church doing here for the community?

WM: They would help, like if a family was in hard luck, the church would take up money. We didn't have no organizations like they got now, all these different organizations like they have in churches. They didn't have that. They would take up an offering, or either they would ask certain heads of the households, men, can you provide this family with some meat, bread, or something. "What can you do?" and either talk to the men of the church or what they called the stewards of the church, and then they would go that way about helping somebody in hard luck.

MF: And so what is it that the church does now for this community?

WM: Oh, we really haven't got started in the community. Our church is being built. But if anybody in the church, members, lives in the community and needs they light bill paid, we takes up a offering for that, you know, every Sunday or every other Sunday we put money into this treasury to help somebody that fallen on bad luck.

MF: And does Ashley and your great-grandnephew also go the church?

WM: Oh, yeah.

MF: Is that part of the requirement of living here, you must attend church?

WM: Yep, they got to go to church.

MF: Right. And so there's the new church being built now, and that's going to be finished in a-

WM: They was hoping it was going to be through in April, so I'm hoping, too.

MF: Very soon.

WM: Uh-huh [yes]. 
MF: And so what do you hope that that church will do for the community?

WM: Really be the same as we was raised up. I'm hoping that we have a clothes bank to have clothes to be able to give somebody and a food bank to help out, and then we already got a fund going where you help somebody with they utilities or rent or something like that, hospital bill or something.

MF: And so would you say that out of all the activities that you do that the church is pretty much your most central activity outside of the home?

WM: Right, yeah.

MF: Who would you consider now to be the leading members of the community? Well, let's say when you were growing up, let's start with then, and there was a problem here in Antioch between two families or something. Who would people go to to try to solve those kinds of issues?

WM: Mostly the deacons. Well, they ain't deacons, the stewards of the church that were Christians, like my dad. I think he's about the oldest man around here. All the other deacons fell up under him. They'd come to him and then he'd go to like Mr. Anderson or Mr. Smith, Albert Smith, and they would all get together and solve whatever problem was going on. They'd talk to them, like just say a man and his wife would get into it, fighting and arguing, and they would call them off to the side, go out and talk to him, especially if they had children. But they got along.

MF: So it was pretty much the deacons of the church who were considered, the people you would go to to try to resolve any kind of problem and things like that. People would turn to the church.

WM: Yeah. Like if they wanted a porch built on they house, the deacons would get together and they would get the materials and they would all go together, go build something for this person, whoever it is, put in windows, anything that was wrong. Especially the elderly of the community. They'd see that they got, you know, that they stayed convenient. If they needed wood, they'd cut wood or Dad would take them wood for the wintertime, make sure they got enough wood to carry them through the cold spells. Because back then in the days at least, the wood stuff would get wet and freeze over and it'd be icy for like two or three weeks to where it would dry out where you could burn it. So if they heard the weather's going to be bad, it's going to snow or going to freeze, then they'd go cut up a whole lot of wood and put into this person's house to last through that spell.

MF: Now were there any women who were considered leaders in the community or important figures that everyone kind of looked up to?

WM: Uh-huh [yes], the elderly, like my mom and Mrs. Andress, oh, I can't think of her name-Mrs. Hattie Revada, and Mrs. May Pete and Mrs. Alma Smith. Those are the older ladies of the neighborhood. And Mrs. Ada Bunton and Aunt Kate. They would look up to them.

MF: So what was it about these women that people felt was important that they should look up to them?

WM: Because they was Christians and they didn't believe in no hanky-panky and lying and fighting, stuff like that they didn't go for.

MF: So they were considered role models? 
WM: They was role models to the younger peoples.

MF: Did they give advice to you ever?

WM: Oh, yes. Whoopings, too. [Laughter]

MF: Yeah, that's usually the worst kind of advice. So do you remember ever as a young girl or a teenager going to any one of them and asking them for help with something or to talk to them about anything?

WM: No, but old times. I'd love for them to tell us about ghost stories and different things that used to happen in the neighborhood. Like one story my daddy was telling us-no, it was my mom. It was a cat that was following them. They was walking by the moonlight, you know, going home, and this cat run out there in front of them and start trotting along with them. And she said they looked at the cat, and then he would stop and look back at them, so they told the cat, you know, "Shoo," and whoever was with them threw a rock at the cat, or dirt or something, and hit it, and the cat got bigger, and they thought, "Oh lord, what is this" and suddenly they got to trotting, and the cat trot right along with them. And every time that this person would throw a rock to hit this cat, it'd get bigger, so they'd go out in full speed then, and start running, and the faster they run, the faster the cat run behind. And they was telling they parents or they grandparents or something, they said, "Aw, that was just Mrs. So and So come to you in the form of a cat, following you all home."

MF: Who told you this story? That's an interesting story.

WM: My mama.

MF: Did she? Your sister was telling us some stories that your mom told her as well.

WM: Yeah, she told us a lot of things about this country.

MF: Do you think she made up a lot of those stories?

WM: I really don't know whether it actually happened or not, but we heard a whole lot of them, from different ones. My dad, we'd sit down between his legs and he would tell us all about different things that happened, until he died he told us about a choir. He was down in the creek, loading the water up, he had take his team of mules with barrels in the back of the wagon, and he would haul to all the neighbors around here that didn't have a well, and he said he was down there getting water, and he heard this choir singing, and he said, "Oh my goodness." He said, "They coming this way?" He said they just kept getting louder and louder coming, like out of Buda towards the creek, and he was dipping that water he said real fast so he could follow them because he figured they would come over there and march up the road, and he wanted to be behind them, because they was singing so beautifully. And he dipped his water and looked like the faster he would dip the water, the closer they would get, so he finally got his barrels full and pull out on the road out of the creek so he could see them, because he figured they was cutting across and they was going to come out up there on the corner, where it made a bend, and he jumped in his wagon and pulled out of the creek and jumped on the road to go up there, he said, and they just kept singing and went all the way on towards north, coming out of the south going north, and went right over his head, he said, and he never did see nobody.

MF: He didn't see anybody? 
WM: He didn't see anybody. And said but they was sure singing. He said, "My goodness, they had the prettiest voices he ever heard." And he jumped and hit them mules and told them, "Get up!" and he went straight to Grandma and told her about that voice he heard, you know, those choir, he said it was a choir that was singing. So those types of things I guess really happened, because other than that, he wouldn't have told it up until he died. But he'd tell us a whole lot of things that happened. I guess they actually happened.

MF: Now your father, did he belong, he was obviously a member of the church, did he belong to any kinds of social organizations, like was-

WM: No. He never belonged to anything. The only thing he'd done other than farm work was work on the railroad track.

MF: Did he do that?

WM: Uh-huh [yes], worked on the railroad track for a long time. My mom was in a tornado. Well, they called it hurricane back then, and he was on the railroad track then, working on the railroad when the cyclone hit his house, and his brother's house, and everybody in the path, and she lost an eye in that hurricane, I mean cyclone. Uh-huh [yes].

MF: That's terrible. LeeDell told me about that storm, that I think your uncle lost one child.

WM: Yeah, he lost a baby girl, but the other kids survived.

MF: Right, right. How did most people in Antioch when you were growing up support themselves? Did most of them farm?

WM: Uh-huh [yes]. If they didn't farm, they worked, took care of the white people's children. The women ironed, and the men, you know, would do they yards or porches or stuff like that. My daddy's brother, he did that kind of work. He didn't farm, Uncle Melvin. He cleaned house.

MF: Uh-huh [yes]. Right, right. Do you feel like being black in Antioch kept, or just being black in general, kept people from getting certain kinds of jobs in Buda?

WM: Oh, yeah.

MF: Do people talk about that?

WM: People of our neighborhood? [Yes.] Yeah, they knew that the black kids wasn't going to get no jobs out here, so that's what a lot of them moved to the city, so when they kids finished school they'd have a chance-if they didn't go to college or get a job over there, shining shoes or cleaning or something. But out here, not unless you went with your parent to work, you didn't work by yourself. They didn't allow them to because they was scared of what might happen to them, so they didn't send they children off to no ranch or nothing like that.

MF: Even around here?

WM: No, oh no.

MF: So do you think that's the main reason why in Antioch the population started to decline is because the young people just left to find better opportunities elsewhere? Is that the main reason why? 
WM: Right, yeah, that's right. Right, yep. They knew they wasn't going to get nowhere here, and then they was getting to grown for they parents to continue to take care of them, so they moved to the city. My oldest brother, he moved to Waco with my mother's sister, one of my mother's sisters lived. He went up there because he wasn't going to be able to get no job other than farming and they didn't like farming. They got tired of that. All of them left home when they got eighteen or twenty-one.

MF: Oh, wow.

WM: Uh-huh [yes], so they could find them on they own. And a lot of them, my sisters, worked in laundries. They got a chance to work in a laundry, different places in the city. We didn't even have laundries out here that I know of. Probably didn't because that's where all the black folks did all the white folks' clothes, you know, washing and ironing.

MF: Right, okay.

Interviewed by: Maria Franklin

April 10, 2009 (3 of 3)

MF: This is Maria Franklin. Today is April 10, 2009. I'm interviewing for the third time Mrs. Winnie Moyer. This interview is taking place in the home of Mrs. Moyer in Buda, Texas. This interview is part of the Oral History Program for the Ransom Williams Farmstead Project.

All right, Mrs. Moyer, what I wanted to talk about today a little bit was growing up when you were a child, and the kinds of chores-I know we covered some of this, but I wanted to talk a little bit more about the kinds of chores you did when you were young, was there a difference between what the boys and girls had to do, and so forth? So can you think back to that time and remember the chores that you had to do?

WM: Yes. The girls had to get the eggs out of the nest from the chickens and the turkeys, and the ducks that we had that laid eggs, and guineas. And the boys packed the wood in for the fireplace and the cook stove. And then we had to make sure all the chickens was in in the evening, and fasten the gate to the chicken pen. And then the boys slopped the hogs, and the girls milked the cows and took the milk in for the afternoon. And then we had to feed the dogs and the cats that we had, and make sure the house was clean. That was our chores for the girls.

MF: Now why do you suppose that the chores were separated out like that, for boys and girls?

WM: Because wood was heavy that you had to pack in, and he didn't want the girls to have to pack the wood in, so they had to stack so much in the house and so much on the porch from the lot where they sawed the wood, and it was heavy to pack from way out there and bring it into the house, so he let the boys do that. [Phone rings]

MF: So what about like slopping the hogs? I mean, a girl could do that.

WM: Yeah. We had to do it after they left home [laughs]. He had a barrel where he mixed all the slop together, and then you'd dip the water bucket in there and get it out and take it and pour it in the troths for the hogs. Sometimes they was running to the troths, so it was so many of them and they was fighting over the troth and you had to push them back and all that stuff to be able to pour it into the troth, so he let the boys do that part. Then the cows would be 
down in the pasture, so we all had to go down there with the dogs and bring the cows back up to the lot where you could pen them in at night.

MF: So you had dogs trained to help round up the cattle?

WM: Yeah, we had dogs-German shepherds. They went up in them bushes. They wouldn't allow us to go in the bushes because they was scared of snakes, so we would send a dog in there after them.

MF: What else were the dogs used for?

WM: Nothing else but to protect the property.

MF: Okay, okay. And in terms of upkeep of the house, like if you needed to repair a fence or things like that, who did that kind of work around the house?

WM: My dad and the boys.

MF: Always the dad and the boys?

WM: Yeah. We didn't do that.

MF: Who took responsibility for running the household?

WM: My mom.

MF: That was a full-time job for her then?

WM: Cooking, ironing, sewing — she did it all. Making clothes for the kids.

MF: Can you remember what other kinds of things she had to do around the house?

WM: Well, waxing the floors and cleaning the windows, stuff like that_-just the general housework.

MF: Now did people hunt and trap and fish for food?

WM: Yeah, a lot of them did. My mom used to go fishing, and I don't know if my daddy ever went fishing or not, but I know my mom did, and my sisters went fishing.

MF: Did you ever go?

WM: Yes. I loved to go [laughs] so I could go play in the water.

MF: $\quad$ So you fished over in Onion Creek, then?

WM: Yes, down there at that creek.

MF: So is that the portion of the creek right there along Cole Springs Road there?

WM: Right, yeah.

MF: And so what would you use for a fishing pole? 
WM: They had what they called Georgia Canes at the time. I don't think they started buying fishing poles until they got grown, but they would use those Georgia Canes. You'd cut them out of the creek, the side of the creek. Some of them grow in the creek, some grow down the side of the creek. So they'd go down there and cut them off from the length that they wanted. Then they'd buy the fishing line and the hooks and put it on there. That's what they fish in.

MF: And what would you use for bait?

WM: Worms. They'd dig up worms out there in the pasture.

MF: And what do you remember catching?

WM: I caught a perch, the first fish I ever caught, was a little perch, so I tried to put him in the jar to keep him because it wasn't that big, but by the time we got home with him, I think he was just about dead because he didn't have no water, so he didn't last very long.

MF: But you didn't eat him because he was too small?

WM: No. I didn't eat fish at all. It had bones in it.

MF: How old were you when you first went fishing?

WM: I think I was about seven, seven, eight, somewhere along in there.

MF: When do you remember having to start working around the house and helping out?

WM: Oh, Lord, ever since I come here. Ever since I start walking anyway.

MF: Is that right?

WM: Uh-huh. We had to fold our own clothes and help Mama wash. She had wash in a two number-two tubs and iron pots. She'd boil the white clothes in that, and we had to put wood around the pot to make the fire and to heat the pot, me and my sister.

MF: And how old were you when you remember doing that?

WM: Oh, I guess about nine or ten, something along in there.

MF: When is the youngest that you can remember that you had to help out around the house?

WM: Oh, we started I guess when we started walking because we had to pick up our shoes and put them up on our bed, and our dirty clothes, she had a pasteboard box in the corner for the dirty clothes, and then we had what you call an apple basket, you know, they had baskets with tops on them for the fruit, and Daddy would always buy the bushel-that's what they call it, the bushel of apples-and we used those for our clean clothes.

MF: And you're brother Moses mentioned that your dad killed a lot of rabbits.

WM: Oh, yeah. We used to do that all the time.

MF: Now how did he catch them?

WM: He shot them. He would blind them with the headlights of a spotlight. He always had a spotlight on his vehicle, and he would shine a spotlight on that rabbit, and he couldn't see 
which way to go, and he'd follow the light, then when he got close enough he'd shoot it. Jackrabbits and cottontails.

MF: So do you remember watching him do this, then?

WM: Oh, yeah, many times.

MF: Did he ever hunt with dogs?

WM: No, he'd never hunt with the dogs, but my oldest brother did, and second brother with the neighbor boys, they'd go hunting with the dogs.

MF: What would they bring home?

WM: Coons.

MF: Did you like eating those?

WM: No. I didn't like coons and I didn't like possums. But they would kill possums and coons and armadillos.

MF: And how would they cook those?

WM: $\quad$ Bake them in the oven.

MF: Is that right? And the rabbits, how would you prepare rabbit?

WM: She did it every kind of way. We had rabbit stew, boiled rabbit, fried rabbit, baked rabbit-you name it, we ate it [laughs].

MF: Did you like it?

WM: Yeah, I liked rabbit.

MF: And did you try squirrel? Did anybody eat squirrels around here?

WM: I didn't like squirrels. Yeah, they killed squirrels, too, but I didn't like squirrels, either. They was too little [?]. Quails, frog legs—they had all that.

MF: Frog legs too?

WM: The bullfrogs, they'd cut the legs off. But they'd never stop jumping in the skillet so I didn't like that. [Chuckles] They'd be frying them and they'd just be jumping up and down.

MF: And what about turtles, did people eat turtles around here?

WM: No. We had turtles. We had all sizes of turtles, but we never-

MF: That was nothing that you ate?

WM: No.

MF: And deer? 
WM: Oh, yeah. We had a lot of deer meat. Deers and goats and sheeps, pigs, cows. We had all that.

MF: In terms of going hunting, when would your dad usually do that? I mean, since he was busy so much.

WM: Dusk-dark.

MF: At dark?

WM: Dusk-dark, they'd go hunt.

MF: And what about during the weekends? Was that reserved for different kinds of things?

WM: Church.

MF: Saturday and Sunday church?

WM: Well, Saturday we'd go visiting, family visiting. After we finished with all the chores, and we'd go family visiting. And then we'd get back in time to put up the stock before dark. And then a lot of times if you thought you'd going to be over there until dark, especially when he sold wood and butter, eggs, and stuff like that to the city peoples in Austin. And syrup, we made syrup. Molasses was what they'd call it, and when he know he had a truckload to get rid of, you know, it might be dark, so we'd put the cows up and the horses and stuff and feed the chickens early before we left to go to town. Then we'd be over there until half the night sometimes. But we would go to the movies when we got over in the evening down on Sixth Street. My mom would stay with cousins of ours and neighbors and some of the friends we knew in Creedmoor, they would all stand on the corner while we go to the movie.

MF: What was family visiting? You said that you did it on Saturday.

WM: We'd go see my dad's sister and my mom's sisters that lived in Austin. She had two sisters over there, three until one of them passed away.

MF: Do you remember what their names were?

WM: Aunt Pinky and Auntie Willie and then Mattie was my mother's sisters. My daddy's sister, he didn't have but one, and that was Aunt Addie.

MF: So she would have been an Addie Harper?

WM: Hill—she married a Hill.

MF: And then the other three sisters, your mom's sisters, were they all married in Austin?

WM: They wasn't married. They husbands had died. They was single. When I remember, start remembering.

MF: So that was kind of a tradition that you kept up every Saturday? You'd go out there to see them?

WM: Right. Anybody that was sick or was in the hospital, he'd go visit them, or at a rest home. Friends, he had friends that he was raised up with, we'd go visit them, like Mr. Carl Bunton, and, oh, different ones that was, uh, came along with my dad. We'd go by they houses and 
visit. And Miss January in South Austin, that was a friend of his. We'd go see them. And the Satterwhites, they lived in South Austin.

MF: It sounds like from everything that we've talked about that the community here really helped each other out a lot, quite a bit. So what kinds of things—did you share food? I mean if you caught a deer, would you just keep that for your own family, or-?

WM: Nm-mmm [no], he would always share-whatever meat Daddy had, he'd share with everybody, I don't care who it was. When he'd kill a hog, he'd give them bacon and give them ham, you know, and stuff like that. If they didn't have eggs, he'd give them eggs. Just milk, butter-we had to churn butter. That was one of the things me and my sister had to do was churn the butter. And on the weekend when we had ice cream, he'd make the boys turn the ice cream freezer until they left, then we had to do it.

MF: How would sharing in this community take place? Would your father just take up whatever part of the hog he had slaughtered and then go out to some of the families that he knew could use the meat?

WM: Yeah, that's what he would do. Plus he gave them water because they didn't have a well, and he'd haul them barrels of water, down there and fill up they barrels.

MF: Do you remember families that he would help this for?

WM: Ms. Kate, Kate Shine, I think her last name was, and Mrs. Ada, Mrs. Mary Pete, and Mrs. Anderson, and Mrs. Hester.

MF: Now were these women that were widowed then?

WM: Mm-hmm [yes].

MF: So he would give out food or help haul water for women who didn't have their husbands present?

WM: Right.

MF: Oh, okay. Was this typical or was your father the only person-?

WM: No, he was the only person that did it because we was the only one that farmed. Mr. Albert would help out, but I can't think what he actually did because he did a lot of work and never hardly was home. But Daddy just supplied all the neighborhoods, neighbor people down there by the cemetery.

MF: $\quad$ By the Antioch Cemetery? [Yes.] Okay. But to you it seemed like your father was kind of unique in that he did that. You don't think that this was something that the community did for one an other, you think?

WM: Nobody did it but him because he was just about really the only man besides Mr. Anderson and Mr. Albert around. Who lived in this neighborhood. All the young men, they young men and odd men, they all went to Austin to live.

MF: What years would this be do you think?

WM: Probably back in the forties. 
MF: So people had already started leaving pretty much by then.

WM: Oh, yeah. Soon as they got grown, they took off. They was tired of doing the farm work.

MF: And so it was their mothers or grandmothers who were here, left without a man around to help with things around the house and things like that?

WM: Yeah.

MF: Do you think your father, this was something that he did obviously because he was a strong Christian, as you've mentioned, but that this was something that he learned from his parents, that you help your neighbors out?

WM: Yeah, his mother and dad, I'm pretty sure. Grandma was like that. She'd give the shirt off her back for you. And then we had, during that time we had a lot of, they call them homeless now, but transients would come through, walking through our neighborhood.

MF: White or black?

WM: Black or white. Various [inaudible] and black ones, but they was always Mexicans or whites. And they'd come through and, "Can I have a piece a bread?" something like that, and Daddy would say, "Oh sure." He'd say, "Mud [?], go get the biscuits that was left, and bring any meat left in there," you know, and she would see if bacon was left, or sausage, and they'd wrap it in a brown bag and take it out there and give it to them. He didn't turn nobody down. Before the boys left, he had a young man that ran off that was staying on the ranch, and this man would always whoop him with a whip. That's how he controlled his slaves. And this young man ran off from his daddy and mother was living on that place, said he just wasn't going to let that man whip him no more, so he ran off. And he met my brother and them, and they told him "Aw, come stay with us." He said he didn't have nowhere to stay. I don't know where they found him, [Phone rings] in the woods somewhere, and he came to live with us, and George told my daddy he ain't got no place to day. He said, "Well, if you all want to share your bed with him, he's welcome to stay," and so they said, "No, we don't mind." So they let him stayed, and he was practically grown when he left.

MF: How long did he stay with you?

WM: Years. I can't think how many years, but he stayed until he was grown enough to go get him a job.

MF: So how old was he when he came to you?

WM: He was like, I guess around fifteen, sixteen years old. So he was one person wouldn't say no to nobody.

MF: Are you talking about one of your brothers?

WM: $\quad$ My dad.

MF: George, when you said George you meant-

WM: Yeah, George Junior is the one that him and his friends found him out there in the woods somewhere. I don't know where they met this guy at. I been looking for him ever since I been back, but I don't know where he is. They said he was here. 
MF: What's his name?

WM: I can't remember. Joe, I think his name was. I forgot. But he had gotten married and had five kids, and we moved to Phoenix, Arizona, and Daddy would always call Uncle Melvin, his brother that stayed here, and ask him if he'd seen him and worried about him, and he had told him the last time he told Daddy his wife and one or two of the kids was in a car accident and had gotten killed, so I don't know whether he is still living in this part of the country or what happened to him, but I haven't been able to find him.

MF: Now one thing I wanted to ask you about since we're going to be going out there and surveying the cemetery, obviously that cemetery is pretty sacred and special to the community. I mean, people have made a great effort to preserve it and put a chain-link fence around it, and it's in really good shape; people go out there and take care of it. Do you remember attending any funerals when you were younger out at the cemetery?

WM: Oh, yeah, a lot of them. One of our little cousins got killed, a post fell and hit her in the head and she died, Elsa Marie. So we went to her funeral. And then Cousin Leman Taylor, and Cousin Ernest, and uh-

MF: I'm sorry, I didn't mean to interrupt. I was just going to ask do you remember what the services were like? Have they changed from now from back then? I mean, I understand there was a wake, right? Back then you dressed the body and it was presented at the house, right?

WM: Right, you kept it at home until the next day, and then the funeral home would come and get it and take it to the church and then to the graveyard.

MF: And so there would be a ceremony at the graveyard with people present?

WM: Right.

MF: What normally would people bury with the deceased? Did you know or was it usually just a closed casket so you wouldn't know?

WM: No, I don't know nothing but that they was dressed, fully dressed in the casket like they are now. I don't think it's too much different. Only difference in it now is that they don't do it at home no more. I don't know if they would have a special request to have it at home if they would let them do it or not.

MF: Well, they have to embalm the bodies now. But out at the ceremony, what would people normally leave on top of them graves of people who were deceased?

WM: Just flowers. That's all I remember.

MF: Do you remember hearing about any kind of burial practices about, from your mother or father, about how things might have been done during their time that stuck out in your memory?

WM: No, it's always the same in burial. Wasn't no difference.

MF: Now I noticed that, because a number of those burials are unmarked, so I mean obviously some of them might have had some kind of like a wood marker or things like that?

WM: Oh, yeah, they had concrete markers, most all of them. Some of them just had the plaque that the funeral home gives, and some of them would take wood and carve their names in them, 
you know, put them down there to mark the graves that didn't have the money to buy a stone. But other than that, they all really marked-my grandmother's and great-grandmother that's buried up there, they all had markers.

MF: Well, let me switch again to some of these other questions I wanted to ask you. We've talked already a lot about what kind of work your parents did obviously when you were growing up. Do you know much about your grandparents?

WM: Yeah, my grandmother, my dad's mother.

MF: And her name was?

WM: Ella, Ella Harper. She was the greatest thing in life to me. [Laughter]

MF: This is the one who gave you biscuits when you were-

WM: Yes. Yeah, that's the one I had to eat them biscuits and jelly.

MF: And what kinds of things did she tell you about her life?

WM: Oh, she always told us mostly about ghost stories. But she would always tell us how she loved her mom, and she trained her like my mom trained my sister and I how to work, you know, and tell them how the white people would treat you, and what to be aware of, and stuff like that, and don't get mad. She said, "You be a Christian. You Christian, you don't get mad. Things they going to say to hurt your feelings, but you don't get mad, don't mouth back." So she said, "You girls got to learn that. And always sit with your legs closed." [Chuckles] You don't got on pants, you got on a dress-they were constantly reminding us of that. [Laughter] But other than that, she'd teach us about the Bible and tell us different stories in the Bible, children's stories, and how God went about healing people, and there maybe one day you might be a healing. And I used say, "Oh, Lord, I'd love to heal somebody," especially if I see somebody that was crippled. She would just tell us about peoples that was deformed, they called it 'flicted back them, they used the word 'flicted, and not to make fun at them because you don't know where you going in life, and you don't know whether it might happen to you. If you wasn't born that way, that don't mean you don't die that way, you know. So she was a very good teacher, and she would show us how to do some cooking, me rather, how to cook things when I'd go down there and stay with her long enough. And I'd make up her bed, and I'd do things around in the house for her, you know, to earn them biscuits and jelly. Oh, I loved them big old biscuits.

MF: Did she ever telling you things about what it was like to be married or what it was like to be a little girl growing up here?

WM: Yeah, she told us how she'd follow her mama through them woods. They would go to church and sometimes it would be night and they would have to hold onto-my great-grandmother must have wore a lot of aprons, and they would hold on to her apron string, the boys in the back and the girls would hold onto her dress on each side, because it was so dark you couldn't see the hand before, and her grandmother, her mother rather, would be trying to find her way back to the house.

MF: A long church service?

WM: Uh-huh, yeah. I don't know why they would stay until dark, and they had lanterns, and some of them would have lanterns to see how to go down that road. So it was all right. Her mother was a slave back in the slavery days, and how they would ride by, white men, and holler at 
different stuff to aggravate them. And things that they had to go to bed, and they'd be scared somebody going to break in on them, or something, the white folks going to do something to the houses and stuff like that.

MF: Your grandmother told you stories about that, when she was young they would be scared of white people coming into the colony.

WM: Yeah, doing things they don't got no business. Dragging cans behind. They would ride on horses, and they'd put a string a cans together and they'd ride them down the road and make noise, and the dogs would just go wild barking at them, because they always had the dogs. So they went through some rough times.

MF: Did she ever tell you that there was any serious violence, racial violence, when she was-

WM: No more than they would shoot the menfolks, like my-I don't know who-I think they finally said it was a black man that killed my daddy's brother, shot him trying to steal his horse- - he had a racehorse and this man wanted his horse and he wouldn't sell it to him, and so he was out there trying to steal him, and the horse was raising sand, so he knew somebody was out there. So he went out to see about it, and he put his gun in his shirt and he had his hands on his gun so if he saw something he would shoot him. But they said before he got to the lot where the horses was, this person shot him, you know, right in the chest and killed him. And he fell face down with his hands still in his bosom on his gun. So they would do things like that. Kill your dogs if they find out that-like we had German shepherds, a lot of dogs, and they was very smart, and this white man wanted to buy the dogs from Daddy, and he said, "No. They're my kids' dogs, so they not for sale." So then I don't know what, the coyotes or what, started eating this man's sheeps across the road over there on the next road, and he told him that it was Daddy's dogs that was doing that, and he said, "No my dogs don't leave this property." So the justice of peace came out and he said, "George, this man lost a couple a sheeps, and he said your dogs did it." He said, "No, sir. My dogs don't leave my yard." So he said, "Well, they've proved that it was a dog." He said, "Well, it wasn't my dog. It might have been a dog," he said, "but it wasn't my dog." So he said, "Well, I'm sorry," he said, "I have to go by what the man said, and you the only one that got these big dogs over here, and I'm going to have to shoot one of them." So he said, "Well, I sure hope you don't do that, sir, because it wasn't my dog." But he got on his horse and just pulled his gun out and fired it. One of the dogs, I'll try to think of that dog' name, he would always stand between Daddy and the white man, whoever come up to visit or talk to Daddy, he would stand between them, and he set up on his paws or either Daddy would say, "Get back now, get back," and he'd lay down out of the way, but he would still stand between Daddy and that person, and that's the one that he shot. So we just had a fit about it, and Daddy cried. He said, "I just don't know why they would do that. It wasn't my dog." And then that next night I think it was, yeah, the next night somebody went over there and told my daddy's brother that another one of Daddy's dogs, and he said, "It wasn't none of Daddy's dogs." And one of the white men over there live close by told him it was some wolves that was killing his sheeps, they was gray like the other dogs, and he saw a pack of them going to the sheeps, so they killed two or three a his sheep. So, I said, well, that's what he gets for lying, trying to say it was Daddy's dog. He didn't see it, and he didn't know who was doing it, so you know, the justice of the peace took his word for it because he was white. So we had rough time like that, different things that they tried to blame on you. They didn't want you swimming in the creek. They used to pass by, "Get out that water or you going to turn it black." All that kind of stuff. So there was some pretty mean people.

MF: But living here in Antioch, it sounds like people attempted to try to stay here within the community because it was kind of like a safe space? 
WM: Yeah, and they'd watch after each other. We used to kill wild turkeys. Wild turkeys was back, and I got to see two wild turkeys since I been back. Last week I saw one up there at the graveyard, and I was going to take my niece home from school-I picked her up from school and carried her home. And I saw a wild turkey down there by the creek. I, said, well I guess they coming back. [That's great.] You can always tell them because their necks are longer than the regular turkey.

MF: They kind of look like vultures a little bit, too. They're supposed to be really hard to hunt.

WM: Yeah, they was wild enough, but we used to hunt them all the time. We'd go with my second brother down in the woods and hunt wild turkeys.

MF: How would he hunt them?

WM: With a .22. Daddy bought him a .22, and he'd take the gun and go down there and shoot the turkey, and me and Mary would pack them back.

MF: So how would he-

WM: Catch them? [Yes.] Sneak up behind them. We'd stay behind the trees. When they would hear you, they would look around, and we'd hide behind the trees and stay there, and he'd say, "I think I can get this one." So he'd go on that side, and when you'd make noise, they'd turn their head, then he'd shoot them through the neck.

MF: Oh, okay. So you would help by distracting the turkey a bit? [Yes] I see. Which brother was this that hunted?

WM: Joshua.

MF: He's the one who's passed away.

WM: Mm-hmm [yes], right.

MF: And what about when you say you went out hunting quite a bit. I mean, this was on other people's property?

WM: Oh, yeah.

MF: How did people feel about that?

WM: They didn't care as long. They knows you, as they knows you was George's kids or Mr. Searcy's kids, or you know, kids of the neighborhood. They didn't bother you if you didn't bother they animals. [Chuckles] We ran and killed one of Mr. Albert's turkeys, thought it was a wild turkey.

MF: Oh, no! What happened?

WM: He came up there and told my daddy. He said, "Did you all go hunting today?" We said, "Yeah. We got a turkey." He said, "Where'd you get that turkey at?" We said, "Down there at the end of the field," and he had wandered off down there at the end of the field in the bushes, and we didn't know it was Mr. Albert's turkey [chuckles], and we'd shot his turkey.

MF: What punishment did you get for that one? 
WM: He didn't whoop us because he knew we didn't know that it wasn't a wild turkey. And he came, "George, I'm missing a turkey." And he said my wife said the kids was down there hunting today, and he asked, and we told him yeah, we killed a turkey.

MF: Proud of yourselves, right? [Laughter]

WM: And he said, "Well, Mr. Albert says he's missing a turkey." I said, "Well it wasn't none of his turkeys." So he said, "Yeah. I bet it was." Mama had done skinned him dead so we couldn't tell what he looked like. We'd bring them home to give them to her, and she boil that water and set him in there and pick them feathers out of him, after you pull them out they'd come out easier. So we couldn't tell. He said, "Well I'm sorry." He say, "If you need me to buy you another turkey," he said, "I will." So they didn't ever get angry about nothing we did if we made any mistakes around there, like climbed trees and stole peaches and apples and stuff like that I'd get a whooping.

MF: Did you do that?

WM: Sure I did it. [Laughter] Look like Ms. Anderson had the best peaches that was in the colony. They was great big peaches, and I'd climb all the way, look like the biggest one, it had to be one on top. [Laughter] And I'd tie my dress between my legs and climb that tree and go up there and get me some of them big peaches.

MF: $\quad$ So you'd be sneaking up his trees to do that. [Yes.] Now did your mom know you were climbing trees? Because that was very unladylike.

WM: I know! That's why I got a whooping! [Laughs] Yeah, they both whooped me over that one because they sure would tell it, any time they'd catch your children doing something wrong, they'd tell it. If they could catch you, they'd whoop you they selves, but I'd outrun every one of them. [Laughter] I'd beat it home and then run right under mama's dress tail and get the worst little whooping. She'd pin me between her legs and wear out my rear end.

MF: Did she have a stick that she'd use, a switch?

WM: No, she'd use a switch. We had what they called potato bush, which ain't the name, I think they was pomegranate trees, and they didn't break, they'd just bend, and they was keying on the end. She'd take her hand and strip that leaf, and I tell you, I had welts on my leg when she got through with my tail, I'd hurt for days. That's what I felt like, anyway. [Chuckles]

MF: What kinds of other trouble did you get into when you were a kid?

WM: Oh, god [laughs], we was always into something. I was kind of a tomboy when I was little. I didn't want the boys to beat me doing nothing, and so I'd always be doing something I shouldn't.

MF: Were you known as being a tomboy?

WM: The kids, they mad. They said I was double-jointed when I was little because I was so big. But I'd go out there when I'd want some milk, I'd take my tin cup out there and sit down under that cow and fill it full of milk and drink it, and I guess that's why I was so big, you know-much bigger than my twin sister; she was kind of puny. And they would say, "She's double-jointed." I ain't never heard of nobody being double-jointed, and I didn't know what that meant, either. But I'd do more work than she did because she was always so timid. So I guess working and building up my muscles made me look bigger, and I thought I could whoop every boy in Buda. [Laughs] 
MF: You didn't get into fights with boys, though, did you?

WM: Sure I did. I'd throw them down on the ground, then sat on them. [Laughter] They couldn't get up, and my sisters and brothers, too. All I'd do is catch them by the shoulders and flip them. So it'd keep them from hitting me, I'd sit right in the middle of they back and they couldn't get up. [Laughter]

MF: You must have gotten into trouble for getting into fights?

WM: Oh, yes [chuckles], they'd wear my tail out. Yeah, I got quite a bit a whoopings when I was little. And my brother Ollie Joe, he got whoopings every day, two or three times a day. He was so bad. [Laughter]

MF: What kinds of things did he get in trouble for?

WM: Stealing bread out of the house, and biscuits, or taking something he shouldn't take, or chasing the chickens, riding the pigs. [Laughs] You name it, he did it. He was always into trouble-pulling the cows' tails, catch onto the cow's tail and just hold on, and she's be pulling him and he'd be right behind. [Laughs] Oh, I tell you, we had fun, though, and they was some blessed days. Every time I look back on them, I thank god-it was the best time of my life, you know, playing with all these animals. And having pets, because we had a pet Susan, a pig, and we would ride Susan. It was a biggest and the longest pig I ever saw, and she would stop and let us ride her, and she'd keep trotting and ride us down and around the lot, bring us back. Soon I'd jump off, then Mary would get on there, Stubby would get on, and Abe-we had a cousin named Cousin Abraham, he was staying with Daddy, and he would ride him. He would stay with my grandmother. Then he would stay with us after my grandmother died. Until he got grown and left and went on his own.

MF: And who was Stubby?

WM: Elijah.

MF: I guess nobody went by their real names? So was he Stubby, actually?

WM: Yeah, he's short—still short.

MF: Now I know there was a syrup mill that your dad, well your dad had a syrup processing area, and so who helped with that?

WM: Cousin Ted.

MF: $\quad$ Cousin Ted?

WM: Uh-huh, Milton Kavanaugh.

MF: Milton Kavanaugh was his name? [Yes.] And so the two of them would process all the cane syrup?

WM: Yeah. They built a farm, and they had a big tin like the back end of a truck. They had one like that they'd put over this pit. They dug a pit and put iron things over top of it or rods, and set this big old tin thing on top of it, and that's where they put the cane at and the water to make the syrup. And I really don't know what else they put in that syrup, but we would stand back and watch them. 
MF: So you didn't really actually help in cutting the cane?

WM: Oh, yeah, we did the cane. [Laughter] Oh, yes, we did.

MF: Was this grown on your own property right here?

WM: No-

MF: Or across on Mr. Taylor's property?

WM: Yeah, Taylor's.

MF: And how many acres of cane would he grow? Do you remember?

WM: Oh, Lord. Well, he grew a lot of it down here, most all our vegetables and watermelons and cantaloupes was grown on this property.

MF: $\quad$ So he'd grow the cane over here, and you would cut it, the family would help to harvest it. And crushing it, who would do the crushing?

WM: They had a machine. You'd put it in and it crushed it right over top the thing. All we had to do was cut it down.

MF: And so who would usually do that?

WM: Daddy and Cousin Ted.

MF: And then they would have to boil it?

WM: Yeah. He'd get buckets to put it in. He'd go to town and buy a bunch of water buckets. Oh, no, not water buckets-one-gallon buckets-tin buckets, I'd say it that way, and that's what he'd put the syrup in.

MF: And how would he go about selling it?

WM: Go into town, take it to Austin. He would have the half gallons and the full gallons.

MF: $\quad$ And who would he sell it to?

WM: Different ones in Austin. He'd start out on Montopolis, and he'd go through that neighborhood and ask them.

MF: Oh, so he would just sell it out of the back of his truck?

WM: Right.

MF: That must have been hard work, though.

WM: It was. We had to-

MF: Was he the only person here that made syrup that you know of?

WM: Yeah. I don't know nobody else that made any. 
MF: And Milton Kavanaugh, did he live right over here?

WM: Yes, right as you come up the hill, that vacant house to your left, that's where he lived.

MF: What else kinds of things did your father sell? Or your mother, I should say. Or was it usually your father that went out?

WM: Father. Mama didn't do nothing like that. She just went along with us, but she would do the butter. We'd make the butter and wrap it in wax paper, wrap it in wax paper, tape it on the end and put it in boxes for him to sell so it wouldn't melt.

MF: And do you remember what else, kinds of things that you made to sell?

WM: No. There was wood, butter and eggs, milk, cream because he would separate the milk from the cream. Milk, I mean separate the milk, and it would make milk and then make cream, and that's what you used to make the butter was cream. But he had us get the little milk bottles and he'd fill them full of cream, then some for the milk, so he'd sell that a lot of cream and milk. You know, if they didn't want the milk, they wanted the cream, different ones. So he got him a bunch of customers like that and they would order what they want, and then he would go to town and sell it, and if he had more than what his customers wanted, then he'd sell it to other neighbors.

MF: So he had a pretty steady number of clients?

WM: Right, right. He had a lot in Montopolis and he had a lot in East Austin that he would take stuff to but he had him a tablet and he would write it down, what sister so-and-so wanted this, and drop this off at brother so-and-so's house, and all like that, and they'd pay him, and that's the way he got his extra money.

MF: Were there a lot of things out of the garden—fruits and vegetables and things like that, too?

WM: Oh, yeah, he took that, yeah. I forget about the garden. And the fruit-you know, he would take peaches and apples. We had plums, different kinds a plums, different kinds a peaches, and he would take a bushel of those and he'd put like twelve in a bag, and some of them wanted two dozen of peaches, or potatoes, sweet potatoes, and ice potatoes, turnips.

MF: Ice potatoes?

WM: Yeah, we called it. [Chuckles]

MF: Is that just a regular potato?

WM: Yeah.

MF: Why did you call them ice potatoes?

WM: I don't know, that's what they called them [chuckles]. Ice potatoes and sweet potatoes, relish, and different types of vegetables he would take, carrots, and greens, different kinds a greens. And then he would have cucumbers, squash-everything that he raised in the garden, he'd have that in a certain part of the truck and carried that, too.

MF: It sounds like your dad was a pretty enterprising man, like he had a lot of different things going on, because you traveled to pick cotton, but you mostly stayed in Texas to do that, right? 
WM: And Mexico.

MF: $\quad$ Oh, you did it in Mexico as well?

WM: Went to Mexico and picked fruit, fruit like apples off the trees, bananas, grapes-red grapes, green grapes-we'd go out there and pick stuff like that.

MF: Was there a pretty well known circuit that you would travel that you just did every year, you'd hit the same farms?

WM: Yeah, out in Anthony, New Mexico.

MF: In Anthony, New Mexico.

WM: It was just a service station, post office, and the service station was a store, and that was all that was there.

MF: Was there a lot of black families that were there?

WM: Mostly Spanish and white; wasn't no blacks that I know of. And very few, but I think they lived in Los Cruces or some other little towns in Mexico. But we I think was about the only black folk. We had one lady, I don't know her name, that we used to go to her house you know, to them every year and pick they farm.

MF: Was it like a six-month period where you did a lot of this traveling and picking?

WM: Yeah. We would go like-

MF: What month would you start?

WM: We'd start in August.

MF: And where would you start?

WM: July, I think it's July, then we'd go to September because we would always miss the first two or three weeks of school because of being in West Texas.

MF: Now that was the cotton harvest that you were following, right?

WM: Right.

MF: $\quad$ So you'd leave here and go out to West Texas?

WM: In May, I think it's in May when we would go to Mexico to pick fruit-May or June, one of them months, I can't remember which one. But we'd pick fruit there until the cotton got ready, and then we would go to West Texas and Floreada [?].

MF: What was it called?

WM: Floreada, Floreada, Texas. We'd go and pick from Mr. Bob Hinesly, that was his name.

MF: Hinesly?

WM: Uh-huh, Bob Hinesly. 
MF: $\quad$ So he owned a big cotton farm out there?

WM: Uh-huh. And we'd go there every year and pick cotton until they made cotton pickers. And I was too glad to see them cotton pickers [laughs], machines to come pick the cotton instead of you picking it. And his son had came out of the service, and he finally bought one of those machines. Mr. Hinesly got pretty old, so his son took over. And I think we went just a couple of years after he took over, and after that he bought him one of those cotton pickers, to pick cotton.

MF: So you would go from here, travel down to Mexico, and when you finished harvesting there you would go to West Texas?

WM: Yeah, most of the time. Sometimes we'd go to East Texas and chop castle beans that they made castor oil out of, and we'd go down there in Corpus Christi and down east. I can't think of all the little towns we'd go to when we'd go down there and chop castle beans and cane, you know, stuff like that, chop that. And then we'd come back home, then go to Mexico. No, we'd go to Mexico first and come back. Lord, I forgot how we went, it's been so long, how we went and how we did it, but that's how we did and went all over East Texas doing that.

MF: $\quad$ Picking the beans for the castor oil?

WM: Yeah.

MF: What were they called again?

WM: Castle beans. We'd go down there and chop that and then come back. I'm trying to figure out how we actually did it. And school was out in May, so when school was out, we'd leave.

MF: And so you'd be gone from May to September?

WM: No, May to October or Christmas.

MF: To Christmas you were-

WM: Yeah. We'd stay down there in West Texas until Christmas, and it'd start snowing and couldn't do no more work, and have all his cotton picked. Once we'd finished his fields, then we'd load up and come home.

MF: When did you stop picking the cotton?

WM: About a week before Christmas.

MF: You're kidding?

WM: Yep [chuckles], and we'd get home a couple days before Christmas and go out there in the woods and cut us a tree and put it up, and we used peppermint canes and cotton to decorate our tree, cotton balls. She'd buy cotton balls and we'd pick them off and put them all over the tree with the canes-We didn't have no lights, electric, we just had lamps. Levening lamp, what you call a levening lamp. It was just as bright as those bulbs.

MF: $\quad$ Glad to be home for Christmas?

WM: God, yes. Then we'd start school in January_always missed the first half of school. 
MF: How did your parents feel about you having to miss the first part of school? Did they ever say anything?

WM: He would help us. He didn't like that. He wanted to get the work done so make the money to last us, because once January came in, we had some winters then, sometimes the icicles would last and would freeze over the ground, and all the trees would be frozen, so we had to have money to last us through the winter. And if it played out before the winter played out, then he would get food on credit at the stores in Buda-Ms. Stacy and Mr. Clark, they owned the two grocery stores.

MF: Now who took care of the farm animals and what not while you were gone?

WM: $\quad$ My uncle. He would come.

MF: Which uncle was that?

WM: Uncle Melvin. He'd help feed the animals while we was gone.

MF: This is your mother or your father's?

WM: My daddy's brother, him and his son, and Mr. Albert-he would help see after the animals. Sometimes he'd let, especially his cows, he'd let them go down to Mr. Albert's lot and he would take care of them.

MF: What do you remember most about having to travel and do that work?

WM: Oh, I just loved it because we'd stop in neat little towns and get barbecue, and grocery stores and get cookies. I loved vanilla wafers and ice cream, and we'd get ice cream and vanilla wafers. And then for sandwiches we'd get the potted meat and crackers, and stuff like that, and then soda water. And they called it pop; they would [?] call it soda water, that's what it was during that time. And we'd get to see different things. And on Sundays we didn't have no church to go to, so we would go riding through the West Texas and seeing all the different stuff that we don't get to see on Sundays. After we'd get up from breakfast, he'd load us all up and carry us to town, and get to buy new blue jeans and chemise shirts, and new boots. We'd enjoy that. And after we'd do all the shopping, then he'd carry us through the country and through these little towns and visit there and let us see, you know, what they was like.

MF: So you weren't going to church while you were out of town, then?

WM: In West Texas? No. They didn't have no black church in Floreada. I don't even know where they did have black churches around there.

MF: Did they have a lot of little towns where blacks were living, though?

WM: Yeah. They was living there, too, but I don't know why they didn't have a church. If they did, my daddy just didn't go, but he'd read the Bible to us, you know, and prayer - that was every day, in the mornings and then in night.

MF: So you were out doing most of this work from the time- - you were how old when you started remembering getting on the road and having to pick cotton and things like that?

WM: Most all our lives. Every winter we'd go, and the other kids, the grown kids was little, they went, you know, so he was doing it before we came along. 
MF: Was this something that his parents also did or is this-

WM: Something he did. His parents didn't do that. They didn't even leave Buda I don't think to go no further than Austin or Kyle or San Marcos. We belonged to the AME church and we'd go to different quarter, annual conferences and different stuff like that in different towns when it was close by-if it was in Kyle or San Marcos, or Manchaca, then we'd go there.

MF: $\quad$ So was this typical for the colony that people actually traveled around quite a bit to pick cotton on other people's land? [Yes.] Did other families travel as far out as you did?

WM: No. I don't think none of them did. They just picked cotton around here, them that did pick cotton. But other than that, I don't think they left here.

MF: Now do you think the reason why your father did was because you could earn more money? [Yes] He did it for the money, you think? [Yes.] And what did he do with that-I know he had eleven kids to support [laughter] — but what do you think he was-? Did he save that money for something? Did he have a goal?

WM: He saved it up, and like we had a farm oil tractor, which is made out of all metal, and he wanted a tractor that had tires because he'd never seen a tractor with tires and he finally saw-No, that was the farm oil that come out with the tires on it. We just had a regular tractor, metal tractor, and he wanted a tractor with tires and he wanted a new pickup, later model truck, so that's what he saved his money for, to buy a bigger truck to go to West Texas. Because he would take single guys in Austin or a couple that wanted to go to West Texas. The pickup was too small, so he bought a big truck and put a tarp over the top of it with metals and closed it in, so he could haul quite a few people. We was small, so he'd put us up to the front of the truck on a mattress, and give us our quilt and pillow, and the rest of them would sit towards the back.

MF: Wow. How many people could he fit in the truck?

WM: Oh, god, quite a bit. He had a great big truck and they'd have they own bunks.

MF: And so would he charge these people for the ride?

WM: No. He took them free and then they would pay him for gas money and rent for rooms. He'd get them a place to stay.

MF: Where did you all stay when you were in West Texas?

WM: In the house.

MF: In a separate house that the white folks had for-?

WM: Yeah. They'd have a house for us, and then one for the hired hands, and they would stay. Some of them would go to town and stay.

MF: What was the difference between you and the hired hands?

WM: We were George's kids, but we all did the same thing-work. It didn't make no difference and that and my mom, she would take a, we had what you call a little oil stove, and she'd take it to the field and make hamburgers and hotdogs and stuff like that to eat-sell them, sell hamburgers. 
MF: So you all, your parents were always thinking about how they could make, turn a dollar?

WM: Yeah. [Laughter] They didn't leave nothing unturned.

MF: That's pretty good. Moses had mentioned that when you left the colony in 1955 was it, that he pretty much just let all the animals go.

WM: Yeah, he sold them.

MF: $\quad$ Did he sell them all?

WM: He sold them all because he wasn't planning on coming back.

MF: He held onto his 10.5 acres, sold the animals and whatever he could, I take it. But why was it that he needed to leave at that point? Because was it things had gotten so bad?

WM: Because they told him he could make more money if he lived in Arizona. They was paying more out there then they is here in Texas, Mexico, and they were, so he made quite a bit there.

MF: $\quad$ And what did he do when he first got out there?

WM: We went to Florence, Arizona when we first went there, and then we stayed at somebody's, some white person had gave him a name to go out there and pick for. And we went to that man's house and then we found him in Florence, Arizona. He asked where he was. He told him that he had picked out some houses that we could stay in that was vacant, and we stayed in Florence, kind of in the black neighborhood where he led us to. And that's where he lived until he finished this man's farm. Then he told him about a guy in Phoenix, that we could go to Phoenix, and they had better houses. Those houses that we lived in had dirt floors. They didn't have no concrete floor.

MF: One of the things that I wanted to ask you about here, we've been talking about the kind of work that your family did to support itself. But in terms of wage labor, that is getting a job in Buda or on another farm here in this area, did you know a lot about how people tended to think about how some jobs are reserved for whites? It was understood that whites only did this kind of work and that there were jobs that were reserved for blacks here. Did you have a sense of feeling of that?

WM: Oh, yeah. Then my parents—-mother rather; Daddy only did farm work. Mother would go out and do housework when they would call her to come to work. I think she worked for most of all the white folks around in the neighborhood in Buda. And she would do the ironing and washing most of the time, and cleaning. But, they would have to go through the back door; they didn't come through the front door. And then she had to carry us with her-she didn't have nobody to watch us. We'd go and play in the backyard or sit in the backyard until mother got through.

MF: Did she ever talk about what it was like to do that kind of work?

WM: No. It was just tiresome, you know, standing on her feet ironing like that. They'd have bundles of clothes for her to iron, and she would have to stand there ironing, didn't give her no chair to sit down in or nothing like that. So it was hard. She and my grandmother both did that.

MF: Ella Harper did that as well? 
WM: Yeah, ironing.

MF: Do you remember how old she was when she stopped probably?

WM: No, but I know she made it to probably about seventy something before she stopped working. Yeah. Because we got her, it was at home she was ironing. Once I had a picture of her on eightieth birthday, she was standing there ironing, and when she looked down, look like her eyes was closed and she didn't look up, so it looked like she standing there ironing sleep. What I find myself, with my eyes are just like hers-if I don't raise my eyes up, look up, and you see a picture of me, it look like I got them closed, so I know I took that after my grandmother.

MF: And what other kinds of jobs did the black folks do in Buda?

WM: Cousin Ted cut hair, and he was the first black man to cut hair. They would do fences, and the Revadas did cement work, stuff like that.

MF: Now you said your cousin Ted did hair. Did he have a barbershop or did he just-

WM: At his house. But I think before we was born I think they gave a place up there in the back of some building. I heard when they first started doing stories on Antioch, I heard one of the ladies said that he was the only person they gave a shop to, to do work in Buda, but I don't know what years it was, but I heard them say that.

MF: Were there any women who did cosmetology, beauty shop kind of thing? No women.

WM: No. At the house. [Laughter]

MF: But your cousin was getting paid for his cutting hair and shaving?

WM: Yes.

MF: And what other kinds of work did black men and women do here?

WM: I think that's about all I know. I can't remember what they did before I came along. Mostly since I come along that's what they did, and a lot of them went to town and worked. They didn't want to do no work out here.

MF: They didn't want to farm, you mean?

WM: Yeah. They didn't want on no farm. They worked in the city or to the laundries. A lot of them did laundry work. But some of them did stores, like my older sister, she worked at Kress's store. Some of them did cooking at the university, stuff like that.

MF: Which university?

WM: Over in Austin.

MF: At UT?

WM: Yeah. But other than that, most women's took city jobs. They didn't do-people like my mom and Mrs. Alma and Mrs. Mary Pete and Mrs. Hester, those ladies stayed and did housework here. And, Mrs. Hattie Revada, they did housework with different ones. 
MF: It sounds like when you were here in the community when you were young, it was pretty much your family and then a few other families, and then a lot of women whose husbands had passed on and whose younger sons or daughters might have left.

WM: Left, yeah.

MF: So there weren't a whole lot of people probably living in the colonies when you were maybe like ten, twelve years old. Would you say that's accurate?

WM: Yeah. We had a quite a few, but it wasn't that much. It was mostly older peoples, wasn't too many younger peoples. The Revadas and the Searcys and the Harper children was the only ones really was over here in this neighborhood. The rest of them was across the railroad track at what we called a Prair[ie]. And, they lived out on the Prair[ie] next to I-35 out there.

MF: Did they have any connection to the-

WM: Oh, yeah, we all went to the same school.

MF: The Antioch School.

WM: Right.

MF: $\quad$ So those kids came over here to attend your school?

WM: Right.

MF: And what about church?

WM: Same thing. We was Methodists, so we had church two Sundays out of the month, and I think it was second and forth, and they have church at the Baptist Church the first and third, and we'd go over there on the first and third.

MF: $\quad$ Do you remember any of the people that lived over in the Prair[ie]?

WM: Oh, yeah. A lot them youngsters are still out there, the parents is all passed away, you know, Cousin Inez and stuff. But a lot of the children are still living, and a lot of them still living, and a lot of them still out there.

MF: $\quad$ And what were their last names?

WM: Ralston, the last name Ralston. They're is still out there.

MF: So let's talk about the church since we're on that subject. How did the new church come about, building it?

WM: That we have now?

MF: Yeah, that you have now.

WM: We was in Manchaca going to church up there, and-

MF: At which church in Manchaca? 
WM: AME, Bethel Manchaca. And one of the owners of the property decided to sell it, and he sold the property without telling the church that he was selling the property, but his grandfather donated the property for the church to have. And I don't know whether they finally paid for the grounds or not, but they bought the property I think behind the church, and they switched properties and let the church come in the front. But I don't know whether they switched the titles or not, but they must have had it, really owned it, because after we got into that conflict with him about it and he had sold it, well then the AME came in, the bishop, and found out on record that they did own the property, so they in turn, turn around and sold it to the guy that wanted to buy it, and that mean, you know, that we had to leave down there from having church, but we left a little before all of that expired because of the minister there, and we came here, came home rather and started going out there to the Baptist Church.

\section{MF: When was this?}

WM: This was back in '80, I think. And I told me my family, I said, "Do we-" Lived here all our lives, most of lives, I said, "We had a church here," you know, so I said, "Let's try to raise money, you know, cooking and selling fish dinners and stuff like that, raise the money and get us a church, and then see if we can find a preacher that will help us." So they said, "That's a good idea." But we was going to church back at the Baptist Church, Center Union. And Daddy said, "Well, you think that'll work?" I told him, "Yeah, we can get some property here and buy us a piece of property and put us a church up." So one of our cousins that lived in Houston, Dorothy, she was a Kavanaugh, Dotson, Sam Dotson's daughter, and she came. She always come to visit us when she come. So she was out here and we was talking about it. Her daddy'd died, you know, and she was taking over the property that he owned, so I asked her about selling us some of the property to build a church, to put a church back in the neighborhood. So she says, "Well, you spoke a little late." She said, "I already promised it to somebody that they buying it," and that's where the church used to be, where we was trying to get.

MF: What happened to the original building where the church was?

WM: They tore it down. And she said, "Oh, I'd been more than happy to sell it to you if you had a spoke about it first." So she said, "But if I hear of anything, I'll let you know." So I said okay. And she went back to Houston, and she called George Smith, who stayed down there, there's a trailer house right down from the graveyard, she called him and told him to tell me to get in touch with her right away. So I said, "Well what's wrong?" He said, "I don't know, but she called me back and told me to make sure you called her," and he gave me the phone number. So I called her, and she said, "Martha, I got fifteen acres down there where the old school used to be, and it's family property." It was Cousin Ted's property, and he had donated to six of his nephews, give them two and half acres a piece, so she said, "and my daddy got two and half acres down there, and that's big enough to put a church on if you want it." I told her, "Sure, that'd be nice because that's where our school was." So she said, "And I'll tell you what else to do," and she gave me her auntie's number in Austin and she gave me her cousin's number in Austin, and then she told me about another cousin that had interest in that property that Cousin Ted had gave him. She said, "You call these folks up. They live in Austin, and one of the cousins, Cousin Leslie, he had past away, so he didn't have no kids by his wife and she still living. Go see her. She got a home and she not going to ever come to Buda, so see if they will donate the property to you or sell it to you." So I told her, "Sure." So in daytime when I didn't work, I went to Austin and visit with these people and I told them what I wanted, and they was more than happy. She said, "Get a quitclaim deed, so go to the library or go to the county seat, she said, and get you some quit claim deeds. And if they agree to give it to you, you have to go to a judge and sign that deed, and then deed it over to the church." So I said, "Okay." She said to deed it over to me, and I told them I didn't want 
nobody deeding me no property, you know. We want a church, we want to put a church on it. I said, "We could deed it over in the church name," so then we had to get a name for the church, so we talked to her daddy, and he said, "Why not name it Antioch. This is Antioch Colony. Just name it Antioch Church." I said, "All right." So then I said, when I go to them, I tell them they thought that was so good and wonderful, so they said, "No, I'm not going to never live out there," so they deeded it.

MF: How many acres did you get then?

WM: Just about eight acres, 7.6 acres, I think it is.

MF: So that was originally Kavanaugh land?

WM: Right. It was Cousin Ted's property.

MF: And was he an actual cousin to you?

WM: Uh-huh, my daddy. So that's how we got the property for the church. It's like down there. We could have got some more property, but our other cousins was stubborn, and if they wasn't we would've got the whole fifteen acres if they hadn't been stubborn.

MF: Well 7.6 is pretty good, though.

WM: Yeah, it is. We appreciate what we have, but if they would've cooperated, we would have had the whole fifteen acres.

MF: So it's in the name of the Antioch Church?

WM: Right.

MF: So when did you actually get the deed to that 7.6 acres?

WM: What year it was? It was in the eighties.

MF: So it's been some time. So it's taken twenty years to-

WM: Twelve, twelve years. It wasn't in the eighties; it's in the nineties because it's twelve years that we been trying to build a church. So I can't remember what year, but it's twelve years. We just celebrated our twelfth anniversary last Sunday, for the church anniversary.

MF: $\quad$ So once you had the church named and you had the property, then what needed to be done next that you had to start raising money to build this church, right?

WM: And get a pastor.

MF: Now there weren't that many people living in Antioch, though, at that time?

WM: Oh, no, wasn't nobody living here but us and my cousin right at the graveyard.

MF: Was that Nell Anderson?

WM: Nell Anderson. Yeah, she and her husband, and us, and Mr. George Smith. He was one of our cousins, and didn't find that out until before he died. [Chuckles] 
MF: That he was a cousin?

WM: The old folks didn't tell you nothing [laughs]. And I was telling them about it, and he said, "Your daddy never did tell you?" I said, "No, my daddy ain't never told us we was kin to you all." And we was raised up together, and he told him about who the relatives was that was related to join us onto them, and it was my daddy's peoples. But I didn't know that like I said until just before he died, he told us all about it. He would've told more than that when he was talking to Ruth and Mary about different, how we got joined in together and about different things that happened, and so she was sitting there with her mouth open and looked at him so hard, so he said, "Oh, I better not tell you all nothing else." [Laughter] She was looking so disappointed. I said, "Well why didn't you tell me?" So he just told me that we was blood related. You know, and he named relatives, but I don't remember their names.

MF: So what was your first step in trying to get the church built then?

WM: Find a preacher, so we was going to the Baptist Church, and Reverend Stick was going out there and he was an assistant pastor to the pastor that was there. I'm trying to remember who was there. We talked to him about, you know, that we was trying to get a church, and since he didn't have a church, would he be interested in helping us, and he said, "Aw that's a big job. I really don't know. I hardly think so. But give me your number. If I change my mind, I'll call you." I said, "Okay." So I gave him my phone number and we went on. I told Mary, "Well, don't worry about it. We'll find somebody in Austin to come out here." And I said I had a couple of preachers in Austin that I really liked that was really for real preachers, and I said I'd call them and tell them that we're trying to start a church here. "Aw no, they might want to be a AME church." I said, "No. We going to be a nondenominational church. We ain't being no more AME. I don't want to be bothering with them folks."

MF: So can you tell me the history behind why you decided to be a nondenominational instead of AME?

WM: Because of the residing elders and the bishops. You know, they don't let you keep the same pastor for so long. Some of them stay a long time, then they change and send them somewhere else. So I said whoever we get to be the preacher, we going to let them be the preacher-you know, don't want to be changing and going to annual conferences and missionary meeting. All that's all right, but I don't see it all being Christianity like. That's the getting together, that's alright, that's fine, just like we go to three o'clock service to different churches. That's fine. You know, but they have you raising all this money, and when we needed money to help us to reestablish the church that we had in Manchaca, they didn't give it to us, all the money we raised to help ourselves to get the get the church in good shape because it's falling apart, I guess it's a hundred and something years old, and they didn't give it to us. And every year we had sent so much money to the annual conference. You had to pay that money. So I said, "No. We don't want to do that no more. I don't think God is pleased about that. We'll just be a nondenominational church and all the money we raise will go into our church and help the needy. I think that God would be pleased with that." So when we met the pastor, when he decided that Tuesday he called me, that Monday and asked me, "Well how many people do you think will go to the church?" I said, "I really don't know because a lot of relatives had moved to Austin, so I don't know if they'd come back out here to church or not. A lot of them wasn't going to church either. So I said, "We might be able to persuade them to come to church if we get a church." So he said, "Well, where you going to have church at?" So I said, "I don't know. We'll find somewhere," because I'd never thought about it. So he said, "Well, get as many people as you can, and have them at your house, and I'll meet you all at about six o'clock in the evening." I said okay. 
So I called my sisters and brothers up and told them what he said. And he did. He came over at six o'clock. He told me he had thought about it and prayed about it and so he's going to take us on, try to raise the money, because I told him we had gotten the property. You know, when I met the preacher we had already got the property, so I told him, I said, "We has the property that my relatives donated to us, so we got somewhere to build a church. We just got to get organized and raise money to build a church." So he thought that was good. He saw we was serious about doing it, so he said, "Well, yeah. I'll help you all. I'll take the job on." So we said okay. So we started having church in my family room, until I went around and this little lady, Mrs. Gou [?], I met her up in Buda one day and I was at the store and I was telling her about it, and she said, "Oh, give me your phone number. I'll help you all find somewhere to go." She said, "I live in Onion Creek Senior Citizen. We don't do nothing up there in our little game room on Sundays, and I'll talk to the manager and see if you all can have church up there on Sunday mornings." So I said, "Aw. Well how much they charging?" and she said, "Oh, no sister. I'll talk to the manager only, and I'll see, but I don't believe he'll charge you anything." So she called me back and told me the owner said, yes you can have church there as long as you want, so we went up there and that's where we started having church at.

MF: And what year did you start doing church services there then?

WM: It was twelve years ago, so I really got to do some math.

MF: Twelve years ago, that would be the late nineties then.

WM: Yeah, probably about '97 or '98, somewhere in there. Probably about '98, I think.

MF: And so you've been having church service there since then?

WM: We had church there until our congregation got too big for it.

MF: How did it grow?

WM: The people started coming when they found out that we had a pastor and we was having church.

MF: And so how many people did you start with in the late nineties?

WM: Oh, I guess about twenty, fifteen, twenty.

MF: And then it grew to how big?

WM: Oh, about thirty, I think, because we didn't have no place to sit, and a lot of them had to stand up, so we went to looking for another place, and Mrs. Gou with her little sweet self, she called the schools. She said, "They got areas there that you can have church in." And she didn't know they was going to charge us, but they started out charging us $\$ 50$ a Sunday, so he said he didn't think that was fair because he was taking up like $\$ 100$ or $\$ 200$ a Sunday, and we didn't have no utility bills or nothing, so all we had to do was just pay the school, and put money back for the needy. And that's what we did, and we called a school and she told me, "Come in. Fill out a application." So me and my sister went up there, and she was a secretary, so she filled out the application for having church in the cafeteria. They told us we could go there and have church. So that's what we did, clean up until our pastor fell dead. He had a heart attack.

MF: Oh, no. When was this? 
WM: On the first of December, I guess in 2001, I think it was. We was at the Buda Fest, we had marched in the Buda Fest, and he was there driving the van that we had bought, and we was in the parade. Me and the kids was marching in the front of the van to be in the parade. And he went home that night, and I think she said he got up to go in the kitchen to get him some water or something and started back to the computer. He was on the computer and started back to the computer and fell face down, had a massive heart attack.

MF: So that must have-

WM: Oh, just shocked us to death. Yeah, it was bad but he had got an assistant pastor, he was teaching ministers over in Austin at Mount Olive. He was teaching those young ministers, well, I guess young and old, over there. He had a class I think Tuesday and Thursday. He was teaching a class over there. And one of the guys had came out, joined church and was assistant pastor, Reverend Barber, and he took over after he passed away. I told we'd rather him. He said, "You all don't want to get nobody else." I told him, "No, since he's already here. We'd rather just go with him to keep the church going." So we kept having church in the cafeteria at school, and he was there about a year, two years, after the pastor died. He said he just couldn't handle it. You know, after the Rev died a lot of the members left because he wasn't as good a pastor as the regular pastor as far as preaching and going on, you know. And a young man, so they went to the Baptist Church, a lot of them did, and we just kept going. We didn't stop. And when he left, well, we had to find somebody else.

And a friend of mine, a Barry Franklin, owned a funeral home, and I always called him for advice about different stuff. And I'd called him and ask him about a minister, and I told him that Bobby had left. So he said, "What?" So he said, "Well, I'll see what I can do. I know a lot of young ministers." I know him being a funeral director, he would know a lot of people, you know. So he told me, "I'll call you back. I know a young man looking for a church, so I'll call you back." So I said, "Okay." And he did, and he gave me this man's number and told me to call him, so I did. He was assistant pastor to Daddy's church and then he had left, wanted to get his own church, and I called him, and he told me sure he'd come out and try out. And he was a good preacher-he preached very well. But he was, I guess you call them money hungry [chuckles]. So he stayed there a couple a years, and he didn't want to be the pastor no more, taking too long to build a church, and we ain't got this and he'd complain about a secretary, my sister, and he just asked her to resign because she was making too many mistakes, which she wasn't, but his wife and cousin was working on the board with her and they was plotting against her, and I didn't know that, and he was, too, because he was getting them to do it. So she said, "I'm tired of this," so I said, "Well, just quit. You don't need no headaches behind no money." And I said, "God'll take care of it," so she did. She resigned. And no sooner had she resigned, it wasn't two Sundays after that, he come up saying that that he wanted to go to Austin and get a church. He wanted to move Antioch to Austin. "No, you ain't moving Antioch to no Austin. We in Buda and we going to stay in Buda." You know, I said, "We ain't built—we aren't trying to build no church in Austin. We trying to build up a colony. You know, so we not going nowhere." So most of the congregation was his relatives and friends, you know, so he said, "Well, I'm resigning," and I said, "Well, go ahead if that's what you want to do," you know. And my oldest sister looked at him. She told him, "You better make sure that God's in the plan if it's what you want to do, not because you want to do it. Be sure that God told you to do it." "Oh, yeah, oh, yeah" he said, and she said, "All right." So he left.

And then we started to-she went back to the bookkeeping, don't need a secretary, books, and everything, and I can't remember if they took them with them or what, but I know they took the organ. And then when we went to the bank to get her name put back on the bank account, we found out he'd took $\$ 23,000$ [What?] out of our fund and left. So it knocked a hole in us so. Plus we had to start looking for a minister, and then we tried out quite a few 
of them, but they didn't seem to be real interested in building a church. One of the guys that was there, he did talk to be interested in it, but I didn't like his technique, the way he was doing things, so I thought about him. Then we had a Reverend Bird to come out whom we had known, since Reverend Stick used to teach him in his class. So I thought about it, and I thought, "Well, let's try him out." So we did. We had him to come out and preach a couple of Sundays, and then we had a couple of ladies come out and preach, and I guess about four or five men. And I got to thinking one night and I was laying there and thought, "Lord, who is the right person, after this guy done did us in, would the next person do the same thing or what?" And He spoke to me and told me to try Reverend Bird.

So the next day I called his pastor, and I told him, I said, "We been knowing him a long time. What you think? Would he make a good pastor?" and he said, "Oh, yeah, he'd make a good pastor." Said, "Contractor that builds houses and stuff, so he'd be good to help you to build a church.” So, I say “Good." He said, “And you don't have to worry about money because he makes money and he got money, so you might not even have to pay him until you get the church build." So I said, "Oh, well that sounds good." So I told my sister and them about it, and he said, "Well, call him." So I said, "Well, next time he comes out, because every time we try out somebody, he wanted to be there," and I said, "We can't pay you and them, too." He said, "You don't got to pay me. I'm coming on my own." I said, "Oh, okay," because we'd give them $\$ 50$ to come out and try it, to preach. And so he said, "I'll be there," and he would. He'd be there every Sunday, whoever we tried out to preach, and then we decided to get him, and we been moving forward ever since. For the last two years.

MF: When did you break ground on the church?

WM: Oh that's about a year ago, yeah, the first year he was there.

MF: And so you've basically raised all the money that you've needed on your own, just the congregation, to build a church?

WM: Mostly. People donate. We had a lot of people donate because we had a couple come in, a white couple. We had gotten a free press to put it in the paper, and we had a white couple that came in one Sunday when we was having church there in the conference room. They was doing something to the cafeteria, so they put us in the conference room. They came in and they wrote us a check for $\$ 1,000$. And then a black couple that's going to a, I call it a Catholic Church, but I found out it wasn't a Catholic Church-the church up on the hill from the creek. And they gave us a $\$ 1,000$ check, you know, service. And several people just come by and visit us and stayed in the church service, and they would leave us a check on Sundays. So that start building our treasury back up. And then a lot of them send it through the mail because we put it in the paper, in the free press, and gave our post office box, if they wanted to help us, they could send a donation through the mail.

MF: And so you have the money in place to actually finish the church?

WM: We out of it now. We done used all we had saved up, so we been having barbecues to raise money, and then there's still peoples that still sending us, after they find out we did the groundbreaking, letting them know we is going to build a church because we didn't like to say working on it for twelve years, and having gotten nothing over there on the property, and they didn't know whether we just collecting money and wasn't going to build a church or what, so we had to let the public know that we are going to build a church, and we had groundbreaking and put that in the paper. So then they started back to sending us donation.

MF: And so how much more money do you think you need to raise to finish the church? 
WM: He said $\$ 70,000$. So I got the lady from Kitty, from American-Statesman, and she's going to do a article on us in the paper.

MF: Do you know when that's going to be?

WM: Well, I talked to Rev last night and he said she called him and got some more information from him, and as soon as she get the photographer out there to take a picture of the church, then she would put it in the paper. So I don't know whether he made it out there yet or not. She haven't called me back.

MF: So you're hoping to have it done in the next year or so?

WM: Oh no, next two months.

MF: Next two months? Do you think you can raise the money in the next two months?

WM: I hope so. [That would be fantastic.] We praying that we will have it ready in the next two months to go in. Right now Reverend Sweet at Hayes Hill got us out of the cafeteria from paying them the $\$ 100$ a Sunday to have church there.

MF: Oh, it's gone up to $\$ 100$ a Sunday now?

WM: Uh-huh. They got the new principal in there after the other one left, and it went up to $\$ 100$ a Sunday, so the fifth Sunday, when the fifth Sundays come, well that's $\$ 500$ a month, so we was paying the regular $\$ 400$ when it's just four Sundays. So he said, "You'll could have that money putting on your building," so he gave us a space up there at his church in a building that he has that we can have church in.

MF: So you've been doing that?

WM: Yes, and he don't want us to pay him. He said, "No, you take that money and put it into your building." And the guy that donated our foundation, he belongs to that church, and he was a blessing to us. He gave us another $\$ 3,000$ on our church anniversary. He gave us a check, him and his wife.

MF: And so how big is the congregation now that regularly attends?

WM: About fifty people.

MF: Most of them live here in the colony?

WM: No, a lot of them in Austin.

MF: And so it is people that have connections, then, to the colony, or not?

WM: Yeah, because a lot of them my great-nieces, and they comes out with they kids, and then some of them just peoples from Austin.

MF: Well, I'm going to go ahead and end it here. 


\section{Minnie Mary (Harper) Nelson}

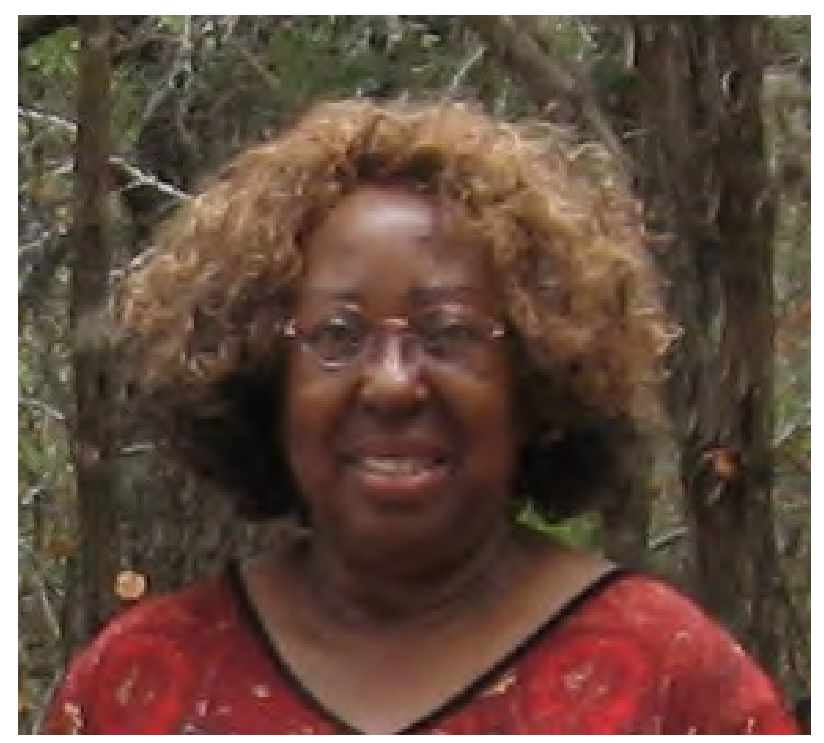
Birth Date
$7 / 29 / 1937$
Residence
Antioch Colony, Buda
Time Span
1937-1956

Note: ${ }^{* * *}$ within brackets indicates revisions to transcript made by interviewee.

Interviewed by: Maria Franklin

March 18, 2009 (1 of 2)

MF: This is Maria Franklin. Today is March 18, 2009. I'm interviewing for the first time Mrs. Minnie M. Nelson. This interview is taking place in the home of Mrs. Nelson in Buda, Texas. This interview is part of the Oral history program for the Ransom Williams Farmstead Project.

I thought we would start with questions about what it was like growing up in the Taylor home, the Taylor house. Because from what I understand, you actually didn't live on this land right here, but across the road in a house that was built by a man named Mr. Taylor, or owned by him anyway. Is that correct?

MN: Correct. John Taylor.

MF: John Taylor. Now who is he?

MN: He was the man that owned the home, the property.

MF: So your parents raised crops on this land that we're on now, right? 
MN: Correct.

MF: So at that time your father did actually own this land.

MN: He didn't own this land until 1948.

MF: Nineteen forty-eight. And who did he buy the property from?

MN: He bought it from the Kavanaughs.

MF: That was ten acres and-

MN: Ten and a half acres.

MF: Ten and a half acres. Okay. Can you tell me about the house? What did it look like? What was it built of? How many rooms did it have?

MN: Oh, it had about one, two, three-three or four rooms to my knowledge. It had a fireplace, and it had a kitchen, and a large dining room, and a porch on the south side and a porch on the west side.

MF: Which porch was the porch you call the "gary"?

MN: I guess we called the one on the south side.

MF: How big was the house? Do you remember?

MN: How large it was?

MF: Was it as big as the house that you're in now?

MN: Larger.

MF: $\quad$ So it was a pretty good size. [Yes.] Who did you share a room with?

MN: My twin sister.

MF: When you were being raised in that house, I know not all 11 siblings were there, right? Is it correct that some had moved on by that time?

MN: I think so. In the beginning it was probably all 11 . Then my oldest brother and my second oldest brother, they had moved on.

MF: Then in terms of the house, then, it was a wooden house?

MN: Wooden house.

MF: And it had a wood floor?

$\mathrm{MN}$ : Wood floor.

MF: Was it one of those ones that were built on cedar piers?

MN: No doubt, yes. [Laughter] 
MF: $\quad$ Electricity and plumbing?

MN: No electricity at that time. We had lamps, an Aladdin lamp. We had an outdoor toilet.

MF: Where did you get your fresh water?

MN: They had a cistern. And they had a windmill, well water, the windmill that pumped water.

MF: How far did you have to walk to get to the cistern?

MN: Oh, it was about maybe twenty-five feet, I think.

MF: Oh, not that far.

MN: Twenty-five, fifty feet. Not that far.

MF: Whose job was it to get the fresh water?

MN: It was all of our jobs. All of us. Because if we even did need-We had a faucet at the back of the kitchen door, so there's water come into the kitchen, you know, to use. The windmill pumped fresh water, especially when the wind blow. All of us would get water. We only got water when we needed to have that in the house for something with more water like taking a bath, like that. But other than that, my daddy also hauled water from the creek for the cattle that we had living on the farm. My daddy was a successful farmer.

MF: $\quad$ So you raised cattle?

MN: We raised horses, cows, chickens, calves, turkeys, ducks, dogs, cats-

MF: Hogs.

MN: -hogs, horses, mules.

MF: Wow. Pretty busy place.

MN: Very. [Laughter]

MF: Do you remember other structures or outbuildings around the house? You mentioned there was a cistern out there, there was also an outhouse you said.

$\mathrm{MN}: \quad$ Yes.

MF: And I think Mrs. Moyer mentioned a smokehouse.

MN: Smokehouse.

MF: Were there any other kinds of buildings or work sheds that you remember outside?

MN: Yes. They also had sheds for the cows and sheds for the horse. They had a huge barn to the west side about maybe 100, 150 feet, a large barn that stored a lot of things in there, equipment and things that the Taylors had. Areas where they stored corn, hay. That's how large it was.

MF: So it's a pretty extensive settlement. 
MN: Building, mm-hmm [yes].

MF: Were there any areas around the house that were used for household work? Did your mother or father, kids, do work outside the house?

MN: Gardening. Area there where he saws wood. We went up in the hills and collected wood to saw and rick and sell.

MF: And laundry I assume was done out there?

MN: The laundry was-we had a garage out there where you put cars, you know, my mother had a wash machine out there, the old-time wash machine, which you put in and wring it. So that was the laundry area.

MF: $\quad$ Mrs. Moyer mentioned number-two tubs.

MN: Those were the size of tubs we used. When mother washed, she had one for rinse and washing, rub board before we got the washing machine, and then she had one for rinse, bluing which rinse clothes in which whitened the clothes. Then she had one to rinse the bluing out. Then we also had an area where they had a pot where they boiled corn to make hominy. That was the area there.

MF: Oh, okay. Was it a big iron pot that you used?

MN: A large iron pot.

MF: Now I noticed there's one sitting in the front yard over there. Was it like that one?

MN: In my yard? Yes. That size or larger.

MF: Larger than that even?

MN: I think so. Because they had different sizes.

MF: What was that size used for, the one that's in your front yard?

$\mathrm{MN}$ : It was given to me. It was given to me by my friend.

MF: I can tell that's an old pot.

$\mathrm{MN}$ : It is.

MF: [Laughter] Where did you bathe?

MN: Oh, bathe. In the tub.

MF: In the washtub?

MN: Yes. In the room. She would go in there and fix the water, and we would bathe in there.

MF: I asked because my dad mentioned number-two tubs. He said, “Oh, yeah. That's what we'd wash our clothes in. We'd also bathe in them, too." [Laughter]

MN: Your dad? 
MF: My dad grew up in the country in Oklahoma. Growing cotton out on the acreage that they owned.

MN: My husband's family is related to the Franklins. I don't know which set, but they are related to the Franklins.

MF: He's here in Texas?

MN: We were told that we were related to the Franklins. I don't know which ones.

MF: I know. That's exactly right because a lot of people took that name after emancipation. A lot of African Americans took that name just like Washington. It seems to have been a popular name that people took, so it's hard to know who's related to who because it's such a wellknown name. I wouldn't be surprised, though. Texas is not that far from Oklahoma, and I do have family out here. I do have family out here.

What kinds of things did you grow in your garden?

MN: Name it! I recall pinto beans, black-eyed peas, okra, tomatoes, cabbage, greens, lettuce, and I'm trying to think of that one particular hot relish. They grew that and potatoes. Because I had to go and pick out, dig and find a potato, and that was the worse nightmare until I found it.

MF: Was it tough to get them out of the ground?

MN: Yes.

MF: [Laughter] I never had to do that.

MN: It had a flower, green flower, plant rather. My mother sent me out there. Gave me a fork. "Go out there, Mary, it's getting close to suppertime, I need some more potatoes. Go out there and dig under that green plant and get me a potato." I went out to dig under this green plant for potato. I dug, dug, dug, dug and couldn't find it. I knew my parents were very strict-they would give me a whipping if I didn't bring that-she-if I didn't bring that potato back into the house. I just cried and went in, "Mama, I can't find it." "You keep digging, you will find it." She didn't try to help me out at all.

MF: How old were you?

MN: I don't even know.

MF: I bet you remember that, huh.

MN: Maybe five, six. Six or seven years old. Might have been eight. But anyway, I better go get a potato. I dug and dug until I hit something hard. When I hit that hard, I thought it was a rock. I just kept digging around it, and there was a potato. I'll never forget that. That was the happiest time of my life. I got that potato and took it in the house very gladly. Well, that was one of the things in the garden, speaking of the garden, and that was one of the things that I had experience with.

MF: Was everybody expected to pitch in, though, growing things in the garden?

MN: Yes. 
MF: And there were probably things growing there year-round, right? I mean seasonal kinds of foodstuff that you could grow in the garden. So it was a year-round project keeping that garden going.

MN: Yes. And then the time come when you had to clean it all out. The dead stuff that was left over, you know, and get ready to fertilize it and get it prepared for the next season.

MF: What did you use for fertilizer? Do you remember?

MN: I don't know what they used for fertilizer.

MF: Well, you were out on a farm so there was plenty of manure to be had.

MN: Yes. No doubt. And they had-what was the things they put in the garden for that? I know they put ashes to get rid of the ants.

MF: Oh, okay.

MN: Mm-hmm [yes]. But what they used for fertilizer, I don't really recall. Goes to show you I was much too young. I'd hear him say fertilizer, but didn't tell us what the fertilizer was. You know, it's been a long time.

MF: So you grew a lot of the stuff right there on the farm for eating and whatnot. What kinds of things did you go into town to buy for the house?

MN: Not too much, because my father would order our coats from Montgomery Ward for the winter.

MF: From a catalog?

MN: Yes, catalog type. My mother made all our clothes because she got the material from the flour and material from the meal. Then she bought material to make our dresses with.

MF: So when you say flour, you mean flour bags?

MN: Flour sacks.

MF: $\quad$ Flour sacks.

MN: Mm-hmm [yes]. Flour sacks. She made all of our clothes. So we didn't have to worry about shopping in town for clothing except underclothes.

MF: Was that pretty common for other families around here that the mother would make the clothing?

MN: To my knowledge-I'm sure they did, because they were buying the same things that we were. Because we were on a farm. They might have had to do more because we were on a farm. And she had a sewing machine and she sewed very well. She made the curtains for the house, she made the bedspread and she made the curtains and bedspreads match. Then she would have us get the sacks from the hog feed, shorts, what you would feed the hogs, then she'd have us to take that, wash them and clean them good. Then the people that give her things, you know, and they gave her a lot of stockings. And she would have us to sit on the floor, especially when we can't go out to play and it's raining, we were in the house, and she'd 
have us sitting around the fireplace and taking those stockings and threading them through the sacks from the hog feed to make rugs to go on the floor.

MF: Oh. That's clever.

MN: Yes. They were always keeping busy doing something, I tell you. If she wasn't doing that, she was reading us books, telling us stories.

MF: Oh, okay. What kind of books? Do you remember what kind of books she read to you?

MN: No, I don't remember. Most any book. Like the ones about-Let me see if I get it right, it's a squirrel, but what is it? I never get that name. Thought I'd forget it. A book about squirrels. The other book's about-oh, Hansel and Gretel. Most of the stories she'd be telling us about things that happened in life, you know, of different things. I know she would always tell us, "You see that sign out there says, 'Keep out.' That is people's property, private. If you go over there, they'll kill you, and nothing to be done about it." And that really scared me. So they would tell us about signs and things. She would. But her main thing was baking, cooking all the time. And so, therefore, we spent too much time with Mother except when we couldn't get outside. Main thing we were all in the garden or she baked and cleaned the house and went to work while we were out in the field helping Dad, you know, doing things. So it was a busy family. Getting ready for church on Wednesday night, Sunday school, eleven o'clock service, three o'clock service, sometimes six o'clock service.

MF: All on one Sunday?

MN: One Sunday.

MF: So you would go to service on Wednesday and Sunday?

MN: Sunday.

MF: And which church was this?

MN: Antioch Community Church.

MF: I have a map, and I'm wondering where this church is. Because one of the things we've been interested in is where the churches moved over time and where the school was located. This is a map that dates to 1958. It's what we call a topographic map.

MN: Fifty-eight?

MF: Yes. This is 1958. So here is the Antioch Cemetery right here. So this is Old Black Colony Road. It shows the school here. See that right there. And then the church here.

$\mathrm{MN}$ Which school?

MF: It just says Antioch School right there on Old Black Colony Road. And on the same side, it shows a church right across from the cemetery-well, close to it, anyway. Is that the church you went to?

$\mathrm{MN}: \quad$ Yes.

MF: And that was called Antioch- 
MN: Community Church. Antioch-AME Church is what it was called. AME Church. Back up here, the school here has to be the late school in '58. But back earlier in the years they had a church and a school back, you know where LeeDell [***Bunton] carried you?

MF: Yes, he showed me the ruins of something that he said were the church and the school.

MN: That was the old school two-story building, and then about 100, 200 feet they had put another church, they had a church built. Being that it was so rugged to get to the church, they had it moved up about, oh, let's see, Kavanaugh's house, that old house you saw down there. Well, the church was on this side. The late church was on this side of the Kavanaugh property, because it was on the Kavanaughs property, the second church.

MF: Okay, so the original church where LeeDell and Frank Wilson took me and Nedra, then, is where the original church and school were located?

MN: To my knowledge.

MF: Was that standing-Do you remember when that was standing still?

MN: Yes. I remember it was two-story. The windows were all out of it and all that, but it was twostory. Then I think we had a church at the bottom down there.

MF: Okay, so was it one building or two buildings?

MN: It was two buildings.

MF: Two buildings. And the two-story one was the-

MN: What they called the Sonic building, Sonic, called the Sonic. And then we had church at the bottom until that moved over and built us one church that was there.

MF: The two-story building was used for a school?

MN: It was before my time.

MF: And it was used for a church and for a lodge it sounds like.

MN: Yes, a Masonic lodge.

MF: Then they built another building, a separate building that was used for a church. In that same location?

MN: Right opposite. I don't know how far apart. I think it was up like, by my recollection, around 100 feet apart, I guess.

MF: So the church that's on that map that dates to 1958, do you remember when that church was built?

MN: No, not exactly, because I was a young girl going there.

MF: But that's the only church you remember ever going to as a kid?

MN: No, I went to the church over there. 
MF: $\quad$ Oh, the other one.

MN: The first one you were talking about. I went over there as a young child. When it moved over here I was still young, you know, to this other church.

MF: Then the school, that one that says Antioch School, right here-

MN: Oh, I went to school there. I went to school here. I started school here and I finished up there at eighth grade because you had to go to high school to go to ninth grade.

MF: Okay, I see. That's helpful. Thank you.

The other kinds of things I was going to ask about are hair and beauty products growing up. Your mother did your hair for you?

MN: Until we were old enough to do our own.

MF: And how old was that?

MN: That's a good question. Oh, I guess about-They always started out really young, and my mother did my hair, plus my older sisters, they'd wash my hair and then did it. Dressed our hair until we got old enough. And I think when I got old enough to do my own was about twelve-yeah, eleven, twelve and thirteen I know; eleven and twelve and on like that, you know.

MF: What did you use in your hair?

MN: They had Royal Crown and pomade. They used to have Excellento.

MF: Excellento [laughter].

MN: You never heard of Excellento?

MF: No.

MN: That's a scalp treatment. In like the Band-aid boxes? It was in that style and it was yellow and black writing. The ingredient was kind of a yellowish color.

MF: So you would use that on your scalp?

MN: Scalp. And the Royal Crown, you used that on the hair. And I think there was some kind of pressing hardware used. The funny thing is that people that I know used to take a ducking [?] cloth of jeans and heat that, and that would help press your hair.

MF: What kind of cloth?

MN: Blue jean.

MF: And heat it?

MN: Yes and put it to your hair. But they had pressing combs. I was thinking of weird ways that they would do certain things. They found a way to do whatever they needed to do.

MF: Right. If they didn't have a pressing comb they could use blue jeans and heat it up? 
MN: Yes.

MF: How would they heat it up?

MN: A smoothing iron.

MF: Okay, and use that on your hair. I've never heard of that, I don't think.

MN: There's something else they used to use, I'm trying to think, on your hair, because I was the type of person who always liked to do hair, fool with hair.

MF: Why do you suppose women or young girls were pressing their hair back then?

MN: Because of the kinkiness of the hair. The elasticity drawing up your hair.

MF: Nowadays it's fashionable to go natural right?

MN: To an extent. [Laughter]

MF: Back then it sounds like everybody got a press and curl.

MN: No, they did not. They didn't like—older people, they didn't like the press and curl.

MF: The older people did not.

MN: No. They felt like it would burn your hair off, and it would if you didn't pay attention to the temperature. So to my knowledge, they always used, I mean natural. You know, oil in your hair. Wash it, oil it, and comb it with a little water. That's the way it was when mostly I was coming up to be old enough to comb ourselves, but there wasn't no pressing comb going on. They didn't allow that.

MF: But your mother, you said, had one.

MN: As we got older she did, because she'd press her hair. All of them had to do that. They would press their hair and let it cool off before they'd curl it.

I was coming up from the ranch, and my daddy used to go get wood on the ranch to saw and cut up, you know, and rick. And he came up one time had a load, and I looked to the garden, because around March time that's when things start coming up that you had planted. I was looking to the garden, and I saw this lady. You know, how rows, you know. She was stepping row to row. She had her hair straight down like as if it was cooling off so she could press it. Her hair straight down with a comb in her hair. My vision told me that was my mother. When I got out of the truck, I looked at my dad, but when I looked at my dad he had got mad or he had a different countenance. So I got out of the truck, I run into the house, I wanted to ask him, "There goes Mama across the garden," you know, but his countenance throwed me off. So I ran in the house to ask mother what was coming up. This lady had on a dress. When I ran in the house to ask my mother what was coming up, my mother was sitting at the ironing board with a stocking cap-that's another thing they wore, stocking caps, you know, cut off the stocking at the top part they always used to use those garters to hold the stockings up. So she had a stocking cap tied on her hair, and she had on a khaki set, shirt and pants. I guess one of Daddy's, I guess, but she had on a khaki set. I said, "Mama, how'd you change clothes so quick?" She said, "I've been at this ironing board all day." I know it takes all day to iron my clothes. I said, "I just saw you go across the garden." She said, "I haven't been out there. You must have seen Aunt Nena." I said, "Who's that?" One of those Kavanaugh people, you know, 
Kavanaughs, and Taylor, she's related in there. [Daughter comes in] So anyway, she was evidence it wasn't her.

MF: You thought it was your mother, and your mother said it was a Kavanaugh.

MN: Yes.

MF: What was she doing out in the-she was out in the garden, did you say?

MN: But that was a spirit.

MF: $\quad$ Oh, I see.

MN: It was a spirit. And so when I-then after she said it wasn't her, I'm going to go look for the lady. It was getting kind of dusk dark, you know. We also had a chicken pen, too. I forgot to tell you out from the smokehouse, after the smokehouse there was a chicken pen where we had the chickens. They had a spring for some reason up on the smokehouse, and we kids got to playing one day and we knocked it down, so we couldn't pick it back up there because we knocked it down. I went looking for this lady out by the smokehouse. I could just see it now, looking at you. And I couldn't find that lady nowhere, but I know she should have been-actually she was coming towards the smokehouse from the garden. I knew she should have been around somewhere. So all at once I was looking, couldn't find her, and I heard the spring screech. I was like a roadrunner [chuckles], roadrunner spinning trying to get out off that ground and get out back around to the house, you know, the front. Because I heard that spring I know that be that lady, because I didn't see her.

MF: Now, you still don't know who the woman spirit-who the spirit was in terms of-

MN: $\quad$ My mother said Aunt Nena.

MF: Aunt Nena. And Nena was passed away by this point in time.

MN: Yes, passed away.

MF: $\quad$ So your mother had seen her before? Is that—are you saying that your mother had seen that-

MN: I think how she portrayed alive, you know. Still, you know, how they did, you know, in those days. So she knew it had to be Aunt Nena. So some people said when the dead-the Bible says when you're dead it's a void between-they don't come back, but that tells me spirit wanders, you know. Anyway, that's the moral to that story. Seeing a spirit. It's not the first time.

MF: Not the first time for you or for people here?

MN: $\quad$ For me and my families, seeing spirits. And people laugh, they would call it ghosts, people laughed at us when we said, "We saw this. We saw that." Like the fire my daddy used to tell us and other folks said. A long time ago they used to see a fire on top of the Taylor house. They would come up and tell George everything's on fire because they know they saw a ball of fire on the house.

MF: What do you suppose that means, when you see fire like that?

MN: I would like for you and your group to tell us, because we have a history of that here. 
MF: Here in Antioch?

MN: Yes. Now my place here, when we first moved back when my home got burnt, we had a garden out here. And with me working for the state and my sister, Daddy would tend both gardens. One evening I came home, and as I drove in, I saw Daddy coming out of my garden with a green shirt on, a straw hat, and his Dockers, because he wore Dockers all the time. So I got out of the car and my sister worked, she took care of our parents, she would say, "I got mom and dad's food on the stove, so when you get in all you do is warm it up and give it to them, you know, before they get ready to go to bed." So I went up to check, and when I went in the house, my daddy hadn't had time to beat me in the house, I thought I left him out in the garden, right, being that I saw him in the garden. And when I went in the house my daddy was sitting down in his chair shucking corn. I said, "Daddy, how'd you beat me in the house, and I saw you coming across my garden out there?" He said, "Mot-" He called my twin sister Winnie, he calls her Mot. "Mot had me working shucking corn all day. I haven't been out in your garden." That's the second time of me seeing someone in an area that was not there.

The third time I went over, like I said, to tend to my parents and it was kind of late that night. I went over and was talking with them. You know, feed them and talking with them, they got to bed and it was time for me to come back. At that time it was around 9:30, and when I came out of the house I discovered a fire in the back of my brother's yard. But it was up like so. You know like when you barbecue in a barbecue pit? I said, "What they doing barbequing this time of night?" you know. I made no remarks or anything. I just went into the house. The next day, he said, "We weren't out there." My twin sister came home. I don't know how much time span between my time and her time. She came in. She saw the same fire. She went over there and knocked on the door, and told them, "You all got a fire in the back yard." They were asleep. She got off at ten, this is around eleven by the time she got home, quarter to eleven, eleven. They got up said, "We haven't had no fire, not barbecueing. We all are asleep." And his brother-in-law was over there and he says, "Martha you must be drunk or something. What you been drinking?" Well, she doesn't drink, neither do I. She said, "I ain't drinking nothing. I saw a fire there out there." They went out and there was no fire. So that was the part I wanted to bring up to you about finding out whether or not this was a burial ground for Indians, because there have been so many visions.

MF: Right. Do you think the visions are related-so you believe the visions may be related to the deceased Native Americans who might be buried here on this property. But could it be related to the deceased that are buried at Antioch Cemetery?

MN: People have been seeing the ones that I've seen is here in the family, like my dad, okay, and my sister Ruth, who you'll get a chance to talk to her tonight, she's seen several visions. My sister, the trailer house she got there right now because she's built all around it, she seen a fire at the end of her trailer. What we need to do is talk to somebody that knows that and pinpoint where we saw these visions, and they can let us know whether there has been graves prior of the history.

MF: So do you think—so to you it seems kind of ominous that-like maybe there shouldn't be houses on this land if it's a burial—if there are burials present and the fires are telling you something?

MN: Telling my parents something for years and years ago. My parents, you know, seen things before we were born. When we were born probably because he was up there at the Taylor property. The first homes built on this property was my sister and I when we came back here in '79. The first trailer on this property was my trailer.

MF: $\quad$ Was it ' 79 or ' 76 ? 
MN: I came back to the state in '76, and lived in Austin until I came out here and bought a trailer and lived out here in Buda.

MF: $\quad$ I see. In '79 is when you bought your trailer here.

MN: First trailer put on this property.

MF: Got you.

MN: Then hers came right behind me, so it was '79, too.

MF: But the fires you've been seeing for a lot longer than that, right?

MN: I was working for the state. In 1977 I started working for the state. So from '77, they downsized in '92 or '93, two or three years. I was still there in 1993. So from '76 to '93 I worked for the state, and that vision we both saw-[interview interruption.] As I first stated, that's in between the time my sister and I first saw the fire in my brother's back yard.

MF: Okay, so the fires are recent, fairly recent. You didn't see them-you never saw them back when you were a kid.

MN: If I did, I didn't know it was a fire.

MF: So I can see now why you think the fires might be related to you having built homesteads on this property. Because before there wasn't any homesteads on this property, where you're seeing the fires.

MN: No. And then, too, they said there used to be Indians over in this area. From the creek they told me back this way was Indian reservations, I suppose.

MF: Right. More than likely.

MN: They told you about the tunnel. You know, they have the Antioch mine. Did they tell you about that?

MF: Antioch mine? I've just heard about the quarries around here, but not a mine.

MN: The what?

MF: The gravel quarries. But I haven't heard about a mine. There's a mine here?

MN: It's in the record at the courthouse. Antioch mine.

MF: What were they mining?

MN: A mine, like you go underground.

MF: Yes. They must have been extracting something out. Normally you build a mine to get copper or to get some other kind of-

MN: Looking for gold.

MF: Yes. So do you know what they were mining down there? 
MN: No, because they tell me people go in there and come out. Some people came up and never came back. So that would be a good history for you to look at, the way it's running from. And I have a guy that's on the Historical Commission. He was on there, now he's on something else. But he told me about a mine. There's another guy who was helping us with our property, Antioch church property, and he knows about the mine. Spanish guy. He told us about the mine.

MF: Was this a mine that your ancestors had created, or are you saying that this dates back much further?

MN: Evidently much further, but it's on record. Antioch mine, and I don't know who in particular lives near the mine or on the mine with the route of it where it's running. See what I'm saying? The route it's running. I'm not sure who's close, but I do know if you look, like do you see where that dead grass is? Can you see that dead grass over there?

MF: Yes, I can. Just past the fence.

MN: Just past my sister's house right there. Far that way, oh, about 500 feet, 1,000 feet or so. Anyway, there was a Taylor house over there.

MF: Another Taylor house?

MN: Mm-hmm [yes]. John Taylor's son lived over there. There's a little hill, what I'm trying to say, in the back of his house, they would never allow us when we visited them to go out that door. We could not go out that door. Finally, I peeked out one day anyway. I opened that door (hardheaded kids), and it's a little hill, like a little mountain there. Therefore, it could have been the peak of the mine. In olden days, they didn't tell you a lot of things.

MF: Yes, so no one ever told you why you shouldn't go through the back door of that house?

MN: No, they would not.

MF: But you think it was related to the mound that was back there.

MN: Evidently. That was supposed to be like a sacred place.

MF: So you think it was related to the Native Americans who lived here?

MN: Somebody. [Chuckles]

MF: Well the only other people who were here really before you guys were, were the Native Americans.

MN: The Indians and the Native Americans. So between that generation, you know, what we call that settlement of people. I would love to learn more about it. I hope I didn't swell your head.

MF: No, I think that's an interesting-my question would be-okay, I can understand why you would make the link then again between the possibilities that this area was settled by Native Americans and that this might be some kind of-

MN: Indians. Both.

MF: I am using them interchangeably, Americans Indians and Native Americans, so when I say Native Americans I mean Indians. Sorry for the confusion. So if this was sacred land and 
their spirit still rested here, there might be visions that people are seeing that are related to that. My question would be why, if you are also so very closely located to Antioch Cemetery, and there are unmarked burials out there as well, do you think any of the visions that you might be seeing or there may be other things related to the cemetery and the deceased who are buried there that still kind of make themselves present in this community?

MN: I don't know what to say. I don't think so. I don't know because like I said, on this property, this [inaudible], and as far as I can remember, I don't remember nobody else having gardens or thing going on. You know, I mean people that lived out here, but never none worked the garden. They always went to Austin to work or probably worked for somebody around here, but my daddy was the farmer over here, to my knowledge. I know they said the Grants had a gin and all that, but probably when I was coming up, I didn't realize it, you know.

MF: Yeah. I guess my question would be, for example, there are a lot of African American beliefs regarding how to properly bury the deceased so the spirits can rest. That you always made sure that you had a proper burial for a loved one. You got burial insurance. There were various things that you did to try to make sure that at least your loved ones got a proper burial. Some people would leave personal belongs of that person in the burial with them. Some people would break a plate or bowl on top of the burial to ensure the spirit was at rest.

MN: Never heard of that one.

MF: You never heard of that one. But there's a whole range of different African American beliefs about making sure that when a body is laid to rest that the spirit is at rest as well, because otherwise that spirit could roam the land. That's why I was asking about the cemetery, because if you believe that Native American spirits could be restless or sense a presence that's not supposed to be here maybe, on top of their burial grounds, why wouldn't that apply also to the African Americans who are buried here? I guess is what I was asking.

MN: I don't know if I can answer that question correctly, but it's a possibility.

MF: I'm just wondering why if it applied to the Indians here why wouldn't it apply to the black folks.

MN: I don't know whether it's the black folks or the Indians. Which ones?

MF: Yeah. There's probably-I definitely think there are unmarked burials, and there could be some that are close to that road or some that there might be a part of the development on. The burials probably didn't stretch as far as the housing development over there, but just a thought. Maybe that fence is going on top of some-

MN: I hear what you're saying, but I'm thinking about the slaves. Someone showed us over there to the far east of the graveyard there was a hole over there. Someone said they used to throw the bodies of the slaves in there. I'm not sure. So I was thinking I wonder if they had never gotten proper burial and their spirits are wandering. Whoa, that would have had to be way back in the eighties.

MF: I've never seen a spirit myself. My dad saw his father when he was younger. His father had passed away when he was like two or three, and then he came back to visit my dad and his brother.

MN: So that's what I'm saying. So now I'm confused by-I know the Bible-I believe the Bible is true, but it says a body that can't come to you and you can't go to them. But why is it that out of nowhere unexpectedly-you know, I'm thinking about my mother going across the garden. 
See if any of that-you don't realize it exists until it happens. Then when you speak of it, you find out that's not reality. It's not real. You following me?

MF: I do follow you.

$\mathrm{MN}$ : So why is that?

MF: It must seem more real because it's happened more than once to you and your sister, and other people around here have also seen spirits.

MN: When you least expect. Just like you and I sitting here talking. We look out there and we see maybe a cat going down the road, like one of my sisters seeing a horse coming up the lane. Anyway, we were thinking it would be a horse or cow or whatever. We come to find out the people out on the porch don't see anything at that particular time. Why are we seeing it? That's the mind, you know.

MF: I don't have explanations for that. I can find out if there were Native Americans. I doubt that this is a burial ground.

MN: I hope not. Will they make you move if you have a house on a burial ground?

MF: Nope.

MN: They won't.

MF: No.

MN: The society won't-

MF: No. This is private property, so you own the property. No.

MN: Well, good. But anyway, it's strange. I'm going to tell you something else that's strange in terms of the property. We're speaking of unknown things. Lightning one time. My mother said, "Hear that?" and twice overheard it. I even think one time I overheard it. Lightning. They say lightning strikes a pot. Mother said lightning struck and hit that pot, and the pot sounds up comes between the fence and my house back here and all the way back to the trees right there in that corner. She said that lightning hit a pot out there. So the pot had to be a pot of gold or something treasure that the American Natives left hid.

MF: That's what your mom believed?

MN: Yes. So I need to go buy one of those things that do this, you know.

MF: A metal detector.

MN: Yeah, a metal detector. I don't know if I could find it or not. Maybe you guys could find it. [Laughs] If it don't move, they say as far as you'll find it, if not you won't find it.

MF: How long ago was this?

MN: When we was coming up as children.

MF: It's been a long time ago. 
MN: It's been a long time ago is correct. I'm seventy-one years old, so it had to be like I was-I do remember so when do you start remembering?

MF: At least five years old.

MN: Five, six, seven, eight, something like that. So eight from seventy would be seventy-two andI mean eight from seventy would be seventy-two and one be. What am I trying to say? I mean sixty.

MF: Sixty years ago?

MN: Sixty years ago. So I was about eight or ten. I'm trying to catch my age in there.

MF: I've not heard that one before, that if lightning strikes an iron pot, that it must be where Native Americans-well, the Native Americans here did not have gold.

MN: I don't know what them Indians had.

MF: $\quad$ Not gold in this area. Well, your mom said it was treasure, right.

MN: Treasure. All she said really was a pot. I said, "What's a pot?" And she said, "Like we cook and boil in." So she wouldn't know, but that was my interpretation.

MF: Oh, okay. [Laughter]

MN: Pot of gold. They were hiding gold and hiding this and hiding that. And who knows what they had coming from other countries? Who knows what they have found being in this country. You understand what I'm saying?

MF: The Indians?

MN: Yeah. American Indians. Who knows what they found around here? You know, near the canyon there's that mine out here. Who knows what's in that mine?

MF: Well, people have gone in and not come out you said, right?

MN: That was told to me.

MF: It's a place to stay away from.

MN: And they said it starts from the creek and it comes through the colony somewhere in the colony.

MF: That's interesting. I haven't come across a reference to that yet, but I'll ask the historian about the mine.

MN: It's on record down there in San Marcos.

MF: Yeah, that's what you said.

MN: Do some research. You'll see it when you do your research on Antioch Colony. Antioch mine. Who would own the mine? Antioch mine. Who would own that mine? Just that part that goes across-so anyway, I don't mean to hold you up. 
MF: No, no, you didn't. All of this is important. All of this is important.

Let me change the direction of the questions then, and ask some questions about Antioch and growing up in the past, and what it's like now, and how things have changed.

MN: Tremendously.

MF: Yeah. What kinds of traditions did your family have that they passed on to you? Your parents? What do you remember?

MN: Like, for instance, being on a farm?

MF: Any kind. Anything that your parents felt was important that they taught you that you try to teach your children?

MN: Spiritually. Mostly spiritually. And being a missionary. Helping the elders. Raising the children. Setting up your family. Staying in church. Growing a garden. Taking care of whatever your possessions were: a home, the garden. Grow things in the garden. Plant trees. The Taylors had a big orchard in the back of the house where we used to live, large orchardhad peaches and plums and figs. I don't know what all other fruit they had out there. I know I'd sit here and inquire about the type of figs, the yellow figs, the red figs, fig tree, and then what's the other tree. Fig tree. Yellow fig, a red-the red ones. And they had large peaches, plums. I don't know what all they had, but there was a huge orchard out there. Then it grew into an orchard, they had it.

MF: Things have changed obviously here out at Antioch and so. But what kinds of traditions have you tried to pass on to your own children and your grandchildren?

MN: The main tradition-we don't have anything hardly left anymore. You know, like churning butter, getting milk and churning butter, getting butter from the milk. That I tried to pass on to them. We used to have a separator where we separated the milk, you know. But I told them about it. I did buy a churn and bought some milk with my children and showed them how to churn milk.

MF: How long did that last?

MN: Not very long, because I wasn't interested that much anymore. The main thing was going to church and serving the Lord, participating in the church. Just don't be a benchwarmer. Participating and reading. Reading the word, going to Sunday school at church, and activities. One thing in particular I passed on to them is playing softball. Sports.

MF: Did you play a lot of games like that when you were a kid?

MN: When I was going to grammar school, we played a lot of basketball. Grammar school, then junior high. Softball was the main key thing.

MF: Now why is it that you thought it was important that the kids play in team sports?

MN: Because it was good physical exercise and participating with other people. Exciting. So they all came up in sports. Their daddy was a football player in high school, and I was a basketball player, so this is what the game of the day is.

MF: $\quad$ So you encouraged both the boys and the girls. 
MN: Yes, if they liked it. Because there wasn't no cotton to pick, no cotton to chop. Couldn't pass it on to them. We worked in a town, so therefore there wasn't too much we were doing out here except for living, going to church and activities. Prayer service, like that. So that's why they didn't like the country. Wasn't nothing exciting going on.

MF: You didn't like the country or your kids didn't?

MN: $\quad$ My kids didn’t.

MF: $\quad$ Because when you moved here, so you bought your-you moved here in '76.

MN: Seventy-nine.

MF: Seventy-nine. So how old were your kids? How old by then?

MN: They were born in the sixties. Early sixties. The oldest one was born in '60 and on down to '64. So '64 to '74 the one born. Sixty-six was the last child born. So from sixty-six years to-

MF: So some of them were teens when you came back here, some of them were teenagers.

MN: Not quite. Elsa was born in '60. Stephanie, she was ten. And I left there; sixteen. Yeah, they were teenagers.

MF: Right. But when they came back here—because you were in Arizona at this time?

MN: Yes.

MF: You were living in the city?

MN: Yes, Phoenix.

MF: $\quad$ So you came back here, but you were in Austin first.

$\mathrm{MN}$ : Yes.

MF: And then came here in '79. And which one of your kids did you bring with you here?

MN: All of them.

MF: $\quad$ All of them, but they were a bit older at that point.

MN: Yes. The high school. My son, he was in junior high. And the girls, they were in high school. I forgot. That's right. They went to Lanier High School.

MF: Right. So they didn't like living out in the country?

MN: Wasn't nothing out here but a house. All these houses wasn't here. Just our house.

MF: What did you want for them to know about Antioch and being here that was important to you? What were you hoping that they'd get from being out here?

MN: The history of Antioch, of their grandparents, their great-grandparents, which I never knew of my great-grandparents. Only met, seen two grandparents. The mother on my dad's side and the mother on my mother's side, she was a bit sick when we were coming up, so we didn't 
see much of her. So there wasn't very much history. So I didn't realize how much history we had here until lately. I just know that they always tell me 94 percent black this colony was when we moved out here. That was in '79. That the present time weren't. Then I was trying to find eight acres of land behind the cemetery that George Smith told me was my father's. I did a lot of research, but I couldn't find it. I found the man's name, which was George Champ, but I couldn't find where he left him a will. He told me in 1998 that he saw that. He said, "Look, somebody left Daddy_ - he called my daddy Daddy because they raised him. And he said somebody left my daddy some property, willed my dad some property. After that I could never find it and the lady down there, this white lady told me, "You can't go back up there." Up in the archive file, I couldn't go back up there. I said, "Why?" So Ollie told me, Ollie Giles, she's a black historian in San Marcos.

MF: Oh, right, I’ve heard her name.

MN: She told me, "Yes, you can go back up there." But they didn't want me to find that because so many have bought and sold, bought and sold, bought and sold-

MF: Oh, I see. That you might have a claim on property that right now belongs to someone else. [Yes] They can't keep you from knowing that.

MN: Well, they tried to and they did. I never could find it. I searched many history books down there. All I could find is George Champ.

MF: So George Champ-your father was named after a man-

$\mathrm{MN}$ : One of the slave owners.

MF: Right. The man who left him the property was someone who was a blood relationship to him.

MN: No.

MF: And he was named for that person, though.

MN: He was named after that person.

MF: So this is the person who supposedly_because him and his wife died without leaving any children behind, right?

MN: Yes. They didn't have no children.

MF: So he wanted to leave your father his land, but now you don't know who the land belongs to.

MN: As I researched, I saw where it went from person to person and he lost his property little by little. But when the will was made-I don't know because I could never find it.

MF: I see.

MN: And I see why they did later. That different ones was buying it off. I went to one lady that bought some of the property. She said, "You'll find it before you die, but if you find it you let me know, because I got a lot of people to sue." That's the words she left with me. "I got a lot of people to sue." So that tells you that they been selling it off. This one buy it, then they find out it's inherited property, they get rid of it. Sell it to somebody else. From their own races. So I never found out those acres, where they were. My dad did come to me in a dream one time, because I worried about it so much. He always told me, “Just let it go Mary, don't worry about 
it. Let it go." I told him before he died about it, but he was getting older then, so it didn't matter any more. Just use what you have. I was asleep one day and he came to me in my dream and he-as pretty sunshine as it is today, and I was up at the graveyard. That's where the scene took place. And he showed me behind the graveyard, he pointed east. And from the end of the graveyard, like it was a square. Okay, that north end of it he pointed east, and the same north end he pointed south. So those are the directions he showed me in my dream.

MF: So you think it's property that's actually-then that would be property owned by the developers.

MN: Yes. It would be some property. They have awarded us 1.68 acreage, but they haven't turned it loose yet because they have a lien on it. And the lawyer that won't turn the lien, won't give us the lien.

MF: We can have a conversation about this later about the developer, because I actually talked to the developer because I had to get his permission to survey his 1.6 acres to try to find any potential unmarked burials that might be associated with Antioch Cemetery. So I'll tell you about that conversation.

MN: I'm glad I mentioned that.

MF: When we're not on tape, I'll tell you about that. [Good!]

So you brought your kids out here. They missed the city, but you wanted them to partake in the history of their family, their ancestors. What did your parents pass on to you about what it was to own this land and to live on it?

MN: To take care of it, and use it, and to keep it clean. Do what we could with the portions that we have. We divided it among 11 children.

MF: Did they ever tell you to hold onto the land? Not to sell it?

$\mathrm{MN}: \quad$ Yes.

MF: They did?

MN: Yes. Hold on to your property.

MF: How do you plan on passing on your property?

MN: Paying my taxes, keeping them up. Planning on how to will, it's still a puzzle because I have five children.

MF: You have lots of kids, huh.

MN: I know. I wonder which way is the best?

MF: Are all of them living here in Buda?

MN: No, they're scattered.

MF: When you left Antioch, why did your family leave?

$\mathrm{MN}$ : Left Antioch? 
MF: In the 1950s.

MN: Oh, my daddy was a contractor, and so things were getting very scarce around here. Couldn't get work to do. I think there was a draft going at that time because we couldn't sell things, and the way it did sell-he'd go up there to sell it. He said the guy up there, Mr. Barton, he was there with his hay or something he was selling, and they went on to the white people first and wouldn't buy his. Then when they would get to him, they were out of money. So therefore it was tough for him to get things sold. He was a very successful farmer. Anything he touched grew.

MF: At some point, though, he wasn't able to sell things.

$\mathrm{MN}$ : Excuse me?

MF: At some point things weren't going as well.

MN: Yes, weren't going well. Or the growth, making money. So someone told him about Arizona, and he left and went to Arizona.

MF: Did he know anyone there?

MN: $\quad$ Not to my knowledge.

MF: You didn't know anybody there. You just picked up and moved the entire family out there?

MN: He did, yes. Yes, because my sister and I were staying and going to high school at our sister's in Austin.

MF: Which sister?

MN: It was Emily Hill.

MF: Okay, LeeDell's mother.

MN: Yes. She had a home over there and some children so we stayed over there, me and my sisters, and went to high school, Anderson High School. So when summer come, June came, then he sent for me and my sister. So then we went to Arizona and there we lived with our parents. Then I got married. I got my own home and my children. I finished high school up there. We both graduated. So he went there to make a better living for the family.

MF: Did that prove to be a good move in that sense?

MN: Very good move. Excellent move. Out there he got to working and started buying homes. He bought homes, because I was the one who had to go to the title company to take the payment. He was a very successful man. To my knowledge he's been successful all his life businesswise. He passed that on to us, how to buy. He didn't sell anything. He had about seven homes. He kept them all until my sister Winnie and I came to Texas. The reason we came back to Texas, I had a dream one night that I was moving. I was living in a Thunderbird Estate. I had a three-bedroom home, maid quarters and a top overseer, double-car garage, and a large washing room. I had a dream one night that I was moving, but I didn't know why. I had a sign up to sell it. No, I saw a sign in my dream. So when the real estate came and put a sign up, they put it right where I saw it in my dream. So there was a move for me. So that's why I'm back in Texas. 
MF: I see. Was this a good move for you and your family?

MN: Excellent, because there we were able to bring the families back together and to restore the property that my father had here, the ten and a half acres, which we weren't really aware of too much and not paying attention. So, when we came back and moved here, he began to sell some of the homes to give us money to buy a well after we moved out here. That's how we got the well. Whatever else we needed, he was able to help us get that while he was yet there in Arizona. Then my sister enlarged her home so she could bring our parents here where we could see after them. When she finally brought Dad here, my other sisters, brothers moved here step-by-step, one-by-one, I'd say. So that's why we filled up the acreage here because they came home. So when you said, "Was it a good move?" I think it was a very good move, excellent move for the family to bring them together.

MF: What do you see as Antioch's future? That is, do you see the younger generation staying here after you all are gone?

MN: I wonder about that. They are so scattered right now. They love to come. This is big country, so they can come out and play softball, holler as loud as they want to, play, have fun, ride bicycles, you know. When people started moving in-none of this was here when we came. None of this. You know, like all of these houses over here? That house right there on the corner, it wasn't there. Only house that was there was the Moores'. That's the one down the street where you see a white house way back. They were the only one here. And we got electric. God's been so good to us. Everything we attempt to do in getting electricity, getting the well, we got it. People been waiting for years they say they have never got-waiting on people to help them. I mean the company. When we got here, everything just fell in line. They gave us everything we needed and wanted. They said, "How'd you all get it so fast?" Prayer and supplication. We prayed, our parents were praying, family, you know. So their prayers helped us. And we came with a hard heart to help ourselves and our family and the community. Whichever way we could help in the community we would just love to do that. So I think it was a great move.

MF: Right. But you're not sure if the young folks will because they are so scattered away. I mean, whether they will come back here to continue the tradition of maintaining this land, living on this land, and taking care of it.

MN: I wonder about that. It is a very good question. I'll be watching my children as they grow, as they come around, what they show interest in, and at this point I don't think I got a one would be interested. Because when I was here, I had a garden. I'm trying to get a garden going, ants just run us out of here. I forgot about the ashes to put in there.

MF: To get rid of the ants?

MN: Those ants tore us up.

MF: The fire ants?

MN: Fire ants. I worked at the school, supervisor at the school at Martin Junior High, I was talking to the principal one day. And so he was talking about how he went out to the garden. That's the principal. He had a large garden. He used to work at night. I said, "How do you work out there with all these ants so bad? The ants run us clean out of our garden." He said, "I use grits."

MF: Grits? 
MN: I said, "Grits?!" I was like you. "Yes, because if they eat grits they'll swell up and die." Then I lost all that opportunity I could have a garden growing.

MF: Grits don't cost anything, either. [Laughter]

$\mathrm{MN}$ : No.

MF: And they're safe for your garden, right? It's not like putting pesticide or something out there.

MN: Yes. Unless I use washing powder. Another Spanish lady, he was a Spanish guy. Another Spanish lady told me about ants in the home or wherever to use Tide washing powder. So I took that one day. You know how they make mounds in the summer time? I took that and spread it all around that mound. When I went to work, I come back and I took a stick and stirred it up. No ants. So, it's good to talk to older people, talk conversations, you learn things.

MF: You always learn something new.

MN: You learn something new. Like this white lady at the-I hate to talk call racist people, but this is what told me. I was sitting in the audience, not the audience, but the waiting room. We were just having a conversation about different things, you know, and someone struck up something about rats. This white lady said, "You know," she got into the conversation. She said, "You know, you take steel wool, and wherever the rats are coming out at, ball it and you put it in there and they eat it and it kills them. I said, "Why?" Sharp. Those three things that people have said traditionally-

MF: Just very common sense, no mess, cheap. You don't have to bring in an exterminator.

MN: No odor. [Chuckles]

MF: No odor.

MN: It's very interesting. So those are things I also passed on.

MF: I'm putting this in my mind too. Because I garden. We don't have any fire ants yet, but-

MN: Where do you live?

MF: I live in South Austin.

MN: No fire ants?

MF: Not yet. Knock on wood.

$\mathrm{MN}$ In your landscaping?

MF: None.

MN: Well they probably put something in when they landscaped your property.

MF: We did a lot of the landscaping and taking care of it.

MN: You did? 
MF: In South Austin; we're close to the city, so you know that land has been landscaped and landscaped and dev-

MN: Developed.

MF: Exactly. Our house was built in the 1920s.

MN: The home you have.

MF: $\quad$ Mm-hmm [yes]. It was built in 1926.

MN: Older home. Solid.

MF: Yes.

MN: I find a lot of those homes are very good material and solid.

MF: It's an old home. I like old houses.

MN: That's great. I do, too.

MF: I like old neighborhoods.

MN: So do I. I like old furniture. Antique.

MF: Me, too. Exactly. [Laughter]

MN: When is your birthday? I'm a Leo.

MF: I'm a Sagittarius.

MN: A Sagittarius. It's not too far apart.

MF: No. December 12 .

MN: My husband's Sagittarius, and I'm a Leo.

MF: Sagittariuns like to get out.

MN: So do Leos. They are hard workers.

MF: Yes, that's right. That's right. I don't know. I'm trying to think-I don't think I know any other Leos right off the top of my head. Know plenty of Sags, though.

MN: Hit this family up. We're full of them.

MF: I always get along with other Sags.

MN: You don't or you do?

MF: I do. Definitely. What was I going to ask about? Oh, relationships between whites and blacks growing up here in Antioch-do you remember what that was like? 
MN: Yes, very much so. We've had-I guess every state you go in, you find different race of people, some very pleasant, some unpleasant. But that was the same we had here. To my knowledge, some pleasant and some unpleasant. But to my parents and us, we never had hardly no problem out of them. They did their thing. My daddy was a very spiritual man, and they didn't fool with him too much. If they know anything about God, they don't fool with God's children. The problem they had, maybe not speaking. I don't know too much about bad things. My dad and I had a couple of run-ins with a couple of people, but they got off his back because they know he didn't play. He wasn't that type of person. When we first came here, the minister that helped us redevelop, reconstruct, resurrect the colony was Gregory Steck. We were the first people to my knowledge that went up to the city hall and let them know our vision of the colony. He was the one that opened our eyes up that this was a postslavery colony, and how old it was, and the things that were swept under the rug. He opened all that up and went to city hall. I started to say about Harpers, our family. I saw a man that used to be the principal of the school here in Buda. When I told him who we were, he said, "If you are anywhere like your dad, you will be very successful." You know, it would be good. The last words I didn't catch. I surprised by him complimenting my dad. My dad and the Harper family weighed a good relationship evidently, I would say, a respect here in the colony. Because when people heard the Harper family, they backed us up. In other words, "You leave those folks alone."

MF: Black and white?

MN: The white did. No doubt the blacks, probably because most of the blacks moved away, you know. But I've heard a lot of compliments about the Harpers. If you're a Harper, they kind of lean towards you. That's what I'm saying. We never had no problem. If we did, we didn't know about it. If we did, we would speak our piece, then they'd go their way and we'd go ours, calmly. But we haven't had no problems.

MF: There wasn't really a whole lot of events that would have made the newspapers or anything like that that happened in Buda between whites and blacks that you remember growing up?

$\mathrm{MN}: \quad$ Oh, no.

MF: Never anything like that.

MN: I can't say never, but it haven't in my generation, to my knowledge. If it did, it was swept under the rug. Because we tried to do right and did right, and we didn't have a problem. If someone was acting a fool would come by here talking up, clowning up, some white kids come by doing something stupid, hollering out the 'n' word, we let them know, "You got some people coming through the colony using the 'n' word." You know. Other than that there shooting around here for September dove season. They come over-they always come to our rescue when we called the officials of anything of misunderstanding. We didn't have too much of that, though. Only one incident with my brother, but when you talk about my brother, you talk about me. There was a man that went in and rented house and tried to take over it like a squatter.

MF: A white man.

MN: Yes. So he had to take him to court to get him off of his property. So that's the only thing we had. My other sister is going through the same thing with her house. They gave her a house, and now she wants to take over it and don't want to move it.

MF: Someone living on this road? 
MN: Mm-hmm [yes]. My sister Ruth on down there.

MF: There's a woman living in that house?

MN: No. She was renting that house to my sister, and they had some difference. She came out and took out the air conditioning, and then she won't move that trailer. Then when my sister ordered her to move it out, she moved out, and then she won't come to that trailer. Going to sit there until she sell it. It's inconvenient to her. She can't get another one put on there with that trailer sitting there. So she had to take her to the justice of the peace in Buda to order her to move it. So I'm referring to the question that you said about having difference with white people.

MF: This was a white woman that lived down here?

MN: No, she doesn't live there, she just rented her the house.

MF: That's what I meant. She rented her the house.

MN: On her property, you see. My sister's property. All this property here over to the-

MF: Okay, so this white woman wasn't actually living there.

MN: No. She rented her the house, I said. I kind of talk??? sometimes.

MF: So the teenagers running through here yelling the 'n' word, was that when you were younger or recently.

MN: Since I've been here. I think they got rid of them. We haven't had no problem out of them.

MF: So this was in the seventies, eighties?

MN: No, it was probably around 2000. Probably around 2002 or 2001 when Reverend Steck had opened up the worms about this being a post-slavery colony that was swept under the rug, and our folk didn't know it. Until it was opened up, and he had the flag removed. You remember that?

MF: The Confederate flag?

MN: Mm-hmm [yes]. I think they-

MF: Reacting to that?

MN: To my knowledge. Other than that, we don't hear anything, see anything, haven't been bothered with anything thrown in the yard or anything like that.

MF: Did the law or whatever, or whoever was the law in Buda at the time when you were a young girl, did they ever have any reasons to come up here? Do you remember ever seeing any of them come up here for any reason? Whites coming into this area for any reason? Into Antioch Colony?

MN: My mother worked for them, and my daddy built hedge and picked cotton in the areas where they have on his own. 
MF: Right, but that would take them out of Antioch to go work for white folks. [Yes] But white folks didn't have any business coming into Antioch for any reason, did they?

MN: They always came back because my daddy always sold—-they come by to buy hay, or corn, they would come by and get syrup. They made syrup, him and his cousins. Called him Ted Kavanaugh, but Sylvester Kavanaugh, our cousin, he built a shed out there for making cane. We grew cane about where I'm living at right now. So they made syrup out of cane and they would come over and buy syrup. That's why they were in here. They'd come over telling about some work that needed to be-they would like for him to do. Things like that.

MF: Were they pretty respectful.

MN: To my knowledge. It takes them to tell you how they really treated them. When we were kids, they didn't always tell us everything.

MF: Now, how-were you taught then as a young kid to act a certain way around whites that came into the Antioch?

MN: Just mind your own business. Mind your own business, ignore them, and if they did anything they shouldn't do, report it.

MF: Is that what you were taught as a young child?

MN: Yes. Report anything to your parents. These people did this did that. To my knowledge they seem to have gotten along. What was her name, 'round that time-? Anyway, they were neighborly like. They were neighborly. Even people that didn't live in this colony, they were neighborly like. Come by my mother grew beautiful flowers, and they would go by, and they would stop and come over, and get a bouquet of flowers from my mother. You know, there's people to my knowledge, they mind their own business, and my family, my mother rather, and my older sister worked for some of them in their homes. So they knew. The people, nice people, they mind their own business. At work they help themselves.

MF: But it sounds like people pretty much kept to themselves. You interacted when you had to, and that was mainly work-related.

MN: Mainly work-related, because in those days we didn't go to their church and they didn't come to our church. That was the secret to that. We went to school. And we went to a black school. No one had to bother with those other races of people.

MF: Do you think growing up in Antioch since this was an all-black community made it easier? You were sheltered maybe more from racism than in Austin?

MN: Yes. I was so glad to get back to Buda. When I go over to Austin, especially when on the east side where a lot of blacks were, the kids would seem to be very rude, they were fighting all the time. I didn't like over in Austin at all. I was glad to have a peace of mind and get back to Buda.

MF: Do you think-well, in Austin, too, there were more spaces where blacks and whites actually had to interact because they had shops there and things like that. Did you notice that racism was worse there for blacks than here in Buda?

MN: I heard about it being so. It was bad. Wasn't too many blacks out here. They had moved over or whatever. A lot of them-I heard over the years, a lot of them had problems with other 
races of people, but this is why they left. This is why they left here and went to Austin. To go to school, it was about the only high school.

MF: $\quad$ Left here in Antioch?

$\mathrm{MN}: \quad$ Yes.

MF: $\quad$ So you think some people did have problems with whites? [Yes.] But to your knowledge, you and your family for the most part-

MN: No, because we left here.

MF: In the fifties.

MN: Mm-hmm [yes].

MF: $\quad$ So you're talking about people who stayed past the fifties.

MN: Past then and before that, too. Like I said, I don't know about other people lives except when they're talking in conversations. You hear how they were treated by this person or that person. Most people around here worked in Buda. Especially farmers bailing hay. They worked for the people, and this person would send you to the next field to their friend to help them with their crop, bailing hay, chopping cotton, picking cotton. So they kind of communicated like that.

MF: I'll ask a few more questions. How about we go for about another five minutes?

MN: At your pleasure.

MF: What is it about knowing your history that you feel is most important to you?

MN: Most important?

MF: Is there anything about the past?

MN: Having parents, having strict parents. [Laughs] They were strict. I had a good life. I had a good life. Important thing really was learning to do the tradition that the family had, like milking cows and slopping hogs. Oh, I didn't like that. And learn how to shuck corn. Do the things of a farm, you know. Churning that milk, I hated that. Ice cream, I didn't hate it but, you know, it was a lot of work and you had to stick right with it. Fixing, turning for ice cream on birthdays and Sundays, you know. They had the ice creamer you used to have to turn by hand. You ever heard of that one?

MF: Yeah, and they had rock salt in there, too.

MN: Rock salt. You had to sit on it to keep it from turning. You had to turn, turn, turn until it made. The same thing about butter. I had to do a lot of churning for butter. Someone fool around and broke the top on the churn. You couldn't do it because it would slice you up. So they had these tin buckets where they used to sell syrup in, and another wash them out and clean them up. If we had more milk to churn than we had a churn, she'd put it in that bucket and we had to shake, shake, shake until it made. That was so difficult to me because I didn't know how it was going to make it in a bucket. So she said, "You'll hear the sound." I think I was five or six. "You'll hear the sound of the shaking and you'll know that the butter has made." You open that top, look in and you'll see that yellow butter on top of the milk. So there 
were a lot of exciting things that I learned coming up. And most of my happiness in life was really learning things in the country. I didn't know how well and how good it was. Because it was all I knew. That was happiness to have a solid foundation. Learning to do something that's worthwhile and be more meaningful and you can use it in the future.

MF: Things that you can do for yourself.

MN: For yourself and for your family, teach them how to help themselves, because they don't have anything like that anymore to an extent. But the main thing is learn how to take care of your home. How to manage, how to cook, and how to buy groceries.

MF: Now, I notice you have chickens out there.

MN: Those belong to my nephew.

MF: Which nephew?

MN: I think Robert. The one next door. He loves all those kind of things. The strangest thing, speaking of chicken, happened in-When you come up in a country home, they teach you how to observe and listen and think and hear distress, you know, or hear something. So about a week ago, maybe a month ago, or maybe it was here lately, the rooster crows all the time. I don't know why they love to come over here to this porch, unless my husband eats and throws stuff out there, I don't know what, but they're always over here on the porch. This chicken had four chickens, and the rooster comes up on the porch, hollering, my husband wasn't thinking and he run him away. He turn around and come right back crowing. I said, "Dear, something's wrong." I said come to the window, he looked out. "Something's wrong. This rooster's trying to tell you something." I could hear the mother under the house here, and it was something had caught one of her chickens. He was trying to tell us that, which I finally got together, because actually he only had three. I said something had caught one of his chickens and he was trying to tell us to come to his rescue. That was very strange, but it's true. You have to watch animals, you know, they will tell you something. I hated so bad I couldn't find it. I looked. I came out on the porch and I looked, because I knew what was happening. But around the side of my house, it's all closed in. So I thought maybe there was a peek hole, maybe one of the chickens got in and couldn't get out. But I looked at the peek hole and I didn't see it. So for the life of me, I don't know what happened to that chicken. But speaking of the chicken, that rooster was trying to tell me that. That was interesting. I would love for them to learn a lot of our history, but we had a family reunion not too long ago. We've been having them since '79. We asked the mayor of Buda to come over, and he did. He gave us a clamation. What do you call it for a family reunion history? Nineteenth of June.

MF: He gave like a-for nineteenth of June, for Juneteenth?

$\mathrm{MN}$ : Yes.

MF: He gave some sort of a proclamation-

MN: Proclamation, but it was for the family reunion.

MF: Did he read the Emancipation Proclamation then?

MN: He talked on it. He might have read it, but he talked to so many of them. Like we had over 300 people here. So it was kind of a distant way. But he was telling the young folks. I remember him telling them, "You young folks need to learn your history. We have a very 
beautiful, a rich history." He said, "And you need to learn of your history and help in your history." We had people from all over, and all they wanted to do was eat.

MF: How do you think history helps young people?

MN: To appreciate. To know where their ties lay. To help them to grow. Having a family reunion is one way of not marrying or dating your relatives. [Laughter]

MF: Is that important, too?

MN: Very. To me it is. Because in the Bible, they had no choice. But that is one of the main things.

MF: I guess that would be a problem around here if everybody is so closely related.

MN: Some are related, but they've all moved away. Majority. But you go out there and you meet someone you don't know.

MF: The next thing you know, you find out it's your first cousin, right?

MN: Yeah. Second cousin, third. My daughter brought home a young man one evening and introduced him. I kept looking at him, and I said, "Your face sure looks familiar like somebody I really know." I said, "What's your last name?" He told me, and I said, "I'm sorry, but you're my daughter's cousin.” I won't say which one it was, but that's why I'm answering your question in a big way. [Laughter] So I said you'll learn. Then my sister went and she went to a funeral and you know how you go to the house and there are a million people? When she walked in this lady was sitting there looking just like her, and when she said, "Baby, you look so familiar." And other people were telling her she sure does favor you. So she asked her what was her name. The guy she was dating. She said, "This is your cousin." [Laughter] So I'm answering your question real big, so you remember this as you bring your children up.

MF: I will. I'll make sure to give them pictures of everybody. This is off limits.

MN: And let them know. The ones you know. You'll know who all strayed away from the pillar or post, but let them know this is part of your genes, your history. I'm going to shut up.

MF: I was hoping next time that I come out to talk to you that you can maybe show me some old photos or some heirlooms that you might have that you can talk to me about.

MN: Very much so.

MF: That would be great. I'm going to go ahead and turn off the recording now.

Interviewed by: Maria Franklin

April 10, 2009 (2 of 2)

MF: This is Maria Franklin. Today is April 10, 2009. I'm interviewing for the second time Mrs. Minnie Nelson. This interview is taking place in the home of Mrs. Nelson at in Buda, Texas. This interview is part of the Oral History Program for the Ransom Williams Farmstead Project. 
Mrs. Nelson, I wanted to go ahead and start where we left off. I want to go ahead and start where we left off the last time. The questions I'm going to ask you now are about family and community. When I ask you to define family or who do you consider family, what comes to mind when you use that term?

MN: $\quad$ My parents, my sisters and brothers, then I go down to my husband, my children, my grandchildren, my great-grandchildren. That's about the size of my family. One, two, three, four generations.

MF: So when you were growing up in Antioch and it was you and your siblings, when you said family, who else did that include for you as a kid when you thought family?

MN: My sisters and brothers—my parents and my sisters and brothers.

MF: Anybody else?

MN: At that time I was conscious that's all there was.

MF: What about Ella Harper?

MN: My grandparents. I only saw two grandparents. One was my dad's mother. She was ablebodied and living in the home. My mother's mother was on a bed of affliction when I saw her, so I didn't see too much of her. Those are the only two grandparents I was able to see. The rest of them was gone on. And my aunties.

MF: Yeah, because your sister mentioned that you did family visits on Saturdays to see your aunts in Austin.

MN: Yes. My dad would go on Saturdays. Practically the only time he had to go because he worked as a farmer. He was always busy. So Saturdays normally it was, or either Sunday evening late if we wasn't having church.

MF: So it sounds like family was definitely people who were kin-related, but it was more of an extended family, right? It wasn't just your brothers, sisters and your parents. You thought of everybody as family that was kin-related.

MN: Yes. Cousins and friends, church friends.

MF: And church friends as well you include as family.

MN: Members in other words.

MF: What made them family to you?

MN: Because they would sit down and talk to my mother and dad, and whatever needed to be done, mother would tell us to do something. They said, "You heard you mom-you better go do it." You knew we were going to do it anyway because we were going to get disciplined if we didn't. If mother was busy trying to get one or two of us dressed, they would comb the girls' hair, and they used to come up, when we was kids coming up, and they would bathe us girls in a tub, number-three tub.

MF: Number-three tub—not the number twos. [Laughs] 
MN: Number threes are big ones. And I'm glad I went through those ordeals because that helps me to learn how to hygiene myself more so. That meant a lot for them to be neighborly like that. They were very neighborly. That was considered family, too, I would say.

MF: When you were growing up, who taught you the proper roles of about how to be a woman, how to be a man? Where did you learn those things, who did you learn those things from?

MN: My parents, my mother and dad. My dad was always outspoken. He'd always get on me because I was always tomboyish.

MF: Is that right?

MN: I was very tomboyish because my brothers and my nephew were always around dad. They were shooting marbles, they were climbing trees, they were slinging slingshots and making those shooters. I was always observing, and I wasn't always observing mother in the house because I got run out of the house because I always wanted to go to sleep. And the preference that I wanted to go to sleep was that my dad farmed at night. Drove the tractor.

MF: At night?

MN: Yes. It had lights on it. Down below it's called Smithville, and he would plow at night. I couldn't sleep until he'd come home in the morning as the sun come up he'd come to take care of the cows, the pigs, feed the chickens. I couldn't sleep until I heard that tractor stop. When he come up on the place and it stopped, then I'd turn over and go to sleep. And it was time to get up. Then after we had breakfast and go and do our chores, I'd go in the house and sit down by the bed and go to sleep because I couldn't get in the bed then. Once you are out of that bed, you were out unless you are sick. I would go in and sit down by the bed, and mother would have it so pretty made up. She would fix curtains to match the bedspread. It was just exciting to be in there. Clean, the window open, the air blowing, and I just wanted to get into bed and go to sleep because I hadn't slept. [Laughter] But no deal. I'd get out there and do something.

MF: $\quad$ So you wanted to play with the boys, but those were not considered appropriate things to be doing as a girl.

MN: Yes. They got a slingshot. I wanted a slingshot. They have a shooter. I wanted a shooter. I wanted everything they were playing with. Participate in it. They'd climb a tree. I wanted to climb a tree, but I was always scared.

MF: Would they let you play with them, the boys?

MN: Oh, they would try to fix me one, too. They didn't pay no attention to whether you were a girl or boy. I wanted a slingshot, they would try to fix me one.

MF: That's nice.

MN: They'd go and climb on top of a house. I wanted to climb on top of the house, too. I had a cousin that jumped off the house like he was going to fly. I told Daddy, and he said, "Oh no, don't you do such a thing. You'll fall and break an arm." They told us to stay out of those trees. "Stay out of those trees. You'll fall and break your arm." So therefore, I just enjoyed more the boys than the girls. I used to have a twin sister. My other sister was older, you see. They'd be around mama talking and learning the bees and the birds, and I'd be out there chucking like the boys are playing marbles or hooking in marbles. That's the way I was. 
MF: As you got older, though-

MN: Each cycle of time that come taught you. At a certain age, you'd learn certain things. A little older like coming to be a teenager you learn certain things.

MF: What kinds of things did you learn?

MN: You learn how to take care of your hair better because you're getting older. And you learn when your monthly periods come around to take care of yourself and during that time (mother taught us that, you know), and making sure we brushed our teeth. There was dynamite under that. Oh, he didn't want us to have no kind of candy. That was hard because our mother cooked cakes and pies and things. We see other kids going around with candy, we wanted it. Especially I was like that. He would buy us Colgate toothpaste. Today we still have that toothpaste and toothbrush for us to brush our teeth. They taught us the step-bystep things you learn when you first get teeth and learn how to brush your teeth and bathe and wash your hair. Especially on Saturdays you had to get your hair done up for Sunday. Because on Sunday Daddy didn't want nothing done except warming up food. Mother had to cook on Saturdays. On Sunday the food would be prepared. You just warm up what you warm up and you're there because you had 3:00 service to go back to. Sunday school, 11:00 service, 3:00 service and next I know we're having a 6:00 service. We had time to do nothing except go to church, sit still and be quiet and learn.

MF: So when you were a teenager, were there more expectations for you to not be a tomboy and to do things lady-like?

MN: Yes.

MF: What kinds of lectures did you get about that from your mother?

MN: My dad. I was such a tomboy he would tell me, "Go in and talk to your mother about this," or "Go tell your mother about that," because he would be watching, and I wasn't being a young girl, I was trying to play with the boys. "No, you go in the house."

MF: $\quad$ Oh, he would stop you from doing it.

MN: Yes. If they climbed the fence, I wanted to climb the fence. "Things you just don't do, Mary." One time he told me, "Mary, you're too pretty a girl to be so tomboyish." [Laughter] I didn't even know what that meant. And right today my sister and them tease me. Especially my twin, you know, she was always alert, and I was always sickly like. They had so much meat, and to see the blood running out of the meat, that turned my appetite. Especially when they'd kill hogs. Whatever they killed, I didn't like for them to kill chickens. They used to go out there and catch one of those chickens out of that kitchen, and mama would wring the neck. Oh, I just felt so bad and sick while they're killing this chicken. I hardly wanted to eat the meat, you know. So, I was a very delicate child. I didn't have a good appetite.

And so my twin sister, she always had a brain for both of us, Moyer. When Daddy bought an iron and it come dysfunction, he would fix it, get the electrical cord and fix the iron. He taught my sister how to do that. She was more alert somehow than I was of learning things, skills. Like in math, she beat me in math. I beat her in reading, I beat her in writing. But she would beat me in math. She was good in reading, too, but I was more fast, alert in learning spelling and reading than she were, but she learned. But she did more hands-on, hands-on. When we got the vehicles and driving the vehicles, Daddy would tell us things to do. I think because of my being sickly like she caught on faster. When the car would stop because of the gas line, he showed her how to take it loose, let that gas run out and plug it back in. $\mathrm{He}$ 
showed me when a car wouldn't start to check your-what do you call those things? I forget what it is. But anyway, he'd go out there and check it because sometimes it would come loose. Anyway, I would do that and the car would start. I started driving when I was eleven years old.

MF: Was that—now that was not typical. Did your father-it's clear he thought you were tomboyish and that boys and girls were supposed to play different kinds of things, but he also showed you how to fix stuff and he let you drive.

$\mathrm{MN}$ : Yes.

MF: Was it because he just kind of felt like everybody in the house should have some practical skills? Why do you think he allowed you to do that, even though you were a girl?

MN: Well, we all wanted to learn how to drive. Typical kids, you know, their parents drive. Your dad rather.

MF: Your mom didn’t drive.

MN: No, my mother didn't drive. You get a certain age and stage, you want to do certain things. He knew that mother needed to go to the store when he couldn't be there to take her to the store shopping. If the next in line was old enough and mature enough, he let you drive. Teach you how to drive, how to stay on the right side of the road, how to stop-just main courses in learning how to drive. How to look to see if anything's coming. Knowing how to stop. Start and stop. I got the main job of learning how to drive, more so. My sister, she wouldn't do it to an extent, so that made me have to be the one to drive.

MF: When you became a teenager then and you had to drive, did you get the car to go different places?

MN: No way. I got the car to go where I was supposed to go. To the grocery store, take mother to town and come back. A few relatives we went around town just to see. Like go over to her sister's, over to a friends of hers. She knows someone was sick, we'd drive over there. As far as this, "Oh, I'm going over to my girlfriend's in the car. We're going to a movie," no way.

MF: They didn't want you out with your friends on your own?

MN: We went on our own, but with dating times. We went on our own like that, but as far as going to pick up my girlfriend and say, "Let's go out," or "Let's go shopping."

MF: $\quad$ Forget it.

MN: Forget it.

MF: Did they think you were going to get into trouble?

MN: Parents just didn't do those things in those days. My girlfriend to my knowledge they didn't have friends come over. You know, a girlfriend come over and say, "Let's go this, let's go do that." You stayed to yourself and your family category. Maybe church or socials.

MF: What about the boys, though? Were they allowed to go out with their friends to town and do things?

MN: Yes. The boys always had number one. 
MF: Okay, so it was different. The girls couldn't do that, but the boys could.

MN: Yes, if they had a way, they would go. They would catch a ride. The main thing is my daddy would take us to town. Sixth Street was the main point. We went down on Sixth Street and you'd walk around and see things, shopping, get some hamburgers, go to a movie. At a certain time through his route, like hauling up rick wood and cream and milk to the customers, and butter, so while he was making those rounds, we were able to go to the movies down on Sixth Street, the Ritz Theatre, and they had a Harlem Theatre. We went to the movies, but at a certain time he'd be back, we had to be standing on that corner so we could catch that ride back home. We lived out in the country, and this was in Austin. So, it was a nice social life.

MF: Who were your best friends growing up?

MN: They're still around out here on The Prair[ie]—we called it The Prair[ie] at that time. Out here east of Buda they went to school, they came over here and went to school. So they were out of school. Main thing they went to high school at Anderson High. I saw them, but everybody's went back home. Home. We didn't go playing around getting in cars. If we got in cars, it was with boyfriends or something, but it wasn't with our girlfriends. Our girls-we weren't that close like that. You know what I mean. Close with playing sports and activities or dinners.

MF: Like the boys were, you mean?

MN: Huh?

MF: You mean you weren't close to your friends?

MN: I mean like kids are today. I come by and pick you up, and we go to this party. Nuh-huh. No, we didn't do that. We'd see them here and there. We'd see them downtown. And they didn't come to town too much. Those days we mostly entertained ourselves at home.

MF: How old were you when you were allowed to start dating?

MN: Fourteen.

MF: Fourteen. That's pretty early, though. So what did a date consist of?

MN: Going to the movies.

MF: Did you have to be chaperoned by a sister or brother or anything like that?

MN: No, just me and my sister. One time we had a brother that had to chaperone us. I guess we pitched enough of a fit about it when we got old enough we didn't have to. The boys were, somehow they found us in the country. They asked our brothers, I guess. But they would come out and ask our parents for our company, and that's how we went to town to movies when we were with our boyfriends.

MF: What did your mom tell you about dating or boys or what to be careful about?

MN: Yes, she sure did. She said make sure when you're on your period-you make sure four or five days before you try having relationships clean yourself good before you have a relationship. She didn't say go out and have it. She just said make sure you take these steps, precautions.

MF: Against getting pregnant? 
$\mathrm{MN}: \quad$ Yes.

MF: $\quad$ So she didn't tell you not to.

MN: Typical. She told us we had to take care of ourselves so you won't just go out and get pregnant. That paid off.

MF: Was that different from what your father told you?

MN: He always sent us to mother. Things of women's nature he would send us to mother to talk to the girls.

MF: But your mom didn't tell you not to have sex. She just said-

MN: Yes, they were saying don't go having no sex, but you know teenage kids. They're going to do what they want to do when they get behind their parents backs to an extent. So they would tell us don't be going out and doing this kind of thing. But if you do those kinds of things, make sure you have this and that so you won't become pregnant.

MF: Wow. That's pretty enlightened for back then. Don't you think? The kind of advice your mom gave you was pretty progressive, I think. For back then instead of keeping you in ignorance, she actually tried to tell you and educate you.

MN: She'd educate you all right, but I was the shy kind. I didn't want to hear all that. [Laughter] I wanted to go out there and ride a horse. [Laughter] Ride the horses, climb the trees.

MF: So you weren't interested in getting pregnant anyway.

MN: No. I was running around with my brother and cousin. I sure wasn't getting pregnant, having no relationship. So I wasn't worried about that. But as I grew older, and teenager girls end up talking and different things, you learn girlish things. Some things your parents don't tell you. Brothers used to have books they'd be looking at, and they wouldn't let you see it. Wasn't old enough. You learn things as you grow older.

MF: How many kids do you have of your own?

MN: Five.

MF: I know you've got boys and girls.

MN: Two boys and three girls.

MF: Were there things that you told your kids growing up that you remember your parents telling you?

MN: Yes. I read in a book one time or magazine where this lady said she told her children to tell her anything. Ask her any questions. [Interruption; paused tape.]

MF: You were talking about the kinds of things you would teach your own kids that your parents taught you.

MN: Yes. I would tell my boys. It was difficult for me raising boys and telling them what to do. How to do it because my learning was from my mother, and the things my dad would tell my boys and my brothers I wouldn't know. I always told them if you have a question or anything, 
feel free to come to mama and ask her. One day my oldest son asked me about something. He tells me about what this lady had said. When he got to talking, I said, "Don't ask me ask your daddy." He looked at me and frowned. I said, "Come and ask me anything," but when it come down to that, I didn't know. I didn't know what to tell him. I said, "Go ask your daddy."

MF: I guess he didn't want to do that.

MN: No. He thought he'd do just like I said, "You can come and ask me anything." But I wasn't thinking when I said anything. It should be I should be more knowledgeable to tell them about girls and how to handle themselves more so.

MF: Well you probably know a whole lot about that, too, though.

$\mathrm{MN}$ : Now.

MF: From a different perspective, anyway. What about your daughters? What kind of things did you tell them about-?

MN: Same thing my mother told me about keep yourself clean at all times. My mother said, "Make sure you wash all four of your hairs." I said, "Oh Lord, I only have one head. What is she talking about?"

MF: Oh, I remember this. I think we talked about this before. [Laughter]

MN: Did we? I was so shy. I was some kind of child. I didn't care about cooking. All I cared about was reading and playing, spelling. But when it come down to standing up and cooking, one thing steered me from cooking because in those days you did not waste food with my parents. And my sister would. She would try it. She would do the opposite. They would tell her not to do it, and she'd do it.

MF: Which sister was this?

MN: Ms. Morgan, my twin. I was always afraid. When they said don't do something, you ain't going to catch me trying to do it more than one time. If I did it around my sister and brother were doing it or something I'd do the same thing they do. Nuh-huh. I'd rather get me a book or sit down. I didn't want my bottom whipped, because my dad didn't play. My mom and daddy, they'd put it on you so you wouldn't forget. So therefore, to make a long story short, I only told the children what I understood and I knew: how to take care of themselves, and keeping their bodies clean, and their teeth, dressing nicely, and taking care of themselves when their monthly time come around. Evidently they must have heard me, because they didn't have any children until they were grown. So anyway, a lot of time you answered them the more you know, because it got to where they started teaching them things in school. That helped them a lot, and the less I had to tell. The less I knew, anyway.

MF: Were you thankful for that?

MN: As long as it's right. Long as it's right.

MF: Do you think women had it harder in this community, in Antioch, growing up than men?

$\mathrm{MN}$ : No, the men.

MF: You think the men did? How so? 
MN: Yes, men. I think they had it hardest. They would yield to women more than they'd yield to men, which they should yield to men because they are providing to the family, you know. To my knowledge, the men in this community did not play. They did not take it lightly when they would make mockery of you. The men didn't play-none of them.

MF: You talked a little about the kinds of games you played as a child. You said you wanted to do whatever your brothers were doing. But do you remember the kinds of toys people had? Other kinds of toys besides sling shots and marbles. What kinds of things kids did back then?

MN: Bicycles. My daddy bought my oldest brother a bicycle.

MF: What was his name? Your oldest brother?

MN: $\quad$ Not my oldest, my second oldest, Joshua. They always got away with things to me. They would have bicycles and they would let them drive the car, drive the tractor. That was always-I wanted to do the same thing, you know, but they would always get first choice.

MF: The boys did.

MN: Yes. He was older than I was anyways. But his brother under me, he would get to do things with him, you know, do things. But out there in the fresh air doing things. Mother had us scrub the porch, wash the dishes, pick up clothes, help with the laundry.

MF: Did you see yourself becoming a wife and having a family and working the same way that your mother did around the house?

MN: Down the road I did. We used to get to talking as to how many children we were going to have. I would say, "I don't want two children. I want four children: two girls and two boys." This one says, "I want this many children." "I want that many children." I didn't see myself having all them children. [Laughter] Because I come up in a big family. I want to be able to take care of them and help them because mama and them took care of us very well. They knew how. What they didn't know, they learned. That thing I did. We did talk about that. And what kind of husband we're going to have. What do we know about what we're going to have? [Laughter]

MF: Was it expected that you would at eighteen get married and have kids? What kinds of expectations were there for young women that came from this community?

MN: Graduating from school and going to college. All I could think about was college, college.

MF: Did your parents tell you about that or was it something-?

MN: Yes. Going to college and all. But they said we don't have no money to send you. You have to go through a different program or activity to go to college. But when I graduated, I couldn't go to college because I needed money. I didn't have the tuition, and they didn't have that. So I was just content. I just went out and worked. Not having very much skills except going to school-what I learned in school was more history and physics. So that wouldn't put you out there on the type of job you wanted. But they also had openings for nursing. I started feeling nursing. I was always afraid of sick people anyway, and didn't like being around older people. So this guy started talking to me about nursing, he made it real harsh for me. You either got to want something or you don't want it. So this white guy was telling me about how hard it was, and he was talking loud, saying, "You have to do this and learn to do that and blah, blah." I said forget it. I always read a story about Florence Nightingale, and it always inspired me to want to be a nurse because how she took care of people and how she sat with 
them. And I always wanted to do that. Coming up? No. Old folks, late at night, there are slop jars, you had to go clean it up, throw it out, make up their beds. It wasn't my cup of tea. My mother did it. My dad was there and sister. But that just wasn't my cup of tea. But, as I came through life, and I realized when I went to Travis State School working, I worked as a custodian. Then I moved up from a custodian.

MF: At what school? I'm sorry.

MN: Travis State School. They had a school out there for the mentally and retarded children.

MF: This is in Austin?

MN: Mm-hmm [yes]. East of Austin. When I went out there, and come here in '76, and I got a job in '77 working there, and I moved up to a supervisor. I had to go to school for two years at the Austin Community College for business management, and I did that, and I was supervising there for eight years in the Housekeeping Department.

MF: In what?

MN: Housekeeping Department. That was a great challenge for me, teaching all kinds. They gave you so many employees to teach. You know, grownups. Had a few teenagers, but I don't think I had many teenagers. Most of them were middle-aged in their twenties and thirties. Then in the colleges they had these mentally children that was teaching them how to go out in the community and work in certain programs, so we helped teach them different things: how to clean, how to take care of themselves and cooking, and their floors and things like that. Then I stayed until they started downsizing. When they started downsizing, they had a lot of free programs that you could go to. They had one in computer, they had one in nursing, and they had one in drug and-what do you call it? Dependency counseling and drugs. I took up that. I took up all three of them at different times. I didn't pursue but one, and that was the nursing. A field that I never thought I'd be in.

MF: Especially when you said you were afraid of blood when you were a kid and didn't like to see the hogs getting slaughtered.

MN: Blood and people aching and their paining, and I'm feeling so sorry and I can't help them. That just blew my mind. Oh no, you know. But after I started working with it, working with older people, you see where they have come, where they're reaping what they sown, whether their body is in the condition they are in. You can't help them, but pray for them. So I took up that field. I passed a course, and then I got in a job working for the companies, different companies. And, I started liking it. Helping the elders. The one day I walked in there and I addressed myself as Minnie, I said, "I'm one of your CNAs, and I've come to help you. What can I help you with?" She looked at me and she said, "Pray for me." I made that prayer for her. I asked God to give her strength and courage to help her overcome her problem that she was having. Ease her aches and pains. And she said, "That helped me more than anything." Then I'd go and see others. There was this Spanish lady said, "Oh, I knew you were coming." I had just introduced myself. "I knew you were coming." I said, "Now, how she know I'm coming?" They didn't tell her I was to help. "I knew you were coming because I needed help. I knew that you'd be here to help me." They encouraged me.

MF: That's great.

$\mathrm{MN}$ : If I could help somebody else, then my living shall not be in vain. That's why I just went on and do sometimes. "I don't want you to touch me. I don't want you to help me." "Fine with me," I said kindly, and I'd walk away. I'd tell the instructor or the nurse that she don't want 
any help. Then she says, "Well, you go help this person." You find all kinds in the hospital taking out their anger, their pains on whoever comes around. I understood why. We all got to go through something down that road. Sooner or later. It might be in a hospital, it might be in a home-no telling where it will be. But we have to reap what we sow, and a lot of things we have to sow, we cause ourselves to be in this predicament. We won't take care of our bodies. Eating proper. Resting proper. Exercising proper. Unless they exercise-they mean that although I don't follow it like I'd like to, but that's to keep the blood circulating, keep your bowel system opened up. You know? It really helps your body a lot to exercise.

MF: How long have you been nursing, then? When did you start nursing?

MN: I started part time when I was in Travis State School. I finished up back in '93.

MF: You mean you retired from it?

MN: Yeah, I retired.

MF: In '93?

MN: Mm-hmm [yes]. Then I went to a school, Martin Junior High, here in Austin down by the river. I went over there and worked for a couple of years. Then I went on and retired from them. So after I went and retired from them, then I started looking up different agencies to work for. So that's where I continued to work here.

MF: Where you just have to see a few patients every week or something like that?

MN: Yes. Until I got this last practicum here, and they send me for a loop. They kept me working nineteen out of the twenty-four hours. Every time they would call, I would call my husband, "Well, how you doing? Doing all right?" I know he couldn't take care of things. He used to wash and do everything until he got his leg amputated. I said, "I won't be home tonight." Sometimes I went to work and I'd tell him, "Well, somebody didn't show up," so he wouldn't think that I just staying over. That I didn't stay over to make the money to help us. It paid off. It paid off good.

MF: Because you had five kids to raise, too, right?

MN: No. They all raised themselves, but—this is here lately.

MF: Oh, lately. Recently. I'm sorry.

MN: Yes. It was here. You asked me how long I worked. I worked from-since I got into the program as a CNA, which is a certified nurse's assistant. I used to work in the hospitals. They were the agency that kept me in the hospital all the time. Working in there taking vital signs. That's all I did: took vital signs. Seventeen people. When that was over with, I'd go and do little odds and ends. I would work with the nurses when they would take care of the tubes in people's stomachs and different other things, the amount they're breathing. Just whatever else they needed me to do to assist. That's what I am, an assistant. From that point of view, speaking of how long I worked, that was from like 1995 to now, to 2008. I haven't worked since I had the accident in August. So, that's how I got in that field.

MF: How'd you meet our husband?

MN: At one of those Carver Theaters. 
MF: One of those what?

MN: Carver Theater back in-I was about fourteen or fifteen, I think.

MF: Were you fifteen when you met Mr. Nelson?

MN: Sixteen going on seventeen, I think it was.

MF: Wow.

MN: I had dated another guy before I met him. Then I met him. One day I was in a movie and I had my niece with me. They had these love seats. I don't know if you remember they used to have love seats in the theater-they called them love seats. It's a bigger seat, wide enough for two people. I had my niece, and one day this guy come up and wanted to sit down with me and my niece. I looked at him, and so I just kind of scooted over and put my niece in my lap. He introduced himself, and I don't know how he knew who I was in this theater. I don't know how he knew my name, but he did. And so that's how I met him, in the theater.

MF: $\quad$ So you started dating after that?

MN: A couple of times later. Because I already had a guy I was dating, and then one day he didn't show up or something, and so I started dating him. He knew the guy, and the guy knew him.

MF: That must have been interesting!

MN: That was some kind of challenge for me, breaking up with one and going out with the other.

MF: Is Mr. Nelson from Austin?

MN: Yes. He was born and raised out in Del Valle, but he's mostly from Austin.

MF: When did you get married, what year?

MN: In 1959 in Arizona in the Town Chapel AME Church. That's our picture right there.

MF: Oh, I see it.

MN: My granddaughter's making that for our anniversary, our fiftieth anniversary. They got the cards and the paper and all that, and they created that. They took copies of the wedding-I can't show it to you because we're talking-but they took copies of my wedding picture from my sister because mine got burned up mostly. And, that's what they're doing. They're putting the picture on there from the time I got married and now for my golden anniversary that's coming up in June. They're trying to help me get ready for that. I want to go to Las Vegas for my golden anniversary.

MF: That'll be nice. I like Vegas.

MN: It's a fun place.

MF: It is fun.

MN: They've got Circus Circus. I've never been to Circus Circus.

MF: That's been there for a long time. 
MN: I know, but I've never been there.

MF: $\quad$ Circus Circus is fun.

MN: I just want to play golf and in a hotel mess around with a machine. But I've never been to the Circus Circus.

MF: It's not the most exciting place out of all the new casinos, anyway.

MN: Oh, really?

MF: I don't think so. It's got—it's very family-oriented. They got a lot of things for small kids.

MN: That's the key. I asked her-after they told me that, I said, "Well that's key. That the children are going to enjoy themselves."

MF: $\quad$ Oh, so you're going to bring your kids with you?

MN: They're going to bring their kids with them.

MF: Oh, well okay. Well, then, yeah. If you want to bring small kids, that's a good place to take them to, definitely.

Let me ask you. You said you were delivered by Mrs. Revada the midwife, right?

MN: Midwife, yes.

MF: Who named you?

MN: My mom and my dad. Mother said she named us Minnie and Winnie after two little pigs.

MF: After two little pigs?

MN: That's what she said. And my dad named us Mary and Martha, but the mistake was, on our birth certificate the man didn't put Mary and Martha on there. And here in the Bible he recorded all the information from death and birth, so he had Minnie and Mary Harper. He had Martha's as Winnie Martha Harper. So our birth record's in the Bible, but our birth certificate had Minnie and Winnie. When we went to high school they only went by our first name because they had to have our birth certificate. That's how we got named. And so help us, we are just like Mary and Martha in the Bible. Just like them. Winnie's cooking and always asking me to come in and help. Mary's always got a book, or if someone comes around talking about the spiritual, I'm sitting at their feet listening. I couldn't help myself.

MF: Who taught you how—how old were you when you had your first kid?

MN: I was going on twenty-two. I got married in '59, and my oldest daughter was born on our wedding day-Our anniversary day. On our anniversary.

MF: And who taught you how to take care of that child?

MN: Oh, different ones. I've always been so spoiled all my life. Not knowing that, but people caring, especially my twin sister. She was there for me during my whole pregnancy.

MF: But she didn't know how to take care of kids, either. 
MN: I should say so. I had all those brothers to take care of who was coming up like nephews, playing, packing around on our shoulders-

MF: Okay, so you had some experience.

MN: Yes. And my sister had children that we helped her with. Especially when it come down to cleaning them up, you know, changing their diapers or giving them the bottle.

MF: Was your mother around?

MN: Oh, my mother just passed in-

MF: I mean to help you with the kids when you had your own kids.

MN: My own children? Yes. My mother, my father, my sisters. For me being quiet and not outgoing, wasn't very much. They're just excited, twins. They helped me a lot. They helped me with my wedding. Then I had my first child. My husband had gotten us an apartment when we got married. Then when I had my first child, we got a home. Got us a home, and we had our first child in the home. So we've had a good marriage so far. Up and down, but my father taught me, and my mother, stick with your husband. If it was left up to me, probably nobody would know where is my last track. [Laughter] Over the years, difficulties. And then a lot of the different problems I had I would tell my parents, you know, say some girlfriend we often talk about different things, you know. But my daddy always told me, "Stick with your husband." Because of my parents, a lot of times I took a lot of things most women wouldn't take. My dad's always been a man, man on top of men. You know, strong spiritually. He went forward in front of his wife, prepare, provide. I thought my husband was supposed to have been like that. I'd always tell him, but he wouldn't tell me. He didn't know. He didn't want me to know he didn't know. So one day I was telling Daddy and fussing about, "My husband didn't do this and didn't do that." He looked at me, and he said, "Mary, there are boys that don't know." Oh, that just cooked milk. That just cooked my cookie. I said, "What?" "There are boys that just don't know. They haven't had the experience to do the things that you see I do all the time." He didn't have no car. He didn't have no parents. I didn't think of it that way. I thought if he was a man, he was supposed to know. It didn't work that way. So I guess a lot of times I probably drove him away telling him, "Do this, do that." He didn't even want to tell me, because he figured I'd have a fit because he didn't know. I was always the aggressive person. I can't help it. My parents, my mother worked all her life. My daddy worked and did things that provided. They looked down from season to season. They looked out farther. So that's just the way I was. Summer's coming-we have to do this. Winter time is coming-we have to do this for the winter. He didn't have a mother since, I don't know, he was ten or fifteen. Not fifteen; eight or nine years old. I don't know when his mother passed. He was just about twelve, maybe eleven or twelve years old or something like that when his mother passed. And his life went on. I would tell his sister the things he would do and how he would act, and I couldn't understand that, you know, like I said. I came up under two parents, and they were Christian parents. She said, "Well, Mary, he just don't know no better because he come up under two mean fathers, his father and his stepfather." Then he got tricked into going into the service. Man, his brother-in-law, friend said, "I'm going to go down and sign up for the army."

MF: Your husband served in the army?

MN: Yes. The friend didn't go down and sign up. My husband went and signed up. What a fine friend. He got called into service. So really there's a lot of things that men should know and understand, but he don't because he always cooked. He works on cars pretty good. After he 
learned to get them, he learned to work on them when we needed it, to save us some money to an extent. The small things.

But considering we're at forty-nine years, which I never thought we'd be. That was a life. And God has blessed me because I stayed as a wife. I took the good with the bad. No sins are any greater than any other. One sin ain't no greater than the other sin. So therefore you sin talking too much or eating too much so you can't tell somebody, "You're sinning, you're doing this." Look at yourself. I learned that over the years. Look at yourself. What have you did that's not right? You know, when you look at yourself long enough, you don't have time to fuss about somebody else's problem. Take care of your own. So I'm going to hold on to Jesus' unchanging hands. When things wouldn't go right, I had something that said, "Lord you helped me with this and help me with that." And, He did. Even with difficulties, problems with the marriage. I said, "God, you take over. Hold my head up and go on and do what I got to do as a woman." You know, that's what I did.

MF: How did your parents help you when you first got married? Was it expected that your husband would just take you and find you a place to live, and that he was going to take full care of you? Or did your parents try to pitch in to help you get started?

MN: No. He took care of us. He had an apartment when I got married. And when I come in with a child, he went and made arrangements to get a home. We had a home to go in. My parents didn't help me. The only thing my parents helped me with was when I was getting married. They bought me my dress and sent me out to go shopping for my dress and shoes for the wedding because we did that in church, a large church. He kept me-anything I needed for my wedding, he helped me. The people-by being members of the church, Town Chapel AME Church in Phoenix, Arizona, between Washington and Jefferson Street-they helped me with the reception. And one lady drove a Cadillac. She came to my home and picked me and took me to church, you know, for that. And another lady that worked in the kitchen, she helped with the reception. So it was real nice.

MF: When the rest of your other siblings and your brothers and sisters got married, was it kind of like, "Okay, you're on your own now?" With your families like, "Now you've got to go out and earn a living on your own and take care of your own family." That kind of thing?

MN: Yes. They expect them to do their job. You're not there with your parents-they expect you to do your job.

MF: It seems like nowadays parents help so much.

MN: Oh, it was worse nowadays.

MF: That's why I'm asking, because it seems like now your parents will help you with just about anything. There are people who still live at home who are thirty-five years old. But back then it seems like there might have been a kind of difference-

MN: They stirred the nest in those days. Only way they could help you, is if you could help yourself. [Laughter] You know, if you got laid off or something or the rent was too high and you couldn't afford it, they'd let you stay there until you get your own. When the time come and you've got enough money to get your own, you're out. Now it's worse because I hear so many people talking about how parents have to pick up the pieces. How those that can. Helping them with their children, helping them with theirselves. I was shocked one day when I heard a lady say, "I had to buy my son a new refrigerator. He just don't take care-_" Blabbing about the children not taking care of things, he and the wife. And she had to go buy him a new refrigerator. I said, "Nuh-huh. I thought black folks the only ones going around 
doing things like that. Helping one another." But I found out over the years they are in just as bad a shape. You know, the same shape. I bought some stuff from a guy who sells stuff, and I said, "Well, I like this buffet." He said, "Yeah, I was getting that for my daughter." I looked at him and the thing that I was buying, "Oh, don't give it to your children. Don't let your children have it." Said to myself that's what I'm getting it for my children. And one day, he said something to me. I said, "You know what? You told me not to let my children have this. Your daughter had one. She's married." I let him have it. I got a good job working for the government. Her son, our husband has a good job working for the state. Both of them. I said, "And they make good money." I said, "My kids don't make that much money. You're telling me not to let my kids have what I bought, like stereos or rings or furniture. You're telling me not to let my children have it, and they don't have that kind of money coming in. But you get it for your daughter, and she has everything she needs and more?" He just dropped his head. "You just don't tell me what not to give my children when I know they're in need. I don't buy just to say, "Okay, you can have this for the heck of it." I see their needs, but they don't see their needs. They just don't think like that, like I did. I was raised up as different. A different society, a surrounding, a different atmosphere you're living in. If you don't hear these wisdom and knowledge words consistently, you fade away with the wicked way of the world, and that gets you in a lot of trouble. So I let them go until they get burned. Mostly give them the long end of the rope; they break their neck. Of course you have to pick it up sometime, but they've got to learn. I was always trying to keep them from learning. You know what I mean? The hardship. If they needed money, I tried to help and give it to them. I said, "You ask people for money, you will get yourself in trouble if you don't give it back." "But with me you won't be getting in trouble except by praying God will fix you from it." He'll control you.

MF: Since you mentioned God, how important is religion to you and the church? Because you're a member of Antioch church, right?

MN: Yes. It's very important. Because I'm still on a line of trying to go straight for that narrow pathway that I have been taught. Now and then I find a trap, as my daddy used to say. But that's the way that lead us to destruction. So, I'm glad I'm in the community where my parents were raised up and my relatives that I know when I was a child coming up they were praying out loud in church, praying for their families and their children. I'm glad that I could seek the right way. Stay on that path. Praying for my family, my children, praying for help to help the community and our church building. I'm there to help pay my tithes and offerings. Take positions in the church. Help the church keep functioning in the manner it's supposed to be functioning in. Praying for my children. I have to tell you this. On last Sunday a week ago, not this past Sunday, a week ago, we needed money to get our roof on our church. They had asked this white church up there. I hate to say the racial way, but to know who I'm talking about, the white church, the Baptist church, the pastor said he's going to help us, going to give us $\$ 1,000$. So, I heard that, and it was so enlightening to me. I asked God. I said, "God, let somebody else help to add more. Because you know how roofing is, for the church. Let someone else help us to add on to what the church is giving us." So when we had our church anniversary at this church, this white man was really sweet. He preached at our church anniversary. After the church was over, I had taken up collection and everything I was looking for the $\$ 1,000$ they were going to give us. I know it was going to be an addition, right? But I had asked God for more help. And so this white couple was sitting back there, but I thought they were just coming here because the church family lets them come down when we have an anniversary, just to have it in the area there and he preaches. So when my sister, the secretary, she always figure the money and hand it to me to deposit. So when she gave me the deposit slip I looked at it, and I thought I saw $\$ 300$. But when I took a good look at it, it was $\$ 3,000$.

MF: Oh, my goodness. 
MN: Mrs. Franklin, I couldn't help but cry. I couldn't stop crying. So, I finally controlled myself, and then when it was over, they asked, "Does anyone have anything to say about the program?" A lot of people at church didn't know this. I got up to tell them, and I started crying again. I finally got my composure together, and I said, "I can't help but cry because God has heard my cry. I know I'm not the only one praying that we get a roof on our church and have the money." I said, "But when the Baptist church was giving us a donation, I asked God to double it again more." I said, "When I looked at the deposit slip, it said $\$ 3,000$ more than the $\$ 1,000$ they were going to give us." I couldn't help but cry. God heard my cry, but he didn't only hear my cry but other folks were praying the same prayer. But the prayer that I had prayed, He answered. I did always say He'd come as a twinkle in the eye, quicker than you could blink your eye. That's how the Holy Spirit will hear your cry. I've seen that come to pass so many times. So, I was just happy. I had to tell you that because He has helped us so much in so many ways, and so quick. So for all you do hold on to God enchanted hand and ask the Holy Spirit to help you because Jesus left. He said he couldn't leave until He sent us a comforter. He sent the Holy Spirit to be our comforter. That's what we should mostly call on, the Holy Spirit. When Holy Spirit would talk with God: Father, Son and the Holy Ghost. Holy Spirit is the Holy Ghost so when we call on Him I finally learned that. That's why we get our answer.

MF: It's clear-I know that we've talked about how your parents were very strong Christians and so this was passed on to you and your brothers and sisters to follow your religion and so forth?

MN: Yes. Generation. Generation after generation.

MF: So do you see that continuing with folks? Well, with your kids and the other young — the next generation of the Antioch descendants? Has that continued, do you think?

$\mathrm{MN}$ : Yes. We raised them all up in the church. They all participate as long as we have a hand on them.

MF: As long as you have a hand on them? [Laughter]

MN: As they got older, you know, they start departing different ways and different religions. I'd often tell them, I said-They came back and then they leave, and oh, I done found a complaint for this and complaint for that. It was just, "Grandma this and Grandma that." Well, they're older, and they come up strict religion, and they trying to get it through your heads. I was like their mothers and sisters. They would be telling me and be grouchy, and they would be fussy, but that's the way they came up. I'd tell them all, "You're like this aunt or that auntie," and she would cry. That's my sisters. They don't know no better. They didn't have no education. " Oh, how bad I felt after I did my complaining. So, this is what they do with my sisters here, you know, they complain about them and they fuss too much. And, "They this," and "They that." I sat there and I told them like my mother told me. They didn't get a lot of education, either. They went to the worldly life to have fun because they come up under strict discipline. So, they love you but be nice to them. The best way to whip your enemy, my daddy always say, is to be kind to them. That's what I teach them when you say telling your children about.

And they all been in church, and of course when they get husbands and boyfriends, they stray the other way, and they pick a church of their own. Our church may have been dull to them. You know how it is. Sometimes it has musicians, and sometimes it don't. I guess they want things more exciting. So every last one of them went to different churches except my second oldest girl. She was in a different church, but then she came back. Then she got married, so she's there helping out. But the other two are in two different churches. They're more like a 
holiness church. I said, "Well Lord, as long as they're serving you, that's what counts. It's not me they're serving, it's you." As we are getting older, and our eyes are getting dim and can't keep up with the Bible readings, you should be there to sit beside us to help us keep up. And sing. Help sing in the church. Our voices are getting low. You know, they aren't as strong as they used to be. I said, you kids need to be in there helping. "We coming. We are. You all get that church built." All the same kind of excuse, but they are learning something out there. They are hearing the Word. It's not the way we were taught. As long as they understand we're serving Jesus Christ. None of this cult bit. You know what I'm saying?

MF: $\quad$ Oh, right.

MN: So I leave them alone. If God sees fit for them to come here, he'll send them. That's the best feeling I ever had in my life when I turned things over to Jesus and tried not to do it myself. Not believing in me. Believing in God. Didn't realize a lot of things I was doing, there was an "I." And my daddy always said, "Mary, don't say I." They never calls us Minnie and Winnie; they calls us Mary and Martha. "Don't never say I." One time I got up in church and I was talking about a program they was going to have, and I was going to do this and I was going to do that. Well, if you going start a program, you're the one who's supposed to lead the program. That's the way I had referenced, right? And you getting help. So after church my daddy told me, "Mary, don't ever say 'I', because you will find yourself doing it by yourself." And that's what happened. "Come on, you all, help us do this." "You said you're going to do it." "I said 'I,' but that means you're going to help me!"

MF: We.

MN: Yeah. We. I missed what the single and the plural. [Laughter] I missed that part. But my daddy was very disciplined. He helped me so much more than he have an idea.

MF: Who's that who helped you?

MN: My dad.

MF: Your father, okay.

MN: Disciplining. If you sang wrong, he'd tell you, "You're off key." He'd tell you. You got to speak or say something, "You better be clear." I'm stopping up in this air.

MF: That's okay. We're going to stop here anyway.

MN: I hope I haven't detained you too long or said the correct words. I hope I answered your questions.

MF: This was perfect. 


\section{Marian Missouri (Harper) Washington}

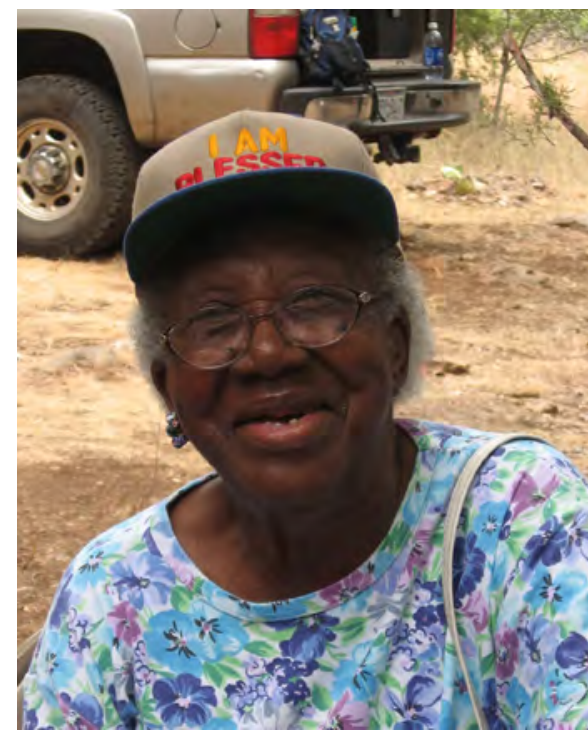

$\begin{array}{ll}\text { Birth Date } & \text { 1/18/1925 } \\ \text { Residence } & \text { Antioch Colony, Buda } \\ \text { Time Span } & \text { 1924-1946 }\end{array}$

Interviewed by: Nedra Lee (accompanied by Maria Franklin)

March 16, 2009 (1 of 2)

NL: Good morning. This is Nedra Lee. Today is March 16, 2009. I am interviewing for the first time Mrs. Marian Harper Washington. This interview is taking place in the home of Mrs. Washington in Buda, Texas. This interview is part of the Oral History Program for the Ransom Williams Farmstead Project.

So Mrs. Washington, thank you for talking to me today. We're actually going to just start our conversation off by talking about the house that you were raised in. Do you remember when it was built?

MW: The house I was raised in?

NL: Yes, ma'am.

MW: No, not exactly. I was born here in Buda, and the location where I lived. Mrs. Giberson, Mary Giberson I believe her name was, she told me that where I was born and raised, that we lived Bill Barber's place, because I told her I didn't know, because she lived there one time, I told her I didn't know who owned the property. At the time my grandma stayed on it, my great-grandma, she lived on that property, and my grandma did, too. My great-grandma lived next to 966, over that way, right on the corner of Old Black Colony Road, run into 916, they lived on the corner down there of Old Black Colony Road on that north side. I was small, but I'd go down there all the time, and my other grandma, my dad's mama, she lived on this 
property, too. And she only had one daughter, my great-grandma had one daughter, Daddy's grandma had one daughter. His mama's mama had one daughter, and her name was Ella. My grandma's name was Ella, and the one daughter that she had, my great-grandma, was named Adeline, and she had one daughter which was named Ella. Her daughter was named Ella, my dad's mama, her daughter, was named Ella, and she married the Harper. Now my great-great-grandma was married to a Greene, Oscar Greene she said was her husband. You know how kids, they ask questions and things. I said, "Grandma, who was your daddy?" just like that. She said, "Oscar Greene was my daddy." And I don't know where Oscar Greene was born or whatever, but he had a connection with the Taylor farm and the Kavanaugh farm. She come up out of the Kavanaugh farm, the Kavanaughs, they all up there, right up the road over there where we said that's where we lived a long time, when I was big enough to know when we lived up there, and they raised us right up there. That's where we had the farm and all these chickens and animals and stuff. And the place that we was on belonged to Taylor. Taylor married into the Kavanaugh family. His wife's sister was named Sally. Taylor's wife was named Sally, and she had a sister, she used to tell us she had a sister, Adeline had a sister, and the sister was in the slavery. She said she was slavery, a slavery sister. In other words, she was in the slavery. I don't know when slavery was over. When was that over? What they call, the war was over.

NL: $\quad$ On June $19^{\text {th }}$ ?

MW: That was, yeah, supposed to be freed in June the $19^{\text {th }}$. We used to celebrate that date. But I read in the papers where the President, Lincoln or whoever he was, signed that out in September. They got it mixed up with the $19^{\text {th }}$ of June. They didn't know they was free until the $19^{\text {th }}$ of the June, but he said he had signed it out sometime in September, I forget the date. But they went on the $19^{\text {th }}$ of June, that's what they went by. And the Fourth of July was, what they call it, Emancipated Day or whatever back in that time. I was small but I remember a whole lot of that there. And my daddy and his brother, a younger brother, Melvin - we called him Melvin, his name was Frances, we always called him Melvin-and he had a brother named Melvin. The youngest brother was named Danzy after his daddy. I think she had three girls: Ella, Ada, and Minnie. My mama also had sisters. She had a sister named Pinky Tennon—name was Tennon before she married-Pinky Tennon, Willie Tennon, Mary Tennon Shelby, and Maddie. They was her four sisters, I think.

NL: You mentioned the Taylor farm. How long did you live on the Taylor farm?

MW: We lived in Austin, and my dad and them, he lived here in Buda with his mother, him and his brother Finis was the last two boys that left home, two oldest boys were in the service, Art [?] and Lemuel [?], and-What did you ask me, dear? When we lived in the Taylor farm, that belonged to the Kavanaughs and the Taylors, and we lived on they farm. But when old man Taylor died, he had two sons, Ernest-we called him Ernest, but his name was Kevin-and Leeman. Them was his two sons, and he had about four girls. Those two sons run the farm after he died and everything. Then they had two sisters to die, one that taught, Nena Taylor was her name. And Nena Taylor, she had sister named-these were Mr. Taylor's children. She taught school out there on Goforth, and then she got sick and after getting sick, her sister Roberta Taylor Jackson, she was in the service. She was a-what do you call these here nurses in the service?

NL: $\quad$ A WAC?

MW: A major, a head nurse like what you call them, the name.

NL: I've never heard of that before. 
MW: You haven't? Like the doctors have certain types of nurses around? This one here was one of the head nurses like, but they called it another name. And she took her place and taught the school after that. She taught it in her place after she got sick and wasn't able to teach, so there was two teachers in that family. Three. There was one that lived in Houston. She died in Houston. Her named was Inez Roberta Taylor. I believe that's three I do know of, I do remember. And she married a lawyer and she moved to Houston. That's where her kids come up, in Houston. They were raised around here for awhile, but I mean after she got married and went to Houston, she had them all with her.

NL: Did you live in a big or a small house on the Taylor farm?

MW: On the Taylor farm, it had about three rooms, about three rooms not counting the kitchen and living room.

NL: What other rooms did it have? Did you have a living room? [Yes.] A dining room? [Yes.] Could you draw out the plans?

MW: At that time, we-well, I couldn't draw it, but I know it was like a porch, we called them garries, with a long porch on there. And my first husband was a Bunton. They had a big twostory house right up here. You used to could see it up on Old Black Colony Road up there. When I married, in the two-story house, me and my husband stayed upstairs. That was my first marriage. And then after that, I left home and got married. I was twenty-two when I married Bunton, but Bunton is really not no relationship; he just Bunton by marriage and my sisters.

NL: Now did the house on the Taylor farm that you lived in when you were young, was it two stories?

MW: No. It was just a big bungalow, something like a bungalow. Bungalow house, they called it. The house right up here on this side was a bungalow. A man had it moved from Austin by the university when they were getting rid of a lot of houses out at the university, people were buying them, like in the Army they was buying, what'd you call them, barracks. A lot of people wanted to buy barracks, and ever since I been grown and old and everything, it's bursting out here. They was selling barracks, so when I guess they rebuilt or done something, but they was selling barracks. Because my sister wrote me and told me about it, and you could get it reasonable and have it moved on your property, stuff like that. We didn't ever do that, but at that time they did do such. And then my daddy moved from his home here in Buda to Austin. And he worked for a lumberyard. Working for this lumber yard, I don't know if it's called Lawton Lumberyard at that time or not, but it belonged about then to Lawton Lumberyard. And where he worked them, and this black man owned it, and his name was Lawton. He worked there, and he got in trouble and the man fired him.

NL: What happened?

MW: Daddy did sashes, he did sashes for window. That's the work he done. Then there was a white guy. He thought it was sweet, tried to make him stop doing his work and help him do his work. He made deliveries. The things that he made and fixed, this white boy made deliveries. And he was running late I guess or something, but he tried to make my daddy stop doing his work and load his truck, his car. So they just got into it about that because he wouldn't stop and help him. So they got into a fight.

NL: Was it a fistfight? Oh, wow. 
MW: They got in a fistfight. My daddy cut him. He must have made him do that. I don't know if you want to make public something like that. Anyway, he just jumped down on him. He said he tried to run from him, keep him from fighting, and he had a shed, and he had to stoop to run under the shed. And Daddy went to duck and stoop, he caught him by his jumper and pulled him back, and that's when they turned and went to fighting. He made him do it because he tried run to keep from fighting because he know the trouble he would be in. So he ran up to the boss's house and told his wife what had happened. She made him, "Get out! Get out of here!" He was bleeding. Don't put that in there. [Laughter] But that did happen. I told Martha that one time. Somebody was interviewing, this white fellow out of Austin, a young man, and she was trying to tell him [inaudible]. Don't tell him that!

And after the fight, she made him get out. He went on home. Called his mama and went home. He said he wanted to get home before the police come to arrest him. And he said he prayed that night that he wouldn't be in jail on Sunday morning. And they came and got him before midnight. He wanted to be out of there before midnight. After midnight, it's another day. He wanted to be out of there. He said he prayed to the lord, and his mother and the two older boys come and got him out of jail. And it seemed like his prayers was answered because he didn't want to be in jail because he was a Christian man and he didn't want that against him. So I guess the lord forgive him and he got out.

NL: How long did your father stay in Austin after that fight?

MW: Oh, well, he was living in Buda going back and across.

NL: $\quad$ So he was living here in the colony?

MW: Yeah, and then he was going back and forth. Then he bought a home over there for us, and it had a dining room, bedroom, kitchen and so on. We lived on Sixteenth Street in Austin.

NL: Did you all stay there for a long time?

MW: We stayed there for quite a while, and they broke up for a while and he brought me and my brother, was the only two at that time they had, brought us to his mama out here in Buda. And we stayed there until they drove up here, until they actually got the Taylor farm and everything like that, after all of that. And we were living, like I said, with a garden and all this stuff. Meal and syrup and stuff that he learned how to do over at the Taylor place, because that's what they did, plowed the corn and stuff like that. And we had hogs, chickens, turkeys-all of that stuff.

NL: On the Taylor farm, where did you all keep all the chickens?

MW: We had chicken houses we'd keep them in.

NL: Did the hogs have a house, a little special place or a house to go to too?

MW: Yeah, like a lot for a hog, for cattle, and stuff like that.

NL: Were there any other buildings on the Taylor farm that you can remember?

MW: Well, like a shed, a building, yes.

NL: What did you keep in the shed?

MW: Cows, fenced in, you know, and a shed open for them to go under in the sun and whatnot. 
NL: Was there any electricity or plumbing inside of the home?

MW: No, no plumbing and stuff like that. We made firewood. We cut wood. It was a wooded area. We'd cut wood to make fires for the stove. And you had a fireplace at the Taylor place. They'd cut it a little long ???. When Daddy sawed up-he sawed wood and took it to town and sold it. He sawed card wood, they called it, for a fireplace. It was about like that. And the kitchen stove, he had about like that, about twelve-foot cut. And it wouldn't be as big around wood if in for the fireplace. It started off with small, but they put a log in there about like that, make it last a long time when it got burning good.

And then he, later years, we traveled back and forth south, picked cotton, and north and pick cotton-West Texas, they called it. We'd go there. Cotton was ready early in the south. We'd do it, and by the time we finished it up, we'd come this way, be in the north in West Texas. So we did that on top. They call it top, oh it'd be so cold in Caprock, way out there in West Texas. And we was on a farm they called Bob Hinesly's farm. That's who we picked for, the boss we picked for. And then he had neighbors that we helped out, too, around there, picking cotton. So we missed part of school by going picking cotton. We'd go in September and getting ready down there in of July. We'd come home after September. It was time to go to school but we went picking it the other way, West Texas. When we come back, we come back after Thanksgiving.

NL: $\quad$ So you would leave the colony, go and pick cotton in West Texas or maybe in South Texas, and then you'd pick cotton maybe for what, a month or two months?

MW: We picked up until July and September, when it got ready in the West Texas. We'd go there until November and come home for Thanksgiving and Christmas.

NL: And you would come back to your home on the Taylor farm?

MW: Uh-huh [yes]. Yeah, when we left, we'd come back there.

NL: So what type of work would you have to do when you got back to the farm?

MW: Well, we still had cattle to take care of, and the chickens and stuff, that kind of work. But that was like, your home, whatnot, but my daddy and my oldest brother worked on the Heep's farm. They fixed fence and dig holes, stuff like that. That's what they did. That's the kind of work a cattleman or a horseman, you know, would have, that kind of work. So they would dig postholes, stuff like that. So the man told Daddy, my brother worked right along with him, and he told him he did as good a job working with him and he would pay him the same as he paid my daddy, like a dollar a day or whatever at that time, a dollar a day, 50 cents. It was an hour, a dollar a day, something like that. They call it a dollar a day because you worked eight hours you got eight dollars. That was the way they paid in them days.

NL: Did your mother work as well?

MW: Yeah. She picked cotton with us. When cotton passed, she'd cook, you know, she'd go early and prepare dinner for us, go by the hour to the car, put rocks out there to make a fire to warm up some corn, and corn time coming and ? we call it. She would fix that corn in big pot and make a fire out of wood. They didn't have no Foreman Jones and all that kind of stuff, microwaves and that kind of stuff back in that day. Cook stove, they called it. And then they had a cook heater, a round potbelly heater. You ever seen one of them?

NL: No, never. 
MW: Anyway, it's sort of like a metal stove, and then it had-we got a little bitty one out there that's a keepsake. And the cook stove had four burners and it was iron. And the oven, you'd open it up and two racks in it and cook bread. And the heater pipe would go out the house and go up and go out the pipes, go up and go out the wall. You don't remember none of that?

NL: I don't remember any of that.

MW: Well I mean the fire, the kind of fire you had before we had an electric. Stuff like that. That's where the fire was, I mean the way they heated stuff. And in the cotton patch they didn't have no stove at all. They would just build something like a barbecue thing in the ground and cook on that.

NL: What kind of meals would she cook?

MW: She would cook biscuits and cornbread. Biscuits, Daddy fixed a iron cover, a tin top. He covered this big pot, this big skillet and she'd put them in that skillet and put that top on and put some coals on top of the pot, the top, and that would brown the bread. It was funny coming up in that way. It wasn't too far from slavery that we got in that shape. And we'd go fishing all the time. Whenever the weather rained so we couldn't work in the field, we'd go fishing and catch a lot of fish, all around here. That creek going there called Onion Creek, it went all the way around and went up that way. We lived back over there one while on a farm called Drake Heller's farm. And we were close to the falls, two fall. We would, when it come a bad rain, a whole big rain, that water would come down, fill up Onion Creek and run over the bridge, you know, and you couldn't go back and forth over until a certain time, until it run down. That would do that, but it's been awhile since we had that kind. But we lived by it and we could hear it over here when it got full and got to running. The little fall would run over and run into the big fall. They way about as full from here to that house on the end down there. And we used to fish up there. And we could have a good way of making a living, gardening and fishing. And like I said, he made syrup, sold syrup and sold chickens, we sold eggs and all that kind of stuff. Made the butter.

NL: Who made syrup?

MW: Well, my daddy - the man that owned the place, they made it and he learned him how. Them boys, they leased it to him. That's what they did, they leased it to him. And he worked the farm. And working on the farm, he worked like third and fourth. Some guys would work half and half, and he would work third and fourth. The boss got the third bail of hay and he got the rest, so that's the way it was, third and fourth. The owner would get the fourth. He'd get all up to the fourth, you know, like a measuring cup.

NL: $\quad$ So your father made window sashes, he picked cotton, he also-

MW: And then he was a contractor. He'd take people back and forth, haul them in a truck. Neighbors would go with us.

NL: Now can you tell me more about your mom's type of work? Did she have a garden?

MW: Yeah, we had a garden. We had a garden and she'd work in the garden. And cook food out of the garden. And then my daddy bought a, we had cows. We were big enough to milk cows, all us kids, most of us. And we would milk them. We'd slop the hogs. In wintertime they killed a hog, we had our meat, pork. Wasn't no care to eat too much pork in those days. We had hogs and cows. And they'd have them cows dressed out yelling. And the hogs, we'd kill them. And we ate everything about the hog. We did. We'd eat chitlins. You ever eat chitlins? 
MF: Oh, yeah, smelly things.

MW: Oh, we'd eat chitlins, so like I said the feet, and so they didn't even leave nothing. I had a cousin that liked the rooter.

NL: What's the rooter?

MW: Where they rooting in the dirt, on the hog.

MF: Oh the snout! I've had pig ears, pig tail, chitlins. I've never had the rooter, though.

MW: Well my cousin, he liked that rooter. My daddy liked the ears. He liked pig ears and pigtails.

MF: You'd eat the skin too, didn't you? The cracklins? The pigskin, did you eat that, too?

MW: Yeah.

NL: $\quad$ Now since there was no electricity, how'd you all store the meat?

MW: Well they cured it. They cured it. And they put it in the smokehouse, hang them sausage up and Mama make sacks and stuff them. But they had a casing, they called it, which was an entrail, you could stuff that. You could eat sausage in it. It's skin like. You could get that, too, from the skin in them. Stuff it, stuff it, you know. And that all come from the hog. Mama made them sacks, and they could breath through the flour sack, and they bought feed for the hog, what you called shorts, and they'd fill it up in a big barrel, pour water in, and it'd swell up, and they'd feed a bucket of that to the hogs. Plus food, like old bread and potatoes and stuff like that would go in with it. And then they'd feed them solid corn when they got ready to sell them, they'd fill it with solid corn so that they'd have solid, wouldn't be soft and flabby, they'd be solid. The fat would be solid like you get. They call it jowl to put in the beans when you cooking. That's sowbelly.

NL: Sowbelly?

MW: Yeah. But sometimes the little tits would still be on it. Wouldn't even buy that at the store. But they'd be salted all down. They'd be cut off, you know, it'd be smooth, but you could see where they were. The hog have lots of tits on their stomach. And they had dogs. They had some dogs was trained real good, Go Boy. They were greyhounds and he'd call them Go Boy and something else they called the girl, I forgot her name. But they were good racing dogs. And they had house dogs, I mean dogs that were watchdogs, they would bark when people come around. They had one, a brindle dog named Sunny Bank. He went over and-and dirt caved in on him. He was digging after an armadillo, they went in the hole and he was after them. So him digging and hearing him dig a tunnel or something, fell in on him and killed him, he suffocated. That was my uncle's dog, and they used to hunt all over there in the place back over there called J. Keller farm.

NL: What kind of animals would you hunt for?

MW: They'd hunt for rabbits, squirrels. Squirrels and rabbits. And when it's deer season they'd hunt for them, too. And quails, birds, doves. I don't know. They say if you cook a dove and the breast, the meat come off, it writes on there, writes something about the Lord, like-What the money say, "In God we trust"? Well, it would say something like that in its breast of this turkey, I mean this quail. And you'd boil them all the meat come off, you'd just see that fat bone. That's talk. I don't know about that. 
NL: Now did your parents ever shop for food?

MW: Shop?

NL: $\quad$ Like at a store.

MW: Yeah, they shopped. They shopped at a time when it was-what'd you call it when you couldn't get stuff? Sugar and grease, like lard and sugar and stuff like that you couldn't get enough?

MF: They were rationing things?

MW: Yeah. The food still rationed before the food stamps come out, food stamps. And they used to call it commodity, started to-well, it's still coming from the government. They were the ones that were doing this to people that wasn't able. My mother, when she couldn't read and write too well. My daddy did pretty good. He went for Sixth grade, he told us. And it was hard for keeping - stay in school. And they tore down the school, a brick school right where that sign is when you go down that hill that's talking about the church, used to be a big school there. They built a big brick school there. And they took pride in school and they wouldn't let you go no higher than the seventh grade, the blacks. When I left there, I was in the seventh. When I got to Austin, they put me back in the seventh. I went to Kealing for a while. They put you back in the seventh because they figured that these people in the country knowed enough or raised you well enough in school to know the seventh grade, so they put you back to try again. And sixth months they put me back up: high seventh. Then I passed to the eighth twice because when I left here I was in the seventh and I passed to the eighth, but when I went there they put me back in the seventh.

NL: And this still at Kealing?

MW: Yeah. I used to go to Blackshear before Kealing. Kealing was junior high. Blackshear was a-what'd you call a school for young ones?

NL: Elementary, like elementary school?

MW: Yeah. Elementary. It used to be called Blackshear, then it went from Blackshear to—no, it used to be called Gregory Town. And it went from Gregory Town to Blackshear, in the names. Well I went to there when we moved to Austin, Gregory Town, me and my sister that's next to me. She went to different classes than I did, when we was going to Gregory Town. And I went to-she didn't go to Kealing. I went to Kealing. She was gone at that time. She had went to Dallas or somewhere. She went to Dallas and lived with her uncle until she got her a job and started working and got her own apartment.

NL: Now what was the name of the school where the new church is?

MW: Antioch.

NL: Antioch? Did your father go to Antioch?

MW: Yeah. Well no, I'm going to tell you about this lodge, well, I'm going to tell you about they had a lodge up here, and when the windows blew out of the bottom, we went to school upstairs. They went to that school in that day. We had a teacher that come in before I left school named Robbie Lee Ball. She was a Kerr and then she was married to a Ball, and he was in the service. He used to come school there with her on the weekends. And they went to school, this Robbie Lee Ball got with the principal and had them let them have school at night, so 
they could sort of catch up, you know, with where they left off at. And I had an uncle and his wife to go and a cousin and some more of them that went to night school to build their grades up and whatnot. I don't know when they stopped that, but they had a chance to go to night school. See they don't have no more night school. They been wanting to have night school here for the people that were short on their education. But that never did happen anymore. And like I said, kids grown bigger and they left and went to town and got jobs. I had an aunt and me and my sister stayed with a auntie, my mom's sister, and went to school until we thought we didn't need to go or have to go and got jobs. And you have to pay a fine now if kids don't stay in school.

NL: $\quad$ Now you mentioned the school used to be a lodge. There was broken windows at the bottom [Yes], and it used to be a lodge [Yes], and so the classrooms were on the top floor?

MW: Yeah.

NL: And the lodge was on the bottom floor?

MW: Well, they wasn't having any, used to be a lodge, and it was vacant when they started having school in it. Well, you know, how they broke out the windows and stuff, shooting, hunting rabbits and stuff. This was an old empty building sitting there, so they had to fix it up. But they never did put windows in the bottom. We still went upstairs. And bathrooms were out the back. There's a trail behind where the building, where they're building now, you go back there that was the ease way, come through there and go around. And when they tore that school down like they did, we was all born here in Buda, neighborhood or people out on the Prairie, everybody was just going there. And then they tore that school down. Before they tore that school down they had a Baptist Church over here on Cole Springs, and then they moved that church. It burnt down - they said it moved that church to out on Goforth. The lumber that was good enough to use, they used it and moved it out on the Prairie.

NL: What was the name of the church that burned?

MW: Methodist, African Methodist.

NL: Was that the colony church?

MW: Uh-huh [yes].

NL: $\quad$ So did the church ever-

MW: It was the colony, it was in the colony when it was down here on Goforth, over in the colony. They moved it out there on Goforth. They moved the lumber and other stuff out there. And the Grants' daddy, the Grants I went to school with, their daddy and their brother moved it in wagons, moved the stuff all out there in wagons. And I guess they added to it and maybe bought a trailer or something-they added to it and built a church out there and a school. And the school and the church was about from my house to my sister's house, just about a block apart. And then when they tore that school down, we had gotten big and they wouldn't allow us to go no further than the seventh. But they had to the twelfth grade, but we couldn't go after seventh. We had to leave here and go to town. [Pause to answer phone.]

NL: We have an additional person who's joining us for the interview, Dr. Maria Franklin. Mrs. Washington, before we stopped for a brief second you were actually telling us about the school, or one of the schools that was actually located here in the colony. So can you actually take us back and tell us about the first location of the school. Because we were under the impression that the first location was located further back in the colony, not actually where 
Cole Springs Road is, where the new church is being built [yes]. So can you actually tell us about that and maybe clarify the locations?

MW: Well, there was two there, too, up there. No, there was just only the church, one church there then that come away.

NL: Where? On Cole Springs or further back?

MW: Further back, over here towards the cemetery, where the cemetery, right on that side of the cemetery, they built the church there. But there wasn't no school there. The school wasn't full, like I said with that building over there, was the school before that. And then they built this over here. But what they had took that stuff out on the Prairie earlier and made the church out there because there was Methodist-I mean Baptist, missionary church. And this one the last church we had here was right down there across from the cemetery. That was a Methodist Church in this colony, it's in the colony, and the cemetery-all of that's in the colony. And that school where they're building now is where we left from when-because they tore it down. They tore it down because the kids had gotten to the seventh grade, some of them, some of them never did get to the seventh grade, but they had gotten to the seventh grade and then they passed them on and they had to leave there because they wouldn'tLater on there's two or three girls that graduated up here in Buda. They got to go to a twelfth grade school, but we wasn't allowed to go.

NL: Do you remember the names of the three girls?

MW: Let's see, Grants. It was Ralston, three Ralston girls that lived out across the highway. That's where they lived, on the other side of the highway. Alestine and her two sisters-three of them, two of her sisters and her, Alestine Swan. But before she was a Swan, I forget what she was, but she's a Swan now. And her sisters, two of them, they had two brothers, two of them are Swans, and the other of them was they sister, I forget her last name.

NL: Do you remember any of the teachers at the Antioch School?

MW: Yeah, both Taylor teachers I told you, two or three of them, Taylor teachers, there was two of them. One of them was married to a Grant, one of them teachers, Nena, she was married to a Grant once. After that-you know, they separated-she had two children. Nena had a boy named Bruce and a girl named Ethel. Them was Nena Taylor's children. And I don't remember Roberta having any, but Inez had a boy and a girl, Evelyn and George. They used to visit us there when we stayed there when they was in Houston. They visited us when we stayed there in their grandparent's place. And those are the only schools there were. So the last one was in Buda. They built all white ones, built some new white ones, but they didn't build no more for Buda. And after I had left, my younger brothers that went, they went to Yancy's, L. C. Yancy and George Smith taught school. And also Geneva Bunton. She was related to my husband, first husband. Geneva Bunton was his niece. She taught school out there. Then they had a lady named Rhone come from-when Robbie Taylor, when Mrs. Robbie came I was telling you we got the school going through, the night school going through the principal and everything, when she came and did that, that let the people that missed out of school build up a little more. And the Taylor girls' mama taught school here in Buda. So did them other two I told you about, Jackson and Nena, they taught school here in Buda. And then before her there was a Cora Kavanaugh, that's where the name Kavanaugh come in. There was Hal [?] Kavanaugh's wife. She was a Kavanaugh. There's a whole bunch of the Kavanaughs and a whole bunch of the Taylors, and they were related people. Then they, when my grandma come in related to the Kavanaughs, my daddy's mother. So after that church, that church didn't burn down. It stayed there a long time. They might have tore it down. They might have tore it down for some purpose. I don't know. 
NL: The church?

MW: Yeah. I don't know how that church got—stopped using it.

NL: Now this isn't the church that burned down, that got torn down?

MW: They tore it down, I guess. It belonged to somebody's property. It was on somebody's property that it wasn't supposed to be or something like that, and they tore it down. They tore it down. That's what they did. And moved it to Manchaca. So I heard, tore it down and moved it to Manchaca. And it was a Kavanaugh and a Dodson woman-they were related, too. She was a teacher, and they moved it to Manchaca. We went to church in Manchaca for quite a while because all of them old preachers and old people were gone and we had new people coming in. We had a woman preacher from Waco; she preached awhile. We had about three different women preachers, but I was in Arizona during that time that they done the teaching, the Sunday school and church, I mean.

NL: Well, I have another question about the school. How many kids were-?

MW: In the school? Oh, it was quite a few different families, quite a few kids in the school. I don't know why they did that. They tell me that Mr. Grant, he's the first one that they come back and apologize or something or other, and wanted him to send his kids back to school, but he wouldn't do it after they put them out like they did. He wouldn't send them back, and I guess that's why they tore it down. He was going to send his back, and we had left and went to town and stayed with relatives and stuff, and other families done the same thing, went to town, kids, you know, so that just left nobody to go there much. But they didn't have to tear it down. They could have made something else out of it, but they just tore it down completely.

NL: $\quad$ So were there usually about two or three teachers in the school?

MW: Yeah, that's what I was about to say a little while ago about these different teachers I was talking about, the Robbie teacher, they was built up quite a bit when they first built the church, the new two schools and everything. Oh, it got, it multiplying there was lots of kids. And she had, the principal, to get her some more help. She had a man out at Kyle was a principal. And the Yancy boy was a principal. They was teachers after we had done gone away. We was gone cotton picking and whatever else, but we wasn't going there at that time. Daddy had a big family and quite a bit of his kids going and relatives' kids, you know, so she asked for help, and he sent a woman here that come from, Miss-I forgot her name now, but she's from Virginia. And another lady came in and taught after I done left. Then after they tore it down, it come down to where it was just one. I guess they wasn't getting enough salary or whatever.

NL: What were some of the things that they taught in the school?

MW: They taught algebra, but I wasn't getting algebra during that time. I passed to it, but I didn't take algebra. And they call algebra now something else. What is civics?

NL: Say that again?

MW: Civics.

NL: Physics?

MW: No. 
NL: $\quad$ Science?

MW: Science I guess. I guess that's what it's called. They had a specific name that they go through now. They didn't have that when I went to school. They had geography, arithmetic (and what they call it, you know the names aren't the same now), geography, arithmetic, English, speller, and that's about all they had. But they did have this, if you got to another grade, they did have, well I guess they-

MF: I thought you said specifics, something like that.

MW: I was trying to say civics.

MF: Oh, civics!

MW: Yeah.

MF: It was like government?

MW: Well, whatever it is, it's a schoolbook. They teach it.

MF: Did they teach any history?

MW: Yeah.

MF: Did you have to learn history in school?

MW: Yeah. That was geography back in my time.

MF: Yeah, you're right. They have different names for things now.

NL: Now did they teach black history?

MW: Yeah, I guess they did, black history. They didn't come by too much of everything about the blacks until they bought that book, and that book was old, the book that you see. And they had no black pictures in there-all white pictures.

NL: Okay, because one of the reasons why I was asking you that is we often refer to black culture when describing what we see, like old practices that have been passed down to us, and one of the things that I was hoping you could tell me is what kind of practices or beliefs were done in here in Antioch that you feel represent black culture?

MW: Belief?

NL: $\quad$ Uh-huh [yes]. Maybe like you were telling me about the dove or the quail that when you would open the quail up they would have an inscription on it.

MW: That's what they say. I didn't ever see that.

NL: Well could you tell me any more beliefs like that, that you learned while you were here in Antioch?

MW: No. Like I say, I didn't know about that, I just heard that they say that. I never tried to cook one and see if I seen "In God We Trust" on the breast. 
NL: Did your mom have any sayings she would always say to you or pass down to your and your sisters that you remember today?

MW: $\quad$ No more than church, missionary work.

NL: Was missionary work important to her?

MW: Yeah. They had an organization they called Missionary. That's why some churches, Baptist Missionary, and we had African American. We were sold down in slavery, they sold us, they sold the black people in slave times, and they give it to endorse the name-whatever that man is that bought you, you become their name. My auntie told my sisters their name before, they knew their name was Morris, and so that's some person that buy you in slavery. Know much about slavery?

NL: I know a little bit about it, a little bit.

MW: Well, they said after we was called African Methodist Episcopal Church. That's the church that we had. And the first one was in Philadelphia. It was built in Philadelphia. They tell me that it's still working in Philadelphia. And white people couldn't go—the black people couldn't go to they church at that time at all. And some of them, you know, like a favor to them, they helped them get a building which is called a smith shop, a blacksmith shop, and they met. They got together and they met there, and they founded this church, built it up to this church that they got. They didn't ever think they would get a church like that, you know, but they did. And scripture work, they did. And they wasn't going to get a college, a black college, and we got a college in Waco. That's the first black college. I didn't go there but I have people that live there and I visit there a lot. And you can see it from the highway when you're going to Buda, to the right there, a big red building, a long red building, that's the college. You ever heard of the college in Waco, Waco College?

MF: I've never heard of Waco College. I know that's where Baylor is, and do you know if there's a-is there a black college still there?

MW: Yes.

MF: $\quad$ And it's called Waco College?

MW: I forget what they call the name of it, but it's in Waco.

NL: And it's a college that was started by the African Methodist Church?

MW: Uh-huh [yes]. It's a college there. And I heard of one, they name these places baseball player, Rice, Orange Bowl is in Rice they said, and different places where the games is. You know when they built that thing down there in Houston, big old dome, what was that thing?

MF: The Astrodome?

MW: Yeah, and stuff like that. Anyway, it was for studying for culture and whatnot. I visited a college down-Prairie View. I have a cousin that goes there. She said she made two years. She was trying to go further, but she made two years. And you go around, so like you see things. You see a baby in a big old jar about like that, sitting up in there, look like he's alive. We'd go around and look at things like that that they had in some kind of liquid or something, that they look like they wasn't dead, just sitting up there asleep, little babies. And I thought that was strange. But that's a college I guess for nurses to go to, and they look at these things, and some of them faint. You know, they're testing you, what you can take, what you can stand 
when you see all of this. And lots of them I imagine they did that, taking their nurses, like you bring somebody in the hospital all bleeding and everything, they got to fall out, faint you know, before they got to take it and made nurses, head nurses and so on.

NL: Now did everybody go to the African Methodist church, when you where growing up?

MW: Blacks, all the blacks did.

NL: Was there a Baptist church also in the colony?

MW: Mm-hmm [yes].

NL: Well, do you remember the name of it?

MW: On the Prairie there was a Baptist.

NL: $\quad$ So the church on the Prairie was Baptist, and the church on Goforth was African Methodist?

MW: No, it was Baptist on Goforth. We had Methodist over here, Methodist church was across from our cemetery, but then that was a Methodist church. The old school that they had down there, well they just had school in it, but they had a church, too, that was Methodist. They had a Methodist church down there by the school, and then over here they had just a school that they put up on the other side of the cemetery.

NL: $\quad$ So how many churches were here in the colony total?

MW: Just two: one Baptist and one Methodist.

NL: So what was the name of the Methodist church?

MW: African Methodist Episcopal.

NL: They didn't call it Antioch African Methodist Episcopal?

MW: Nm-mmm [no], just Antioch was the area where it's at. And the school, it might have been called Antioch back in them days. Before then, you know.

NL: $\quad$ So they called the Methodist Church African Methodist. What did they call the Baptist church?

MW: Missionary.

NL: Missionary Baptist? [Yes.] What other families went to the Methodist church that you can remember?

MW: There were lots of Buntons, lots of Grants, lots of Harpers. And a whole lots of them. They might have been called Antioch, you know, just like a community. It's the community that's called Antioch, and these churches were in the community.

NL: Right, because we have a map here, and this map dates to 1958, and so here's the cemetery right here.

MF: $\quad$ So it should give you an idea of where everything is, that should be the cemetery, this is Old Black Colony Road. Here's a church right here close to the cemetery, and there is something 
called Antioch School right here, on the same side but down the road. This right here is Cole Springs Road right there.

NL: $\quad$ So can you actually tell me, like right here on the map, where was-?

MW: This is the cemetery right here?

NL: Right here, this is the cemetery. So this is the gate, and then this is inside of the cemetery. In 1958 the map said there was a school here.

MW: Up there? In '58. It must be the two-story school that I was telling you about.

NL: The one with the windows broken out? [Yes.] So they tore the school down a little bit after $1958 ?$

MW: Yeah, it'd have to be. After 1958, because where was I in 1958? There's no telling where I was at that time, because I had done married and left home.

NL: Was this the first school in the colony?

MW: Yes. They were using it as a school, but like I said, that's where that what-you-call-it was at.

NL: Where the lodge was.

MW: Mm-hmm [yes]. They used it as a school after they stopped having a lodge. That's why it broke down, like the windows all out of the bottom and everything, people hunting down there and breaking them out. But they didn't do it to the top, so that's where they had school up there.

NL: Now where was the church, the Methodist church?

MW: Back this way towards the cemetery.

NL: $\quad$ On the map, would it be right around here?

MW: Where the cemetery at? [Right here.] Yeah, it would be over on that side.

NL: Okay, and where was the Missionary Baptist Church?

MW: The Missionary Baptist church? The Baptist wasn't over here; it was over on the Prairie.

NL: How far is the Prairie from Old Black Colony Road?

MW: It's a good ways. You can go down Main Street Buda and go that way, and you strike it going that way, after you cross that railroad track, going that way from Goforth. And it's between Buda and I-35, that's how far you go.

NL: Was the Prairie part of Antioch?

MW: I don't know if they called the Prairie part of Antioch or not. I just know there was a church over there because across the creek over there it was cross Onion Creek, and we were over here.

NL: So was it just a community of people living in that area? 
MW: Yeah. Community of people who live over in the Goforth area.

NL: Prairie, and Goforth were not the same communities as over here in the colony; they were different communities?

MW: No, but they did work together. Kind of like we'd go to their church, and they would come to our church, like that.

NL: Were they related to any of the families here in the colony?

MW: Yeah, I think.

MF: $\quad$ By marriage maybe? People probably married.

MW: Yeah. And then there was Smiths, a whole bunch of Smiths, all of them boys are dead now. I went to school with, every last one of them. There was five boys, and all five of them were in the service. I went to school with all of them here in Antioch. When they tore it down, you know, all the people had to go to town, all of those out here had to go to town if they wanted to further their education.

NL: $\quad$ So when they tore this school down, so all of the communities, Goforth, Prairie, and Antioch all went to this school right here. [Yes.] When they tore it down, everyone went to the one main school in Buda?

MW: The one main school in Buda?

NL: Or just one school, I'm assuming, for black children in Buda?

MW: Nm-mmm [no]. They went on this side; they didn't go to no white schools over there. Some of them went after they tore it down and people moved away, then they went there. Well, like I said, they made an error by tearing it down because they begged pardon and realized and wanted them to send the kids back, and they wouldn't do it after they done tore it down like they did, they wouldn't send them back. Then that's why they tore it down, because they wouldn't have them to go back there. They didn't want to go, and the parents didn't want to send them.

NL: What kind of traditions have your family been able to keep alive here over the years?

MW: The church that they used to have. That's why it's named that, you know, but there's no church there now. They're trying to build a church, and we had a preacher that come down to get it off the ground, got it started, but then he died and we had to get another preacher. So we accepted another preacher, and our bunch was too small, seemed like it wasn't enough money coming in for him and he quit. It got to be small after that. You know, all of the grown ones had been gone one way or the other, and wasn't nobody left here. But we are about the last big family around here at that time. That were left here, you know, stayed here the longest.

NL: Were your parents deeply involved in the church? [Yeah.] When you were growing up? [Yeah.] Did they hold any positions in the church?

MW: Well, my daddy was a steward, my mother was a missionary worker. And we had choir. Most of the children, you know, in here were choir members. And the Methodist would let a woman preacher preach, but Baptist didn't want women preachers, but they would accept them as a speaker or mission, something like that, but they wasn't behind the pulpit, they had to have 
their little platform thing, took them to the side. They stood behind it, they didn't let women stand behind the pulpit. Some wouldn't accept them one way or the other; some wouldn't accept them no kind of way, but later years they would begin to let them speak behind their own pulpit.

NL: Do you remember what it was like getting ready for church when you were growing up?

MW: Oh yeah, we was country raised, and so we was just ready to go home and play shooting marbles and play ball and all that kind of stuff. We played ball at school. Softball was the girl's team. We had a nice time doing that. My sisters under me, boy, they loved to play. We'd play cards, and we had a time playing this one and playing that when we'd play cards. And we'd beat'em [chuckles].

NL: Now would you play these games after church?

MW: No, not after church. Dad and them said they had a game going after church. I don't know if they played ball much or not, they might have. But we'd play it after church, mostly but not too much. What they had was a gig race. Do you know what a gig is, a horse to it, sort of like a buggy, but it's just one seat. They took a picture of LeeDell up there in Buda, and his mother was in the buggy with the man that brought him into the world, Dr. McCormick was his doctor.

MF: He said that he was the first one that was born to a doctor here.

MW: Black. First black man born. It was midwives before then. My brother, I had a brother that had a midwife. The twins had a midwife. Ruth and Emily, they were born in Austin. And George, my oldest brother, they were born in Austin. I was born in Buda, Eunice was born down south in Harlingen, Texas. We was off cotton picking down there somewhere during that time, and she was born in Harlingen. And the rest of us was born in Buda or in Austin. But like I said, they had midwives in the country here. Let's see how many of them was midwives. Moses had a doctor. Dr. Lauderdale was the doctor along in that time. They had doctors, but the midwives could cut the string, you know, and they went from there. They would have a doctor to check them afterwards. The doctor would come and check them even after they done cut the string and whatever they done did. That's all they could do. They couldn't do no surgery or nothing like that. Daddy always believed in the doctor, they used to call it homeopathic doctor, and that's kind of like some kind of doctor, you know. I don't know what kind it is. They didn't believe in surgery, they believed in medicine and stuff, and that's the way they would cure you.

NL: Where did you all get your medicines from?

MW: We had a drugstore here in Buda.

NL: Do you remember the name of it?

MW: I think it was called Sun Bills.

NL: Did you ever do any home remedies, too? You or your parents?

MW: No. What do you mean by home remedies? Like they're doing nowadays?

MF: Like Mrs. Moyer told us that your mom and father would sometimes put ash and soot on burns, or sulfur. 
NL: $\quad$ She would call it horehound.

MF: Yeah, she’s like, “Oh yeah, those home remedies!" [Laughter]

MW: Oh, yeah, old medicine like that, that's what they went with. I got a book called Head Book, and they tell you a whole lot of stuff you can do, and they did it in them days. They put turpentine, nine drops-I think it was nine drops, but anyway, they put so many drops of turpentine in a saucer, like they drink coffee out of, put it under the bed, it would evaporate, and your fever would all go away. You know, I think it's like you believed in something, it will happen. Like if you spiritual, and you believe the Lord's word, it comes true. Well, I think they put their faith in that and it would happen.

NL: They didn't call it home remedies then. Was there a name for that?

MW: No, they didn't call it home remedies. I have a book to say it all there, to say that kind of stuff. About tooth pull, bang on your tooth in a little old bag about like that, like a tea bag, you put it back on your tooth. I had an abscess once and that doctor, that's what he gave me. And so that's a home remedy thing, like you know, and tea! Some type of tea would do that, would take down the abscess. That's one of the things Daddy was calling it home pasture. They didn't believe in medicine and doing everything but surgery.

NL: Home pastures?

MW: Yeah, that's what he used to call them. But that's the type of doctor's name they got now. There's doctors now that do that. I don't know if you call it allergist doctor, or what you'd call them, but most of them don't—-they might have started doing it later years.

MF: I think we call it homeopathic, which is using natural things for healing. [Washington: Yeah. Trying to help yourself.]

NL: $\quad$ Do you ever use any of the things you learned from the home pasture, or that you did growing up? Like do you ever use any turpentine?

MW: Well, like I say, I don't know what the name was nowadays, but I guess we do. Some of it they probably do, like that my placing the thing like that, toothpaste. Head's book will tell you something about that, what you can do. That's why I say it's just like to help, if you can do this and do that. I had appendicitis one time, and you know it can get ripe and burst. My momma's sister gave me a teacup of olive oil with a teaspoon of soda stirred up in it, and I drank it, and I never did have it no more. So maybe she believed or what. I never did have my side affect like that no more. So I think that's something like the home pastures doctor, that's what he'd always say. And then there'd be a Walkin man going around selling stuff. You ever have a Walkin man come around to you selling salve, rosebush salve, all kinds of flavor, stuff like that?

NL: It was a Walkins man?

MW: Yeah. They have one called L. B. Price would sell spreads, and he would sell food coloring and all this kind of stuff. He would sell spreads that you could throw over your couches and chairs, and they call him the L. B. Price man.

MF: The L. B. Price man, so he is like a walking catalog! [Laughter]

NL: What else could you get from him? 
MW: Like I said, you could get all kinds of food, pepper, salt.

MF: Was he black or white?

MW: He was white.

MF: He would come over into Antioch or into Buda?

MW: Well, he would just come around to people's houses that would buy this stuff from him.

MF: So he would sell to black folks, too, then? [Yes.]

MW: I don't know if white people would want to buy any-they probably did, but I know that black people would buy them to cover their couches and stuff. We had iron beds then. You know, there's no iron beds nowadays. They got them with the big old polished silver headboards and stuff. We had iron beds, slats under our mattresses. Now they got a box spring.

MF: So when you say back then, what time period are you talking about, 1940s?

MW: I was born in 1925, and I would have to be four or five years old to remember. Born in 1925. I'll be eighty-four January eighteenth.

NL: Ms. Moyer also told us that your mom also shopped out of a Sears catalog, too.

MW: Buy clothes out of the catalog, mm-hmm [yes]. She remembers that! [Laughs] They sure did. And we had a cousin who sewed cloths by patterns, and she would make our clothes. They'd buy a bolt of material, and she would make our dresses for school. They'd get that Walter Field catalog and Ward. Was it Ward then? Walter Field, and Penney's, I believe it was. Then there was another one called-Walter Field, Penney's, and that was when we were younger, the Walter Field catalog, but they did the same thing with Montgomery Ward and Penney's, order the stuff you know, and they'd have all kinds of stuff, materials and stuff.

NL: Besides clothes, what else could you get from the catalogs?

MW: Well, the material it probably run cheaper for a bolt, you buy a whole bolt and make several dresses. Things like they would do, making robes for the churches, they get big bolts and somebody that knew how to sew would do them. And now they're doing T-shirts with names on them [chuckles]. Yeah, every church they have a T-shirt made with name in it. Buda had T-shirts that would say "Buda" on the back of it. Kind of like that man's shirt that live around here.

MF: $\quad$ Mrs. Washington, you remember your mom shopping from catalogs in the 1930s say?

MW: I don't know what year it was, but I know like I say, I was born in '25, so I had to be at least five or six to remember that.

MF: $\quad$ Sure. But she could have gone into Austin maybe to a department store. Was it a problem shopping for things like nice dresses?

MW: Yeah, we did that in later years, you know, as we got older she'd go to town. Place in Austin they called-oh, I forget the name of them now, but they was the cheap stores, Jewish stores run by Jewish people. And they used to tighten them clothes up on you and make them fit, and when you'd get home they'd fall off of you [laughs]. They'd catch a little boy's coat in the back and tighten it up, and oh it'd look good on you. [Laughs] And when you'd get 
home, it's all-it's too big, you know what I mean, they didn't measure you right. Didn't put no measuring around here, measuring, nothing like that. They did when they made suits different places. But that's the way them Jews did.

MF: $\quad$ Could you take it back?

MW: Mama would sew them up, make them fit.

MF: Was it a problem for blacks shopping in Austin in some of these department stores? Is that maybe why they used catalogs and stuff?

MW: Yeah, it was for some time. You remember the store, though. Scarborough's and what other store was that? They wasn't too far apart; one was on that side and one was on this side. Yaring's and Scarborough's. Montgomery Ward. No. It was called Scarborough's and Yaring's. There were two stores a long time ago. Now you want to go in and try on a hat, you'd have to put paper. They'd put paper, something on your head, to try that that on. Because you know how we have our hair straight and the grease all in it, they didn't want to give you a chance to put that in that hat and somebody come along and wouldn't buy it.

MF: So they only did that to black people?

MW: Yeah. I never seen it do it to white, but they did it to black because they know how they did their hair. Sometimes they would dye their hair, and that would mess up a hat if you didn't have something on your head. Trying on shoes, they had a little footlet to put on your foot to try on the shoe. That's the way they were.

MF: $\quad$ So they let you in to shop for things, but they treated you differently once you were in their shop.

MW: Yeah. They just wanted you to, you know, not to eat in the store, nothing like that. I don't know, it was just a lot different now than it was in them days, because see, me and my mama, I went to work with her when she went to work. She worked for about everybody in Buda. Lots of them were real nice to her and they liked her, but lots of them were still slavery type, they didn't want you to eat in their house. Go eat outdoors under a tree, or either on the back screened-in porch. That's where they'd bring our dinner to. And my dad and them when we went to Arizona, they cut yards, the people would fix him a lunch, but they bring it out to them out there somewhere. They'd sit in the shade out somewhere outside in the yard and eat the food. But they would fix them a meal when they came to work for them that way. Sandwiches. One lady fixed some sandwiches for me, but she fixed some tuna salad, and I made a sandwich out of it. She asked me why did I make the sandwich out of it because I didn't know that was for her supper. I thought to myself, I did know it! But I made myself a sandwich of it. Because she would buy better stuff. She would buy some bologna or something like that to make me a sandwich out of. But it was a sandwich, so I didn't bother about it too much. I used to carry some of the time I'd carry my sandwich with me from home. Like I'd leave early and didn't get to eat, take me a sandwich with me, then when I'd get a break, I'd eat it.

NL: How old were you when you started working with your mom?

MW: We would make a fire around a pot, because they used to boil their clothes, and they boil them in a big old dunking sack so the rust wouldn't get on it, and they'd boil them in that pot. A lot of women had that pot. They kill hogs, they'd used that pot to make cracklings, boil cracklings in there after they cooked the fat all out from them. So we would make the fire and keep the fire going. They'd take a stick, they'd tromp them clothes. Start them off in 
cold water, then tromp them. They'd get them clean. Put some lye on some of them. But their clothes were never as dirty as the black folks clothes, no way. It really didn't look sometimes like they need no washing. You know, when they stripped their beds and stuff like that. But then that's what she had to do. They had three tubs: a tub you rub in, big tub that you rub in, and you could mix some warm water with it if you wanted to and wash; then they had two for rinsing, a big rinsing tub and a smaller one. And the smaller one they would put bluing in it.

NL: $\quad$ So you helped your mom with the washing. Did you help her with any other tasks or jobs when you went to work with her?

MW: Oh no, we'd just keep the fire around the pot, and yeah, hang them up on the clothesline. We'd get them out of there and hang them up. They had a washer like this, you'd run them through there and get the water out of them. Them kind of washing machines that they had at that time, we'd run them out of there, yeah, we'd rinse them. I'd do the rinsing, you know, after she'd wash them and throw them in there, sudsy—sometimes it'd be so sudsy we'd have to change the water because it was probably too much soap there.

NL: Now where'd you get the water from?

MW: They had hose they hooked to a hydrant, and we'd fill up the tubs and get them all ready for her. They would give her the powder soap and stuff to put in.

NL: Did you iron, too?

MW: Yeah.

NL: $\quad$ Any mending?

MW: Yeah. I ironed, when I started working for myself, you know, started doing housework myself when I left home. Well, I'd wash and iron clothes for people, too, just like my mama do it. But they wasn't as slavery type as they is here, like they was in Buda. You know, they were nice people. One lady told me she liked my ironing so well she'd like to put me in business. [Laughter] And I worked at laundries, too, and I did like when I went to town I worked at laundries, and I did like the-you know, in a laundry they pass the material to you. You do the back, you do the sleeves, something like that, and somebody do the legs. You'd go around. Took three people before it's ready. So I did that. I liked to iron the seams in legs. They got a little thing to put the shoulders over and stretch it a little. I got a little one in there now to stretch an arm on for myself. They didn't have any now, but they had an ironing board to fit all of that. Then I don't know what happened to it, but I worked for a woman in Dallas that had a little miniature ironing board. Like a sewing machine or something, you'd put your foot on it and roll it through there, like you would a manual, a sheet, putting it through a manual. That's what I did to it in Waco. Supposed to work two of us: I had an end and she had an end. We'd lay it to get that straight going through that manually, we'd call it. And you'd get to the other side, both people would catch it and fold it. So I worked with that, you know. I worked with that when my first husband went to Waco. Ft. Worth, Ft. Worth. Rented a room and stayed up there. It was quite a while before we came back to Buda. So that's the kind of work I was doing when I was up there.

NL: Did they pay you a lot for that type of work?

MW: Yeah, we got paid, I've forgotten how much it was. But then it used to be like five cents on the dollar, and I remember when it went to six cents on the dollar, I still didn't know the meaning of it, what they were saying. [Chuckles] And I worked at Woolworth, and I worked, like pick up the sandwiches and deliver them. I'd fix them, and they had the hop girls to come get 
them. I made the sandwiches and stuff like that, and they would come and get it. Like they'd take the orders, whatever they wanted. Well, I would fix it up and they carried out. You know, delivered.

MF: When were you working at Woolworth?

MW: That was back in the thirties. During the time I was staying about going back to school.

MF: How old were you when you were working for them?

MW: I was pretty young. They collected dishes and carried them up. I worked up on the floor, a bakery. I worked in the bakery department upstairs. Then I worked downstairs when I was making those sandwiches and they was picking them up and carrying them out.

MF: And this was in Dallas?

MW: No, this was in Austin.

NL: Was that your first job when you left here?

MW: Yeah, that was my first job when I left here. Plus doing domestic work for some people, too. I worked at Woolworth for quite a while.

NL: So you actually worked at Woolworth's and did the clothes. That's a lot.

MW: Yeah. I liked working at Woolworth's. When we worked in the bakery department icing cakes, and sometimes we'd break them. Sometimes we'd break them on purpose! [Laughter] And then we can have them and break them up, you know, split them up. [Laughter] Probably broke them on purpose, but some just accidentally broke, you know.

MF: This was an all-black crew that you had working back there? Did they just have all blacks working?

MW: They had quite a few blacks. The white ones were the ones that carry out, you know, little hop girls we call it, take the food. They'd come and get it, you know, downstairs. Like all kinds of little drinks, milkshakes and malts, sandwiches.

MF: So they'd have white girls serving the customers that came in, but black folks making everything.

MW: Doing all the work, yeah.

MF: Were blacks allowed into Woolworth's to eat as customers?

MW: Well, no. They would eat in the back. I rode a bus and went through Waco to the back, couldn't come in the front. Get off that bus. So that was part of the slavery left over.

NL: How long did you stay at Woolworth's to work?

MW: I stayed there quite a while, during the time I had stopped going to school, that's when I started working there. I'd go in the morning. It was like an eight-hour job.

NL: How did you get there? 
MW: I don't know, really. They just needed help. You know how you go to the employment office?

MF: Yeah, but were you living in Austin? [Yes.] And so did someone ride you there? Did you take a bus? Or how did you get to work?

MW: Yeah, I'd take a bus. Because this place was on Congress Avenue, Woolworth was on Congress Avenue. That's where I worked, but I lived on Rosewood with my auntie at that time. So the buses was running.

NL: How long did you live in Austin after you left the colony?

MW: Oh, a long time.

MF: Do you remember when you moved out to Austin from here?

MW: No, because when I left here, like I said, I went cotton picking all around in other counties, and did that for a long time. Then like when we went on cotton picking and come back and started school at a certain time. But after I left there completely and there wasn't no school and went to Austin, I stayed in Austin from the time I left Buda for school, I stayed there from then on.

MF: So it was probably before you were twenty years old, when you were in Austin? You weren't quite twenty years old; you were still younger?

MW: Mm-hmm [yes]. When I went to Kealing, the girls harried me because I was eighteen years old, "Ah, she's grown! She's a woman!" That's what they'd be whispering and saying to somebody, you know, when they find out my age. [Laughs] Kind of embarrassing. "What's wrong with a woman going to school?" But going to that school where they were, I guess they thought I was old enough to been going to somewhere else, or college or something, going by the age, you know. Nah, that was because we went to the country schools, and they didn't go as fast as schools in town. But a lot of times they didn't have the appropriate education, neither, either going to town. Nm-mmm [no].

MF: Were there other family members living out in Austin when you were living there?

MW: Yeah. Not in my family, but relatives.

MF: Do you remember Emma Bunton living there in Austin?

MW: No. There was an Emma Bunton out of their family, but she was Emma Lyons after she married, but she was a Bunton. There was Lillie and them's grandma. But I didn't know that much about it except know their name, you know, stuff like that.

NL: Did anybody else leave with you from the colony to go to Austin?

MW: No. Families left on they own. I mean the parents sent them to relatives, like we did. They had relatives over there and they'd go to school, because one of the Grant girls lived with her older sister that lived in town. Her name was Cora Grant, and she married a Davis. She had a daughter. I think somebody told me they buried her daughter just recently, her granddaughter, Cora's daughter's daughter.

MF: Cora Grant, is she related to Lillie Grant?

MW: That's her sister. 
MF: So it was like Lillie, Lola, and Lorene, and Cora. [Yes.] So Cora Grant married a Davis? [Yes.] Do you remember what his first name was?

MW: Something like Albert or Alfred, something like that. And I went to school with them over in town, some of them. They were going to school when I wasn't because I was going cotton picking when they sent their children to town to go to school. Well, we went to town, too, but we went at a different time. And them twins, Oscar and Arthur, they had about three sets of twins in their family, the Grants. Lorene had a twin, and Arthur and Oscar. I hear Oscar is in a nursing home now, rehab place or something.

MF: That's right.

MW: And some more that was twins. Like I said, about three sets of twins in there. And on my mama's side there was twins, but they were way back before she got twins. My mama got twins, too, Martha and Mary. But it was a long time apart before they got a-their mama had a sister named I think Laura, something like that, but she had twins. But from then on, Laura Spencer or something like that, she had twins, and from then on up until it got to Mama. Now we got a brother with two sets of twins, one of his son's child, he died.

MF: Which brother is this?

MW: Joshua.

MF: He had two sets of twins?

MW: Yes. His son had two sets of twins, Joshua Junior. I have to show you that eulogy, or did you see it?

NL: Do you want to look at these, then maybe we can stop for the day for another interview? Because we have lots of questions that we want to ask you that we haven't even scratched the surface on. So maybe we can start looking through some of the photos.

MW: I've got Martha there by the place where the thing going to go, and the groundbreaking and stuff. See them with the shovel? That was the groundbreaking with the one preacher we had.

NL: This is at the new church?

MW: Yeah, where it's going up at, where it's going to be.

NL: Is the new church going up on the same ground that the first church was? In the same area?

MW: Nm-mmm [no], no. The first church was one we was talking about, the two-story place where the what-you-call-it was. That's in the colony, all right. This is considered in the colony, but not the same spot.

NL: How far is this church from the old church?

MW: Well, it's not near no church. Oh, the only church this one's close to is the one I was telling about that's across from the cemetery.

NL: Did you attend the groundbreaking? [Yes.] And where are you in this picture?

MW: This is Winnie and my sister, they were at the shovels. 
NL: So that's Minnie and Winnie?

MW: Yeah, shoveling. I thought to myself there ought to be some stewards, but she is the president of missionary, and she's doing this or something.

NL: $\quad$ This was just on February twenty-first, 2007.

MW: Yes. And these people behind, like one of these men is the head of the thing after the other one died. They all come from his church. Wallace.

NL: $\quad$ This was the minister? [Yes.] And he died?

MW: No, that minister didn't die; the one before that. His name was Steck, Gregory Steck. And he drawed up a lot of stuff for the church, maps for us and stuff like that. He was a board member of the school, and he had a chance to get in there with the school people and help projects and things they would help him do.

NL: This is your mom, Mrs. Emma Harper. Did you tell me that she was a Tennon [?] at first?

MW: Mm-hmm [yes], she was a Tennon and she married a Harper. She was a Tennon maiden name.

NL: Did she ever tell you where she met your father?

MW: In the country, out in the colony. She met him through some friends that lived-you know when you cross the railroad coming into Buda and go down that road that way? Well, Friends used to live down there, and he had a sister that lived down in there and her and her husband. And she married a Friend, his sister married a Friend, and they lived down in there. Get on down there, some bridge they cross, and one side is a Heeps'. Heeps got a side over here and a side over there. That big old thing down on Main Street after you leave Buda going out by the HEB and around, that big old thing sit over there, that was Heeps' dairy, was part of Heeps' dairy. I don't know what they going to do to it or what they going to make out of it, but it used to sit on the hill over on this side of the highway. One of those girls had a partnership with a man, Bradley. She wind up killing him. It was two Heepses, Herman and Boone, and they had nieces, it was his nieces, like his sisters' children or brothers' children or something. But he was in partnership with her. They were going to make the old home a place like a museum, and people could come back from south and they could plan parties, stuff like that. That's what they wanted to do. And I don't know what he wanted to do, why she wound up killing him. He tried to beat her out of it, I guess, some kind of way.

NL: It says here your parents were married for seventy years. [Yes.] And they had eleven children. [Yes.] And you're the oldest.

MW: Oldest girl. I had a brother older than me.

NL: You mentioned that your mom was in that storm in Kincheonville. Were they married at the time?

MW: Yeah, they was married at the time they lived in Kincheonville. That's where her eye got put out. And Daddy worked on the railroad. Him and his brother, because his brother's wife was in the storm, too, but she wasn't damaged as much, but the brother's children was.

MF: There was one child that got killed, right, and the other two survived, is that correct? 
MW: Yeah, right, mm-hmm [yes].

MF: $\quad$ One of the girls died.

MW: Yeah, the youngest one. Her name was Minnie. She died. When they found her, she was just wrapped up in barbed wire, she just bled to death. And the other two that lived was about maybe from here to the road apart from one another in the cornfield or cotton patch, one.

MF: Wasn't one with a dog? I thought LeeDell said one was like next to a dog. That there was a little baby boy that was protected by a dog when they found him. I thought that's what he said.

NL: I remembered him saying the dog actually didn't make it, but the dog was covering him in the storm.

MW: There was a little boy with my mother, a little white boy. And he said, "Mrs. Harper, can I go with you? All my family is dead. Can I go with you?" I don't know if he said Mrs. Harper or Mrs. Joy, "Mrs. Joy, can I go with you?" And she said yes, she caught him by the hand and carried him with her. And they passed an old empty school, and the windows was out. The bottom of the window used to be low in school back at that time in the country, so she crawled in that school. It was pretty low, you know, where you could just crawl over in there, and she just fell off over in there. And the tornado had stripped her naked, and a lot of newspaper was in the bottom of the school. She climbed over in there fell in there and wrapped up all in newspaper and stuff. Because she said she said she had on some lace-ups up to here, what they call them kind of shoes, and she didn't have a one on. Didn't have nothing on. No I mean it stripped her naked, and I mean you would think lace-up shoes, they're tight. But it was powerful. It stripped her naked. And she had a deep scar right in here. A 2x4 hit her in there and she had a deep scar. It got well, but it was just, you know, a hole still, sinking hole. And she got arthritis there real bad before she died. When she would get up she would just stumble across the house, arthritis. She stumbled in order to stand up. So I don't know, but it was a terrible storm. My dad said a skillet drove in the tree.

MF: Do you remember what year that tornado was?

MW: Nineteen twenty-two. And my sister next to me had silver dollars, one of 1925 and one of them 1922, and my oldest brother, we're about two years apart, it was his birthday and she gave it to him. I got mine now, a silver dollar, 19 and 25. Hers was 1926; she had one, too. Them was the dates of our birthdays. We just sort of kept them, you know, saved them. I don't know if they're worth anything or not, old money stuff.

So that's all the eleven children you see there. The first one was born, his name is John, I think he must have been born during the storm, because she didn't have no children when she was in the storm, wasn't no children. But when she mentioned John, undoubtedly, she was with him. Most likely I don't know. And [chuckles] my brother, he asked me, "Where did John come in at?" I said, "I don't know, but Mama told me she had someone named John. Said he was matured enough for her to know he was a boy. So I figured it must have been a miscarriage or something, that's my judgment, because Daddy would never claim it. He would never claim it.

MF: So you think she miscarried, and that was how she knew?

MW: That must have been. That's what I'm saying, it must have been a miscarriage.

NL: You think that she- 
MW: I believe she was. I didn't see it, but I know she didn't have no children as we know of until after the storm. She didn't have none before the storm. So like I said, I assume that, because she did tell us that. And my brother hadn't heard it. "Where did John come in?" I said, "I don't know. Mama had John before everybody else." My brother George, oldest one. But she had told Martha and them, too, because they knew. She told me that she had a boy and they named him John. But like I said, you know men, he didn't tell us that. He didn't let us know that. But she did, sure did tell us. And then she had one stillborn, which they all remember. What was his name? They named us all out of the Bible, every last one of us, including the girls.

NL: $\quad$ Did she talk about the storm a lot?

MW: Yes, she told us all how it happened. You know, it just hit all of a sudden. And she ran to try to go in a barn, a big old barn on the place where they lived there. If she had gotten the door back, then she wouldn't have got hurt in the storm because she would have got off in that big barn. Unless it was tore all apart, you know. But it didn't tear it up, and she couldn't get the door open. And so she went and got in a trough, at the barn, you know, a trough, and they had some stuff pile in on and covered up, so something must have hit her and knocked her eye out.

NL: To close out for the day, this is an obituary for brother George Champ Harper.

MW: Yeah. So he got the same children, I mean would be on his thing.

NL: Now is this your father?

MW: Yes, my dad. And that's him and her.

NL: This name actually sounds familiar. We've seen this name, George Champ Harper, before in the colony. Is he named after someone in particular?

MW: Yeah, he named after a man named Champ, and he told him he was going to will his property to him. He said he was a little boy, but he remembered, he said, "When I'm gone, someone will my property to you." And he used to go with my grandma, Daddy's mama, down there, and she'd go down there and cook for him. He was blind and elderly man and everything; she would go down there and cook for him. And I think his wife must have already been dead, too. And he told him that, and he remembered it. But we asked him how come he didn't never get it. He said his mother didn't ever dig into it and see what about it or get documents for it, and that's why they just took it. And then, too, it was paying taxes on the property and stuff, and after they died and they had no will for nobody, the state just took it.

MF: So your father never did get the land, then.

MW: No, no, he never did get it. Documentized, you know, never did get it put down for proof. And all they had to did was keep the taxes up and have a deed, show that they gave it to him. And this lady give the property for Clarisa Smith, she was Clarisa something, they donated property for the school. I forgot what her husband's name was.

NL: Was it Elijah?

MF and NL: Elias?

MW: Yeah, yeah. They donated land for the school. They're the ones that had the lodge. 
NL: Did the older Champ, did he own a lot of land?

MW: Yeah. I don't know how much. But he had land over there near their school. He had property over in there. So it's one of them things. A lot of people have been trying to find out about it because other people that knowed him, you know, might have been a relative or something. His dad was a Harper, and that man was-what was he? I forgot what the man was that did it. And his wife, she was gone when my grandma was over there working and helping him. His wife had died, but I don't know who his wife was, I forgot. I think maybe she might have been someone related to them Buntons.

NL: They didn't have any children?

MW: Nm-mmm [no], they didn't have any children. So he just remembered he told him that, and she knowed it, too. But like I say, I guess there were too many stipulations to it, or whatever it was. But they didn't have no children, so I don't know what they meant by the stipulations. Too much had to be done, you know. They didn't take over or didn't do or something, I don't know. But I went down to the courthouse down there with my sister Mary and we found it-you know, his name down there. But after that, this person would buy that land, he'd either sell it off or do something with it, another one's buying up, pick it up. You know, that's the way people do people's homes now when they see they about to lose them. The tax eat it up, they say, you know. And if somebody pay your taxes, you got to pay them back. I thought that wasn't no good law, to let you pay taxes on something that wasn't theirs and belonged to somebody. And then when they do it, they buying it like. But then when you get ready, it's yours, you've got to prove that it's yours by your paying taxes every year. If you don't pay the taxes, somebody would pay the taxes on your property, you've got to pay them back before you can clear that property. That is going in the back of somebody-that doesn't make sense. You be charged for hitting somebody in the back. You know, charge you for that, but they do. That's one of the laws of the road. Maybe you couldn't move, they run into you. Maybe you sitting at a red light and couldn't go no further, and they'd bump you in the back. I never did drive or take no test or nothing, but I know they supposed to stay a car behind to have enough room to stop! [Laughter] All of them drive but me. All of them could dance but me. [Laughs]

MF: You couldn't dance?

MW: I wasn't no dancer.

NL: What about cooking?

MW: Oh, I could cook. My mama learned me how to cook. I'd stand on something and reach up, cook and wash, too. Wash clothes, I had to get on a bucket, stand up on a box or something to stand up to rub that rub board. [Chuckles]

MF: How many siblings did your mom grow up with? How many brothers and sisters did your mother have?

MW: She only had two brothers, and I believe four sisters.

MF: Did any of them live here in Antioch?

MW: Oh no, they all lived in Austin. Penfield, around in there. She lived in Penfield in Austin when she got married. 
MF: Did she consider herself a country girl still, even though she was from Austin? Did she kind of grow up more in a rural area?

MW: Yeah, that's kind of a rural area. It was a place in Austin. In the Austin area, it runs so far also by South Austin, it's a different area. So they was in South Austin. That's what that area was.

MF: Before it was developed then, so it was still kind of farming areas out there?

MW: Yeah, mm-hmm [yes]. They used to pick pecans. The man owned a pecan farm on the bottom, and they'd pick up pecans on the place they stayed on, and that's the same place where she was she got in the storm.

NL: We've talked for about two hours today, so why don't we go ahead and end.

MF: Oh, do you have any heirlooms that were passed down to you?

MW: You see that little magnet over yonder? That was from on my mama's side. That little blue thing is telling me what pages to find to see her.

MF: Page 20. This is recent. This just came out in January.

NL: I'm going to end the tape right here.

Interviewed by: Nedra Lee

March 18, 2009 (2 of 2)

NL: Good morning. This is Nedra Lee. Today is March 18, 2009. I am interviewing for the second time Mrs. Marian Harper Bunton Washington. This interview is part of the Oral History Program for the Ransom Williams Farmstead Project.

Mrs. Washington, why don't we actually pick back up at a conversation that we were just having a few seconds ago off the record when you were telling me about some of the jobs that you had held over time. One that we mentioned, I believe actually on Monday or on the $16^{\text {th }}$ was actually talking about your work at Woolworth's. So before we actually talk about that, why don't you actually tell me about the first time you left the colony and why you left the colony.

MW: Oh, I left because we went on cotton picking, and stayed through time when I should have been going to school, but we stayed there from around September through November when we got back from it, and school went like two semesters, six months in the city. And then it pass you again. But I left here in the seventh grade. And when I got to Austin, when I decided to go to Austin school, I stayed over there with the relatives and things and went to school over there. And I don't know exactly just when I stopped going, but I was still in the same grade when I left, stopped school, you know, because they put me back. And then they signed me back up, but I didn't go to eighth grade. I didn't make eighth grade steady, so the seventh grade highest, the seventh highest I went through. You go to all of them one time in the country. You do it the whole twelve months; they didn't split it up like that. In the city every six months you got a card, you know, approved, meaning your way able to do it, your schooling, you know. And so, but I did pretty good for writing. Afterwards, I mean I could write good, and I did pretty good at my reading, spelling, so on. I learned my spelling like spelling syllables. I could spell thing in the syllables, but it might not be right, but it'd 
be close to it. [Chuckles] And sometimes it would be perfect, it would be really right perfect. I was telling my sister about that. I said, "That's the way I used to, you know, do my spelling." We had books to spell, and you had books sort of like a Bible, a concordance, what I was calling a dictionary, something like that to learn what words is. So I went on from there.

So then I started to working before I stopped school. In Austin I started working in the neighborhood. I lived down on Third Street in Austin, and I worked off of Third Street down on First Street, and Second Street. There was streets in between them where me and my sister next to me would do domestic work. You know, we were washing other people's clothes. We'd wash them one day, and the next day we'd iron them. And that way we would make a little change for help us in school ourself. And then my daddy would sell rabbits and syrup and eggs and milk and all that stuff over in town, and he was selling to my people I was living with. My relatives that I stayed with, they'd take-he would supply them with that as a payment, a helping, you know, helping them for letting us stay with them for a little of nothing. Wood, he would give it to them on credit, I mean give it to them freely, and some of the food they would buy from him, milk and rabbits. Some of them old ladies didn't like rabbits, but a lot of them liked them. They'd buy them rabbits. They'd have a dog race in Austin, and they would race them dog, rabbits with them dogs, electric outfit there. Have you been in Austin-you probably haven't been in Austin long enough to know Pete Gilbert. He had a racetrack down in Manor, and we used to go down there a lot of the time. So when they catch them and kill them, people there would buy them. They would buy them, and take them rabbits home and make chili out of them and everything.

NL: Chili?

MW: Yeah. Rabbit chili.

NL: Rabbit chili. Was rabbit chili good?

MW: Yeah, it was good.

NL: It was good.

MW: It's a jackrabbit and a cottontail. Now the jackrabbit, meat was more red like steak. My exhusband used to call them the running steak. [Chuckles] That's a running steak, because their meat was nice and red, you know, like chicken legs and so on. They was shaped different, you know, but they were good. May could cook five of them rabbits and pour the grease all off of them, and make a gravy to them. And it was good eating.

NL: Interesting. What else would you put in it?

MW: You would season it like you would lamb, maybe a little black pepper and a little salt, probably more salt than we need, you know, getting it at that time, but they would season it in salt, pepper. And now sometimes them old big ones, we'd call them old, they'd marinate them in a little vinegar. And some of the people, ranch people would use dry wine. They would cook it in dry wine, you know, cooking wine they call it. They'd use that, but we would use a little vinegar. And kill the hog, they'd buy their salt, which was called season salt. It was brown like brown sugar. And they'd season it up real good. And in the summertime we had a smokehouse, they'd hang it up in the smokehouse. I know I told you about my mother making them sacks out of flour sacks so that the air would be cool. And then some of them, later the people would make them out of the casing. They'd call that their casing. It ain't nothing but that bowel in there like chittlings, they would get that and stuff it. Yeah. The hot sausage used to get the stuff like that. That's where they'd come from. Yeah. That's the casing. 
NL: Didn't know that. Wow!

MW: The casings from the hog, they'd put it in. But like see, I don't know where Daddy got the salt. They'd make it from some of the other older farmers. Flour sacks was kind of thin, anyway. My momma made sheets out of them. You could get a big hundred-pound shorts, for hogs, and they started making them in a print. No, flour was made in a print sack, and she'd make pillowcases and make sheets out of them. It'd take about six, seven longwise, and about eight crosswise, and she'd make sheet, bedsheets. We didn't have king size and queen size like they do now days, but they're regular beds. A regular bed, and it was an iron bed at that. And we three sisters slept in one bed.

NL: In one bed.

MW: Yeah.

NL: Now when you were growing up, you shared the bed with them at the Taylor house?

MW: Yeah.

NL: Where was your parents' room in relation to your bedroom at the Taylor's house?

MW: Oh, no, they was up in the front like kind of west of our room, and that was like east. The dining room was in the middle. And they had the porch run north and east in the front.

NL: Now what'd you do on the porch?

MW: We'd sit out there and cool. In the summer we'd sit out there. Then my mother-in-law had a wooden swing. You see these swings they have. We had a cousin that had one, too. They'd sit on the porch and swing. We didn't never get the swing tight, but we could sit in chairs on the porch.

NL: Right. Because there was no a/c back then?

MW: No.

NL: No. How'd you keep cool then?

MW: It would get cool. It would just cool off, and the wind would raise up and cool us off. The wind, and then we had a lot of trees around us, you know, and that would help. The trees would hide the sun, mostly from us on the porch, because we had a lot of that. And we ate fruit, good fruit, because we had an orchard. They had an orchard. And I mean we still used the orchard when we moved there. They could come up and get some of the fruit and stuff, but we got all we wanted right there. My mom and them, grandma and them made preserves, peach preserves, and all.

NL: And would they can them?

MW: Yeah. No, they didn't can them. I think they had a way of canning them or something, but they made quilts. They have a club that made quilts, and if your parents helped them with the quilt, you got a quilt. And all of these people, and then people right here, you ever seen the quilts in frame?

NL: No. 
MW: They put it up like this here, like a tent kind of when it's going up. And they stand up and work under it and be quilting quilts. And it looks some like that, but it's patched right, but they have patches. They make them patches out of old overhauls and duckings and stuff like that. They come in a square, and some of them would make a star, shaped in a star. And in school, we learned out how to sew what you call a yo-yo, we'd put yo-yos, little round material like this, and we would hem it, and as we would hem it all the way round. And then you run a string through so your thread, what you're sewing with, you pull it all together, and then there'd be a little patch-They'd be meeting one another like you tying a knot. And then we'd use the knot part to sew it into the quilt. And it was full of yo-yos, full of patterns like that.

NL: Wow! Did you all keep these quilts?

MW: The ones when we made at the club. And this one at school, we'd just make them and demonstrating them at school, because me and a girl crocheted a little purse, a little purse about like this, that was wool yarn. At school, it's the job that they had. I mean some they wanted to do like home economics and whatever they call that cooking and so on, the title. I mean they had a title to it. And we would cook together at school. They were giving us, what do you call it, this commodity stuff. And they'd bring a bunch to school, like a case of milk, a case of peaches, and stuff like that. And me, and one of my girlfriends, we two at a time would cook, me and her would cook. And then she started letting a boy and a girl cook, learning the boys how to cook, too. And we would do that from breakfast on, until we could cook oatmeal and stuff for breakfast, because one of the girls wouldn't eat oatmeal. [Laughs] She wouldn't eat oatmeal. She ate it at home, but she would not eat that oatmeal they cook at school. I wonder why.

NL: But were you learning this here in the colony or were you learning this in Austin?

MW: That's in the colony.

NL: Wow! So who was the home economics teacher?

MW: Ms. Robbie Lee Bowles. And she home was in Seguin, and she'd drive up every week, and room with my mother-in-law. She roomed, because we were right up from the school where she lived. And she'd room with her up there, and come up here and work. Now I went under other teachers before her, but that's the one, that left from here on was her.

NL: Now did all teachers, when they would come up to teach in the colony, would they always live with a family here?

MW: Yeah, most of them would.

NL: How long would they live with that family?

MW: Some of them was out of Austin, so they didn't have much of a problem with coming out here and stay with her grandma. This lady was her grandma, and she'd stay with her. Come out Sunday evening, stay all week, and then she could go back home on the weekend if she wanted to. And another one, that one, like I said, was a niece of my ex-husband, Bunton. And there was some of the Taylor women, it was two of them I was telling you about was teaching us, taught out on the Prairie on Goforth. One taught that was in the service, and she was a registered nurse in the service, so she taught school for her sister that got sick. And she was older than the sister that got sick. And then the other one's name was Inez, but they went by Taylor before they married, all of them. And so she lived in Houston, that one, and she had a boy and a girl, George and Evelyn. This lady, a Kavanaugh teacher that taught us just had one son, Cora Kavanaugh. She used to teach school, and she taught me and my oldest 
brother, because these others wasn't going to school. And then after Ms. Cora come, that's when the Millers and Taylors and things come along after Ms. Cora. Ms. Cora was the first one.

NL: $\quad$ She was the first one?

MW: Uh-huh [yes].

NL: Were they nice teachers?

MW: Yeah, they were nice. They were nice. This last one was a little more up to date in the way of things of that time, you know, than they is of this time. But other than that, they were good teachers. They taught you kind of like they were your parent. They did. They taught kind of like they were your parents or something. They were nice to you. They encouraged you to be obedient to your parents, and how to come to school, and your attitudes and so on. I used to pout with mine. The kids would make me mad, and I'd pout. I'd walk in the school, throw my books down on the desk. And she'd like, "Go back and shut that door." I would open the door and push it back and go back and throw my books down. I don't know what made me do that.

NL: Which teacher was this?

MW: Ms. Robbie. Yeah, and she'd get on me. And she'd say, "Go back and shut that door right, and put them books down right." Oh, boy! I did it, though. [Laughter] That was just being ugly. I don't think my momma and them know nothing about that, though-if she didn't tell them, I didn't tell them! But I seen that she just really wanted us to learn, you know, and that's what it was. It was love she had. I didn't get mad at her or nothing. They knew how to call your pout, you know, you want to do things wrong or do something ain't right, you know, because like I said, I was getting even with them, I guess. I don't know what.

NL: Was she your favorite teacher?

MW: And she was a good teacher. I liked her. Me and one girl, she'd take us home with her. She lived in Seguin, and when school was out, and got ready to go home she'd take a girl with her, help her clean up on a Saturday when we all help her clean her house up on Saturdays. So she took me once, and took another girl. The one I said made these purses and things. We'd go down there. I would go to church with her that Sunday morning, you know, she's a church lady, and come on back. And the other girl, she liked to go down there. She said, "She's got a house like a white woman." [Laughs] She did have a nice home, you know, compared to some of these we have, you know, here. Teaching school, she made, you know, good money, but they still didn't get paid them days like they do now days. Always right now they're over talking about women teachers' salary, wanting to raise salaries. Well, they did that back in them days, too, but they never got near as much, you know, pay. They got a living, I guess, a living out of it. And Ms. Robbie, she didn't have no children. Her husband had a child in the service, and she went and got it. He told her all about it and everything, so she flew down and got him. They let her have him. He was like Chinaman type. He looked like a Chinaman kind of. When she got sick we went down to Seguin and seen her a time or two. She made hats, pretty hats. She'd say, "You all come visit me enough, I'll come give you all hat." She done made you a hat. She married another man. Like I said, she didn't have no more children, just that boy she went and got from her husband. His name was Ball. It was her married name. Her maiden name was Kerr, and they home was in San Marcos. Because one of the students from my school lived down there with they parents when he was going to college. I think there's a college down in San Marcos. Anyways, it was a higher grade school. And he stayed with them. He cut the lawn. They had a little stand, sell food, soda water and stuff like that on their place. And he would help her around there with that, ice down pops and stuff, and cut 
their yards, and so on like that. Most of the time that looked like he didn't get no lot of salary for that, because he was giving him a hand, helping them because they knew his people up here in Buda. And then he went to school in Austin, and then he taught here in Buda behind some of these other teachers, George Smith. That's his little place down there across from there on this side, a little trailer. He's dead now, but he had a bunch of children. Some of them are dead. He had a girl to become-what do you call it when they send them out to different places? What they call these women preachers? Missionary.

We got a couple of them in our church now beginning to preach, because there as so many Baptists people didn't want women in the pulpit especially, but they've beginning let them speak at different, especially a woman missionary, they'll speak like that. Well, I couldn't see why, and some, the Methodist preachers, they never was too concerned about it. A woman can help herself preaching, you know, if she knows what she's doing. But for some reason the Baptists was real different from that. My husband I got now is a Baptist person, and I'm Methodist. But finally when we got married he started going to my church, Grand Chapel on Twelfth and Chicon, that's where I used to go. And when we married, well, he finally joined my church. Then we came, when we come home, we went to church in Manchaca. They call it Little Bethel Manchaca. We went there a long time, because at that time we didn't have this church in the colony. And we just have a good time. And the preacher, we had one preacher catch the bus and come out here and stay with my grandmother, because she didn't have no husband and her children were grown and gone. He'd come out here and stay with her overnight and go back up. Well, Sunday evening, Monday morning go back to Manchaca. He worked at a bakery in Manchaca. You know, so many people thinks that they can get supported with money, preachers and things, but money, but people just didn't have it in the country like that. And what they would do, go to house to house, the stewards, and collect food. Like could buy it at the store like they do now, and they could elect, especially the staple stuff they know people would use and eat like coffee, stuff like that, because we know they believe they make coffee, bright morning coffee, all those names. [Chuckles] And they'd drink it hotter than anybody I ever saw. They'd pour that coffee in a cup, and they'd just be steaming. In a little bit you'll see them drinking it. I liked coffee. Mine didn't stay hot like theirs was. I don't know if that was keeping them warm, if they wanted to be warm. [Laughter]

NL: Probably waking them up.

MW: A lot of people, truck drivers and things would drink coffee to stay awake driving up and down the road, but after eight hours they were supposed to stop and go to bed, but a lot of them, you know, kept going. And these places where they stop and eat or get their coffee, they would have some kind of No Doze pill that they would take, they could get them at them places. They were looking for them. They'd get them anyway when they'd go over their eight hours. And that might be cause lots of them to have had wrecks or whatnot, jackknifing trucks. I'd just be trembling when we go to town, so many trucks up and down the road. And big trucks, you know, seem like they just shake the car when we go by. It's dangerous and scary.

NL: Now Mrs. Washington, can you remember what Mrs. Robbie's house looked like?

MW: Oh, it was a nice place.

NL: What was it made of?

MW: Brick, outside brick. And I think she had, I forget just how many, well, she had two bedrooms, you know, and kitchen. And I don't know, I don't think she had a dining room. She might've had in there. Most of the houses back in them days they had dining rooms, big tables and 
buffet and all that matching. That there thing is old. My daddy bought that. He bought us table. When we were growing up, we had that. He bought it on South Austin.

NL: $\quad$ So this was actually, this was with you ever since you were a child.

MW: Heirloom, you would call it. Yeah.

NL: Was this in the Taylor house?

MW: No, we bought it. You know, I told you we stayed over here. Did I tell you the house burned down? Our house that we stayed over here on what they call Jake Heller's part. And, that was just a man of the colony, a white man of the colony. And we stayed over there on his place. He had a house off over there, and we stayed in that house. And it burned down. It didn't burn down on its own. Ruth and Emily set it on fire, playing.

NL: $\quad$ Your sisters?

MW: Them two little ones. [Chuckles] The third girl, Emily, and Ruth. They were the last two before the twins. And my daddy plowed. He had an acre that would go from here to Ruth's, I mean land that would go from here to Ruth's, and he plowed with mules. So he would come downhill, go up there, and make a turn around, and come back down here. Well, they was out there playing. And it was hot that day, and Daddy said, "You all go to the house, and play in the shade." We had a big shade tree in front of the house. "Go to the house and play in the shade. Get out of that sun." They took off and went. And when he went this round, and got up there, and turned around, the house was on fire. And he turned the team a loose, and run all the way home, to make, to see if they got out of the house. So they got out all right. Ruth had stuck a nail in her foot or something another, they were younger. Emily stooped down, and let her get on her back, to come out with her. She wouldn't go off and leave her. She couldn't make it because she was crippled. She could go, you know, but she was crippled, so Emily got down and let her get on her back, and then took off. And then they went on out there on the side of this fence running like that, and Daddy coming this a way, and he seen the heads. And when he got closer to where he got to them here back to the house, he saw their heads, and he seen that they were safe. And that's what scared him to death.

NL: Oh, my gosh. How did the fire start?

MW: Children just do little funny things, as Art Linkletter says. [Laughter] They was striking matches to wallpaper. We had wallpaper house. I mean they papered them houses inside. Instead of just painting, they would paper them with wallpaper. And it was a thick wallpaper, you know, pretty thick that, you know, to keep it up good, stay up, pretty colors, or whatever, you know, fix it up nice. And on the outside they would put slats on the cracks where you meet like this, the lumber meet, they'd put another one about like this over all the way down on the crack, and they call them slats. And we used to take a stick or something and go around and around going bmp, bmp, bmp—playing, you know. And it'd make somebody inside know somebody's out there, somebody's doing something. We'd do some silly things because Art Linkletter says so. My mother was pregnant with Lee, and them same two got up on the house, threw a snake down on the porch. [Chuckles] She was pregnant. They throw this snake down on the porch. They didn't think, you know, it was going to harm her or anything. It scared her, you know. It scared her. That scare could've made a mark on the baby or something. I jumped off of it myself, and I didn't think it was very high, but I guess climbing around like monkeys was like children, like a boy or something. I've got a niece would just climb like a monkey all the time, all up on the porch and just climbing. I don't know what made them do that, but they would do it. But it didn't look like it was that high. It looked like it was all right for me to jump down there. It seemed like my legs went up in my stomach. 
NL: Oh, my gosh. What kind of snake was it?

MW: The snake, I think it was either like one of them little rat snakes or a chicken snake, probably the chicken snake or something like that. He was already had been killed. Someone had killed him already. And they just got a stick and got it and dropped him on there. And she didn't know if he was a live snake or a dead snake, was scared pretty bad. Like I say, you do things that you don't realize are harmful. And like they set the paper on fire, let it run for a little bit, they put it out. They set the fire from, I mean it would go up a little bit higher the next time, and they'd put it out. And it got too high for them. It got too high; they couldn't reach it and put it out. And then there's curtains there, too, that helped make it burn a lot more. You know, it had those curtains you could pull down, sort of like plastic. You ever see them kind? You'd pull them, and they'd go up. If you don't pull it down to where it'll catch, it'll fly loose and go back. Well, those kind of curtains. Anyhow, that caused it to burn down, because they had it cut out of there, them little legs could only get so high and everything, so they know they better get out of there. But my daddy was scared they're going to go run and shut up in a closet or cover up their heads in the bed or something. And so like I said, when he got closer to the end, he could see them out there. So that was a relief to him.

NL: No, this didn't burn did it?

MW: We got that afterwards.

NL: You got it afterwards.

MW: After it burned we got that. And it had a long table. It had fit what they call armchairs on each end, and two sides had three on each side, six and two, eight chairs. And then it had a big thing on the side that's called a buffet. And he bought the whole set, the buffet went with it, and the table and eight chairs, and the buffet, and this china closet.

NL: Did he buy any plates to go with it?

MW: We didn't get it at the time, but we bought it later, bought my china later. The old people had something about that size, but it was screened in, shelves and screened in. And they would keep stuff, you know, in the wintertime-I mean the summertime when it got hot. And when he milked the milk, we had what you call an icebox. I don't know if you remember that? Your great grandparents I bet had one. They called it an icebox. They'd get fifty pounds of ice, and put it in that box. That was one of those old-fashioned ones. I mean that's the way-they didn't have electricity and stuff like that then. And they put that fifty pounds of ice in there, and they set stuff around it, you know, and it would keep it cool enough that it wouldn't spoil. And the milk, they put it out the window on a shelf, but it's screened all in, and they set it out there on the shelf, and let the window down like air come in from the back because it's all screened in, like an air conditioner in the window or something, they'd let the window down. And it would slide back, you know, and get the stuff out, and then I'll pull it in and out then. And it kept good, because he bought a separator, what you call a separator, and that's what they use when they make cheese out of the milk and stuff, they take there at the cheese factory. Well, he bought this here thing that you could-oh, it had a whole bunch of tubes that go to it. Mary and Martha, they did that. That's after I done gone away from home and everything. They was at home and they did this. He'd get that, and he'd go to almost like, Turnerville they call it, a Turnerville town. Did you ever hear of Turnerville going east? Well, there's this little place where the cheese factory was. So they'd carry it down there to have them to separate the milk from the cream, and they make cheese out of the whey. You'd clabber, you'd have to clabber. It'd have water standing on the bottom about this high, it'd rise up, and that's called whey at the bottom, and it would rise up and it's like cottage cheese you'd buy. But they would have all the juice out of it, mashed out of it, to where it just would 
be cottage to you, like it is now, but it'd be packed so that you could just cut it like in slices or something. And Hog Head cheese, they used to do that way, too. Out of the head they make Hog Head cheese. Do you ever eat any?

NL: $\quad$ No, I've never had it.

MW: Have you heard of it?

NL: I've heard of it.

MW: Hog Head cheese, it tastes good, but nowadays it's not like they used to make it, because they would have finest premium hamburger, and it would be mixed up. Pig's feet, do you know how pig's feet gel and go on. Well, that would gel all together, and you could slice it. [Phone rings] So we wasn't no poor children. Walk up there and see what's going on.

NL: Now you mentioned a mark on the baby. What's a mark? How do you mark a baby?

MW: You know like you have a, well, when they pregnant, they crave stuff. You're having cravings, things like that, and I don't know, you just did mark it some kind of way. Now which one of them was it? Let's see. When she was carrying some of the kids, I forgot who it was now. Emily, the third girl, when she was born, she was born in Austin. When she carried her, she was out to the woodpile. I don't know how full, but she wasn't too full to not get around too much. And a man came along and talked to her, a fellow we know, a neighbor who lived in Manchaca, came all down here, and visited. He visited us all the time when he'd come by. And Momma was out there at the woodpile. So he walked up on them, and she didn't see him, and she jumped and grabbed her head like this. And my sister's hair is curly just like his.

NL: What?

MW: Yeah. Curly, but we all had kind of bad hair, nappy, kinky, and hers is curly. My sister didn't have to press her hair like we pressed ours. Her married name was Ivory Schwartz. Yeah. Now I had a cousin, he had a patch of grapes in his back, because they used to crave grapes, and they just lay it flat, there's a spot of them. So things like that that could happen, it will happen to them. That's what they call a birthmark, or made a birthmark. The only birthmark I got I know of is I got a mole here. My momma had a mole, and I got—my sister, Mary, have a mole right on her nose. There's about three of us, my oldest brother had a mole, I had one, and Mary had one, a little pimple up there. It just stayed up there. I used to fool with it and so what. You know how they pick blackheads, and I thought it was a blackhead. At one point I kept messing with it and messing with it, and made it bigger than what it was, but that's all it was. And so different things when they craving and when they carrying a child. Sometimes they want something that they haven't even been eating, but they want it, you know, so that do that.

NL: Now what was the name of the store in South Austin that your father got the cabinet from?

MW: I can't think of the name, but it wasn't far from Big Bear, if you remember Big Bear on south Austin. Big Bear was a part of the river, you know. Their store was in a swank. You'd come down a hill, and then go up a hill like that. To the east side, they had a whole bunch of little huts, and they were kind of like little hotels or something. I don't know if they call them townhouses or what, but there was a whole lot of them. You could just look across there and see them. Okay. We had a flood and they were covered.

NL: What? 
MW: The flood was in 1935, a flood, and it covered all of them little taverns down there. It's just like sometimes you see these, a whole bunch of little hotels, look like little hotels together, they're close together, and each one of them is an apartment for somebody. Well, they were covered. It was as high as this ceiling.

NL: Oh, my gosh. Was anybody hurt or killed?

MW: The Colorado, the Colorado, you know where the Colorado bridge is. Well, they were on that east side of that. And so it's like a creek bed or something like that. But anyway, just covered the top of them. The water was plum over them things. In the years later, they cleaned them out, and then rebuild like they do when they tear up stuff, with the tornado and stuff. Some people will rebuild and stay put, and some don't want to do it. They'd get on out. This last one a lot of people stayed that they thought ought to got out. They advised them to get out, but they didn't. And they didn't think it would be another one for years, you know, but they were fooled. It came another.

But my husband's sister was down in Georgia or Florida, whichever place that was. And she was studying to be an evangelist, and they go to church on Saturdays. So she'd come by here and talk a lot of times some of the time. I don't know how much an evangelist she was, but she was a kind person in a way, because she stayed with us when she'd come from down there for a while. And she stayed in Massachusetts. She had a daughter in Massachusetts, and then she's got a son that's down there in Georgia, somewhere in Georgia. She had two children.

NL: Were those stores black owned?

MW: They're the ones that go by Washington High. That's why my name come in as a Washington. That's us right by the window. The picture by the window, there's a man and a woman.

NL: Now that's your second husband? [Yes.] Where'd you meet him?

MW: Here in Austin. He was born down in Lytton Springs, but he'd come to Austin. He's got relatives up here, and he'd come back. His daddy was up here lots of time, and worked up here. But he was slow about going back home when he was supposed to. He had some aunties and sisters and things, this is his mother right there by him, close to him there. That's his mother. And his sister, the one I was talking about, she looks like her, and he favors her a lot. But she's been dead a long time. He was about five years old when she died. But he remembers when she died. Well, he did, I don't know if anybody helped him do it or not. But the doctor was giving her pills, and you know, then they give you the coated pills, and they'd be sweet from the beginning. They'd get them pills. I think his sister was talking about, he did anyway, I know, because he told me that they used to get their momma's pills and suck them, and eat them. But when they got the sugar off of them they were nasty and bitter, because I have taken pills that were sweet like that, and then you get that off of them, they're bitter, so you better swallow it while the sugar was on it! And so the doctor wanted to know why she was taking so much of her medicine, because they were sucking the sugar off of them and throwing them away, and she wasn't getting them. I said, "You all could've killed your momma by doing that. That could've been the cause of her death." That's what I told him. It might not have been, but they did that. She didn't get her medicine at one point. She was supposed to and all the time. Like I said, she had one of them husbands that drank and stayed away from home. So that's what happened. She had sisters and things to help her to look after, you know. Got four sisters. But he was just a rough little old boy, doing mischievous things that they used to do, you know. They'd shook at him, chunk at him, an auntie, say, "Boy, you something else." You don't never start spanking or chunking at me! 
NL: Now how'd you meet him in Austin?

MW: Well, he went on a cotton pick with us one time. That's when we first met.

NL: How old were you when you met him?

MW: When I met him? He looked like he was about twelve, but he was I'll say-Well, I'm eleven years older than him. I'm eleven years older than him. He was seventy-two his past birthday, past June second. And let's see, my other husband was twice my age.

NL: Did you meet him in the colony?

MW: Who?

NL: Your first husband.

MW: Yeah, he lived in the colony, lived right up there where I was telling you where the church and the school was. They lived right up there. And that was her son's child that teached down there, and come out here. Her name was Geneva. And she taught from the twins. She didn't teach me. I was gone, you know. Later she taught these kids. They was they teacher, and that Smith man, too, the one I was talking about, because I went to school with him, the Smith man.

NL: Your first husband?

MW: No, the Smith man I told you lived across from the cemetery, where that other church was built at one time. They just said that the owner tore that house down and had it moved to Manchaca. She was named Mary Jane Doyle Dotson. She married a Doyle and she was a Dotson. Her daddy was Roy Dotson. They lived in Manchaca. He was born and raised in Manchaca. So I hear that it was on the wrong property, as to why they tore it down. She helped to build it, so she had kept, Manchaca to put it on their property. And then she built her a house up there, up in Manchaca. My first husband said she built a $\$ 35,000$ home. At that time I guess that was cheap at that time according to what they are now days. $\$ 35,000$, so she had a nice big brick home up there.

NL: $\quad$ So most houses in the Colony weren't made of brick?

MW: No. Lately years it made brick a lot of them. Like you see this new pass up and down there, it wasn't brick at first. They turned it into brick. It was just like a plank house.

NL: Plank house? [Yes.] How big were they? Or how many bedrooms did they have?

MW: I don't know. I never did go in they house, but you know, you all see how it looks when they're building it a little bit. So about the same size that they're building, they just would be doing it good.

NL: Now was the house that you grew up in on the Taylor farm, was that a plank house?

MW: Mm-hmm [yes].

NL: What about the one on the Kavanaugh farm?

MW: They were plank. Most of them. 
NL: Did everybody in the community build those houses together?

MW: No. I don't know how they come about them, but see they got the land, and so they put the houses on the land. And after they got that land like they did, everybody, they just had some carpenter build them a house, because the one that we lived in down there belonged to the cousins, the Kavanaughs up here. The Taylors, that was his son's house. When me and my first husband stayed, that's the one that I tell you they put them slats on after they put it together. Even on these trailer homes they put together, they've got to put them together with like a slat. That little black mark you see where they're mixed together. They never had one like this, that they'd call that, what they call that like they would a church. Beams. What kind of beams they call it? Well, I can't think what they call it, but it's a big name. You see them in most churches there. You don't see that in those trailer houses or no regular houses like that. Cathedral?

NL: I don't know the name of them.

MW: It's something like that, but you know, if you'd be in a big church, and you look up and see those kind of things. I think they call it cathedral, cathedral ceiling or whatever, but the type of things up there. But you know, they're made out of pine or oak wood, and you look like you think that's a solid thing, because they've got two leg planks up like that, and one like that, and then up against the house. So it's just hollow through there. It's like going through a tunnel, through that stuff up there. I thought of it just one big plank like that, but it's small planks, like a one by one on each side, and under here. The one under that is a $2 \mathrm{X} 4$, and the one up yonder is single, 1X1. I've never seen no other trailers with this in the ceiling. If you look up at Mary's and you'll see it's one of the older ones. And this is 14X72, 14 across, 72 long. And it was made down in the valley down south there somewhere. I can't think of the name of the place where it come from. It had all of that in it when I got it. And the lumber was much better, this here paneling was much better. And this is, I've been in it for twentythree years, and I don't know how long somebody was in it before the twenty-three years, but it's held up for twenty-three years for me here, and I haven't had to have too much done to it. Like I told my husband, you keep up with stuff like you do a car. If your house goes leaking or something, you do it right then, don't wait until it fall all apart completely. But I couldn't sense that into his head, he talks more of cars. Anyway, I've been blessed so far.

NL: I wanted to ask you something else about the houses. The plank houses in the colony, were most of them one-story or two-story?

MW: There's very few two-story around here, but like I said, the Buntons, them's property up there, it wasn't his property, but his grandparents. They was the house.

NL: Your husband, Bunton's.

MW: Yeah, my first husband. He came in as a Bunton, but he's no relation to me. He's just kin to me by marriage. Well, he got people, you know, that he's kin to. His daddy was a Bunton, so that's where he started out as a Bunton.

NL: What was his father's name?

MW: Augusta Bunton.

NL: Augusta Bunton.

MW: We called him Gus, but Augusta was his name. 
NL: Now which one of his relatives had the two-story house?

MW: That was my ex-husband's mother's house. It was her house, the two-story one up here. Well, there wasn't anymore two stories outside that old school that I told you they had. And the rest of the schools, they wasn't two stories. It was just that one two-story. All other schools were single like a house.

NL: $\quad$ So if you had two stories, did it mean you had a little bit of extra money?

MW: Well, that's the way they build it. It's more like an attic. It wasn't a big room up there. It was a small room like a little kitchen or something, but that's what they called it an attic.

NL: Just to store stuff.

MW: Yeah.

NL: So where would people store stuff in the houses that weren't two stories?

MW: Load up too much, like you see in here. Let's put everything all in a single house, single room. But some of them would be pretty good-sized rooms. Like if they had two bedrooms, both of them wasn't the same, big, like now they talk about master bedrooms and so on. Well, they just had one big one, and the other one was smaller. In Arizona where we bought our home, we had a master bedroom, and the other one was smaller, kind of like that one in there, and a single bed. I come about a king-size bed from people I work for doing domestic work. They bought them a new one, you know, and they give me that one. One of them I paid for it through my work for them. Like what she paid me, I let that go on it for about twice, and it's like giving it to me in a way. And then I had one that give me, her husband went in the service and had stuff from over there shipped here, that type of stuff, and she gave me a dresser and a bed. The one that they had before he went in the service and all of that. She gave me the older one. And it was good. That bed had one great big round mirror go all the way around. Then they had two side things on it, and across in the middle here was glass. It lasted a long time.

When I called myself started housekeeping myself, my first husband, I don't know if you would remember that or not, but I know your people older than you would, they would buy like the table and stuff like we was talking about, they'd buy that, and they'd buy a china closet, they called it then, because they're bigger than that. That's a small china closet. They buy some big ones. Mary had one with lights in it and big. The one that got burned down up here. They burned that house. It's been burned down. It burned down in this last part of last year, or early part of last year. This year, no, this is nine. This come in the eight, this happened in eight. And that's why Martha has so much stuff over there, they packed all they could over there, that they thought they could use, and so much of it they just couldn't use. That's why she's so junked up with stuff. And then people that know you begin to give you stuff on top of what you got. And then when our house burned down, people momma worked for over in Buda, they just supplied us with stuff, beds and stuff like that. And you been bought some, you know, after it burned down. And then they started to just giving you and helping you, so you just wind up with a whole lot of stuff. That's the way a lot of it come here. A lot of people's stuff they give them, they would give it to us if we wanted it, and I didn't have no room for none of it.

NL: Well, tell me something, after the house burned, on Mr., you said Heep's property?

MW: We could keep the property? 
NL: No. I was asking when the house burned when you were younger, it was Emily and Ruth burned the house down, on Mr. Heep's correct? The white man whose property it was, what was his name again?

MW: That was the Taylor property. No, not the Taylor property. The Taylor's that lived up, it was his nephews that took over stuff after his sisters-he had some sisters and he had, it was two brothers. They had two boys. And their sisters had children, like that. His sisters had children, like the one in Houston had two, Nina, she had a boy and a girl in Houston, Inez. And Roberta didn't have any, the one I said taught in her place, she didn't have no children, so they didn't have too many.

NL: Now were they black or white?

MW: Black. Far back it might've been some mixed. Far back, you know, because this one in Houston was a light color, Nina was light colored, and their daddy was a light man. Like I said, it's mixed back there somewhere, because his wife had a sister they said was in slavery. She had a half sister that was in slavery. So that was probably where that mix come up at. And they wanted to know about her, her half sister, these Taylor's down here, wanted to know about that. They got papers and stuff, too, it's in that book, the Taylor's, the man that come here and bought this stuff. Now this Ransom man, you're talking about, William, I know a lot of Williams. I wonder if there's any relation to any of them.

NL: Well, we'd love to find that out. I mean it'd be great to actually try to track down some of his descendants if possible.

MW: Because there was some Williams that lived on the prairie out there, and one name was Emmett William, one they called Jack William. Jack William was a half brother to Emmett.

NL: Do you think you could put me in touch with any of them?

MW: Well, they're mostly all gone. They probably have all died out. Now they got some children. Everett William's dad is gone. And then Grants, they were related. And I think you said, have you talked to a Grant boy? Or you're supposed to or-?

NL: I think we're supposed to. But I'd love to find out some more about some Williams. Williams, you know, is near the Prairie.

MW: Yeah. I did know the older ones, but they've gone on, and have children. They've got a daughter, and where is that daughter at? She way up the country. And she's got a brother named-Imogene was their daddy. Their daddy's name was Imogene Williams. That's the children's daddy. And their daddy's daddy was Williams, Emmett Williams. Emmett was their daddy's daddy. The boys are their children. This girl and boy, her name was Wanda Lee, I believe that's her name, Wanda something. Imogene and Reese, them was Mr. Emmett's boys. And these children I'm talking about is they children.

NL: Okay. Maybe I can try to find some of them and track them down.

MW: Well, they're so far off. You might be able to find them. I've got a cemetery thing that has all the people that contributed to the cemetery, their names are in there. They got their name on that church come up built out there. That was they church, too. It wasn't far from it, because they just live up there on I-35 from Goforth. And these children are all out of town. Their parents died, and they're all out of town, like in other states. I'm trying to think where one live. That boy is in California, what is his name. He looks just like his daddy. I can't think of his name right now. 
NL: While you're thinking about that, I just wanted to go back to a question that I had for you. How many whites were living in the colony?

MW: Oh, white families. None of them, I don't know. Like the ones we worked for and stuff like that?

NL: Well, there were whites who did live in the colony?

MW: The ones we worked for, yeah. Yeah, them were all white who we worked for. It sort of reminds, like you said, slavery time, how they treated you.

NL: Because I only thought the colony only consisted of black families who owned their own land.

MW: Well, it's black, but they work for white people, is what I'm talking about.

NL: And they were pretty much really close by?

MW: Yeah.

NL: But they're not part of Antioch.

MW: Yeah. Antioch reaches so far, Cross Creek, they always called it Cross Creek. Over here all Cross Creek is Antioch. Now down Goforth where I was telling you about, that's not considered as the colony. Lots of them over there went over here in the colony school. That was the closest school for them. And then like I said, when it got to where segregation come about, you could, they would let the black go to their school. They put them out in seventh grade, and then later tore the school down.

NL: What were the relationships like between the blacks and the whites when you were growing up? I know you said it was like the slavery times for some of the workers, but did they get along? You know, just living next to each other.

MW: Yeah, they got along good. The ones we worked with that had children, they were all good, nice children. And I had cousins who lived in quarters, we called it, where they had little places to stay there all the time and work. And, I had two of them, two sisters. One stayed right across the railroad track on that side. They were remodeling a big house. And she stayed in service over there. Them people were called Servants [?]. Their last name was Servants. And he would, you see these things that carry gas with big shiny body, he droved one of them all the time to other places. And they had different jobs. The ones, the Bartons up there, he was a professor, and he had a son named after him, and a daughter. His daughter's name is Annie, I think. And people like that, they come and get along good, you know. Some of the white people were really nice, you know. There's some that the lady, like I was telling you, we couldn't eat in the house, but there was some where we could eat in the house. And the Staten's [?] quarters right over here next to that senior citizen place over there-there's a senior citizen place right off over there-and her son would go down to their momma's and eat most of the time. They weren't too particular about their wives' cooking, especially the one I worked for. I worked for one. My cousin worked for the parents, and I worked for one of them boys, called Jack Barton. And his mother-in-law was from Weslaco, and she'd come up there sometime and visit them. They'd fix dinner. I think I fixed that dinner. I think I fixed that dinner for them, but anyhow, because his wife wasn't much on cooking. She opened a can of corn, and when it gets hot, she put some butter in it, and she'll season it up, you know, let's put some butter in it, and green beans and stuff like that. Maybe she just wasn't taught or didn't know how to cook, but that's the way she did. He'd go down to his momma's and eat. $\mathrm{He}$ ate there that day when momma was up there. And when they get through eating, she's 
going to take everything off the table that's, you know, big chicken legs and the thighs, she's going to move all of that, and left me a wing and a neck on the platter. Her son said, "Don't bother the table, Momma. Mary can take everything off." He said, "Don't bother it." Said, "Leave it alone. She'll put it up." She was putting up that, you know, and left me a wing and a neck on this platter. Chicken fried, and put it on a platter. Like I said, some of them were just different. In town, a woman told me, "How you know that wasn't my supper? Why'd you eat my tuna fish?"

NL: I remember you telling me about that.

MW: She was from Beaumont. They just had it tough in those days. They've given me lots of nice things, and they've given me lots of things I could've thrown away, but I take them, you know, like that. They call their self helping me and doing for you, you know. She'd fry food, pool the grease up and save it for me, like I wasn't able to buy some grease. Lord, like we used to get, you know-we used to make it with the hogs. Cook the cracklings and get that grease off of them. We used to grease our legs with it, like Vaseline.

NL: I didn't know that. [Laughter]

MW: I mean, you know, we cooked with it. We seasoned beans good, because it's got that beef, I mean pork, flavor.

NL: $\quad$ Flavor already in it, yes. Now tell me, do you think growing up in an all-black community, do you believe it helped to shelter you from the racism that other blacks faced?

MW: Help them?

NL: Like it helped protect you or shelter you from racism that other blacks say, you know, in other towns may have faced?

MW: Yeah. Helped them?

NL: Helped you. By you growing up here in Antioch, which was an all black community, do you think it helped shelter you from racism that maybe other black people would've experienced in other areas?

MW: Yeah, they would sometimes. Because when some girls used to ride by our house where we stayed. They were riding on horses going to school. And they come back by our house, they stop and rest, and want some water, and we'd give them water. And then when they leave they'd call you niggers. They done got water and everything, take off and, "You nigger, you." [Chuckles] They were just silly children. They stayed up the street from us, but they went to school on horses, but we didn't go to white schools then. And they'd pass by there and stop and chunk rocks and all that kind of stuff, and we were trying to be nice getting them water, you know. Now days they come all in your house with your kids. That's a big difference, you know. Some of them don't realize it, sometime will question their parent, "Did you do that?" when they hear it, you know, like how they did us. They didn't know that they did, the parents did the black like they did sometime. They didn't teach them that. They didn't let them know, you know, they did all of that. They just know that you worked for them, you know, that you worked for their parents, because they'd be running around there. One little old boy told his momma I spit on him. [Chuckles] But what was happening, I was cleaning the vacuum cleaner. He's standing around there wanting to what you're doing, and how come you're doing this and this and just talking, you know, and I sneezed, and a little flew out on him. Because he was right up on me, a little bit flew out on him, and he told them that I spit 
on him. And I tried to explain to her what happened. But I still worked for her. She didn't get rid of me for the time being.

NL: What did she say?

MW: Nothing. Nothing. I've had them just chastise them, you know, saying, "You don't ever do that. Don't say that." Because my sister worked for one that called her black all the time. And then when she'd run into them in the store somewhere, "Hi, Grandma. Hi, Grandma." That's what they taught them, like they call old ladies aunties, you know. White people say, Aunt Ellen, Aunt this person, like that. They just called them auntie because they're old. They used to call men Uncle Tom.

NL: Even if your name was David, they would still call you Uncle Tom?

MW: Mm-hmm [yes]. Call him Tom. Tom sometimes was a person, they called them Uncle Tom, Peeping Tom, you know, just like sometimes they'd be, you know, sneaking around, stuff like that, they called them Peeping Tom. But they just call him Uncle Tom if that's what they're talking about. But some people had the name Tom, so they couldn't get away with too much, because they understood the-what you call it—like the segregation, but they called it another name.

NL: Jim Crow.

MW: Well, it was Jim Crow times then. [Chuckles] Yeah, it was Jim Crow times then. Yeah, that's what they said about a poor person, was a Jim Crow. First time I heard that word in a long time, a Jim Crow time. Woolworth's was, that's what they say, because, you know, we'd go through there on the bus, and it'd stop. They'd wait on everybody else before they would you. And the bus would pull off before you get your food eaten. And the sign "To the Back"-go to the back. You know, when you every time off that bus, you don't fall in the front door, you go around to the back.

NL: Was that how it was when you would catch the bus to Austin, too?

MW: No, not to Austin. Just like go up to El Paso way, you've got to go through El Paso, on up to Phoenix and wherever, and stop in between.

NL: $\quad$ Now the bus to Austin, was it segregated?

MW: Yeah. It wasn't segregated until the emancipation or whatever you call that, segregation. It wasn't segregated then.

NL: Right. But when you would ride the bus to Austin from the colony, was it segregated? Would you have to go around, like go to the back?

MW: You know, in Austin? Because we didn't have them out here.

NL: So you wouldn't have any buses in Austin?

MW: No. You would have to walk to I-35 and catch it on the flyway. On I-35 or somebody to drop you off or something, you've got to go that far.

NL: And you could sit anywhere you wanted on those buses? 
MW: Nm-mm [no]. Well, on that bus, yeah, but most people so used to going to the back that they would go on to the back, because that's the way they're used to doing it. Then when I'd ride in Austin that way, because one lady pushed a nun or something another off the bus, and they put her off the bus. And they're blaming black people doing the same to some of them white people, you know, they're going to take up for them. And it said, "Go to the back, to the back, to the back," the old driver would be saying. They put it this way. "Fill up the back first, and then come on to the front." You know, like that, so a lot of black women would just sit down as soon as they got in the door good, way up there, you know. But they didn't allow them to do that, unless the bus was filled up that full, and then that happened right in Austin. And then they'd argue with one another something on the bus, people would with other people on the bus, especially the white kids when they got off, the college kids and everything, they would mess with them. And the colored would get up and give you a seat. If it was a crowded bus, you know, the men would get up and give you their seat. Some of the younger women would give the older women their seat, you know, just respectful. But them others, shoot, they ain't going to move. You would be standing up holding the straps, and you would have ride sometime all the way that way. But when other people would have respect, they'd say, "You, take my seat." If you had a bag, they'd say, "Let me hold your bag." And they'd hold a bag until you got ready to get off. It would be better than trying to hold it standing up, you know. So they been that a'way for a long time. We've come a long way, as they say. The Alamo, down near the Alamo there's government or something they call Houston, Sam Houston. You ever hear about him through history? [Yes] I didn't know much about him, but I mean I've heard, he was a president or something of the Mexican Territory. And they named a school Sam Houston in Austin. Do you remember that? It was off of Eleventh Street over there.

NL: Oh, the college, yes. I didn't know that they named it after him.

MW: Well, I don't either, but some of his people way back or something other, you know like they mix, could have been, but like I said, in the slavery time we get their names when they buy us out of African, whatever they call us, African. One woman said on the news, "Send them back to Africa." She means to send them back to Africa, because that's where they need to be, back in Africa. [Chuckles]

NL: Did any of the elders ever tell you about the problems that they faced with racism?

MW: White people? They never talked about it.

NL: Never?

MW: Nm-mmm [no]. They figure we didn't know, they wasn't going to tell them. You know, we learned some of it through school, or if you didn't go to school you didn't learn none of it but what your parents told you. Like that book I was telling you about, I saw that book somewhere, it said civics, well, we they didn't have that when I was going to school. They've got it nowadays, but they didn't have it when I was going to school. I thought it was something like an algebra. After the eighth grade you can study algebra, but you can't get algebra until after the eighth grade, see, and I never got to the eighth grade. And I thought algebra would go something like arithmetic, but you use the alphabet. That's what I thought, sort of like arithmetic but you use the alphabet instead of numbers. I never did get that far to know really how that went, because I never did take it.

NL: Did you remember attending any funerals when you were young? [Yes] Whose funeral did you attend? Do you remember any of these funerals?

MW: I remember on my people's side, yeah. 
NL: Do you know if people would place objects when they would actually bury people, like at the grave? Would they place flowers or what types of flowers they would place there? [Yes] What else would they place there?

MW: They'd put a headstone at their feet. They don't put it at the head, they put one at the foot. They might put one at the head sometimes. But it's just made out of tin, little tin plaque sitting down there. And then the weather will wear that out, wash the name off and stuff like that. It doesn't last long, they just put it temporarily because they expect for their people to put a headstone on there. But it showed the head and foot. And my nephew LeeDell put a headstone on my mama, on my daddy, and on his daddy. He's always been a kind, helping person. That's another thing that caused my husband to be a little salty, because I have him pay my bills for me. I give him the opportunity to pay my bills, and I'm on the verge of a divorce. [Laughs] I'm tired of this. [Laughter]

NL: Do you remember if people would place any other objects with the deceased besides the headstone and the footstone and the little tin, would anybody put anything else down there? Like would people leave anything, maybe leave a bottle, or maybe something that they used to go in the cemetery with them?

MW: Nah, no more than if their house burned down, you see them old brown snuff bottles around. Leslie had some for a long time. I don't know if he's still got them or not. Because when the church burned down down there, when I was telling you about the church on Goforth, see, that's considered as a colony, too, coming on this side of the creek. They're square bottles and they're round, and they have a cork in them. That was what they dipped snuff. They have some snuff they call sweet snuff. Have you ever heard of Sweet Gary? That was the name on some snuff, but it was sweet. That's what my aunties and grandma smoked, or used. Put their stick in their jar and just pull it up full with snuff. And they would be spitting and spitting ever so often, you know.

NL: And they would put those out in the cemetery?

MW: No, but they had them, you know, they must have had them around the church some kind of way, empty the bottle and throw them on the ground, something like that. When it burned down, it showed them, they found them. And boys hunting rabbits and stuff, they up that stuff. I had one of them things on the railroad, I think they call it a stave, an iron thing, it's heavy. That bright light you see there that's blue, I had one of them a long time. I wonder what happened to it. It blue at night, you see it go by, it's blue, and then it turned red when it was getting close like that. I've had one of those, I picked it up off the track. Well, when they change them or whatever, they throw it to the side.

What about ironing, we ironed with a heavy iron, smoothing iron. That's the kind you all use?

NL: No, it's still like the old irons were, the heavy metal ones, except there's a lot of plastic on it. So it is plastic, like almost at the heater, and it has a metal plate on it, and you just use that.

MW: Got a little tank for gas, you use that one?

NL: No, not for the iron. For the irons you put water in it, put a little bit of water in it and the steam-mm-hmm [yes].

MW: Well, they had an iron that had a little gas tank on the top, and boy we thought we were in high water then, thought we were really doing good, didn't have to sit them on the coals no more. A furnace, they'd have a bucket like a furnace, and they have charcoal in it, and it would have a little grate on top of it. You'd set your irons on it. That's what my aunties and 
them did in Austin, they ironed that way. But my people in the country, they had a fireplace, and they kept that wood on it when it would burn down to them red coals, they would set the iron on it.

NL: And that's how they would warm it up.

MW: Mm-hmm [yes]. And then they had some that the handle come off. You put it on it, and when you get ready to get it off, you put the handle on there. But that gas one, you'd go phutt, phutt, phutt, phutt when you're ironing, because that's the gas getting caught up, whatever. And it had a nice blue flame, just like this furnace on gas in here, nice blue flame. And they was really nice. When we got a house in Austin after we got married, and some people had it, and they had a daughter and her husband went in the service, and it was their home. And after they went in the service, she moved with her parents and rented it out. And we got in there and it had a heater in the wall. We were used to all them stoves and stuff; wasn't used to that. That was a little bit better. And it had an iron fence around it. So we really had a nice place!

NL: Where was your house in Austin?

MW: Right off of Twelfth Street. There's a man they call Mr-—he had a brick house in the front for himself on Twelfth, and then he had a bunch of little houses. He come down the little hill there, and it was back down in the hill behind the park, Rosewood Park right back in there. I stayed there a long time. But that's the neatest house we ever rented. It looked nice. We liked that furnace. You've seen them in the church and things, way before they got them like they got them now. They about this tall. And you get down there, learn how to light it, and it just makes a nice-come on and off, just like this electricity do here now, and it come on and go off, come on and go off. But it was sure nice.

NL: What would you do for fun when you were living in Austin?

MW: Run around little honky-tonks, clubs [chuckles] and stuff.

NL: Do you remember any of the names of those clubs?

MW: Yeah, there's the Zanzibar. It was a big new place they built in Austin one time. And they had Carver Theater right down the street from it, coming towards I-35 on Eleventh Street coming that way. And we'd go to the Carver Theater. Then they had Ritz was the oldest theater. It's further up on Twelfth Street. And stuff like that. Those picture shows. And like I said, the honky-tonks, because that's where they were really winding up down there [laughter]. But then they had clubs were nice, you know, you could get to dinner, you'd get served nice food and stuff. Maybe a beer with your food if you want it. But they didn't allowed to have the kitchen in the joints connected. You'd have to go a door or two further or whatever.

NL: What would you do for fun here in the colony?

MW: Well, these older ladies had what they called entertainment, they would call it, and they would make-my mother-in-law sold peanuts, little plastic cup like that of peanuts for maybe 15 cents, a quarter. And they was, like they do now, raising money for the church, stuff like that. And older days when we'd come, they had ball games and horse races and dog races and stuff like that that they had fun with. Daddy said every Sunday when they got out of the church, they would go gig riding, racing in their gigs. I don't know if he had one of them. But my grandma had a buggy, because I used to ride it to work with her. See, a buggy had two seats in it, and maybe a little thing in the back like a truck, and I'd always go to work with her and ride with her. Like I said, we'd go with them to work, we'd make fires under the 
pots to boil to clean the clothes. And then at home we did the same thing, the clothes. But we didn't have a smooth clothes line, we had a barbed-wire fence wire, hang them on a barbedwire fence, and it'd hold it like it's got pins in it. It was smooth when you got clothes pins. [Chuckles] So we finally went from barbed wire to a smooth wire. [Laughter] You know, it's funny. The neighbors over here, they had one, it's a round one. You know, you've seen them in people's yard.

And my brother-in-law, Mary's husband, he put my sister up with Grandma when she moved here. She moved here from California, and she lived in Dallas a long time. Otherwise she was away from Buda fifty-seven years. We were almost like strangers, but I went to visit her in California. She was in San Francisco, and I went up there and visit her. She was in Daly City up there once, but I've been with some neighbors in Daly City. But she moved over there, too, after that. Then she lived on post one time when she first went there, on post there in California. San Francisco she stayed the most at Bev's [?] place, with little neighbors around. You know how people buy up them big houses and everything and rent them out, like they do, a contractor, well, they wanted to go up on the rent, and they like sold out to somebody else, so she had to find an apartment somewhere else. But she was kind of a particular one, very particular. [Chuckles] But I learned to go along with her. I told the twins, "You know Unie has been gone for fifty-seven years. How she going to know what all we done down here?" [Laughs] She used to visit, and she'd just enjoy herself when she visited us. But when she come down here, and everybody was so poor off like, she said that wouldn't happen. Because she give them money to go to school. I did, too, those twins. I'd give them lunch money because they'd come by my house when I lived in Austin, I'd give them lunch money to go to school, try to help them out. And I bought the gowns for graduation. My daddy always counted on me to do things like that, you know, stuff like that.

And they lived-they went out there in ' 56 , they went in '55, and the kids stayed here through college with Emily and her husband. They lived on Fourteenth Street off of Twelfth. He let them live and stay with them and go to school until they finished graduating. Then after that, they went to where they were. So I didn't go. I went out there visiting, and I said, ooh, I can't live out here! Too hot, too hot. It was eight o'clock at night and it was over 100 degrees. They got used to it after being out there so long. And you have to come used to those kinds of things, but it was just hot, hot, hot. I said I can't stay out here! And I'd wind up going where they was because they kept saying, "Come on! You get $\$ 2$ an hour out here!" I was getting $\$ 2.50$. [Laughter] No, I was getting $\$ 1.75$, they were getting $\$ 2$. I said it's a quarter more. I was still getting along just as good as they was. [Chuckles] You know, getting along the same way. That's the way the towns are. Then you go north, as they did in Roots [?], and you'd get more money, and more house rent too, and all of that. You know, everything is different. Every state carries its own presidents and stuff. Every city. Like we had to learn the capital of different cities. You know Austin is the capital of Texas.

NL: I want to ask you more questions about you growing up and your family. When you were growing up, who taught you about the proper role for a man and for a woman? Who taught that?

MW: My dad. He taught that to us, you know.

NL: What did he say?

MW: Well, he would tell us what the difference when you get married, you supposed to be honest with one another. He said the Bible says to act like Jesus was with his parents and the church, you are a twain [?], you two, and you supposed to have some of the same ideas or some of the same ways, and not just be completely different from one another. Because he would say, you know, you pulling against instead of together. And, so all of these things that 
married people should do. He told my mother when they got married, "Now you can't get out there and dance and go on now, because you married!" [Laughter]

NL: Your mother used to like to dance?

MW: She couldn't hold her peace. She would go to these ladies that'd give these entertainment, she would go dance, that's what he said. And then he was kind of jealous, too. [Laughter] Yeah, like I was telling you, they all can dance and they all can drive a car, but I'm slacked in that. [Laughter] Every one of them can.

NL: What did he teach his sons about being men?

MW: Same things, about how to treat a wife. Not go courting on her and all that kind of stuff. They tell them all about it, you know, tell them about it. The preacher in our Sunday school was talking about the man that had so many concubines. So I said, "What is concubines?" So he explained it. See, women that like they doing, they got a learn there is concubines. That's what they're called in the Bible. And the real truth is that's whores on the street, you know. And a man is a dog-it be said in the Bible. And I read that in there, and I used to quote scripture that he read to us. I tell my brother sometimes, I say, "Daddy taught you better than that." "Ah, he taught me the same thing he did you." I say, "Yeah, but I listened, and you ain't listening." [Laughter] He talked about the woman meeting Jesus at the well, and got to talking to her, wanting cool water, and He told her the water that He would give her would last forever, she'd never want no water no more. Then they got to talking to one another, until she told Him she had five husbands, and the one she got now wasn't hers. She goes out and tells everybody, "I met a man that knew everything about me." Yeah, that's in the Bible. I try to figure these things out, but you know, you can't in a way. I said why would they preach about man being a dog? Well, that's what he was, he just had more women than his wife. And some of them act like they can't get along without it.

NL: So how did your father learn about this? Who taught him?

MW: His mama most likely taught him. His daddy died at an early age. He's fifty-four years old-he was a young man. So I don't know if he was jealous of Grandma or not, but I know that Daddy said that, and it seemed like because of his weakness or something, it seemed like that's why the Lord took him early. But then they take them young, they take them old, they take them middle age and all kind. Even to baby, and the baby hasn't had a chance to sin, so he know he got a light soul that way. But you have to pay for them sins. They don't realize that. You have to reap what you sow. Sow some bad ones, you're going to reap some bad ones. Good ones, you're going to reap good ones. They got a song out about he hopes his good outlasts his bad [laughs]. About as much bad as there is good, that there's the same both ways.

NL: Did your father's parents live in the colony? [Yes.] And where did they come from before coming here?

MW: We stayed in Austin a long time. I think I mentioned his job was working at the park. And because he didn't pay - the man asked him, do you pay your poll—they don't call it vote like we do. And he said no, he didn't think he had to pay no poll, but as a citizen you're supposed to have. He told him no. I don't even think he knew what they was talking about, really. He told him no, so they fired him. Fired him just because he didn't pay poll tax.

NL: He came here?

MW: Yeah. I don't think he done no more work after the lumber yard work here. 
NL: Now is this your grandfather or your father?

MW: My father.

NL: What about his father?

MW: Like I said, I didn't know much about his father.

NL: Because he passed early? [Yes.] What about the mother?

MW: Oh, she was sweet. She was a good lady.

NL: What was her name?

MW: Ella. And she had a daughter named Ella after her.

NL: Was she living here in the colony? [Yes.] Pretty much as long as you knew?

MW: She lived in the colony because all her children were born here. The two oldest boys were in the service. Then she was a bachelor for a long time. She didn't marry no more.

NL: Did she ever tell you how she ended up—how she came here?

MW: No more than through these tales and stuff. She had a half sister they said was born into slavery, and I don't know if she ever remember her or not, but that's what the children located in history. My mama said — well, my mama didn't say that. Mary Martha said Mama's sister Willie says she said they came here as Moores. That is a slavery name. I didn't never understand that. You know, you got a parent and you know his name, but why would slaves name be his name? That's the way they do when they buy them. They like sell them. Especially the Africans and things like that. I never know, talking about how they come here on the boat, something like that. They boated them over here. And, a lot of people just know that most of the black peoples were African Methodists. And I guess that's why they named the church African, Episcopal, African Methodist Episcopal Church. So they have different patterns and different orders. For one thing, that's the way they do. But there ain't but one God they got to serve. They ain't got no two or three Gods. They may have a bunch of other gods, but serving the right God, the true God.

NL: What were the particular burdens of being a woman in this community?

MW: Having to raise the children mostly by yourself is one of them. They had husbands, but they did most of the teaching and stuff like that. My mama didn't go to school long, and her daddy used to say none of those girls had much education. They call them old maids because they hadn't had much education, you know, and had few children. But it don't have to be that way all the time. You can seek wisdom and knowledge. You know? You can learn, ask the Lord. That's the way I gets by, put my trust in Him.

NL: Growing up here, do you think there was any difference in how the way men and women behaved and their responsibilities? Were they different from maybe other places that you have lived and been?

MW: Yeah, fighting go on. They'd pull apart women, you know. You could stay together, you grow together, and you pull apart, you part from one another. You don't have the same ideas, you don't have the same nothing. Like twins, you twain when you get married, there is two of you, and you both should have the same ideas and the same ways to get along. But when you 
are trying to look in somewhere else and over the fence and whatnot, that's not together. So there's been a lot of that amongst my family, and other people, neighbors and whatnot. I've seen it, you know. And I've seen women not teach their children-they just don't know the way. They get out there and do what the children is going to do, but they have been where they're trying to go. I tell Lee when he gets to talking to me, I say, "I've been there. I've been where you trying to go. You trying to go the wrong way." [Chuckles] They don't want to hear the truth. They always say the truth hurts. My sister Ruth says, "Why you say the truth hurts?" I said, "Because you feel sorry for that person that's doing what he's doing, and you know what he's doing, and you just feel sorry for him." So it hurts you for them to know what you do do, and they see you.

NL: Did you recognize this stuff as more and more people began to leave the colony, this stuff happening?

MW: Well, the older ones has gone out, and the younger ones is going to go. They ain't going to stay in the country. They like the city. When we come back from the cotton patch, come back home, we used say Eleven Light City_it had eleven towers. We was going back to the Eleven Light City, we was so happy to get back home. [Laughter] Really, you ask anybody, there's eleven towers, them big old towers. We had one not too far from my house when we lived on Sixteenth Street. We had some neighbors that lived across that bought a new home, and they was named Fields, Mary Fields was the woman's name; I forget the man's name. But they bought a new home across from us, and we'd go out there and play under that light. That light was between us and them, you know, like your light shines in the road. And bats would fly down there to us. We'd be running around out there. Once they fly down low, it be dark to them, and they'd just be flying all kind of ways. We'd just be running and playing. [Laughs] Bats.

A nephew took me to San Marcos to a cave down there, and they told us to put on some shoes that wouldn't slide and go on down in there. So we put them shoes on and went down in there. But it was over 85 degrees-it was hot down in there. It was sultry like, you know, down in this cave. We went way down. And this big old flat round rock, and they said you could cook an egg on that rock, just break an egg on there and it would cook because it was red hot. And the cement-type stuff, you know. I enjoyed it, but I don't never want to go back! [Laughs] It was something strange and new, but I don't want to go back, like the Grand Canyon in Arizona. Yeah, the Grand Canyon, my nephew took me there to see the Grand Canyon. We took pictures and everything. We had a good time. He's always been nice to all of us, but I was sort of special. But he been nice to all of us. He'd come here visiting on a job he had this a way that was close by, and he'd take us out to dinner, give us all a big red rose and take us to dinner. He'd do things like that. Ain't none of his brothers did it! [Laughs] They all right, but they just selfish and tight, you know, them brothers. They want you to let them have, but they don't want to let you have. That's the way they are. My dad, he had faith in his boys I guess because he named them out of the Bible. They didn't turn out like them Bible names! [Laughter] And he named us, too: Emily, Eunice, Mary, Ruth-they all in the Bible. I don't know what he thought that'd mean. Maybe he thought they just would be good people, good children.

NL: Growing up, what did your parents expect of you?

MW: To be obedient and do like they tell you! That's what they expected. Listen and mind, and you get whooped. The Bible says don't spare the rod. They didn't spare it. They done hit you with it. [Laughs] Mama, she was a good runner. She tried to catch me one day though, and she couldn't catch me. I forgot what I'd done. Really, I don't know what I'd done. But whatever it was, it was enough for a whooping. And she got after me, and she was right on my heels. I 
was running as fast as I could run, up in the fields where Daddy was plowing. I thought he was going to take up for me! [Laughs]

NL: He didn't?

MW: Unh-uh [no]. He stopped them mules, he says, "Whoa," I be in front of them. "Whoa, stop." I be up in front of them. And then I turned then, since he wasn't helping me, and come back towards the house, just flying. She never did-she give out, she never did catch me. But she had switches planted behind the door. That night when I got home, I got it.

NL: What other things would happen to you if you didn't follow their rules?

MW: They whoop you.

NL: That was it, huh?

MW: Yeah, they'd give you a good whooping. They'd talk to you and tell you what they was whooping you for. I heard somebody say, "Well, sometimes kids don't know what you're whooping them for." But you would know them days, because they'd tell you. "I told you to do such at such a time and you didn't do it." Bam! More licks. [Chuckles] Yeah, they would tell you. They'd let you off at times. You know, you was supposed to got one back then, but they didn't get you, they let you get by. And so next time they don't let you get by.

NL: Do you have any children? [No.] Do you know who delivered you?

MW: Dr. Lauderdale. No, Holsclaw. Holsclaw, he was the first old doctor. Lauderdale followed him.

NL: Were you born in a hospital or were you born here in the colony?

MW: I was born in the colony. Doctors would come to the houses then. Them days they'd come out to the houses with their satchels. They'd come out in a buggy, like the old-timey was. If they didn't have a car, they came riding out there in the buggy. They didn't have telephones, either, to call them. Somebody would have to go over and knock on the door and have them to call, like that, walk and get them. Then later the ranchers started getting phones in their house, and they had their own phone that they would ring like cranking up a car. We had a car you crank up, old Ford Model A, whatever they called them back in them days. And so they would get answers like their phone number would be like a person would ring you two times, they'd know who that belonged to. And one ring it three times-well, anyway, they knew it wasn't theirs, because theirs would have to ring about three times to be their phone. And then if it rang two and stopped, well, then they knew it wasn't nobody trying to get them. Yeah, they had us fixed up then in the rancher we worked for, me and my first husband, the Kirkendalls. And there was lots of them. They had their own cemetery over here in Kyle. And they had a little girl named Marian, and she died on a chicken bone, she choked to death on a chicken bone. That part of the wing, you know, that little skinny part on there. They always wouldn't never give the children a wing after that because it could get crossways in there sometimes. She choked to death on that wing. And she had two aunties, and Marian named her daughter Mary, and the other one named Dorothy, and she married, her daughter married a Kirkendall. No, it wasn't a Kirkendall. Who'd she marry? There's a street in San Marcos that's named after him. I can't think of the name of it right now, but she married different. And Dorothy had a boy, and she had a girl and didn't have no more. But they daddy had two boys, didn't have no girls, had two boys. When me and my husband stayed up there on the ranch, we stayed on the ranch a lot of times, I would help her clean up and do stuff like that. And when they had company, boy, big old party or something, he would help clean up the dishes. Me and him both would wash up the dishes. And other times he would come like mop 
the house and the hard work, like he'd come in and mop the house. And a lot of young men worked like that, like a woman in white people's houses. Because he used to work for some people in Austin, he would do stuff for her, he would do stuff around there.

In Austin, I don't know if you ever heard of it, I think they executed a Holmes boy, William Holmes. They drug him, that's what they did. Maybe they didn't drag him, but they did drag a man in Waco in the square back in them days, they drug a black man. And they claimed that he as after a white woman. They claimed that this one was after a white woman, but they never showed up in court or nothing, like she done lost her mind or she wasn't right, she would never show up in the court. So you know then that they be after them black men their selves. But they didn't want to believe it. My ex-husband say, she go get in the shower and tell him to bring her a towel. She was knowing what she was doing.

NL: What did he do?

MW: I guess he took it to her. I don't know what he done. [Laughs]

NL: Was there a courtship period between you and your first husband?

MW: Sure, they would do that. And the white people took black men, but they don't want it publicly. That's the trouble. But they ought not to stand by and let one get killed because of their lie. They might not have been lying, but I mean because of that. That's the way slavery got started. I learned more about it when they showed Roots, how they did, you know. I worked for an old lady, and, "Marian, cut that off." She was listening to it until I got come in the door. "Marian, cut that off." It was George and his wife, what you call them, had the girl that worked for them, he had the laundry, had a cleaning place. Do you remember seeing that story of a black girl working for a black man?

NL: George and Weezy's. The Jeffersons?

MW: Yes. They had a cleaners, you know, and this old black girl worked for them, Florence. She would kneel like he was a white man, you know, get on her knees and wipe the floor just like they had to do for them white people years back. They'd have you slopping those mops around, you'd get on your knees and wipe their floor. My sister told them she wasn't getting on her knees to mop no floor! [Laughs] Some of them told us she'd come a long ways, she could go a long ways with that, you know, not doing slavery type of stuff. And they wanted her to wash a window, she had to climb out on the roof and wash the upstairs window, but she didn't do it. She said, "You climb out there and you fall."

NL: They would ask women to do that?

MW: Yeah. Wash the window, sweep the garage. I swept garages for her. And rake their carpet in they house. The carpet. They had a rake especially, rake that carpet to make it stand up, the shag. Stand up like that. They didn't make me, but I had to keep a job. I had to make a living, you know, and I did what they asked me to do. [Rake the carpet.] But they liked me for it. Like they said, they begin to have more work, and I said no, because this one after she learned what I did for her neighbor, she wanted me, and I told one, I say, "I'll work for her, but she'll have to pay me more than you paying." That's what I told her.

NL: Now did she pay you more?

MW: No. She let her know already what she give me, and she wouldn't back down off of it. But I told her ahead a time when anybody else ask for me, tell them you don't know what I charge. For what I give her, she probably be expecting looking for more, but you know, whatever, she 
didn't. And then I heard one of them talking on the phone that I work for, they were Jewish people but they were really nice, and she was telling some old friend she was talking to, says, "Oh, you know, she cleans stoves!" Whoever was working for them put they by them or they wouldn't do it, one. You know, oven get messed up. I'd clean the oven, and that's something that they hadn't been used to, somebody else doing it for them. Later they had a model of stove that would clean itself, but then they didn't. And another one I worked for out in South Austin there somewhere, she liked bacon and eggs, and boy, grease would be all over the stove and I've had to clean that up. You know, pop it out. I think they got some kind of thing now with holes in it you can put over it to kind of save that popping all out. With a handle or something they call a beater [?] It would catch the grease, you know, it wouldn't pop all that on the stove. She was a teacher, and she wanted that eggs and bacon every day, every morning when I went there. Some of the stuff that we don't need, we want it bad and we get it. See, that's what cause a lot of our trouble.

I gave my sister Emily a card for her birthday the sixteenth of February, and Ruth's daughter is the sixteenth of March. She called the other day and talked to her, but she forgot it was her birthday, so she reminded her, and she told us about it. Well I don't know just about when all of them birthday is; sometimes I forget my own. [Laughs] Forget my own birthday and my own anniversary and all that sometimes. I'm getting older, you know.

I saw something in my diagnosis where they treated me for memory. You know, the diagnosis says for memory.

NL: Well, I think your memory is doing pretty good today!

MW: [Laughs] Well, anyhow, I guess I was forgetting a lot because I was forgetting my appointments a lot. And I had to insist on my sisters to take me back and forth to the doctor. That burned me up, because my husband wouldn't take time to do it, and this time he was off, and he told me, "You make your appointments for Monday and Tuesday, I can take you." Any other time he couldn't take me. He could. He could take hisself fishing when he get ready to go. But he just that kind, he's selfish.

NL: Did he court you at all?

MW: Yeah, we courted about seven years before we married. [Laughs]

NL: What about your first husband, did you all court, too?

MW: Yeah, we courted, too. I went off with him in the cotton patch. I wasn't married then. [Laughter]

NL: Did you all go on dates?

MW: Yes. After I left from out here and went to town, and he found out where I was over there, he would come over there all the time.

NL: $\quad$ This is the first one, Mr. LeeDell?

MW: The first one.

NL: What did your dad say?

MW: Oh, he didn't like it. But you see, I didn't tell him. I went to the courthouse and got married. But I didn't let him know it until after it happened. 
NL: Were you still young when you got married the first time?

MW: Yeah. He blamed him more than he did me because he was a schoolmate to my dad, so they went to school together. Then you up and marry my daughter, as young as she is, or whatever. That's what he didn't like about it. Then he thought he was kind of abusing me in a way. You know, being the old man he is, and young people. But he treated me nice until he got drunk. When he got drunk, we'd have a fight. But other than that he treated me okay. He did most of the cooking because he knowed I come up in a big family and I done a lot of cooking, so I couldn't cook just a little bit, I always cooked a whole lot of stuff, and he's have to eat three meals a day of the same things. [Laughter] But he would do the cooking most of the time because I just couldn't slow it down to two people, I'd been so used to cooking a big pile of something for the family. Mama learned me how to cook early. Wash and clean, too. So I was a good housecleaner because she was. She worked with them people, she was a cleaner. Mary and Martha and them, they learned how to be there, too. Martha, it don't make her too much difference, but Mary is a thorough person. She'd wash those windows all day long. They would move stuff and get behind the corners. That's what my mama used to do. And when they worked at Travis, them people that worked there thought they were crazy. They put more work on them because they come in and do it just like that. They didn't like that. [Laughs] Because they was giving them praises for doing work like that. It'd been a long time since they seen that kind of work. You know, they'd hit hard spots and go on. And then some of them talk on their job, on their phone. Think they going to know their phone going because you talked over? Some of them do that, you know. But I didn't never do that, because I knew they would know it when they got their bill, and they wouldn't want you to be doing that. You ain't working when you doing that.

But that lady, they gave me vacation money. I never know you could get vacation money except for business, like they would give you vacation time. But I never know there was people to do it at their home that way. But she would give me for two weeks vacation, money. Because I was working all the rest of the time. She would write a list for me, a list this long. Do this and do that. She didn't want to give me time to rest no kind of way, or time to sit down and play around, you know, call on the phone or something. Because things she'd lay down for me to do, if I'd done them, I wouldn't have time to do that. Take me all that time. Wipe out of the bottom of the cabinets, all that kind of stuff. Some of them so far back I had to get down on my stomach and reach back there. You know, big cabinets in the back of the open doors. But I just went on and did what they asked me to do, because like I say, I had to make a living. I wasn't going to make the wrong style of living. I'm going to make an honest living. And so that's that way I was brought up. I had girlfriends and things that would wait until night to work. Unh-uh [no], I couldn't stand that. But if you deal with them and go around with me, then maybe you like them. People would say you just like them girls that run the streets, if you hang around with them. I just remember how I was brought up, and I tried to live like that. And some of these children, like their parents coming up kids, they'd talk back to them and say things to them, you know, and they should have not spared the rod. "Well, you do this and you do that." You know, you didn't want to see that and look at it. She got a little girl, Kinasia [?], Martha fooled with her a lot and keep her a lot, too. Kinasia and Saya [?] was the other little one. But Kinasia got a little brother now, and they about the same size. And they something else. They let them watch the wrong things on TV. She would dance herself, oh, she would just dance and cut up. I said, "You all better run that kid. She's going to embarrass all." [Laughs] They let the people know how their parents are, because they couldn't do it unless they let them. If they teach them and spank them when they do it, they'd learn to quit. So that's what it is.

I was talking about that cord a while ago, that's an old lady on there now, long hair and have it gray. But she say, you know, "What we eat what makes us sick." [Laughs] But she knows 
how we eat, so half teasing. Because she eat hearty at times, but it's for her heart, and she wasn't eating what she should eat. Emily. She's bashful, too. She's always been bashful.

NL: Well, we've done two hours today, so I'm going to end the tape here. 


\section{Joan Nell (Revada) Limuel}

\section{No photo}

$\begin{array}{ll}\text { Birth Date } & \text { 3/24/1934 } \\ \text { Residence } & \text { Antioch Colony, Buda } \\ \text { Time Span } & \text { 1938-1947 }\end{array}$

Interviewed by: Maria Franklin

April 3, 2009 (1 of 3)

MF: Can you just state your name, ma'am, please?

JL: Joan Limuel.

MF: Okay, that's perfect. I just wanted to make sure that it was recording. All right. This is Maria Franklin. Today is April 3, 2009. I am interviewing for the first time Mrs. Joan Revada Limuel. The interview is taking place in the home of Mrs. Limuel in Buda, Texas. This interview is part of the Oral History Program for the Ransom Williams Farmstead Project.

Good morning Mrs. R-I was just about to call you Mrs. Revada because that's what Les kept on referring to you as, but I know now it's Mrs. Limuel. I wanted to started with what you remember-Well, first a little bit about what you already told me about how you got to be here. So you were born in Llano, Texas.

JL: $\quad$ Born in Llano, Texas. And my mother died when I was four. That was my maternal, on my maternal side. My grandmother kept us until I was four. And my paternal grandmother lived here in Buda. So my mother didn't want us separated. Everybody wanted to take-my sisters were twins, there was four of us. And somebody wanted to take my brother, somebody wanted to take me, and somebody wanted to take the twins, but my mother didn't want us separated. She said I want 'em all raised together, don't separate 'em. So my paternal grandmother was the only one that could take all of us and not separate us, so that's why we wound up here in Buda, with her.

MF: Now where was your father? What happened to your father?

JL: $\quad$ My father, well, he was, he was around, but he, you know, he couldn't, he couldn't keep us because he had to work. I guess, I don't know. Anyway, my grandmother took us. My grandmother and grandfather, and that was how we got here to Buda.

MF: Okay, and you mentioned that the name Revada came from your Mexican, was it your greatgrandfather?

JL: $\quad$ Great-great.

MF: Great-great-grandfather. Can you tell me about how he married your great-greatgrandmother? 
JL: Yes. Let's see, he was my great-grandfather, not my great-great, my great-grandfather. He came over here from Mexico, and I don't know how he met my grandmother Tennessee, who was an ex-slave, but they married and they had what, like fourteen children, something like that.

MF: And now what was your great-grandfather's name then?

JL: Francisco Revada.

MF: And your great-grandmother's name was Tennessee?

JL: $\quad$ Tennessee. Her last name was Bolden.

MF: $\quad$ And so where did he meet Tennessee? Where did Francisco meet Tennessee?

JL: [Laughter] That I don't know. They just wound up here, I guess. I don't know, was he in Buda or somewhere?

MF: Okay, so he, so they did end up married and here in Buda. And he's the one who originally bought property in the colony. [Yes.] Okay. So, the part-

JL: The property was on the other side of the creek. The colony was considered on this side of the creek.

MF: You mean Onion Creek, right?

JL: $\quad$ Mm-hmm [yes].

MF: Okay, and his property is on the other side of Onion Creek?

JL: Yes. Where the Buda Elementary School is now downhill, the downhill campus. Right there, that's where they bought property.

MF: And do you know when that was?

JL: I don't know, but I guess you could look it up in the- at the courthouse.

MF: Right, but he, and he bought that property from a Kavanaugh you said, right, the Kavanaugh family?

JL: I don't know who he bought that property from. My grandfather that bought this property bought it from the Kavanaughs.

MF: $\quad$ Okay, so Tennessee and Francisco then had a bunch of kids.

JL: $\quad$ Oh, yes.

MF: And one of them was your grandfather, the one who bought this property here? [Yes.] Which is actually in Antioch, because it's on this side of the creek? [Yes.] And what was his, your grandfather's name, who owned this house?

JL: Dan Revada.

MF: Dan Revada, and who was he married to? 
JL: Hattie Sneed.

MF: And they had you-no, they had your father.

JL: $\quad$ My father.

MF: And his name was?

JL: Velma, and I don't know why they named him Velma. And his brother Langston. And there was two girls, Anthy Lee and Ladys.

MF: Okay. So there were four kids by Dan and Hattie? [Yes.] All right. And Velma was your father? [Yes.] And so your father married?

JL: $\quad$ Sophie Peters.

MF: And where was she from?

JL: Mason, Texas.

MF: And they had you?

JL: And my brother Velma Jr. He was the Junior. And my sisters were twins, Loyce and Joyce.

MF: Loyce and Joyce? There are a lot of twins I see in the colony, it seems like. That lots of people have had twins here.

JL: Yeah, yeah. Mary and Martha.

MF: Right, exactly. And so you came here at four, and were living at that point then, over where your great-

JL: $\quad$ No.

MF: On this property here. Right, okay, sorry. What do you remember about the house? Is this the actual house right here?

JL: No, we lived in the house that my brother lives in now. That was the first house.

MF: When was that built?

JL: I'd have to say, if he bought the land, shortly afterwards. I can't remember when they purchased the land. Did I tell you it was in the forties?

MF: Yes, you said it was in the forties. You didn't say whether there was a house standing on it or not.

JL: No, no. My grandfather and them built that.

MF: Okay, so that was probably-

JL: $\quad$ There were no houses here. And they had to clear the land. It was you know, grown over.

MF: And how many acres? 
JL: It's almost three acres. Two point, 2.8 something. It's almost three, just three acres.

MF: Three acres, okay.

JL: $\quad$ And he paid $\$ 50$ an acre.

MF: Oh, what a deal.

JL: Yes.

MF: I'd imagine it's worth considerably more than that now.

JL: Yes, it's worth a little more.

MF: Okay, when you came here to live with your grandparents then, because your grandfather was still living, right?

JL: $\quad$ Oh, yes.

MF: So it was your grandmother and your grandfather. What did they do for a living, to make a living?

JL: $\quad$ My grandfather was a farmer. He worked out, farm, you know, on other people's farms and things.

MF: Did he use his own tools or did he just give it, provide his labor?

JL: Just his labor.

MF: Okay. And was this for other, for white farmers that lived in the area?

JL: Yes, the white farmers.

MF: Okay, and your grandmother?

JL: She worked day work. She used to go to Buda and do day work for the people.

MF: Okay. So I noticed that you have a garden outside, and that you got chickens outside. Was that something that you did back then as well?

JL: $\quad$ Yes, yes. We had a garden. We had a big garden. And we had chickens, we had a milk cow. I had to get up every morning and milk the cow. We had hogs, you know, turkeys. And it was all right here on this land.

MF: Right here. And so you raised most of your food. Did you ever go to town to shop for things?

JL: $\quad$ Yes, she had to buy meal and flour and sugar. Not too many things, but, you know, some things she had to buy at the grocery.

MF: Was it just the four kids, you and your siblings, that she was raising? Or was there anyone else here at that time?

JL: $\quad$ Yes, my cousin was here with us. She lives in Austin. 
MF: What was her name?

JL: Katie Revada.

MF: And was she older than you or the same age or?

JL: $\quad$ She was a little older. What happened-it's a sad story, but I'll tell it. Her mother lived on a farm, and the man that owned the farm, somehow or other they got together and had this baby. Well, the wife of the man was so mad, because she's white, you know, he had this black woman on her land with this white baby, and she told her, "You either gonna move off the land, or you're gonna get rid of that white baby." Because she knew it was her husband's baby. So she came to Buda, and my grandmother was up there in Buda, and she said, I got to get rid of this kid because I don't have no where else to go. And Ms. Howe told me to either move off the land or get rid of this white baby, so do you know anybody that want her? [Oh, no.] And she gave it to my grandmother.

MF: But were they related though, then?

JL: No.

MF: It was just some woman that just-

JL: Just up there trying to get rid of this white baby because she had to either do that or get off the land. And she didn't have nowhere to go, you know.

MF: This was no-so you call her your cousin, Katie your cousin, even though she was no blood relation to you?

JL: No, but she's been in our family since she was, before she got to be two years old.

MF: That's very sad.

JL: $\quad$ She is our cousin, I mean.

MF: Does she appear white? Does she look white? Or does she look like she was mixed?

JL: I'll show you a picture of her-it's a white lady.

MF: Oh, wow, okay.

JL: Even when our black people couldn’t work downtown Austin, she passed for years.

MF: $\quad$ Oh, is that right?

JL: $\quad$ Yes. She passed for years as a white woman. She had a good job, you know, so nobody faulted her because, you know.

MF: She had such a hard life and abandoned such a-

JL: And, yes, and if that was the only way you could make ends meet, and you know, nobody knew she was black.

MF: Right, and so she lives in Austin now? [Mm-hmm.] Do you still stay in touch with her? 
JL: Oh, yes. She's just, she's a member of our family. She was in our family before she was two years old, you know. We the only family she knows. She's at every Thanksgiving dinner, Christmas dinner, family reunion, birthdays, whatever.

MF: Family-family.

JL: She, that's cousin Katie, yes.

MF: And your brother lives right here, next door. [Yes.] And what about your twin sisters?

JL: We lost Joyce, she had a stroke [sorry to hear that] and she passed away. My other sister lives in Austin.

MF: In terms of living here when you were a kid, did you have a well on the property? Is that how you got your fresh water?

JL: We had no well. We had to go to the creek and get water.

MF: Well, thankfully it was just right across the road there. So you, so all the kids get together, you had to go out there with buckets of-

JL: We had little-I guess a gallon, you had two of them. Everybody had two buckets. When my grandmother got ready to wash, do you know how many times we had to go up and down that hill to get water? I mean, we had to literally, she had a wash pot and two tubs, and one blueing tub. She had three tubs. And she scrubbed on that scrub board, you know. She didn't have no washing machine. Times were hard. It was a hard life. We had to get wood. She had a wood stove. And it's sitting out there in the yard, if you want to see it. And yes, we used to have to lead the cow down to the creek to drink. You know, a cow can drink 40 gallons of water, did you know that?

MF: No, I didn't.

JL: A day.

MF: Oh, my gosh.

JL: $\quad$ Mm-hmm [yes], in a day.

MF: It would have been better just to keep the thing down there.

JL: $\quad$ Yes, but you know you had to bring her home to milk her. [Right.] But anyway, we had a rough life.

MF: When you came here at four, did you remember working and trying to help around the house as early as four, as soon as you came here? When did you-

JL: $\quad$ Oh no, no. Not that early. But, let's see, I started to school when I was six. I know sometime between six and eight years old, or maybe ten, I don't remember, I had to milk the cow. And we had to go out in the pasture and get wood for the cooks' stove, and get water from the creek. And, I remember a lot of things.

MF: What about helping out in the garden or feeding the chickens and all that kind of thing?

JL: Oh, we had to, in the summer we had to go pick cotton. We had to go to the cotton fields. 
MF: Is this where, on the farms where your father was working then?

JL: Yes, we had to pick cotton, we never chopped but we did pick. That was the most miserable thing. The ground was so hot, your feet was burning, and the sun was so hot, your head, your head would get so hot, it would feel like your head was on fire. I mean, it was just horrible.

MF: How old were you when you first had to go and do that?

JL: $\quad$ Oh, I guess about ten, something like that. Yes, we worked in the fields.

MF: All through the summer? Oh, I guess while they were harvesting the cotton anyway.

JL: $\quad$ During cotton, yes, when the cotton had to be picked. And when lunchtime came there was no shade trees, so we had to crawl up under the wagon to try to get out of that sun. That sun was so hot. It was horrible; bad. I wouldn't ever want to live that life no more. Like people say the good ol' days, there was no good ol' days for me. Not then. I mean, can you imagine? We had no running water. You'd work in the field all day, but you couldn't bathe when you got home, because you just-

MF: $\quad$ Too tired.

JL: You didn't get home till dark. And sometime we just went to sleep in our clothes, and then get up the next morning and go back to the field. And we always had to leave to be there just when you could see, so it would be dark. We would be getting up, you know, trying to get to the field, just when the sun was coming up so we could, you know, start the day.

MF: Do you remember whose land you worked?

JL: No, but I remember it was, it was close by, it wasn't that far away.

MF: $\quad$ So around here in Buda.

JL: It was, see, before Buda built all up, all that used to be farmland.

MF: And did you work different farms, or did you just work one person's land?

JL: Yes, we worked a lot of different farms. We went from farm to farm, whoever had cotton to be picked.

MF: Did you ever have to travel outside of this county to work?

JL: $\quad$ No. Just in Hays County, like San Marcos, Kyle, Manchaca. All that was farmland before they started building all these houses and things. It was just farmland.

MF: Did you ever see any whites out there picking cotton? Or was it all black labor?

JL: I never seen no whites.

MF: $\quad$ Lots of kids though, black kids.

JL: $\quad$ Lot of kids, people that we know that lived in Manchaca. The Sorrells, I don't know if you interviewed any of them, but there's a big family of them that lived in Manchaca. And they owned a lot of land there, and we used to be in the field with them, you know. 
MF: Did you ever have to miss school because you were-

JL: We never had to miss school, because all the cotton would be picked around here.

MF: $\quad$ During the summertime.

JL: $\quad$ And we never went off to, we didn’t ever miss any school, no.

MF: You were lucky in that sense, I know talking to some of the Harpers that they, they traveled.

JL: $\quad$ They did, they used to never come to school until after I think around January, somewhere like that. They missed a lot of school.

MF: In terms of, I know there were a couple of women in your family who were midwives. Can you talk a little bit about them?

JL: That was Aunt Maggie. That was my grandmother's sister.

MF: And she served as, did you ever, did she ever talk to you about what it was like to midwife? Did you know anything about what she did?

JL: $\quad$ No. She, see Aunt Maggie would have been along with like my mother or somewhere in that age bracket. So by the time I was what, ten, twelve years old, I think she had quit doing it. You know what I'm saying, she did it back earlier.

MF: Back in the day.

JL: $\quad$ Mm-hmm [yes].

MF: $\quad$ And who did she live with? Where did she live?

JL: $\quad$ She lived - the first place I remember her living was over here on the Barton's place. She was a, like they live-in, not live-in maid because she had a house and she had children, but she lived on their place, you know, and took care of their household. She worked for them, you know. That's the first place I can remember her living. Then she moved, she worked for a doctor here in Buda, I can't remember his name, but he had two boys. And she took care of them, and that was, you know, what she did. Just take care of people's houses and they children and stuff like that. Yes, she was a midwife. She delivered, I think she delivered the twins, the Harper twins.

MF: Yes, I think she did, as a matter of fact, I think Minnie mentioned that. And then the other Revada, Pinky was her name?

JL: I don't know who that was.

MF: $\quad$ Okay. I thought I mentioned-I could be mistaken, I could be mistaken.

JL: $\quad$ I don’t know.

MF: Now, growing up here, do you remember people using home remedies or things like that? Collecting herbs and things like that for healing or for medicinal purposes?

JL: I'll tell you what, the first time I saw a doctor was when I delivered my first child. Never saw a doctor. 
MF: How old were you when you delivered your first child?

JL: Twenty-one.

MF: Wow. So your grandmother-

JL: We just didn't have no money. You know people poor, they didn't go to the doctor. If we caught a cold, we got castor oil. If we had a sore throat, she would a take a teaspoon of sugar and put a couple of drops of kerosene oil or turpentine or something on it and make you, you know, things like that. Then they made that horehound candy, what they call horehound candy. They'd take this weed, those horehound weeds and make candy. Crystallized, kind of like crystallized, and then, oh God, that was bitter, bitter, bitter, bitter. And then in the spring we had to take molasses and sulfur. They'd take that powdered stuff and stir it up in some molasses and give it to you. And that would keep you from getting boils or sores or things like that, you know. Yes, they had home remedies-that's how we made it, you know.

MF: Did anybody ever pick any herbs or anything like that for treating illnesses? Or cuts or burns or-?

JL: $\quad$ No. I'll tell you what they did for bleeding, they would put cobwebs. They'd try to find some cobwebs to put on it, or mud. Did you know mud, if you, if something stings you like a wasp or a bee, you get a thing of mud and put it on that, for some reason it'll stop that burning. Mud.

MF: Yes, I’ve actually heard that as well.

JL: $\quad$ Only time I remember my brother went to the doctor, he was down there in the creek and cut his toe almost off. They had to take him up to Buda, and Dr. McCormick stitched it so it stayed on, you know, but it was a bad cut. And that was the only time, the only connection I know to a doctor.

MF: Are you older than your brother?

JL: $\quad$ No, he's older than me.

MF: Okay, so it's your brother, then you, and then the twins were born, okay. You mentioned you know, that nobody around here had money, so people must have reused things all the time. Do you remember like, because people now days are so proud that they recycle their bottles or whatnot, but back then it was probably, nothing went to waste, I assume.

JL: Well, I didn't get to tell you about during the war, during World War II, everything was rationed. They had ration books. And you'd tear out a little coupon if you wanted to get ten pounds of sugar, you had to tear out this coupon and get ten, and that's all you could get for that month. If you wanted to buy a pair of shoes even, you had tear out a, did you know anything about that? Back in World War II?

MF: Only because I've read about it.

JL: Everything was rationed. We had to save-even the toothpaste came in a metal tube. They come in plastic now, but back then they came in, toothpaste came in a metal tube. And when you got through squeezing all that toothpaste out, you saved everyone of them, anything metal had to be recycled, had to go back, you know for them to build, I guess, make ammunition or whatever they would do with it. But, mm-hmm [yes]. 
MF: What about around the house? I mean people have talked about making clothing out of flour sacks and things like that.

JL: $\quad$ Oh yes, my grandmother, she made all our dresses and underpants, our panties, our slips, our dresses. She made every-everybody would sew. And she had one of these machines that you do like that, a pedal.

MF: The pedal, right, right.

JL: When she died it was in that house over there, when she died it was still in there.

MF: And so all the, was this something that just the women did, was the sewing?

JL: Women did. She made coats, she made our winter coats. She would take a big coat, you know, old coat, and cut another coat out of it, you understand?

MF: $\quad$ Sure, I do, I do.

JL: $\quad$ She made everything. She made our dresses.

MF: She do much quilting?

JL: They did quilting. I still got some of her, the quilts that she put together.

MF: Okay, you'll have to let me take pictures of them at some point.

JL: But they're not quilted, they're not quilted. They just the top part, I don't know if I, we'd have to make that another project.

MF: You have a lot of stuff here of hers.

JL: $\quad$ Oh yes, pictures. I got so many pictures.

MF: You mentioned that you did all kinds of chores from the time you were a kid. Were their chores for boys and chores for girls, like the sewing, was that something just the women, the girls learned how to do?

JL: $\quad$ Yes. But I milked the cow because my brother didn't want to learn how to milk a cow. He tried, he just pretended like, he just didn't know nothing about it. But I was always, I always wanted to learn how to do everything. You ever heard that saying, the less you know, the less you have to do? My brother was like that. The less he knew, the less he had to do. So he said, I don't know how to milk it, I don't know how to milk it, I can't.

MF: And they let him get away with that?

JL: $\quad$ Uh-huh. And I said, I want to do it. Big Poppa-we called my grandfather Big Poppa-teach me how to milk, and he showed me how to do it. From then on, that was my job, I had to get up every morning. Coooooold! I remember my hands used to be so cold. And I would, it was, the barn was way down on the end of the land down there. Down there where that last house is now, that's where the cow barn was. And I had to go down there and my hands would get so cold in the wintertime, you know. But anyway, yes, I learned how to milk the cow. I always wanted to do something. I don't know why, I just teach me how to do it, I can do it. I was cooking and I was about twelve years old. I could cook bread, cook a meal, you know, make a cake. I just always wanted to learn everything. I don't know where I-and I used to read, 
read, read. I loved to read books, magazines, labels on a bottle, anything, just let me see. And my grandmother used to get mad at me, "Get your head out of those books and come on here and do this!" I'd have a book, I was always sitting somewhere, reading something.

MF: And how much younger were your sisters than you were?

JL: Two, two years. We were all two years apart. My brother is two years older than me, and my sister is two years younger than me.

MF: Okay, so you weren't a whole lot older than your sisters, but did you have to take care of them, too? Was that part of your responsibility?

JL: Oh, no. They were-we come along, you know like when I was ten, they were eight. When I was twelve, they was ten. It wasn't, they weren't babies, you know or nothing like that. Pretty close together.

MF: Now did, did people in your family hunt or fish or trap animals?

JL: $\quad$ My grandfather did, but my grandmother was very funny. She would cook a squirrel and maybe a rabbit, but not a coon, not a possum, not nothing like that. She wouldn't. "Don't bring that thing in here!" She liked doves, you know, and quails, and she'd cook a squirrel, maybe sometime a rabbit, but no possum or coons. "Don't bring it in here! I'm not, that's not coming in the kitchen!"

MF: And what was it about—why do you think she didn't like coons or possum?

JL: I don't know. No armadillos. You know a lot of people ate armadillos, possum, squirrel. I mean coons. Not her. The only thing she would eat would be a squirrel or rabbit. A young cottontail rabbit, you know something like that.

MF: And so you didn't, you never had any possum?

JL: $\quad$ Oh, no. We never ate nothing like that. We had hogs and you know, we had-my grandfather had a smokehouse where he would smoke all the meat. [Phone ringing]

MF: Did you want me to stop so you can answer that?

JL: No.

MF: So fishing, who taught you how to fish?

JL: My grandfather, I used to go with him fishing. Every time something was going on, I always wanted to be there. Hunting, fishing, whatever.

MF: Fishing, where did they take you for fishing then?

JL: Just down at the creek?

MF: You'd just walk down at the bottom of the-

JL: $\quad$ But you know, they doing a lot of dredging up above there, and the creek don't run no more. But when I was a kid, the creek was always full of water.

MF: What kind of fish did you fish out of there? 
JL: $\quad$ Oh bass, catfish, perch. You know. But now that they dug so many, dug that gravel pit, the water don't run no more.

MF: Well, catfish, did you catch those fish different-[someone enters house, pause in recording] So you would go with your-I was asking actually, so perch, did you use different kinds of fishing techniques to catch, depending on what kind of fish you were trying to get?

JL: No, we just had a cane pole, with a line on it, with a hook on it.

MF: And what did you use for bait?

JL: $\quad$ Worms or minnows. Sometimes we'd catch minnows, which is little fish about that long. And you just put it on there, and the bigger fish eat it. So my grandfather would always catch him, catch some minnows. And we had a trap, you just put some bread in there and the minnows go in there. He'd catch big bass, like that, you know. And I never will forget. We'd come home and my grandmother would, she always cooked biscuits, biscuits, biscuits. She'd have a big pan of biscuits, maybe she'd fry some potatoes or something. She'd fry that fish and it would be so good.

MF: So did your mom clean everything? So she would clean the fish?

JL: $\quad$ No, my grandfather would clean the fish. And my grandmother, we haven't talked much about her but she was mixed with German. She was very, very, very clean.

MF: Sneed? Is that where the-

JL: I don't know. See, the black people just took other peoples' names, [right] so it doesn't matter. You know, like my grandfather on my mother's side. This man was named Joshua Peters, a white name bought him from down in Tennessee when he was eight years old. So his name is Sam Peters.

MF: But not because they're related, but because he was enslaved by him.

JL: $\quad$ Because he was enslaved, and you had to take the master's last name. So Sneed, I don't know who, you know, she had to take Sneed as her last name, but I knew she was part German because you could look at her and tell she wasn't, what you would say a typical African American. She was mixed, you could tell she was mixed with something.

MF: Why did you think it might be German as opposed to-

JL: Because of her features. She was big, tall.

MF: Okay, so she didn't know, she didn't know herself what her ancestry was?

JL: $\quad$ No, but I know. I know that somewhere down the line she was mixed with German. And her daughter, the one I told you to interview, I'm going to show you a picture of her. She has snow-white hair, which is typical of people that had red heads. You know a redheaded person, their hair will turn snow white. Just white like that shirt up there. And most of them, most of the German people you know, their hair turns that white silvery color. And I'm going to show you a picture of Anthy Lee, and you'll see. You'll know that she's not a full-blooded African American, she's mixed with something. Of course, there is very few pure blooded African Americans left.

MF: I totally agree. I don't think there's any, actually. 
JL: Because all of them are mixed with something.

MF: We're all mixed with something, I agree. A lot of white people, too. [Yeah.] Why don't we go ahead and, since I know your friend is waiting for you, I'm going to go ahead-[Interview ends.]

Interviewed by: Maria Franklin

May 18, 2009 (2 of 3)

[Prior to the interview, Franklin asked Mrs. Limuel to identify students who were photographed in front of Antioch School, 1921.]

MF: Okay, so you were saying who was who now?

JL: This is Aunt Ladys. That's my auntie. That's my daddy's sister. This here is also my daddy's sister, but let me tell you what happened.

MF: Okay, this is your daddy's sister right here? What's her name?

JL: $\quad$ Her name is Ladys. And this is Mary Lou, May Lou.

MF: May Lou. And these are both your aunts then?

JL: Yeah. But he was married to her mother. He had this one out of-

MF: Out of wedlock.

JL: Out of you know what. They was stepsisters, half sisters or whatever you call it.

MF: Half sisters.

JL: I think this is my daddy right here. And this is, I don't know if this is Uncle Lang. I don't know who that is, but I think this is my daddy here.

MF: So that's Velma?

JL: I think so.

MF: And this you said was Jose?

JL: Yeah.

MF: Everybody called Joe?

JL: Joe.

MF: And he was your uncle by marriage?

JL: No, that was my grandfather's sister's child, so he wouldn't be my- 
MF: Oh, it was your grandfather's sister's child. So that would be-would it be Otis?

JL: No. That was Aunt Delia's child. His last name was Reyes. Joe Reyes.

MF: Okay, and so he was your grandfather's sister's child?

JL: Yeah.

MF: And your grandfather's name is?

JL: Dan.

MF: Oh right. Dan, okay.

JL: $\quad$ Aunt Lee can tell you everybody on there. She know them all. Ask-I think this lady's name was Taylor.

MF: Did you call her Nana?

JL: Nana Taylor. I think that's what Auntie said her name was. That's Aunt Ladys right there and that's May Lou. I don't know who these twins are.

MF: There's a lot of twins at Antioch, wasn't there?

JL: $\quad$ Mm-hmm [yes].

MF: That's what I keep hearing. Is there a TV or something on in here?

JL: $\quad$ Let me turn that off.

MF: Yeah, okay, because it's going to pick up on the microphone. Thank you.

JL: I'm going to go over to my br-when my brother gets back, he knows everybody on there, too. I'm going to go over there and ask him.

MF: This is Maria Franklin. Today is May 18, 2009. I'm interviewing for the second time Mrs. Joan Revada Limuel. This interview is taking place in the home of Mrs. Limuel in Buda, Texas. This interview is part of the Oral History Program for the Ransom Williams Farmstead Project. All right, so we were just talking about these old photos, and that's a picture of Antioch School in 1921.

JL: 1921.

MF: Right. So you've identified on there your father.

JL: That's my daddy.

MF: Velma Revada.

JL: And this here is his sister, Ladys Revada. And that's Mary Lou Revada.

MF: Her half sister?

JL: $\quad$ Mm-hmm [yes]. 
MF: And so you were saying that Ladys was your grandfather's legitimate child. That is he was married to the mother.

JL: Yeah.

MF: And what was the mother's name that he was-

JL: Hattie.

MF: Hattie. Sneed, right?

JL: $\quad$ Yes.

MF: But May Lou was born out of wedlock.

JL: Yeah.

MF: Then the gentleman standing next to the teacher there is Jose-

JL: Joe.

MF: Or Joe Reyes.

JL: Joe Reyes. Mm-hmm [yes].

MF: And he was your grandfather's-

JL: $\quad$ Sister's child.

MF: And what was her name, your grandfather's sister?

JL: Delia Revada.

MF: Delia Revada.

JL: Reyes. She married a Reyes.

MF: Right. Okay, and you said you remember the teacher there, too. Do you know who she is?

JL: I think her name is Miss Taylor. Nana Taylor.

MF: Okay. You've been in that school.

JL: Yeah.

MF: You said you went to that school.

JL: No. No, I didn't go to it. They had built another school because this one was-I've been in this building, because it was next door to the church. We used to go to this church. This was the old Methodist church up in the colony, and this was right next door to it. Of course, it was abandoned, but we used to run over there. You know how kids are. Run in there and play.

MF: $\quad$ So it was a-well, you can tell by looking at it that it was a two-story school. 
JL: Two-story. Yeah.

MF: $\quad$ Did they use it for anything besides teaching the kids?

JL: $\quad$ Yeah. Aunt Lee said they used to have all the Masonic meetings or any kind of meetings they had, they used to use it for that, too.

MF: Okay. When did that school building collapse? When was the last time you remember running into it?

JL: I don't know, but-let's see, I was about ten, so that was '44. It was already out of use then. They had rebuilt the black school down here on Black Colony, the new school. They built another school.

MF: Antioch Church right there. So you were a member of that particular church until when?

JL: Well, I must have been about ten, something like that, and we used to go to this church. Then in '48 my daddy sent for us and we left and went to California. But up until that time we attended this church.

MF: Do you remember anything about the inside of that church?

JL: Yeah. It had wooden floors and-yeah, I remember.

MF: Pew.

JL: $\quad$ The pews. The wooden benches. They were hard. [Laughter] No cushions on them. Just wooden benches.

MF: Do you remember who the pastor was at the time?

JL: No.

MF: $\quad$ Long time ago, I know.

JL: Yeah, that was a long time ago. I don't remember.

MF: Would it fill up every Sunday?

JL: Not really, but I'll tell you who was there every Sunday with his whole family, and that was Mr. Harper. George Harper. He had a lot of children. And we were there. And the other Harpers, which was Mr. George's brother Melvin, he had Harry, Nellie Marie and I can't think of the little girl's-Elsie. I think her name was Elsie Marie. They used to go there.

MF: This would have been-the two Harper families were related because the two fathers were brothers.

JL: Yeah.

MF: I see, okay. Who do you remember going to school with you at Antioch? Oh, you had actually said you didn't go to that school.

JL: I didn't go to that school. But when I went to the second school, it was all the Harpers: Emily, Ruth, Mary, Martha, Joshua. All of the Ralstons: Laura, Eddie, Alistene, Drausy. It was a big 
family of them, too. They all went there. And I'm trying to think of the other kids that was there. Oh, Nellie Marie and Harry and Elsie-well, she was too young. The little one was.

MF: The other Harpers.

JL: The other Harpers were there.

MF: So those were pretty much all your playmates as well, then.

JL: Yeah. Oh, yeah. We used to have Easter programs at the church, this church here. We would have to leave before dark, going up to the Harpers, and we'd go from their house to the church, because we walked all the way through the colony, all the way up there. You know where the Harpers live now.

MF: Yes.

JL: $\quad$ We walked up there before dark, went to our Easter practice. We'd practice our speeches and whatever. Then Mr. Harper would drop us off, bring us home. He had a truck, and we used to ride on the back of his truck, and he'd bring us all home, you know. I remember that. We used to go up there before dark. They would still be milking the cows and feeding the hogs, and we used to pitch in and help them with their chores so they could get through so we could go to the church. Mr. Harper, he was so faithful to being in the church and all. We had a good time.

MF: We talked a little about your family history already. A couple of things I wanted to ask you then. Your grand-it was your grandfather, Francis Revada?

JL: $\quad$ Great.

MF: Great-grandfather. He's the one who came out of Mexico and married your greatgrandmother, Tennessee.

JL: Tennessee.

MF: Can you tell me anything about your great-grandparents that you know? Like when they were born? Or where they're buried?

JL: Yes. Grandma Tennessee is buried up there. Now he's buried-Aunt Lee said he's buried at Reiner Branch Cemetery, which was-there was just a few people buried over there, and then they quit burying over there because it was so rocky.

MF: Reiner Branch did you say?

JL: $\quad$ Mm-hmm [yes].

MF: Where is that located?

JL: When you go up 967, when you go in that steep curve like that. Where the water-there used to be a branch - when we say a branch, it's water. You know where the water runs. So they called it Reiner's Branch. I guess the people that owned it was named Reiner. Anyway, they called it Reiner Branch. Aunt Lee said it was a cemetery called Reiner Branch Cemetery. It's back off in them woods somewhere. We don't even know where he's-I asked Aunt Lee, "Do you think you could find it?" I guess Aunt Lee was about-when he passed, she was real young. 
MF: That would have been her grandfather, right?

JL: Yeah.

MF: You said that Tennessee is buried up here at Antioch?

JL: Yeah.

MF: But she doesn't have a marked-

JL: No, her grave is not marked. It's a lot of Revadas buried up there, with no markers.

MF: Right, you were saying that. And when did—do you know when she passed away or when she was born?

JL: I have it written down.

MF: Okay, I'll ask you that at some time later when we can get the information. That would be good to know. So Francis and Tennessee came here to Antioch when? Do you know about when they came here?

JL: I don't remember what year, but it must have been early because for as long as I can remember Aunt Lee, when she was a little kid, and she's ninety-five, when she was a little kid she said she used to go to her grandmother's house.

MF: Okay, so you think they came there before 1900 ?

JL: Probably somewhere in that area. Yeah.

MF: What did Francis do for a living here? Do you know? Did he work as a laborer-

JL: $\quad$ Farm work. He- they farmed and — what do you call that when you farm for somebody else?

MF: Sharecropping.

JL: $\quad$ Sharecropping. Right.

MF: So he didn't own his own land when he first came?

JL: I don't think so, but they bought that land right there where that elementary school is. They had land there on Onion Creek from the creek up to there.

MF: Was that Francis that bought it or one of his sons that ended up buying that?

JL: No, it belonged to him and Tennessee. I don't know what year they bought it. You might could look it up from the courthouse.

MF: And we might already have that document. I'll have to check with the historian that's working on the project. So who-what were the kids that Francis and Tennessee had?

JL: $\quad$ I have a book. Could I be excused and go get it? It has all the dates in it.

MF: That would be great. 
JL: $\quad$ My grandmother's name was Tennessee Boldin Revada. She died in 1932. She was ninety years old. Her birth date—-the day I don't know, but the year was 1840 .

MF: Who were their kids, then? Tennessee and Francis?

JL: His name is Francisco.

MF: Oh, Francisco? Okay.

JL: Here we go. Polly Revada, Andress Revada, Leland Revada, Ada, Delia, Walter, Jim, Dan, Lucy. Let's see who else. That's it.

MF: $\quad$ Okay, so they had one, two, three, four, five, six—-they had nine kids.

JL: Yeah.

MF: Which one of their kids, then, is your grandfather?

JL: Dan.

MF: Dan is your grandfather.

JL: Mm-hmm [yes].

MF: Now, who did Dan marry?

JL: Hattie.

MF: Hattie Sneed, right?

JL: Hattie Sneed.

MF: Now you don't know where Hattie Sneed came from, right? I think I had asked you that before.

JL: $\quad$ No, but I can ask Aunt Lee where they came from.

MF: All of these kids were born here in Antioch? Were all of these kids born in the colony?

JL: Yes. In Hays County.

MF: Dan and Hattie had how many kids then?

JL: $\quad$ Four.

MF: They had four. What were their names?

JL: Velma.

MF: That's your father, correct?

JL: That's my father. Who's next? Ladys, Anthy Lee, and Langston.

MF: And then Velma marries- 
JL: Sophie.

MF: And what is Sophie's maiden name?

JL: $\quad$ Peters.

MF: Do you know where she was born and raised?

JL: In Mason, Texas.

MF: Where did they meet? Do you know?

JL: $\quad$ My daddy was a baseball player in the Negro League. He played with the San Angelo Sheep Herders and, of course, they went different places playing ball.

MF: Now, I had asked you before, that Luvenia Bunton married into the Revadas, right? So she married-

JL: Now, see down there you should put Oddies down there. That was my grandfather's son.

MF: Your grandfather had a—so they had Velma, Ladys, Anthy Lee, Langston—

JL: And Oddies was Dan and Luvenia Bunton's son. See my grandfather-

MF: Oh, he had more than one wife.

JL: Yeah. He was married to Luvenia Bunton.

MF: So that was his second wife?

JL: Yeah. Hattie was his second wife.

MF: Hattie or Luvenia was his second wife?

JL: Luvenia was the first wife.

MF: Luvenia was the first wife, okay. And then Hattie was the second wife.

JL: Mm-hmm [yes].

MF: Okay, so under Luvenia and Dan they had Oddies, and he married Maggie.

JL: Let me tell you how that went. Wasn't this something? Dan, Walter, Jim and Andress married four sisters. Their baby sister-listen to this—-their baby sister married Dan's son by Luvenia Bunton.

MF: That's-[laughs]

JL: $\quad$ See Maggie Sneed was my grandmother's sister. But she married Dan's son by—his son was older-do you understand what I'm saying?

MF: Yes, I understand. So some of these folks are related in two different ways. 
JL: $\quad$ Two different ways. Four brothers is married to four sisters. So all the women was my aunties and all the men are my uncles. We double kin.

MF: Right. [Laugher] Was that hard to keep track when you were younger?

JL: $\quad$ No. It wasn't. It was Aunt Ella and Uncle Jim. Aunt Eula and Uncle Walter. Aunt Fanny and Uncle Andress. You know, then later on they say, "Oh yeah, we all sisters and brothers." I knew Uncle Walter and Uncle Jim and Dan and Andress were brothers. They were all Revadas. Then I found out that my grandmother Hattie and Fanny and Eula and Ella were sisters. Aunt Maggie was the youngest Sneed sister, married Uncle Oddies, who was the[laughs] It must have been a shortage of men or something back in them days. Lord, Jesus.

MF: [Laughs] The reason why I'd asked you about Luvenia Bunton-Because I was talking to you before about the connection between different African-American communities, and I'd noted that one of the women that I was going to be interviewing, Robbie Dodson Overton, that was her-that's one of her, I think, great-aunts or something. Luvenia Bunton. So you two are somehow related. So I was just trying to figure out what her connection was to Antioch Colony. And that's it. Her family had married into the Revada clan here.

Do you know who of these folks are buried here at Antioch that you know of besides Tennessee?

JL: Let me see. I've got it written down here somewhere. I know Aunt Delia is buried there. I know my grandfather is buried there. I've got it written down here. Okay. I told you my grandmother's name was Tennessee Boldin?

MF: Boldin.

JL: Boldin Revada.

MF: Before you had said you didn't know where she was born and raised, right? You said she was an ex-slave.

JL: $\quad$ Yeah, she was definitely an ex-slave. Let's see, if she was ninety years old in 1932, what year was she born?

MF: $\quad$ She was born like in 1840, 1838.

MF: 1838.

JL: Yeah, that's what I got her down, born in 1840. Okay, she was a slave. She had a brother named Jack Boldin, Susan Boldin, Dan Boldin, and Walter Boldin. These were all her sisters and brothers. They were buried in the Antioch Cemetery in Buda.

MF: Tennessee's siblings? So her siblings at some point came to Antioch with her and her husband? Is that what happened?

JL: I don’t know. That's what I got down here.

MF: That's interesting.

JL: I don't know if that's true. I'll have to ask Aunt Lee about that.

MF: Is that who would have told you, is your Aunt Lee? 
JL: $\quad$ This is what I think. I had all this information on her. Then it says brothers and sisters: Jack Boldin, Susan Boldin, Dan Boldin, and Walter Boldin. Down here I wrote buried in Antioch Cemetery, in Buda. I think I was talking about Grandma Tennessee. I don't think these people were buried up there.

MF: Or that they ever came to Antioch then.

JL: $\quad$ No. They lived in Austin, I think.

MF: Oh, okay. Are there any other places besides Antioch and-

JL: $\quad$ Oh, wait a minute. Write this down. My great-grandmother had one more daughter named Lula, Lula Bedall. She married a Bedall.

MF: Your great-grandmother. So that was Tennessee.

JL: Tennessee. She had one more daughter.

MF: With Francisco or-

JL: Yeah. Lula. Lula Bedall.

MF: So she had ten kids altogether then. You'd mentioned that a lot of the Revadas were buried at Antioch, but most of them were probably unmarked.

JL: Unmarked. Unmarked graves.

MF: Where the fence is now, you're pretty sure they are buried within the fence-line, though. Inside the cemetery as opposed to outside, right.

JL: $\quad$ Oh, yeah. They were buried in a line there.

MF: Do you remember who they were buried next to that might have marked graves? Do you see what I'm saying?

JL: My grandmother's grave and my grandfather's grave is-on that line. I remember my cousin, we called him Buster. What was his first name? Let me see if I've got it written down here. Anyway, he's buried there and I know Aunt Lucy's buried there.

MF: And they both have markers.

JL: Nm-mmm [no]. They have no markers.

MF: Well, what I'm trying to figure out is, you know, if I walked out there and you said, "Well they're buried on the line with burials that have markers on them, and these are where the markers are." I'm trying to figure out which line they're buried on.

JL: Just look for Hattie Revada and Dan Revada.

MF: Okay, so those are marked.

JL: Yeah. And they're buried on that line. With Andress and Fanny Revada.

MF: Okay, so Hattie, Dan, Francis, and who was the last name? 
JL: Andress.

MF: Andress. Okay, so all four of them are buried with markers.

JL: Yeah.

MF: And the rest of your family are probably on the same line with them. Okay.

JL: $\quad$ Oh, I've got my grandfather's and my grandmother's—-they were married December 25, 1865.

MF: Oh, wow.

JL: I got that from Aunt Lee.

MF: Okay, Christmas Day. Your father, Velma, married Sophie Peters of Mason, Texas, and had you, and who are your siblings?

JL: $\quad$ My brother, he's the oldest, Velma junior. He was a junior. I'm next in line. Then the twins, Loyce and Joyce.

MF: $\quad$ Loyce and Joyce?

JL: Joyce. Joyce.

MF: All of the siblings are surviving?

JL: No, Joyce passed away. She had a stroke. [Oh, okay.]

MF: Your brother lives in the house right over here.

JL: Yes.

MF: Right next to you. Where is Loyce living now?

JL: In Austin. She's in Austin.

MF: Do you see her much?

JL: Mm-hmm [yes]. Every celebration. Like we had a big dinner. Oh, they gave me a big birthday bash on my seventy-fifth birthday. A surprise. And it was so weird. I walked in there and they hollered, "Surprise!" and I said I wonder what these people are hollering. I was looking to see what they were hollering. They had a big cake with my picture on it.

MF: $\quad$ Oh, nice.

JL: When I was eighteen years old. It was so nice.

MF: Oh, you probably didn't want to eat that cake, huh?

JL: Oh, yeah, we ate it. It's so amazing how they can put your picture on it.

MF: I've seen those. It's pretty neat. 
JL: $\quad$ So then my auntie, she was up here from San Antonio, the one that's ninety-five. She came. Oh, God there were so many people there.

MF: So that's Anthy Lee, the woman who's in San Antonio, and she's ninety-five.

JL: Yeah.

MF: I'll have to get her contact information.

JL: $\quad$ She's the one I get all my information from.

MF: One of the things I want to start asking you about, then, is Antioch, in terms of the traditions here. You remember it as a child. How have things changed? You mentioned before that you came back in 1984 to live here in Antioch.

JL: Yeah.

MF: This is a different plot of land than what your forefathers had originally, right?

JL: Yeah. My great-grandfather had the land down there where the Buda Elementary is right there down to the creek.

MF: What happened to that land?

JL: $\quad$ They sold it.

MF: Okay. How did you come by this property here?

JL: My grandfather had bought this already before they even sold that.

MF: Do you know what year he bought this property?

JL: I've got the deed. Do you want to see the deed?

MF: No, that's okay. I was just wondering. I mean, I will, yeah. I'll ask you about that.

JL: I think it was 1940 or something.

MF: And he passed it on to you and your brother?

JL: No, it's heir property. In other words, it's still in Hattie and Dan Revada estate.

MF: Okay, I see. And what will happen to the property for the next generation. Have you decided?

JL: $\quad$ Aunt Lee is the last living child of theirs. So what she did, she signed a quick deed to me, to leave it to me and Joe.

MF: I see. And will you pass it on to your kids, do you think?

JL: Yeah. Just pass it on down the line.

MF: Are your kids interested in staying here and keeping and holding the property?

JL: Oh, yeah. My daughter stays here with me. 
MF: Does she know very much about the family history and Antioch's history and whatnot?

JL: Oh, yeah. We have a family reunion every year.

MF: Is that right? Here?

JL: Right here.

MF: Oh, wow! How many people—how many Revadas and related folks show up?

JL: It will be just hundreds. We call it a family and friend reunion. All the kids bring their friends. And the grandchildren bring their friends. And then Martha and Mary, all the Harpers come. The Sorrells, which is another family that we've known since I was a child. The Ralstons. All the families from around here come. It's a good bit of people. We send out fliers about a month before, and we never have a shortage of people.

MF: I bet. That's great. How has the community changed, do you think? Since you can remember it as a child, what has changed the most about it?

JL: Oh, my. First of all, the growth. When I was a child, it was just country. Everything. They done built all these different developments. There wasn't none of that here. All that was cotton fields. People raised cotton over there. Now it's houses. Garlic Creek, Emerald Forest, this, this, this. Just people, people, people everywhere.

MF: How do you feel about that?

JL: It doesn't bother me, but it's just getting kind of crowded. The traffic is horrible. No matter where you going, what time a day it is, the traffic is bad. Other than that, it's okay.

MF: What's important to you about holding on to this property in the face of all this developing? All the development that's going on? Why did you come back here and stay here?

JL: $\quad$ I just love this place. You know I lived here when I was a kid. Over in that house right there. It's sentimental to me. I got pictures. These two big oak trees here? When I was about eight years old I was sitting down between those two trees with my doll. The trees were about that big around. You couldn't imagine. I guess over seventy years-that was over seventy years ago, how small those trees were.

MF: Yeah, you could put a treehouse in those trees now.

JL: I just look at that picture and say, "God, that's them same two big oak trees there."

MF: Right.

JL: But they grow about that much each year. So you take seventy years. They grew pretty big.

MF: What do you hope your kids appreciate the most about Antioch and the colony?

JL: Well, the history of it. They know the history because I'm the historian of the family. My oldest daughter, she lives in that house right down there.

MF: What's her name? 
JL: Valerie. She said, "Oh, Momma, how can you live out in this country. I can't live out here." She wanted to be close to me. All of my kids wanted to be close to me. So she said, "I'm going to buy me a mobile home and put it out there. Momma, you need somebody_" I was living out here by myself. "You need somebody close by. You don't need to be out there by yourself." So she bought that little mobile home, moved out here, and says, "Oh, I couldn't imagine going back living in Austin. It's so quiet and peaceful. Never hear ambulances, never hear fire trucks."

MF: [Laughter] I would love it. My kids-if my kids saw those roosters and stuff you got back there, you'd never be able to get rid of them. They'd be chasing those chickens all over the place. They'd love it.

JL: $\quad$ You should see the kids when they come out here for the family reunion.

MF: I bet. All this space to run around. You don't have to worry.

JL: Chickens! Chickens!

MF: Oh, yeah, those chickens-

JL: I used to have some goats out there, but those goats they eat up anything and jump on top of everything. I had bought some hedges and planted all down-seventeen dollars a piece. Them goats ate them hedges!

MF: Yeah, that's the problem with goats.

JL: Then they got out and got in my garden. I had a garden over here then. They even ate the onions down. You know the green onions? They even ate them down to the nubs. They ate everything down to the ground.

MF: Had to get rid of the goats, huh?

JL: I called that man and said, "Please come up here and take these goats away. I don't think I want goats no more."

MF: Yeah, get yourself a nice cat or something. No it's nice out here. I love coming out here to interview people because it's so nice and quiet. I think to myself, the kids would love it because it's so quiet.

JL: This is my sister that passed away.

MF: Okay, so this is Joyce. Wow, she's pretty.

JL: And this is Loyce. That's when they were younger in high school.

MF: Are they identical twins? It's hard to tell from the pictures.

JL: No, they are not identical. That's all three of us. That's an old picture. This is my sisters when they were in Blackshear Elementary.

MF: Where was this picture taken?

JL: At my grandma's house. Now that was on the land over there before they sold the land. 
MF: $\quad$ So this is Antioch then.

JL: Yeah. That's before they sold that land to Buda Elementary.

MF: Oh, wow, look at this.

JL: $\quad$ And this is us.

MF: Oh my gosh.

JL: $\quad$ Now this is my grandmother and Anthy Lee. Look at that. That's Grandma Hattie and that's Anthy Lee on that donkey. Ain't that something?

MF: That is something. That's a very old photo. You know what's great? She's smiling. You don't normally see people smiling in these very old photos, you know. That's a great picture. When was this taken? Let's see. There's not a year on here, but this has got to be pretty old. Because you said Anthy Lee was like ninety-five and she can't be much more than two in this picture.

JL: $\quad$ Not that old, is she? I don't think she's that old.

MF: Wow, that's amazing. Did she give you this picture? Your aunt?

JL: Yeah, she told me to have one made up, "And give me my picture back."

MF: Right. [Laughter] That's the thing-

JL: $\quad$ This is when we were in California in '49. See on the back there it's written on the back'49. Yeah, that was in ' 49 we lived in California. Now my daddy was in the navy and so was my brother.

MF: Where in California were they stationed?

JL: $\quad$ San Diego.

MF: In San Diego. Nice weather there.

JL: This is just some pictures we took in these last years, all three of the sisters.

MF: So this is before your sister passed away.

JL: Yeah.

MF: When did she pass away? Because these don't look too old.

JL: She's been gone about a year. No, two years. About a year and a half or something like that. Not very long. And this is us. I just saved some of these old pictures.

MF: Nice fro you had.

JL: Oh yeah. I loved my fro. I hope they go back to it. [Laughter] Here's one.

MF: That's great. I love that with the dashiki. That must be what, the seventies? Yeah, 1978. Wow. This one is beautiful. I love this one with the kids. 
JL: [Chuckles] Yeah, that's us.

MF: That's amazing. That's great. Now who are you planning to passing on all of your old photos on to?

JL: $\quad$ My daughter.

MF: How old is your daughter? Valerie, right?

JL: $\quad$ Valerie was born in '53. Monica was born in '61.

MF: Monica. That's my sister's name. You don't hear Monica very often. That's not a usual, typical American name.

JL: $\quad$ Did I tell you Lucy Revada? I've got it down here; she was born in 1876, died in 1941.

MF: Who did she marry? Do you know?

JL: She wasn't married. That's the one that went and had to go to the state hospital.

MF: Okay, so she died at the hospital, then.

JL: $\quad$ She died in the state hospital.

MF: Do you know where she's buried?

JL: Yeah. At Antioch, but it ain't got any marker on her.

MF: She's another one buried there.

JL: $\quad$ And Buster and Leland. Leland Revada is buried up there. That's my daddy's-my grandfather's brother. Leland.

MF: And Buster? Who was he?

JL: $\quad$ That was Aunt Maggie's son. Her oldest son. He got hit by a train.

MF: He got hit by a train?

JL: $\quad$ Mm-hmm [yes]. In Fort Worth or-yeah, I think it was in Fort Worth. They found him on the railroad tracks. He's buried up there. I think I have it all written down, who all is buried up there.

MF: $\quad$ Now a lot of these Revadas were here and lived in Antioch. Why did people start leaving? And when did people start leaving? Why did people start leaving the colony?

JL: Well, Uncle Jim and Aunt Ella moved to New Mexico. See, they were all farmers and after they-Aunt Ella and Uncle Jim had such a-well, they didn't have such a big family, but they had a pretty big family. I'd say about ten.

MF: That's big. 
JL: They took their children and moved because, you know, the farming around here, it was okay, but you had to work year-round. You can't just work like in the summertime and get by all the rest of the year. So they moved to New Mexico.

MF: When did they move? Do you remember?

JL: $\quad$ It had to have been back in the late thirties or early forties. I'd say in the late thirties, like '39 or something like that. They moved out to New Mexico. Uncle Walter and Aunt Eula moved to Brady. Raised their family up there. They had four kids. Uncle Andress and Aunt Fanny, they lived right there. He passed away, and she had to go to a nursing home. That piece of land up there just as you go up Black Colony on the left-hand side is the photography shop.

MF: Okay, and that was their land.

JL: $\quad$ My aunt had to be put in a nursing home. Her niece sold the land for $\$ 700$.

MF: Oh, no!

JL: $\quad$ Seven hundred dollars—-that's what she got for that land. Okay, then my grandfather died first and then my grandmother died. They stayed here until they died. Then my daddy went into the navy, and that's why he was in California. That's where he died, in California.

MF: Did he get drafted?

JL: No, he volunteered.

MF: He volunteered to go.

JL: $\quad$ He volunteered because he had all four of us, and they wouldn't have took him. He didn't tell them he had us until he got in there.

MF: Do you think he joined the service because he thought he'd be able to support you better?

JL: $\quad$ Yeah. They sent us a check, which lifted us up out of poverty a little bit. At that time my grandmother and them, she would just do day work and my grandfather would do farm work. It was pretty tough to have four kids.

MF: So, a lot of people left because the farming was a hard life for little returns.

JL: Yes. There wasn't enough to support those big families they had.

MF: How did the Great Depression—do you remember how that might have impacted the community here? Do you remember the Depression having much of an influence in the 1930s?

JL: I was born in '34, so I didn't-

MF: Hard times is hard times with the Depression or not.

JL: I can't remember back that far, but I-all I remember my daddy saying during the Depression-He said they used to open a package of cigarettes and put them in a box, and you just go there and I think it was two cents for one cigarette or something like that. And he said people would just go buy one cigarette. 
MF: Instead of a pack, because they couldn't afford a pack?

JL: They couldn't afford a pack. It was pretty tough.

MF: I'm sure it was.

JL: $\quad$ My father was born in 1910, I believe, so he was-

MF: $\quad$ So he would have definitely remembered a lot of what was going on.

JL: $\quad$ Mm-hmm [yes]. He remembers how it was back in the late twenties.

MF: Did he tell you much about what the relationships were like between folks living here and the white community in Buda or in other places? Did he talk much about the racism that people had to face back then?

JL: $\quad$ Oh no, but we faced it. You know we had to go around to the back of the buildings to get a hamburger. They had a hamburger place up there. You had to go to the back door. You know how it was. They had a train station up there, a depot, and they had colored waiting room and white waiting room, colored bathroom and white bathroom. You know like that. Everything was segregated. Oh yeah, I remember all of that.

MF: Did you have to have much interaction with whites living out here in Antioch?

JL: $\quad$ No we didn't.

MF: Kind of sheltered from having those kinds of everyday relationships with whites, then.

JL: $\quad$ They just didn't come over to Black Colony. See it used to be no white people living over on this side of the creek. This was all black people. The white folks lived on that side and we lived over here. The only time we went across the creek was when we had to go to the grocery store or you were going through Buda going to Austin. But, no, there wasn't much interaction.

MF: Were there much troubles, problems with whites at all? Did your father or grandfather ever talk about that? Or your mother?

JL: Only thing they talked about Aunt Lee would tell me about it when they shot Mr. Smith in the back. He was-

MF: Is this the guy that someone was trying to buy his horse?

JL: $\quad$ They traded. These boys traded. I guess they was like teenagers and this man came back and wanted his horse back. Wanted to take the horse back. Mr. Smith said, "No, they made a trade. If my boy had got the horse and I wanted to come back and get the horse back, you wouldn't give it back to me." So he wouldn't do it, so they said he was going up Black Colony going home in a wagon, driving a wagon back then, and they shot him in the back.

MF: What happened because of that? Was that the end of the story? Did anybody get arrested?

JL: I don't know, but somebody said that Miss Montague-Mary Montague's daddy was the sheriff and somebody killed him. They don't know. They thought it was a black man, but I don't know. That was a little before my time, but I did hear them talk about how they shot Mr. Smith in the back. Then I heard them talk about how Mary Montague's daddy was the 
sheriff, and how he was so mean to black people, and one day he come up dead. You know we just have to let all that rest. Ain't nothing we can do about it.

Only interaction that I ever had was we couldn't ride the school buses. Black people wasn't allowed to ride the school buses so the white kids would be on the school bus, they'd fill these balloons up and throw them at us and bust-they'd throw them at us and get our clothes wet. That was evil. Evil. That was so evil. It was so mean. We had to walk to school, and they got to ride to school. Yet still when they passed us, they would throw them water balloons out, and hit us with the water balloons.

Alistene, I think Alistene, after they integrated the school, some of the Roystons went to that school up there and some of the Sorrells. They said they had hell.

MF: $\quad$ I bet.

JL: $\quad$ They fought every day. They hated. They hated them up there. They didn't want them in the white school.

My little granddaughter did an interview. She interviewed me. You know, they had to do that for a school project, and she said, "What area would you like to, if you could, live in?" I said, "I'd like to live after they integrated the schools so I could have went to a decent school, because that one I went to was pathetic. "Separate, but equal." That was the biggest lie they ever put out. Wasn't nothing equal about our school and the white school. We didn't even have a water fountain. We had to take water in a bottle, because if you didn't, you didn't drink no water until you got back home. You had to take your own water to school. You know you had to take your lunch, but they didn't even have a water fountain at the black school. It was horrible. We had an old coal stove. Everything in there was smutty, black. You could just run your hand across the desk like that and it was black. When you sneezed, blow your nose, black. It was a wonder we didn't all come down with lung disease.

MF: Right. Exactly.

JL: But that's the only heat we had.

MF: What about books and that kind of thing?

JL: We got the old hand-me-down books from the white school. Pages torn out of them, written in, scribbled in. Yeah, we got a dirty deal on that. Anybody said it was equal, "separate, but equal," that was a falsehood.

MF: It was just separate.

JL: It was just separate- that's all it was. Wasn't no equal to it.

MF: Do you think integration was a good thing for this area then?

JL: I'm glad that my grandchildren get to go to a school that's warm in the winter and cool in the summer. That school I went to was cold in the winter and hot in the summer. We had no air conditioner, not even no fans. And you know how hot it gets in Texas. God, it was miserable. I'm just glad that they've got-Yes, I think that integration, I think it was time for them to quit saying "separate, but equal" and say everybody should be equal. When she asked me what area I would like to live in, I said, "I sure would like to live, if I could live in the time after they integrated the schools." And I would have liked to go on and got more education, but it didn't work out that way. But I hope my grandchildren go on and, you know. 
MF: Are these Valerie's children?

JL: Monica's daughter.

MF: $\quad$ And so they are here in Buda.

JL: Yes.

MF: Where do they live in Buda? They live, oh, they're the ones that live in this house here. I see. And how old are her kids?

JL: $\quad$ Thirteen and fourteen. And they are too awesome. They are awesome. I mean the oldest one, the oldest one made the High Steppers at Hays High School. She's the only black on the roster. She made it out of eighty girls that tried out, she made it.

MF: That's fantastic.

JL: $\quad$ They could never outdance us. There's just some things they could never do good as we do. My daughter said, "If she doesn't make it, I know there's something wrong."

MF: $\quad$ Something's fixed. So they're doing well in school?

JL: Oh, yeah. Both of them are on honor rolls.

MF: That's great. Have they said what they want to be yet?

JL: $\quad$ They keep changing.

MF: Well, they are thirteen and fourteen.

JL: The youngest one says she wants to be a veterinarian. She loves animals, loves horses. Wants to be around a lot of animals. The other one, she can't make up her mind whether she wants to be a lawyer, a doctor, what else did she say? Then she says, "Granny, do you think I ought to be a lawyer or a doctor?" I said, "It doesn't matter." She says, "Well which one should I be, because one day I might want to run for President." I said, "Well, you would have to be a lawyer first and then you can go from there."

MF: Just follow in Obama's footsteps.

JL: $\quad$ She says, "One day I might want to run for President." She sets herself way up.

MF: That's good.

JL: I mean she—-there's nothing short about her.

MF: That's great. Was she born in Buda, then? Was she born and raised here in Buda, or did they move here from Austin or someplace else?

JL: She was born in Austin, but she's been out here ever since she's been born.

MF: I guess if you're in Buda that's the closest place to be born is Austin. That's right. 
JL: Anyway, one day she says, "Daddy, are we rich?" "No," said Monica, "we're not rich." "Well, are we poor?" She said, "No, we're not exactly—. We're doing all right." "Well, Daddy, are we middle class? What are we?"

MF: $\quad$ She needed an answer.

JL: "Are we rich, are we poor, are we middle class? What are we?"

MF: Kids these days, huh?

JL: $\quad$ They are something else. They are just too cute. I get so tickled. "Daddy, can you take us to Chili's? We want to go eat a steak." He said, "Well, we have to plan on that. That doesn't fit in our budget." "Well Daddy, how much money do you have?" That High Steppers, it cost $\$ 1,000$. That's what the family has to come up with.

MF: For the uniforms and all that?

JL: $\quad$ For the uniforms. They go to camp.

MF: Travel. Wow.

JL: $\quad$ She told her daddy, "Daddy, I made High Steppers. I'm in the High Steppers now, and you need to pay $\$ 1,000$. I have to have my uniform, this_-"

MF: Well, and you don't want to disappoint her.

JL: Then Sam got sick and he had to go to the emergency room, and he was passing a kidney stone. He came back home, and said, "That girl made me throw a kidney stone."

MF: She's probably just getting started, too. That's the scary part.

JL: He said, "A thousand dollars! Couldn't you get in nothing cheaper?"

MF: The chess club or something, right? It must be really affirming for you that your grandkids are doing so much better than you were able to do at that age. Because you couldn't imagine an opportunity like this for yourself.

JL: Oh no. We couldn't even go to the white school. I'm telling you what kind of shape they put us in. And the school didn't go no higher than the eighth grade, so when you got to the ninth grade, you just had to drop out. They didn't care. Eighth-grade education, I guess they said, "That's good enough to clean our houses, and mop our floors." Because what could you do with an eighth grade, you know. So we had to go to Austin and start the school over there. Yes, that's where I graduated.

MF: And that's what you did. You said you went to Anderson?

JL: Anderson High School.

MF: When did you graduate there? What year?

JL: $\quad$ Fifty-two.

MF: Did you have any classmates from Antioch there, too? Do you remember? 
JL: Yeah. If they wanted to go to high school, they had to go there. That's the only high school-

MF: But do you remember which of your classmates went there?

JL: $\quad$ No, I don't remember. I think they just didn't go no higher. I know the Harpers didn't. I don't remember any of them going no higher.

MF: I think one or two of them might have gone over to Anderson. I can't remember which ones. Some of the younger ones. The ones-I think there were two sisters that didn't end up going to Arizona because they were at the high school out here. They were staying with relatives. But yeah, you're right. It must have been tough.

JL: So anyway, it was pretty bad. You couldn't get no higher than the eighth grade. If you did, if you went any higher than that, you had to leave Buda.

MF: You had mentioned that your Auntie Lee is, that you've gotten a lot of information from her. It sounds so much like you know so much about the history here. Who taught you a lot of that history? Was it her? Or your parents-well, your mom died when you were four, right? So she was the one who told you a lot about Antioch, and who your folks were and so forth?

JL: $\quad$ Mm-hmm [yes]. Yeah. You know, you just pick it up. I knew all Uncle Oddies's kids. And I knew—nobody in their-out of four children, my father was the only one that had kids.

MF: Your father was the only one who had kids out of four?

JL: Yeah. Uncle Langston, Aunt Ladys, and Aunt Lee, them three didn't have no children.

MF: So your Aunt Lee that's surviving, she never married? Or she just never had kids?

JL: Yeah, she just didn't have kids. And it's so funny, on my mother's side, Aunt Nell, Aunt Emma, and Aunt Irene-my momma was the only one out of them three girls that had kids. Wasn't that something?

MF: Wow. Do you think it was because people chose not to have kids? Or do you think for some of them they just could not have kids?

JL: They just couldn't have kids. You know they didn't choose not to. There was no birth control.

MF: It's not like that today. I didn't want to assume, because some people probably might have chosen, but yeah, you're right. You get married, you have kids.

JL: I think it was some organic, something wrong with their bodies, I mean, you know, that they never conceived.

MF: You never know what a lifetime of hard work by the time you're twenty-five or thirty?

JL: Yeah.

MF: Poor nutrition or whatever. You know, there could be a lot of different things that work against you. [Right.] Definitely.

We talked about when you were growing up, like you'd go fishing, things like that. Do you remember the kinds of games and stuff like that you'd play when you were a child? 
JL: Oh, let's see. Well we had bicycles. We used to go riding on the bicycles and go visiting. Go down to Aunt Fanny's.

MF: Fanny's?

JL: $\quad$ She lived right there where I told you going up Black Colony.

MF: Yeah, right. Oh yeah, the land where the photography studio is now.

JL: We used to go down there to see Aunt Fanny and Uncle Andress. We just played dolls and we had a dollhouse. We had a playhouse. What we called a playhouse. And what we did, we'd take some wire and go around like this and broke off about-my grandfather had that so clean down there it looked like-

MF: Oh, he just had it cleared off, you mean?

JL: It's done growed up now, but that was so-this place is beautiful when it's cleaned.

MF: I think it's great now.

JL: He had that branch-we call it the branch because water runs down there and run into the creek-he had that so clean. And down in the branch, the bottom of it is solid rock. We would sweep it, sweep it real clean, take and put wire around these trees, roped it off. This is our playhouse. We had an old foot tub, turned it upside down, that was our stove. You know how kids play, and we'd play playhouse. Play in the playhouse. Oh, we'd love that.

MF: I was going to ask, it was your grandparents that raised you, right? You said that when your mother died when you were four, your father left you here with your grandparents. They were the ones that taught you proper behavior for a girl, let's say. What kinds of things did you learn early on to do and not to do? What were you supposed to do as a young girl growing up here in the colony?

JL: You spoke when you were spoken to. You didn't run. Kids nowadays, they have no manners. We had to say, "Yes ma'am," "No ma'am," "Please," "Thank you." We had to do all of that because you just didn't talk to nobody just, "Yeah" "Nah" "Eh." You had to say, "Yes ma'am" if they asked you a question.

MF: There must have been for girls-were they stricter? Do you think they were stricter on girls than they were on boys?

JL: Well, I guess so. But we didn't have that problem because we were back in these woods and there's no neighbors, so you know, we didn't have no visitors.

MF: Yeah, but there were other boys in the colony.

JL: Yeah, way up there, way up there. But who's going to walk way down here?

MF: So they didn't talk to you about dating or those kinds of things?

JL: No.

MF: Didn't have to. 
JL: We weren't allowed to date. We weren't allowed. I mean you know, we didn't-the only place we went to was to school, to Sunday school on Sunday, and that was it. And to the cotton fields when we had to go pick cotton. We'd go fishing or something like that. But there wasn't no kids around us. You know, we were kind of isolated.

MF: Growing up in the house, did you have responsibilities? It was you and your three siblings, so you did have a brother here. Do you think he was treated differently than you and your sisters were treated in terms of the kinds of work you had to do around the house and whatnot?

JL: Not really, because he had his chores. He had to feed the chickens, feed the hogs, get wood in, get water in. I had to milk. He didn't want to learn how to milk, so I learned how to milk the cow, so I did all the milking. My sisters did most of the dishwashing and cleaning and doing in the kitchen. Me and my brother did most of the outside work. We had to lead the cow down to the water hole, because you know a cow can drink forty gallons of water, and wasn't nobody going to pack her no forty gallons of water up that hill.

MF: No. And you were saying that's where you got your fresh water, too, was down at the creek.

JL: $\quad$ Oh, yeah. We had to drink out of the creek. We didn't have no well. No. So we drank water out of the creek. Didn't kill us.

MF: No. I'm sure it was a lot cleaner back then, too, than it is now.

JL: We had a bucket of water with a dipper in it, and everybody drank out of that dipper. Now if you did that, you'd probably all be dead. Ain't that weird? We had a bucket of water with a dipper. You just go there and drink your water. If you didn't want all of it, we had a wash pan there, you'd just pour it in the wash pan and put the dipper back in the bucket. My grandfather, my grandmother and all of us kids drank out of that dipper.

MF: And there was no electricity out here.

JL: No electricity.

MF: And outside toilets, right? You had outside toilets?

JL: $\quad$ Outside. Outhouse.

MF: You had a privy, yeah. Where's that privy now?

JL: It was back there, but my brother tore it down.

MF: But the hole is still probably in the ground someplace. Or filled in.

JL: Well, it's filled in now and washed over. That's been-my grandmother died in '54. It's been a long time. It was leaning like this, so he just knocked it down. But anyway, we had no water, no electricity, and we had-see them lamps up there up on top of that shelf? That's the kind of-

MF: Oh, yeah, right, the old-

JL: No. Right there where the dishes are.

MF: Oh, the lanterns. You mean the oil lamps. 
JL: The oil lamps. That's what we had. And the kerosene was like 15 cents a gallon. We used to go to Buda and get a gallon of coal oil.

MF: Was that considered expensive, 15 cents a gallon?

JL: $\quad$ Expensive. My grandmother wouldn't let us light the lamps. She would say, "Go to bed before it's dark. You don't need the light. That's just wasting coal oil." So we had to go to bed before it got dark.

[Interview interrupted; recording paused.]

MF: What else did I want to ask about? So as a teenager, then, you had already moved. You were in California as a teenager, then?

JL: Well let's see. When did we leave here? In '49, or '48 or '49. See '44 I was ten. I was about fourteen.

MF: $\quad$ So you were a teen when you left [yeah], but you spent most of your teenage years, the older years in California.

JL: I went to finish the ninth, tenth, eleventh grade, them three grades in California. Then in 1951 I started to Anderson High. We came back to Texas, and I started to Anderson High School and finished in '52. That's what I was doing back down here. When we left California, my stepmother didn't want us to come back. She didn't want to be bothered with us anymore so-my daddy had married again.

MF: Were your grandparents still alive then?

JL: Yeah.

MF: So when you came back, you were able to stay with them?

JL: $\quad$ No, I stayed with my auntie. My mother's sister, Aunt Nell.

MF: In Austin.

JL: $\quad$ She lived in Austin, and we went and stayed over there with her.

MF: I see. Who were you named after? Were you named after anyone?

JL: Aunt Nell.

MF: Okay. So it's Joan Nell. Who named you, do you know?

JL: $\quad$ My mother.

MF: Do you remember anything about her? I know you were really young when she passed.

JL: No. Not a thing. I don't remember nothing. I don't think-even my brother was six, I don't think he can remember nothing.

MF: Did anybody tell you who you were delivered by? You were delivered by a midwife, I assume. 
JL: I think so. No, I think maybe a doctor. I got my birth certificate. It's got some doctor's name on there.

MF: You had a relative who was the midwife here.

JL: Yeah. Maggie.

MF: Maggie was the midwife.

JL: She delivered Mary and Martha. [Minnie Harper Nelson and Winnie Harper Moyer.]

MF: Right. They mentioned that. Do you know much about the kind of work she did around here?

JL: $\quad$ She just did a lot of babysit—nanny work, keeping people's kids. You know, go to their house. Keep their kids and clean up. You know.

MF: Did you know her very well?

JL: Aunt Maggie, yeah!

MF: Did you ever see her at work taking care of other people's kids?

JL: Well, she used to take care of these two little boys. And of course the old swimming hole was right there, so everybody had to pass by here going to the swimming hole. We didn't have no swimming pool in Buda, so all the white, black, blue, green-everybody used the same swimming hole.

MF: Oh, so that wasn't segregated.

JL: $\quad$ No. The swimming hole wasn't segregated. She'd come by here with them two little boys, go down there, they'd play in the water, and then she'd go back.

MF: $\quad$ But she had kids of her own.

JL: Ten!

MF: Right. This is the woman.

JL: That's Oddies's children.

MF: So that's probably where she learned a lot about child delivery, infant care, and all the rest of that stuff, was through that.

JL: $\quad$ She probably delivered some at home.

MF: It's just interesting. That's one of the things I was interested in was the midwifery work. Who was doing that kind of work here, because people didn't have access to obviously a hospital, or a lot of people couldn't pay for a doctor.

JL: Couldn't afford it.

MF: So she probably did a lot of medical treatment, too, for people.

JL: $\quad$ She probably delivered a lot of more kids around here, but I don't know. 
MF: And she probably got paid instead of in money in kind, right? Like someone would give her some chickens or something like that, right?

JL: I know some of the people around here had molasses mills, they made molasses. Killed a hog. It was kind of like a community where if the Smiths' killed a hog, everybody got a piece. When the Joneses killed a hog, everybody got a piece. You know, everybody shared. If this man was raising sweet potatoes, he'd give everybody some sweet potatoes.

MF: Is that right?

JL: Yeah. That's how they made it.

MF: Neighbors relying on neighbors.

JL: Cornmeal, they would take the cornmeal and grind it. They'd give everybody a little cornmeal.

MF: What other kinds of things did people do to help each other out here?

JL: Well, the ones that had mules and wagons, they would haul water. They would come to the creek down here, fill up their barrels and haul water, and they would sell water for a nickel a barrel or 15 cents a barrel, or whatever they-yeah, they'd haul you water.

MF: And then Mr. Harper had the truck. You mentioned that he would take the kids to-

JL: Oh, this was years later.

MF: Oh, you're talking about before that.

JL: I'm talking about when the colony first started. At least they had-people would pay to have water hauled, because there was no wells. I forget who she told me used to haul water.

MF: Timmens maybe? No. There is a name I've gotten of someone who would haul water for folks and sell it for like 25 cents a barrel or something like that.

JL: And then there was one that would bring ice, the iceman, if you could afford it. You'd get you fifty pounds of ice, wrap it up in some newspaper. My grandmother used to do that. Try to save it, you know.

MF: Did people do this kind of - So, okay, years later when you were a child, what kinds of things did people still do for each other? The neighbors, how did they help each other out?

JL: $\quad$ They still would-If Mr. Harper killed a hog, we'd still get some fresh meat.

MF: $\quad$ So you said if Mr. Harper killed a hog, he'd make sure you had some.

JL: $\quad$ He'd say, "I got some fresh meat." Then when my grandfather would kill a hog, you know, he'd share it with the neighbors. Well, we didn't have no neighbors, but like the Harpers. It was a lady that lived between here and the Harpers on Black Colony, right along there, all them nice houses right along there-there wasn't nothing there. The white people bought all that land up, and the black people lost their land. What happened, the older people died and the young people moved to the cities and the taxes, and they come along and got it dirt cheap. But all along there was black people living. It was a lady live along there, we called her Miss Lizzy. He used to take her meat up there and give her meat. 
MF: Do you know what her last name was?

JL: Robinson. Lizzy Robinson. They had a little shanty, a little shack. I guess it was two rooms. Her and her daughters lived in there. She had what, two or three girls living with her. We used to give her meat, take her some meat up there. You know, just shared different things. It had kind of wore off by then because people were doing pretty good. Some people were getting checks. Some people were getting help from their kids, you know, and stuff like that.

MF: And there were few people left. Probably by the time you moved to California there weren't as many people here, right?

JL: $\quad$ Even like the Harpers. They left and went to Arizona. They just couldn't make it here. There wasn't enough work. Where they could work year-round, you know.

MF: Were your grandparents members of any social organizations? Masons or anything like that?

JL: I think my grandfather was. I think he belonged to the Masonics. They had a chapter out here. I heard Aunt Lee say they used to meet up here in this building.

MF: At the old school?

JL: $\quad$ The old school. She said, "Pop and them would go up there when they'd have their meetings up there." I sure want you to talk with her.

MF: I would love to talk to her. I'll get her number from you. The only other questions I have, have to do with the household, that is what your family did to support itself, but you had mentioned that your grandmother did day work.

JL: Yeah. She did day work. Did washing and ironing.

MF: And then your grandfather worked as a laborer, did you say?

JL: Yeah. Farming. He did a lot of farming.

MF: On other people's property, not on this property here.

JL: No, not here. Just on other people's property.

MF: Usually around here in Buda, or did he have to travel around much for that?

JL: No, just around here in Buda. Niederwald, Creedmoor. You know, all these little places around Buda.

MF: How old was he when he had to stop working? Because that's hard work.

JL: Well, I don't know. When he died, he was working, and the doctor said he had a heat stroke. It was hot, like 102 degrees that day, and he was out there working. It just got too hot, and he passed out. By the time they got the doctor to him, he was gone.

MF: In what year was that?

JL: $\quad$ Oh, '52, I believe. I'd have to look that up. I think it was back in '52.

MF: So he was out picking cotton when that happened? 
JL: $\quad$ No, he was chopping in the yard. He was doing yard work in somebody's yard up there in Buda. Then he passed out, and the doctor said he just got too hot. He had a heat stroke. It'll take you out from here. Your body get too hot.

MF: $\quad$ Oh, yeah. Absolutely, if you're not hydrating yourself.

JL: $\quad$ They said he was just wringing wet. His clothes were just soaked to him.

MF: A lot of times you don't even realize it's happening. Your body goes into shock from losing too much fluids.

JL: It's funny, because my very best friend and her husband was up there at the lake the other day, and it was hot that day. And of course where they were, it was sand, so I guess that made it hotter. Anyway, he didn't realize he'd got that hot. All of a sudden he just got nauseated, like he was going to pass out. I said, "Rose, get him in the camper." They were in an RV. I said, "Get him in the camper, wet some towels with some cold water and wrap it around his neck, cool him down." If you get too hot, I said, put it around his neck because that will cool the blood that's going to his brain. I said-so she worked with him, worked with him, and finally got all right. She said he was in bad shape, just sweating. Sweat just running off of him. I said, "Rose-" I didn't know what to tell her to do because he'd already had one heart attack. I said, "Are you sure he's not having another heart attack?"

MF: How old was he?

JL: He's my age, seventy-five. I said, "Well cool him down. Put some wet towels on him. You know, he's got too hot." After a while I called back, and she said, "He's sitting down here eating a sandwich. He's all right."

MF: Well, thank goodness. [Laughter]

JL: $\quad$ She said, "Joan, I wish you was up here. You a nurse. You know what to do for him." I said, "Cool him off-that's all you have to do."

One time I went fishing, it got so hot. I could feel myself going away, and I just jumped off in that lake and went under that water and come up. That's the only thing that saved my life. I was getting a-oh, Lord, it was so hot. I was getting-I looked in that water and something said, "Get in the water. Get in the water." I just tseww. When I come up like that "Oh, God," I said.

MF: "What was I thinking sitting out here baking myself?"

JL: Baking in the sun.

MF: For a fish.

JL: Texas will get awful hot.

MF: It will. It does. Yes. We're going to be digging this summer in this heat, too.

JL: And the humidity, it raises the temperature so high.

MF: You mentioned that you did nursing. How long-you don't do that anymore, though, I take it.

JL: Oh I'm retired, honey. 
MF: I didn't want to assume, because my mom is seventies and working still.

JL: $\quad$ I started school in 1962.

MF: Nursing school, you mean?

JL: $\quad$ Mm-hmm [yes]. I finished in 1963. I'm just a LVN. I'm not an RN. I retired in '96.

MF: From where? Were you working at a hospital here in Austin?

JL: Well I was working at San Marcos at a retirement center. That was my last job. But I retired when I was sixty-two.

MF: [Phone rings; answering machine picks up.] You get a lot of telemarketers.

JL: "The warranty on your car is expiring." I don’t even have a car, lady. For goodness sakes! I wanted to show you something. Can I show you something?

MF: Yes, absolutely.

Interviewed by: Maria Franklin

July 1, 2009 (3 of 3)

MF: This is Maria Franklin. Today is July 1, 2009. I'm interviewing for the third time Mrs. Joan Nell Revada Limuel. This interview is taking place at the home of Mrs. Limuel in Buda, Texas. The interview is part of the Oral History Program for the Ransom Williams Farmstead Project.

Thank you again, Mrs. Limuel, for agreeing to wrap up this interview. So I just have a series of questions left about relationships between the different African American communities and some questions I want to ask you about the past here and what do you think about the history of Antioch. So to begin, one question that we had was, in previous conversations that you and I have had, I've talked about the archeological site where a family that was headed by a woman named Sarah Williams and her husband Ransom Williams back in 1870, lived out by Bear Creek, and we're doing the research there now. Now had you ever heard of their names, Sarah and Ransom Williams?

JL: $\quad$ No, I hadn't.

MF: And had you, growing up here, heard of a Mary Williams Davis or a Will Williams, their children, by any chance? [No.] Okay. Now in terms of your family members, did you or do you have family members who intermarried with spouses from Manchaca, Kincheonville, or any of the other black communities around here, east Austin? I remember I think you and I talked previously about your uncle. Was it Oddies Revada_-yes]—who married Luvinia Bunton-

JL: Bunton, yeah.

MF: -from Manchaca. Do you have any other relatives that you can think of who chose partners from other communities outside of Buda? 
JL: Um, no. I don't know, my grandfather's brothers, and I don't know-I think they married people from Austin, if I'm not mistaken. My grandmother, I think, was from Austin or Cedar Park or close to Bastrop or something like that. But I don't, I don't know anybody that used to live in Manchaca.

MF: Okay. How about your aunts and uncles? Did they marry anybody from say Kyle or Creedmoor or-?

JL: $\quad$ No. Um-

MF: Was it typical, then, for your family to marry folks from here-

JL: $\quad$ From Buda.

MF: Okay, so they pretty much married-

JL: One of my aunts married somebody that was from Buda.

MF: Which aunt was that?

JL: $\quad$ One of the Walkers, and he was a Walker. But his, uh-let's see. I think his grandmother was a Bunton.

MF: Okay. From Antioch?

JL: Yes, from the colony, yeah.

MF: Okay. Which aunt was this?

JL: The ninety-five-year-old lady that lives in San Antonio?

MF: $\quad$ Anthy Lee.

JL: Aunt Lee, yeah.

MF: You call her Aunt Lee?

JL: $\quad$ Aunt Lee [pronounces it with a long "a"]. But her name is Anthy Lee, yeah. But she married a Walker, and I think his mother was a Bunton, but she married a Walker. Mm-hmm [yes]. Yeah, his mother was Kate Bunton or Katie Bunton.

MF: Oh, yes. Okay. I've heard that name.

JL: $\quad$ Mm-hmm [yes]. But not Aunt Kate. The one we call Aunt Kate that used to live up here.

MF: Oh, okay. Yeah, that's the one I was thinking of.

JL: $\quad$ No. She would have been that old. Because I met his mother, I knew his mother. So she was still living up until, say, ten years ago or something like that. And, Aunt Kate died years back.

MF: Back in the fifties, yeah. Right. [Mm-hmm (Yes).] What about your other uncles and aunts? Did they marry other-did they have other partners that they took spouses from Buda? 
JL: $\quad$ No. My Uncle Langston, which was my daddy's brother, he married a lady from Austin. And Aunt Ladys, she never married. That was Aunt Lee's sister. And my daddy married my mother, who was from Mason, Texas.

MF: Right, okay. I see, and that's the four.

JL: $\quad$ Mm-hmm [yes], that was the four.

MF: Right. When you were living here, was it common for your family to take trips to Austin or to any of the other African American communities around here?

JL: Yes. Well, they would go to Austin because we had relatives over there. My grandfather's sister, Aunt Dellie, and other relatives that lived in Austin. So they did go to Austin.

MF: Did they live over in east Austin?

JL: South, south Austin.

MF: One of the things that people have mentioned is that Austin was a place that you sometimes went there for the weekends to enjoy yourselves for leisure. [Yes.] Did you ever do that on Saturdays or Sundays?

JL: Yeah, like for a movie. You know, we didn't have no movie theater out here, so we'd go to Austin, go to the movie.

MF: Which movie theater would that have been?

JL: Well, we usually went to the Harlem Theater, which was on East Twelfth Street. I remember it was 9 cents.

MF: For a movie, huh?

JL: $\quad$ My aunt used to give us a nickel and four pennies. "Here's your show fare." She'd give all of us 9 cents. Wasn't that something? 9 cents!

MF: And that theater's long gone now.

JL: $\quad$ They tore it down, mm-hmm [yes].

MF: Right. Did you ever go out to Sixth Street? That's another place that folks have mentioned that the African Americans gathered.

JL: $\quad$ We used to—we used-yes. They—my grandmother and them would go down, and they had-I don't know if it was Handy—no, not Handy Andy, but uh-Anyway, there was a food store down there. They used to go buy different things, you know, like sugar and coffee and whatever. I can't think of the name of it. I thought it was Handy Andy, but it wasn't. It was something-Piggly Wiggly.

MF: Oh, they had a Piggly Wiggly here?

JL: They had a Piggly Wiggly down on Sixth Street, and everybody would go down on Sixth Street to Piggly Wiggly and buy groceries because they were cheap, you know.

MF: And African Americans were welcome there? 
JL: $\quad$ Oh, yeah, mm-hmm [yes]. It was just a grocery store. Yeah. And um, it was really a big deal, you know. My grandmother would say, "We going to Austin," and we'd get all-because she always washed our clothes and put that heavy starch and ironed them and those little dresses would be standing out like [chuckles]-

MF: Right! So it was a special occasion to go out to Austin.

JL: Oh, it was a special occasion to go to Austin.

MF: Oh, okay. So you got dressed up?

JL: Got dressed up, put on a little pinafore, them big ruffles on the shoulders, those little pinafores. She made all our clothes.

MF: Right, you had mentioned that.

JL: Yes. She made all our clothes, even our slips and our panties. She made everything.

MF: Right. And now, how did you get there? Did your father have a car? I mean your grandfather?

JL: $\quad$ My grandfather, yeah.

MF: Grandfather had a car?

JL: Yeah, mm-hmm [yes]. We had some kind of -I don't remember what kind of - whose car. I think it was his car or my uncle's or somebody. But, yeah, we used to go. That was a big thing to go to Austin.

MF: Yeah, that's what people had mentioned, that it was a big deal-

JL: That was a big-

MF: - to travel out from the country out to Austin. [Yes.] Let me ask you about growing up here in terms of the problems that the community faced. You were pretty young, but you left here when you were what, about a teen, right?

JL: I was a teenager, yeah.

MF: So you probably remember some things. Can you recall if there were-you know, when you think back, what some of the biggest challenges might have been for people living here?

JL: $\quad$ The biggest challenge was there wasn't no work here, nothing but farming and picking cotton, chopping cotton. I think that's why some of the people moved away from here, because there was nothing to do here. I mean now you look at Buda, you say, "Oh." But back then, all that's built up out there was nothing but fields. There was no, you know, there was no Cabela's, no Jack in the Box, no Dan's Hamburger Stand. It just wasn't nothing to do here, really. If you didn't work for Heep's Dairy Farm or if you didn't work for the Highway Department, then all you had was during the summer was pick cotton or chop cotton or pull corn or rake hay, you, things like that.

MF: Okay. Well, how would you describe the greatest strengths in the community?

JL: Well, I think the greatest strength was just sticking together, you know? Like if you heard somebody-For one thing, there was two sets of twins in the community, and 
my grandmother took real good care of our clothes because she-Well, the other twins were younger, so she would give Mrs. Harper the twins' clothes for her twins. When my grandfather would kill a hog, we would make sure that this one and that one and that one got some meat, you know, and the same thing when they would kill a hog, they would-

MF: $\quad$ Share it.

JL: $\quad$ Share. I think that was the greatest strength was just sharing everything, you know. If you had a mule and a wagon and you could haul me some water, you know, and maybe I could give you some of this or that, you know trade out, a couple of chickens or a turkey or you know, stuff like that.

MF: Sure. What were the joys of being part of this community?

JL: It wasn't very many. Unh-uh [No]. I enjoyed the church. You know, we used to go to Sunday school every Sunday. I liked the school, we had fun at school. But it was hard here, you know? We had no electricity, no water, no running water, no lights. You know, we had to use kerosene lamps. It was a hard life, and the good ole days, those weren't no good ole days, not to me. You know, you have one pair of shoes. You wear that pair out and you can get another pair. But I mean the kids have so much today. They have so-three or four, five pair of shoes. "I don't like that." "I don't want that." "I don't eat that." It wasn't like that. When I was growing up, whatever was put on the table, you had to eat it or just go hungry. "I don't eat beans." "I don't like this." "I don't want that." Unh-uh [no], there wasn't none of that. You just ate what was-them bowls was set on the table, and you ate that or you just went to bed hungry, you know? Now kids, they tell they daddy and mama what would they would eat and what they don't want to eat. [Pause for telephone call.]

MF: All right, what is it about knowing your history that's most important to you?

JL: $\quad$ I just like to know everything that I can know about the past. I just, I read everything. I just-I don't know. It's just something about the past that just fascinates me, and I look at all these people on these pictures. Do you remember that movie Dead Poets Society? [Yes.] How you'd look at a picture and you'd think they used to live and how they life was. Now they all gone, just like dust.

MF: So you've been collecting your family history for a long time. What is it about-I mean in collecting it, there must have been in your mind a reason why you think it's important to have all this collected and documented.

JL: $\quad$ Oh yeah, and I just collected and write down everything that I can record, so the children coming on after me, my grandchildren, my children-mostly my grandchildren, because my children, you know, they are a little up on our history, you know. They know about my grandmother. My grandfather was a slave. But the young children coming on, she looked at me and she said, "Granny, was all black people here slaves?" and I said, "Yeah, most of them was slaves." "Your grandmother was a slave?" They don't-you know, and that's just one thing about the school. I don't know why they don't teach the black kids nothing about they history. I mean, you know, it's just like we just phantoms. We just all of a sudden one day just appeared here. They don't tell them how we got here. They didn't know that we were brought over here on ships. And you ask them about Frederick Douglass or you ask them about Tubman or some, "Who? I don't know what they did. I don't know." And like we celebrate the $19^{\text {th }}$ of June because that was the day the slaves were freed in Texas. "I don't know. It's just a fun day. Time to go out and have a picnic or something," you know, but they don't know the meaning of it, you know? So if you don't know that, then you think everything was like it is now always, and it wasn't. I mean even fifty years ago, if you go back fifty years, 
you just—and they don't think nothing about Obama being President. "Why shouldn't he be President?" I mean, you know! I got a little—my little grandson, he say, "Obama's President." He's about five, six years old. "Obama's President. That's my President. He's like me." I said, "Yeah," and his mama say, "Darius, Obama is all of our President." "Did he say he wanted to be everybody's President or just my President?" You know. But they don't even know the significance of that.

MF: Yeah, I wonder about my kids, two and four, they're growing up with a black President, and they're going to think that that's normal, unless I tell them otherwise!

JL: Oh, yeah. So, "Granny, why did you put his picture? Why-?"

MF: Oh, wow. I never thought I'd see it in my lifetime.

JL: I didn't either. You know I didn't. And I think about all those that done marched on and they didn't get to see that, but it just wasn't for them to see. Then I think about all them old people that just hated us so. I just wish they could have saw it-more than us seeing it, I wish they could have seen it. But you know, it's some out there right today that's just- they could just almost commit suicide. Never thought they'd see a black man in the White House. They are just so upset about it. I mean you wouldn't believe the things they say. Like even the kids at they schools, they say, "Granny, you know what this girl told me? A black man shouldn't be in that house. It's called the White House." I said, "Well, we might just have to paint it black. If they don't want a black man in the White House, we might have to paint the White House black and then we'd have a black man in the Black House." [Laughter] But can you imagine? And now you know they got that from-they mama. "He shouldn't be up there. He has no business in there. That's the White House." So even that, and my little granddaughter, the one that's in High Steppers, say, "I hope when I go to college, Granny, I see more black people there." You know, she—-there are maybe two, maybe three black girls that go to Hays High School.

MF: Oh, I didn't—-that's it?

JL: Oh yes. It's very-you could just spot them out when you walk up there, and say, "One, two, three. Oh yeah, okay. That's us. That's us." But anyway.

MF: Wow. That must be a challenge.

JL: And it's a challenge. I mean, it's a trauma. Not a trauma, but-I mean, you just want to see more of yourself, you know.

MF: Of course, of course.

JL: It's like when television first came out, there was no black people on television. It was like we didn't even live in this country. There was none of us in this country because you never did see us on TV. You never-it was all just Andy and Opie and Aunt Bea. I mean, you know all of that. Now, kids turn on TV, BET, "Oh, we going to look at this and this and this." Now they don't even realize that it used to-It was like we wasn't even on the Earth, like we didn't even live here or we didn't even exist. Of course, now they have to recognize us because we got a black President. [Laughter] What can we do about that? Yeah, they have to say, "Yeah, they have some black people in America, mm-hmm [yes]. They fooled around and elected one President." [Laughter] Yeah, they'd have to acknowledge it now. "Oh yes, a few of them living there," mm-hmm [yes]. 
MF: Right, right. You mentioned Juneteenth. Did you growing up here in Buda, was that an important holiday people celebrated?

JL: Oh, that was the cat's meow.

MF: Who taught you about Juneteenth? Did you know as a child? You mentioned that kids now don't know what it means, but did you know?

JL: Oh honey, oh, yeah.

MF: You did know.

JL: $\quad$ See, we had black teachers. We had black teachers, black grandmas, black mamas. Everybody knew the history of slavery and how we got to be where we were, you know, and the teachers-

MF: So you were taught that in school.

JL: $\quad$ Yes. We were taught it. You know, "Well, the $19^{\text {th }}$ of June is coming up. That's the day that they finally told us that we was free." You know, it came out in January, but of course we had to wait on somebody to come from somewhere to tell us that it was [chuckles], that we was free. But anyway. See, we used to have it right down there where that house is.

MF: Which house?

JL: $\quad$ Down under the hill. That was $19^{\text {th }}$ of June grounds. Oooohhh-

MF: Oh, is that right? So was that just for the colony or-?

JL: $\quad$ For the community and Kyle and Manchaca—anybody that wanted to come.

MF: Right down here off of Cole Springs Road?

JL: No, right down under the hill here.

MF: Right down at the end of your hill.

JL: Yeah. You know where that house is sitting? [Yes.] All of that was the $19^{\text {th }}$ of June ground. All back up under them trees. Them old men would come and barbecue all night long. You could hear them, "Ha ha ha ha," laughing. See, we always lived-we lived in that house-

MF: The pink house right over there, right, yes.

JL: - -so we could hear. It was just right across the branch there. What we call a branch is where the water run, not a branch from a tree [chuckles]. One time I told that lady, "Now, when you cross the branch," and she's--"I looked and looked for that branch in the road, and I didn't see a tree branch." I said, "No, honey. Branch means where the water-" But anyway, right across the branch there, they would barbecue all night. Because the white people in the community-I don't know if they felt like, "Well, we kept them in slavery so long, give one of them heifers and kill a hog and take it over there to them." They would give a whole cow, calf, and a hog for the black people to barbecue. So them old men would dig a-they'd dig a pit bigger than this table, and they'd put this grill over it. You know, put this, and they'd build this fire and they'd put that meat on and they'd sit there and watch it all-We could hear them laughing way in the night. "Ha ha ha. Ha ha ha." They'd be down there you know- 
MF: Drinking probably.

JL: - playing dominoes, drinking beer or whatever. So the next day, here would come everybody bringing tubs of food. They had them number-three tubs. You know, they was that big around. They'd bring - oh, the men would build these tables out of wood from tree to tree like that, you know? It was a grove of trees, and I remember-and the women would come with them and they'd spread them white tablecloths on there and set all that food out. God! Cakes, pies, and you know, when you're a kid like that, and somebody would be over here making ice cream. Somebody would be over here cutting watermelons. They'd bring watermelons and slice and you would just be hooo! It was a fun day.

MF: So that was-it sounds like it was the most important holiday in the colony.

JL: In the colony. It was. It was the most important holiday for-and especially being in June, and it's warm, you know, and you out in the open like that. They would play ball. They had a baseball field over here where there wasn't no trees. It was like a field, and they would play, the men would play baseball over there. Of course, all the little kids would be running, seeing what they could grab, eating all that cake and ice cream, getting a bellyache. But it was a fun day. Nineteenth of June. Nineteenth of June.

MF: And was that something, do you know, that they celebrated here from way back when they founded the Colony? I mean, did your grandparents grow up celebrating it and so forth?

JL: $\quad$ Oh yes, yes. They had been celebrating it. Oh, Lord, yes. Anybody in Texas know what the Juneteenth means. Except these young kids. You know, they don't know nothing. "Juneteenth? What? Daddy, what's the Juneteenth? What's that?" They don't, they just don't know because they've never been taught, and I've told-“Granny, who is Frederick Douglass? Why you got his picture on the wall?" I said, "You have to read his biography so you can find out what he did and who he was and you know-" It's like-My ex-husband used to say, "Don't be no Texas buffoon. Don't be a buffoon." "Granny, what's a buffoon?" "Somebody that's-" you know. I'd say, "Read, read, read, and find out who these people were," you know, because I got—downstairs I got um, I got um-What's her name? Oh, heck. I'll have to go down there and look, anyway. You know, the one that freed all them slaves with-

MF: Harriet Tubman?

JL: Yeah. The one that said, "If you hear the hounds, just keep running. If you see the lights, just keep running and don't ever look back."

MF: Now you mentioned-I know we had this conversation before, that you planned on passing the land on to your daughter and that you hope it stays in the family, but you also mentioned that like the kids nowadays just don't know their history much and so on and so forth. So in thinking about some of those things, what do you see are the challenges of, for example, your grandchildren if they stay here in the colony and in Buda, what are the biggest challenges they'll face in this community?

JL: The biggest challenges-I don't believe there's a place for them here. I mean they want to go to college and they want to do things, and what we have here is just a lot of land and a lot of-I don't know. What would they do here? If one wants to be a veterinarian or if one wants to be a doctor or lawyer, what can you do in Buda? Or you could live here and commute, but you'd have to find employment probably in Austin or Houston or Dallas or somewhere. I don't see nothing here in Buda for-

MF: Do you think the younger generation is going to want to stay here? 
JL: Nm-mmm [No]. I don't think so.

MF: How do you feel about that?

JL: $\quad$ Well, I feel like if it was something here for them, but I just don't see anything here for them. I don't-you know. I just, I think-I don't know where destiny would lead them, you know, and I don't know what they'll do, but you know, it's all right growing up here. But you know, it's like that song they always ask me to sing. "Granny, sing that song. Sing that song." It's "Summertime." They like to hear me sing that part where [sings], "One of these days, you're going to rise up singing, spread your wings and take to the sky. But till that morning, ain't nothing going to harm you, your mama and daddy standing by." They liked me to say that. And then that part where it says, "If daddy's rich and your mama's good-looking." "Is my daddy rich?" "No, your daddy isn't rich [laughter], but your mama's good-looking." [Laughter] We got half, right? [Laughter] Those kids keep me on my toes, I tell you.

MF: I bet, especially at this age, huh? [Yes.] What do you think about-Now growing up as a young girl and then a teenage girl, how did things change for you compared to what your granddaughters-you know, the rules they have to live by, the expectations of a young girl. I mean, how much has changed?

JL: $\quad$ Everything has changed, and we just have to live with it. But the kids, I don't know. When I was growing up, if a girl got pregnant, she was-that was a disgrace, and oooh, they put her out of school and stuff. Now they just walk around in school. They mix all in with the other kids. They don't say, "You can't come because you're expecting." I mean the morals, I mean they-When I was coming up a teenager, the parents and the schools, they tried to protect us to make us, you know. But now, oh, it's all right to get—Look at these teenagers going out and getting in packs, ten or twelve of them, "We all going to get pregnant. We all went out and had sex tonight," you know, and things like that, and you just wonder how can you protect these kids from-? "I want a tattoo. Mary got a tattoo. I want a lip ring. I want a ring in my nose."

MF: You don't want those.

JL: $\quad$ Not in my time, I tell you! That went in your nose, going to snag all them boogaroos [laughs], and that one on your tongue will be full of bread, stinky. "Granny, why don't you get you a tattoo?" "No, I don't think so." Your body's your temple. You're not supposed to mark it up. But you just try to think how can we protect these kids? There's just so much out there. You know, just_Sam say, "I got to get my shotgun. I'm nailing all these windows down and I'm sitting at that door with my shotgun. I'm going to have to kill me somebody." Because when I was growing up, if the grownups saw you hugged up with a boy, they'd say, "That ain't no way to-Take your hand off of that girl!" Mm-hmm [yes]. I remember when I was graduating from high school, walking, holding hands with my little boyfriend, and this teacher was leaving the school. We had just had our march, how we was going to march in-you know, our graduation practice. "Turn that girl's hand a loose! You ain't got no business holding her hand!" "Yes, ma'am. Yes, ma'am." He was scared to death. Scared him to death. So anyway.

MF: Very different.

JL: Oh God. One time when I was in high school and we were-once a week on Thursday we went to the library. Now this is all-black school, see. We had black teachers, black-they didn't put up with no foolishness, see. These little young teachers they got now, all they do is just come to school and they not-our teachers went to church with our families, so she-and there we walk up, "Miss Green! Hi! How is Joan, they all doing in English?" "Well, she's doing pretty good." But nowadays, the teachers never see the mothers and fathers. They don't know. 
Shoot. We had to walk our talk because the teachers, we'd go to church on Sunday and there sat Miss Green and Miss Frasier and Miss Smith and Miss Brisby, and you sitting there looking, "Lord, I hope she don't tell them. I hope my grade--" And then they would spank you. I mean you know like Miss Brisby, she'd, "Did you get my lesson last night?" "Well, I, I, I, I didn't_-" "Put your hand up here." Turn that hand up like that. Pow, pow, pow. "Now tonight when you get home, you do my homework. Don't come up here with no excuses." Well, the next day, you wasn't going to come up with no excuses. That hurt. They cared about the kids learning. They took those spankings out of school. They took the spankings out of the house because now, kids three, four years old, "I'll call 911 on you. Don't you hit me!" I saw a kid in the grocery store spit in his mama's face. Not a black kid, but a kid [chuckles]. "I want this! I want that!" and she had him sitting up in the basket. She said, "No. No, Billy, you're not going to get that. No, Billy, you're-" Poo, he spit right in her face. I stood there and said hmm. Now it wasn't a black kid, but anyway, they took the spankings away from us. We can't-We can't discipline. You can't do that because they'll call 911 on you. So now you in a pickle. They took spanking out of schools, spanking out of the house. You can't just-they just tell you what to do.

MF: Hmm. Now back then, do you remember the relationships between your grandmother and your grandfather? How would you describe relationships between men and women back then? Because nowadays, a lot of people say that women have more rights and it's not uncommon now for men to be doing housework and things like that. Growing up, do you remember that your grandmother had a place in the house and your grandfather had-you know?

JL: My grandfather wore the pants in the family.

MF: No questions asked?

JL: $\quad$ But my grandmother told him how he could wear them. She was the matriarch. Mm-hmm [yes]. She was a strong woman. Mm-hmm [yes], yeah.

MF: How did she show that strength? I mean, what did you think about her was strong?

JL: "It's either my way or the highway."

MF: Is that what she would say? Oh, wow.

JL: $\quad$ My grandfather was real meek. He didn't try to, you know, go against what she wanted, but yeah. Whatever Big Mama said_-[chuckles] That was our Big Mama and Big Papa. Whatever Big Mama said went, you know. Big Papa could suggest something, but what Big Mama said-

MF: Wow. Do you think that was typical? Were you taught that that was typical? Or did you know that that was not what other families had?

JL: Well, we didn't have no other guide to go by, because look, we lived ten miles from the next family. We didn't know what they were doing.

MF: And your mother was passed away by the time you said you were four, right, so you-

JL: Oh, yeah, when I was four years old. Yeah, but they got along. I mean they had a good thing. It's just that he was laid back, like "Well, whatever. Whatever your Big Mama say. Whatever you-" You know, Big Papa'd go, "Oh no, what did you Big Mama say? Well, that's the way it gotta be, then." He wasn't going to get into it. "Hey Big Papa, can’t you tell her to let us go, 
something?" "Did your Big Mama say you couldn't go? Well, you can't go then," and that was it. Whatever Big Mama said, mmm, yeah. But that was his way. I don't know if that was his way or just staying out of it, you know, not crossing her, you know, because there was things going on. Like up in the colony, we wanted to go to this girl's wedding, and Big Mama said "Nah, don't need to go." "Big Papa, tell her to let us go. We want to go up to that wedding." No, we didn't get to go. Mm-hmm [yes]. Yeah, she was very—my grandmother was part German.

MF: You had told me that.

JL: $\quad$ Big, tall, buxom.

MF: Was she very strict?

JL: We didn't get to go nowhere unless she was with us or it was-well, we could go to Sunday school, and we could go to the $19^{\text {th }}$ of June picnic. We could go to Austin with her. Very strict. She didn't-

MF: So you didn't date until pretty much—well, you said you had a boyfriend in high school.

JL: Just a-you know, what that is, just holding hand boyfriend.

MF: Okay. So that's the one who would pick you up at the house here and take you to a movie or something like that?

JL: Oh no, unh-uh [no]. Nothing like that. Unh-uh [no]. No, no.

MF: Your grandparents would have disapproved?

JL: Yeah. They would—They just didn't believe in that, unh-uh [no].

MF: So when could you start dating? Because at some point you had to meet your spouse and-

JL: $\quad$ After, after I-let me tell you what I did. When I finished high school in May of '52, in June I was back in California with my daddy. I went out there, and I started to Los Angeles City College, and then I started dating the kids' daddy, Monica's daddy, my daughter and my other daughter down here, my son that passed away-their daddy. We got married, but he was my first date, date-date. You know what I'm talking about? [Yes.] First date date, and I was what, nineteen, twenty? Something like that. Yeah. Yeah. Oh, I wasn't going to dare try to be dating nobody. And we had a girl come up pregnant in high school when I was in the twelfth grade. She was in the eleventh grade, I think, she was behind me. "Dolores is pregnant. Dolores." I said, "Ooo, she been doing the nasty. Lord," I said, "she ought to be ashamed." No, we didn't fool around like that [chuckles]. We hold hands.

MF: And that's it.

JL: $\quad$ That's it. That's as far as you going, buddy. Oh, Lord. Girls were scared of getting pregnant then, and they didn't want to be. They didn't want that, you know. Them teachers would tell you, "You need your education. Let these little old boys alone. They don't want to do nothing but get in your pants." I mean they talked - that's the way they would tell us, you know.

MF: Mm-hmm [Yes]. Do you know if your brother Velma was taught, you know, don't be messing with these girls and you can't-?

JL: I don't know, because- 
MF: Was he given different treatment because he was a boy maybe?

JL: I don't know. But when-I think he was twenty-something when he got married, the first marriage. He met this girl in California, and she got pregnant and I guess she told her mama, and they told him, "You going to marry my daughter." See, that's the way it went, then, too. If you -if a girl was in the family way, they come looking for you — the daddy, the brothers. "You going to marry my sister. You're going to marry my-you ain't—unh-uh [no]." "Yes, sir. Yes, sir. I'm going to marry." [Chuckles] Them boys wasn't going to say no. And that man would be holding a shotgun. You talk about shotgun weddings, mm-hmm [yes]. Yeah.

MF: You've seen a few?

JL: That's why girls didn't do that, because yeah, shoot, that's the first thing. "You've got to marry my daughter." Unh-uh [no], they wasn't going to let you off. Like now these boys, they nothing but sperm donors, and they just go around donating their sperm and walking on, going on. Some of these twenty-, twenty-two-year-old boys got five or six kids in the world, I mean by different mamas. "There my baby's mama, that my baby's mama, and that my baby's mama," you know, and it's just pitiful. They just leaving them babies and they ain't giving them no support. They're not-I was telling Sam. I said, "That's why we have so many mass murders and serial killers," and people just walk off and leave their kids. "You know, my daddy didn't care nothing about me and blah, blah, blah, and my mama left a note and walked off and left us." So he just started killing women. He was mad at his mama and he just start-every woman he saw, he was going to kill. You know, it messes up kids' minds. You know, you have to be careful with the children when they're growing up because they become something. They can be angel babies and turn into devils.

MF: Now you mentioned that you met your husband, Mr. Limuel. What was his first name?

JL: Oh no, no. This is my second husband.

MF: Limuel is your second husband. [Yes.] Okay, I'm sorry. Who was your first husband?

JL: $\quad$ Sneed, Alvie Sneed.

MF: Alvie Sneed? [Mm-hmm [yes].] Now there's S-n-e-e-d?

JL: Mm-hmm [Yes], but that's a different Sneed from my-

MF: I was going to say, just a coincidence, then. [Yes.] Okay. I mean because it is an unusual name, sort of.

JL: $\quad$ This is the way people put it: "That's the red Sneeds over here and then that's some black Sneeds over here." Them Sneeds was then red Sneeds that I married, and them other Sneeds over here, Jess Sneed and them, they was black. They was dark-skinned, you know? That's the way people-“Oh, them red Sneeds? Oh, yeah. Them black Sneeds? Mm-hmm [yes].” Ain't that funny, how they would say that. "Oh, them black Sneeds." "Oh, yeah, I know Jeff and soand-so. Oh, them red Sneeds? Oh, yeah, that's so-and-so and Leon," and you know, call them all by name.

MF: So he was in California. Was he from there, Mr. Sneed?

JL: No. Me and him went to high school together here. 
MF: Oh, I'm sorry. Okay. I thought when you went to California that's where you met your first husband.

JL: $\quad$ No. he was the one I was holding hands with, and then I left here, went back to California. Well, he had an uncle that lived out there, so when I left and went to California, he wanted to go to California. He wanted-His mama say, "He worried me!" so she bought him a ticket and sent him out there and he moved-You know, he stayed with his uncle, and I stayed with my daddy. I stayed with my daddy, and he stayed with his uncle. Then he called me and said, "I'm here. I'm in California." What? You know, it was kind of like-

MF: It wasn't planned for you, then.

JL: It wasn't planned, no.

MF: I mean for the two of you.

JL: $\quad$ So anyway, then we-

MF: But he did follow you out.

JL: Yeah, he came out behind me.

MF: Yeah, because you were there.

JL: I said, "I'm going back to California. I hate Texas. I hate Texas. Oh, God, I hate Texas." Well, see, I had lived in California—eighth, ninth, tenth, eleven-four years before I came back here. So we left here when I was a teenager, I think about fourteen. When I came back, I was ready to graduate high school. But I was out there about four years.

MF: So you did most of your high schooling out in California and then finished-

JL: Junior high and high.

MF: And then you finished up at Anderson.

JL: I just went one year at Anderson High School, and- "Daddy, send me a ticket so I can come home. Daddy, I hate Texas!"

MF: But you went to Antioch all the way from $\mathrm{K}$ to eighth grade, then?

JL: $\quad$ Yeah, $\mathrm{K}$ to eighth, and then from eighth to twelfth I went in Los Angeles.

MF: I see. So the Sneed that you married, though, was from Austin, then.

JL: Yeah, he was from Austin.

MF: In east Austin, or do you remember where he lived?

JL: He was from Manchaca.

MF: There you go! I was asking you-

JL: You know the Pickards? Remember I told you they used to ride to school with Professor Pickard? 
MF: $\mathrm{Oh}$ !

JL: $\quad$ They all lived in Manchaca. The Pickards and the Sneeds, and anyway, they used to ride to school with him.

MF: You know, when I was talking to Marcus Pickard, he said that was one of the things that his father taught at Anderson High School [yes.] and he would take some of the black kids out there because they didn't have any place else to go to school. They couldn't go to school in Manchaca.

JL: Oh, yeah.

MF: $\quad$ So a number of those kids would ride with him every day to school.

JL: Yeah, they all did. His sisters-it was five of them. It was four girls and one boy, and Jimmie, Pearl, Billie, Bobbie, and Al.

MF: And which one was your husband?

JL: $\quad$ Al. And they all used to ride with Mr. Pickard. He'd bring them all in the high school because it wasn't nowhere else for them to go.

MF: Right. Was your husband from a farming family in Manchaca, then?

JL: They lived on a ranch. His daddy was working for this doctor, and it was a ranch. It wasn't a farm. They had animals-cows, goats, sheep. So he was like a rancher. Build fences and feed the cows, milk the cows, whatever, you know. It's a little different than farming. Farming is you know, plowing and planting and harvesting. But anyway, they lived on a ranch, Dr. Granbury's ranch.

MF: That's interesting. And where is your husband buried?

JL: Oh, they cremated him.

MF: Mr. Sneed? Okay.

JL: $\quad$ Mm-hmm [yes]. They cremated him.

MF: And he passed away when?

JL: $\quad$ Uh, I think about four years ago.

MF: Oh, I'm sorry to hear that. I didn't realize it was so recent.

JL: Yeah, about four years ago. Oh, we've been divorced what, since '61.

MF: Oh, okay, I didn't know.

JL: Yeah. We divorced in '61. I married Limuel and a few other people.

MF: Before or after Limuel? [Laughter]

JL: Before. Yeah. I was married four times. 
MF: Oh, wow, okay. But you only had kids with Mr. Sneed?

JL: That's all. Not that I wasn't exposed [laughter]. I guess God said, "That's all I'm going to give you." I never got pregnant again, never. That was it. But I was with Limuel twelve years, from 1980 to '92. He died in '92.

MF: So that was while you were living here, then, in this house.

JL: Yeah, mm-hmm [yes]. He got sick. One summer, one July, he started running this high fever, and he started swelling. His stomach got swolled up. His feet started swelling. I said, "You better go to the doctor," and he was in liver failure with cirrhosis of the liver. He lived one year from the diagnosis. They diagnosed him this July and he died this July. One year, mmhmm [yes]. He went from like 240 or 50 pounds down to just-I mean he was a big, strapping man, you know. He just-that liver failure is bad. And he was younger than me. He was, let's see. I think he was about eight or nine years younger than me. You know, you always think, "I'm going to get me a young husband and then, if I get me a young one, see, we'll grow old together. He'll be around." Unh-uh [no], that ain't the way it work.

MF: Not always. [Unh-uh [no].] Especially for African-American men. [Yes.] They don't have a very-

JL: $\quad$ But the doctor said it wasn't that he drinked; it's what he drinked — the cheap-he said if you'd a been drinking a good scotch, a good gin or something like that, but that Thunderbird and that MD 2020-all this stuff that he drinked when he was drinking, it just shot that liver. So I lost him. I'm not thinking about marrying again. [Chuckles]

MF: No? Four is enough?

JL: I got enough. I think I got enough.

MF: I don't know, you could make it an even sort of like six or something like that, half a dozen.

JL: Yeah, cheaper by the dozen.

MF: $\quad$ And your kids, where were your kids born then after you married Mr. Al Sneed?

JL: The first one was born in California.

MF: Where in California? I'm sorry.

JL: $\quad$ Los Angeles, Good Samaritan Hospital, where they rushed Bobby Kennedy. Remember when he got shot?

MF: Mm-hmm [yes]. Which one is your oldest?

JL: Valerie. Valerie is the oldest, and she was born at Good Samaritan Hospital in Los Angeles. And, Terry, my second one, I was down here at my grandmother's funeral, and she died in August, and Terry was born in January. So what was I? Four months pregnant or something? My aunt-I'll tell you, this family is run by matriarchs, what the women say. She say, "You don't need to go back to California." I said, "My husband's in California. I got to go back." "You don't need to go back. You're fitting to have a baby. You stay here till after that baby's born." Five months I had to stay here till the baby was born, and he was about six months old before she would let me go back. 
MF: You're kidding! What did your husband say?

JL: "You—when are you coming home? When are you coming?" So anyway, finally when Terry was about, I guess he was about-maybe not six. Maybe he was about three months old or something like that. She'd say, "Well, you better go on and see about your husband."

MF: Who was taking care of your daughter Valerie at the time?

JL: $\quad$ She was with me. She was with me.

MF: Oh, gosh, okay. Well, you had a lot of family around to help you, though, right?

JL: Oh, Aunt Nell lived next door. I lived in an apartment here. See my auntie, she owned a lot of apartments, and so her house, her big house was right here. We called it the big house. Then she had these-this was a duplex. Then she had a duplex here, and then she had a house here and a house here. All this—she owned, let's see, how many lots. One, two, three, four lots on that street.

MF: Where was the street?

JL: $\quad$ Washington Avenue in Austin, Texas. So she owned all that land, I mean all that property. So I was living in this apartment right next to her big house, next to the big house. I didn't have no problem, honey. She'd come get Valerie, take Valerie and be gone all day with Aunt Nell. I didn't have nothing there but the baby.

MF: Was Aunt Nell married at the time? [Uh-uh [no].] Is this the one who did not marry, who stayed unmarried?

JL: $\quad$ No, unh-uh [no], that's not her. Aunt Nell is on my mother's side. Yeah, she married twice. Her first husband died and then she married Flowerton [?]. They divorced, and she never married again. But that was on my mother's side. Aunt Lattice, the one that didn't ever marry, was on my father's side. But anyway, yeah. And then Terry was born here because I was down here for my grandmother's funeral, and Aunt Nell wouldn't let me go back. So he was born at Holy Cross Hospital in Austin. And then I went back, and Monica was born in California. She was born in Los Angeles, mm-hmm [yes].

MF: Okay. Your grandkids, were they born here in Buda, or in Austin, I should say?

JL: Austin, yeah. They were both.

MF: Right, right. And you just have two granddaughters?

JL: Oh no, unh-uh [no]. I got_-[chuckles] Valerie got two girls, and Terry had four girls—little Monica, Margaret, and Terry Ann, and Jenny. So I have plenty of granddaughters.

MF: Six granddaughters.

JL: Nine. Four, five, six, seven, eight, nine.

MF: Who are the other three? You said Valerie had two girls, Terry had four girls, and then-

JL: And she got three. Monica's got three, so that's what?

MF: Three girls or two girls and a boy? 
JL: All girls.

MF: You got nothing but-

JL: $\quad$ All girls!

MF: You've got nine grandchildren, and they're all girls?

JL: $\quad$ All girls. No boys.

MF: What are the chances of that? That's, gosh!

JL: I tell you, this family, the women are so strong, I guess they just overpowered the men. [Laughter]

MF: Wow! That's pretty amazing.

JL: Yeah. No grandson.

MF: $\quad$ And I assume your kids are probably done having kids?

JL: They're what?

MF: I'm assuming none of your kids are planning on getting pregnant again? I mean, you know, having other kids.

JL: $\quad$ Oh, no, no, no. They already got-I already got great-grands.

MF: And your son's passed away, too. [Yes.] I remember you telling me that.

JL: $\quad$ And I got great-grands, and now I got two great-grands, that are boys. No, three, three. Jenny has a boy. Desiree has two boys. Mm-hmm [yes], Rhonda's got a girl and Shay's got a girl. Those are my great-grands.

MF: It'll be some time before they have kids.

JL: Oh, I hope so.

MF: Right! Or hopefully! [Laughter]

JL: Hopefully. Yeah, I hope so. But anyway, yeah. That's how it went. No boys.

MF: Now let me ask you; this is my last question. Is there anything that I have not asked you about that you think is important for me to know?

JL: $\quad$ Mmm, not really. I'm just glad that you kind of working on the cemetery out there, but I'm sorry that we never got to put no markers on those people's grave, but I know they're buried there because some of them I went to they funeral. Uncle Leland, Aunt Dellie, Buster-I didn't go to Grandma Tennessee's funeral because I wasn't born then, but my uncle told me, "Your grandma's buried up here. Aunt Inez is buried up here," and these are people that, that-Even Aunt Lee, I think she was-I forget how old she was when Grandma Tennessee died. Well, Aunt Lee was born in 1915, and I think I got Grandma Tennessee- 
MF: I know you spell her name, it's Anthy Lee, right? A-n-t-h-y. So Anthy Lee would be L-e-e, right? Did people just call her Lee? They just shortened it?

JL: We called her Aunt Lee. Lee is like a middle name.

MF: Oh. So Anthy Lee is not one name.

JL: Oh no. It's two names.

MF: It's Anthy?

JL: $\quad$ A-n-t-h-y. Anthy, Anthy Lee. I'm trying to see when she died. She died in um, '32. Aunt Lee would have been-five and twelve-seven-Aunt Lee should have been about what, twelve years old when Grandma Tennessee died.

MF: Hmm. She remembers her?

JL: $\quad$ Because she died in 1932, and Aunt Lee was born in 1915.

MF: She would have been seventeen. So she definitely would have remembered her.

JL: Yeah, that's what I'm thinking.

MF: Now, I got her number, but I wasn't sure if you'd already talked to her and told her that I might be calling, because I didn't want to call her and have her-

JL: $\quad$ I'll call her and tell her.

MF: $\quad$ Okay, because I need to try to interview her in the next couple of weeks. So I can drive down to Austin. I could even go down probably tomorrow.

JL: To San Antonio?

MF: Yeah, and talk to her.

JL: $\quad$ Yeah. She-I don't know if I mentioned it to her, but I'll do it again because she'll be tickled to death to see you, honey. [Imitates Anthy Lee] "Yeah, uh-huh [yes.]

MF: And what's her last name?

JL: Walker.

MF: Now she didn't have any kids, did she?

JL: No, except my adopted cousin. I told you about that, didn't I?

MF: The white woman? I mean the woman who [yes] your grandparents took in? So Anthy Lee raised her?

JL: Yeah, she took her when she was two years old. Mm-hmm [yes].

MF: Oh, I thought your grandmother was the one that took her.

JL: No, she did, and my sister. She passed away. 
MF: Oh, I'm so sorry. This was a year ago, wasn't it?

JL: Yeah. She went right behind Terry. Terry went in October, and she went in February. I got this little write-up about Juneteenth. And each one of those little black dots there is some of the slaves-those are the slave ships.

MF: Right. I've seen this. This is a slaving ship called The Brooks. Yeah, I've seen a picture of that before.

JL: Do you ever want to go to Africa and see where they loaded them on them boats?

MF: One of these days I will.

JL: I saw old Bush over there. I just thinking, "Well, I know it didn't mean that much to him." But I sure would like to go over there, see where they loaded them on that ship. That would just almost make me, you know-You know, some things just move you like you could just realize how they felt, chained and led and put on them ships. And every time one of them would die, they just throw them overboard like a piece of trash.

MF: They threw sick ones overboard, too. They didn't have to be dead.

JL: $\quad$ No, but I'm just saying.

MF: $\quad$ Mm-hmm [yes], I know. It was horrible.

JL: $\quad$ Horrible, and they said it was so close together and they had them chained. You know, I was reading in a book the other day. I can't remember what book I was reading in, and it said do you know there are some people that think there's the white race and God created something a little over a beast and that was to wait on the white people, which was the black man, you know? He was a little, not quite a beast, but just something that was put here on Earth to wait on the white people. Some people, they have that belief in they mind.

MF: That's why they kept African Americans as slaves, yeah. Absolutely.

JL: Yeah. Didn't want them to read and write, didn't want them to-I guess just didn't want them to be human. But yet and still they hung them for crimes. You don't go out in the field and hang a cow. If you think I'm a beast, how can you hang me for a crime when you say I'm a beast, that I'm not a man? So how can you hang me for a crime? You don't hang your cows. You don't hang your horses. You call them beasts, you know. But you hanging me, you hanging us for crimes and saying that we're not men. What logic is that?

MF: None.

JL: I bet you just think, what's going on in my head. Sometime I wonder myself, but-

MF: I think about the same things.

JL: I'm like the Indian. You know, the Indians, it's hard for me to understand what they were thinking to do the things that they did. You know, I just-

MF: What do you mean? What things that they did?

JL: $\quad$ You know, the things they did against our people, my people. I say our people, but I'm going to say my people. I just—the things they did against the Indians! 


\section{8 "I'M PROUD TO KNOW WHAT I KNOW"}

MF: Oh yeah, okay. I see what you're saying.

JL: I just-you know. They did some horrible things against the Indians, too.

MF: They took their land. Oh yeah, absolutely. I'm going to stop this now.

JL: Okay. 


\section{Anthy Lee (Revada) Walker}

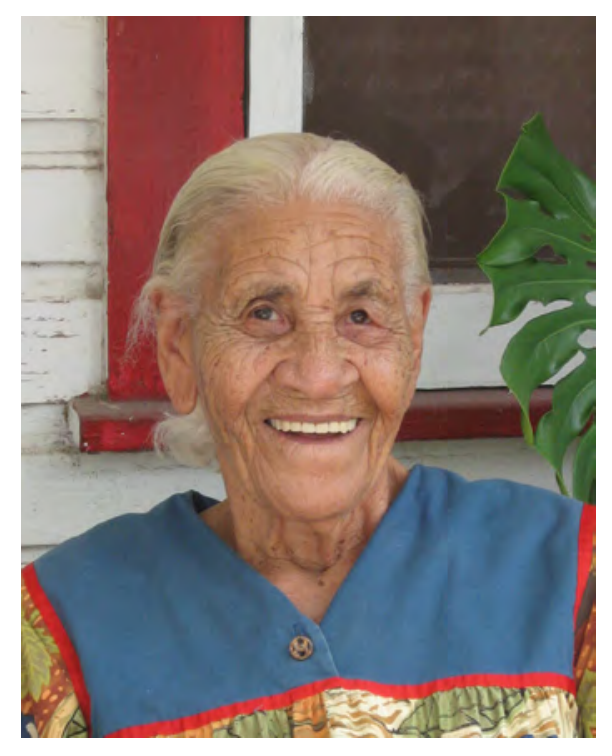

$\begin{array}{ll}\text { Birth Date } & 9 / 14 / 1915 \\ \text { Residence } & \text { Antioch Colony, Buda } \\ \text { Time Span } & 1915-1931\end{array}$

Interviewed by: Maria Franklin

July 23, 2009

MF: This is Maria Franklin. Today is July 23, 2009. I'm interviewing for the first time Mrs. Anthy Lee Revada Walker. This interview is taking place in the home of Mrs. Walker in San Antonio, Texas. This interview is part of the Oral History Program for the Ransom Williams Farmstead Project.

Mrs. Walker, can I ask you first of all when you were living in Antioch, where did you live in Antioch? What was the address?

AW: When I was living in Buda, what was my address?

MF: Yes, ma'am. Do you remember?

AW: $\quad$ No. I just know we lived on rural, you know, a route. That's all I know.

MF: What was the route number? Do you remember?

AW: No, that I know. I don't remember.

MF: Okay. Is it anywhere near where Joan Nell, your niece, now lives, off of Cole Springs Road? Did you live close to there? 
AW: Oh, well, I lived close to Cole Springs, you know.

MF: You did?

AW: Yeah.

MF: Were you living on your parents' property at that time?

AW: I was living with my mother and daddy at the time.

MF: Can you tell me the names of your parents? Your parents' names?

AW: Hattie and Dan Revada.

MF: Hattie, what was her maiden name?

AW: Sneed.

MF: Okay. And how many brothers and sisters did you have?

AW: Three. I have a half brother, and there's four of us, two girls and two boys.

MF: What was the name of the half brother?

AW: Oddies Revada.

MF: Oh, he was your half brother.

AW: Uh-huh [yes]. He was my half brother because my daddy was married twice. He was married to a Kavan-yeah, I guess it was a Kavanaugh—no, it wasn't. It was a Friend. You've heard of the Friends, didn't you?

MF: Yes, ma'am. Your father's first wife was a Friend.

AW: His first wife was a Friend.

MF: And that's who Oddies was born to?

AW: That's Oddies's- that's my oldest brother. And he just, you know what I mean, he was just a brother because I didn't know any better. You know, I just know all of us was the same.

MF: And did your father's first wife die?

AW: Yeah, she died at his birth, at Oddies' birth.

MF: And then your father remarried Hattie Sneed, and had four children by her. [Mm-hmm (yes).] And it was you, and then who are your brothers and sisters?

AW: Langston, Velma, and Ladys.

MF: And so Velma was Joan Nell's dad, right?

AW: Daddy. Uh-huh [yes]. 
MF: Okay. Now did your father own his own property in Buda?

AW: Did he own any property? [Yes.] No, he didn't own any property, because the property he owned was in Austin out there from Cedarbreak [?]. He had property there. But when he came to Buda, well, he worked for third and fourth, I know we-That was the landlord he had, and he would get a fourth and the landlord would get a third, because he used his own mules, and that's what he had, Big Kit, Little Kit, and Beck.

MF: What was the last thing called?

AW: $\quad$ Beck. Beck was the mule's name.

MF: Oh, the mule's name.

AW: I'm talking about the mules.

MF: He had three mules.

AW: Had four.

MF: $\quad$ Four mules. And that's what he did his farming with?

AW: Uh-huh [yes].

MF: I see. And what was the landowner's name, the landlord's name?

AW: What name? Well, the one he worked for first was Crews, Frank Crews. The next one was John Howe. And that's when I said we stayed on that rural route, and I don't know. It's just, I don't know. I was just so glad to get a catalog. You know, get to see the pictures.

MF: So your father was basically a sharecropper, who worked somebody else's land.

AW: Yeah, that's what he did all that time until they started closing it in on that. And when he left and went to Winters, that's what he did, he went sharecropping out there.

MF: Winters?

AW: $\quad$ Third and fourth in Winters, Texas. That's where he would be doing out there. And they had Deberoke [?] cultivators, and be fine to cut the grass and stuff. Because when you went out there, it was a raggedy field, and that's what he went out there for. He always went to these fields that wanted Johnson grass taken out.

MF: What kind of grass?

AW: Johnson grass.

MF: Johnson grass. Okay, so like a weed. Was it a weed, Johnson grass?

AW: Yeah. Have you seen Johnson grass? Or do you know what it is?

MF: I'm not sure.

AW: Well, it draws up and makes a seed, and it just gets all over everything. You know, when the wind would blow, it would travel. And that's what he went out there for, to work on that. 
MF: $\quad$ Out in Winters, Texas?

AW: In Winters, Texas. And then we left Winters and came back to Buda. And then he went up on Barber's place and he started doing that sharecropping, you know, up there. And he just worked that two years. And then the rest of it, it was just a mess because they just give him all the stuff he got made, you know. And so he made an awful lot of money on that.

MF: Did he make a lot of money sharecropping?

AW: Oh, yeah. He made good. What he could've bought anything he wanted, but he never would. I don't know why they, you know, we didn't own other land, because the place where we were staying the man wanted to sell that to him, and he wouldn't take it.

MF: He wouldn't buy his own land. And you don't know why?

AW: No, I don't know why. I was so mad because I wanted to stay there. It was an old house, two stories, and I loved it up there.

MF: And that was in Buda?

AW: Yes. I hunted, and I killed polecats, possums, and you know, a coon—anything I get a hold of.

MF: Did you say polecat?

AW: Yeah, polecat.

MF: What's a polecat?

AW: He's that black cat that's got that white up and down his back, you've got to take bushy tail, and it's up, and he shoot that muss, you know.

MF: Oh, skunk?

AW: Skunk, yeah.

MF: Okay. And you can eat skunk?

AW: I did that. No, we didn't eat them. I killed them for their hide. And then I got, I worked at that, because my brothers, that's what they used to do, you know, but they got such a little for theirs, you know. And so I cleaned all these hides, and put them up. You've got to have them green, you know. Green means that you ain't killed them, you know. You put in that thing you had pulled out the-but I'd fix them in there, you know. So I had a whole wagonload. My daddy would take them to Buda, and he got $\$ 185$ for my hides, you know. And I got 50 cents.

MF: Oh, no. For all that work?

AW: For all that work.

MF: Okay. Let me ask you something. You said that you treated the hides. So you had to dry them out basically, right? What did you mean by greening?

AW: When they're green, you don't do nothing to them. You just skin them and just throw them in the pot, you know. But if you dry them out or you put that stick in it and stretch out this- 
MF: Spread out the hide.

AW: And then tack it. And then you scrape the outside, get all that fat off, you know. Well, I didn't do bad. I did all the hides like that, but I didn't wait until they got dry. The man wanted them green, just like they were, you know.

MF: $\quad$ So when you say green, you mean that you don't treat them.

AW: Don't treat them, unh-uh [no], at all. Don't do anything to them.

MF: $\quad$ So your father didn't own any property in Buda, but you were born there on someone else's property that he was share cropping. That's correct, right?

AW: $\quad$ Mm-hmm [yes].

MF: And so were you the oldest, youngest child out of the five?

AW: I was the youngest one.

MF: You were the youngest one, and Oddies was the oldest.

AW: Oldest, uh-huh [yes].

MF: What kind of work did most of the people in the colony do at that time, that you can remember?

AW: Did I know? Aunt Kate, and she was like-

MF: $\quad$ Are you talking about Katie Bunton, Katie Friend Bunton?

AW: No, it was Aunt Katie. She was the same name that Oddies' mother was.

MF: Friend.

AW: $\quad$ Mm-hmm [yes], Aunt Kate was. She was a-

MF: $\quad$ But she married a Bunton, Katie married a Bunton, right?

AW: Well, you know, on the wrong track now. Aunt Kate, she married, yes, she did marry a Bunton. But she wasn't a Bunton, you know, before. She was-

MF: $\quad$ She was a Friend.

AW: Well, we're talking about it, and you say yeah, you knew that you had talked to them.

MF: I talked to LeeDell, and I talked to Lillie Grant. And Lillie Grant is Kate's I think granddaughter or grandniece. I mean they're somehow related like that. So yes, I've talked to a few people who Katie Friend Bunton was related to.

AW: Friend, Friends.

MF: That's right. 
AW: That's what I was trying to get in there. I didn't want to get that wrong. And I know I remember Aunt Kate, and then she married, let me see, was it Gunshime [?]? No, Gunshime was her son.

MF: Was Katie around your age or-? She must've been older than you, right?

AW: Oh, a lot older than I was, yeah. She had kids.

MF: Your age, right. So you said you were born in Buda, and you lived there until you were about sixteen, right?

AW: Yeah. I mean I was just around until I was sixteen. I remember I was sixteen then. And then I had been everywhere, and I got New Mexico and Colorado, and all them places, you know.

MF: Where your father was sharecropping. [Yes.] Or working on other people's farms, okay.

AW: Yeah, I was working for this-I mean I was working at this place, and she had a dude ranch.

MF: You worked yourself at a dude ranch?

AW: I cooked at a dude ranch.

MF: Where was that dude ranch? Where was it located?

AW: In Buda, out on, as you're going out to Dripping Springs or Driftwood. Driftwood would be better because it's close to there. And you know, they had a place that the people always went and got wood, and it was given to the black people. I don't know what ever happened to it. I never knew, you know, anything about it. I didn't know anything about it, you know. You know, when you were that age, you weren't supposed to know anything. You're supposed to be dumbfounded, you know. If they ask you about something, "Well, I don't know." "Were you were right there at the house." "I still don't know."

MF: Well, can I ask you, what other family did you have living in Buda at the time?

AW: Well, I met the Colemans, and I met the Smiths.

MF: The Smiths were there?

AW: Yeah.

MF: But these were not related to you; they're just other neighboring families.

AW: $\quad$ They were neighbor families, or some of them was married into the family. Like the Smith was married into my family, and my daddy's family. I know very little about them. They lived in Kyle. You went by wagon, and you didn't go too far, you know. You just drove from one town to-I don't remember going to Kyle anytime. You know, like on the $16^{\text {th }}$ of September I went, because that was, you know, my birthday. It was close to my birthday, and they gave me that privilege to go.

MF: Go to town.

AW: Yeah. And so we'd all go, and we'd go on truck. We had cars, but they never did use them. My daddy, like, he sharecropped. Well, then he'd go to town and work for the motor company, and all them people. And he said that everyone he worked for, they'd sell the best cars, you know. 
Cadillacs, you know, they sell the best cars. And he'd be selling cars, you know what I mean. I don't know who the-well, that wasn't none of my business. I didn't have to fool with that.

MF: Can I ask you, did you have any relatives living in Buda when you were growing up, other Revadas besides your family? I mean did you have uncles, aunts there?

AW: Yeah, I had an uncle.

MF: Who was your uncle that was living there?

AW: $\quad$ Andres. And Leland.

MF: Leland. Are these Revadas? Okay.

AW: Walter.

MF: Walter Revada?

AW: $\quad$ Mm-hmm [yes]. Jim.

MF: And did they own their own land out there?

AW: $\quad$ No. All of them were working for someone else, you know. Uncle Leland worked for the steam shovel, you know, where the steam at the gravel pits, you know.

MF: Oh, the gravel pits. Okay.

AW: Well, he worked that. Him and Uncle Walter, that was their job. And of course, my daddy did work some on running that train, you know, when he put up them lights, red lights to stop you to tell you the train is coming. Well, he was putting them up in Buda, and where else I don't know. Well, in Manchaca, I think in Manchaca, because the train hit the car what he's on. And the doctor said well, there wasn't anything wrong with him, you know, so he didn't get any money for it. He could've sued the company, you see. That same doctor, Dr. Holsclaw was the overseer, and I think he got the money, but my daddy didn't get nothing.

MF: $\quad$ So you had four uncles who were living in Buda that you can remember. Were there other Revadas living out there at the same time? Or Sneeds, your mom's family, were there any Sneeds in Antioch?

AW: No. They lived around close, but they didn't live in Buda.

MF: Was she from Manchaca, your mother?

AW: Bluff Springs.

MF: Where was she from?

AW: Who, my mother? [Yes, ma'am.] Oh, my mother, where was she from? Bluff Springs.

MF: Was she from nearby?

AW: Yes, it's near this city, you know, near Buda. But like my daddy, he came from Austin. And how they met, I don't know. 
MF: Your father was from Austin? Wasn't he born in the colony also, though, your father?

AW: $\quad$ Come to Buda?

MF: No. Wasn't he born in Buda, your father? He wasn't. He was born in Austin.

AW: $\quad$ He was born in Austin, in Cedar Break. Yeah, that's where the movie stars have got all their homes at now.

MF: Okay. I don't know where that is.

AW: Right out of the city. I mean, why you could be going to San Angelo or anyplace, you had to go through Cedar Break to get there. It's on that highway. I couldn't tell you where it is.

MF: It's off of I-35, though, is what you're saying? Is that the highway you mean, 35?

AW: Yeah. Like any place you'd want to go, you know, you had to go through Cedar Break to get out of there.

MF: Okay. And that's where your father was born? [Mm-hmm (yes).] Dan Revada?

AW: $\quad$ Mm-hmm [yes]. Andres, too, and all of them were born up there.

MF: Okay. When did your family come to settle in Buda?

AW: $\quad$ Settle in Buda?

MF: Yeah. I think it was Joan Nell who told me they came in the late 1800s to Buda, that Francisco and Tennessee Revada.

AW: Tennessee, they followed their daddy. His daddy lived here. He owned a place up on the side, a farm.

MF: Where?

AW: And so he owned that.

MF: He owned a farm where? Where was the farm?

AW: In Buda.

MF: Okay. So Francisco owned that farm or his father?

AW: Uh-huh [yes]. No, Francisco is the one that owned the farm.

MF: But you said that Tennessee followed her father. Was Tennessee not married to Francisco?

AW: Tennessee was married to Francisco Revada, and then he bought this place down in Buda where the school is down there.

MF: Okay. Where the elementary school is there.

AW: Joan Nell remembers that. I think they talked about it, because they used to go down there all the time. But who they sold their farm to, I don't know. 
MF: So your father then was born to Francisco and Tennessee, right? Your father, his parents were Francisco and Tennessee? Your father's name was Dan, right? [Yes.] And who were his parents, Francisco and Tennessee, right? [Yes.] But they lived in Buda, so why wasn't he born in Buda? That's what I'm trying to figure out. Since they owned land-

AW: Oh, Tennessee?

MF: Yes, ma'am.

AW: $\quad$ She come from Tennessee.

MF: No, no. I mean, okay, your father, Dan, he was the son of Francisco and Tennessee. Is that right? [Yes.] And Francisco and Tennessee lived in Buda.

AW: $\quad$ They lived in Buda, but they weren't born in Buda.

MF: Right. But what I'm trying to figure out is why is it that their kids, you said their kids were born in Austin.

AW: Well, I said Austin, because that's where Cedar Break is, right out of Austin, then you're going through Austin.

MF: Right. But why weren't they born in Buda, since that's where there their parents lived? I'm trying to figure out, was there a hospital out there or something?

AW: No. They had I guess midwives or whatever you call them. I don't know what you would say. But you see that was way back, and so I don't know about that.

MF: $\quad$ So what I'm trying to say is, did Francisco and Tennessee move from Buda to Austin where their kids were born?

AW: $\quad$ No, they lived there.

MF: $\quad$ In Buda?

AW: $\quad$ They lived in the Cedar Breaks. They lived in the Cedar Breaks.

MF: Oh, okay. But the Cedar Breaks was not in Buda?

AW: It was not in Buda. It was more out of Austin.

MF: But they still owned property where the school is right in Buda?

AW: Well, he bought that place. When he left the Cedar Break, he bought that place up there.

MF: Oh, okay. That's what I was trying to figure out. I've got you. So they lived in Cedar Breaks first, and then moved to Buda, but by the time they moved to Buda, they already had all of their kids.

AW: Yeah.

MF: Okay. That's what I was trying to figure out. I thought they came to Buda first, and then went out to Austin. Thanks. Sorry about that. 
AW: $\quad$ Four sisters married four brothers.

MF: Yes, right.

AW: Joan Nell told you that.

MF: Mm-hmm [yes], she did. And so one of their kids, Dan Revada, was one of the four brothers, right? Your dad, your father was one of the four brothers that married four sisters, right?

AW: $\quad$ Yeah, married to my mother.

MF: The four Revadas married Sneeds, yeah.

AW: Aunt Fannie and Aunt Eula, and then Maggie married my brother, my oldest brother.

MF: $\quad$ Now let me ask you, have you ever heard of a family by the name of Ransom and Sarah Williams? Ransom would've died probably about 1904, but they would've had kids. Will Williams, who settled in Creedmoor. Mary Williams-

AW: $\quad$ Oh, they were on the other side on the Prairie, we called it. They stayed in Buda, but it was on the Prairie.

MF: Well, they were living actually in Manchaca, outside of Manchaca. Do you know where Onion Creek is?

AW: The Picketts?

MF: No, Onion Creek. I'll show you a map later and ask you that question then, because I think it'll help if you see a map. Let me ask you, you had mentioned that you'd spent your first about sixteen years in Buda, in the colony, right. Can you tell me which church you belonged to?

AW: Methodist Church in Buda, up on the hill where the school was. The church was here, and the school was over here.

MF: Was it a wooden church and school? Here let me show you a picture, maybe that'll help. I think I've got a picture. Is it this school?

[Note: The photo shown to Mrs. Walker is of the original church and school in Antioch; it is included in the photos donated to the project by LeeDell Bunton.]

AW: $\quad$ Oh, in the picture here?

MF: Is that the school?

AW: Yeah, this is the school. This was my teacher for all the years.

[Note: The second photo is of a group of students and the teacher taken in front of Antioch School in 1921. It is included in the photos donated to the project by LeeDell Bunton.]

MF: Is the church and school that you went to?

AW: Yeah. Over on the hill. And this is Nina Taylor, that's the teacher. That's her sister back there, Inez. 
MF: Inez Taylor?

AW: Uh-huh [yes]. And right here is my first cousin, Joe.

MF: What was his last name?

AW: Revada. He was born in Buda, but he left there. I can't see that. I'm trying to see that guy's name. Oh, that's Phillips, that's a Phillips there.

MF: Which one, him?

AW: Uh-huh [yes]. That's a Phillip, and this is-we always called Willy Gooseneck, but her name was Willy-let me see. We called Charlie "Charlie Payday." I know them people's names just as good, but I, you know, their names come and go.

MF: Is there anybody else that you recognize in the photo?

AW: Oh, yeah. That's my cousin right there, Nettie Basped.

MF: Which one? This one right here? [Yes.] Nettie? [Yes.] And what was her last name?

AW: Basped.

MF: Okay, got it. And who else do you recognize?

AW: And this is Sammy Hardeman.

MF: This little kid right here? [Yes.] Sammy Hardeman.

AW: Don't ask me how you spell his name, I don't know. And that's Jody Hardeman right there.

MF: Jody, his sister?

AW: Uh-huh [yes].

MF: Are you in this picture?

AW: No, I'm not in this picture. That's the teacher's son-let's see what his name was-Eugene.

MF: Eugene Taylor?

AW: $\quad$ Eugene Tyree.

MF: Tyree? [Yes.] Nina's son, you said. Okay.

AW: And that's Bubba.

MF: $\quad$ This kid right here?

AW: Mm-hmm [yes]. Bernham. And that's my brother right there, Langston.

MF: This one right here?

AW: Mm-hmm [yes]. I guess you already know Velma, who Velma is. 
MF: Where's Velma?

AW: That's him right there. And that's Pauline Basped. And that's Mary Lou Searcy. And that's Carlton Taylor. And that's Ethel Grant. And that's Mabel and Francis, twins.

MF: Do you know what their last name is?

AW: $\quad$ Espinosa. They're from Kyle. They were in Buda at that time. I don't know what they were doing in Buda, but anyhow, they were going to school up there. Yeah, I know everybody on this picture.

MF: But you still can't remember this woman, her name right here, Gooseneck that you said was her nickname? [Phone rings, paused recording.] Okay, so it looks like I got everybody. That's Nina Taylor. Joe Revada, your cousin. That's Inez Taylor, and that's Nina's sister you said. [Yes.] There's Velma.

AW: That's Velma, isn't it?

MF: Yeah, that's what you said, Velma. That's a Phillips.

AW: $\quad$ Phillips, Eddie Phillips.

MF: Eddie Phillips. That's Nettie Basped.

AW: Yeah. And that's Pauline Basped.

MF: Right, Pauline Basped, her sister?

AW: Her sister, uh-huh [yes].

MF: And this little boy right here is Sammy Hardeman, you said.

AW: Yeah. Her name was Charlie-I'm trying to think of Charlie.

MF: You said Jody Hardeman here. Oh, the tall one, you mean.

AW: This was Hardeman here.

MF: Sammy Hardeman.

AW: And as I said, we always called her Willy Gooseneck, and I don't know why. I can't think of her name now. Her name, she's-

MF: Now Nina's son, you said was Eugene Tyree. [Yes.] But was he a Taylor, his last name Taylor then?

AW: Cora was Tyree's mother, and she taught school out on the Prairie. And Nina taught school on the hill.

MF: $\quad$ So was Tyree, though, was that just his middle name?

AW: Tyree Kavanaugh. Well, he went by Kavanaugh, I think. I don’t know. No. I think Tyree was his name, his last name. 
MF: Okay. But his mother was Nina Taylor. So Taylor, is that her maiden name?

AW: Nina Taylor, that's this lady, and this one's sister.

MF: Right. But she married a Tyree?

AW: No, they wasn't married to the-he wasn't married. He was going to school. This was his teacher.

MF: Right, but you said that this was her son.

AW: No.

MF: Oh, I thought you said that was her son. I'm sorry. Whose son was Eugene Tyree?

AW: Cora, her name was Cora, and she married a Kavanaugh, but she already had Tyree.

MF: $\quad$ So Eugene Tyree is Cora Taylor's son?

AW: Cora Kavanaugh's son. You got it?

MF: Yes, I do.

AW: I'm still trying to think of-

MF: And this is Bubba Bernham?

AW: Yeah, Bubba Bernham.

MF: I think I got the rest. And this is Carlton Taylor here.

AW: There's some more Bernhams out there.

MF: Ethel Grant, she must be a relative then of Lillie and all those other Grants out there, right, Ethel Grant?

AW: She was related to Lillie and-

MF: And Lola, and Larene, and Lorene. And these are the Espinosa twins.

AW: Yeah, but her husband's name was Grant, Tommy Grant.

MF: And this is the same school that's in this picture, right? [Yes.] Do you remember that school very well?

AW: Yeah, I remember that. This is the schoolhouse here.

MF: Well, this says it's the church. This is the school. It's a two-story building, the school, right? [Yes.] That's it right there.

AW: This is the one where I went to school at.

MF: That's the one you went to school? [Yes.] What do you remember about that building? Can you remember anything? 
AW: I remember there's two stories, and I remember they had that lodge there, their lodge, you know.

MF: Masonic or Eastern Star?

AW: No, it was the Woodmans.

MF: Woodmans? Was that sort of like a men's club or something like that?

AW: It's like the Masons, you know.

MF: Woodmans, I hadn't heard that yet.

AW: Well, it was a Woodman, and Coleman run, he was the big cheese over that. Freddy Coleman's daddy.

MF: Were they black? They were black, right?

AW: Uh-huh [yes]. And he was-Well, he had that farm right next to the cemetery. It's Fred andwhat's his brother's name-It's just two boys and one girl.

MF: And he was in charge of the Woodmans Lodge?

AW: Yeah, he was in charge of the Woodmans Lodge and the Masons.

MF: Both of them? And the Masons as well?

AW: Uh-huh [yes]. See, my daddy was a Mason. Langston was a Mason. Velma was a Mason.

MF: And they would meet in the school?

AW: He was in California there when he joined the Masons. I don't know when he joined the Masons, but I know Langston was in Austin.

MF: And what do you remember about the inside of the school, when you were a kid?

AW: When I was a kid?

MF: Yeah. What do you remember about the inside of that building?

AW: Oh, when I was a kid, I remember when I first went to school. I wanted to go to school the day when they had this picture made, and my mother put me on a dress that she had pressed over, you know. And I know she had pressed over it. I know it wasn't washed and then pressed, but that's the way she would do my clothes. She made me take them off, and then she'd press them over, and then she wouldn't have to wash them, have so much big wash. And I got to the school, and my brother had never been tardy, that was Velma. And I was so mad, I got to pulling his hair and everything, and I said, "I don't want to go to school with this dress on." And they were going to take these pictures, you know. "I don't want to go to school." He said, "Well, you don't want to be tardy." "I don't care, just take me back. Leave me alone. I'll go back myself." He put me on his back and ran all the way back, and then went back to school, and got there just before the eight o'clock bell went off. And he said, "Momma, whatever you do, don't never put her a dress on that she don't want on, because she ain't going to wear it. She's going to have something to do about it." And Mother said, "Yeah, I'd have had something to do about it if I-" And of course my daddy was there. He didn't believe in 
whooping me. He whooped all the rest of them, but he never did it to me. He never spanked me. He never touched me.

MF: Why do you think that is? Why do you think he never spanked you, your father?

AW: I don't know whatever I did. Well, I was never wrong. I was always right. And he would tell them, say, "Well, she don't do nothing wrong for me to whoop her." He said, "But you all are so hardheaded, you all go and do what you ain't supposed to do. So you don't know better, but you all do it." He said, "She don't." He said, "Come in and you ask her about it, she'll 'Oh, yeah, I did that." And she explains why she did it. He said, "Do you sit down and ask her?" And that's why he asked her, my mother, because she come in, she paddled my back end, she didn't care. If he wasn't there, I got it. My sister didn't. She hardly ever got a whooping from my mother, but my daddy got on her for talking back. And I asked her why would she talk back every time. She didn't know. She just talked back. It just makes me so mad. She would be just like she was grown, and she always wanted to be the baby. And she wondered why my daddy didn't ever whoop me. He said, "She don't do things like you do." He said, "You talk back. You do lots of things that you're not supposed to do." She kept doing them.

MF: Let me ask you, all of your brothers and sisters, you all went to this school obviously, right?

AW: Yeah, we all went to school.

MF: Can you tell me about the inside of that school? Do you remember what it looked like?

AW: Oh, yeah. It had a light color wood it was made out of. And they were real slick, and had the black arm down here on the side. And there should be two in each seat, you know.

MF: $\quad$ So you're talking about the desks?

AW: Desks, uh-huh [yes].

MF: Wooden desks.

AW: $\quad$ Mm-hmm [yes]. There would be two in each desk. And Annie and I sat together all the time, and I was out of school-I don't know why I couldn't go to school that day. But I didn't go-

MF: Was Annie, are you talking about-

AW: Annie Smith.

MF: Annie Smith. So she was a friend of yours?

AW: $\quad$ Oh, yeah. Me and her were just like that together everywhere we were at. And so she was-I don't know what it was, but anyway when I come back to school, at the head of the class, they put you back there, you know. And you had to spell until you passed everybody, you know. And everybody missed that particular word. I think it's o-u-t out. And everybody was trying to get it. And Annie said, "Oh, I got you now." She was the head of the class, you know. She was going to stay at the head. She missed that one. I got back in the same position-I was in the first place. But we always had, you know, talk and just have a good time. And she always wanted, she's going to marry somebody in my family so I could be kin to her, so we could be kin. And she did marry a guy that was kin to me.

MF: Who did she marry? 
AW: She married Scales. I don’t remember his first name, but I know he was a Scale.

MF: So what kinds of things did you Annie do together for fun? What kind of games you played or things you did?

AW: Oh, we didn't have any games like that to play, we just had-You just caught what you could get over to the others had their games, you know, the older ones, you know. And she had an older sister named Lois. Her and my sister was good friends. But A. J. Smith and my sister was really close, because they were born the same day. It was Lillie Smith's, I mean Lillie Grant's husband. And he would always talk about what a good time he had when he came around us, you know.

MF: So what kinds of things did you do to have fun when you were young?

AW: Oh, go and sit on a rock and talk, gather flowers, little flowers. You know, they're so tiny you'd get a whole lot of them, you had to get all of a lot to make a bouquet, you know. And algerita, I don't know what you know about algeritas.

MF: Oh, those bushes with the little berries on them? [Yes.] Yes, I know what they are.

AW: Well, we'd go out in the pasture, and get them, you know. They'd just be budding out, when our schools would be closed, you know. And we'd eat them things. They were sour, you know.

MF: You're supposed to beat the bush to get the berries off, aren't you?

AW: Yeah, the berries, but we weren't getting the berries. We were getting the flower. That flower is real sour, and so we'd get it and eat it, you know.

MF: It doesn't sound very good.

AW: Yeah, we would. And always dividing our lunch together, you know. I brought this, I brought that; you give me this and I'll give you that. That was our [inaudible], our most thing that we did. But we had a good time. A lot better than what they're doing now. But it's different scales, you know.

MF: And you had to work, you said, when you were living at home. You must've had chores around the house to do, right?

AW: Around the house?

MF: Yeah. Did you help your mother out or father out around the house?

AW: Oh, yeah. I always wanted to do what she did. I learned how to cook. I was eleven years old and my first biscuits I made, and I thought I was doing real good. And then when I was going to school, I would go to work in the morning, and come home and go to work in the afternoon after I got home. And I'd go up there and wash the people's dishes, and they'd pay me a dollar and a half a week.

MF: Is this over in Buda that you would do that?

AW: In Buda, at Rackless.

MF: That was the name of the family? 
AW: Mm-hmm [yes]. And I thought, well, I wanted my own money, but I'd never get to save it. My daddy said, "You get $\$ 100$, I'll put it in a bank for you." I got up to $\$ 100$, and went and looked in that place where I was saving it at, and there wasn't nothing in there. I said, "Every nickel I get now, I'm spending."

MF: What happened to your money?

AW: Well, I don't know. My brothers or-I always had a piggy bank, and I'd get 50 cents in quarters people give me, you know.

MF: And you think your brothers took your money?

AW: $\quad$ Oh, yeah, I know they did! They were going off having a good time.

MF: Right. Spending your money, huh?

AW: $\quad$ Mm-hmm [yes]. And then they were in a hurry one night, and so they took my bank. A big ole bull hit him and broke him in two, right half in two.

MF: Did they get in trouble for that?

AW: No, they didn't do nothing to them. They just thought I should, you know, I should've known about it, you know. I said, "No." I said, "I know they had cut the hole bigger where I put the money in, dropped the money in it." And the thing was so heavy, you know. And 50 cents and 25 cents, I didn't have any pennies in that thing back then. Because all my dimes, I always put them in a dime bank, you know. I'd always try to save money, and I'd always lose it. It's been that way all my life, even now. All my nephews come, and all they want to do is steal something, you know, my money, and take care of them. And they can eat, sleep, and don't pay no bills. So I've had that on my hands, and that's Oddies' kids. And I'd say, "Why did he have so many?" And now their families are coming down here on the $29^{\text {th }}$, and I just went and had them boys, and they want to come stay with me. I got my thing around my neck. I don't need nobody, and I don't want nobody. I talk to my cat, and I said, "That's as far as I go."

MF: $\quad$ Now Oddies' kids must be grown men, though. Your nephews, if they're your older brothers' kids, they must be like in their fifties. I mean they're grown older men, right?

AW: Oh, they're grown. I mean Don, that's Oddies' daughter's son. My oldest brother's son, his daughter's kid, I've kept him. And then I kept Oddies' oldest son, not his oldest son because his oldest son was killed by a train. And then Oddies' baby's son, he came down here with a whole lot of stuff out there. "I don't want to hear this," I said, "that's nothing but a lie," you know. He's telling me what his daddy had told him. I said, "You didn't tell me what your daddy_-" I said, "If your daddy's said anything, you give Aunt Lee something, and don't be short." And then he trying to make out like Oddies told him that give him my home. I said, "You bought a home, didn't you?"

MF: So you helped to raise your brother's kids. Did you help to raise them or-?

AW: No, I didn't have to raise them. They just come to me in spots, you know. And so this boy, I say, "You know, I didn't know you was still living. I thought you were dead. I hadn't heard from you." And he never come to see me, nothing, then he come telling me all this stuff. I said, "Don't tell me. I know better." He said, "You know, you know better." Well—but Oddies, he just told me that he know what he did wrong, but he started getting his check from the government. I was getting mine already, you know, it's up at the bank, that's where I have 
mine come to the bank. When he went and they-you know how they do, they want somebody to give them-well, I told them, I said, "Yeah," I said, "He can-"

MF: Okay, so your daughter is Katie, but is this the one who was adopted? [Mm-hmm [yes].] And this was the one, from what I remember that your niece Joan Nell told me, this was a black woman who had a child by her white employer, and then was forced to give that child up. [Yeah.] But the baby was white, and so you took that child and raised her. Wow.

AW: When I was sixteen years old.

MF: You were sixteen when you took the baby?

AW: And my mother, you know, I would always tell my mother, "I wish you'd have another baby." She'd say, "You gotta be kidding." She said, "I tell you what. If you get one and bring it here, I'll help you raise it."

MF: That's what your mother told you? [Mm-hmm (yes).] Or you told your mother?

AW: $\quad$ My mother told me. And uh, well, they was lonesome for somebody else, too, you know, I guess. This baby, I remember my mother said, "Well, you have to take care of her now. That's going to be your responsibility." "Oh, all right." So the first time we went out, she didn't have any shoes. I made her some out of blue velvet, and put a little pasteable sole in it. And then she, my mother, she was a good seamstress, so she had a-a lady had to give her a blue dress, great big blue dress with dots in it, you know, little blue dots, and she take it and made a little slip. Oh, she just felt so proud of that, you know.

MF: How old was Katie when you adopted her, when you brought her home with you?

AW: Well, I guess she was about one.

MF: One. So she wouldn't have remembered her biological mother or anything.

AW: No, she wouldn't remember things.

MF: Were you the one who met the mother, or was it your mother who brought the baby home? Because I think the way Joan Nell tells me is that this woman was in Buda, I don't know, standing outside a store or something looking for somebody to take the baby. What happened?

AW: No. Well see, well, I didn't know nothing about the white parents or nothing. I was just so glad to get a baby they give to me, you know?

MF: So it was Katie's mother who gave it to you? [Mm-hmm (yes).] What did she say to you?

AW: She didn't say nothing. She just uh, "You sure you want this baby?" I said, "Yeah, I want the baby."

MF: And she told you why she was giving the baby up?

AW: No, she didn't tell me why.

MF: Okay, where do you think Joan Nell heard the story that she, this woman had gotten pregnant by her employer and the employer's wife told her she would either have to leave or give the child up. [Mm-hmm (yes).] Is that true? 
AW: That's true about that, on that side. That's you know, on the other side, you know. I don't know about that, but that's what they said after I got her. But they was so happy that I got her, and then I had to pay $\$ 5$ for notaries right here, but I couldn't write it up in my name because my parents was living and I was too young. So they had to put they [signatures] down here, but I had to pay them that $\$ 5$. My mother and daddy had to pay them that $\$ 5$.

MF: But you raised Katie. [Mm-hmm (yes).] So let me ask you, when did you actually marry, because you were single at the time, right? [Mm-hmm (yes).] Obviously. Okay. And so when you married, it was much later? When did you actually marry Mr. Walker?

AW: Oh, well it's in there in the book. I don't know.

MF: You don't remember how old you were when you married?

AW: No, I never kept up with that. Just like people when they die, you know, they say, "When did your mother pass?" I don't know.

MF: Was Katie young when you married Mr. Walker? Was your daughter grown or was she still a child when you married?

AW: When I married? [Yes.] She was grown. She was already growed up, see. She was going to Tillotson.

MF: Huston-Tillotson?

AW: Yeah, Tillotson College in Austin. She's—and she went and got a degree like at the post office. So she retired from the post office.

MF: Okay. And she's your only child, right?

AW: $\quad$ Mm-hmm [yes], yeah, and she send me $\$ 200$ practically every month.

MF: And she still lives in Austin?

AW: And I tell her, "Well, you don't have to send me that, any of that money. You was my pleasure," and she said, "No, you were mine." Said, "I don't know where I'd have been if it hadn't been for you. I just don't know what would have happened to me." I said, "Well," I said, "all I can remember about you was that pink bow and ribbon."

MF: $\quad$ Oh, in her hair.

AW: My mother just tied little-and she didn't have no hair. She had a little peak up here, and so she'd tie that piece of pink ribbon up there on her head. I made them shoes that I think about. I sit there at night and sewed them shoes at ???. And I was trying to work, too, you know.

MF: Right. I was going to ask. Okay, so you're sixteen and you've got this one-year-old baby. [Mmhmm (yes).] How long did you stay with your parents before you moved out by yourself with your child?

AW: Oh, I never did take her with me. She stayed with my mother and daddy. Mm-hmm [yes], yeah, because she did-well-

MF: And when did you leave your parents' home? How old were you? Do you remember? 
AW: Well, I was about twenty—nineteen or twenty, something like that. And I went out, then I started working at the drugstore, and then I started making, you know, my own money.

MF: Was this drugstore in Austin or in Buda?

AW: In San Angelo. I worked out there. Well, I was doing good, and I would have still been out there, but my mother couldn't stand it. She said the river come right up to where I was staying on the Third Street and it come right up to the porch and went back, and they was looking for it to overflow San Angelo, and she said I had to leave and come home, and so she come out there and I went back with her. So that's it.

MF: Well, let me ask you, growing up in Buda, was that a close-knit community in the colony?

AW: Oh, yeah.

MF: Yeah? What was the best thing about that community that you remember, that you liked the most?

AW: Well, I think it was close, it was friendly, because we was always there. You know, it wasn't no-you go to downtown, very few black people in Buda would be up there, and we'd walk from the bank down to where the trains stop there at the end and walk back up to the-back up. Down on the end, it was a place where they had cold drinks, you know? So we'd go down there and get us a cold drink, and then we'd come back. We'd pay a nickel for it.

MF: And so you would go down with your friends into Buda to get something to drink?

AW: Yeah, we'd go down there. We'd come back and we'd go there-you know, you could go in a confectionary and buy ice cream. We'd go get an ice cream cone. And Miss Hacker, she was a real fat lady. She looked like a lady on one of these silver dollars, you know, with all her hair on her head. She had long hair and she just had it all balled up on her head.

MF: A white woman.

AW: Mm-hmm [yes], and she was good to all the black children. We'd go in there and sit in there a while and eat candy.

MF: You were allowed in the store? Because-

AW: Yeah, we was allowed in the store.

MF: Do you remember much, though, about segregation in Buda? Racism?

AW: $\quad$ No. When I-everybody I-I worked for practically everybody in Buda. Everywhere I went and worked, I'd go there and they'd say, well, I was good for cleaning up, you know. I'd go. I ate with them all. And then the people down on the lower end, I slept in the front room. They didn't want me to say I slept in the front room, but that's where I was sleeping at, in the front room. She'd say, "If you tell people that, they wouldn't believe it," you know, thinking that they would let me stay up there and sleep in they company's bed, you know. And I'd say, "Well-" I didn't care whether they cared or not. It didn't make me any difference just so I didn't sleep outside. And whenever it was late, I didn't go-they didn't-I wouldn't pay anybody to let me go down on that hill. You know, walk down there and go-and so they didn't take me and so I'd sleep in. Me and that big fat girl over there would sleep together. And when we was on a trip, that's where we slept. We'd take a bath. Whoever be to take a bath, if I beat her, well, she had to wait until I got through. 
MF: When you say take a trip, what do you mean, take a trip?

AW: Well, we left and went to New Mexico.

MF: And you traveled with this white family to New Mexico?

AW: $\quad$ Mm-hmm [yes]. Everywhere I went, I traveled with white. When I went to Colorado and everything, I was traveling. They was white and they was the Kirkendalls. So I never segregate. My brother, he couldn't stand it. He didn't want nobody call him a Negro. He didn't want nobody to call him a Mexican. Well, what is you? You got to be something. I thought it was a silly thing.

MF: Which brother was that, Velma?

AW: Langston. Oh, he was something else. He [inaudible] a Negro. He went down there and they called him a Mexican down where he was married, you know. They called him a Mexican. Some of the colored guys, you know, called him Mexican. He went, he got his cousins, the Searcys, and his-it was three of those boys, and there they went down there and they was having a big dinner, church dinner there. They got on table and then walked the table, kicked stuff off. He was that mean, you know. You just didn't call him-you just call him Langston. Langston, really - don't call him nothing else. Don't put nothing else out there when it come to him. He sure didn't—he didn't like it.

MF: What do you think about what's happened to the colony now? I mean, you say you go back there quite a bit now.

AW: Yeah, I go, I go back.

MF: I'm sure it's changed. It's changed quite a bit, hasn't it?

AW: It's changed quite a bit, but Uncle Charlie Bunkley and his wife, Aunt Adeline, and her daughter, well, I know them, and we'd come down-I'd come down. We'd come over there. And I don't know how, but they had ice every time we went there, and she'd make lemonade. Fix some cookies, oh, they just did everything. We'd sit out there, and Oddies' oldest son, the boy I said that got killed, well, we'd go there and sit in the shade of the house and eat, have the best time. Our mother would say, "You're not supposed to go by there. Those people is elder people. So you got to-" "But Mama, they tell us to come by there." And so my mama went by there and told them you know, we was bothering them. You know, just send us home. If they couldn't do nothing about it, just send us home. And she said, "No, we want them to come. We have lots of fun." She said, "That's our pleasure, is seeing them come," you know?

MF: Seeing who come? Oh, they were talking about you.

AW: Yeah, me and my cousin, and she was-

MF: What was your cousin's name?

AW: Oh, Buster Revada. We had such a good time, you know, going to see them. He could tell us so much about the Chisholm Trail. It started right out from they house.

MF: Which trail?

AW: Chisholm Trail. You know where they- 
MF: Chisholm Trail. Oh, where they drove the cattle?

AW: Cattle. Long years ago, you know. That was way before our time. He was a elder old man, you know, and very frail, so-

MF: And this was in Buda? That's where they lived?

AW: Mm-hmm [yes]. And then the druggist is the one-He knew him, and he liked Uncle Charlie, you know, Uncle Charlie was his friend. He'd say they used to come by Uncle Charlie's when he was driving those cattle, you know, and he would always go on a trip. You know, he'd go so far up and then-like Missouri and all then. Then he'd come back, you know, on a train. He'd ride horseback up there, but he come back on a train.

MF: Mm-hmm [yes]. Let me ask you, did people help each other out a lot in the colony?

AW: Yeah, they was pretty good about that.

MF: Mm-hmm [yes]. What kinds of things would people do to help one another out?

AW: You know, I can't understand how um, Martha and them didn't take her back. They never mention Uncle Charlie and Aunt Adeline, and that was they grandmother's mother. But that wasn't his daughter, you know, but he was married to her. I thought they was close-knitted, but they wasn't. They never-and there was someone-Dansey, you know what I mean? He was their uncle, and I never saw him down there. We couldn't stand it, not going by there and speaking to them. Even if we couldn't stop, we had to come from school, you know, and were able to- they was always glad to see us, you know.

MF: Who? The Harpers? Who are you-?

AW: Aunt Adeline and Charlie Bunkley.

MF: Okay. Well, the thing I was asking you about, though, is what kinds of things people did to help one another out.

AW: That's what I said. I didn't ever remember doing anything for them, and they were elder people, you know what I mean?

MF: Yeah. What about your own family? Like one of the things I heard is that people, if you slaughtered a hog, you would make sure you shared it with other families.

AW: Oh, anybody that-you know, if they come around and ask for something, everybody give, you know. They were good about that. And if anything happened, you know, in the house and they needed something, they'd give. I think it was pretty good living. Of course, we never had to ask for anything. We had everything.

MF: $\quad$ You did pretty well? Your father did pretty well?

AW: Mm-hmm [yes], yeah, and he had — he raised hogs—big bone Poland Chinas and little bone Poland Chinas. Little bone was about this big.

MF: Little bone and big bone. What did you call them?

AW: Poland Chinas. 
MF: I've never heard that term before.

AW: Pigs. Well, he raised them, and this old sow, she had twelve pigs, and my daddy and mother told me, "Don't ever go up there and get in that pen with that sow. She'll just chew you up." "No, she won't chew me up." "Oh yes, she will," and I thought, well, I'd put a saddle on and try to ride her. The saddle-you could never keep a saddle straight on. Don't try to put a saddle on a hog. You can't saddle a hog.

MF: I don't plan on doing that! [Laughter]

AW: Well, anyway, we tried. I tried it, but then I'd get on her and catch her by the ears, and this old sow, you know she's just grunting all the time, you know, and they said, "Don't you go up there and get her," because that old hog got some pigs now. So I went up there, and I wanted to get in there with that hog. She had them little pigs, you know. So I got in there and got to playing with the pigs, you know, and she got to grunting and went and laid down in the water hole to cool. Then I laid down on top of her, and all the pigs was there. Mama said, "Where's that kid? She been gone too long." Mama said, "You got a shotgun? I'm going to go up there and kill that hog because he done kill my baby." When they come up there, he told me, he said, "Come on, Mama." I said, "Look." I was laying up there asleep on the hog's hip and all the little pigs was just-they just wish they had a Kodak. You know, they could take a picture.

MF: Mm-hmm [yes]. How old were you?

AW: Oh, I was about, I was about eight years old, I guess. I knowed better than to do what they said not to do, but I did that. Papa said, "Baby, is you asleep?" I woke up yawning, saying, "I was until you woke me up!" I was laying on top of that pig. But they had to wash them. He washed them pigs and clean them all off and then put a water pen and some mud and stuff over there so they could get over there and wallow in it. They'd wallow in that big dirt, he'd have to get in there and wash them and clean them, and they'd be just as clean. They'd come out there, them pigs come out there like they knowed what was going on, you know? I can understand that.

MF: Let me ask you about your mom and your father. What do you remember most about your mother, Hattie Sneed? What kind of woman was she?

AW: Oh, she was perfect for me. You know what I mean? She was a perfect mother is what I would say, and I'd say my daddy was perfect to me. They was two people and I thought was just it. You know, wasn't nothing else like them.

MF: What kinds of things did they teach you?

AW: Well, they taught me not to lie, and not to steal, and all of that stuff, you know. They told me all of that, and I'd say, "Yeah. Well, I'm listening." You know what I mean? I did. I listened to them. I know what they meant when, what they was saying, and that's the reason I didn't get so many whippings, you know? It was on that account. But everything somebody did, they wanted laid on me, and I didn't do it, you know. I know. She'd say, "Anthy Lee, what do you want?" I'd say, "I want something that ain't no hand-me-down. I can tell you that for sure. I want something that is right for me and not right for my sister that she wear two years and then give it to me. I don't want that." They thought that was being smart, you know? My mother said, "You always looking at something." I'm looking to see how it's fitting, you know. Everything had to be just right for me. And clothes I'm wearing, or anything, you know. But first being particular about what they called me, they called me Anthy Lee, and lots of them do. I said, "Well, it don't make me no difference. Just call me by my name. That's all. I know 
what you're talking about." I said, "Will you call me by my name?" I didn't have to have no handle on it. A lot of people, if you don't call them Miss So-and-so, or they don't like-you know, that's what you supposed to do. But I always knowed to call people that I thought older than I was, I always put a handle on their name, you know.

MF: Mr. or Mrs.

AW: But anybody younger than I am, I just-

MF: $\quad$ First name.

AW: It didn't make no difference where you were white or black. I never-I played with white kids and I didn't Miss So-and-so, Miss So-and-so, you know. Unh-uh [no]. I just called them by their name, and I work for Marsha, the Kirkendalls, call her Marsha, didn't care, you know? I called her Miss Kirkendall, you know, because that's who I was working for, you know? But unh-uh [no], I didn't bother about that. And I would see lots of them over here, you know. Everybody would tell me over here at the church, and they, "Miss So-and-so." I'd say, "Oh, you talking about So-and-so." I'd say, "Oh, I didn't know they called him Mister," because I said, "I don't put no handle on nobody's name. You know what I mean? If they younger than I am, why they just another person." That's the way I felt about it, and still feel that way about it. Lady called me over here, she called Miss Valerie, her name, you know. Miss So-and-so. I said, "What is your name?" She said, "My name's Josephine." I said, "Well, all right, Josephine. All right, Valerie." Maria, I called Maria "Maria." She said, "You don't never tell nobody Mister." I said, "No." I said, "I'm older than you all are."

MF: Can I ask you about when you were growing up in Antioch? Who taught you-you mentioned that your parents taught you a lot about not lying, not stealing. It sounds a lot like you know, teachings that you'd get from the Bible. But who taught you about what was the proper behavior for a young lady?

AW: Oh, well if you were right, you're leg cocked up like I got mine crossed now. You supposed to sit right, you know? All of that kind of stuff.

MF: Who told you those things?

AW: Well, my mother. That's why I say I had a perfect mother.

MF: Very good role model, hmm?

AW: "Don’t sit with your leg crossed. Sit this way. Pull your dress down like this."

MF: Mm-hmm [yes]. What did she tell you about boys?

AW: She said, "When you go_-" Boys?

MF: Yeah, dating.

AW: She didn't ever mention no boys to me. She was always telling us, my sister about—she was twelve years older than I were. She never mentioned boys to me.

MF: Not like stay away from them or wait till you're older to date, that kind of thing?

AW: Oh, you don't-yeah, you don't do nothing that showing them that-you want them to come to you. Stay out of that. Don't do that. And my daddy said no, because- 
MF: [Part 2] Okay, I'm going to go ahead and continue the interview now. The other questions I was going to ask you about are the house that you grew up in. Now, you said that you moved around a little bit, right, from different properties when you were younger living in Buda? [Yeah.] But you said that the house-which house do you remember the most that you could describe to me?

AW: $\quad$ That I went to?

MF: No, that you lived in growing up in Buda.

AW: In Buda? [Yes.] Well, I lived in the house I was born in, and on the share farm, this man built us a new home.

MF: What was the name of the farm?

AW: Frank Crews.

MF: Oh, Frank Crews. Okay. [Mm-hmm (yes).] Okay. So you remember that house that you lived in on the Crews' property?

AW: Yeah. It was a brand-new house.

MF: Was it made out of wood?

AW: $\quad$ Everything, we had carpet-not carpet on the floor, but a mat on the floor, and we'd take it up and my mother and clean under that because the dirt and everything would go through that mat, you know. Then wash the mat and that and put it back in there.

MF: How big was the house? How many rooms did it have?

AW: Rooms? Let's see. It had uh, my bedroom and my sister's and two brothers'-three, four. Four bedrooms with my mother's.

MF: And it was a wooden house?

AW: It was a wood house.

MF: Did it sit on top of wooden piers? [No.] A raised floor?

AW: $\quad$ No, it was just a plain old wooden house with $2 \times 4$ s, you know, running up underneath it to balance it. That's just the way it was.

MF: What kind of roof did it have?

AW: $\quad$ Uh, shingled. Shingled.

MF: $\quad$ Shingles. [Mm-hmm (yes).] Wooden shingles?

AW: Wooden shingles, mm-hmm [yes].

MF: And did it have a porch?

AW: Oh yeah, it had a porch. And out in the front, we had a swing and it would swing you so high, you go up there and you hit the trees. 
MF: The branches?

AW: Mm-hmm [yes]. It was dangerous, but we had it, you know. My brother and them liked to live dangerous. They wanted everything. Like they said, "Well, let's kill you." That's all we had.

MF: Did you have an outhouse, privy, to use the bathroom?

AW: $\quad$ Oh, no, it was outside.

MF: Yeah, an outhouse, right? [Mm-hmm (yes).] Outside, yeah.

AW: And toilet paper was a catalog.

MF: A catalog? [Yeah.] Like a Sears or a Montgomery Ward catalog? [Yeah.] Okay. What about your fresh water? Where did you get water? Did you have a well or a cistern?

AW: No, we had — they brought it in a barrel, a wooden barrel, drinking water.

MF: Where did you get the water from?

AW: From the big place where they had the windmill, you know. It had that pump, and they bringing the water up and they put in the big tank. You know, it'd be a tank, and then you draw your water from there. Yeah, you know.

MF: Okay, and then you'd put it into a barrel and then-

AW: $\quad$ Bring it home, mm-hmm [yes]. They'd bring it home in one barrel emptied out and that was drinking water, and then you covered that barrel, kept it covered with a ducking on top to keep it cool, you know, in the coolest spot you can get for your water. But in the end that's all we had, you know. Then had those galvanized tanks that you use on the side. You had a spigot in it, you know, to let your water out. That was for washing your hands and taking a bath. That was on the place, that was Crews' place. But on John Howe's place we had a hydrant. It wasn't in the house, but it was right out in the front, you know.

MF: $\quad$ So it was a pump?

AW: It had a pump to bring the water up. It furnished the water all day. The people that lived on that place, the water would go downhill, and we was the only one that had a pump. It had a big fig tree there, and it had the best figs, blue figs, you know. Sweet and good, you could eat them.

MF: And this was on John Howe's place?

AW: $\quad$ Mm-hmm [yes], and then it had a ladder that went up on the side of the, where the fountain was. It went over on the side and you could look down in the tank with your head up there. You could go up that and look down in that tank. Oh, it was kind of cozy, you know. It was nice to have water in your home.

MF: Mm-hmm [yes]. Now you mentioned that you hunted some animals for their hides. Remember you told me about your dad going in and selling those skunk hides and whatnot? [Yeah.] How did you learn how to hunt? You hunted those animals yourself?

AW: Yeah, I did them myself. 
MF: No, did you kill those animals, though?

AW: Oh, yeah.

MF: Did you go out there and get them? Who taught you how to do that?

AW: Oh, I learned how to shoot, use a .22, you know.

MF: Who taught you how to use a .22?

AW: $\quad$ My brothers.

MF: Okay. Did they hunt a lot for food?

AW: Well, see, that's what they did on these other places, you know. But up there, they didn't stay with us, you know. They was running around somewhere else, and they go up there, get up every morning before I go to school, go and get that polecat. My mother said, "You're going to get polecat all over you one of these days."

MF: I would have been afraid of that.

AW: $\quad$ But I just take it and cut around it. That knife cut it, you know. You cut around each leg and then you pull that apart. Then you turn it-You got to, when you put your foot on that and just catch him put him from the bottom, just pull it up and it would come off right away. It's tender, you know. It come off good. Polecat was easy to skin. Then when you got up to the throat, you cut around that, cut around that, then went up side his head and you pull it out and it just come on off, that scalp, and he just be nothing but just a frame, you know.

MF: $\quad$ So your brothers taught you how to hunt and skin animals? Your brothers?

AW: I learned that from looking at them.

MF: Yeah, mm-hmm [yes]. Did you ever hunt animals to bring home to eat for your family, like rabbits or possums?

AW: No. Possum, I skinned many possum, but you know, a dog won't eat a possum, but he'll eat a polecat. A skunk.

MF: Okay. So does that mean that you would not eat a possum at home then?

AW: I wouldn't eat a possum. I never eat a possum. I never did like a possum. He had too much grease in him. And a lot of people just loved them, you know, and they'd tell me about them. I'd say, "I don't see nothing good in them." And yet when my mother cooked a steak from the hog, I just pulled the grease out and would just spread and just eat that grease. They had to watch me because I'd eat-That's all I want, and right now, I don't care about a whole lot of meat, just so much meat and that's it. I like the fat stuff, but I don't want no possum in it. I can just tell a possum. It's just got a smell to it and it come to you.

MF: So were there any animals that you hunted or your brothers hunted or your father and you brought them home to eat then?

AW: Well, we liked a rabbit. You know, we called them swamp rabbits. They were around a creek, you know, and my daddy would kill them. He killed one. My mother wouldn't cook them. She didn't like rabbits. We didn't have no rabbits. A lot of people said, "Well, we eat such-and-such 
rabbit." Uh-uh [no]. We didn't know what a rabbit was until we got out on our own. Then we knowed what a rabbit was.

MF: Okay. So what would your dad do with all those rabbits he shot, then, if your mom didn't cook them?

AW: $\quad$ My daddy was a good hunter. He'd bring quails, and that's what he liked to shoot is the quails and doves, you know. He'd bring them in, you know. Clean them. He'd have them cooked and then split them down the back, split him wide open like that. My mother would cook them, but she never cooked no rabbit. She'd always have a headache when a rabbit come in, and when you cook the rabbit, he said, "Mama don't feel too well. I'm going to cook a rabbit." "All right." Brother, he'd pick that rabbit and make chili with it, chili. You talk about something good-they were just so good. But I guess that was him fixing that rabbit—once a year we could get that.

MF: How old were you when you learned how to shoot a rifle?

AW: Oh, I was about eight, eight.

MF: Eight? [Mm-hmm (yes).] Wow.

AW: Oh, yeah.

MF: Was it pretty common for girls to learn how to use a rifle to hunt?

AW: No. My mother could shoot, though, anything.

MF: Oh, is that right? Okay.

AW: She was a good marksman, you know what I mean. So I guess it just come natural for me to shoot.

MF: Okay. So did you see any of your other friends who were girls that could shoot? You were the only one?

AW: They didn't know nothing about cleaning no-you know, cleaning nothing. No animals, nothing like that.

MF: But it sounds like you liked going out hunting and skinning animals and stuff.

AW: Yeah. Well, that was so easy for me to do, you know. I could do it so fast, you know. I could put out them skunks and be back, have five or six.

MF: How do you hunt a skunk? Where do you look for them?

AW: When I'd go, they're in a trap, see.

MF: Oh, you'd set a trap.

AW: I'd set a trap and it would catch the skunk. I'd shoot him in the eyes, you know, to keep from ruining his skin, you know.

MF: Did you make your own traps? [No.] Or were they store-bought traps? 
AW: $\quad$ They just-My brother and them left a whole bunch of them there, you know, and my mother was glad to get rid of all them things because they bothered her chickens, you know. She had 500 chickens when I was doing all this hunting.

MF: $\quad$ So your parents sold a lot of dairy products, like eggs?

AW: $\quad$ Eggs and bacon.

MF: Did they sell that? I mean they must have been selling eggs if they had that many chickens!

AW: Oh, yeah, they had to sell. Well, she sold more eggs than she did anything because she sold setting eggs, you know, and you got fifteen for so much, you know.

MF: $\quad$ Fifteen what?

AW: $\quad$ Eggs to set under your hen, and you get to buy and people come by and buy them because they want those Rhode Island Reds and [inaudible] eggs. Mm-hmm [yes].

MF: Okay, so your mom sold eggs. What else did your family produce to sell? Do you know? Do you remember?

AW: Well, they sold butter, too. Sold cream, rather. Yeah. You know, they had a cheese factory there in Buda.

MF: No, I didn't know that.

AW: Well, they did, and they would buy the cream, you know, to make the cheese and cottage cheese, you know.

MF: So how many cows did you have? You must have had a lot of dairy cows, did you?

AW: I had about forty, mm-hmm [yes]. Yeah, them big old cows like that.

MF: Right. Did you have to milk the cows?

AW: Yeah, they had to milk the cow. I never learned how to milk a cow.

MF: Did your parents hire help to help them with collecting eggs or milking the cows or anything? No.

AW: Everything was done by the inside the family.

MF: Okay. So it sounds like your family did quite a bit of things to raise money for themselves, right?

AW: Yeah, they was always doing something on the outside to make extra money, you know.

MF: Mm-hmm [yes]. What other kinds of things do you remember your mother doing to help?

AW: Yeah. She made a-I tell you, she did a lot of quilting, and she would do that and people would bring her big old sacks of remnants, they called it, and she would make quilts. She sold them for $\$ 5$. And I mean they was, wasn't just plain, she'd make them real neat. And that's one thing I could help her with was to hold the things back so she could roll it tight, you know, and then sit there and sew. And she would sew. The funny thing I couldn't ever figure 
out, she never-you never saw her play a piano, and if there wasn't nobody there but me and her, well, she'd get down and she'd play that piano, you know. I can remember she used to play the piano and sing.

MF: You had a piano at your house? [Huh?] Where was the piano? In your house? Your family owned a piano?

AW: Always was a piano. I can't remember when we didn't have a piano. We always had one. It was upright, you know. It was a tall back, and I guess she saw the kind that sits way up there on top. Then the Kavanaugh's bought that. Mm-hmm [yes]. L. D. Bunton's sister was the one that bought it.

MF: Let me ask you, I had asked you where you went to school, and you went to this Antioch School until what grade?

AW: I went there until I was in the eighth grade.

MF: Okay. Did you go to school after that? Did you continue your-?

AW: No, I didn't go to school after that. I went to school—She taught us the ninth grade, which was, you know, she wasn't supposed to, but she did, the teacher, and she told us she taught us the ninth. Fractions was real good, and we had-it seemed like algebra was just so free and good. I look at it now, I don't know way from bull on it.

MF: Neither do I, so-[laughs]

AW: One of those things, there are all of these numbers and all them $\mathrm{Zs}$ and things. I said, "Oh God, just take that away." But then when I come here to San Antonio, I went to school down there at Singer Sewing Machine Company. Then they want me to take a job there.

MF: Doing what? What kind of job?

AW: Teaching, teaching the others how to sew. You know, teaching people how to sew, how to use a pattern. Brother, I could take a little piece of cloth and get it all around there, have it straight and get the-I would always learn that they count in the little box. You know what I mean? I made a coat, and I thought, "Well, nobody going to wear this coat." Put it on here on the inside, I didn't have enough material to come all around or anything, so I pieced it together, sewed it together-you know, the blocks I had and sewed them together-and then cut it out and made the thing so they was straight, and pressed it. My Aunt Eula, she got that coat. She said she just wore that coat. She loved that coat. She said she wore that coat all the winter, you know, and stayed in it. She stayed in Brady, and she'd say, "I wouldn't take nothing for that coat." She bought me a pair of earrings. They were so big - black, you know, and they got large stones and, you know, on down there. You know, they're not real stones, but they just that googly stuff.

MF: $\quad$ Now why did you end up leaving Buda?

AW: $\quad$ Because I had to go and take care of Joan and them. Joan's mother was sick, and my brother-[Note: Joan Nell Revada Limuel, Walker's niece.]

MF: Okay. So where were they living at that time?

AW: San Angelo. 
MF: Okay, so you drove out, so you went out there to help take care of her.

AW: I started helping take care of her, and I got a job working at the drugstore, and I was the cashier there at the drugstore.

MF: $\quad$ So you just went ahead and stayed.

AW: $\quad$ Oh, yeah, I went ahead and did-And I was staying there just, just doing fine until this big rain come and it was about to wash San Angelo away, and then my mother said I had to come home, and I guess she was right, you know. I don't know.

MF: So you went back to Buda?

AW: I went back to Buda, and then I was there about, let's see, I don't know, about three months, and then I went to the ranch, started working at this dude ranch cooking.

MF: And that was in San Angelo again?

AW: $\quad$ No, this was in Buda.

MF: Oh, excuse me, in Buda. Right, you had mentioned that. Okay.

AW: Right off of-you know, just the way you going up home, you know.

MF: $\quad$ Off of I-35?

AW: I had to-oh, well it was a good piece to go to work.

MF: Do you remember the name of the ranch?

AW: Yeah. 101, 101 Dude Ranch. He played polo. He did everything. He had all them rich people, sisters and brothers. He try to use all their money and his, too. You know how some of them will do. Going to have one black sheep in the family.

MF: Well, I've just got a couple of more questions for you. The first one is, it seems like-I mean you remember so much of your history. I mean you're able to look at a photo that dates to 1921 and name everybody in it. So it seems like that the history that you grew up with is very important to you, and you've been willing to share what you know about it with me and other people. [Mm-hmm (yes).] Why is this history important to you?

AW: Important to me? [Yes.] Well, I just want people to know what I did at that time and how I did, and I was shooting a gun at that time. Then when I went to the ranch, I shot quails and we'd bring them home, and me and the oldest boy would clean them and cook them. He was always my helper, you know. And I'd make all kind of dough, you know. Light bread dough, you know, yeast dough.

MF: Well, what's the most important thing about this history to you that you want other people to know about Antioch Colony and your family.

AW: Well, tell them I loved it. It ain't nobody I met I didn't like. So I'm fond of the Harpers and all the rest of them. I don't know how fond they is of me, but I like them all. I really do. So that's the way it is. When you just go home, well, you're just at home-everybody's your friend. You just be at home. And too bad you didn't get to see-before he passed. A. W. Wright. You know, he was older than I was. They build him a home down there on the older place, his mother's 
place, and he always raised a good garden. My sister, she married one of his cousins, and they had-his mother had raised this boy and she married him. And A. W. would always [inaudible] or anything out of that garden, he'd bring it up there, you know.

MF: A. W. Wright was his name? [Mm-hmm (yes).] Was he a relative of yours or just someone else who lived in the colony?

AW: No, he would just—my sister was just married into they family.

MF: Which sister? Ladys. [Yeah.] Is that your sister's name?

AW: He was a Stevens, the boy what she married. But he and her didn't make it together.

MF: Let me ask this last question. Is there anything that I have not asked you about that you think is important for me to know?

AW: No. That's what I was trying to think of. No, because I told you about Grandma, what my grandmother said, what my grandfather had this place in Buda, they bought the place down in Buda, and they come from Cedar Breaks to Buda. That's about the main thing that I want you to know about.

MF: $\quad$ Okay. Well, thank you very much for this interview, Mrs. Walker. I really appreciate it. Thank you. Okay, I'm going to turn this off now. 


\section{Lillie Grant}

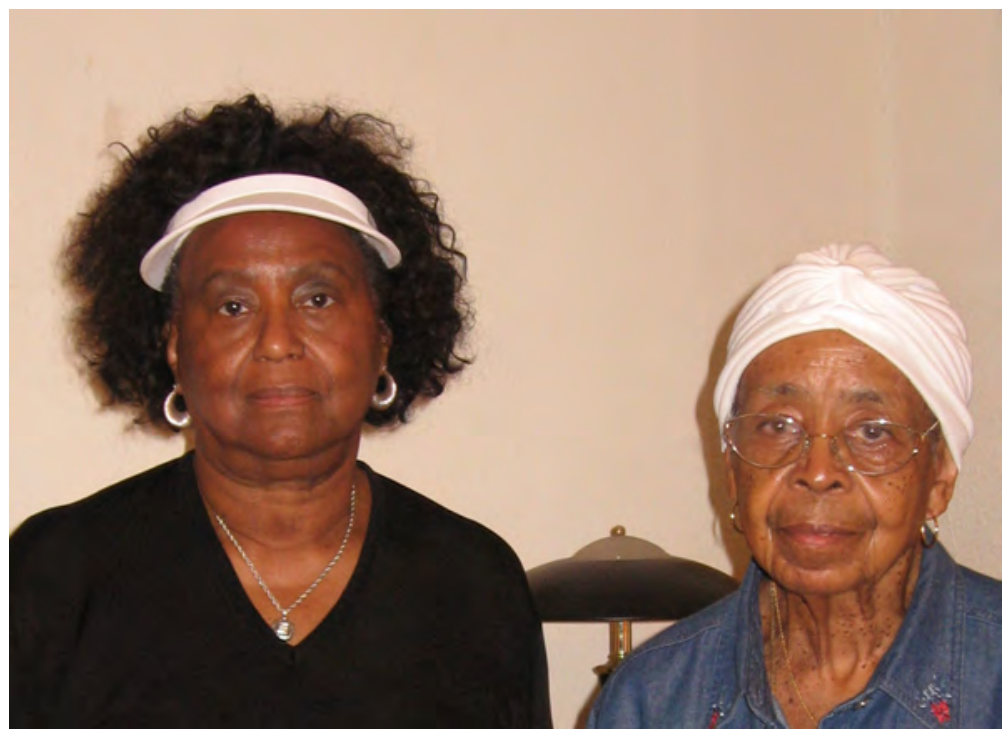

$\begin{array}{ll}\text { Lillie Grant (pictured at right) } \\ \text { Birth Date } & \text { 10/18/1923 } \\ \text { Residence } & \text { The Prairie, Buda } \\ \text { Time Span } & 1923-1940\end{array}$

Note: ${ }^{* * *}$ within brackets indicates revisions to transcript made by Mrs. Wanda Washington.

Interviewed by: Maria Franklin

(Present during interview: July 20, 2009

Wanda Williams Washington)

MF: This is Maria Franklin. Today is July 20, 2009. I'm interviewing for the first time Mrs. Lillie Louise Grant. This interview is taking place in the home of Mrs. Grant in Austin, Texas. This interview is part of the Oral History Program for the Ransom Williams Farmstead Project.

Mrs. Grant, can you tell me first off where you were born and raised in Antioch?

LG: $\quad$ I was born in Buda.

MF: The house and land you lived in, was that owned by your mother and father?

LG: That's where we lived; we lived on a farm.

MF: Your mother and father, do you remember their names?

LG: Yes, my mother's name is Ola Grant, and my father is Lonnie B. Grant. 
MF: Do you remember when Ola Grant was born?

LG: I've got it written down, but I can't remember that.

MF: I can get that information later; that's not a problem.

WW: You're going to have to speak a little louder, Lillie.

LG: Yeah, well, I didn't know [chuckle].

MF: Do you remember what your mother's maiden name was?

LG: Bunton.

MF: She was a Bunton. [Yes.] And she was born and raised in Antioch as well? [Yes.] Were they farmers? [Yes.] Do you remember what you raised on that farm?

LG: Yes, it was a big farm; seventeen acres. We raised everything. We had cattle, horses, chickens, and one dog.

MF: What about crops?

LG: Crops, we had crops. We had a big farm.

MF: What kinds of crops did you raise?

LG: Well, we raised corn. We had everything.

MF: Did you sell those crops [Yes.] to make a living? [Yes.] Did your father or your mother do any other kind of work besides work on their own land?

LG: No, they worked on their own land, on our own land.

MF: What year where you born in?

LG: $\quad$ I was born in '23.

MF: Nineteen twenty-three. Were you delivered by a midwife?

LG: No, a doctor.

MF: A doctor, okay. You were born in Buda then? [Yes.] Okay, and how many brothers and sisters did you have?

LG: Had sixteen-sixteen of us.

MF: $\quad$ Sixteen brothers and sisters? [Yes.] That's amazing.

WW: No, can I interject? [Sure.] Okay, no, there were sixteen including her.

MF: Yeah, that's quite a large family even for back then. I think you're the person with the largest family that I've interviewed so far.

WW: Excuse me, Lillie—with Marvin it made sixteen? [Yes.] Okay. 
LG: He was counted in. My mother and father had two sets of twins: a set of girls, and a set of boys.

MF: How long were your parents married?

LG: I don’t know, I can't tell you that right now.

WW: She doesn't remember.

MF: They were only married to one another, I take it? [Yes.] They are buried at Antioch cemetery, is that correct? [Yes.] The land that they owned, that seventeen acres, was that something that was passed down from the Grants, all the way from the beginning? [Yes.] Okay, and as a girl, as a young girl, do you remember what life was like in Antioch Colony?

LG: Well, we had a good time. We had to go—we were raised on the Prairie, though.

MF: On the Prairie, okay. Yeah, I know where that is. So your seventeen acres were in the Prairie and not in the colony?

LG: No, that's right.

MF: Which church did you belong to there?

LG: Well, a Baptist church, Center Union Baptist church.

MF: Center Union, and which school did you go to?

LG: The school there in Buda. I don't remember the name.

MF: Was it the Antioch School, where the other kids went? [Yes.] Do you remember much about that school?

LG: Well, we had a good time over there in the colony when we went to school over there. We went to school in the hack. Because we came from a big family, we had to go over in the colony for school.

MF: How did you get from the Prairie over to Buda to go to school? Did you walk that distance?

LG: $\quad$ No, my daddy had a wagon and a hack, like a little buggy, and we would travel like that, until the last younger ones-my daddy bought a car, and we rode in that.

MF: Oh, okay. Did your father use mules or horses out there? [Yes.] Did he ever get to own a tractor?

LG: $\quad$ Yes, he did.

MF: Eventually? [Yes.] Did he grow any cane for syrup or anything like that? [Yes.] So he had his own syrup mill?

LG: No, not a syrup mill; he had to take it to another place to get it, make syrup out of it. But we had a lot of cane; we made syrup.

WW: He had a dairy, too. 
MF: Is that right? So he must have had quite a few dairy cows.

LG: Oh yes, mm-hmm [yes].

WW: They would milk, and he would take it and sell the milk.

MF: Do you remember where he would sell the milk?

LG: $\quad$ Right there in Buda.

MF: Okay, to mostly white families? [Yes.]

WW: Actually, they were not white families. I don't know what you would call it, but he would take the milk and sell it to the-

LG: The creamery.

MF: Oh, got you. Okay, I see. Did you have to do any work out on that farm?

LG: $\quad$ Yes I did! [Laughter]

MF: What do you remember about that?

LG: Well, I had to do a little of everything. We chopped cotton, corn, we had a big garden, we raised, you know, all of our vegetables. We did a little of everything. But I had to milk, too.

MF: You had to milk?

LG: Milk in the mornings and at nights.

MF: How old where you when you remember having to start working on that farm?

LG: Well, I guess I was about seven years old, something like that.

MF: Quite young. And everybody had to pitch in?

LG: Oh yes. I'm next to the baby, so, you know, there was a lot of help that was older than me.

MF: Do you think you got preferable treatment from your parents because you were the youngest?

LG: No, I wasn't the youngest; I'm next to the baby.

MF: Well, close, though. [Yes.] Right, and your mother, do you remember the kinds of work she did around the house? Did she make your clothes, for example?

LG: Yes, she did. She made our clothes.

MF: $\quad$ Pretty much everything? [Yes.] Did she do any quilting?

LG: Oh, yes, we quilted.

MF: What other kinds of things were the women responsible for around the house?

LG: $\quad$ Cooking, and washing, and just fixing our meals on time. 
MF: What do you remember helping your mother with?

LG: With, well, when I was little I would bring in the chips for wood.

MF: The chips?

LG: Yeah, you know how they would cut wood and make those little chips? So we had to do that for our stove. We had a wood stove, and those chips started the wood, you know, burning and all. I learned how to do that at an early age.

MF: Where did you get your fresh water?

LG: Well, on the house we had, it was called a cistern. A well with a concrete bottom and sides, and then we had to run a water pipe to the cistern, and that was our drinking water. And we had another well out in the field where the cattle drink from and all. So we grazed cows on the road, and brought them back in and let them drink water and then we [inaudible]. [Chuckle]

MF: Now, you had mentioned that your family did not have to work on other peoples' land growing up. [No.] So you were able, your family was basically able to make a living, just working on your own land. [Oh, yes.] Was that true for the other families that lived in the Prairie?

LG: $\quad$ No, it wasn't many people that were able to do what we did.

WW: They were more or less self-contained there. Her father could possibly do everything. So my mother always said to me, and my mother is her sister-

MF: Could you say your name?

WW: Wanda Washington.

MF: And could you mention what your mother's name was?

WW: Fannie Williams was her sister. I think she was very proud, and I can understand why, and she said "we were never a poor family." We were never a poor family. They had seventeen acres. He could do everything. He could even shoe horses for the, for the people there.

MF: Oh, okay, I was going to ask if there were other things he did besides farming.

WW: Farming, the dairy was big, you know, and he was shoeing horses for the other people. What else did he do?

LG: $\quad$ The other people around, they were white. They would bring their horses over to get them shoed there. There was a blacksmith's shop—that's what my daddy would call it.

MF: He had a blacksmith's shop right there on the property?

LG: Oh, yes.

WW: On the land.

MF: Oh, okay. So what's happened to that land, that seventeen acres? 
WW: They eventually sold it over the years. I think they sold it in 1996, they sold it two weeks after-we were talking about that at breakfast— two weeks after my mother passed away.

MF: $\quad$ Oh, so they held on to that seventeen acres for all that time? [Yes.]

LG: Well, we had a little house after, my mother and father weren't able to be on the farm anymore, well, then we had this little house and they moved in there.

MF: $\quad$ So your parents stayed there til they passed away?

LG: Yeah, in the little house, mm-hmm [yes].

MF: Now what happened to the community out at the Prairie? Did eventually people leave and just not come back?

WW: There are still people who live on the Prairie, because when you said "Janet," they're still living on the Prairie. They're not related to us. We don't have any relatives, do we, living on the Prairie? [No.] No, but there are still people—actually, she grew up with me, I know one of the girls that still lives out there [***Geneva]. But relatives, no, we don't have any relatives that live on the Prairie.

MF: That was considered an African-American community right? [Right.] But a small one, a smaller one than in Buda, would you say?

WW: When you say in Buda, do you mean downtown-?

MF: The Black Colony, where the Harpers and all those folks lived.

WW: Well, you know what, I'm not that familiar with the colony because—did any of our people live in the colony?

LG: Yeah, Grandma Emma Bunton.

WW: Buntons, they lived there.

LG: $\quad$ Aunt Kate.

MF: I saw where her house was, actually.

WW: Okay, well, that's the colony, and you all were living on the Prairie.

LG: You saw whose house? Emma Bunton?

MF: Katie's house.

LG: Katie's house, yes.

MF: Well, it's collapsed now, but LeeDell Bunton owns that property, so I've been out there a few times and looked around because we might be doing some archeology out there, hopefully. How are you related to Katie Bunton?

LG: Well, my grandmother, Emma Bunton, and Katie Bunton were sisters.

MF: Okay, that's what I thought, but I just wanted to hear you say that. 
LG: My grandmother Emma had a house in Buda town, just across the railroad tracks, and she worked there. And when she lived there for a while, she asked the man that owned the house to sell it to her, and he sold it to her. She paid for it, and he said, "Emma, if I had known you was going to pay for this house, I wouldn't have sold it to you." But he was a really nice guy. But he wouldn't say it in a mean way; it was nice, he was good to my grandmother.

MF: I had mentioned to you both that Emma Bunton comes up in a 1930 census record living in Austin. [Yes.] I want to say on East Seventh or East Eight street; East Seventh, I think. Does that ring a bell to you [yes], that she lived in Austin for some time?

LG: Yes, and then she passed away when she was on Seventeenth street.

MF: I said she was living at the time with her mother, Eliza? Oh well, I might not have mentioned that, but on the census record it shows her living with-

LG: Oh, was she a Harper, Eliza?

MF: I think she might have been a Friend.

LG: Okay. Well, that was Emma Bunton's brother.

MF: Oh, okay, the Friend? I could be wrong. There is an Eliza living there with Emma and then there is a Mary Davis Williams. Now does that name at all strike a bell? Mary Williams Davis, excuse me Mary Williams Davis, who is listed as Emma Bunton's cousin, actually.

WW: Lillie, when she mentioned Friend, you didn't think that, you're talking about friend as in friend in a relationship, like you're my friend, or did you think of the last name-

MF: $\quad$ Last name, last name.

LG: That's, that's grandma's last name, Emma Bunton.

MF: Her maiden name was Friend, right? [Yes.] All right, exactly, so that's why it must have been her-

WW: Katie Friend. Yes, okay, got it. [Right.]

LG: And her brother was named—what did you tell me a while ago?

MF: Well, I don't know about the brother's name, I can't remember. It was Emma Bunton living there, and I believe with her mother who was widowed at the time, and then Mary Williams Davis, who's listed as a cousin.

LG: Well, was she living there?

MF: Well, she was widowed also, so looks like you had a house of women who didn't have husbands, who were widowed. Did that name strike a bell to you? Mary Williams?

LG: Well, that sounds like they were cousins. That was Louis Anderson's stepmother.

MF: We have not been able to find any information about her.

WW: You know, I was writing this so I could ask Beulah. Okay, Mary who? 
MF: Mary Williams Davis. I'm going to stop the tape for a second.

[Interview pauses.]

MF: Okay, so we are continuing with the interview. I was just about to start asking Mrs. Grant about the house that you grew up in, and what you remember about that house. How many rooms did it have?

LG: It had four rooms, but they were large rooms. And when we were growing up, we had two beds in each room, with a three-bedroom house with a large kitchen and a long table. We could all sit down at the table and eat at the same time. We had-on each end we had chairs on each end, and benches on each side, so we could fit in there real good. My mother had a large stove to cook on, and the stove had a reservoir on the back of it where you kept hot water, you know, just like a tea kettle. That's what that was for. We had a big pantry with food in it like potatoes and things like that and onions. It was cool. You know, the houses were built up off the ground and it made the vegetables cool; we put our potatoes underneath there.

MF: Underneath the floor?

LG: Yes, because the house was built up high, where you could go under there and it'd stay cool.

MF: Oh, okay, so it was like a root cellar.

LG: Yes, and then the house, we didn't have air-conditioning or anything like that. They built houses then with windows, and they made the house where the breezes would go through the house and keep the house cool. We had a large front porch, and we had a swing on each end of the porch, and we were able to sit out there and swing and play and do what you want to do there.

MF: Did you have electricity?

LG: No, we had lamps.

MF: Do you remember when you had electricity in the house, when it finally came to your house?

LG: Well, it was, I guess it was about-I wasn't home when we got electricity.

MF: You had already left by then?

LG: Yeah, mm-hmm [yes].

MF: And what about running water? You said you had a cistern, so I guess you didn't have running water.

LG: No, no.

MF: Did you have an outhouse?

LG: Yes we had two. [Laughter]

MF: I guess with that many kids!

LG: Well, one for the boys, and one for the girls. 
MF: Oh, okay, out back?

LG: Out back and further apart-you know, they weren't together. They were kept nice, and the boys took care of theirs.

MF: What kinds of chores do you remember doing outside? Did your mom do the laundry outside?

LG: Yeah, we had two wash pots and three tubs to wash in. We had one for washing the clothes and then two for rinsing. And in the meantime she would put white clothes in the-what do you call it? In the, uh-

WW: In the pot to boil?

LG: Yes, what's that called?

WW: Boiling pot.

LG: Well, anyway-

MF: Like in a big cast-iron pot?

LG: Yeah, I got one out here in the back yard. I can't recall the name of it.

WW: Is that the one you had growing up?

LG: Yes.

MF: Oh, I'll take a picture of you by that pot if that's okay.

LG: Okay.

MF: That would be a nice picture. What kinds of other things do you remember that your family would do outside?

LG: Play ball. And my brothers liked to go hunting, and my father.

MF: Hunting — can you tell me a little bit about what they brought back from their hunts?

LG: Rabbits, and birds.

MF: How about squirrels?

LG: We didn't have many squirrels on the Prairie.

MF: Raccoons?

LG: No, I don’t remember seeing any raccoons.

WW: Possums.

LG: Possums, mm-hmm [yes].

MF: Did they bring back possums, then? 
LG: No, we didn't eat possum. [Laughter]

MF: Not that I can blame you.

LG: We had plenty of chickens.

MF: And would your father slaughter a pig from time to time?

LG: $\quad$ Oh yes, a lot of times. And I'll tell you how we would kill hogs. We didn't have any place to preserve them, you know, except a smokehouse, and stuff like that. But we would share with other people. When a family would kill this time, and then the next time the other person would kill and divide the meats.

MF: Okay, so people shared a lot out on the Prairie, the families did?

LG: Well, some of us, you know, shared more than others according to who wanted to help.

MF: Let me go back to the house that you lived in. You said it was on piers, or it was raised up. [Yes.] So it was on wooden piers?

LG: Yes, that's right. And we played there, the small ones played under the house, because it was cool enough.

MF: Oh, could you sit up, underneath the house? Was there enough room for that? [Yes.] Oh wow, I would have been scared.

LG: Well, it was cool, you know, because we didn't have air-conditioning. You know, on hot days we played underneath the house.

MF: I see, I see. Do you remember any of the neighbors' kids you that would play with, besides your brothers and sisters?

LG: Yes, Minnie Kay Underwood, Mabel Anderson—she was a Searcy at that time. Those were my friends that were my age.

MF: What kinds of games did kids play, besides, you mentioned ball?

LG: Well, the girls, my daddy would make dolls, dancing dolls, and they were on a pole, and we would shake the pole, and the doll would dance on the end of it.

MF: Your father made those for you?

LG: Yes, mm-hmm [yes]. He was a good—he could do mostly any kind of carpentry work.

MF: Do you know if he built the house that you lived in?

LG: Well, he didn't build it; I guess he helped build it. And the small house they moved into he practically built that; it was a three-bedroom house.

MF: So the family house that you grew up in is not the house that your parents ended up retiring in; they built another new house for themselves afterwards.

LG: Yes, that's right. 
MF: $\quad$ So you mentioned that by the time you came along, your older brothers and sisters had left the house.

LG: $\quad$ Yes, they were able to help with the younger ones, you know.

MF: How many people at one time lived in that house, that you can remember?

LG: $\quad$ Lived in the house?

MF: Lived in the house with you. What's the highest number of brothers and sisters that you had living in the house with you that you can remember?

LG: I guess it was like ten.

MF: Okay, so there were ten of you, plus your mom and your dad?

LG: Yes. The others were grown.

MF: And you said you had three bedrooms or four bedrooms?

LG: Well, there were three bedrooms, I guess, and then the kitchen.

WW: You mean the first house? The first house was four big bedrooms.

LG: Was it four?

WW: Yeah, the small house had three.

LG: Yes, that's right.

WW: Because I remember going to the first house.

MF: How long was that standing for, the big house?

WW: I remember when I was about eight or nine years old going to the big house, because there were about four of us. I'll show her that dress. There were about four or five of us who slept in this big bed, and my grandmother made britches quilts [Mrs. Grant laughs], heavy quilts. And we'd all sleep in the bed. But the quilt was so heavy, we would say turn and everybody would turn. So I must have been about eight or nine years old when I remember the big house.

MF: Okay, so that would have been how long ago then?

WW: I'm seventy-six so—sixty-eight years. A long time.

MF: What happened to that house? Was it dismantled?

LG: No, another family moved in it, and shortly after they moved in there, it got burnt down.

WW: Then Grandpa built another one, didn't he?

LG: Yeah, that was the little house. 
WW: That was the little house that-oh, wait a minute. You know the little house that Bobby Jean stayed with Grandma and Grandpa; that was not the little house?

LG: No, that's the big house there. But see, the Abrams moved in it after Mama and them moved out.

WW: So there were three houses they stayed in. [Yeah.] There was the big house I remember when I was a little girl, when Marrietta was still at home. [Yes.] Okay, that was the big house with the four big bedrooms, a big house.

LG: Yeah, that's the big house.

WW: And after that they moved to another house.

LG: Yeah, well that one was just called the little house.

WW: The little house. So is that the house that was sold in '96? [Yes.] The little house?

LG: I guess so. Yeah, it must have been.

MF: But then nobody lived there but grandpa, grandma, and Bobby.

LG: $\quad$ Bobby stayed with them in the big house.

WW: In the big house, too. Okay, but in the little house it was only grandpa and grandma. [That's right, yes.] So then all of the children moved out of the big house then, and none of you were in the little house? [No.]

MF: Can I ask you, how old were you when you left home?

LG: Oh Jesus! [chuckles] I was seventeen.

MF: What did you do when you left home?

LG: I married.

MF: Who did you marry?

LG: Albert Junior Smith.

MF: Albert Junior Smith. And where did you move to with him?

LG: Well, when we got married we stayed with my mother-in-law and father-in-law in Buda. About a year there.

MF: Do you remember the names of your mother-in-law and father-in-law?

LG: Yes, Alma Smith was the mother, and Albert Smith was the father.

MF: Okay, and were they farmers out there as well?

LG: Yeah, they had a small farm.

MF: Okay, so how did you meet your husband? 
LG: Well, going to school.

MF: So you've known him since he was a child? [Yes.] Okay. So what was courtship like back then? [Laughter]

LG: I guess it was fun. We enjoyed it.

MF: I mean did young people date? [Yes.] How old were you when you were allowed to start seeing a young man?

LG: I guess I was about sixteen.

MF: Sixteen, okay. So you dated for about a year before he asked you to marry him? [Yes.] How old were you when you had your first child?

LG: Well, I didn't have any children.

MF: You didn't have any children? [No.] Okay. What did your husband do for a living?

LG: Well, he worked on a farm, and then came to Austin and got a job at Crown's Candy factory, and made candy.

MF: So you moved out here with him to Austin then, when he got that job. [Yes.] How old were you when you moved to Austin?

LG: I was about nineteen, I guess.

MF: Let me ask you also about growing up. Was it your mother who taught you about the proper roles about being a young woman? [Oh, yes.] What kinds of things did she tell you?

LG: Well, she would tell me how to dress, and she taught me how to sew, I learned how to sew under her.

MF: Did she have a sewing machine?

LG: Oh, yes, she had a sewing machine.

MF: What kinds of other lessons did your mother teach you?

LG: How to cook.

MF: And in terms of like, respect to your elders and things like that, who in your family taught you those things?

LG: $\quad$ My mother.

MF: It sounds like your mother was your main role model.

LG: Yes, she was.

MF: Was that true for all of your brothers and sisters?

LG: Yes, it was. We all got along; we were a happy family. 
MF: What else can you tell me about your mother? What do you remember the most about her?

LG: Well, helping me, teaching me how to sew, and-and I just think about her a lot. I learned how to make Dutch-doll quilts and tops. I didn't ever quilt them for anybody, but I would make them and give them to my sisters.

WW: She can show you those. She can take a photograph of a quilt that you made.

MF: Oh I'd love to do that. Your father, what do you remember about your father?

LG: Well, I worked in a field. I never did like fieldwork. I liked staying in the house and cooking and helping my mother. But I didn't like chopping cotton and pulling corn and stuff like that.

MF: Did you grow a lot of cotton out on that farm?

LG: Yes, we did, pick cotton, mm-hmm [yes].

MF: Carrying that heavy sack around, right? Right. Your father, did he have a big hand in raising the kids, or was it mostly your mother that did that?

LG: $\quad$ Both of them.

MF: Both of them did, okay. And what do you remember your father doing with the children in terms of raising them?

LG: Well, he taught us how to do everything. There were more girls than there were boys, so we had to work in the field, too, like they did.

MF: Did he make a difference between the girls and the boys? Did the boys have to do certain kinds of chores and the girls had to do certain types of chores?

LG: No, we would work together.

WW: But what she told me was that the dad was more lenient with them than the mother; the mother was more strict and would spank them. But they could get away with even cursing sometimes with the dad, and the daddy would just laugh at them. There were some stories that she told about the boys, and how mischievous they were and how they [laughter] operated on the hog and all that. All he did was sew the hog up, and he didn't even spank them, things like that.

MF: Operated on the hog? [Laughter]

WW: He bought them a knife.

LG: Little bitty knives, I got them in there.

WW: You still have the knife?

LG: He bought them little pearl-handled knives about this long from town and he gave it to them. He didn't have to buy me anything. I followed the boys. [Chuckles] When my baby sister was born, my mother said, "go play with the boys," and see, they were a year older than me, and I had to play with the boys. When my sister came down, she had a little girl, and still, see, I didn't have anybody, and I'll just go play with the boys. So I played with Oscar and Arthur, 
and when my sister brought her little boy down here, he was my brother, too, so, his name was Lonnie Albert, so I had another boy to play with. [Chuckles]

MF: They got you into a lot of trouble?

LG: No. Well, about the pigs, well, when my daddy bought the knives, one of the brothers said, "Lets go operate on the pig." So the other one said, "Okay!" And I was with them. I went and sat on the fence, you know, the hog pen is wood, and I sat on the fence and watched them cut the little pig's stomach, the intestine came out a little bit and I said, "Come on, lets go up and tell my daddy that we operated on the pig." So my daddy said, "Oh my goodness!" he said, "Come down and show me which one you operated on." So we got out and that little pig's intestine was coming out a little bit. And my daddy told one of the boys to go tell mother to give him a needle and thread so he stitched back that pig.

MF: $\quad$ The pig lived?

LG: Yes. [Chuckles] Then my mother had some chickens, little chickens, you know, how they clutter together. In the wintertime they were all together and we thought they were going to die, I'm still sitting on the fence, following them around, playing with them. And they said, "Let's bury these chickens for mama." So they got the chickens and one of my brothers prayed for the chickens and the other one preached, and I sung "Nearer My God To Thee"! [Laughs]

MF: You dug a hole and tell me you didn't bury those chickens!

LG: $\quad$ Yes they did, but it wasn't deep enough to kill them. [Laughter] So I said, "Let's go tell mama we buried the chickens for her." So I'm still following them around, and I didn't have to say anything or do anything, I just watched it. They went up there and said, "Mama, we buried the chickens for you." And she said, "Where did you bury them?" And he said, "Come on." So they showed her where they buried the chickens, and the chicken's head was coming out [laughter]. And we didn't get whoopings for that, but it was pretty funny.

MF: At least they were still alive.

LG: So when they tell us not to do something, we knew better than to do it the next time.

MF: What kind of punishment did you get if you got into trouble?

LG: We would get spankings for it.

MF: I heard tell from other people that the whole community kind of watched each others' kids [yes], and if a neighbor saw you doing something bad, you might even get a spanking from them.

LG: Yes that's right, and then when you get home you get another one.

MF: Now the church, can you tell me a little bit about how important the church was to the community? You went to Center Union?

LG: Center Union, yes, but it was moved from over in the colony on the Prairie, next to the school.

MF: Were your parents both pretty religious people?

LG: Yes, they were. 
MF: What did they teach you about your faith or the importance of church?

LG: Well, at the Sunday school, we were taught to love and to share, you know, and all. That's how we came up, you know.

MF: Was everybody a member of the church who lived out in the Prairie?

LG: $\quad$ Yes, all of us. Yes, all of us were.

MF: Did the church do other things for the community besides have services, and that was once a week on Sundays, I take it?

LG: Yes mm-hmm. Well, we had a service that would have box dinners, and we would sell each others' lunch boxes, and that's where they made money for the church. I don't really know how to put it, but in a way we would sort of trade boxes, you know, you eat somebody else's food.

MF: I see. And you would give a donation for that? [Yes.] And on Easter, and on Christmas did the church do things?

LG: $\quad$ Yes, we had Easter programs and Christmas, and we all had, you know.

MF: Do you remember anything about the church building? You said it moved. Is it still standing, though, the building that the services were held in? [No.] It's long gone.

LG: The church, right there where it is now, the school was right next to it.

MF: The next question I wanted to ask you about was the people you were related to in the Colony, in Antioch Colony or in Manchaca and whatnot, because it sounds like you had relations among these various folks. Now, you were related to the Buntons over in Buda? [Yes.]

WW: Well, [*my] mother was a Bunton.

MF: Right, your mother was a Bunton, so and then Emma Bunton, was your mother? [Note: Emma was Washington's great-grandmother, and Ola's mother.] No your mother's sister, excuse me, Ola's sister. You were related to the Smiths by marriage, over in Antioch. Are there other families in Antioch who you're related to by marriage or by kinship?

LG: $\quad$ Mary Anderson was my mother's cousin.

MF: Mary Anderson. I'm trying to think, is that any relation to Nell Anderson?

LG: Yes, that was Cousin Mary's son.

WW: Louis Anderson. Yeah, she said, Nell Anderson.

LG: Nell Anderson was a Harper, and she married Cousin Mary's—that was Mary Anderson, that was my mother's cousin.

MF: Are there other names in Buda who you can think of that you might be related to?

LG: Audrey Bunton, that was Aunt Kate's granddaughter. You probably have her. 
MF: LeeDell does on his family tree. [Yes.]

LG: She's the only one living there in Buda that's my cousin.

MF: Mrs. Washington, you had mentioned that you were related somehow to Robbie Overton, by marriage, was it?

WW: Yes, but that's on my dad's side.

MF: Okay, can you tell me how that-?

WW: I really don't know. I just know that we were talking about that not too long ago, that my grandmother, who was Lanie Williams, her maiden name was Madearis, and she was related to the Overtons but I don't know how. I really don't. We don't have that many relatives on my dad's side; it was a small family. But I know that she was related to the Overtons because she would come from Buda to Austin and stay with her son [Note: Maurice], and then she would visit [*her cousins] the Overtons. [*I think she also visited her cousins the Doyle and Hurst families.]

LG: $\quad$ Mary Jane Doyle.

WW: They were from Manchaca.

LG: Yeah, she was a Dotson or something.

WW: A Dotson.

MF: That's right.

WW: Robbie was a Dotson, Robbie Dotson Overton. But I really don't know about that. Now my Aunt Beulah might be able to tell you more about that than I.

MF: The reason I'm asking these questions about people who you might be related to is because one of the things that I have been interested in is how African American communities were related to one another, and what the marriage patterns were, because we know that folks weren't isolated into these little colonies but they had kinship relationships, and oftentimes they took partners from outside these communities as well. So that's why I was asking about who you might be related to.

WW: Yeah, when you hear us naming these people, then it sort of comes together.

MF: $\quad$ Oh, yeah. I mean someone will mention something and it will be a name that came up with another person that they had never even met before who was related to that same person, so that's why I was asking who you were related to. Now Lawrence Williams was your brother. Where did the Williams name come from?

WW: It's my grandfather, my dad's father was a Williams.

MF: Where did that family originate from, do you know?

WW: I really don't know. Again, Beulah might be able to tell you that. If you hear me calling them by their first names and they're my aunt, like I said Lillie, that's because we grew up around them and we were not that much younger than they were, so we would call them by their first names. So half of my mother's siblings, the older half we called aunt [*and uncle], 
the younger half, because we were around them, we called them by their first names. Now, Beulah is ninety-two years old. I call her Beulah; she's my aunt. And that's because she and my uncle did not want us to call them uncle and aunt. They still wanted to be young, so we called them Beulah and "Reesy" [*Maurice], and that's why we called them those. And some of her sisters we called by their first name: Marrietta, Lola, you know, that's because they were the younger ones and we grew up around them. So that's why we don't call them aunt, we call them by their first name. Your question was?

MF: I had asked you originally where the Williams name come in?

WW: The Williams name came in because [*that was my grandfather's last name.]

MF: What was his first name?

LG: $\quad$ Emmett.

WW: Emmett Williams, and her name was Lanie Madearis Williams. My dad was Imogene Williams (it's a girl's name, but they wanted a girl even though he was a boy), and Maurice Williams [*was his brother]. But Beulah is more able to tell you about the Williams side than I am.

MF: I was just curious, I mean Williams is a very popular name, and I understand that it probably has nothing to do with the people who we are researching.

WW: It may not, and maybe Beulah knows, but I don't.

MF: $\quad$ Right, but it was just something that I wanted to follow through and make sure I at least knew, since I came across a Lawrence Williams.

WW: I want to say they were from Oklahoma also, but I'm not too sure. Beulah will have to tell you that.

MF: Besides the Overton connection potentially, I know you said you weren't sure how, were there other names that come to mind of folks who lived in Manchaca? Or Kincheonville, which is further?

WW: Well, Kincheon, the Kincheons were related to my grandmother [*Note: Lanie Madearis Williams]. T. W. Kincheon and his son died not too long ago, and I don't know how, I really don't. Like I said, I don't know that much about the Williams.

MF: Now where was your grandmother born?

WW: Where was Big Mama born? I don’t know. Beulah would know. Wait a minute, somewhere, Onion Creek? Does that sound right?

LG: Yeah, yeah.

MF: What's out there? There is Buda, Onion Creek, Kyle, San Marcos-

MF: Onion Creek would make sense. There were a lot of Kincheons that were out there, in that area.

WW: Well, I know she was related to the Kincheons. 
MF: That's another connection that I've seen too.

WW: I don't know.

LG: What about Manchaca?

WW: All I know about Manchaca is Johnnie Mae [*, Coleman Overton's family, the Hargises,] and the Howards.

MF: Howards; how were you related to the Howards?

WW: Her sister was married to a Howard. [*My aunt, Gladys Grant, married Jesse Howard.]

MF: Was it Jesse?

LG: Yes.

WW: That was her brother-in-law. [Doorbell rings] I'll get it, Lillie. Johnnie Mae's mother, what was her name? Stella Black, what was Stella's name? [Note: Estelle Hargis Black; Mrs. Black was interviewed for this project also.] She went to school with mother. They were from Manchaca.

MF: Let me ask you, you started off school at Antioch School. [Yes.] Then did you go to junior high school after that?

LG: Yes, but what happened was my daddy took us out of school because the principal there closed down our school, I believe, and then we had to go to another school which was in the Colony, and that was too far for us. So he had us, he rented a house in Austin, and my second oldest sister $\left[{ }^{*}\right.$ Cora] took care of us while we were in school.

MF: That's a pretty big sacrifice for him to make, I mean to get a house in Austin to ensure that you got an education.

LG: $\quad$ Yes. I was telling her about Cora, and my daddy renting this house.

WW: There were about ten of you-how many did you say were there? I think you were telling me about that the other day and you said there were ten.

LG: Okay, so I said ten?

WW: Okay, so there were sixteen, and one died. Okay, so there were about five who were older and had moved out. There were ten who he moved to Austin with Aunt Cora. The one in the picture right there.

LG: That's my sister.

WW: That was the sister who was over in the house in Austin so that they could go to school.

MF: So you went to Kealing, I take it?

LG: I started there, then we moved back down here the next couple of years, and they built this other school that was across the creek there, going over in the colony. That's when we came back, back from Austin back to school. My daddy, seeing that we had, you know, a school to go to. 
MF: So you went from elementary school in the Antioch School, the little wooden schoolhouse they had over there that they had on, I think, on Old Black Colony Road? Does that make sense?

LG: No, that was a rock house.

WW: Rock school.

LG: But this other one got torn down before they moved it over there. That's when we came back, so Lewis and Lawrence [*twin brothers to Washington] I think started there at one time.

WW: See? That's what-now they would remember. I have to ask them. They went to school with Oscar and Arthur [*Grant's twin brothers]. That's her brothers, the youngest ones, my brothers.

LG: They were twins.

WW: My twin brothers. And I just went with them, but I was not in school. I was too young, but Mother sent me with them. But the school that I remember is not that rock school. The one that I told you I remember was the frame school.

MF: The one out in Antioch?

WW: Yeah, and I keep telling her that the one I remember is the one across the creek, and next to the Methodist Church. I'm not too sure. My brother, I can ask my brother.

MF: [Flipping through paper] I think I might have a picture of that.

WW: Probably wouldn't remember that.

MF: Well, I mean just the location.

WW: I did not know-Mother went to Anderson, so I did not know that you all moved back. She went to Kealing and she went to Anderson.

MF: Yeah, that's what most people tell me.

WW: Yeah, so I don't know when you all moved back to [*Buda].

LG: Well, the younger ones came back.

WW: Oh, okay, well then maybe-okay, so they lived in Austin when Grandpa rented the house in Austin, sent Aunt Cora and you all. Okay, well then Mother finished Kealing, and she went to Anderson. So then you all were much younger, so maybe that's why he moved you all back to Buda.

LG: Yeah, after the rock house was built.

MF: After the rock school was built, and that must be this school here then, see where the cemetery is? Does that make sense?

WW: Yes, yes, see that's the one I remember. I don't remember the school that was next door to Center Union. Beulah told us about that, one of my other aunts. She can tell you more about that. 
MF: This is from 1958, the map.

LG: Yeah, that's about right.

MF: So that school would have still been there in 1958.

WW: Yeah, that's the one that I remember. I don't remember the other one.

MF: Yeah, that's the one that most people seem to—did your parents go to school?

LG: Yes, they did.

MF: Did they go to the one in Antioch?

LG: No, they went- they went, no.

MF: Okay, do you remember where they went to school, where they were educated?

LG: I guess in Buda, but I don't know, you know.

WW: You don't know the school.

LG: Unh-uh [no]. The other school was next to the Methodist. It was a two-story.

WW: Yeah, but we are talking about grandpa and grandma.

LG: But I don't know what school they went to; I can only say what church they had over there.

WW: What church was that, the Methodist church?

LG: The Methodist church, and probably the school next to it.

MF: That was Antioch.

WW: That's the one I remember. So you think it was there, and grandpa and grandma also attended that school?

LG: Probably did.

MF: They probably had to.

LG: Because it was before my time. [Agreement]

MF: It had to have been; that was the only school there for blacks in that area.

WW: Yes, it had to be that.

MF: Yes, because they could both read and write, right?

LG: And it was a two-story like, something like that. Well, that's it.

MF: $\quad$ Mm-hmm [yes], I have seen a picture of it from 1921 with kids standing outside. 
WW: Because my grandmother, the one I'm calling Big Mama, she went to the last grade and was able to teach, she told us. So she went to the ninth grade in school. So apparently it was that school.

MF: People told me that if you went to like eighth or ninth grade and if you wanted to go further, you'd have to go to Austin to get your education. That you had to-

WW: Yeah, but I know at ninth grade, I guess being black, then you could teach the other kids. She was the midwife, too.

MF: Beulah?

WW: My grandmother was; she delivered.

MF: Oh your grandmother, are you talking about this grandmother?

WW: No, I'm talking about on the Williams side.

MF: What was her name again?

WW: Lanie. L-a-n-i-e Williams.

MF: And what was her maiden name?

WW: Madearis.

MF: And she was a midwife also. [Yes.]

LG: Well, my grandmother Bunton was a midwife.

WW: Oh, she was, which one?

LG: Both of them-Aunt Kate and Grandma Bunton. Aunt Kate was.

WW: Who was the doctor that attended your birth?

LG: Dr. Holsclaw. There were two doctors here in Buda at that time.

MF: That must have been somewhat rare, though, for a doctor to-well, were you a twin?

LG: No, that was my sisters Lorene [*and Laurine]. There were a set of girls, and then a set of boys.

MF: Were all your parents' kids born with doctors in attendance, or did most of them-

LG: No, I don't know if it was from Marrietta down or something like that.

MF: I was going to say that was probably rare for back then.

WW: It was, but then their family was rare [chuckles]. Because of my grandfather, and the property and everything that he could do, and he just didn't take no for an answer from-

LG: Anybody. 
WW: -Caucasians. And in fact, Lillie was just telling me the other day that they came to have him sign something, and he refused to sign, and they followed him from one end of the-what did they want him to sign, Lillie?

LG: Something concerning the school.

WW: Oh, they were upset when he took you all out of school, and then they wanted him to sign something.

LG: $\quad$ I guess he filed charges on them, the guy for doing that, closing the school down. It was too far for us to walk, and he took us out and put us in school in Austin.

MF: Okay, and that's when you moved to Cora's house, your sister's house. [Note: The house was not Cora's, but she ran the house and household.] [Yes.] Did your parents talk much about the kind of racism that they had to face?

LG: Well, yes, but my father could always take care of it. [Chuckles] They didn't fool with him.

MF: And when you say "take care of it," did they not-

WW: That's what my mother said, they did not—-that's why-My mother said that they did not face discrimination, racism, because of her father, because he didn't need anything from them-they needed something from him.

MF: You must have remembered segregation, also.

LG: Oh, yes.

MF: What do you remember about Austin, when you were going to school there?

LG: Well, it was all right, we went to a colored school there.

MF: From what I have been told is folks in Manchaca and Antioch on the weekends would go into Austin for entertainment, shopping and things like that. Do you remember doing that when you were younger? Going into Austin when you were younger?

LG: Well, I'd go in with my parents. We were too young to go in by ourselves, at our age we went in with them.

MF: Do you remember where African Americans used to gather, in Austin?

LG: $\quad$ On Sixth Street.

MF: [Laughter] That's the staple answer, but I have to ask!

WW: I remember that. I lived through Jim Crow in Austin. [Laughter]

MF: Right. And where would you go? People have mentioned the Ritz Theatre, different kinds of restaurants.

WW: Upstairs-we couldn't go downstairs.

LG: Chinaman's Restaurant. 
MF: Yeah! That's the other one that people mentioned! Chinaman's Restaurant, right.

WW: What?

LG: Chinaman's Restaurant.

WW: Really? I never heard of that.

MF: Robbie mentioned that to me.

WW: Oh, really?

MF: Yeah, she did. Going in there and having something to eat. So that was a pretty big deal for people to go in, people would get dressed up and go to Sixth Street, wouldn't they?

LG: My father would bring us to town, and park his car and let us go in Chinaman's and eat, and shop around.

MF: What else do you remember about Sixth Street back then?

LG: $\quad$ No more than, you know, going there on Sixth. Well, we went to Levine's, and that's where my father bought our clothes there.

MF: That's another store people have mentioned before is Levine's. I had asked people this question, but it seems like these businesses were white owned but they had black workers there, and it was understood that these were places where blacks could congregate and come in. Is that what you pretty much remember as well? [Yes.] In the school, even though it was a black school, do you remember being pretty happy there as a student and getting the education that you felt you needed?

LG: Yes, mm-hmm [yes].

MF: What do you remember about the teachers there?

LG: Well, they were nice. I had to learn to mix with the other children when I wasn't used to one class being so large.

MF: Right, because the school you went to was much smaller.

LG: Yes, and then there we would have different grades, and she would have classes instead of a group like I did when I came to Austin.

MF: Was this Kealing, Kealing Middle School, or was this Anderson?

LG: I started at Blackshear [*Elementary].

MF: Oh, Blackshear. So you were really young when you came out here [to Austin]. Did you finish up at Blackshear-?

LG: No.

MF: No, so you had to return to Austin before you finished?

LG: $\quad$ Yes, I did. 
WW: When did you go to Kealing?

LG: I didn't go to Kealing. I came back to Buda.

WW: Oh, okay. I thought you went to Kealing.

MF: The other questions I wanted to ask you about were, what do you think were the strengths of the community that you were raised in, out there in the Prairie, or you know, including the Prairie and the colony? The strengths, what were the strengths of the community-the things that made it a good community to be raised in?

LG: Well, I guess Buda, I think, was the best.

MF: What was good about it?

LG: Well, I used to play and going on with my neighbors, you know, children and all like that and of course then work.

WW: Everybody was close, weren't they? The neighbors and all, and then you had a lot of activities that included the neighbors. You remember the birthday parties? This is what I remember, the birthday parties; you celebrated a birthday by waiting late at night. I remember they were celebrating my grandfather's birthday and it was late at night, it might have been about ten o'clock, and everybody was aware of the fact that they were celebrating his birthday. What they would do was congregate at the house, but they would make noise before they got there. And then once they got there, then the ladies would bring in cake and ice cream that they had made and then celebrate his birthday. Now that's what I remember when I was a little girl. I was not living there, I lived in Austin, but we would go out to celebrate the birthdays. You remember that, Lillie? Maybe it didn't happen when you were little.

LG: No, I don't think it happened, unh-uh [no]. Could have and I just don't remember.

WW: I remember being very, very young, like about four or five years old.

MF: Do you remember Juneteenth? Did you celebrate Juneteenth? [Yes.] From when you were little?

LG: Yeah, we would always come to Manchaca and celebrate. There was a big park there in Manchaca.

MF: $\quad$ Yeah, Mr. Pickard had mentioned that. That was sort of like the black Fourth of July. [Yes.] And so everybody would come out from the Prairie for that, for the most part?

LG: Yes, I think so.

WW: They played baseball, because I remember my dad and them would play baseball.

MF: You remember it growing up as well?

WW: Yeah, I remember that. I remember going out early. The men would go out early, like my grandfather, would go out early and they built a pit, and they would put a metal thing [*grate] on it, and then they would put the pig on there or the cow or something and they would barbecue it. Then the ladies would come out in the morning and they would have the food. [*Some years later] we would laugh about it, and we said, "Okay, we ate potato salad when it was out in the sun all day long and it didn't make you sick, but now you 
can't do that." But that's what I remember: they played ball and we stayed out there on the Juneteenth all day.

LG: Oh, and they had music.

MF: Would you say that that was the biggest holiday that blacks celebrated?

WW: I would think so. [Me, too.] Because on the Fourth of July they had to work. I remember distinctly that that was the black holiday. On the Fourth of July they were not allowed to be off, they had to work on the Fourth of July.

MF: Do you remember other times when your family or your community came together to celebrate anything? What were the special times? You mentioned birthday parties were a pretty big deal.

WW: There was probably a church activity, wasn't there?

LG: Yeah, just like those dinners I was talking about a while back.

MF: Yeah, where you exchanged the box dinners, right.

WW: And didn't the men get together to play dominos?

LG: Oh yeah, they played dominos.

WW: And they would listen to the fights, Joe Lewis.

MF: Did you have a radio in your house growing up?

LG: $\quad$ Oh yes, a Victrola. At that time we didn't have electricity or anything like that, but we had a Victrola that you wind up.

WW: My cousin has it.

MF: You're joking!

WW: She has it. Lillie had it first and then-[LG: I gave it to her because she was raised at home]. So they have the original one. I'm wondering if she has some of those records.

LG: She said she had, well, she said that-and I have some; I didn't give them all to her, the rest of the records. See, during that time black people wasn't making records then, but now they do. And what we had was cowboy [laughs].

MF: That was the best you could get back then, huh?

LG: That was all you could get! [Laughter]

MF: Some things have changed. [Yes.]

LG: $\quad$ There was a white guy across the field from us, he'd see us and he'd start singing to, "Get along little doggies, get along-"

WW: Would you like some water? 
MF: I'm fine, but maybe your aunt might want to take a break.

LG: No, no thank you.

WW: We have diet pop, would you like diet pop?

MF: I'm fine, thanks, but I'll stop the recording for right now.

[Interview pauses.]

[Part 2]

LG: What are you going to ask me?

MF: Okay, well the question that I was going to ask was why have you agreed to do this oral history in terms of why do you think it is important for people to know about your experiences, and your family's experiences?

LG: I like it because I have started it myself, trying to get-like, there are eight sets of twins in my family, and they are very close. My sister, Lorene, she had a twin sister named Laurine and she passed away at an early age; she was an infant when she passed away. The next year my brothers were born, Oscar and Arthur, and those were the boys I played with. The next year I was born, in '23. Then my baby sister, three years younger than I am, so we were all small together.

MF: $\quad$ Now you've told me a lot about what it was like playing with your brothers, and what life was like out on the farm, and how your father was able to resist a lot of the racist attitudes because of the strength of the person that he was, and so forth. Why do you think that it is important for people to know this history about growing up on the Prairie?

LG: Well, I'd like my nieces and nephews to know something and remember something that has happened at an early age. I think that was the best time of our life, because growing up as children. Well, that's all I can think of right now.

MF: How do you think this history would help your nieces and nephews?

LG: Well, to know how we made it through and how we lived, and how they should live, and maybe life would be better and easier for them than it was for us. But there were good times in our lives. We made it, and they can make it, too, if they try.

WW: We made it under adverse conditions. We had to be strong enough that we could make it; and we did, under adverse conditions, we were able to prevail, and we made it. Then the history should be, this is the history, and everybody should be aware of it. They have not been in the past; there was just very little information about black people and the struggles. So this is history, and it should be known. But it also tells the strength of the black people and how we were able to prevail under these adverse conditions.

MF: What would you like to see done with your oral history? It would be easy enough for me to make copies of it and give you enough for your nieces and nephews and so forth. Is there something else that you can think of-?

WW: No, just having it available for people. You know, just having it available for people who are doing research. Just making it available for people who do not know what the history was 
like. Just available information. I can't see too much that can be done with it other than for people to know that this is information. So what would you [*do with it]?

MF: Well, long term what I would like to see done is that, like you said, but I would probably just add to it so it would be more of a formalized, public education project that could congeal around these oral histories. So for instance, like I said, have some kind of an exhibit. One of the things I was thinking about was the Antioch community has been trying to rebuild their church, and they're close to finishing construction on it. And what I would like to see is a proper archive set up in there with these oral histories housed there, all the information that we have collected on the project about Antioch housed there. And then, maybe, you know, do some kind of online exhibit.

WW: Just to educate the public.

MF: Yeah, and then it could be housed in the heart of the community. There's a public education day-I told you I was an archeologist—at the Society for Historical Archeology Conference, a year and a half from now we're going to have a public education day. There are probably going to be 100, 200 people who go through there who are educators, and schoolchildren and so forth, and I'd like to have this component of the project somehow be a part of that so that people can see these are some of the experiences that African Americans had in this area during Jim Crow. The people who are descendants of ex-slaves. You know, a lot of people don't even realize that Antioch Colony is right outside Austin. I was ignorant of that fact. So I would like to see this become part of that public education day. I'd like to see somehow getting these collections-you know, we wouldn't be able to do all of the transcripts because there is too much, but taking portions of everybody's oral history and condensing them into some kind of a book, not make a profit from, but give out free. To the people who not only contributed the oral histories, but members of your family and then other educators that are around here that might be able to use those oral histories. So I agree with you completely, to have this research accessible, but also to try to help it along and get it out there in different kinds of ways. So that's what I'm thinking of long term. I need input from folks. I don't want to do stuff that people think will not be something that they think is good, in the best interest of the community, that these oral histories are all about. I don't know; there could be disagreements between people about what should be done, but the only way I'm going to find out is to talk to people and to find out about what other people, what you all think.

WW: Have you found anyone who is resistful?

MF: No, not at all. And what's amazing to me is how consistently some of the remarks are as to why they wanted these oral histories to be done. When you said that you wanted your nieces and nephews to know, that's one thing that has come through again and again: I want my grandkids, I want my nieces and nephews, I want these young people to know this history, because it's important and they don't know it, they don't appreciate it enough, they don't know the struggles that this community had to go through to make sure that they had the opportunities they got.

WW: Well, the only way that they would know that it's available to them is for us to tell them. Otherwise are you going to publicize it? Is it going to be somewhere where they would know, "Oh look this is, you know-"

MF: Well, one of the things that I can do-in terms of keeping it within, you know, just the folks who I've been interviewing and their descendants, that will be easy because I can make DVDs of all of this stuff, and those kids will have no excuse not to know that history because I can get everybody's transcripts together, the digital recordings, and say, "Here's a shoe box. 
It's got everything that I've collected on it." You know, old photos if I've scanned any, anything like that. So it will be their responsibility.

WW: Yes, what I'm saying is that we could more or less publicize the fact that it's available, but then how would, let's say, not [universal], but how would it be known that it's available for other people who are not associated with us?

MF: Right, so that's why I think that this Texas Beyond History project would be ideal. Because, if it's online, it's widely accessible. I mean you don't even have to be in this country to get it, right? I mean anybody who is searching African American history in Texas, boom, that website will pop up with the site on there about this project. Getting access to the oral histories won't be a problem because they'll be housed some place public, the university. Anybody who is a researcher who's interested in reading about Antioch can just walk in there and talk to an archivist in there and say, "Hey, I heard that there was this oral history project. How can I get-" And since everything is digitally recorded, it will be easy enough.

WW: Now when can my kids, let's say, go on the website and be able to [*access this]?

MF: What we're trying to do is we have already shot film footage of some of the descendants have come out, LeeDell Bunton was one of them and a few others have come out to the site. I'm taking Robbie out there next month. And so we had a film crew from UT come out, we interviewed them on the site, and they've also been doing video footage of the archeology. We've already started trying to think of how to get an online exhibit together. The thing is we need to raise money to actually have the online exhibit put up. So this is not for profit, but this is something that we have to try to get grant money for in order to pay to have somebody who is an expert on the web and all the rest of that. What we do is we gather everything that needs to go up; they put it all together and then put it up on Texas Beyond History and it would be up there permanently. And so, it might be another six months before we can raise probably about $\$ 10,000$ to get that done. That's what I'm hoping. But that's not the only thing that could be done, but that would be a really good one, because that site is already established, people already know about it. Since it's associated with the University of Texas, it's one of the main things that educators already go to, to find out about Texas history. Right now there's hardly anything on African Americans up there. There is the Texas History Handbook online, I think the other site is called. So that's one of the things that needs to be done for sure. The other thing is, I teach courses on African American history and archeology at UT, and I would love to use some of this oral history project for my students to look at and write papers on, or do things like that. I think it would be a very educational thing for students as well.

WW: Have you found any other colonies?

MF: There has been a lot, oh yeah, freedmen colonies? Yeah, I worked in one in Dallas. Dallas, people don't realize-

WW: No, I mean in the Austin area.

MF: Well, Clarksville, Kincheonville, there are various places-Manchaca, Onion Creek areathere are various places where ex-slaves came to settle black enclaves. As a matter of fact, there is a book that just came out on freedmen colonies in this area written by a historian. Now I haven't gotten it yet, and I don't know if she did anything on Antioch. Her book is titled Austin, so she might not have gone as far as Buda. But Antioch Colony is mentioned in a book that I picked up on Texas freedmen colonies. I don't know if you saw that article that was written by the Austin American-Statesman in 2000 on the Antioch Colony had a reunion in 1999, and there were about 300 people that came and they interviewed various folks. 
WW: Was that the Harper reunion?

LG: Yeah, it wasn't that many people there, though.

WW: It wasn't 300 people, was it?

LG: $\quad$ No.

MF: This is in the late 1990s?

WW: It might have been that, because we said it really wasn't our reunion, although they invited us, but it was more Harpers, and we aren't related to the Harpers.

LG: That's what I was asking you about the other day, and I said, "The Harpers probably told you everything."

MF: No, but then they couldn't tell me about your experiences.

LG: That's what you told me. But see, I was thinking that myself that—are you still taping?

MF: I am still taping. I can turn this off, though. 


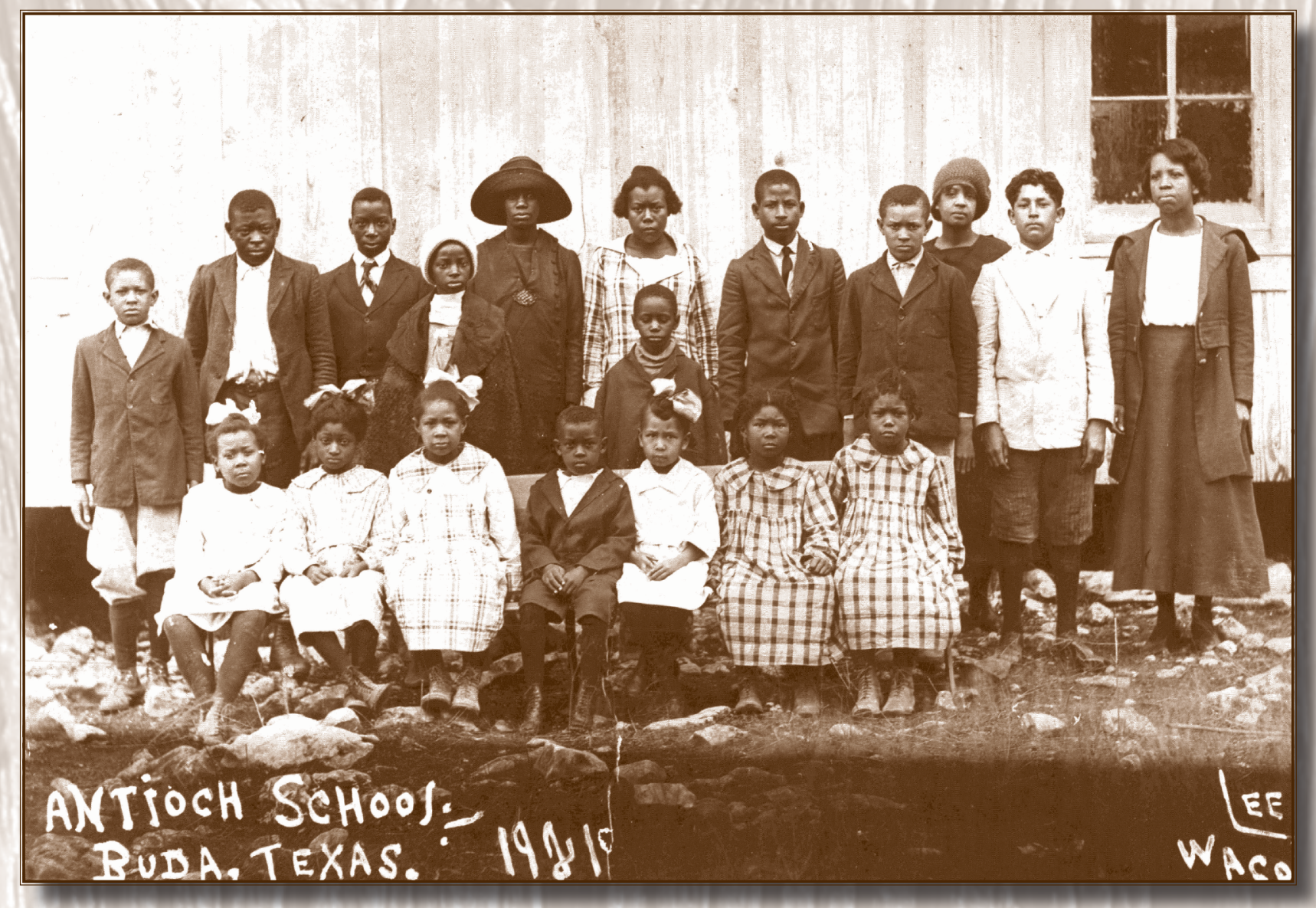

